\author{
Universidade de São Paulo \\ Instituto de Física
}

\title{
Medida do alinhamento atômico de Ta, W e Au por impacto de elétrons pela distribuição angular dos raios x L
}

\author{
Suelen Fernandes de Barros \\ Orientador: Prof. Dr. Vito Roberto Vanin \\ Co-Orientador: Prof. Dr. José María Fernández-Varea \\ Tese de doutorado apresentada ao Instituto de Física \\ da Universidade de São Paulo para a obtenção do \\ título de Doutora em Ciências.
}

Banca Examinadora:

Prof. Dr. Vito Roberto Vanin - Orientador (IFUSP)

Profa. Dra. Elisabeth Mateus Yoshimura (IFUSP)

Prof. Dr. Eduardo Chaves Montenegro (UFRJ)

Prof. Dr. Mauricio Moralles (IPEN)

Prof. Dr. Túlio Costa Rizuti da Rocha (LNLS) 


\section{FICHA CATALOGRÁFICA}

\section{Preparada pelo Serviço de Biblioteca e Informação}

do Instituto de Física da Universidade de São Paulo

Barros, Suelen Fernandes de

Medida do alinhamento atômico de Ta, W e Au por impacto de elétrons pela distribuição angular dos raios x L. São Paulo, 2018.

Tese (Doutorado) - Universidade de São Paulo. Instituto de Física. Depto. de Física Experimental.

Orientador: Prof. Dr. Vito Roberto Vanin

Área de Concentração: Física Atômica.

Unitermos: 1. Física experimental; 2. Raios x L; 3. Anisotropia; 4. Alinhamento atômico. 


\title{
University of São Paulo \\ Physics Institute
}

\section{Measurement of atomic alignment of Ta, $\mathrm{W}$ and $\mathrm{Au}$ by electron impact from L x-ray angular distribution}

\author{
Suelen Fernandes de Barros \\ Supervisor: Prof. Dr. Vito Roberto Vanin \\ Co-supervisor: Prof. Dr. José María Fernández-Varea
}

Thesis submitted to the Physics Institute of the University of São Paulo in fulfillment of the requirements for the degree of Doctor of Science.

Examining Committee:

Prof. Dr. Vito Roberto Vanin - Supervisor (IFUSP)

Profa. Dra. Elisabeth Mateus Yoshimura (IFUSP)

Prof. Dr. Eduardo Chaves Montenegro (UFRJ)

Prof. Dr. Mauricio Moralles (IPEN)

Prof. Dr. Túlio Costa Rizuti da Rocha (LNLS) 



\section{Resumo}

Foram realizadas medidas do alinhamento atômico do Ta, W e Au por ionização da subcamada $\mathrm{L}_{3}$ desses elementos por impacto de elétrons, via distribuição angular das linhas de raios x L, empregando alvos finos. As medições foram realizadas na linha de feixe de 10-100 keV do Microtron de São Paulo. Os alvos foram confeccionados no Laboratório de Filmes Finos, pela técnica de deposição física de vapor (alvo de Au), e no Laboratório de Materiais Magnéticos, pela técnica de sputtering (alvos de Ta e W), enquanto que a caracterização deles foi realizada no Laboratório de Materiais e Feixes Iônicos, pela técnica de espectrometria de retroespalhamento Rutherford. O Microtron de São Paulo, bem com os laboratórios onde os alvos foram confeccionados e caracterizados, estão no Instituto de Física da Universidade de São Paulo. Os raios x decorrentes da ionização dos alvos foram detetados simultaneamente por três Silicon Drift Detectors localizados a $31^{\circ}, 90^{\circ}$ e $125^{\circ}$ com relação à direção do feixe incidente. A determinação da eficiência de pico dos detetores foi realizada com um modelo analítico testado separadamente. As intensidades das linhas do multipleto de raios $\mathrm{x} L$ foram ajustadas em um único procedimento empregando funções Voigt para descrevê-las. O parâmetro de alinhamento $A_{20}$ foi estimado a partir do conjunto de intensidades das linhas $\mathrm{L} \ell, \mathrm{L} \alpha_{1}$ e $\mathrm{L} \alpha_{2}$. A fim de comparar os resultados experimentais com as previsões teóricas foi calculado o parâmetro de alinhamento com a aproximação de Born de ondas planas não relativística, empregando as aproximações de Hartree-Slater e Dirac-Hartree-Slater para descrever os potenciais atômicos. Os resultados experimentais confirmaram a emissão não isotrópica dos raios x decorrentes de vacâncias preenchidas na subcamada $\mathrm{L}_{3}$, sendo que a magnitude desta anisotropia varia com a energia do feixe de elétrons incidente. Além disso, foram observadas anisotropias de sinais opostos para as linhas $\mathrm{L} \alpha_{1}$ e $\mathrm{L} \alpha_{2}$. A dependência em energia do parâmetro de alinhamento $A_{20}$ mostra uma queda rápida de $A_{20}$, com duas inversões de sinal, uma em torno de $2 E / E_{\mathrm{L}_{3}}$ e outra em torno de $8 E / E_{\mathrm{L}_{3}}$, e um valor não nulo de alinhamento em torno de $10 E / E_{\mathrm{L}_{3}}$, para os três elementos estudados. A comparação dos resultados experimentais com os cálculos realizados mostra um bom acordo até cerca de $5 E / E_{\mathrm{L}_{3}}$ para o feixe de elétrons incidente, a partir deste ponto o experimento evidencia uma segunda inversão no sinal de $A_{20}$, que não é prevista por essa teoria. Este é, a nosso saber, o primeiro trabalho a quantificar o alinhamento atômico na ionização de átomos pesados por impacto de elétrons, via distribuição angular de raios x na faixa de 1 a $10 \mathrm{E} / E_{\mathrm{L}_{3}}$.

Palavras chaves: Raios x, emissão anisotrópica, alinhamento atômico, seções de choque, SDD. 


\section{Abstract}

Measurements of the atomic alignment of Ta, W and $\mathrm{Au}$ after the ionization of the $\mathrm{L}_{3}$ subshell of these elements were performed by electron impact via the angular distribution of x-ray lines employing thin targets. The targets were made in the Laboratório de Filmes Finos, by the technique of physical vapor deposition (Au target), and in the Laboratório de Materiais Magnéticos, by the sputtering technique (Ta and W targets), while their characterization was performed in the Laboratório de Materiais e Feixes Iônicos, by Rutherford Backscattering Spectrometry. The Microtron of São Paulo, as well as the laboratories where the targets were made and characterized, are placed at Instituto de Física of the Universidade de São Paulo. The x-rays from the ionization of the targets were detected simultaneously by three Silicon Drift Detectors placed at $31^{\circ}, 90^{\circ}$ and $125^{\circ}$ with respect to the direction of the incident beam. The determination of the fullenergy peak efficiency of the detectors was performed with an analytical model previously tested. In the data analysis the $\mathrm{L}$ x-ray multiplet lines were fitted in a single procedure employing Voigt functions to describe them, and the $\mathrm{L} \ell, \mathrm{L} \alpha_{1}$ and $\mathrm{L} \alpha_{2}$ lines were employed simultaneously in the estimation of the alignment parameter $A_{20}$. In order to compare the experimental results with the theoretical predictions, the alignment parameter was calculated with the non-relativistic plane-wave Born approximation using Hartree-Slater and Dirac-Hartree-Slater atomic potentials. The experimental results confirmed the nonisotropic emission of $\mathrm{x}$-rays from filled vacancies in the $\mathrm{L}_{3}$ subshell, with the magnitude of this anisotropy varying with the energy of the incident electron beam. In addition, anisotropies of opposite signs were observed for the $\mathrm{L} \alpha_{1}$ and $\mathrm{L} \alpha_{2}$ lines. The energy dependence of the alignment parameter $A_{20}$ shows a sharp fall of $A_{20}$, with two sign inversions, one around $2 E / E_{\mathrm{L}_{3}}$ and another around $8 E / E_{\mathrm{L}_{3}}$, and a non-zero alignment value around $10 E / E_{\mathrm{L}_{3}}$, for the three studied elements. Comparison of the experimental results with the performed calculations shows a good agreement up to about $5 E / E_{\mathrm{L}_{3}}$ for the incident electron beam, from which the experiment evidences a second inversion in the sign of $A_{20}$, which is not predicted by this theory. This is, to our knowledge, the first work to quantify the atomic alignment in the ionization of heavy atoms by electron impact, via an angular distribution of x-rays in the interval from 1 to $10 E / E_{\mathrm{L}_{3}}$.

Key words: x-rays, anisotropic emission, atomic alignment, cross sections, SDD. 
"A mente que se abre a uma nova ideia jamais voltará ao seu tamanho original." (Albert Einstein) 
Ao André 


\section{Agradecimentos}

Muitas das pessoas que cruzaram meu caminho nestes últimos dez anos deveriam de alguma forma estar nestas páginas de agradecimento. São tantos os nomes que é impossível um agradecimento individual. Então, de uma forma geral, muito obrigada a todas as pessoas que passaram pela minha vida, e também as que continuam nela, e que me apoiaram durante essa minha trajetória. Mas, de todos esses nomes, quero relacionar alguns que eu não poderia esquecer, e esta tese não estaria completa sem meu sincero agradecimento a eles.

Agradeço aos meus pais, Marli e Rubem, pelo apoio desde o início, pelo carinho e pelo amor ao longo de todos os anos de minha vida.

À minha irmã Samara pela compreensão e ajuda com as tarefas que não pude fazer por estar trabalhando nesta tese, pelas conversas sobre os experimentos e cálculos deste trabalho, quando eles davam certo e também quando não davam, e pelos raros encontros nos shoppings no final do dia.

Agradeço ao meu irmão Washington pelas conversas, incentivos e conselhos desde quando iniciei meus estudos na primeira série do ensino fundamental.

Ao André, por ter sido o companheiro que ele foi durante todo esse tempo, por toda a ajuda ao longo deste trabalho, pela compreensão e por estar sempre disposto a me fazer sorrir.

Ao meu orientador Prof. Dr. Vito Roberto Vanin por sua paciência, motivação e imenso conhecimento. Sem a sua orientação e ajuda contínua esta tese não teria sido possível. Seus ensinamentos fazem e farão parte dos meus caminhos daqui em diante.

Ao Prof. Dr. José María Fernández-Varea por ter acompanhado o desenvolvimento deste trabalho, estando sempre disposto a esclarecer as dúvidas, revisar os textos e colaborar com cálculos e sugestões.

À professora Prof. Dra. Nora Lia Maidana, pelos conselhos e sugestões, pelas ajudas 
com o alinhamento do arranjo experimental e por ter me dado a oportunidade de ser monitoria das disciplinas que ministrou em 2017.

Ao Prof. Dr. Marcos Nogueira Martins, por disponibilizar o laboratório para a realização de todos os testes e experimentos prévios deste trabalho, e por assistir aos seminários que apresentei no grupo, sempre contribuindo com as discussões.

Ao Prof. Dr. Alessio Mangiarotti pela ajuda com o desenvolvimento da parte teórica deste trabalho, pelos cálculos realizados e pelas conversas.

À minha amiga Maria Gabriela pelos raros e longos encontros nos cafés, pelas conversas, pelo incentivo e pela amizade de mais de 20 anos.

À minha amiga Monaliza por todas as experiências compartilhadas e pelo companheirismo ao longo de todo esse tempo na nossa salinha.

Aos colegas Juan e Osvaldo por estarem sempre dispostos a discutir os problemas desta tese, pelas ajudas com o SIMNRA e por tornarem mais descontraídos os momentos no instituto.

Ao corpo técnico do laboratório, Alexandre, Alfredo, Adriano e Roberto; sem eles a realização deste trabalho seria impossível. Ao Alexandre em especial, que acompanhou todo a realização do experimento, sempre disposto a ajustar o feixe nas energias que precisávamos.

Ao Sérgio e ao Antônio, que sempre me ajudaram nas questões relacionadas à informática.

Ao pessoal da eletrônica: Carlos, Eduardo, Renato e Adriano. E aos secretários Luis, Bianca e Juliana, sempre dispostas a ajudar com os problemas burocráticos.

Aos atendentes da Comissão de Pós-Graduação, pelo atendimento sempre gentil e prestativo.

À todos os professores do LAL, por estarem sempre dispostos a ajudarem os alunos.

À FAPESP (projeto $n^{\circ}$ 2013/24803-5) e ao CNPq pelo fundamental apoio financeiro. 


\section{Lista de Figuras}

2.1 Espectro de raios x do Au com as linhas características M e L superpostas à componente contínua. A energia do feixe incidente foi de $18,8 \mathrm{keV}$. A dispersão em energia é $13 \mathrm{eV} /$ canal. . . . . . . . . . . . . . . . . . 8

2.2 Esquema da posição das linhas de raios x L do Au incluídas nos ajustes dos espectros experimentais. A altura das setas não indica a intensidade das linhas. . . . . . . . . . . . . . . . . . . . . . . 11

2.3 Espectros em energia dos raios $\mathrm{x} \mathrm{L}$ emitidos por um alvo de Au sobre um backing de C irradiado com as energias de 13, 35(9), 14, 03(9) e 15, 51(9) keV. A dispersão em energia é $13 \mathrm{eV} /$ canal. . . . . . . . . . . . . . . . . . 13

3.1 a) Sistema não alinhado. b) Sistema alinhado. . . . . . . . . . . . . . . . 20

3.2 Ilustração de um sistema de coordenadas $X Y Z$ usado para descrever a colisão de um feixe de partículas com momento inicial $\vec{p}_{\mathrm{i}}$, cujo momento

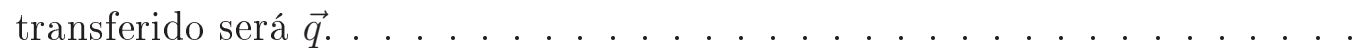

3.3 Representação dos orbitais $J=3 / 2$ em um sistema com simetria axial, em que as populações dos estados $m= \pm 3 / 2$ são representados pelos tamanhos das setas em roxo (linha tracejada) e dos estados $m= \pm 1 / 2$, das setas em vermelho (linha contínua). a) Sistema não alinhado e não orientado, b) Sistema alinhado e não orientado, e c) Sistema alinhado e orientado. . . . . 24

3.4 a) Representação dos vetores de momento angular para os estados $2 \mathrm{~s}_{1 / 2}$ ou $2 \mathrm{p}_{1 / 2}$, e b) da densidade de probabilidade dos estados $2 \mathrm{~s}_{1 / 2}$ ou $2 \mathrm{p}_{1 / 2} \ldots$. . 27

3.5 a) Representação dos vetores de momento angular para os estados $\left(2 \mathrm{p}_{3 / 2}\right)$, e b) da densidade de probabilidade dos estados $\left(2 \mathrm{p}_{3 / 2}\right) \ldots \ldots \ldots$

3.6 Representação dos ângulos $\gamma$, entre a radiação emitida e o feixe de elétrons dentro do alvo, $\theta^{\prime}$ e $\phi^{\prime}$, que representam a abertura polar e azimutal, respectivamente, do feixe de elétrons no alvo, e $\theta$ que indica a posição do detetor para um $\phi$ fixo. As linhas vermelhas se referem ao elétron e em azul ao fóton. 36 
3.7 Esboço que representa o alvo e a possível interação dos fótons em seu interior, com os parâmetros geométricos necessários à fórmula (3.54). . . 37

3.8 Estimativas do parâmetro de alinhamento $A_{20}$, via distribuição angular ou polarização dos raios x, encontradas na literatura para ionização a) por impacto de elétrons [1-3] e b) por fótons [4-10]. O ponto em estrela (preto) é da referência Hrdý et al. [1] para Hg, o ponto em círculo (vermelho) é da referência Aydinol et al. [2] para Xe, o ponto em cruz (preto) é da referência Kahlon et al. [4] para Au, o ponto quadrado (laranja) é da referência Papp e Campbell [5] para Er, os triângulos apontando para a esquerda (azuis) e para direita (verdes) são das referências Küst et al. [3] e [6], respectivamente, para Xe, os triângulos apontando para cima e para baixo (preto e roxo) são das referências Yamaoka et al. [7] e [8], respectivamente, para $\mathrm{Au}$, o ponto em diamente (rosa) é da referência Santra et al. [9] para Au, e os pontos em círculos (cinzas) são da referência Kampfer et al. [10] para W. 50

4.1 Esquema das três linhas de feixe do acelerador Microtron de São Paulo. . . 52

4.2 Imagem da linha de $10-100 \mathrm{keV}$ do acelerador Microtron de São Paulo, com o canhão de elétrons dentro da grande gaiola de Faraday à direita, e a câmara de irradiação à esquerda. . . . . . . . . . . . . . . . . . . 52

4.3 Espectros de um alvo de Au irradiado com um feixe de elétrons com cerca de $31 \mathrm{keV}$ normalizados pela carga. A linha contínua (em preto) corresponde à medição sem colimador e sem o revestimento interno da câmara, enquanto que os pontos (em cinza), à com o colimador de Al instalado no flange e com a região da câmara diametralmente oposta ao detetor revestida por Kapton de $100 \mu \mathrm{m}$ aluminizado. . . . . . . . . . . . . . . 53

4.4 Imagem do copo de Faraday instalado na base de montagem na câmara. . . 54

4.5 Esquema da câmara de irradiação da linha de 10-100 keV . . . . . . . . . . 54

4.6 Imagem da câmara de irradiação com o copo de Faraday, à esquerda, e da torre de alvos, à direita. Na parte superior da torre, o cilindro preto corresponde ao acionador.

4.7 Imagem de um alvo de Au sobre um filme fino de $\mathrm{C}$ depositado em uma moldura de fibra de carbono. . . . . . . . . . . . . . . . . . 55 
4.8 Espectros de RBS de partículas de ${ }^{4} \mathrm{He}^{+}$experimental (pontos azuis) e simulado (linha contínua vermelha) medido a $120^{\circ}$ com relação à direção do feixe incidente em escalas logarítmica (à esquerda) e linear (à direita) para os alvos de: a) e b) $\mathrm{Cu}$, c) e d) Ta, e) e f) W e g) e h) Au. A dispersão em energia é de $6 \mathrm{keV} /$ canal. . . . . . . . . . . . . . . . . . . 58

4.9 Espessuras de: a) quatro alvos de $\mathrm{Au}, \mathrm{b}$ ) três de Ta e c) um alvo de $\mathrm{Cu}$. Os números indicam os diferentes alvos e os símbolos, as diferentes posições. A linha tracejada (em preto) corresponde à média dos dados experimentais e a linha contínua (em vermelho) corresponde à espessura do alvo deste experimento. Para esses alvos a não uniformidade foi estimada em 0,$5 ; 0,5$ e $0,3 \mu \mathrm{g} / \mathrm{cm}^{2}$ para os alvos de $\mathrm{Cu}$, Ta e $\mathrm{Au}$, respectivamente . . . . . . . 59

4.10 Imagem do adaptador de acrílico empregado para auxiliar no alinhamento do arranjo experimental. . . . . . . . . . . . . . . . . . . . 60

4.11 Imagem obtida durante o processo de verificação do alinhamento do arranjo experimental com um dispositivo laser. . . . . . . . . . . . . . . . . . 61

4.12 Arranjo experimental do experimento de distribuição angular com a medida simultânea dos fótons nos ângulos de $31^{\circ}, 90^{\circ}$ e $125^{\circ}$. As setas mostram cada um dos três detetores SD . . . . . . . . . . . . . . . . . . 61

4.13 Esquema de blocos da eletrônica do SDD da Amptek [11]. Os tempos característicos associados com o canal lento estão diretamente relacionados com o tempo de subida e o patamar do sistema de aquisição. . . . . . . . . 62

4.14 Forma do pulso do amplificador lento em um DPP. $\mathrm{T}_{\text {peak }}$ corresponde ao tempo de subida, $T_{\text {flat }}$ ao patamar, $E_{d} \approx$ ao nível de ruído, e $\delta \tau$ depende da energia associada ao pulso.

4.15 Dependência da a) resolução (FWHM) e b) da amplitude da linha $\mathrm{L} \alpha_{1}$, normalizada pela carga e corrigida pelo tempo morto, e c) do tempo morto de aquisição com o patamar $T_{\text {flat }} \ldots \ldots \ldots \ldots \ldots$

4.16 Dependência da a) resolução (FWHM) e b) da amplitude da linha L $\alpha_{1}$, normalizada pela carga e corrigida pelo tempo morto, e c) do tempo morto de aquisição com o tempo de subida $T_{\text {peak }} \ldots \ldots \ldots \ldots$ 
4.17 Dependência da a) resolução (FWHM) e b) da amplitude da linha $\mathrm{L} \alpha_{1}$, normalizada pela carga e corrigida pelo tempo morto, e c) do tempo morto de aquisição com a posição do limiar rápido.

4.18 Sequência de imagens obtidas da seção transversal do feixe de elétrons atingindo o view screen durante a irradiação com elétrons $15,50(10) \mathrm{keV}$. A separação entre os traços pretos no view screen é de $2 \mathrm{~mm}$.

5.1 Resíduos reduzidos dos ajustes dos parâmetros da calibração de energia dos detetores posicionados a a) $31^{\circ}$, b) $90^{\circ}$ e c) $125^{\circ}$ em relação à direção do feixe incidente.

5.2 Diferença em eV entre os valores de energia dos picos calculados com a calibração obtida e os valores apresentados na referência Deslattes et al. [12] para raios x, e na base de dados Laboratoire National Henri Becquerel [13] para raios $\gamma$, para os detetores posicionados a $31^{\circ}$ a), $90^{\circ}$ b) e $125^{\circ} \mathrm{c}$ ) em relação à direção do feixe incidente. . . . . . . . . . . . . . . . . . .

5.3 Diferença em eV da energia da linha $L \alpha_{1}$ do $A u$ calculada com a calibração de energia realizada e com o valor tabelado [12], em função da energia do elétron incidente, para os detetores posicionados a a) $31^{\circ}$, b) $90^{\circ}$ e c) $125^{\circ}$ em relação à direção do feixe incidente. . . . . . . . . . . . . . . . . . .

5.4 Calibração da resolução (FWHM) dos SDDs, para os detetores posicionados a a) $31^{\circ}$, b) $90^{\circ}$ e c) $125^{\circ}$ em relação à direção do feixe incidente. . . . . . . .

5.5 Dependência da função de mérito $\hat{Q}(L ; \Omega)$ com a espessura $L$ do detetor posicionado a $90^{\circ}$ em relação à direção do feixe incidente. . . . . . . . . . . .

5.6 a) Função modelo com os parâmetros ajustados e os pontos experimentais para a eficiência de pico do SDD posicionado a $31^{\circ}$ em relação à direção do feixe incidente. A curva contínua corresponde à situação experimental com a fonte radioativa e a tracejada, com o feixe de elétrons. A linha ponto-tracejada corresponde à eficiência geométrica do detetor. b) Resíduos reduzidos para o ajuste.

5.7 Mesmo que a figura 5.6, mas para o detetor posicionado a $90^{\circ}$ em relação à direção do feixe incidente. . . . . . . . . . . . . . . . . . . . . .

5.8 Mesmo que a figura 5.6, mas para o detetor posicionado a $125^{\circ}$ em relação à direção do feixe incidente. 
5.9 Cortes nas superfícies de nível 3D da função de mérito $\hat{Q}\left(\mathcal{L}_{1}, \mathcal{L}_{2}, \mathcal{L}_{3}\right)+n^{2}$ com $n=1, \ldots, 8$ para: a) $\mathcal{L}_{3}=0,486 \mathrm{~mm}$, b) $\mathcal{L}_{3}=0,4886 \mathrm{~mm} \mathrm{e} \mathrm{c)}$ $\mathcal{L}_{3}=0,491 \mathrm{~mm}$, para o menor valor de $\hat{Q}$ encontrado, que foi de $18,7 . \quad$. . 84

5.10 Espectros de empilhamento experimental (em cinza) e modelo (em preto), expressão (5.15). A taxa de aquisição foi de aproximadamente $56 \mathrm{kHz} \mathrm{em}$ ambos os casos. a) Linhas M não foram atenuadas. b) Atenuador de raios x foi usado para barrar os raios x M. . . . . . . . . . . . . . . 86

5.11 De cima para baixo, as linhas representam espectros de Au adquiridos a taxas de: $3,12,19,26,42$, e $56 \mathrm{kHz}$, normalizados pela carga e divididos pelo espectro adquirido a $1 \mathrm{kHz}$, também normalizado pela carga. Os espectros foram agrupados de forma que a dispersão em energia é $210 \mathrm{eV} /$ canal. . .

6.1 Espectro de raios x experimental (em pontos) e curva calculada com os parâmetros ajustados (em linha contínua) para o espectro de $\mathrm{Cu}$ obtido com elétrons de 15,51(9) keV com o detetor na posição de $31^{\circ}$ com relação à direção do feixe incidente. a) Espectro completo e b) escala expandida para visualização dos picos de raios $\mathrm{x} K \beta$. c) Resíduos reduzidos do ajuste. O $\chi^{2}$ reduzido do ajuste de $1,8 \ldots \ldots \ldots \ldots \ldots$

6.2 Distribuição de escape construída a partir da expressão (6.11) para o alvo de $\mathrm{Au}$ irradiado com um feixe de elétrons de $25 \mathrm{keV}$ e adquirido com um SDD posicionado a $31^{\circ}$ em relação à direção do feixe incidente. A linha preta corresponde ao espectro total, a azul, ao escape frontal e a vermelha, ao escape traseiro. a) Escala linear. b) Escala logarítmica. . . . . . . . . . . 94

6.3 a) Espectro experimental do $\mathrm{W}$ e modelo ajustado na região do tip de bremsstrahlung. b) Curvas de nível $Q\left(\hat{E}_{\mathrm{e}}, \hat{\sigma}_{\mathrm{e}}\right)+n^{2}, n=1, \ldots, 8$ para o ajuste do espectro de W. Ambos para o feixe de elétrons de $36,97(8) \mathrm{keV}$ e o detetor na posição de $31^{\circ}$ em relação à direção do feixe incidente. . . . . . . 95

6.4 Mesmo que a figura 6.3 , mas para o detetor na posição de $90^{\circ}$. . . . . . 95

6.5 Mesmo que a figura 6.3, mas para o detetor na posição de $125^{\circ}$. . . . . 96

6.6 Espectro de raios x experimental (em pontos) e curva calculada com os parâmetros ajustados (em linha contínua) para o espectro de Ta obtido com elétrons de 20,76(9) keV no ângulo de $31^{\circ}$ com relação à direção do feixe incidente. a) Espectro completo, b) escala expandida e c) resíduos reduzidos do ajuste. O $\chi^{2}$ reduzido do ajuste foi de $1,4 \ldots$. . . . . . . 100 
6.7 Mesmo que a figura 6.6, mas para o alvo de $\mathrm{W}$ irradiado com o feixe de elétrons de 100,65(7) keV no ângulo de $90^{\circ}$. O $\chi^{2}$ reduzido do ajuste foi

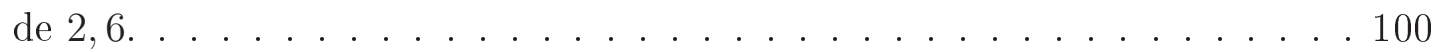

6.8 Mesmo que a figura 6.6, mas para o alvo de $\mathrm{Au}$ irradiado com o feixe de elétrons de $30,62(15) \mathrm{keV}$ no ângulo de $125^{\circ}$. O $\chi^{2}$ reduzido do ajuste foi de $2,6 \ldots \ldots \ldots \ldots 10 \ldots \ldots \ldots$

6.9 Pontos experimentais e curvas calculadas com os parâmetros estimados para o alvo de $\mathrm{Cu}$ nas energias de a) 11,51(6), b) 58, 28(3), e c) 100,60(3) keV para a razão das áreas $A_{\mathrm{K} \beta} / A_{\mathrm{K} \alpha}$ corrigidas pelas respectivas eficiências de pico. . . . . . . . . . . . . . . . . . . . 102

6.10 Fator de correção na distribuição angular devido às transições CosterKronig $\kappa_{\mathrm{CK}}$ em função da energia do feixe de elétrons, para Ta (linha tracejada), W (linha contínua) e Au (linha ponto tracejada). . . . . . . . . 108

6.11 Características do feixe de elétrons ao atravessar o alvo: a) Fração do feixe que passa pelo alvo sem nenhuma abertura $\left(\mathrm{p}_{0}\right)$ em função da energia do elétron incidente, b) dependência do ângulo $\sqrt{\left\langle\theta^{2}\right\rangle}$ com a energia do elétron incidente, para os elementos Ta, W e Au. . . . . . . . . . . . . . . 109

6.12 Dependência do parâmetro de atenuação da distribuição angular $q_{2}$, expressão (3.53), com a energia do elétron incidente, para os elementos Ta, $\mathrm{W}$ e Au. . . . . . . . . . . . . . . . . . . . . . . . 109

6.13 Quociente $q_{2}^{\prime} / q_{2}$, com as quantidades $q_{2}^{\prime}$ e $q_{2}$ calculadas de acordo com as expressões (6.16) e (3.53), respectivamente, para os alvos de: a) Ta, b) W e c) Au.

6.14 Fração dos raios x que conseguem escapar do alvo, sem espalhar inelasticamente, e atingir o detetor, fixo em uma posição $\theta$, para um feixe de elétrons de $13 \mathrm{keV}$ incidindo sobre um alvo de $\mathrm{Au}$ de a) $12 \mu \mathrm{g} / \mathrm{cm}^{2}$ e b) $150 \mu \mathrm{g} / \mathrm{cm}^{2}$. As barras de incerteza representam um desvio padrão, iguais a $0,2 \%$ e $0,4 \%$, nos gráficos a) e b), respectivamente.

6.15 Razão entre o comprimento do caminho efetivo dos elétrons e a espessura do alvo, calculada para um alvo de Au com densidade superficial de $9,6(5) \mu \mathrm{g} / \mathrm{cm}^{2}$ e inclinado de $30^{\circ}$ com relação à direção do feixe incidente, em função da energia do feixe de elétrons incidente. 
7.1 Dependência da função $A_{20}(q, \epsilon)$, equação (7.3), com o momento transferido $q$ para a subcamada $2 \mathrm{p}_{3 / 2}$ do Ar, com energias do elétron ejetado $\epsilon$ de: a) 0,01 Ry, b) 0,5 Ry, c) 2 Ry e d) 5 Ry. A curva contínua corresponde ao cálculo da publicação [14], e a ponto-tracejada aos cálculos deste trabalho.

7.2 Parâmetro de alinhamento $A_{20}$ em função da energia do elétron incidente em unidades da energia do limiar de ionização $E_{\mathrm{L}_{3}}$ do a) Ar e b) Mg para uma vacância criada na subcamada $2 \mathrm{p}_{3 / 2}$ dos elementos. A curva contínua foi obtida da referência [15] e os pontos em forma de $\times$ correspondem aos resultados dos cálculos deste trabalho.

7.3 Diferença relativa do resultado da integral (3.37) em função do momento transferido $q$ empregando os dois procedimentos descritos na seção 7.1.1, para um alvo de Au descrito com o potencial de HS para a energia do elétron incidente de $E_{0}=20 \mathrm{keV}$, com $l_{\max }^{\prime}=6 \ldots \ldots \ldots$. . . . . .

7.4 Mesmo que na figura 7.3, para a energia do elétron incidente de $E_{0}=$ $50 \mathrm{keV}$, com $l_{\max }^{\prime}=9$.

7.5 Dependência do parâmetro $S_{A_{20}}$ para as energias de: 12,$2 ; 20 ; 30 ; 60$ e $90 \mathrm{keV}$ com o número de valores do momento angular orbital $l^{\prime}$ do elétron ejetado incluídos no cálculo. O limite assintótico das curvas corresponde ao parâmetro de alinhamento $A_{20}$ para a energia correspondente. . . . . . 126

7.6 Dependência do parâmetro $S_{A_{20}}$ em função da energia do elétron incidente em unidades de limiar, para $l_{\max }^{\prime}=0$ (azul), $l_{\max }^{\prime}=1$ (vermelho), $l_{\max }^{\prime}=2$ (preto), $l_{\max }^{\prime}=3$ (verde), $l_{\max }^{\prime}=4$ (laranja), $l_{\max }^{\prime}=5$ (roxo) e $l_{\max }^{\prime}=6$

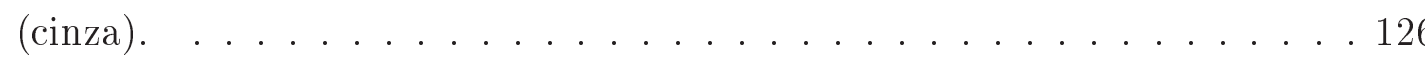

7.7 Valores de $I_{0}$ (figuras de a) até c)) e de $I_{2}$ (figuras de d) até f)) calculados com a expressão (7.4) para o Ta empregando o potencial de HS. As energias dos elétrons estão marcadas na parte superior da figura.

7.8 Mesmo que a figura 7.7 , mas para o Au. . . . . . . . . . . . . . 128

8.1 Os pontos com barras de incerteza (1 desvio padrão) representam os valores experimentais de intensidade das linhas $\mathrm{L}$ do Ta relativa ao dubleto $\mathrm{K} \alpha$ do $\mathrm{Cu}$, na energia de $11,51(6) \mathrm{keV}$ : a) L $\ell$, b) $\mathrm{L} \alpha_{1}$ e c) L $\alpha_{2}$. As linhas contínuas são as curvas correspondentes calculadas com os parâmetros ajustados aos dados experimentais. O $\chi^{2}$ do ajuste com cinco graus de liberdade foi de $10,9 \ldots \ldots \ldots \ldots \ldots \ldots \ldots$ 
8.2 Mesmo que a figura 8.1 para a energia de $30,62(9) \mathrm{keV}$. O $\chi^{2}$ do ajuste com cinco graus de liberdade foi de $5,0 \ldots \ldots 130$

8.3 Mesmo que a figura 8.1 para a energia de $100,60(4) \mathrm{keV}$. O $\chi^{2}$ do ajuste com cinco graus de liberdade foi de $6,2 \ldots$. . . . . . . . . . . . . . 131

8.4 Mesmo que a figura 8.1 para W na energia de 58,28(3) keV. O $\chi^{2}$ do ajuste com cinco graus de liberdade foi de 12 . . . . . . . . . . . . . . . . 131

8.5 Mesmo que a figura 8.1 para Au na energia de $13,35(9) \mathrm{keV}$. O $\chi^{2}$ do ajuste com cinco graus de liberdade foi de $1,6 \ldots$. . . . . . . . . . . . . . 132

8.6 Mesmo que a figura 8.1 para Au na energia de 25,41(9) keV. O $\chi^{2}$ do ajuste com cinco graus de liberdade foi de $13,8 \ldots$. . . . . . . . . . . . . . . 132

8.7 Mesmo que a figura 8.1 para Au na energia de $74,83(7) \mathrm{keV}$. O $\chi^{2}$ do ajuste com cinco graus de liberdade foi de $6,1 \ldots \ldots 133$

8.8 $\chi^{2}$ total para os ajustes dos parâmetros de alinhamento dos alvos de Ta (diamantes vermelhos), $\mathrm{W}$ (quadrados verdes) e Au (círculos azuis) realizado em duas etapas conforme apresentado na seção 6.3, para todas as energias de irradiação. O ajuste tem cinco graus de liberdade. As linhas tracejadas, de baixo para cima, representam níveis de confiança de 1\%, 50\% e 99\%, respectivamente.

8.9 Parâmetro de alinhamento $A_{20}$ do elemento Ta em função da energia dos elétrons incidentes. Os pontos correspondem às estimativas experimentais deste trabalho, a curva contínua corresponde aos resultados do cálculo da equação (3.32) com o potencial de HS, e a tracejada com o potencial de DHS. As barras de incertezas correspondem a um desvio padrão. . . . . . . 136

8.10 Mesmo que a figura 8.9, para o átomo de W. . . . . . . . . . . . 137

8.11 Mesmo que a figura 8.9, para o átomo de Au. . . . . . . . . . . . 137

8.12 Valores do parâmetro de alinhamento $A_{20}$, calculados com os potenciais de HS (linha contínua em preto) e DHS (linha tracejada em laranja), na região $E / E_{\mathrm{L}_{3}}<1,1$ para a) Ta e b) Au. . . . . . . . . . . . . . 138

8.13 Parâmetro de alinhamento $A_{20}$ dos elementos Ta, W e Au em função da energia do elétron incidente em unidades da energia do limiar de ionização da subcamada $L_{3}$ do elemento correspondente. As barras de incertezas correspondem a um desvio padrão. . . . . . . . . . . . . . . . . . . . . . . 139 
8.14 Estimativa do coeficiente representado pelo produto $\xi \alpha A_{20}$ da equação (3.40), para a linha $L \eta$ e multipleto $L \gamma$ dos alvos de a) e b) Ta, c) e d) W e e) e f) Au. A linha tracejada corresponde à média ponderada dos valores. . . . 140

8.15 Seções de choque de produção de raios x $\mathrm{L} \alpha, \mathrm{L} \beta, \mathrm{L} \gamma$, L $\ell$ e $\mathrm{L} \eta$ do Au por impacto de elétrons. Os círculos (em azul) são os dados experimentais deste trabalho, os triângulos invertidos (em laranja), círculos (em vermelho), círculos vazios (em roxo), quadrados (em verde), triângulos (em rosa) e diamantes (em roxo) representam os dados das referências Pa80 [16], Sh81 [17], Ca02 [18], Wu04 [19], Ra14 [20] e Ba15 [21], respectivamente. As curvas contínuas são as seções de choque teóricas calculadas com a DWBA $[22,23] \ldots \ldots \ldots \ldots \ldots \ldots \ldots \ldots$

8.16 Seções de choque de ionização atômica das subcamadas $\mathrm{L}_{1}, \mathrm{~L}_{2}$ e $\mathrm{L}_{3}$ do $\mathrm{Au}$ por impacto de elétrons. Os círculos (em azul) são os valores experimentais deste trabalho. Os triângulos vazios (em vermelho), os quadrados (em verde), os quadrados (em preto), os triângulos invertidos (em laranja), os círculos (em vermelho), os círculos (em verde), os triângulos (em rosa) e os diamantes (em roxo) representam os dados das referências Gr68 [24], Sa71 [25], Da72 [26], Pa80 [16], Sh81 [17], Sc93 [27], Ra14 [20] e Ba15 [21], respectivamente. As curvas contínuas e os pontos em cruzes são as previsões teóricas da DWBA $[22,23]$ e da SCADW [28], respectivamente. . . . . . . . 144

9.1 Dependência da função de mérito $\hat{Q}\left(A_{20}\right)$ com o parâmetro de alinhamento $A_{20}$ estimado a partir das linhas L $\ell$ (linha tracejada azul), $\mathrm{L} \alpha_{1}$ (linha contínua vermelha) e $\mathrm{L} \alpha_{2}$ (linha ponto tracejada preta) do $\mathrm{Au}$, para as energias do elétron incidente de: a) 13,35(9), b) 17,79(11), c) 30,62(15) e d) $50,82(7) \mathrm{keV}$

9.2 Estimativa do parâmetro de alinhamento $A_{20}$ com a metodologia apresentada na seção 6.3, círculos azuis, e empregando somente a linha L $\ell$, diamantes laranjas. . . . . . . . . . . . . . . . . . . 148

A.1 Os pontos correspondem aos valores experimentais de $R_{\text {out }}$ versus a corrente do feixe. As linhas foram obtidas a partir do procedimento $\mathrm{SMP}_{f}$, equação (A.7), calculadas com os parâmetros estimados para os espectros ML (linha tracejada azul) e L (linha contínua vermelha) . . . . . . . . . . 176 
A.2 Fração de perda estimada da taxa de entrada nos espectros ML (em azul) L (em vermelho), avaliada empregando: as informações do DPP (círculos), equação 5.16, $\mathrm{SM}_{0}$, linha pontilhada, e $\mathrm{SMP}_{f}$, linha contínua, equação A.13.

A.3 Razão de alguns espectros ML, normalizados pela carga incidente e corrigidos pelas perdas por tempo morto pelos procedimentos a) $\operatorname{SMP}_{f}$ e b) $\mathrm{EDP}_{i}$, pelo espectro adquirido a baixa taxa, também normalizado pela carga, equação (A.14). Os espectros foram comprimidos de modo que cada bin corresponde a $210 \mathrm{eV} \ldots \ldots \ldots$. . . . . . . . . . . . . . 177

A.4 Mesmo que a figura A.3, mas para os espectros L. . . . . . . . . . . 178

A.5 Médias ponderadas das razões entre os espectros compensados e os espectros de referência para cada taxa de aquisição, normalizados pela carga, empregando os procedimento $\mathrm{SM}_{0}, \mathrm{SM}_{f}$ e $\mathrm{SMP}_{f}$, representados respectivamente por círculos, cruzes e quadrados para os espectros a) ML e b) L. . . . . . . . . . . . . . . . . . . . . . . . . . 178

A.6 Médias ponderadas das razões entre os espectros compensados e os espectros de referência para cada taxa de aquisição, normalizados pela carga, empregando o procedimento $\mathrm{EDP}_{i}$. Os círculos se referem aos espectros ML e as cruzes aos espectros L. . . . . . . . . . . . . . . . . . . 179

B.1 a) e b) Comparação entre o espectro de raios x experimental e a curva calculadas com os parâmetros ajustados para o multipleto $\mathrm{K}$ do $\mathrm{Cu}$ irradiado com o feixe de elétrons de $15,51(9) \mathrm{keV}$ no ângulo de $90^{\circ}$. c) Resíduos reduzidos do ajuste. O $\chi^{2}$ reduzido do ajuste foi de $1,7 \ldots$. . . . . . . . . 182

B.2 Mesmo que a figura B.1, mas para o detector na posição de $125^{\circ}$. O $\chi^{2}$ reduzido do ajuste foi de $1,7 \ldots \ldots \ldots 3$

B.3 a) e b) Comparação entre o espectro de raios x experimental e a curva calculadas com os parâmetros ajustados para o multipleto L do Ta irradiado com o feixe de elétrons de 20,76(9) keV no ângulo de $90^{\circ}$. c) Resíduos reduzidos do ajuste. $\mathrm{O} \chi^{2}$ reduzido do ajuste foi de $1,2 \ldots$. . . . . . . 184

B.4 Mesmo que a figura B.3, mas para o detector na posição de $125^{\circ}$. O $\chi^{2}$ reduzido do ajuste foi de $1,6 \ldots \ldots \ldots$. . . . . . . . . . . . . . . . . . . . 
B.5 a) e b) Comparação entre o espectro de raios x experimental e a curva calculadas com os parâmetros ajustados para o multipleto L do W irradiado com o feixe de elétrons de $100,65(7) \mathrm{keV}$ no ângulo de $31^{\circ}$. c) Resíduos reduzidos do ajuste. $\mathrm{O} \chi^{2}$ reduzido do ajuste foi de $2,5 \ldots \ldots$. . . . . 186

B.6 Mesmo que a figura B.5, mas para o detetor na posição de $125^{\circ}$. O $\chi^{2}$ reduzido do ajuste foi de 2,4 .

B.7 a) e b) Comparação entre o espectro de raios x experimental e a curva calculadas com os parâmetros ajustados para o multipleto L do W irradiado com o feixe de elétrons de $30,62(15) \mathrm{keV}$ no ângulo de $31^{\circ}$. c) Resíduos reduzidos do ajuste. O $\chi^{2}$ reduzido do ajuste foi de $1,6 \ldots \ldots$. . . . . 188

B.8 Mesmo que a figura B.7, mas para o detetor na posição de $90^{\circ}$. O $\chi^{2}$ reduzido do ajuste foi de 1,8 .

C.1 Pontos experimentais e curva calculada com os parâmetros estimados para o alvo de Ta na energia de 10,75(9) keV. a) Linha L $\ell$, b) $\mathrm{L} \alpha_{1}$ e c) $\mathrm{L} \alpha_{2}$. O $\chi^{2}$ do ajuste foi de $9,3 \ldots \ldots \ldots 1 . \ldots \ldots$. . . . . . . . . . . . . . . . . . . .

C.2 Mesmo que a figura C.1, mas para a energia de $13,46(9) \mathrm{keV}$. O $\chi^{2}$ do ajuste foi de 6,9 .

C.3 Mesmo que a figura C.1, mas para a energia de $15,51(4) \mathrm{keV}$. O $\chi^{2}$ do ajuste foi de 3,4 .

C.4 Mesmo que a figura C.1, mas para a energia de $17,79(7) \mathrm{keV}$. O $\chi^{2}$ do ajuste foi de 5,9 .

C.5 Mesmo que a figura C.1, mas para a energia de $20,76(9) \mathrm{keV}$. O $\chi^{2}$ do ajuste foi de 3,3 .

C.6 Mesmo que a figura C.1, mas para a energia de $25,41(15) \mathrm{keV}$. O $\chi^{2}$ do ajuste foi de 7,8 .

C.7 Mesmo que a figura C.1, mas para a energia de $50,82(5) \mathrm{keV}$. O $\chi^{2}$ do ajuste foi de 4,3 .

C.8 Mesmo que a figura C.1, mas para a energia de $74,83(6) \mathrm{keV}$. O $\chi^{2}$ do ajuste foi de 5,2 .

C.9 Mesmo que a figura C.1, mas para a energia de $84,96(5) \mathrm{keV}$. O $\chi^{2}$ do ajuste foi de $14,2 \ldots \ldots \ldots \ldots \ldots \ldots$ 
D.1 Pontos experimentais e curva calculada com os parâmetros estimados para o alvo de W na energia de 36,97(8) keV. a) Linha L $\ell$, b) L $\alpha_{1}$ e c) $\mathrm{L} \alpha_{2}$. O $\chi^{2}$ do ajuste foi de $5,2 \ldots \ldots \ldots$. . . . . . . . . . . . . . . . . . . . .

D.2 Mesmo que a figura D.1, mas para a energia de 100,65(7) keV. O $\chi^{2}$ do ajuste foi de $10,6 \ldots \ldots \ldots 7$. . . . . . . . . . . . . . . . . . . . . . . . . . .

E.1 Pontos experimentais e curva calculada com os parâmetros estimados para o alvo de Au na energia de 12,19(9) keV. a) Linha L $\ell$, b) L $\alpha_{1}$ e c) $\mathrm{L} \alpha_{2}$. O $\chi^{2}$ do ajuste foi de $2,2 \ldots \ldots \ldots$. . . . . . . . . . . . . . . . . . . . . . . . .

E.2 Mesmo que a figura E.1, mas para a energia de $14,03(9) \mathrm{keV}$. O $\chi^{2}$ do

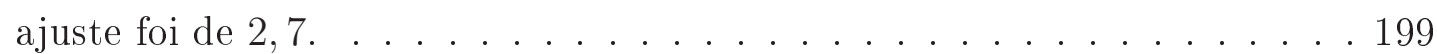

E.3 Mesmo que a figura E.1, mas para a energia de $15,51(9) \mathrm{keV}$. O $\chi^{2}$ do

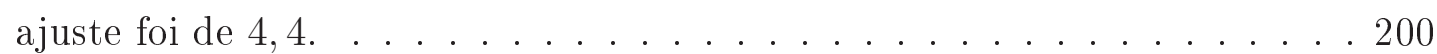

E.4 Mesmo que a figura E.1, mas para a energia de 17,79(11) keV. O $\chi^{2}$ do ajuste foi de $4,1 \ldots \ldots \ldots$. . . . . . . . . . . . . . . . . . . . . . . . .

E.5 Mesmo que a figura E.1, mas para a energia de 20,76(8) keV. O $\chi^{2}$ do ajuste foi de $8,9 \ldots \ldots \ldots \ldots$. . . . . . . . . . . . . . . . . . . . . . .

E.6 Mesmo que a figura E.1, mas para a energia de 30,62(15) keV. O $\chi^{2}$ do

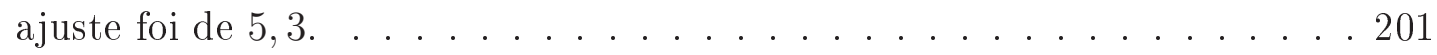

E.7 Mesmo que a figura E.1, mas para a energia de $50,82(7) \mathrm{keV}$. O $\chi^{2}$ do

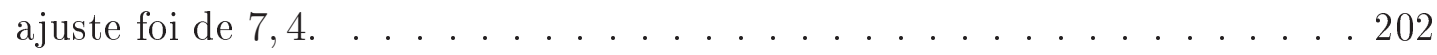

E.8 Mesmo que a figura E.1, mas para a energia de $84,96(6) \mathrm{keV}$. O $\chi^{2}$ do

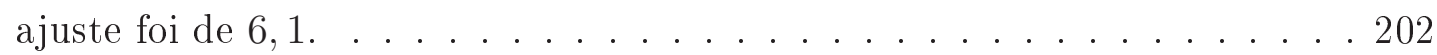

E.9 Mesmo que a figura E.1, mas para a energia de 100,60(4) keV. O $\chi^{2}$ do ajuste foi de $5,0 \ldots \ldots \ldots \ldots$. . . . . . . . . . . . . . . . . . . . . . . . . . 


\section{Lista de Tabelas}

2.1 Correspondência entre as notações de Siegbahn e da IUPAC para algumas transições decorrentes de vacâncias nas camadas K e L. . . . . . . . . . 9

2.2 Relação entre os números quânticos principais nas transições atômicas mais frequentes, junto com a nomenclatura. . . . . . . . . . . . . 10

2.3 Energias das linhas de raios x L do Ta, W e Au obtidas das referências Deslattes et al. [12] e Bearden [29]. . . . . . . . . . . . . . . . . . . . . . . 12

2.4 Energias dos limiares de ionização das subcamadas $\mathrm{L}_{1}, \mathrm{~L}_{2}$ e $\mathrm{L}_{3}$ do Ta, W e Au, obtidas da referência Deslattes et al. [12]. . . . . . . . . . . . . . . . 13

2.5 Energias das linhas de raios x $\mathrm{K}$ do $\mathrm{Cu}$, obtidas da referência Deslattes et al. $[12] . \ldots \ldots \ldots \ldots \ldots \ldots$

3.1 Valores do coeficiente $\alpha$, expressão (3.28), para algumas transições L de interesse neste trabalho. . . . . . . . . . . . . . . . . . 30

4.1 Estimativas das densidades superficiais de massa dos alvos de $\mathrm{Cu}$, Ta, W e Au determinadas pela técnica de RBS. Em parênteses, o desvio padrão em unidades do dígito menos significativo. . . . . . . . . . . . . . 57

5.1 Estimativas dos parâmetros $a, b$ e $d$, expressão (5.1), da calibração de energia (em keV) dos detetores posicionados a $31^{\circ}$, 90 e $125^{\circ}$ em relação à direção do feixe incidente. Em parênteses, o desvio padrão em unidades do dígito menos significativo. Na última coluna é apresentando o desvio padrão (em eV) para a energia de $10 \mathrm{keV}$ calculada com a calibração realizada. 72

5.2 Estimativas dos parâmetros $\mu$ e $\rho$ da resolução (FWHM), equação (5.2), dos detetores posicionados a $31^{\circ}, 90^{\circ}$ e $125^{\circ}$ em relação à direção do feixe incidente. Em parênteses, o desvio padrão em unidades do dígito menos significativo. . . . . . . . . . . . . . . . . 76 
5.3 Valores ajustados para a espessura $L$ e o raio ativo $r_{\mathrm{c}}$ dos três detetores SD empregados no experimento. Os valores fornecidos pelo fabricante para esses parâmetros são de 0,5 mm e 2,3 mm, respectivamente. Em parênteses, o desvio padrão em unidades do dígito menos significativo. . . . . . . . . . 80

5.4 Estimativas de alta precisão para a espessura $\mathcal{L}$ dos três detetores SD do experimento. Em parênteses, o desvio padrão em unidades do dígito menos significativo........................ 8

5.5 Razão $r_{i}$, equação (5.11), com $i$ as linhas $\mathrm{L} \ell, \mathrm{L} \alpha_{1}$ e $\mathrm{L} \alpha_{2}$ dos elementos Ta, W e Au, para o detetor posicionado a $31^{\circ}$ com relação a direção do feixe incidente, empregando como elemento de referência ref o $\mathrm{Cu}$. Em parênteses, o desvio padrão em unidades do dígito menos significativo. . . .

6.1 Razão entre os desvios padrões e as estimativas de áreas das linhas de raios x $\mathrm{L} \ell, \mathrm{L} \alpha_{1}$ e $\mathrm{L} \alpha_{2}$ do Ta para todas as energias do feixe de elétrons incidente,

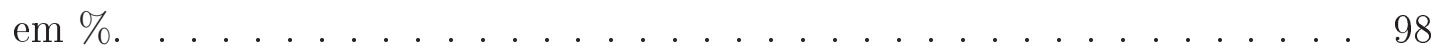

6.2 Mesmo que a tabela 6.1 , mas para o alvo de W. . . . . . . . . . . . 98

6.3 Mesmo que a tabela 6.1, mas para o alvo de Au. . . . . . . . . . . . . . 99

6.4 Coeficientes de correlação entre as estimativas das áreas dos picos $\mathrm{L} \ell, \mathrm{L} \alpha_{1}$ e $\mathrm{L} \alpha_{2}$ do Ta, W e Au nos espectros adquiridos com elétrons de aproximadamente 20,79(9), 100,65(7) e 30,62(15) keV, respectivamente, para o detetor em $31^{\circ} \ldots \ldots \ldots \ldots \ldots \ldots$

6.5 Estimativas do produto $\xi \alpha A_{20}$ obtidas pelo ajuste dos parâmetros da expressão (3.40) aos dados experimentais referente a razão $A_{\mathrm{K} \beta} / A_{\mathrm{K} \alpha}$. Em parênteses, o desvio padrão em unidades do dígito menos significativo. . . 102

6.6 Probabilidades de transições Coster-Kronig para os elementos Ta, W e Au, obtidas das referências Kolbe et al. [30] para o Au, e de Krause [31] para o Ta e o W. A incerteza de $f_{13}^{\prime}$ não foi divulgada pelos autores; foi escolhido um valor típico, mas arbitrário, que pode ser multiplicado por 10 e não afetará a incerteza do coeficiente $\kappa_{\mathrm{CK}} \ldots \ldots$. . . . . . . . . . . . . 108

7.1 Valores do parâmetro de alinhamento $A_{20}$ do Xe para as energias da referência Küst e Mehlhorn [3] e calculados com o programa deste trabalho empregando as aproximações de HS e DHS para descrever o potencial atômico. 
8.1 Estimativa do parâmetro de alinhamento do Ta para cada uma das energias de irradiação. $A_{20}^{\text {raw }}$ corresponde ao valor ajustado para o produto $\xi A_{20}$, $A_{20}^{\text {exp }}$ ao valor corrigido para os efeitos das transições Coster-Kronig, a abertura do feixe de elétrons no alvo e a autoabsorção dos fótons e $A_{20}^{\text {teo }}$ ao valor teórico obtido com aproximação de Born de ondas planas com o potencial atômico calculado na aproximação de DHS. O número entre parênteses é o desvio padrão estimado, em unidades do algarismo menos significativo do valor da grandeza. . . . . . . . . . . . . . . . . . . . . 135

8.2 Mesmo que a tabela 8.1, para o alvo de W. . . . . . . . . . . . 135

8.3 Mesmo que a tabela 8.1, mas para o alvo de $\mathrm{Au} \ldots \ldots . \ldots 136$

8.4 Estimativa do produto $\xi \alpha A_{20}$, equação (3.40), para a linha L $\eta$ e o multipleto $\mathrm{L} \gamma$ do Ta. O número entre parênteses é o desvio padrão estimado, em unidades do algarismo menos significativo do valor da grandeza. . . . . 139

8.5 Mesmo que a tabela 8.4, para o alvo de W. . . . . . . . . . . 139

8.6 Mesmo que a tabela 8.4, mas para o alvo de Au. . . . . . . . . . . . . 140

8.7 Medidas das seções de choque de produção de raios x $\mathrm{L} \alpha, \mathrm{L} \beta, \mathrm{L} \gamma$, L $\ell$ e L $\eta$ do $\mathrm{Au}$ por impacto de elétrons. Em parênteses, o desvio padrão em unidades do dígito menos significativo. . . . . . . . . . . . . . . . . 141

8.8 Seções de choque de ionização atômica das subcamadas $L_{1}, L_{2}$ e $L_{3}$ do $A u$ por impacto de elétrons. Em parênteses, o desvio padrão em unidades do dígito menos significativo. . . . . . . . . . . . . . . . . . . 143

9.1 Estimativa do parâmetro de alinhamento $A_{20}$ empregando as linhas L $\ell$, $\mathrm{L} \alpha_{1}$ e $\mathrm{L} \alpha_{2}$ separadamente. O número entre parênteses é o desvio padrão estimado, em unidades do algarismo menos significativo do valor da grandeza.147

A.1 Estimativas do parâmetro $\tau_{\mathrm{C}}$ em $\mu$ s empregando o procedimento $\mathrm{SMP}_{f}$. As estimativas classificadas de DPP foram deduzidas usando a equação (A.3) com $E_{d}=220 \mathrm{eV}, F=0,08$ para o espectro ML e $F=0,03$ para o espectro L. Em parênteses, o desvio padrão em unidades do dígito menos significativo.

A.2 Valores médios dos parâmetros $T_{a}$ e $E_{d}$ encontrados a partir do ajuste do modelo $\mathrm{EDP}_{i}$ aos dados experimentais para os espectros ML e L. Em parênteses, o desvio padrão em unidades do dígito menos significativo. . 176 


\section{Sumário}

1 Introdução 1

1.1 Motivação ................................. 1

1.2 Estrutura do trabalho . . . . . . . . . . . . . . . . . 4

2 Conceitos preliminares $\quad 7$

2.1 Espectros de raios $x$, nomenclaturas e energias . . . . . . . . . . 7

$2.1 .1 \quad$ Espectros de raios $x \ldots \ldots \ldots 7$

2.1.2 Notação para as linhas características de raios x . . . . . . . . 8

2.1.3 Classificação das transições atômicas . . . . . . . . . . . . . . 8

2.1.4 Energias das linhas de raios x empregadas neste trabalho . . . . . . 11

2.2 Tratamento estatístico de dados . . . . . . . . . . . . . . . 13

2.2.1 Propagação de incertezas e cálculo de covariâncias . . . . . . . . . . 14

2.2.2 Método dos Mínimos Quadrados . . . . . . . . . . . . . . 15

3 Fundamentos teóricos $\quad 19$

3.1 Tensores estatísticos e o alinhamento atômico . . . . . . . . . . . . 19

3.1.1 O operador densidade na base $|J M\rangle \ldots \ldots . \ldots . \ldots . \ldots 20$

3.1.2 Propriedades de simetria dos tensores estatísticos . . . . . . . . . 21

3.1.3 Condições da simetria axial . . . . . . . . . . . . . . . . 23

3.1.4 Exemplos de tensores estatísticos . . . . . . . . . . 25

3.2 Distribuição angular de raios x e o parâmetro de alinhamento atômico $A_{20} \quad 29$

3.3 A medida do alinhamento atômico . . . . . . . . . . . . . . . . . 31 
3.4 Cálculo do parâmetro de alinhamento . . . . . . . . . . . . . . . 32

3.5 Efeitos e correções na medida da distribuição angular . . . . . . . . . . . . 33

3.5.1 Efeitos das transições Coster-Kronig . . . . . . . . . . . . . . . . . 34

3.5.2 Abertura do feixe de elétrons dentro do alvo . . . . . . . . . . 35

3.5.3 Autoatenuação dos fótons . . . . . . . . . . . . . . . . 37

3.5.4 Expressão da distribuição angular atenuada . . . . . . . . . . . 38

3.6 Experimentos de anisotropia e distribuição angular de elétrons Auger e raios $\mathrm{x}$ - revisão da literatura . . . . . . . . . . . . . . . . . . . . 38

3.6.1 Anisotropia pela distribuição angular de elétrons Auger . . . . . . . 39

3.6.2 Anisotropia pela distribuição angular de raios x . . . . . . . . . . . 40

3.6.2.1 Experimentos de fotoionização com fótons de $59,54 \mathrm{keV}$ do ${ }^{241} \mathrm{Am} \ldots \ldots \ldots \ldots \ldots$. . . . . . . . . 40

3.6.2.2 Experimentos de fotoionização com fótons de energia diferente de $59,54 \mathrm{keV}$ do ${ }^{241} \mathrm{Am}$. . . . . . . . . . . . 41

3.6.2.3 Fotoionização por radiação sincrotron . . . . . . . . . . . . 43

3.6.2.4 Ionização por impacto de prótons e íons . . . . . . . . . . 44

3.6.2.5 Ionização por impacto de elétrons . . . . . . . . . . . . 45

3.6.3 Apreciação dos trabalhos experimentais . . . . . . . . . . . . . 47

$4 \quad$ Arranjo e procedimento experimental $\quad 51$

4.1 Linha de feixe do acelerador Microtron . . . . . . . . . . . . . . . 51

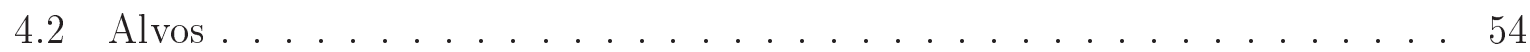

4.3 Silicon Drift Detectors - SDD . . . . . . . . . . . . . . 57

4.4 Arranjo experimental e sistema de aquisição . . . . . . . . . . . . . . . 60

4.5 Configuração dos parâmetros associados ao sistema de aquisição . . . . . . 62

4.5.1 Tempo de subida e patamar . . . . . . . . . . . . 63

4.5.2 Limiar lento e rápido . . . . . . . . . . . . . . . . . . . . 65 
4.6 Escolha dos elementos, energias e ângulos de medição no experimento de distribuição angular . . . . . . . . . . . . . . . . . . . 66

4.7 Procedimento experimental da medida de distribuição angular . . . . . . . . 68

4.8 Procedimento experimental da medida de seção de choque de ionização das

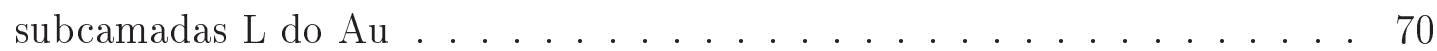

5 Caracterização do arranjo experimental $\quad 71$

5.1 Calibração de energia e resolução dos detetores . . . . . . . . . . . . . . 71

5.2 Determinação da eficiência de pico . . . . . . . . . . . . . . . . . . 74

5.2.1 Modelo analítico para a eficiência de pico . . . . . . . . . . 76

5.2 .2 Determinação experimental da eficiência de pico . . . . . . . . . . 78

5.2.3 Procedimento de ajuste e resultados . . . . . . . . . . . . . . . . 79

5.3 Estimativa da eficiência de pico relativa . . . . . . . . . . . . . . . 81

5.4 Correção de empilhamento e tempo morto . . . . . . . . . . . . . . 85

5.4.1 Distribuição de empilhamento . . . . . . . . . . . . . . . 86

5.4 .2 Estimativa do tempo morto de aquisição . . . . . . . . . . . . . . . 87

6 Análise de dados $\quad 89$

6.1 A função Voigt . . . . . . . . . . . . . . . . . . . . . . . . . . . . 89

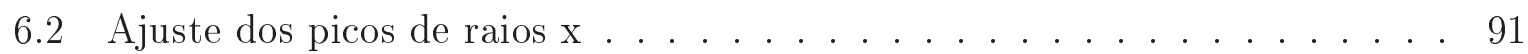

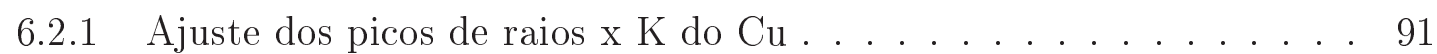

6.2.2 Ajuste dos picos de raios x L do Ta, W e do $\mathrm{Au} \ldots . . . . . .993$

6.2.2.1 Modelo ...................... . . 93

6.2.2.2 Escolha dos parâmetros de ajuste . . . . . . . . . . . 96

6.2.2.3 Exemplos dos resultados e avaliação do procedimento e dos desvios padrões . . . . . . . . . . . . . . . . . 97

6.3 Estimativa do parâmetro de alinhamento . . . . . . . . . . . . . . . 101

6.3.1 Anisotropia do arranjo experimental . . . . . . . . . . . . . . 101 
6.3.2 Análise com as linhas $\mathrm{L} \ell, \mathrm{L} \alpha_{1}$ e $\mathrm{L} \alpha_{2} \ldots . . . . . . . .102$

6.4 Linhas e grupos com emissão isotrópica . . . . . . . . . . . . . . . . 107

6.5 Correções devido às transições Coster-Kronig . . . . . . . . . . . . . . . . 107

6.6 Correção devido à abertura do feixe de elétrons no alvo . . . . . . . . . . . 108

6.7 Correções devido à atenuação dos fótons no alvo . . . . . . . . . . . . . . 110

6.8 Seções de choque de produção de raios x . . . . . . . . . . . . . . . . . . 112

6.9 Seções de choque de ionização das subcamadas L . . . . . . . . . . . . . . 114

7 Cálculo teórico do parâmetro de alinhamento

7.1 Implementação do programa de alinhamento . . . . . . . . . . . . . . . 117

7.1.1 Cálculo do elemento de matriz . . . . . . . . . . . . . . . 118

7.1.2 Integração no momento e na energia do elétron ejetado . . . . . . . 119

7.2 Comparação com os resultados de Mg, Ar e Xe já publicados . . . . . . . . 119

7.3 Testes prévios para o cálculo do parâmetro de alinhamento do Ta, W e Au 122

7.3.1 Integrais radiais, no momento e na energia do elétron ejetado . . . . 122

7.3.2 Convergência com o momento angular do elétron ejetado $l^{\prime}$. . . . . 125

7.4 Detalhes do cálculo para os elementos Ta, W e Au . . . . . . . . . . 125

8 Resultados experimentais e teóricos

8.1 Distribuições angulares das linhas $\mathrm{L} \ell, \mathrm{L} \alpha_{1}$ e $\mathrm{L} \alpha_{2} \ldots \ldots$. . . . . . . . . . 129

8.2 Parâmetro de alinhamento $A_{20} \ldots \ldots$. . . . . . . . . . 134

8.3 Coeficientes de alinhamento da linha $\mathrm{L} \eta$ e do multipleto $\mathrm{L} \gamma$. . . . . . . . . 135

8.4 Seções de choque de produção de raios x e de ionização atômica das subcamadas L . . . . . . . . . . . . . . . . . . . . . 136

9 Discussão

9.1 Anisotropia na emissão das linhas de raios x L . . . . . . . . . . . . . . 145 
9.2 Estimativa do parâmetro de alinhamento empregando três linhas simulta-

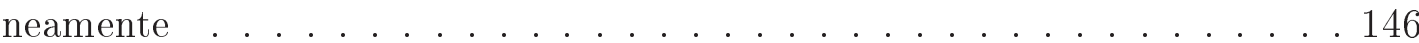

9.3 Comportamento limiar do parâmetro de alinhamento $A_{20}$. . . . . . . . 148

9.4 Estimativas do parâmetro de alinhamento $A_{20}$ acima do limiar de ionização

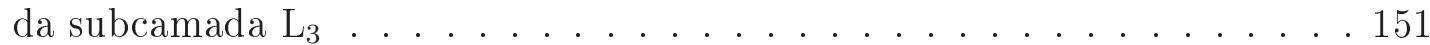

9.5 Distribuição angular da linha $\mathrm{L} \eta$ e do multipleto $\mathrm{L} \gamma$. . . . . . . . . . . . . 153

9.6 Seções de choque de produção de raios x L e de ionização das subcamadas

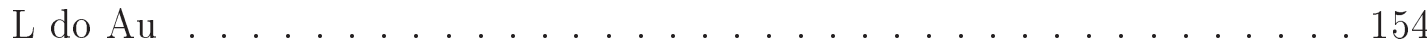

10 Conclusão

Referências

Apêndice A - Estimativa do tempo morto de aquisição

A.0.0.1 Modelo analítico . . . . . . . . . . . . . 171

A.0.0.2 Validação Experimental . . . . . . . . . . . . . 173

A.0.0.3 Análise de dados . . . . . . . . . . . . . . . . . . 174

Modelo Padrão (SM) . . . . . . . . . . . . . . . . . . . . 174

Tempo morto com dependência na energia e com a correção do empilhamento $\left(\mathrm{EDP}_{i}\right) \ldots \ldots \ldots \ldots$

A.0.0.4 Resultados . . . . . . . . . . . . . 175

A.0.0.5 Avaliação dos modelos para correção do tempo morto . . . 178

Apêndice B - Ajuste dos parâmetros dos picos de raios X K do Cu e L do Ta, W e

$\mathrm{Au}$

Apêndice C - Distribuição angular das linhas $\mathrm{L} \ell, \mathrm{L} \alpha_{1}$ e $\mathrm{L} \alpha_{2}$ do Ta

Apêndice D - Distribuição angular das linhas $\mathrm{L} \ell, \mathrm{L} \alpha_{1}$ e $\mathrm{L} \alpha_{2}$ do W 


\section{Capítulo 1}

\section{Introdução}

\subsection{Motivação}

A ionização por impacto de elétrons é um dos fenômenos associados à interação elétronátomo que é importante em muitos campos de aplicação. Quando o elétron atômico ejetado pertence a uma camada interna, efeitos moleculares são secundários e espera-se uma boa descrição do processo. Do ponto de vista teórico, é previsto que a ionização por impacto de elétron conduza ao alinhamento do momento angular do íon resultante na direção do feixe incidente sempre que o momento angular total $J$ da subcamada onde a vacância foi criada for maior do que $1 / 2$ [15]. Em consequência, as linhas de raios x decorrentes do preenchimento dessas vacâncias apresentarão emissão não isotrópica.

A medida do alinhamento fornece informação sobre o processo de ionização ao determinar as seções de choque relativas dos diferentes estados de momento angular dos elétrons envolvidos, e sua explicação é um teste sensível dos modelos teóricos, contribuindo para o aperfeiçoamento deles. Além disso, quando uma radiação é anisotrópica, é preciso conhecer sua distribuição angular para determinar corretamente a seção de choque de produção de raios x, uma vez que normalmente medem-se os fótons emitidos apenas em um pequeno ângulo sólido subtendido pelo detetor. Assim, em princípio, todas as medidas baseadas nesses raios x que não levaram essa anisotropia em conta apresentam um erro sistemático, cuja importância depende da energia do projétil, como será mostrado neste trabalho.

O alinhamento de vacâncias criadas em camadas internas produzidas por fotoionização e impacto de prótons ou elétrons tem sido estudado tanto experimental quanto teoricamente nas últimas quatro décadas $[1,15,32,33]$. O alinhamento atômico provém 
das diferenças entre as probabilidades de ionização dos vários subestados de projeção do momento angular.

$\mathrm{Na}$ excitação por impacto de elétrons de camadas atômicas externas o alinhamento e a orientação são fenômenos muito estudados e bem conhecidos [34,35]. Contudo, apesar do conhecimento das leis básicas envolvidas nos processos de interação dos elétrons com os átomos estar bem estabelecido, o alinhamento atômico e a consequente emissão não isotrópica de algumas linhas de raios x ainda não havia sido conclusivamente observado e quantificado no caso da ionização por impacto de elétrons.

O alinhamento atômico pode ser determinado por meio da medida da polarização da radiação emitida ou da distribuição angular dos elétrons Auger ou dos raios x. Os estudos existentes hoje fundamentados na observação dos elétrons Auger são restritos a alvos gasosos, em sua grande maioria a átomos de $\mathrm{Mg}$ e $\mathrm{Ar}$, sendo que os experimentos realizados até 1994 foram revistos por Mehlhorn [36], que chamou a atenção para a dificuldade associada à interação pós-colisão entre os dois elétrons emergentes e o elétron de autoionização, que tende a deformar as linhas emitidas, além de atenuar a distribuição angular observada. Já os experimentos baseados na distribuição angular ou na polarização dos raios x emitidos são escassos, inconsistentes e em sua maioria afetados por grandes incertezas. As conclusões de Mehlhorn [36] sobre o alinhamento atômico por impacto de elétrons ainda são válidas, no que pesem os trabalhos posteriores, e limitam-se a indicar que o alinhamento é um fenômeno de limiar, sem sugerir a dependência com a energia que foi encontrada neste trabalho, mais complexa e que não pode ser explicada pelos modelos encontrados na literatura hoje.

No Microtron de São Paulo, localizado no Laboratório do Acelerador Linear do Instituto de Física da Universidade de São Paulo, existe uma linha de feixe de baixa energia com elétrons entre 10-100 keV, que opera há cerca de 4 anos [37]. A instalação, projetada para experimentos de interação de elétrons com a matéria, possui uma câmara de irradiação que foi planejada tendo em vista este experimento de distribuição angular da radiação, com janelas espectroscópicas situadas em ângulos adequados para a medição, permitindo minimizar as incertezas do resultado final. O experimento prévio deste trabalho deixou evidente que a medida da distribuição angular somente seria conclusiva com a medição simultânea da radiação em vários ângulos, de modo que foi elaborado um projeto FAPESP para a aquisição de mais dois Silicon Drift Detectors, que permitiram a tomada de espectros de raios x com alta resolução e em três ângulos simultaneamente. Além disso, o Instituto de Física conta com laboratórios onde é possível confeccionar e caracterizar os 
alvos empregados nos experimentos. Entre os trabalhos recentes realizados no Microtron de São Paulo estão as medidas de seções de choque de ionização da camada $\mathrm{K}$ do Au e Bi, de Fernández-Varea et al. [38] e da camada K da Ag, de Vanin et al. [39], as medidas de seção de choque de ionização das subcamadas L do Au entre 50 e 100 keV, realizadas por Barros et al. [21], as medidas de seção de choque de bremsstrahlung duplamente diferencial do C, Al, Te, Ta e Au, realizadas por García-Alvarez et al. [40] e as medidas de seções de choque de ionização da camada K do Te e do Ta realizadas por Santos [41].

O objetivo principal deste trabalho é avançar na compreensão do aspecto ainda controverso relacionado ao alinhamento atômico na ionização de camadas internas por impacto de elétrons, que pode levar à anisotropia na emissão dos raios x. Para tanto, foram realizadas medidas de distribuição angular dos raios x L do Ta, W e Au em três ângulos distintos, para o intervalo de energia desde o limiar de ionização da subcamada $\mathrm{L}_{3}$ do elemento estudado até $100 \mathrm{keV}$, que corresponde à energia máxima alcançada pelo Microtron de São Paulo. Fez parte dos objetivos secundários desta pesquisa quantificar o erro sistemático introduzido nas medidas de secões de choque de produção de raios x L e de ionização das subcamadas L quando se considera que as linhas provenientes de vacâncias na subcamada $\mathrm{L}_{3}$ são emitidas de forma isotrópica.

As etapas necessárias para a concretização desta pesquisa, que exigiu medida precisa das intensidades relativas de emissão, foram:

i) Caracterizar a espessura e a uniformidade dos alvos finos empregados no experimento com a técnica de espectrometria de retroespalhamento de Rutherford.

ii) Testar o modelo analítico de eficiência de pico de Seltzer [42] nos Silicon Drift Detectors empregados neste trabalho.

iii) Desenvolver uma metodologia para determinar a eficiência de pico relativa com precisão da ordem de $10^{-3}$.

iv) Desenvolver um modelo de correção dos espectros medidos com os Silicon Drift Detectors para as perdas devido ao tempo morto durante a aquisição.

v) Desenvolver um algoritmo para o ajuste dos picos de raios $\mathrm{x}$ do multipleto $\mathrm{L}$ representados por funções de Voigt, em um único procedimento.

vi) Desenvolver uma metodologia de análise para a estimativa do parâmetro de alinhamento empregando as linhas $\mathrm{L} \ell, \mathrm{L} \alpha_{1}$ e $\mathrm{L} \alpha_{2}$ simultaneamente.

vii) Modelar e quantificar os efeitos que influem na medida da distribuição angular 
dos raios x para o caso da radiação emitida pela ionização de um alvo sólido por impacto de elétrons.

viii) Desenvolver um programa para o cálculo teórico do parâmetro de alinhamento empregando a aproximação de Born de ondas planas não relativística, conforme apresentado por Berezhko e Kabachnik [15], com os potenciais atômicos calculados nas aproximações de Hartree-Slater [43] e Dirac-Hartree-Slater [44, 45].

Convém acrescentar que os resultados decorrentes das etapas ii), iv) e v) foram publicados em [46], [47] e [48], respectivamente. Esta última publicação traz também uma contribuição mais significativa, haja vista os trabalhos recentes de Rahangdale et al. [20] e Pindzola [28]. Em 2014, Rahangdale et al. [20] apresentou medidas de seções de choque de ionização das subcamadas L do Au para energias do elétron incidente desde o limiar de ionização $\mathrm{L}_{3}$ até $40 \mathrm{keV}$. Embora as seções de choque de ionização da subcamada $\mathrm{L}_{3}$ fossem compatíveis com outros dados experimentais da literatura e com a aproximação de Born de ondas distorcidas (DWBA) [22,23], para a subcamada $\mathrm{L}_{1}$ as seções de choque foram inconsistentes com os demais trabalhos experimentais e com os modelos teóricos. Por outro lado, nesse mesmo ano, Pindzola [28] calculou as seções de choque de ionização da camada K e das subcamadas $\mathrm{L}_{i}$ dentro do formalismo Subconfiguration-average distortedwave (SCADW), incluindo o termo transverso da interação elétron-elétron no cálculo. Embora as seções de choque de ionização calculadas com a SCADW sejam consistentes com os dados experimentais para a camada $\mathrm{K}$ do Te, Au e Ta [28,41], para as seções de choque de ionização das subcamadas $\mathrm{L}_{i}$ do Au os formalismos DWBA e SCADW prevêem basicamente os mesmos valores, que no caso da subcamada $L_{1}$ são quase um fator dois maiores do que os valores experimentais reportados por Rahangdale et al. [20]. Diante deste contexto, Pindzola [28] encorajou a realização de novos experimentos para resolver essa questão. Nossos resultados não confirmaram a discrepância encontrada por Rahangdale et al. [20], mas apontaram para inconsistências nos modelos usados atualmente [48].

\subsection{Estrutura do trabalho}

Os conceitos relacionados à emissão e à nomenclatura de raios x e os métodos de tratamento estatístico de dados são apresentados em separado no capítulo 2, pois eles serão usados de forma recorrente ao longo de todo o texto.

No capítulo 3, encontram-se as ferramentas teóricas necessárias ao entendimento deste trabalho. Discute-se o conceito de tensores estatísticos, fundamentais no estudo da distri- 
buição angular dos raios $\mathrm{x}$, seguido das expressões empregadas no cálculo do parâmetro de alinhamento $A_{20}$ com a aproximação de Born de ondas planas, conforme deduzido por Berezhko e Kabachnik [15]. Na sequência são apresentados os efeitos que afetam a distribuição angular dos raios x em uma medida por ionização com impacto de elétrons em alvos sólidos, com as respectivas correções. Por fim, é feita uma revisão bibliográfica dos experimentos de distribuição angular pela medida tanto de elétrons Auger quanto de raios x, em que o íon foi produzido por fotoionização, impacto de prótons e outros íons e por impacto de elétrons.

O capítulo 4 apresenta o arranjo e o procedimento experimental empregado na realização das medidas, enquanto que o capítulo 5 descreve a caracterização do arranjo experimental, em particular, as calibrações de energia e resolução dos detetores, junto com a determinação da eficiência de pico e do tempo morto durante a aquisição.

As descrições do procedimento de ajuste dos parâmetros dos picos dos raios x e da metodologia de estimativa do parâmetro de alinhamento são apresentadas no capítulo 6 , enquanto que o capítulo 7 traz os procedimentos numéricos empregados no cálculo do parâmetro de alinhamento na aproximação de Born de ondas planas não relativística. Os resultados encontram-se no capítulo 8 e a discussão no capítulo 9 , com as conclusões finais do trabalho no capítulo 10. 



\section{Capítulo 2}

\section{Conceitos preliminares}

Neste capitulo serão apresentados os conceitos relacionados à emissão e à nomenclatura de raios $x$, junto com um breve resumo dos principais tópicos de tratamento estatístico de dados empregados ao longo da análise dos dados.

\subsection{Espectros de raios $\mathrm{x}$, nomenclaturas e energias}

Nesta seção, serão apresentados os espectros de raios x analisados neste trabalho, a maneira como eles são nomeados na literatura, e as energias das linhas empregadas na estimativa do parâmetro de alinhamento.

\subsubsection{Espectros de raios $\mathrm{x}$}

Os elétrons de um feixe, quando atravessam uma amostra, podem colidir com os elétrons das subcamadas internas dos átomos. Devido à interação coulombiana, o elétron do feixe pode ceder energia suficiente para arrancar um elétron do átomo. Nesta situação, o íon residual fica em um estado excitado e pode voltar ao seu estado fundamental emitindo fótons com energias características, que pertencem ao espectro de raios x característicos do elemento. Por outro lado, os elétrons do feixe ao interagirem com o átomo através do campo coulombiano podem ser acelerados/desacelerados e consequentemente, emitirão radiação de freamento. Essa radiação contínua recebe o nome de bremsstrahlung $[49,50]$. O espectro total de raios $\mathrm{x}$ emitido quando um feixe de elétrons incide sobre um material consiste, portanto, de uma parte discreta superposta a um contínuo, como mostra a figura 2.1 . 


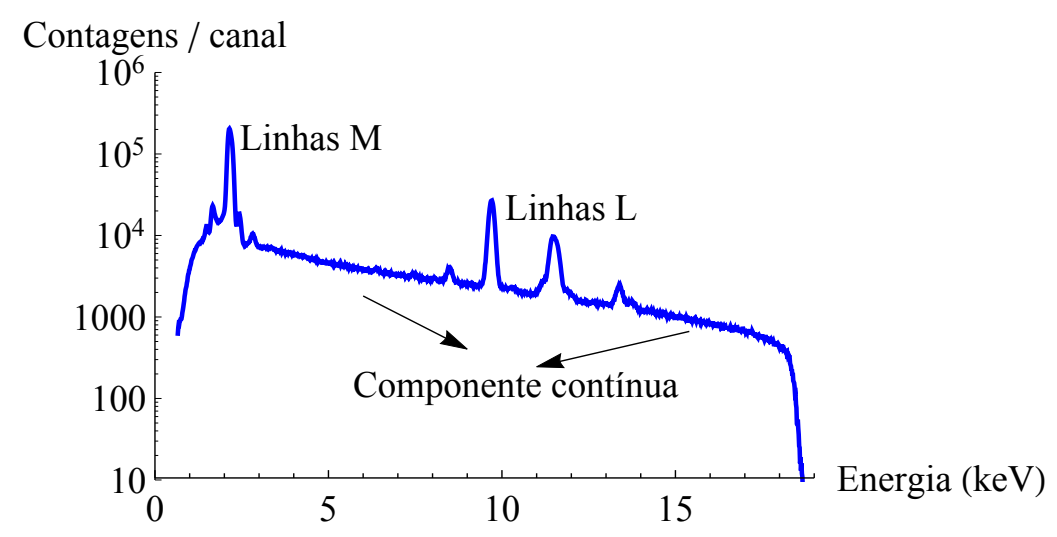

Figura 2.1: Espectro de raios $\mathrm{x}$ do $\mathrm{Au}$ com as linhas características $\mathrm{M}$ e L superpostas à componente contínua. A energia do feixe incidente foi de $18,8 \mathrm{keV}$. A dispersão em energia é $13 \mathrm{eV} /$ canal.

\subsubsection{Notação para as linhas características de raios $\mathrm{x}$}

As linhas de raios x característicos emitidas nas transições radiativas subdividem-se em grupos de acordo com a camada em que a vacância foi gerada. Tem-se o grupo das linhas K, o das linhas L, das linhas M e assim sucessivamente. Há atualmente duas maneiras de nomear essas linhas. A notação da IUPAC (International Union of Pure and Applied Chemistry) descreve quais foram as camadas ou subcamadas envolvidas na transição: primeiro se coloca a camada para onde o elétron decai e na sequência a camada de onde ele partiu [51]. A notação de Siegbahn usa uma letra maiúscula para indicar a camada onde a vacância foi gerada e letras gregas para indicar a intensidade dos picos, com intensidade descrescente a medida que se avança a ordem alfabética, começando pela letra grega $\alpha$; com números naturais como sub-índice se denota o desdobramento. Para uma linha de raios x resultante da transição de um elétron da subcamada $\mathrm{M}_{5}$ para a subcamada $\mathrm{L}_{3}$ a IUPAC estabelece a notação $\mathrm{L}_{3}-\mathrm{M}_{5}$, enquanto que na notação de Siegbahn usa-se $\mathrm{L} \alpha_{1}$. A tabela 2.1 apresenta a correspondência entre essas duas notações para as linhas mais usadas neste trabalho [51].

\subsubsection{Classificação das transições atômicas}

Os estados dos elétrons em uma camada/subcamada atômica se classificam de acordo com o momento angular e com a orientação do spin. A camada K, por exemplo, é formada por um único nível atômico $1 \mathrm{~s}_{1 / 2}$, enquanto que a camada $\mathrm{L}$ apresenta três subcamadas, a $\mathrm{L}_{1}$, que corresponde ao orbital atômico $2 \mathrm{~s}_{1 / 2}$, a subcamada $\mathrm{L}_{2}$, que corresponde ao orbital $2 \mathrm{p}_{1 / 2}$, e a $\mathrm{L}_{3}$, ao orbital $2 \mathrm{p}_{3 / 2}$. Para a camada $\mathrm{M}$ têm-se cinco subcamadas: a $\mathrm{M}_{1}$ que corresponde ao orbital $3 \mathrm{~s}_{1 / 2}$, a $\mathrm{M}_{2}$ ao orbital $3 \mathrm{p}_{1 / 2}$, a $\mathrm{M}_{3}$ ao orbital $3 \mathrm{p}_{3 / 2}$, a $\mathrm{M}_{4}$ ao orbital 
Tabela 2.1: Correspondência entre as notações de Siegbahn e da IUPAC para algumas transições decorrentes de vacâncias nas camadas K e L.

\begin{tabular}{cccccccc}
\hline \hline Siegbahn & IUPAC & Siegbahn & IUPAC & Siegbahn & IUPAC & Siegbahn & IUPAC \\
\hline $\mathrm{K} \alpha_{1}$ & $\mathrm{~K}-\mathrm{L}_{3}$ & $\mathrm{~L} t$ & $\mathrm{~L}_{3}-\mathrm{M}_{2}$ & $\mathrm{~L} \beta_{1}$ & $\mathrm{~L}_{2}-\mathrm{M}_{4}$ & $\mathrm{~L} \gamma_{1}$ & $\mathrm{~L}_{2}-\mathrm{N}_{4}$ \\
$\mathrm{~K} \alpha_{2}$ & $\mathrm{~K}-\mathrm{L}_{2}$ & $\mathrm{~L} s$ & $\mathrm{~L}_{3}-\mathrm{M}_{3}$ & $\mathrm{~L} \beta_{2}$ & $\mathrm{~L}_{3}-\mathrm{N}_{5}$ & $\mathrm{~L} \gamma_{2}$ & $\mathrm{~L}_{1}-\mathrm{N}_{2}$ \\
$\mathrm{~K} \beta_{1}$ & $\mathrm{~K}-\mathrm{M}_{3}$ & $\mathrm{~L} \eta$ & $\mathrm{L}_{2}-\mathrm{M}_{1}$ & $\mathrm{~L} \beta_{3}$ & $\mathrm{~L}_{1}-\mathrm{M}_{3}$ & $\mathrm{~L} \gamma_{3}$ & $\mathrm{~L}_{1}-\mathrm{N}_{3}$ \\
$\mathrm{~K} \beta_{3}$ & $\mathrm{~K}-\mathrm{M}_{2}$ & $\mathrm{~L} \ell$ & $\mathrm{L}_{3}-\mathrm{M}_{1}$ & $\mathrm{~L} \beta_{4}$ & $\mathrm{~L}_{1}-\mathrm{M}_{2}$ & $\mathrm{~L} \gamma_{4}$ & $\mathrm{~L}_{1}-\mathrm{O}_{2}$ \\
$\mathrm{~K} \beta_{2}$ & $\mathrm{~K}-\mathrm{N}_{2,3}$ & $\mathrm{~L} \alpha_{2}$ & $\mathrm{~L}_{3}-\mathrm{M}_{4}$ & $\mathrm{~L} \beta_{5}$ & $\mathrm{~L}_{3}-\mathrm{O}_{4,5}$ & $\mathrm{~L} \gamma_{4^{\prime}}$ & $\mathrm{L}_{1}-\mathrm{O}_{3}$ \\
$\mathrm{~K} \beta_{4}$ & $\mathrm{~K}-\mathrm{N}_{4,5}$ & $\mathrm{~L} \alpha_{1}$ & $\mathrm{~L}_{3}-\mathrm{M}_{5}$ & $\mathrm{~L} \beta_{6}$ & $\mathrm{~L}_{3}-\mathrm{N}_{1}$ & $\mathrm{~L} \gamma_{5}$ & $\mathrm{~L}_{2}-\mathrm{N}_{1}$ \\
& & & & $\mathrm{~L} \beta_{9}$ & $\mathrm{~L}_{1}-\mathrm{M}_{4}$ & $\mathrm{~L} \gamma_{6}$ & $\mathrm{~L}_{2}-\mathrm{O}_{4}$ \\
& & & & $\mathrm{~L} \beta_{10}$ & $\mathrm{~L}_{1}-\mathrm{M}_{5}$ & & \\
& & & $\mathrm{~L} \beta_{15}$ & $\mathrm{~L}_{3}-\mathrm{N}_{4}$ & & \\
& & & $\mathrm{~L} \beta_{17}$ & $\mathrm{~L}_{2}-\mathrm{M}_{3}$ & & \\
\hline \hline
\end{tabular}

$3 \mathrm{~d}_{3 / 2}$ e a subcamada $\mathrm{M}_{5}$ que corresponde ao orbital $3 \mathrm{~d}_{5 / 2}$.

Os dois principais modos de decaimento de um átomo ionizado correspondem à emissão de um fóton característico, quando se tem uma transição radiativa, e à emissão de um elétron Auger, quando se tem uma transição não radiativa.

Em uma transição radiativa $S_{0}-S_{1}$, um elétron de uma camada $S_{1}$ preenche a vacância de uma camada $\mathrm{S}_{0}$, sendo $n_{0}$ e $n_{1}$ os respectivos números quânticos principais com $n_{1}>n_{0}$, e um fóton é emitido com energia aproximadamente igual à diferença de energia entre as duas camadas envolvidas.

$\mathrm{Na}$ transição não radiativa $\mathrm{S}_{0}-\mathrm{S}_{1}-\mathrm{S}_{2}$, um elétron da camada $\mathrm{S}_{1}$ preenche a vacância da camada $\mathrm{S}_{0}$, e a energia envolvida na transição é transferida para um elétron em uma camada $\mathrm{S}_{2}$, que é ejetado do átomo. Nesse processo, as camadas $\mathrm{S}_{1}$ e $\mathrm{S}_{2}$ têm números quânticos principais diferentes da camada $\mathrm{S}_{0}, n_{1} \geqslant n_{0}$ e $n_{2} \geqslant n_{0}$, e o átomo termina com duas vacâncias, uma na camada $\mathrm{S}_{1}$ e outra na camada $\mathrm{S}_{2}$. Os átomos de elementos de menor número atômico, bem como as camadas mais externas dos átomos, são mais suscetíveis a este tipo de processo.

As transições Coster-Kronig (CK) ocorrem entre as subcamadas de uma mesma camada atômica. Uma vacância na subcamada $\mathrm{S}_{0}$ migra para a subcamada $\mathrm{S}_{1}$ mais externa, mas com mesmo número quântico principal, $n_{0}=n_{1}$, e um fóton ou um elétron de uma camada $\mathrm{S}_{2}$, com $n_{2}>n_{1}$, é emitido. Nesse processo, a probabilidade de emissão de um fóton é muito menor do que a de emissão de um elétron, de modo que as transições CK são em geral não radiativas. Para a camada L, por exemplo, as transições Coster-Kronig 
Tabela 2.2: Relação entre os números quânticos principais nas transições atômicas mais frequentes, junto com a nomenclatura.

\begin{tabular}{ccc}
\hline \hline Transição & camadas & $\mathrm{n}^{\circ}$ quânticos \\
\hline radiativa (raios x característicos) & $\mathrm{S}_{0}-\mathrm{S}_{1}$ & $n_{1}>n_{0}$ \\
não radiativa (Auger) & $\mathrm{S}_{0}-\mathrm{S}_{1}-\mathrm{S}_{2}$ & $n_{1} \geqslant n_{0}$ e $n_{2} \geqslant n_{0}$ \\
não radiativa (CK) & $\mathrm{S}_{0}-\mathrm{S}_{1}-\mathrm{X}_{2}$ & $n_{1}=n_{0}$ e $n_{2} \geqslant n_{0}$ \\
não radiativa (sCK) & $\mathrm{S}_{0}-\mathrm{S}_{1}-\mathrm{S}_{2}$ & $n_{0}=n_{1}=n_{2}$ \\
\hline \hline
\end{tabular}

são do tipo $\mathrm{L}_{i}-\mathrm{L}_{j}-\mathrm{X}_{q}$, a vacância inicial da subcamada $\mathrm{L}_{i}$ foi transferida para a subcamada $\mathrm{L}_{j}$, mais externa, e um elétron da camada $\mathrm{X}_{q}$, ou um fóton, é emitido do átomo. Quando as subcamadas $\mathrm{S}_{0}, \mathrm{~S}_{1}$ e $\mathrm{S}_{2}$ pertencem todas a mesma camada, diz-se que se trata uma transição super Coster-Kronig (sCK). Um resumo dessas transições é apresentado na tabela 2.2 .

É usual descrever esses processos por meio de taxas de produção relativas (yields). Adotaremos as definições e símbolos de Crasemann [52]:

1. yield de fluorescência $\omega_{i}^{\mathrm{L}}$ : total de fótons de raios x característicos emitidos em transições para a subcamada $\mathrm{L}_{i}$, dividido pelo número total de vacâncias na subcamada $\mathrm{L}_{i}$;

2. yield $a_{i}^{\mathrm{L}}$ : número de elétrons Auger por vacância na subcamada $\mathrm{L}_{i}$;

3. yield $f_{i j}^{\mathrm{L}}$ : número de transições que levantam as vacâncias de uma subcamada $\mathrm{L}_{i}$ para uma subcamada $\mathrm{L}_{j}$ mais alta, dividido pelo número total de vacâncias na subcamada $\mathrm{L}_{i}$.

Conforme já definido acima, as transições Coster-Kronig podem ser não radiativas ou radiativas, embora estas últimas tenham probabilidades muito pequenas. Assim, escrevese

$$
f_{i j}^{\mathrm{L}}=f_{i j}+f_{i j}^{\prime}
$$

em que a plica identifica a componente radiativa.

Quando se cria uma vacância em um átomo, ele passa para um estado instável. O tempo de vida $\tau$ de uma única vacância em um dado nível eletrônico está relacionado com a largura natural $\Gamma$ deste nível por meio da relação:

$$
\Gamma \tau=\hbar
$$


onde $\hbar$ corresponde à constante de Planck dividido por $2 \pi$. O tempo de vida $\tau$ de uma vacância em uma subcamada interna atômica é da ordem de $10^{-15} \mathrm{~s}$.

No caso da transição radiativa, a largura $\Gamma$ da linha será dada por

$$
\Gamma(X-Y)=\Gamma(X)+\Gamma(Y)
$$

em que $X$ e $Y$ correspondem aos níveis envolvidos na transição [53]. Essas larguras serão tão menores quanto mais externos forem os níveis envolvidos. Assim, nas transições decorrentes de vacâncias criadas na subcamada $\mathrm{L}_{3}$ as linhas terão larguras naturais muito parecidas, e portanto, as vacâncias terão tempos de viva $\tau$ muito próximos. Uma vez que esse tempo de vida é ordens de grandeza inferior ao que se observa no caso de excitações nucleares, é provável que não haja tempo suficiente para o sistema desalinhar, de modo que não deve haver uma atenuação do fenômeno de alinhamento atômico por esse efeito.

\subsubsection{Energias das linhas de raios $\mathrm{x}$ empregadas neste trabalho}

A fim de medir a distribuição angular de algumas das transições L, foi necessário determinar a intensidade de emissão de todas as linhas relacionadas na tabela 2.3. Essas energias foram extraídas da referência Deslattes et al. [12] para as transições que envolvem até a camada $\mathrm{N}$ e as demais foram obtidas de Bearden [29]. A figura 2.2 traz um esquema das posições das linhas do elemento Au. Uma vez que os elementos empregados no experimento têm números atômicos próximos, a ordem em energia das linhas de raios x L na figura 2.2 é a mesma nos espectros de Ta e W, exceto para a linha $\mathrm{L} \gamma_{6}$.

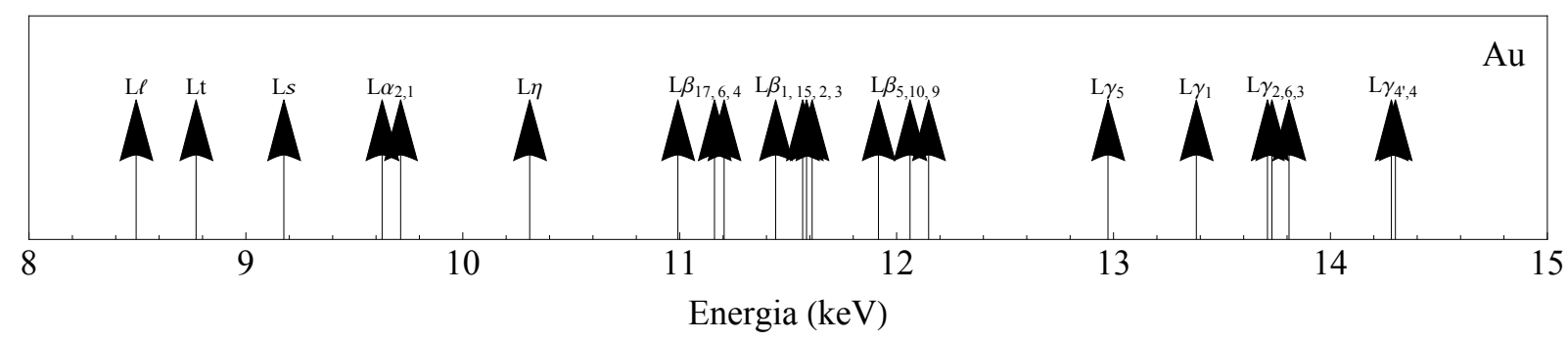

Figura 2.2: Esquema da posição das linhas de raios x L do Au incluídas nos ajustes dos espectros experimentais. A altura das setas não indica a intensidade das linhas.

A tabela 2.4 apresenta as energias dos limiares de ionização das subcamadas $\mathrm{L}_{1}, \mathrm{~L}_{2}$ e $\mathrm{L}_{3}$ dos elementos $\mathrm{Ta}(Z=73), \mathrm{W}(Z=74)$ e $\mathrm{Au}(Z=79)$, todas obtidas da referência Deslattes et al. [12], e a figura 2.3 mostra três espectros adquiridos com energias entre os limiares de ionização das subcamadas $\mathrm{L}$ do $\mathrm{Au}$, primeiro quando somente $\mathrm{L}_{3}$ é ionizada, na sequência, quando $\mathrm{L}_{2}$ e $\mathrm{L}_{3}$ são ionizadas, e por fim, quando a energia é suficiente 
Tabela 2.3: Energias das linhas de raios x L do Ta, W e Au obtidas das referências Deslattes et al. [12] e Bearden [29].

\begin{tabular}{cccc}
\hline \hline Linha & $\mathrm{Ta}(\mathrm{eV})$ & $\mathrm{W}(\mathrm{eV})$ & $\mathrm{Au}(\mathrm{eV})$ \\
\hline $\mathrm{L} \ell$ & $7173,20(31)$ & $7387,82(65)$ & $8494,03(78)$ \\
$\mathrm{L} t$ & $7412,13(35)$ & $7631,41(86)$ & $8770,31(64)$ \\
$\mathrm{L} s$ & $7686,65(38)$ & $7926,44(93)$ & $9174,97(70)$ \\
$\mathrm{L} \alpha_{1}$ & $8146,17(16)$ & $8398,242(54)$ & $9713,44(34)$ \\
$\mathrm{L} \alpha_{2}$ & $8087,93(16)$ & $8335,34(17)$ & $9628,05(33)$ \\
$\mathrm{L} \eta$ & $8428,09(42)$ & $8724,42(25)$ & $10308,41(38)$ \\
$\mathrm{L} \beta_{1}$ & $9343,19(31)$ & $9672,58(10)$ & $11442,45(47)$ \\
$\mathrm{L} \beta_{2}$ & $9651,89(22)$ & $9964,133(78)$ & $11584,75(48)$ \\
$\mathrm{L} \beta_{3}$ & $9487,62(32)$ & $9818,91(46)$ & $11610,5(14)$ \\
$\mathrm{L} \beta_{4}$ & $9212,47(30)$ & $9525,23(54)$ & $11204,81(45)$ \\
$\mathrm{L} \beta_{5}$ & 9875,0 & 10200,4 & 11916,3 \\
$\mathrm{~L} \beta_{6}$ & $9315,40(83)$ & $9608,199(74)$ & $11160,33(45)$ \\
$\mathrm{L} \beta_{9}$ & $9945,6(24)$ & $10291,13(22)$ & $12147,6(12)$ \\
$\mathrm{L} \beta_{10}$ & $9889,3(23)$ & $10228,29(24)$ & $12061,8(12)$ \\
$\mathrm{L} \beta_{15}$ & $9639,50(55)$ & $9947,95(35)$ & $11566,81(80)$ \\
$\mathrm{L} \beta_{17}$ & $8941,76(54)$ & $9268,72(48)$ & $10991,54(72)$ \\
$\mathrm{L} \gamma_{1}$ & $10895,33(43)$ & $11286,00(46)$ & $13381,79(64)$ \\
$\mathrm{L} \gamma_{2}$ & $11217,1(15)$ & $11610,50(44)$ & $13709,70(67)$ \\
$\mathrm{L} \gamma_{3}$ & $11277,68(61)$ & $11680,49(73)$ & $13809,1(11)$ \\
$\mathrm{L} \gamma_{4}$ & 11645,1 & 12063,4 & 14299,6 \\
$\mathrm{~L} \gamma_{4^{\prime}}$ & 11636,6 & 12053,0 & 14280,9 \\
$\mathrm{~L} \gamma_{5}$ & $10570,6(13)$ & $10948,91(39)$ & $12974,43(60)$ \\
$\mathrm{L} \gamma_{6}$ & 11130,6 & 11538,7 & 13730,4 \\
\hline \hline & & &
\end{tabular}


Tabela 2.4: Energias dos limiares de ionização das subcamadas $\mathrm{L}_{1}, \mathrm{~L}_{2}$ e $\mathrm{L}_{3}$ do Ta, W e Au, obtidas da referência Deslattes et al. [12].

\begin{tabular}{cccc}
\hline \hline Elemento & $\mathrm{L}_{1}(\mathrm{eV})$ & $\mathrm{L}_{2}(\mathrm{eV})$ & $\mathrm{L}_{3}(\mathrm{eV})$ \\
\hline $\mathrm{Ta}$ & $11682,1(16)$ & $11132,5(15)$ & $9876,7(12)$ \\
$\mathrm{W}$ & $12099,73(87)$ & $11538,6(16)$ & $10200,1(12)$ \\
$\mathrm{Au}$ & $14355,29(50)$ & $13734,194(70)$ & $11919,694(60)$ \\
\hline \hline
\end{tabular}

para ionizar as três subcamadas. Nesta figura, bem como nas demais que apresentam espectros medidos com os SDDs, a dispersão em energia é de $13 \mathrm{eV} /$ canal, salvo menção em contrário.

A fim de quantificar a anisotropia introduzida pelo arranjo experimental, também foram empregadas no estudo as linhas de raios $\mathrm{x} \mathrm{K}$ do $\mathrm{Cu}$. A tabela 2.5 traz as energias destas linhas extraídas da referência Deslattes et al. [12].

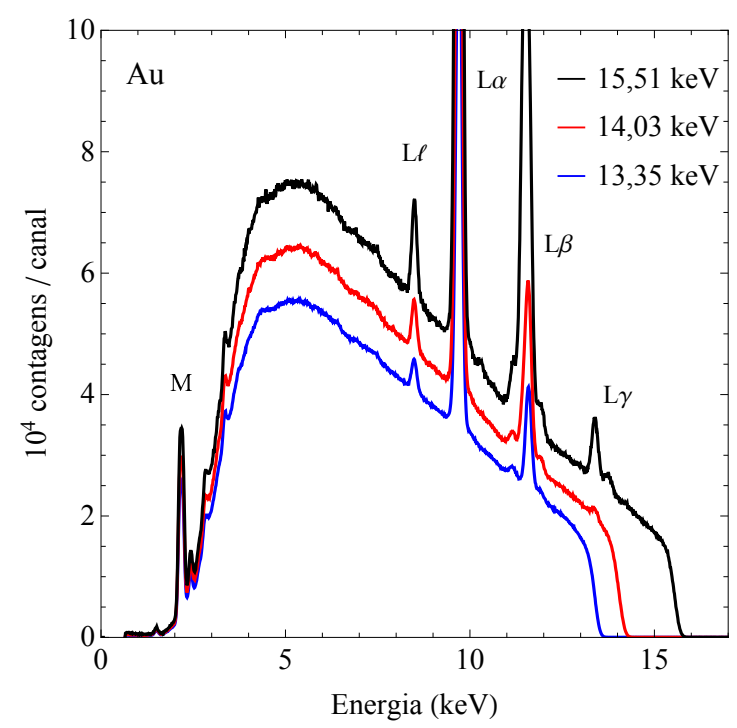

Figura 2.3: Espectros em energia dos raios x L emitidos por um alvo de Au sobre um backing de C irradiado com as energias de 13,35(9), 14,03(9) e 15, 51(9) keV. A dispersão em energia é $13 \mathrm{eV} /$ canal.

\subsection{Tratamento estatístico de dados}

Nesta seção, serão descritos sucintamente a propagação de incertezas na forma matricial, levando em conta a correlação dos parâmetros, o cálculo de covariâncias entre duas grandezas, e o método dos mínimos quadrados na sua forma mais geral. Esses conceitos foram usados nas diversas calibrações do sistema de medidas deste experimento, bem como nas 
Tabela 2.5: Energias das linhas de raios x $\mathrm{K}$ do $\mathrm{Cu}$, obtidas da referência Deslattes et al. [12].

\begin{tabular}{cc}
\hline \hline Linha & Energia $(\mathrm{eV})$ \\
\hline $\mathrm{K} \alpha_{1}$ & $8047,8227(26)$ \\
$\mathrm{K} \alpha_{2}$ & $8027,8416(26)$ \\
$\mathrm{K} \beta_{1,3}$ & $8905,413(38)$ \\
\hline \hline
\end{tabular}

várias etapas da análise dos dados.

\subsubsection{Propagação de incertezas e cálculo de covariâncias}

Nas análises conduzidas ao longo deste trabalho as incertezas foram propagadas na forma convencional, levando em conta, sempre que necessário, as covariâncias entre os dados.

Para duas funções de variáveis aleatórias $z_{1}(\vec{y})$ e $z_{2}(\vec{y})$, tais que

$$
z_{i}(\vec{y})=z_{i}\left(y_{1}, y_{2}, \ldots, y_{n}\right), \quad i=1,2
$$

A covariância entre $z_{1}$ e $z_{2}$ é dada por

$$
\operatorname{cov}\left(z_{1}, z_{2}\right) \approx \frac{\delta z_{1}^{\mathrm{t}}}{\delta \vec{y}} \mathbb{V}_{y} \frac{\delta z_{2}}{\delta \vec{y}}
$$

com $\mathbb{V}_{y}$ a matriz de variâncias e covariâncias de $\vec{y}$ e $\frac{\delta z_{i}}{\delta \vec{y}}=\left(\left.\frac{\delta z_{i}}{\delta y_{i}}\right|_{\hat{y}} \ldots\right)$. A expressão será exata quando $z_{1}$ e $z_{2}$ forem funções lineares em $\vec{y}$.

Empregando o formalismo matricial para descrever a expressão (2.4), para $\rho$ funções $z_{1}, z_{2}, \ldots, z_{\rho}$ de $\mu$ variáveis aleatórias $\vec{y}$, a matriz de variâncias e covariâncas $\mathbb{V}_{z}$ pode ser calculada como:

$$
\mathbb{V}_{z} \simeq \mathbb{C} \mathbb{V}_{y} \mathbb{C}^{\mathrm{t}}
$$

em que $\mathbb{V}_{y}$ é a matriz de variâncias e covariâncias das variáveis aleatórias do vetor $\vec{y}$ e $\mathbb{C}$ a matriz de derivadas parciais de cada $z_{i}$ em relação a cada elemento do vetor $\vec{y}$ :

$$
C_{\nu \lambda}=\frac{\delta z_{\nu}}{\delta y_{\lambda}}
$$

com $\nu=1,2, \ldots, \rho$ e $\lambda=1,2, \ldots, \mu$. Se $z_{i}$ for uma função linear de $\vec{y}$ a equação (2.6) será uma igualdade, caso contrário, as derivadas parciais da expressão (2.6) devem ser calculadas nos pontos do vetor $\vec{y}=\overrightarrow{y_{0}}$ de interesse. 


\subsubsection{Método dos Mínimos Quadrados}

Quando a função que expressa o modelo é linear nos parâmetros a serem ajustados, e as variâncias e covariâncias entre os dados são conhecidas, o método dos Mínimos Quadrados será o melhor estimador a ser empregado [54].

Representando o conjunto de parâmetros da função por um vetor $\vec{p}=\left(p_{1}, p_{2}, p_{3}, \ldots, p_{\mu}\right)$, onde cada uma das $\mu$ componentes corresponde a um parâmetro, uma função linear em $\vec{p}$ pode ser escrita, de uma maneira genérica, como:

$$
f(x ; \vec{p})=\sum_{\nu=1}^{\mu} p_{\nu} g_{\nu}(x)
$$

em que $g_{\nu}(x)$ é uma função qualquer da variável independente $x$, não sendo necessário que a função $g_{\nu}(x)$ seja linear em $x$ para que a função $f(x, \vec{p})$ seja linear em qualquer parâmetro $p_{i}$. Sendo assim, a relação entre cada dado experimental e os parâmetros pode ser escrita como:

$$
y_{i}=\sum_{\nu=1}^{\mu} p_{\nu, 0} g_{\nu, i}(x)+\epsilon_{i} \quad i=1, \ldots, N
$$

onde $\epsilon_{i}$ é o erro do dado experimental $y_{i}$, o sub-índice zero no parâmetro $p_{\nu}$ significa o valor verdadeiro deste parâmetro, e $N$ é o número de dados.

Define-se a matriz de planejamento ou de projeto como a matriz $\mathbb{X}$ de $N$ linhas e $\mu$ colunas, cujos elementos são:

$$
X_{i \nu}=g_{\nu, i}(x)
$$

Com essa definição é possível reescrever a expressão (2.8) como:

$$
\vec{y}=\mathbb{X} \overrightarrow{p_{0}}+\vec{\epsilon}
$$

Os dados e os respectivos erros na expressão (2.10) constituem dois vetores coluna, cada um com $N$ linhas. Os parâmetros também formam um vetor coluna, mas com $\mu$ linhas.

O método dos Mínimos Quadrados consiste em encontrar um vetor de estimativas $\hat{\vec{p}}$ que minimiza a função de mérito

$$
Q=(\vec{y}-\mathbb{X} \vec{p})^{\mathrm{t}} \mathbb{V}_{y}^{-1}(\vec{y}-\mathbb{X} \vec{p})
$$

em que $\mathbb{V}_{y}$ corresponde a matriz de variâncias e covariâncias dos dados experimentais $\vec{y}$. 
Para tanto, basta buscar o vetor $\hat{\vec{p}}$ que seja solução da equação:

$$
\left.\frac{\delta Q}{\delta p_{\nu}}\right|_{\hat{p}}=0 \quad \text { para } \quad \nu=1, \ldots, \mu .
$$

Resolvendo (2.12) chega-se em

$$
\hat{\vec{p}}=\left(\mathbb{X}^{\mathrm{t}} \mathbb{V}_{y}^{-1} \mathbb{X}\right)^{-1} \mathbb{X}^{\mathrm{t}} \mathbb{V}_{y}^{-1} \overrightarrow{\mathrm{y}}
$$

A matriz de variâncias e covariâncias do vetor de parâmetros $\hat{\vec{p}}$ estimados será:

$$
\mathbb{V}_{\hat{\vec{p}}}=\left(\mathbb{X}^{\mathrm{t}} \mathbb{V}_{y}^{-1} \mathbb{X}\right)^{-1}
$$

O resultado da expressão (2.14) será válido mesmo quando a função densidade de probabilidade dos dados experimentais não for gaussiana, quando a função de probabilidade dos $\hat{p}_{i}$ tenderá à normal à medida que $N$ crescer.

No caso de funções lineares nos parâmetros o método dos Mínimos Quadrados é o que fornecerá as melhores estimativas, garantindo a unicidade dos parâmetros ajustados, uma vez que os valores estimados serão não tendenciosos, eficientes e com variância mínima, mesmo quando a função densidade de probabilidade dos dados não for gaussiana. Quando as funções são não lineares nos parâmetros o método mais adequado é o da Máxima Verossimilhança, que fornecerá estimadores consistentes e assintoticamente normais, não tendenciosos e de variância mínima. Nesta situação as propriedades ótimas desse estimador, a saber, não tendenciosidade, eficiência e variância mínima, só serão alcançadas para um grande número de dados. Neste trabalho, sempre que necessário, foi realizada a análise gráfica das curvas de nível dos parâmetros a serem estimados, que devem mostrar curvas elípticas e concêntricas quando as estimativas atingiram seus valores assintóticos. Cabe lembrar que o método dos Mínimos Quadrados e o da Máxima Verossimilhança são equivalentes quando a função densidade de probabilidade dos dados for gaussiana.

A qualidade dos ajustes realizados com os métodos descritos acima foi avaliada com o teste de $\chi^{2}$, onde a grandeza $\chi^{2}$ foi calculada de acordo com a expressão:

$$
\chi^{2}=(\vec{y}-\mathbb{X} \hat{\vec{p}})^{t} \mathbb{V}_{y}^{-1}(\vec{y}-\mathbb{X} \hat{\vec{p}})
$$

Os ajustes foram considerados, em geral, adequados, quando

$$
0,05 \leq P\left(\chi_{\ell}^{2} \geq \chi_{\mathrm{obs}}^{2}\right) \leq 0,95
$$

em que $\chi_{\ell}^{2}$ corresponde ao $\chi^{2}$ para $\ell$ graus de liberdade e $\chi_{\text {obs }}^{2}$ ao valor obtido com a ex- 
pressão (2.15) para o ajuste realizado. Casos particulares foram analisados em separado, e em geral, apareceram nos ajustes dos parâmetros dos espectros medidos. Como esses espectros apresentaram alta estatística de contagem, linhas satélites e de Auger radiativo provavelmente estão presentes com intensidade acima da flutuação estatística, mas o sistema de deteção empregado não possui resolução suficiente para discerni-las. Uma vez que essas linhas não foram incluídas na função modelo, em algumas situações, o $\chi_{\text {obs }}^{2}$ foi mais elevado do que o esperado, mas o resultado não foi rejeitado.

As curvas calculadas com os parâmetros ajustados aos dados experimentais, que aparecem exemplificadas nas figuras ao longo do texto estão, em geral, acompanhadas do gráfico dos resíduos reduzidos $r_{i}$. Esses resíduos podem ser calculados a partir da matriz chapéu $\mathbb{H}$, definida como a matriz que satisfaz a igualdade $\hat{y}=\mathbb{H} y$ e avaliada com a expressão $\mathbb{H}=\mathbb{X}\left(\mathbb{X}^{\mathrm{t}} \mathbb{V}_{y}^{-1} \mathbb{X}\right)^{-1} \mathbb{X}^{\mathrm{t}} \mathbb{V}_{y}^{-1}$, de acordo com

$$
r_{i}=\frac{y_{i}-\hat{y}_{i}}{\sqrt{\sigma_{i}^{2}\left(1-h_{i i}\right)}}
$$

com $h_{i i}$ o elemento da diagonal $i$ da matriz chapéu $\mathbb{H}$, e $\sigma_{i}^{2}$ a variância do dado experimental $i$. 



\section{Capítulo 3}

\section{Fundamentos teóricos}

Neste capitulo serão apresentados os principais conceitos teóricos para o entendimento da distribuição angular anisotrópica observada na emissão de algumas linhas de raios $x$. Inicialmente será feita uma breve descrição dos tensores estatísticos, ferramenta fundamental no tratamento de distribuição angular, tanto de raios x quanto de elétrons Auger. Na sequência, serão apresentadas as expressões para o cálculo do parâmetro de alinhamento empregando a aproximação de Born de ondas planas não relativística para descrever o projétil e, por fim, serão discutidos os efeitos que podem distorcer a medida da distribuição angular em um experimento real.

\subsection{Tensores estatísticos e o alinhamento atômico}

Quando um feixe de fótons ou de partículas carregadas ioniza uma subcamada com momento angular $J>1 / 2$, é esperado do ponto de vista teórico que o momento angular do íon resultante se alinhe com a direção do feixe incidente [15], caracterizando o que se costuma chamar de alinhamento atômico. Esse alinhamento vem do fato de que os diferentes estados $M$ dentro de uma camada não têm a mesma probabilidade de serem ionizados. A grandeza que quantifica a magnitude do alinhamento atômico é o parâmetro de alinhamento, $A_{20}$. Entre as subcamadas atômicos internas, a primeira delas que satisfaz a condição $J>1 / 2$ é a $\mathrm{L}_{3}$, com $J=3 / 2$, e para ela, o parâmetro de alinhamento é definido como a diferença relativa entre as seções de choque de choque de ionização dos 
diferentes estados com número quântico $M$ :

$$
A_{20}=\frac{\sigma\left(\frac{3}{2}, \frac{3}{2}\right)-\sigma\left(\frac{3}{2}, \frac{1}{2}\right)}{\sigma\left(\frac{3}{2}, \frac{3}{2}\right)+\sigma\left(\frac{3}{2}, \frac{1}{2}\right)}
$$

em que $\sigma(3 / 2,3 / 2)$ e $\sigma(3 / 2,1 / 2)$ correspondem às seções de choque de ionização dos estados com números quânticos $j=3 / 2, m_{j}=3 / 2$ e $j=3 / 2, m_{j}=1 / 2$, respectivamente. Nesta seção serão apresentadas as ferramentas necessárias para se chegar na expressão apresentada acima, que define o parâmetro de alinhamento $A_{20}$, e que é válida desde que o sistema estudado apresente algumas condições de simetria.

É comum o uso de diagramas para representar as diferentes situações de orientação e alinhamento atômicos [55]. Esses diagramas correspondem a cortes feitos nos cones determinados pela precessão do vetor de momento angular total $J$ em torno do eixo $Z$. Cada uma das setas representa um estado $|J M\rangle$. A direção delas é a mesma no vetor $J$, e portanto determinada pela sua projeção no eixo $Z$, enquanto que o comprimento delas é proporcional à população do estado. O tratamento formal destes diagramas, bem como da expressão de $A_{20}$ apresentada acima será detalhado nas seções seguintes, no contexto quântico correto. Um sistema com todos os estados $M$ igualmente populados, e portanto, não alinhado, é representado pelo diagrama da figura $3.1 \mathrm{a}$ ), enquanto que um sistema que possui uma população não uniforme para os diferentes estados $M$, e portanto alinhado, é representado pela figura $3.1 \mathrm{~b}$ ).

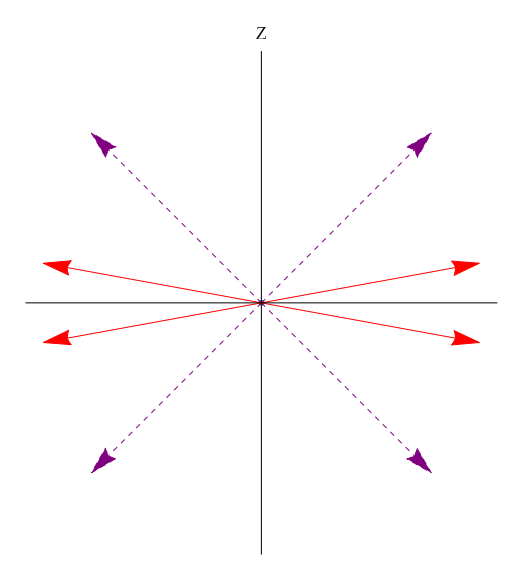

(a)

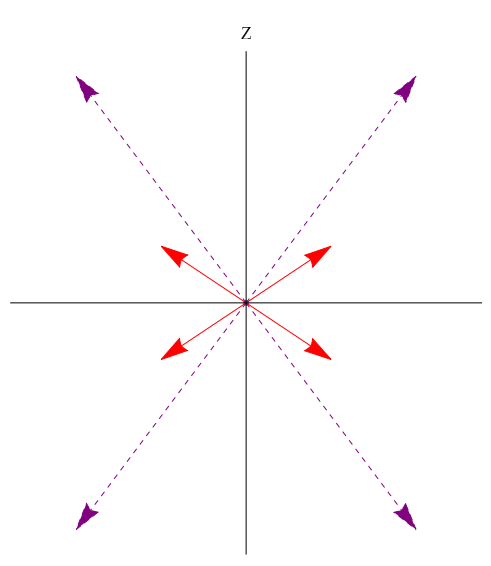

(b)

Figura 3.1: a) Sistema não alinhado. b) Sistema alinhado.

\subsubsection{O operador densidade na base $|J M\rangle$}

Considerando-se um conjunto de partículas em diferentes estados de momento angular $|J M\rangle$, o operador densidade $\rho$, que contém todas as informações sobre o sistema, na 
representação $(|J M\rangle)$ é dado por

$$
\rho=\sum_{J J^{\prime} M M^{\prime}}\left\langle J^{\prime} M^{\prime}|\rho| J M\right\rangle\left|J^{\prime} M^{\prime}\right\rangle\langle J M|
$$

que pode ser reescrito como [55]

$$
\rho=\sum_{J J^{\prime} k \kappa} \rho_{k \kappa}\left(J J^{\prime}\right) T\left(J J^{\prime}\right)_{k \kappa}
$$

em que $T\left(J J^{\prime}\right)_{k \kappa}$ são operadores tensoriais irredutíveis de ordem $k$ e componente $\kappa$, definidos em relação a um sistema de coordenadas fixo $X Y Z$ pela expressão

$$
T\left(J J^{\prime}\right)_{k \kappa}=\sum_{M M^{\prime}}(-1)^{J-M}\left\langle J^{\prime} J M^{\prime}(-M) \mid k \kappa\right\rangle\left|J^{\prime} M^{\prime}\right\rangle\langle J M|
$$

onde os coeficientes de Clebsch-Gordan $\left\langle J^{\prime} J M^{\prime}(-M) \mid k \kappa\right\rangle$ serão nulos, a menos que as regras de seleção de acoplamento de momento angular

$$
\left|J-J^{\prime}\right| \leq k \leq J+J^{\prime}, \quad-k \leq \kappa \leq k \quad \text { e } \quad M^{\prime}-M=\kappa
$$

sejam satisfeitas, e $\rho_{k \kappa}\left(J J^{\prime}\right)$ são os tensores estatísticos, definidos em relação ao mesmo sistema de coordenadas $X Y Z$, como $[15,56]$

$$
\rho_{k \kappa}\left(J J^{\prime}\right)=\sum_{M M^{\prime}}(-1)^{J^{\prime}-M^{\prime}}\left\langle J^{\prime} J M^{\prime}(-M) \mid k \kappa\right\rangle\left\langle J^{\prime} M^{\prime}|\rho| J M\right\rangle
$$

Os tensores da expressão (3.3) são a combinação linear do conjunto de operadores $\left|J^{\prime} M^{\prime}\right\rangle\langle J M|$ de um sistema composto por partículas de momento angular $J$ e $J^{\prime}$, com momento angular total $k$, e componente na direção $Z$ igual a $\kappa$.

A conveniência de escrever o operador densidade em termos dos tensores estatísticos, expressão (3.2), decorre de que estes irão fornecer diretamente informações sobre as propriedades de simetria do sistema estudado, permitindo separar as partes geométricas e dinâmicas que descrevem o sistema em interação.

\subsubsection{Propriedades de simetria dos tensores estatísticos}

Nas seções seguintes, considera-se que o íon formado depois da colisão apresenta uma vacância em uma de suas camadas internas. Por simplicidade, serão considerados átomos com camadas fechadas, então o estado do íon formado poderá ser especificado pelo momento angular da camada eletrônica. Nesta situação, o momento angular será igual ao momento angular $J$ do elétron que estava no átomo antes da colisão [14]. 
O processo de ionização de um conjunto de átomos por impacto de elétrons será discutido em um sistema de coordenadas conforme ilustrado na figura 3.2, no qual a direção do eixo $Z$ foi tomada como sendo a mesma de $\vec{p}_{i}$, que representa o momento do elétron incidente; adotamos $\vec{p}_{\mathrm{f}}$ para o momento do elétron espalhado, de maneira que $\vec{q}=\vec{p}_{\mathrm{i}}-\vec{p}_{\mathrm{f}}$ é o momento transferido.

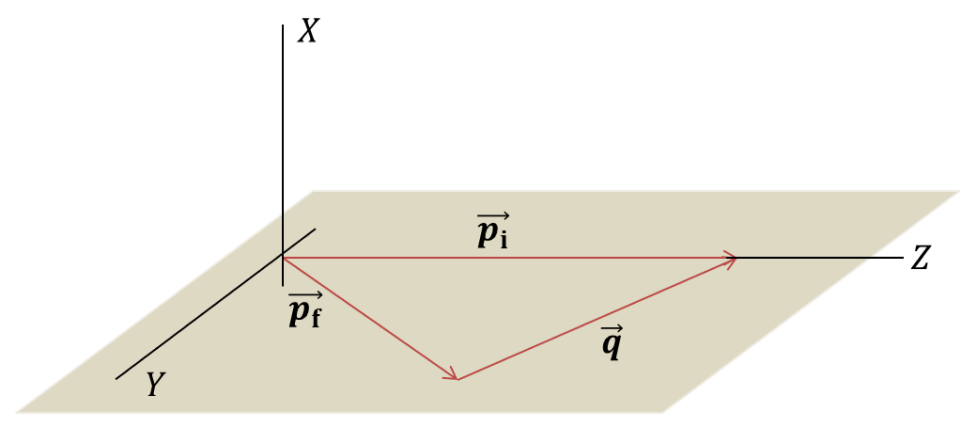

Figura 3.2: Ilustração de um sistema de coordenadas $X Y Z$ usado para descrever a colisão de um feixe de partículas com momento inicial $\vec{p}_{\mathrm{i}}$, cujo momento transferido será $\vec{q}$.

As direções do momento do elétron incidente $\vec{p}_{\mathrm{i}}$ e do momento do elétron espalhado $\overrightarrow{p_{\mathrm{f}}}$ definem o plano de reação. Contudo, quando o elétron espalhado não é detetado, uma única direção, dada pelo elétron incidente e tomada como a do eixo $Z$, é definida pelas condições experimentais. Neste caso, o sistema é axialmente simétrico com relação ao eixo $Z$, e consequentemente, o conjunto de átomos no estado excitado, que constitui o sistema, deve ser invariante para rotações em torno deste eixo. Logo, segue da condição de simetria axial (ou cilíndrica) que

$$
\rho_{k \kappa}\left(J J^{\prime}\right)_{\mathrm{rot}}=\rho_{k \kappa}\left(J J^{\prime}\right)
$$

onde $\rho_{k \kappa}\left(J J^{\prime}\right)$ está definido no sistema de coordenadas fixo $X Y Z$ e $\rho_{k \kappa}\left(J J^{\prime}\right)_{\text {rot }}$ em relação a um sistema de coordenadas rotacionado em torno do eixo $Z$. Esses dois tensores estatísticos estão relacionados por meio da expressão

$$
\rho_{k \kappa}\left(J J^{\prime}\right)_{\mathrm{rot}}=\sum_{q} \rho_{k q}\left(J J^{\prime}\right) \mathcal{D}(00 \gamma)_{q \kappa}^{(k)}
$$

em que $(\alpha, \beta, \gamma)$ são os ângulos de Euler e $\mathcal{D}(\alpha, \beta, \gamma)_{q \kappa}^{(k)}$ corresponde à matriz de rotação $\mathcal{D}(\alpha, \beta, \gamma)=\mathcal{D}_{Z}(\alpha) \mathcal{D}_{Y}(\beta) \mathcal{D}_{Z}(\gamma)$. Para o caso particular de uma rotação em torno do eixo $Z$, tem-se $\alpha=\beta=0$, e os elementos dessa matriz de rotação serão dados por

$$
\mathcal{D}(00 \gamma)_{q \kappa}^{(k)}=\exp (-\mathrm{i} \kappa \gamma) \delta_{q \kappa}
$$


Usando a expressão (3.8) na equação (3.7) chega-se em

$$
\rho_{k \kappa}\left(J J^{\prime}\right)_{\text {rot }}=\rho_{k \kappa}\left(J J^{\prime}\right) \exp (-\mathrm{i} \kappa \gamma)
$$

A relação (3.9), entretanto, deve ser válida para qualquer ângulo $\gamma$ devido à simetria axial, com isso, segue das expressões (3.6) e (3.9) que, para um sistema com simetria axial, os tensores estatísticos que o descrevem devem ter $\kappa=0$. Todas as componentes com $\kappa \neq 0$ serão necessariamente nulas, caso contrário elas violariam a condição de simetria axial dada pela relação (3.6).

\subsubsection{Condições da simetria axial}

Nesta seção e nas seguintes, considera-se um sistema formado por íons de momento angular bem definido, de modo que $J=J^{\prime}$.

Sistemas com simetria axial podem ser classificados de acordo com suas propriedades de transformação sob a reflexão $Z \rightarrow-Z$. Os elementos da matriz referente a esta reflexão são dados por [35]

$$
\mathcal{D}(0 \pi 0)_{q \kappa}^{(k)}=(-1)^{k+\kappa} \delta_{q-\kappa}
$$

Substituindo (3.10) em (3.6), segue

$$
\rho_{k \kappa}(J J)_{\mathrm{ref}}=\sum_{q} \rho_{k q}(J J)(-1)^{k+\kappa} \delta_{q-\kappa}=(-1)^{k} \rho_{k 0}
$$

onde se usou que, como o sistema tem simetria axial, necessariamente $\kappa=0$.

Da condição de invariância do sistema pela reflexão $Z \rightarrow-Z$ (ou pela inversão do eixo de simetria), deve-se ter

$$
\rho_{k 0_{\mathrm{ref}}}=\rho_{k 0}
$$

em todas as situações, o que somente será satisfeito quando $k$ for par. Portanto, sistemas com simetria axial que são invariantes para uma inversão do eixo de simetria são caracterizados por multipolos $k$ de ordem par.

Construindo a matriz densidade normalizada de forma que os elementos de sua diagonal correspondem à seção de choque de ionização do estado com número quântico $M$, $\sigma(J M)$, e seu traço corresponde à seção de choque de ionização do estado com número quântico $J, \sigma(J)$

$$
\langle J M|\rho| J M\rangle=\sigma(J M) \quad \text { e } \quad \operatorname{tr}(\rho)=\sigma(J) .
$$


Para um sistema com simetria axial e invariante para uma inversão do eixo de simetria, é possível mostrar que [55]

$$
\sigma(J,-M)=\langle J,-M|\rho| J,-M\rangle=\langle J M|\rho| J M\rangle=\sigma(J, M)
$$

o que implica que em um sistema com as condições de simetria descritas acima os estados $|J M\rangle$ e $|J(-M)\rangle$ têm a mesma probabilidade de serem ionizados. A figura 3.3 traz esquemas que representam as condições de simetria descritas nesta seção.

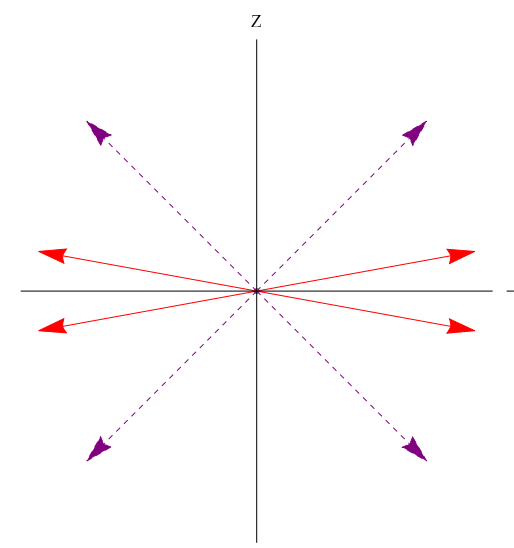

(a)

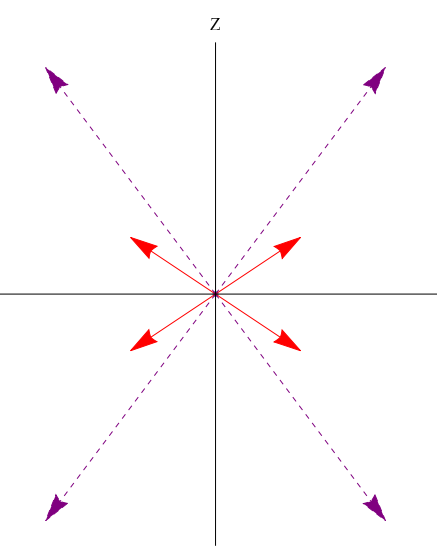

(b)

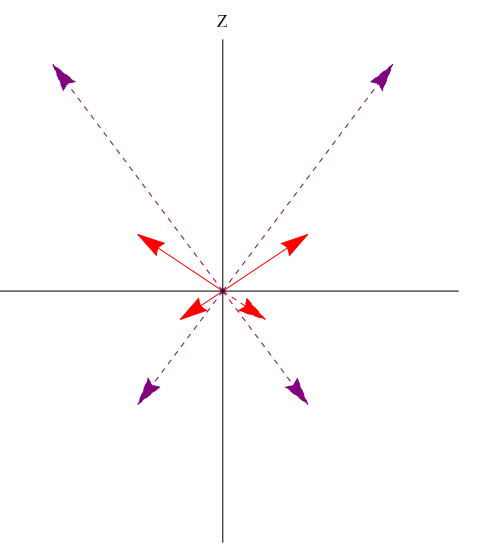

(c)

Figura 3.3: Representação dos orbitais $J=3 / 2$ em um sistema com simetria axial, em que as populações dos estados $m= \pm 3 / 2$ são representados pelos tamanhos das setas em roxo (linha tracejada) e dos estados $m= \pm 1 / 2$, das setas em vermelho (linha contínua). a) Sistema não alinhado e não orientado, b) Sistema alinhado e não orientado, e c) Sistema alinhado e orientado.

Analisando-se do ponto de vista semiclássico, um estado $|J M\rangle$ está associado a um vetor de módulo proporcional a $\sqrt{J(J+1)}$, que realiza um movimento de precessão em torno do eixo $Z$. Na figura 3.3, as flechas apontam na direção do momento angular e têm um comprimento proporcional à ocupação do estado. A figura 3.3 a) traz o diagrama de um sistema com simetria axial, em que não há nem uma direção nem um sentido preferencial: a população dos diferentes subestados do sistema é uniforme. O diagrama da figura 3.3 b) representa um sistema com simetria axial que é invariante para a inversão do eixo de simetria, uma vez que o comprimento das setas é igual tanto para $Z$ positivo quanto negativo, logo segue que o número de átomos no estado $|J M\rangle$ deve ser igual ao de átomos no estado $|J(-M)\rangle$; neste caso, não há um sentido preferencial para o momento angular, mas há uma direção preferencial, portanto o sistema não é orientado, mas é alinhado. Em particular, a figura mostra que o momento angular $\langle\mathbf{J}\rangle$ líquido de um sistema alinhado e não orientado é zero. Nesta situação não é possível identificar se o sistema é composto por um conjunto de íons no estado $|J M\rangle$ ou $|J(-M)\rangle$. Por fim, a 
figura 3.3 c) traz um diagrama que representa um sistema também com simetria axial, mas que varia com a transformação $Z \rightarrow-Z$, já que o comprimento das setas é diferente para componentes $Z$ positivas e negativas do vetor, ou seja, os estados com componentes $M$ e - $M$ não são igualmente populados, e, portanto, há não só uma direção preferencial, mas também um sentido preferencial: o sistema tem simetria axial e é alinhado e orientado. O momento angular líquido neste caso será não nulo, e $\left\langle\mathbf{J}_{Z}\right\rangle$ determina o excesso de momento angular apontando na direção do eixo $Z$.

\subsubsection{Exemplos de tensores estatísticos}

A fim de construir alguns exemplos, considera-se um sistema com simetria axial e que seja invariante para uma inversão do eixo de simetria. Essas condições, por exemplo, são satisfeitas no caso da ionização de átomos por um feixe de elétrons, onde o eixo $Z$ é orientado na direção do feixe incidente, e o elétron espalhado não é detetado, de forma que esta é a única direção definida pelas condições experimentais.

Considerando a matriz densidade normalizada de acordo com a relação (3.12), o tensor $\rho_{00}(J J)$ será dado por

$$
\rho_{00}(J J)=\sum_{M}(-1)^{J-M^{\prime}}\left(\begin{array}{ccc}
J & J & 0 \\
M^{\prime} & -M & 0
\end{array}\right)\left\langle J M^{\prime}|\rho| J M\right\rangle
$$

em que (:::) são os símbolos $3 j$ de Wigner, definidos como

$$
\left(\begin{array}{ccc}
j_{1} & j_{2} & j_{3} \\
m_{1} & m_{2} & m_{3}
\end{array}\right)=\frac{(-1)^{j_{1}-j_{2}-m_{3}}}{\sqrt{2 j_{3}+1}}\left\langle j_{1} j_{2} m_{1} m_{2} \mid j_{3}\left(-m_{3}\right)\right\rangle .
$$

Como o expoente do fator $(-1)$ é sempre um número inteiro, então continua sendo o mesmo quando transposto para o lado esquerdo. Portanto, a relação inversa segue fazendose a substituição $m_{3} \rightarrow-m_{3}$, o que resulta em

$$
\left\langle j_{1} j_{2} m_{1} m_{2} \mid j_{3} m_{3}\right\rangle=(-1)^{j_{1}-j_{2}+m_{3}} \sqrt{2 j_{3}+1}\left(\begin{array}{ccc}
j_{1} & j_{2} & j_{3} \\
m_{1} & m_{2} & -m_{3}
\end{array}\right) .
$$

Usando a relação

$$
\left(\begin{array}{ccc}
j_{1} & j_{2} & 0 \\
m_{1} & -m_{2} & 0
\end{array}\right)=\frac{(-1)^{j_{1}-m_{1}}}{\sqrt{2 j_{1}+1}} \delta_{j_{1}, j_{2}} \delta_{m_{1}, m_{2}}
$$


chega-se em

$$
\rho_{00}(J J)=\frac{1}{\sqrt{2 J+1}} \sum_{M}\langle J M|\rho| J M\rangle=\frac{1}{\sqrt{2 J+1}} \sum_{M} \sigma(J M)=\frac{\sigma(J)}{\sqrt{2 J+1}}
$$

que corresponde a uma constante, e é o coeficiente do primeiro termo da expansão do operador densidade dado pela expressão (3.2).

O tensor $\rho_{10}(J J)$ será dado por:

$$
\begin{aligned}
\rho_{10}(J J) & =\sum_{M}(-1)^{J-M^{\prime}} \sqrt{3}\left(\begin{array}{ccc}
J & J & 1 \\
M^{\prime} & -M & 0
\end{array}\right)\left\langle J M^{\prime}|\rho| J M\right\rangle \\
& =\sqrt{\frac{3}{(2 J+1)(J+1) J}} \sum_{M}\left\langle J M\left|J_{Z}\right| J M\right\rangle\langle J M|\rho| J M\rangle \\
& =\sqrt{\frac{3}{(2 J+1)(J+1) J}}\left\langle J_{Z}\right\rangle \sigma(J)
\end{aligned}
$$

onde usou-se que $\left\langle J_{Z}\right\rangle=\operatorname{tr}\left(\rho J_{Z}\right) / \operatorname{tr}(\rho)[55]$.

Os tensores estatísticos com $k=1$ são, em geral, chamados de vetores de orientação [55]. A expressão (3.19) mostra que a componente zero desse tensor está diretamente relacionada com a componente $J_{Z}$ do vetor $\mathbf{J}$. Observe ainda que se o sistema é invariante sobre uma inversão do eixo de simetria axial, então $\operatorname{tr}\left(\rho J_{Z}\right)$ será zero, e consequentemente, $\rho_{10}(J J)$ será nulo. Esse resultado está de acordo com a equação (3.11), que mostra que os tensores estatísticos de ordem ímpar são todos nulos em sistemas com simetria axial invariantes para a reflexão $Z \rightarrow-Z$. Nesse caso, o coeficiente da componente da expansão do operador densidade da fórmula (3.2) associado à orientação do sistema é nulo, e o sistema é dito não orientado.

Pode-se mostrar que o tensor $\rho_{20}(J J)$ é dado por [55]

$$
\rho_{20}(J J)=\sqrt{\frac{5}{(2 J+3)(2 J+1) J(2 J-1)(J+1)}}\left\langle 3 J_{Z}^{2}-\mathbf{J}^{2}\right\rangle \sigma(J) .
$$

A expressão (3.20) evidencia que a componente zero do tensor estatístico de ordem dois é proporcional a uma combinação quadrática das componentes do vetor momento angular. Tensores estatísticos de ordem dois, $\rho_{2 \kappa}(J J)$, são, em geral, chamados de tensores de alinhamento, de modo que sistemas alinhados apresentam ao menos uma das componentes do tensor estatístico de ordem dois não nula.

Na situação de interesse deste trabalho, as subcamadas $\mathrm{L}_{1}, \mathrm{~L}_{2}$ e $\mathrm{L}_{3}$ de um átomo são 


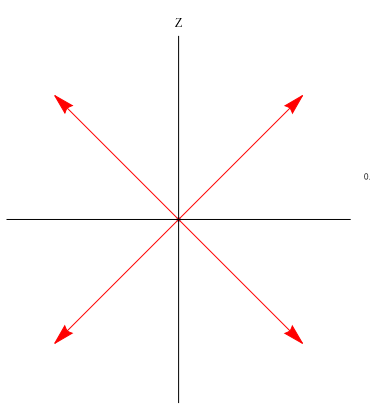

(a)

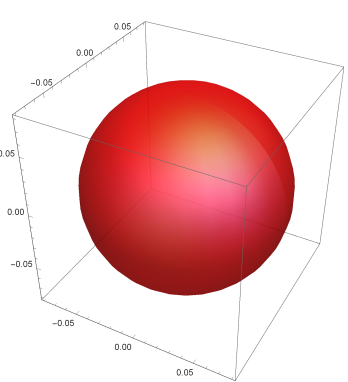

(b)

Figura 3.4: a) Representação dos vetores de momento angular para os estados $2 \mathrm{~s}_{1 / 2}$ ou $2 \mathrm{p}_{1 / 2}$, e b) da densidade de probabilidade dos estados $2 \mathrm{~s}_{1 / 2}$ ou $2 \mathrm{p}_{1 / 2}$.

ionizadas por um feixe de elétrons não polarizado, e o elétron espalhado não é detetado. Tem-se uma condição de simetria axial, onde o sistema é invariante para uma inversão do eixo de simetria axial, $\log \kappa=0$.

Quando as subcamadas $\mathrm{L}_{1}\left(2 \mathrm{~s}_{1 / 2}\right)$ ou $\mathrm{L}_{2}\left(2 \mathrm{p}_{1 / 2}\right)$, representadas na figura 3.4, são ionizadas, os dois estados possíveis para o íon resultante são $\left|\frac{1}{2} \frac{1}{2}\right\rangle$ ou $\left|\frac{1}{2}-\frac{1}{2}\right\rangle$, logo segue da expressão (3.5) que os valores possíveis para $k$ serão 0 e 1 . Calculando os tensores estatísticos possíveis $\rho_{00}$ e $\rho_{10}$ com as expressões (3.18) e (3.19), chega-se em

$$
\rho_{00}=\frac{\sigma(1 / 2)}{\sqrt{2}}
$$

e

$$
\rho_{10}=\frac{1}{\sqrt{2}}\left[\sigma\left(\frac{1}{2} \frac{1}{2}\right)-\sigma\left(\frac{1}{2}-\frac{1}{2}\right)\right]=0
$$

onde na segunda igualdade da equação (3.22) se usou a condição de invariância para a reflexão $Z \rightarrow-Z$.

Esses resultados indicam que os íons com vacâncias nas subcamadas $2 \mathrm{~s}_{1 / 2}$ ou $2 \mathrm{p}_{1 / 2}$ não serão nem alinhados e nem orientados, consequentemente os raios x decorrentes do preenchimento destas vacâncias terão emissão isotrópica. Tal sistema pode ser representado pelo diagrama da figura 3.3 a), onde todos os subestados têm a mesma probabilidade de serem ionizados.

Para o caso de um conjunto de íons com uma vacância da subcamada $\mathrm{L}_{3}\left(2 \mathrm{p}_{3 / 2}\right)$, os estados serão $\left|\frac{3}{2} \frac{3}{2}\right\rangle,\left|\frac{3}{2} \frac{1}{2}\right\rangle,\left|\frac{3}{2}-\frac{1}{2}\right\rangle,\left|\frac{3}{2}-\frac{3}{2}\right\rangle$, esquematizado na figura 3.5, e portanto os valores possíveis para $k$ serão 0, 1, 2 e 3. Aplicando as expressões (3.18), (3.19) e (3.20) 


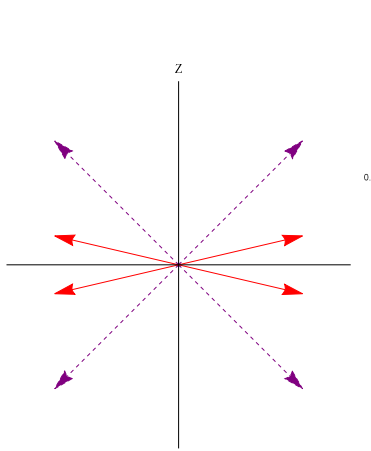

(a)

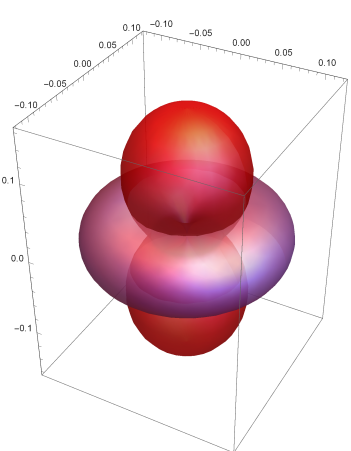

(b)

Figura 3.5: a) Representação dos vetores de momento angular para os estados $\left(2 \mathrm{p}_{3 / 2}\right)$, e b) da densidade de probabilidade dos estados $\left(2 \mathrm{p}_{3 / 2}\right)$.

chega-se em

$$
\begin{aligned}
\rho_{00}\left(\frac{3}{2} \frac{3}{2}\right) & =\frac{1}{2}\left[\sigma\left(\frac{3}{2}-\frac{3}{2}\right)+\sigma\left(\frac{3}{2}-\frac{1}{2}\right)+\sigma\left(\frac{3}{2} \frac{1}{2}\right)+\sigma\left(\frac{3}{2} \frac{3}{2}\right)\right] \\
& =\sigma\left(\frac{3}{2} \frac{3}{2}\right)+\sigma\left(\frac{3}{2} \frac{1}{2}\right) \\
\rho_{10}\left(\frac{3}{2} \frac{3}{2}\right) & =\frac{1}{2 \sqrt{5}}\left[\sigma\left(\frac{3}{2} \frac{1}{2}\right)-\sigma\left(\frac{3}{2}-\frac{1}{2}\right)\right]+\frac{3}{2 \sqrt{5}}\left[\sigma\left(\frac{3}{2} \frac{3}{2}\right)-\sigma\left(\frac{3}{2}-\frac{3}{2}\right)\right] \\
& =0
\end{aligned}
$$

e

$$
\begin{aligned}
\rho_{20}\left(\frac{3}{2} \frac{3}{2}\right) & =\frac{1}{2}\left[\sigma\left(\frac{3}{2}-\frac{3}{2}\right)+\sigma\left(\frac{3}{2} \frac{3}{2}\right)-\sigma\left(\frac{3}{2}-\frac{1}{2}\right)-\sigma\left(\frac{3}{2} \frac{1}{2}\right)\right] \\
& =\sigma\left(\frac{3}{2} \frac{3}{2}\right)-\sigma\left(\frac{3}{2} \frac{1}{2}\right)
\end{aligned}
$$

sendo que na segunda igualdade das três expressões usou-se $\sigma(J M)=\sigma(J,-M)$, já que o sistema é invariante para um inversão do eixo de simetria axial.

Seguindo os cálculos, mostra-se que o tensor $\rho_{30}\left(\frac{3}{2} \frac{3}{2}\right)$ será nulo assim como o tensor $\rho_{10}\left(\frac{3}{2} \frac{3}{2}\right)$, devido as condições de simetria do sistema. Assim, somente os tensores $\rho_{00}\left(\frac{3}{2} \frac{3}{2}\right)$ e $\rho_{20}\left(\frac{3}{2} \frac{3}{2}\right)$ serão não nulos para $J=3 / 2$. Tal sistema, portanto, têm as componentes do vetor de orientação todas nulas e, por isso, é classificado como um sistema alinhado, mas não orientado, e pode ser representado pelo diagrama da figura 3.3 b). 


\subsection{Distribuição angular de raios x e o parâmetro de alinhamento atômico $\boldsymbol{A}_{20}$}

Se um íon alinhado com uma vacância em uma camada interna de momento angular $j_{1}$ emite um fóton ou um elétron, e o íon no estado final de momento angular $j_{2}$ não for detetado, a distribuição angular da radiação emitida é dada por [56]

$$
\begin{aligned}
W(\theta)= & \sum_{\Lambda \Lambda^{\prime}}(-1)^{j_{1}+j_{2}+1}\left(2 j_{1}+1\right)\left\langle j_{2}|\Lambda| \mid j_{1}\right\rangle\left\langle j_{2}\left|\Lambda^{\prime}\right| \mid j_{1}\right\rangle^{*} \\
& \times \sum_{k}\left\{\begin{array}{ccc}
\Lambda & j_{1} & j_{2} \\
j_{1} & \Lambda^{\prime} & k
\end{array}\right\} \rho_{k 0}\left(j_{1} j_{1}\right)\left\langle\Lambda \Lambda^{\prime} 1(-1) \mid k 0\right\rangle \frac{1+(-1)^{f}}{2} P_{k}(\cos \theta)(3.26)
\end{aligned}
$$

em que $\Lambda$ e $\Lambda^{\prime}$ correspondem às diferentes multipolaridades do fóton, $\left\langle j_{2} \mid \Lambda \| j_{1}\right\rangle$ e $\left\langle j_{1}\left|\Lambda^{\prime}\right| \mid j_{2}\right\rangle$ correspondem às amplitudes de transição, o coeficiente de Clebsch-Gordan $\left\langle\Lambda \Lambda^{\prime} 1(-1) \mid k 0\right\rangle$ é a amplitude da componente multipolar $|k 0\rangle$ no estado acoplado $|\Lambda 1\rangle\left|\Lambda^{\prime}-1\right\rangle, \rho_{k 0}$ são os tensores estatísticos em um sistema com simetria axial e $f=\Lambda+\Lambda^{\prime}+\pi+\pi^{\prime}+k$, com $\pi=0$ para transição de dipolo elétrico e $\pi=1$ para radiação magnética.

Para sistemas que envolvem somente transições de dipolo, tem-se que $\Lambda=\Lambda^{\prime}=1$, uma vez que a aproximação de dipolo permite somente transições com variação de uma unidade no momento angular ${ }^{1}$. Com isso, os valores de $k$ ficam restritos a $k=0,1$ e 2 devido a regra de triângulo imposta por $\left\langle\Lambda \Lambda^{\prime} 1(-1) \mid k 0\right\rangle$ na expressão (3.26). Contudo, uma vez que o sistema é invariante sobre a reflexão $Z \rightarrow-Z$, o tensor $\rho_{10}(j j)$ será nulo, como mostrado na equação (3.24), de modo que os únicos termos que contribuem na expressão são $k=0$ e 2 .

Levando em conta as considerações acima, a expressão (3.26) pode ser reescrita como:

$$
\begin{aligned}
W(\theta)= & \frac{1}{3} \sqrt{2 j_{1}+1}\left\langle j_{2}|1| \mid j_{1}\right\rangle\left\langle j_{1}|1| \mid j_{2}\right\rangle^{*} \rho_{00}\left(j_{1} j_{1}\right) \\
& \times\left(1+(-1)^{j_{1}+j_{2}+1} \sqrt{\frac{3}{2}} \sqrt{2 j_{1}+1}\left\{\begin{array}{ccc}
1 & j_{1} & j_{2} \\
j_{1} & 1 & 2
\end{array}\right\} \frac{\rho_{20}\left(j_{1} j_{1}\right)}{\rho_{00}\left(j_{1} j_{1}\right)} P_{2}(\cos \theta)\right) \\
= & \frac{W_{0}}{4 \pi}\left[1+\alpha A_{20} P_{2}(\cos \theta)\right]
\end{aligned}
$$

\footnotetext{
${ }^{1} \mathrm{~A}$ próxima transição mais forte é o quadrupolo magnético M2, para o qual a interferência com o termo E1 é restrito por $\Lambda=1, \Lambda^{\prime}=2$.
} 
em que

$$
\alpha \equiv(-1)^{j_{1}+j_{2}+1} \sqrt{\frac{3}{2}} \sqrt{2 j_{1}+1}\left\{\begin{array}{ccc}
1 & j_{1} & j_{2} \\
j_{1} & 1 & 2
\end{array}\right\} \quad \text { e } \quad A_{20} \equiv \frac{\rho_{20}\left(j_{1} j_{1}\right)}{\rho_{00}\left(j_{1} j_{1}\right)}
$$

Uma vez que o sistema sofre uma ionização tal que os íons resultantes sejam descritos por um tensor com componente $\rho_{20}\left(j_{1} j_{1}\right)$ não nula, o sistema será alinhado. Como consequência desse alinhamento, os raios x emitidos apresentarão uma distribuição angular não isotrópica de acordo com a expressão (3.27), e essa anisotropia será maior ou menor a depender da camada para onde a vacância for transferida. O coeficiente $\alpha$ quantifica essa anisotropia, já que ele depende não só da camada onde a vacância foi gerada, mas também da camada para onde ela foi transferida.

A tabela 3.1 traz os valores de $\alpha$ para algumas transições de interesse neste trabalho, e evidencia que, uma vez que tenha sido gerada uma ionização na subcamada $\mathrm{L}_{3}\left(2 \mathrm{p}_{3 / 2}\right)$, então uma anisotropia maior deve ser observada na emissão da linha L $\ell$, enquanto que uma anisotropia menor é esperada para a emissão da linha L $\alpha_{1}$. Além disso, a tabela 3.1 mostra que as linhas $\mathrm{L} \alpha_{1}$ e $\mathrm{L} \alpha_{2}$ apresentam coeficientes $\alpha$ de sinais opostos, de modo que anisotropias opostas são previstas para essas linhas.

Tabela 3.1: Valores do coeficiente $\alpha$, expressão (3.28), para algumas transições L de interesse neste trabalho.

\begin{tabular}{cccc}
\hline Linhas & $j_{1}$ & $j_{2}$ & $\alpha$ \\
\hline $\mathrm{L} \ell$ & $3 / 2$ & $1 / 2$ & $1 / 2$ \\
$\mathrm{~L} \alpha_{1}$ & $3 / 2$ & $5 / 2$ & $1 / 10$ \\
$\mathrm{~L} \alpha_{2}$ & $3 / 2$ & $3 / 2$ & $-2 / 5$ \\
$\mathrm{~L} \beta_{2}$ & $3 / 2$ & $5 / 2$ & $1 / 10$ \\
$\mathrm{~L} \beta_{15}$ & $3 / 2$ & $3 / 2$ & $-2 / 5$ \\
$\mathrm{~L} \eta$ & $1 / 2$ & $3 / 2$ & 0 \\
\hline
\end{tabular}

Usando os resultados das equações (3.23) e (3.25) em (3.28), para um sistema de íons com uma vacância na subcamada $\mathrm{L}_{3}$, o parâmetro $A_{20}$ pode ser calculado por meio da expressão

$$
A_{20}=\frac{\sigma\left(j=\frac{3}{2}, m_{j}=\frac{3}{2}\right)-\sigma\left(j=\frac{3}{2}, m_{j}=\frac{1}{2}\right)}{\sigma\left(j=\frac{3}{2}, m_{j}=\frac{3}{2}\right)+\sigma\left(j=\frac{3}{2}, m_{j}=\frac{1}{2}\right)} .
$$

Esse resultado mostra, portanto, que a emissão não isotrópica de algumas linhas está diretamente relacionada com o fato de que os estados com diferentes projeções $m_{j}$ não têm a mesma probabilidade de serem ionizados.

Considerando que a interação que gera a ionização seja independente do spin, o que foi verificado experimentalmente por DuBois e Rødbro [57] em um experimento com vários 
tipos de partículas incidentes, o alinhamento pode ser expresso em termos das seções de choque $\sigma(l, m)$. Para tanto, basta levar em conta o acoplamento do momento angular orbital $l$ com o de spin $s=1 / 2$, usando os coeficientes de Clebsch-Gordan, o que dá

$$
A_{20}=\frac{\sigma(l=1, m=1)-\sigma(l=1, m=0)}{2 \sigma(l=1, m=1)+\sigma(l=1, m=0)} .
$$

Observe que em uma situação na qual $\sigma(l=1,1)=0$ o valor esperado do parâmetro de alinhamento é -1 .

\subsection{A medida do alinhamento atômico}

A grandeza que quantifica o alinhamento atômico é o parâmetro de alinhamento $A_{20}$, definido em (3.29), e que aparece na expressão da distribuição angular (3.27). Assim, a escolha deste trabalho foi medir o alinhamento atômico pela análise da distribuição angular da radiação emitida decorrente do preenchimento de vacâncias criadas na subcamada $\mathrm{L}_{3}$.

Na expressão (3.27) a grandeza $W(\theta)$ corresponde ao número de contagens no pico da linha de interesse detetada na posição $\theta$. Portanto, em uma medida de distribuição angular a grandeza fundamental é a estimativa das áreas dos picos de interesse. Essa área deve ser corrigida para alguns fatores associados com o sistema de deteção e a atenuação no alvo. Essa correção foi feita neste trabalho de acordo com a expressão

$$
v=\frac{A_{i}}{Q \varepsilon_{\mathrm{A}}\left(E_{i}\right)(1-\phi) \nu_{i}}
$$

em que o sub índice $i$ se refere à linha analisada, $A_{i}$ corresponde à área da linha $i, Q$ e $\phi$ correspondem à carga incidente e à fração de tempo morto durante a irradiação do alvo, respectivamente, $\varepsilon_{\mathrm{A}}\left(E_{i}\right)$ à eficiência de pico do detetor para a linha $\mathrm{L} i$, com energia $E_{i}$, e $\nu_{i}$ corresponde à atenuação dos fótons com energia $E_{i}$ no alvo irradiado.

Ao longo dos próximos capítulos será descrito como cada um desses fatores foi estimado, e no capítulo 6 é apresentada a expressão final para a estimativa experimental de $W(\theta)$, que é muito semelhante a expressão (3.31), mas corrige o dado experimental para a anisotropia associada ao arranjo experimental. 


\subsection{Cálculo do parâmetro de alinhamento}

Quando a energia da partícula incidente é suficientemente alta, mas não relativística, os tensores estatisticos $\rho_{k 0}$ podem ser calculados usando a aproximação de Born com ondas planas, na qual o elétron incidente e o espalhado são descritos por ondas planas, conforme apresentando em Berezhko e Kabachnik [15]. Com base nesta referência, a expressão para os tensores $\rho_{k 0}$ é dada por

$$
\rho_{k 0}=\frac{8 \pi a_{0}^{2} Z_{1}^{2}}{m_{\mathrm{e}} v^{2} / \mathrm{Ry}} \int \mathrm{d}(\epsilon / \mathrm{Ry}) \int_{q_{\min }(\epsilon) a_{0}}^{q_{\max }(\epsilon) a_{0}} \frac{F_{k}(q, \epsilon)}{\left(q a_{0}\right)^{2}} \mathrm{~d}\left[\ln \left(q a_{0}\right)^{2}\right]
$$

em que $Z_{1}$ e $v$ são a carga e a velocidade da partícula incidente, respectivamente, $a_{0}$ é o raio de Bohr, $m_{\mathrm{e}}$ a massa do elétron, Ry a energia de Rydberg, $q$ o momento transferido e $\epsilon$ a energia cinética do elétron ejetado. O fator $F_{k}(q, \epsilon)$ é dado por $[15,58]$

$$
F_{k}(q, \epsilon)=C(k, l, j) \sum_{l^{\prime}} \sum_{\lambda_{1}, \lambda_{2}}\left[B\left(k, l, l^{\prime}, \lambda_{1}, \lambda_{2}\right) R_{\epsilon l^{\prime}, n l}^{\lambda_{1}}(q) R_{\epsilon l^{\prime}, n l}^{\lambda_{2}}(q)\right] P_{k}\left(\cos \theta_{\mathrm{r}}\right)
$$

com

$$
C(k, l, j)=(-1)^{j+1 / 2}(2 j+1)(2 l+1)\left\{\begin{array}{ccc}
l & k & l \\
j & 1 / 2 & j
\end{array}\right\}
$$

$\mathrm{e}$

$$
\begin{aligned}
B\left(k, l, l^{\prime}, \lambda_{1}, \lambda_{2}\right)= & (-1)^{l^{\prime}+\left(\lambda_{1}-\lambda_{2}\right) / 2}\left(2 \lambda_{1}+1\right)\left(2 \lambda_{2}+1\right)\left\langle\lambda_{1} \lambda_{2} 00 \mid k 0\right\rangle \\
& \times\left\langle l \lambda_{1} 00 \mid l^{\prime} 0\right\rangle\left\langle l \lambda_{2} 00 \mid l^{\prime} 0\right\rangle\left\{\begin{array}{ccc}
l & k & l \\
\lambda_{1} & l^{\prime} & \lambda_{2}
\end{array}\right\}
\end{aligned}
$$

em que $n, l, j$ são os números quânticos do elétron no orbital onde a vacância será produzida, $l^{\prime}$ é o momento angular do elétron ejetado, $\theta_{\mathrm{r}}$ é o ângulo entre o momento transferido e a direção do feixe incidente (escolhida como a do eixo $Z$ ), conhecido como ângulo de recuo, e dado por

$$
\cos \theta_{\mathrm{r}}=\frac{\left(q a_{0}\right)^{2}+p_{\mathrm{i}}^{2}-p_{\mathrm{f}}^{2}}{2 p_{\mathrm{i}}\left(q a_{0}\right)}
$$

e as integrais radiais $R_{\epsilon l^{\prime}, n l}^{\lambda}$ são dadas por

$$
R_{\epsilon l^{\prime}, n l}^{\lambda}=\int_{0}^{\infty} P_{\epsilon l^{\prime}}(r) j_{\lambda}(q r) P_{n l}(r) \mathrm{d} r
$$

$\operatorname{com} j_{\lambda}$ a função esférica de Bessel de ordem $\lambda, P_{n l}$ a função de onda radial reduzida do estado ligado, normalizada de modo que

$$
\int_{0}^{\infty} P_{n l}^{2}(r) \mathrm{d} r=1
$$


e $P_{\epsilon l^{\prime}}$ é a componente de momento angular $l^{\prime}$ da função de onda do elétron ejetado com energia cinética $\epsilon$, normalizada na escala de energia.

Na expressão (3.32) é importante deixar claro que o elemento diferencial é $\ln \left[\left(q a_{0}\right)^{2}\right]$, e não $\left[\ln \left(q a_{0}\right)\right]^{2}$ como aparece na referência Sizov e Kabachnik [58].

Os limites de integração na equação (3.32) na integral em $q$ podem ser deduzidos a partir da análise da cinemática da colisão na figura 3.2 e são dados por

$$
q_{\min }^{\max }(\epsilon) a_{0}=\sqrt{E / \mathrm{Ry}} \pm \sqrt{\left(E-E_{\mathrm{X}_{i}}-\epsilon\right) / \mathrm{Ry}}
$$

com $E$ a energia do feixe incidente e $E_{\mathrm{X}_{i}}$ a energia de ionização da subcamada $\mathrm{X}_{i}$, enquanto que para a integral na energia cinética do elétron ejetado $\epsilon$ os limites de integração vão de zero até $E-E_{\mathrm{X}_{i}}$.

Quando a energia do elétron incidente $E$ se iguala à energia do limiar de ionização $E_{\mathrm{X}_{i}}$, segue da equação (3.38) e da lei de conservação de energia que $\epsilon=0$ e $q_{\min }=q_{\max }=$ $q_{\mathrm{thr}}=\sqrt{E_{\mathrm{X}_{i}} / \mathrm{Ry}}$. Com isso, empregando a expressão (3.32), chega-se em

$$
A_{k 0}^{\mathrm{thr}}=\frac{F_{k}\left(q_{\mathrm{thr}}, \epsilon=0\right)}{F_{0}\left(q_{\mathrm{thr}}, \epsilon=0\right)} .
$$

\subsection{Efeitos e correções na medida da distribuição an- gular}

Viu-se na seção 3.2 que a distribuição angular da radiação emitida pelas transições de dipolo que são geradas por vacâncias criadas em subcamadas com $J>1 / 2$ é dada pela relação (3.27). A fim de levar em conta os efeitos que atenuam a distribuição angular, foi incluído um fator $\xi<1$, nesta expressão:

$$
W(\theta)=\frac{W_{0}}{4 \pi}\left[1+\xi \alpha A_{20} P_{2}(\cos \theta)\right]
$$

Para o caso da radiação emitida pela ionização de um alvo sólido por impacto de elétrons, esses fatores estão relacionados com as transições Coster-Kronig $\kappa_{\mathrm{KC}}$, e com a abertura do feixe de elétrons no alvo $q_{2}$; o primeiro está ligado apenas com a estrutura do átomo, enquanto o último está relacionado também com as dimensões do alvo. Esses efeitos serão discutidos nas seções seguintes, e os correspondentes fatores de correção serão modelados. 


\subsubsection{Efeitos das transições Coster-Kronig}

Uma vacância em uma dada subcamada $L_{i}$ pode ter sido gerada por ionização direta, por transição Coster-Kronig das camadas $\mathrm{L}_{1}$ e $\mathrm{L}_{2} \mathrm{ou}$, ainda, por transferência de vacância da camada $\mathrm{K}$ para a camada $\mathrm{L}$. As vacâncias geradas nas subcamadas $\mathrm{L}_{1}$ e $\mathrm{L}_{2}$ e transferidas para $\mathrm{L}_{3}$ via transição Coster-Kronig não contribuem para a emissão anisotrópica e reduzem a anisotropia observada.

As seções de choque de produção de uma vacância nas subcamadas $\mathrm{L}_{1}, \mathrm{~L}_{2}$ e $\mathrm{L}_{3}$ são dadas por

$$
\begin{aligned}
\sigma_{\mathrm{L}_{1}}^{\mathrm{h}}= & \sigma_{\mathrm{L}_{1}}+\eta_{\mathrm{KL}_{1}} \sigma_{\mathrm{K}} \\
\sigma_{\mathrm{L}_{2}}^{\mathrm{h}}= & \sigma_{\mathrm{L}_{2}}+f_{12} \sigma_{\mathrm{L}_{1}}+\left(\eta_{\mathrm{KL}_{2}}+f_{12} \eta_{\mathrm{KL}_{1}}\right) \sigma_{\mathrm{K}} \\
\sigma_{\mathrm{L}_{3}}^{\mathrm{h}}= & \sigma_{\mathrm{L}_{3}}+f_{23} \sigma_{\mathrm{L}_{2}}+\left(f_{13}+f_{13}^{\prime}+f_{12} f_{23}\right) \sigma_{\mathrm{L}_{1}} \\
& +\left(\eta_{\mathrm{KL}_{3}}+f_{23} \eta_{\mathrm{KL}_{2}}+\left(f_{13}+f_{13}^{\prime}+f_{12} f_{23}\right) \eta_{\mathrm{KL}_{1}}\right) \sigma_{\mathrm{K}}
\end{aligned}
$$

onde $\sigma_{\mathrm{L}_{i}}$ corresponde à seção de choque de ionização da subcamada $\mathrm{L}_{i}$, os coeficientes de Coster-Kronig $f_{i j}$ e $f_{i j}^{\prime}$ correspondem às probabilidades de transferência da vacância da subcamada $\mathrm{L}_{i}$ para a subcamada $\mathrm{L}_{j}$ com a subsequente liberação de um elétron da subcamada mais externa e de um fóton, respectivamente, e $\eta_{\mathrm{KL}_{i}}$ corresponde à probabilidade de transferência da vacância da camada $\mathrm{K}$ para a subcamada $\mathrm{L}_{i}$.

Cabe destacar que tanto na expressão (3.42) quanto na (3.43) o termo $f_{12}^{\prime}$, que corresponde à probabilidade de transferência da vacância de $\mathrm{L}_{1}$ para $\mathrm{L}_{2}$ com a subsequente emissão de um fóton, foi ignorado porque se trata de uma transição de baixa intensidade.

A expressão (3.43) mostra que para energias abaixo do limiar de ionização da subcamada $L_{2}$ e acima do limiar da subcamada $L_{3}$, somente esta última subcamada é ionizada, e nenhum fator deve ser incluído na expressão (3.27) para correção dos efeitos introduzidos pelas transições Coster-Kronig. Para energias acima do limiar de ionização da subcamada $\mathrm{L}_{1}$ e abaixo do limiar de ionização da camada $\mathrm{K}$, parte das vacâncias em $\mathrm{L}_{3}$ foram originalmente criadas em $\mathrm{L}_{1}$ e $\mathrm{L}_{2}$ e, como não são alinhadas, não contribuem para a anisotropia da radiação emitida. Desta forma, um fator de correção $\kappa_{\mathrm{CK}} \leq 1$, deve ser introduzido na expressão (3.27) a fim de dar conta deste efeito,

$$
\kappa_{\mathrm{CK}}=\frac{\sigma_{\mathrm{L}_{3}}}{\sigma_{\mathrm{L}_{3}}^{\mathrm{h}}} \leq 1
$$

que corresponde à fração de vacâncias que foram geradas por ionização direta em $\mathrm{L}_{3}$. 


\subsubsection{Abertura do feixe de elétrons dentro do alvo}

Um feixe de elétrons que incide em um alvo sofre colisões elásticas e inelásticas, que irão ocasionar mudanças na sua direção de propagação e energia. Quanto menor a espessura do alvo e maior a energia do feixe, menor será o desvio que ele sofrerá dentro do alvo. Para energias da ordem de $15 \mathrm{keV}$ e alvos de Au ou Ta com densidades superficiais da ordem de $10 \mu \mathrm{g} / \mathrm{cm}^{2}$, a perda média de energia dos elétrons dentro do alvo é da ordem de $60 \mathrm{eV}$, que é pequena comparada com a energia do feixe, de modo que este efeito não será levado em conta nos cálculos de distribuição angular deste trabalho. Entretanto, a abertura do feixe no alvo pode introduzir uma correção significativa na distribuição angular dos raios x, e será estimada por um procedimento semelhante ao usado na referência do Rose [59], que trata de medidas de correlação angular gama-gama.

Quando não há abertura do feixe pelo alvo, a distribuição angular dos raios x emitidos na aproximação de dipolo é dada pela expressão (3.27). Existindo abertura do feixe, ela será dada pela convolução da expressão (3.27) com a função densidade de probabilidade $\mathrm{F}\left(\theta^{\prime}\right)$ do ângulo de abertura $\theta^{\prime}$ do feixe dentro do alvo, assim:

$$
\bar{W}(\theta)=\frac{\int W(\gamma) \mathrm{F}\left(\theta^{\prime}\right) \mathrm{d} \Omega^{\prime}}{\int \mathrm{F}\left(\theta^{\prime}\right) \mathrm{d} \Omega^{\prime}}
$$

em que $\gamma$ é o ângulo formado entre as direções do fóton emitido e dos elétrons dentro do alvo, $\mathrm{d} \Omega^{\prime}$ é o diferencial de ângulo sólido determinado pelo feixe, e $\theta$ o ângulo polar que determina a posição do detetor de fótons. $\mathrm{F}\left(\theta^{\prime}\right)$ é dada por

$$
\mathrm{F}\left(\theta^{\prime}\right)=\mathrm{p}_{0} \delta\left(\Omega^{\prime}\right)+\mathrm{f}\left(\theta^{\prime}\right)
$$

em que $\mathrm{f}\left(\theta^{\prime}\right)$ representa a parte do feixe que sofreu abertura no alvo, enquanto que o termo $\mathrm{p}_{0} \delta\left(\Omega^{\prime}\right)$ representa o total do feixe que passa pelo alvo sem mudar de direção. $\mathrm{F}\left(\theta^{\prime}\right)$ está normalizada de forma que

$$
\int \mathrm{F}\left(\theta^{\prime}\right) \mathrm{d} \Omega^{\prime}=1
$$

Logo, uma consequência imediata dessa normalização é que

$$
\mathrm{p}_{0}=1-\int \mathrm{f}\left(\theta^{\prime}\right) \mathrm{d} \Omega^{\prime}
$$

e fornece a parcela do feixe que passa pelo alvo sem desviar.

Ao se substituir as expressões (3.27) e (3.46) em (3.45), chega-se em:

$$
\bar{W}(\theta) \propto 1+\alpha A_{20}\left[\mathrm{p}_{0} \int P_{2}(\cos \gamma) \delta\left(\Omega^{\prime}\right) \mathrm{d} \Omega^{\prime}+\int P_{2}(\cos \gamma) \mathrm{f}\left(\theta^{\prime}\right) \mathrm{d} \Omega^{\prime}\right] .
$$




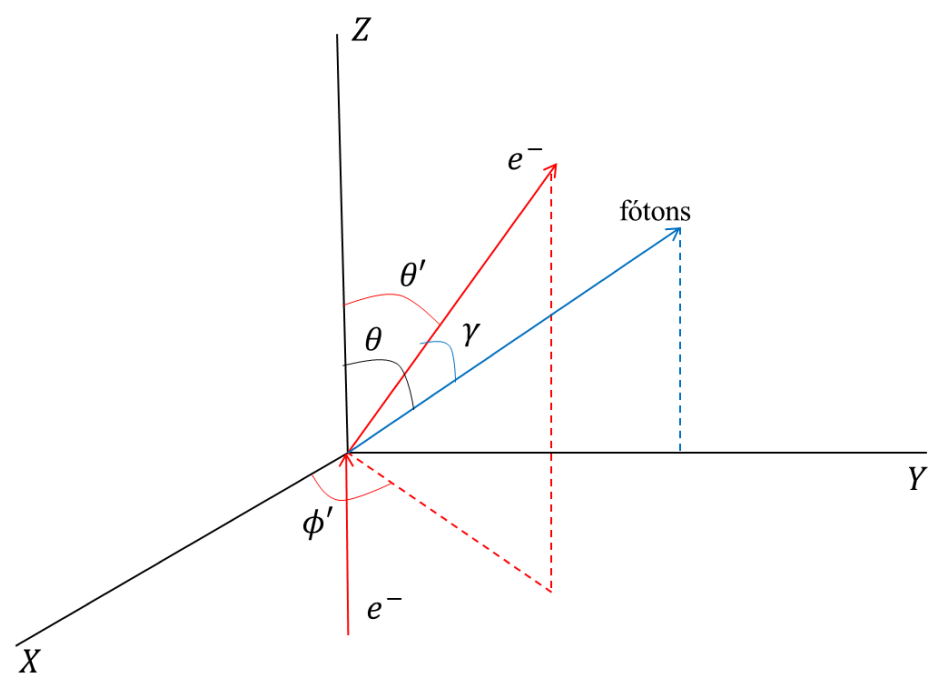

Figura 3.6: Representação dos ângulos $\gamma$, entre a radiação emitida e o feixe de elétrons dentro do alvo, $\theta^{\prime}$ e $\phi^{\prime}$, que representam a abertura polar e azimutal, respectivamente, do feixe de elétrons no alvo, e $\theta$ que indica a posição do detetor para um $\phi$ fixo. As linhas vermelhas se referem ao elétron e em azul ao fóton.

Lembrando que $\mathrm{d} \Omega^{\prime}=\sin \theta^{\prime} \mathrm{d} \theta^{\prime} \mathrm{d} \phi^{\prime}$ e que os ângulos $\gamma, \theta^{\prime}, \theta$ e $\phi^{\prime}$, figura 3.6, se relacionam por meio da expressão

$$
\cos \gamma=\cos \theta \cos \theta^{\prime}+\sin \theta \sin \theta^{\prime} \cos \phi^{\prime},
$$

aplicando o teorema da adição [60]

$$
P_{2}(\cos \gamma)=P_{2}(\cos \theta) P_{2}\left(\cos \theta^{\prime}\right)+2 \sum_{m=1}^{2} \frac{(2-m) !}{(2+m) !} P_{2}^{m}(\cos \theta) P_{2}^{m}\left(\cos \theta^{\prime}\right) \cos \left(m \phi^{\prime}\right),
$$

em que $P_{l}^{m}$ são as funções associadas de Legendre; usando a relação (3.50) em (3.49), e fazendo a integração em $\phi^{\prime}$ chega-se em:

$$
\bar{W}(\theta) \propto 1+\alpha A_{20} P_{2}(\cos \theta)\left[\mathrm{p}_{0}+2 \pi \int \mathrm{f}\left(\theta^{\prime}\right) P_{2}\left(\cos \theta^{\prime}\right) \sin \theta^{\prime} \mathrm{d} \theta^{\prime}\right] .
$$

Define-se

$$
q_{2}=\mathrm{p}_{0}+2 \pi \int \mathrm{f}\left(\theta^{\prime}\right) P_{2}\left(\cos \theta^{\prime}\right) \sin \theta^{\prime} \mathrm{d} \theta^{\prime}
$$

que é comumente chamado na literatura de espectroscopia gama como coeficiente de atenuação da distribuição angular.

A expressão (3.52) mostra que o efeito da abertura do feixe de elétrons dentro do alvo introduz apenas uma constante multiplicativa $q_{2}$, sem alterar a forma da distribuição angular dos raios x emitidos, que continua a ser descrita pelo polinômio de Legendre de 
ordem dois, $P_{2}$.

\subsubsection{Autoatenuação dos fótons}

Suporemos aqui que a ionização pelo feixe de elétrons seja uniforme ao longo da espessura do alvo, o que é uma hipótese razoável quando se tem alvos finos, e que a energia do feixe incidente é suficientemente maior do que a do limiar de ionização. Uma vez que os elétrons perdem pouca energia e a seção de choque de ionização não apresenta grandes mudanças para pequenas variações de energia, pode-se considerar o alvo como uma superposição de várias camadas com espessuras infinitesimais, como ilustrado na figura 3.7. Integrando a atenuação que os fótons sofrem em cada uma dessas camadas ao longo de toda a espessura, tem-se:

$$
\begin{aligned}
\nu \equiv \frac{I}{I_{0}} & =\int \exp \left[-\mu\left(\frac{d-x}{\cos \theta}\right)\right] \frac{\mathrm{d} I}{I_{0}} \\
& =\int_{0}^{d} \exp \left[-\mu\left(\frac{d-x}{\cos \theta}\right)\right] \frac{\mathrm{d} x}{d} \\
& =\frac{\cos \theta}{\mu d}\left[1-\exp \left(-\frac{\mu d}{\cos \theta}\right)\right]
\end{aligned}
$$

em que $I$ é a intensidade da radiação emitida, $I_{0}$ a intensidade da radiação gerada inicialmente, $\mu$ o coeficiente de atenuação do material e $d$ a espessura, todos esses parâmetros referentes ao alvo, e $\theta$ o ângulo entre o feixe incidente e a direção de deteção.

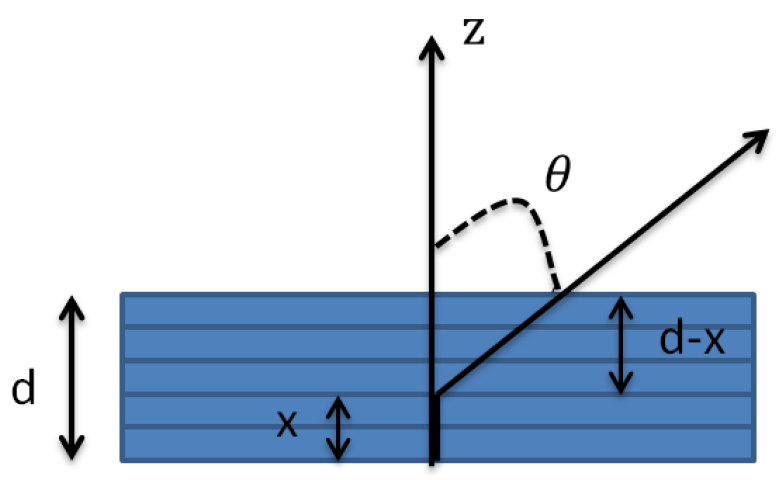

Figura 3.7: Esboço que representa o alvo e a possível interação dos fótons em seu interior, com os parâmetros geométricos necessários à fórmula (3.54).

Essa aproximação foi verificada, no caso deste experimento, por simulação Monte Carlo, conforme será apresentado no capítulo 6. 


\subsubsection{Expressão da distribuição angular atenuada}

Levando em conta as correções acima, a expressão (3.27) passa a ser

$$
W(\theta)=\frac{W_{0}}{4 \pi}\left[1+q_{2} \kappa_{\mathrm{CK}} \alpha A_{20} P_{2}(\cos \theta)\right]
$$

em que o parâmetro $\xi$ da expressão (3.40) corresponde ao produto $\xi=q_{2} \kappa_{\mathrm{CK}}$, onde o parâmetro $\kappa_{\text {CK }}$ faz a correção devido às transições Coster-Kronig e o parâmetro $q_{2}$ leva em conta a abertura do feixe dentro do alvo.

No capítulo 6 são apresentados os cálculos dos fatores $\kappa_{\mathrm{CK}}$ e $q_{2}$, discutido as limitações do uso deste último calculado conforme descrito na seção 3.5.2, e apresentados os resultados das simulações para o fator $\nu$, junto com as previsões da expressão (3.54).

\subsection{Experimentos de anisotropia e distribuição angular de elétrons Auger e raios x — revisão da literatura}

A revisão da literatura sobre a medida do alinhamento atômico por impacto de elétrons a partir da distribuição angular dos raios x mostrou que esse fenômeno ainda não havia sido conclusivamente observado. Assim, a fim de avaliarmos o conhecimento prévio do fenômeno, estendemos a revisão para outros tipos de projéteis: fótons, prótons e outros íons, e para as medidas a partir da distribuição angular dos elétrons Auger. Os resultados obtidos por este último método foram revisados por Mehlhorn [36] em 1994 e mostraram que o fenômeno foi observado de forma conclusiva somente na faixa de energia do elétron incidente de $1,5 E_{\mathrm{L}_{3}}<E<4 E_{\mathrm{L}_{3}}$, em que $E_{\mathrm{L}_{3}}$ é a energia de ionização da subcadama $\mathrm{L}_{3}$. Esta notação será usada nesta e nas demais seções, porque é o fator de escala adequado para relacionar o alinhamento atômico dos diferentes átomos. Sempre que necessário, a energia $E_{\mathrm{L}_{3}}$ foi extraída da referência Deslattes et al. [12].

Essa revisão está organizada da seguinte maneira: a seção 3.5.1 apresenta os trabalhos que mediram a distribuição angular dos elétrons Auger e a 3.5.2, que mediram a distribuição angular ou a polarização dos raios x pelos diferentes tipos de projéteis, apresentados em subseções diferentes. A seção 3.5.3 discute o conjunto de informação experimental. 


\subsubsection{Anisotropia pela distribuição angular de elétrons Auger}

Dobelin et al. [61] mediram a distribuição angular dos elétrons Auger quando a subcamada 3d do Kr foi ionizada por impacto de elétrons. Os resultados mostraram uma distribuição angular anisotrópica, mas com um parâmetro de anisotropia menor do que o previsto teoricamente. Os autores acreditam que essa discrepância possa estar relacionada com o modelo para as funções de onda empregadas nos cálculos teóricos, pois o elétron no estado contínuo foi descrito por funções de onda hidrogenóides com número atômico efetivo igual a um.

Os trabalhos de Cleff e Mehlhorn [32,62], Sandner e Schmitt [63], DuBois e Rødbro [57] e Weber et al. [64] determinaram a anisotropia de elétrons Auger que seguem a ionização por impacto de elétrons em alvos gasosos de $\operatorname{Ar}(Z=18)$. DuBois e Rødbro [57] e Cleff e Mehlhorn [32] realizaram o experimento com sete e cinco ângulos entre $15^{\circ}$ e $150^{\circ}$, respectivamente, os demais efetuaram as medidas em apenas três ângulos. No trabalho de Cleff e Mehlhorn [62], as energias foram de 2, 4 e $16 E_{\mathrm{L}_{3}}$. Os resultados mostraram uma emissão anisotrópica para $2 E_{\mathrm{L}_{3}}$ e $4 E_{\mathrm{L}_{3}}$, enquanto que para $16 E_{\mathrm{L}_{3}}$ a emissão dos elétrons Auger se mostrou isotrópica. Sandner e Schmitt [63] realizaram o experimento com onze energias entre $1,4 E_{\mathrm{L}_{3}}$ e $200 E_{\mathrm{L}_{3}}$, com o intuito de estudar a dependência do parâmetro de alinhamento com a energia do feixe incidente. Para tanto, dois arranjos experimentais foram empregados, um com um canhão de elétrons para a faixa de energia até $5 \mathrm{keV}$, e outro para o intervalo 5 até $50 \mathrm{keV}$. Com esse mesmo objetivo, Weber et al. [64] empregaram energias entre aproximadamente $1 E_{\mathrm{L}_{3}}$ e $4 E_{\mathrm{L}_{3}}$. Para energias entre cerca de $1,4 E_{\mathrm{L}_{3}}$ e $4 E_{\mathrm{L}_{3}}$, os valores do parâmetro de anisotropia de Weber et al. [64] apresentaram bom acordo com os valores de DuBois e Rødbro [57] e com os valores calculados por Berezhko e Kabachnick [65] empregando a aproximação de Born de ondas distorcidas, e um acordo razoável com os valores apresentados por Cleff e Mehlhorn [62] e Sandner e Schmitt [63]. Nos trabalhos de Weber et al. [64] e Sandner e Schmitt [63] a dependência do parâmetro de alinhamento com a energia indicou que o alinhamento é maior na região próxima ao limiar de ionização, caindo rapidamente quando a energia do elétron incidente cresceu.

Borucki et al. [66] realizaram medidas do parâmetro de alinhamento $A_{20} \mathrm{com}$ alvos de $\operatorname{Mg}(Z=12)$ para energias próximas ao limiar de ionização da subcamada $\mathrm{L}_{3}$. Os resultados evidenciaram uma emissão não isotrópica dos elétrons Auger e foram consistentes com as medidas de DuBois et al. [67]. Estes últimos também chamaram a atenção para a estrutura de máximos e mínimos no conjunto de dados experimentais da curva 
de dependência do parâmetro de alinhamento $A_{20}$ com a energia do feixe incidente, que também era prevista teoricamente.

O trabalho de revisão de Mehlhorn [36] comparou os dados experimentais de Ar obtidos por Sandner e Schmitt [63], DuBois e Rødbro [57] e Weber et al. [64], e os dados de $\mathrm{Mg}$ medidos por DuBois et al. [67] e Borucki et al. [66] com os valores calculados empregando os formalismos: aproximação de Born de ondas planas (PWBA) e de ondas distorcidas (DWBA), usando em ambos o potencial de Hartree-Slater. Para o Ar, os resultados entre $1,4 E_{\mathrm{L}_{3}}$ e $4 E_{\mathrm{L}_{3}}$ estiveram em bom acordo com a DWBA, abaixo de $1,4 E_{\mathrm{L}_{3}}$ mesmo a DWBA não conseguiu prever o rápido crescimento do parâmetro de alinhamento com o decréscimo da energia, enquanto que a PWBA somente conseguiu descrever os resultados para energias superiores a $4 E_{\mathrm{L}_{3}}$. Contudo, para o alvo de $\mathrm{Mg}$ os resultados foram opostos, a PWBA descreveu melhor os resultados experimentais mesmo na região próxima ao limiar de ionização. Esse contexto levou o autor a destacar a necessidade de novas investigações teóricas com modelos mais sofisticados tanto para a interação projétil-alvo quanto para as funções de onda dos estados ligado e contínuo.

\subsubsection{Anisotropia pela distribuição angular de raios $\mathrm{x}$}

Neste grupo, a resolução dos detetores desempenha papel importante na avaliação dos resultados, assim forneceremos a FWHM (do inglês Full Width at Half Maximum) dos detetores empregados para a energia de $5,9 \mathrm{keV}$ dos raios x que seguem o decaimento por captura eletrônica do ${ }^{55} \mathrm{Fe}$, salvo menção em contrário.

\subsubsection{Experimentos de fotoionização com fótons de $59,54 \mathrm{keV}$ do ${ }^{241} \mathrm{Am}$}

Kahlon et al. [4] realizaram medidas para um alvo de $\mathrm{Au}(Z=79)$ tomadas com um detetor de $\mathrm{Si}(\mathrm{Li})$ com resolução de $180 \mathrm{eV}$. Os resultados foram corrigidos pela atenuação da distribuição angular ocasionada pelas transições Coster-Kronig e evidenciaram uma emissão não isotrópica para as linhas $\mathrm{L} \ell, \mathrm{L} \alpha_{1}$ e $\mathrm{L} \alpha_{2}$, sendo a anisotropia maior para as linhas $\mathrm{L} \ell$ e $\mathrm{L} \alpha_{2}$, enquanto que uma emissão isotrópica foi encontrada para os grupos $\mathrm{L} \beta$ e L $\gamma$. Além disso, os autores encontraram coeficientes de anisotropia com sinais opostos para as linhas $\mathrm{L} \alpha_{1}$ e $\mathrm{L} \alpha_{2}$, conforme previsto teoricamente [68]. Em um segundo trabalho publicado pelo grupo [69], a polarização das linhas $\mathrm{L} \alpha_{1}$ e $\mathrm{L} \alpha_{2}$ do Au foi medida. Valores não nulos e com sinais opostos para as linhas $\mathrm{L} \alpha_{1}$ e $\mathrm{L} \alpha_{2}$ foram encontrados, confirmando os resultados prévios. A polarização registrada para $\mathrm{L} \alpha_{1}$ foi de $39(3) \%$, o que corresponde a um parâmetro de alinhamento de $A_{20}=-2,99(26)$. 
Demir et al. [70] apresentaram um estudo da distribuição angular dos raios x L dos elementos $\operatorname{Er}(Z=68)$, Ta $(Z=73), \mathrm{W}(Z=74), \mathrm{Au}(Z=79), \mathrm{Hg}(Z=80)$ e $\mathrm{Tl}$ $(Z=81)$. A deteção das linhas características foi realizada com um detetor de $\mathrm{Si}(\mathrm{Li})$ com resolução de 160 eV. Também neste trabalho uma distribuição angular não isotrópica foi encontrada para a linha $\mathrm{L} \ell$ e para o dubleto $\mathrm{L} \alpha$, enquanto que uma emissão isotrópica foi observada para os grupos L $\beta$ e $\mathrm{L} \gamma$. Entretanto, nenhuma estimativa do parâmetro de alinhamento foi apresentada.

As medidas de Alrakabi et al. [71] com alvos de $\mathrm{Au}(Z=79)$, Bi $(Z=83)$, Th $(Z=90)$ e $\mathrm{U}(Z=92)$ foram realizadas com um detetor HPGe com resolução de $180 \mathrm{eV}$ e corrigidas para os efeitos introduzidos pelas transições Coster-Kronig. Os resultados da anisotropia para as linhas provenientes de vacâncias preenchidas na subcamada $\mathrm{L}_{3}$ foram menores do que a precisão do experimento, mas eles permitiram excluir a possibilidade de anisotropia tão alta conforme encontrado por Kahlon [4].

Tartari et al. [72] ionizaram alvos grossos dos elementos $\mathrm{Yb}(Z=70)$, Hf $(Z=72)$, $\mathrm{Ta}(Z=73), \mathrm{W}(Z=74)$ e $\mathrm{Pb}(Z=82)$ para o estudo da distribuição angular do dubleto L $\alpha$. O uso de alvos grossos, segundo os autores, dispensa os cuidados relacionados à uniformidade do alvo, que é uma preocupação quando se trabalha com alvo fino. Os raios x emitidos foram observados com um detetor HPGe com resolução de $180 \mathrm{eV}$. Foi analisada a dependência da razão de intensidades $I_{\mathrm{L} \alpha} / I_{\mathrm{L} \beta}$ com o ângulo de deteção. Assumindo que o grupo L $\beta$ apresenta emissão isotrópica, os resultados não mostraram qualquer dependência angular para esse quociente.

O estudo mais recente com fótons de $59,54 \mathrm{keV}$ do ${ }^{241}$ Am encontrado nesta pesquisa foi o de Akkus et al. [73]. Os autores ionizaram um alvo de $\mathrm{Yb}(Z=70)$. Os raios $\mathrm{x}$ emitidos foram detectados com um $\mathrm{Si}(\mathrm{Li})$ com resolução de $182 \mathrm{eV}$. Os resultados mostraram que as intensidades das linhas $\mathrm{L} \ell$ e $\mathrm{L} \alpha$ variam com os ângulos polar e azimutal, enquanto que os multipletos $\mathrm{L} \beta$ e $\mathrm{L} \gamma$ não apresentaram dependência angular. Não foram apresentadas estimativas do parâmetro de alinhamento no estudo.

\subsubsection{Experimentos de fotoionização com fótons de energia diferente de $59,54 \mathrm{keV}$ do ${ }^{241} \mathrm{Am}$}

O trabalho de Kumar et al. [74] analisou a dependência angular na emissão das linhas L $\ell$, $\mathrm{L} \alpha$ e $\mathrm{L} \beta$ do $\mathrm{Pb}(Z=82)$ com ionização por fótons de $22,6 \mathrm{keV}$ do ${ }^{109} \mathrm{Cd}$ e $59,54 \mathrm{keV}$ do ${ }^{241} \mathrm{Am}$. As medidas foram feitas com um detetor com resolução de $200 \mathrm{eV}$. As razões das intensidades $\mathrm{L} \ell / \mathrm{L} \gamma, \mathrm{L} \alpha / \mathrm{L} \gamma$ e $\mathrm{L} \beta / \mathrm{L} \gamma$, corrigidas pela eficiência do detetor e pela atenuação 
no alvo, não evidenciaram qualquer dependência angular dentro das barras de incerteza. Em um trabalho seguinte do grupo [75], foi medida a dependência angular de emissão das linhas $\mathrm{L} \ell, \mathrm{L} \alpha$ e $\mathrm{L} \beta_{2,5,6,7,15}$ do $\mathrm{Pb}$. O alvo de foi ionizado com os raios $\mathrm{x} \mathrm{K}$ do $\mathrm{Rb}$, que por sua vez foram gerados pelo impacto dos fótons de $59,54 \mathrm{keV}$ do ${ }^{241} \mathrm{Am}$, com isso somente a subcamada $\mathrm{L}_{3}$ deste elemento foi ionizada. As medidas foram realizadas com um $\mathrm{Si}(\mathrm{Li})$ com resolução de $190 \mathrm{eV}$. Nenhuma anisotropia foi encontrada para a emissão dessas linhas também nesse segundo trabalho.

Papp e Campbell [5] estudaram a dependência angular das linhas de raios x L $\ell, L \alpha_{1,2}$ e $\mathrm{L} \beta_{2,15}$ de um alvo de $\operatorname{Er}(Z=68)$. O alvo foi ionizado com raios x $\mathrm{K} \beta$ do $\mathrm{Cu}(8,9 \mathrm{keV})$. Esse procedimento permitiu que somente a subcamada $\mathrm{L}_{3}$ fosse ionizada. Os raios $\mathrm{x}$ foram medidos com um detetor de $\mathrm{Si}(\mathrm{Li})$ com $135 \mathrm{eV}$ de resolução, sendo que um segundo detetor, também de $\mathrm{Si}(\mathrm{Li})$ e mantido fixo no experimento, foi usado para normalização dos dados. Somente a linha L $\ell$ apresentou um parâmetro de alinhamento não nulo dentro das barras de incerteza, de $A_{20}=0,104(32)$.

Sharma et al. [76] fizeram medidas de distribuição angular das linhas L $\ell, \mathrm{L} \alpha$ e L $\beta$ de alvos de Th $(Z=90)$ e $\mathrm{U}(Z=92)$, ionizando somente a subcamada $\mathrm{L}_{3}$ desses elementos com raios x K de $\mathrm{Nb}$ e Mo. As medições foram realizadas com um detetor de $\mathrm{Si}(\mathrm{Li})$ com resolução de $170 \mathrm{eV}$, e os resultados indicaram uma clara dependência angular na emissão das linhas investigadas. Entretanto, nenhum valor foi estimado para o parâmetro de alinhamento.

Santra et al. [9] estudaram a distribuição angular dos raios x L do $\mathrm{Au}(Z=79)$ e do $\mathrm{U}(Z=92)$ ionizando esses alvos com fótons de $22,6 \mathrm{keV}$ do ${ }^{109} \mathrm{Cd}$. As medidas foram realizadas com um detetor de $\mathrm{Si}(\mathrm{Li})$ com resolução de $160 \mathrm{eV}$. Como a energia dos fótons incidentes foi superior à de ionização da subcamada $L_{1}$, todas as subcamadas foram ionizadas e a correção para as transições Coster-Kronig foi realizada. Os resultados mostraram uma discreta dependência angular das linhas $\mathrm{L} \ell$ e $\mathrm{L} \alpha$, enquanto que o grupo $\mathrm{L} \beta$ pareceu apresentar uma emissão isotrópica. A anisotropia do Au variu entre cerca de $4 \%$ a $5 \%$, de modo que o parâmetro de alinhamento do Au, estimado a partir dos resultados da linha $\mathrm{L} \ell$ foi de $A_{20}=0,10(14)$. Já para o $\mathrm{U}$ a anisotropia observada foi cerca de $2 \%$, estimada ser a anisotropia introduzida pelo arranjo experimental, com isso não foi possível concluir sobre a emissão anisotrópica deste elemento.

Kampfer et al. [10] estudaram a polarização das linhas $\mathrm{L} \alpha_{1}$ e $\operatorname{L} \alpha_{2}$ do W $(Z=74)$ ionizando o alvo com um feixe de fótons cuja energia variou entre 10, 2 e $30 \mathrm{keV}$. Os resultados mostraram uma polarização pequena e positiva para a linha $\mathrm{L} \alpha_{1}$, e uma polarização 
um pouco maior e negativa para a linha $\mathrm{L} \alpha_{2}$. A partir dos valores de polarização obtidos foi possível estimar o parâmetro de alinhamento para a energia média da fonte de fótons não monocromática empregada. Os valores encontrados a partir da polarização de $\mathrm{L} \alpha_{1} \mathrm{e}$ $\mathrm{L} \alpha_{2}$ foram $0,11(7)$ e $0,12(7)$, respectivamente, para a energia média de $18,5 \mathrm{keV}$.

\subsubsection{Fotoionização por radiação sincrotron}

Yamaoka et al. realizaram uma sequência de três experimentos para o estudo da dependência angular das linhas de raios x de elementos com alto número atômico. Em Yamaoka et al. [77], alvos de $\mathrm{Au}(Z=79)$ e $\mathrm{Pb}(Z=82)$ foram irradiados, e os raios x resultantes foram detetados com um Silicon Drift Detector (SDD) com resolução de 167 eV. Um alvo de $\mathrm{Cu}$ também foi usado nas medições, de modo que suas linhas de raios $\mathrm{x} \mathrm{K}$ fossem empregadas como monitores, depois de verificada a emissão isotrópica destas. A faixa de energia do experimento foi desde o limiar de ionização da subcamada $\mathrm{L}_{3}$ até pouco acima do limiar de $\mathrm{L}_{1}$, para ambos os alvos. Os resultados mostraram uma emissão isotrópica do grupo $L \alpha$, enquanto que a linha $L \ell$ pareceu evidenciar uma pequena anisotropia. No trabalho seguinte do grupo, Yamaoka et al. [7], o experimento foi repetido com o alvo de $\mathrm{Au}$, entretanto a deteção dos raios x foi realizada com um espectrômetro de cristal dispersivo em comprimento de onda, que apresenta uma resolução muito superior à do SDD. Os resultados evidenciaram uma pequena dependência angular na emissão das linhas $\mathrm{L} \alpha_{2}$ e $\mathrm{L} \ell$, inclusive, de acordo com o sinal do coeficiente de anisotropia calculado teoricamente para essas duas linhas, tabela 3.1. O parâmetro de alinhamento, estimado a partir dos dados de $\mathrm{L} \ell$ foi de $A_{20}=-0,21(4)$ para a energia do feixe de fótons incidente de 13,002 keV. Um terceiro experimento foi realizado pelo grupo [8] melhorando as condições do arranjo experimental, em particular, cobrindo um intervalo angular maior. Além disso, nesse trabalho os autores tinham o objetivo de avaliar o efeito das transições Coster-Kronig sobre o alinhamento medido. Para isso, o alvo de Au foi irradiado com três energias, 13, 14 e $15 \mathrm{keV}$, que estão entre os limiares de ionização das subcamadas $\mathrm{L}_{i}$ do Au. Os resultados confirmaram a emissão anisotropica com um parâmetro de alinhamento ligeiramente menor do que o encontrado inicialmente para $13 \mathrm{keV}$, de $A_{20}=-0,144(25)$. Para 14 e $15 \mathrm{keV}$, o parâmetro de anisotropia, calculado com as informações presentes no artigo, foram de $-0,122(57)$ e $-0,148(66)$, respectivamente.

Küst et al. [6] estudaram a dependência angular da linha L $\ell$ do Xe obtida por meio da ionização de um alvo gasoso de Xe $(Z=54)$ e $\operatorname{Ar}(Z=18)$ com radiação sincrotron linearmente polarizada. O Ar fez parte do alvo, uma vez que a análise foi feita em relação 
às linhas de raios x K deste elemento. As energias de impacto foram escolhidas de forma a ionizarem somente a subcamada $\mathrm{L}_{3}$ e, com isso, evitar correções relacionadas às transições Coster-Kronig. Os resultados mostraram uma pequena anisotropia da linha L $\ell$, sendo o parâmetro de alinhamento de -0,061(43) e -0,044(70) para as energias 4,814 keV e $5,055 \mathrm{keV}$, respectivamente.

\subsubsection{Ionização por impacto de prótons e íons}

Entre os trabalhos de distribuição angular de raios x por impacto de prótons e outros íons encontra-se os de Jitschin et al. [78-80], Barros Leite et al. [81], Papp et al. [82], de Lucio e Miranda [83], e outros que podem ser encontrados nas referências destes.

Em Jitschin et al. [78] o parâmetro de alinhamento foi estimado a partir de um experimento de polarização dos raios x L com alvos de Xe $(Z=54)$, Dy $(Z=66)$ e $\mathrm{Au}(Z=79)$. A faixa de energia do experimento foi de $250 \mathrm{keV}$ a $6 \mathrm{MeV}$, sendo que para isso três aceleradores de íons foram empregados no experimento. Os raios $\mathrm{x}$ foram detetados com um $\mathrm{Si}(\mathrm{Li})$ com resolução de $175 \mathrm{eV}$. A polarização foi determinada para as linhas $\mathrm{L} \alpha_{1,2}, \mathrm{~L} \beta_{2,15}$ e $\mathrm{L} \ell$, e partir desses resultados foi estimado o parâmetro de alinhamento para cada energia incidente. Os resultados estão em acordo qualitativo com a previsão teórica, sugerindo inclusive a mudança de sinal do parâmetro de alinhamento com o aumento da energia do feixe incidente. Além disso, os autores chamaram a atenção para o fato de que os dados experimentais de alinhamento em função de $\left(v / v_{\mathrm{L}_{3}}\right)^{2}$, com $v$ a velocidade do feixe incidente e $v_{\mathrm{L}_{3}}^{2}=2 E_{\mathrm{L}_{3}} / m_{\mathrm{e}}$, parecem seguir uma curva universal, independente do número atômico $Z$ do elemento no alvo. Um segundo experimento, desta vez de distribuição angular, foi realizado pelo grupo [79] com alvos de Xe $(Z=54)$, Dy $(Z=66)$, Au $(Z=79)$ e $\mathrm{U}(Z=92)$ e uma faixa de energia do feixe incidente ligeiramente maior, de $150 \mathrm{keV}$ a $10 \mathrm{MeV}$, o que envolveu o uso de quatro aceleradores distintos. Um detetor de $\mathrm{Si}(\mathrm{Li})$ com $180 \mathrm{eV}$ de resolução foi empregado para detetar os raios x emitidos. Os resultados confirmaram a anisotropia e permitiram o estudo do parâmetro de alinhamento com energia/velocidade do feixe incidente. Os parâmetros de alinhamento dos quatro alvos estudados versus a velocidade do projétil incidente em unidades de $v_{\mathrm{L}_{3}}$ foram dispostos em um único gráfico junto com alguns outros encontrados na literatura. Os resultados foram razoavelmente compatíveis entre si e pareceram seguir uma curva universal, em acordo com o trabalho prévio [78].

Barros Leite et al. [81] mediram o parâmetro de alinhamento de átomos de $\mathrm{Pb}(Z=82)$ a partir da medida da distribuição angular da linha L $\ell$, ionizando um alvo desse elemento 
com prótons de 0,4-3,0 MeV. Os raios x foram detetados com um $\mathrm{Si}(\mathrm{Li})$ de $180 \mathrm{eV}$ de resolução, e os resultados foram corrigidos para a atenuação da distribuição angular pelas transições Coster-Kronig. Os resultados mostraram uma emissão não isotrópica desta linha e permitiram avaliar a dependência do parâmetro de alinhamento com a energia do feixe incidente no intervalo de $0,4-3,0 \mathrm{MeV}$.

Em Papp et al. [82] a ionização do alvo de Th $(Z=90)$ foi realizada com um feixe de prótons com energias de 1, 2 e $3 \mathrm{MeV}$. Os espectros foram medidos com um detetor de $\mathrm{Si}(\mathrm{Li})$ com resolução de $133 \mathrm{eV}$. Um segundo detetor, com resolução de $180 \mathrm{eV}$, mantido fixo em todas as medições, foi usado como monitor, de modo que os espectros foram normalizados pelos espectros adquiridos no detetor monitor. Os resultados, corrigidos para os efeitos das transições Coster-Kronig, mostraram uma distribuição angular não isotrópica das linhas $\mathrm{L} \ell, \mathrm{L} \alpha_{1}$ e $\mathrm{L} \alpha_{2}$. Além disso, os autores obtiveram coeficientes de anisotropia com sinais opostos para as linhas $\mathrm{L} \alpha_{1}$ e $\mathrm{L} \alpha_{2}$, e chamaram a atenção para o fato de a anisotropia diminuir com o aumento da energia do feixe de prótons incidente.

de Lucio e Miranda [83] estudaram a dependência angular de emissão da linha L $\ell$ dos elementos Ce $(Z=58)$, Nd $(Z=60), \operatorname{Eu}(Z=63)$, Dy $(Z=66)$ e Yb $(Z=70)$, que foram ionizados com íons de ${ }^{12} \mathrm{C},{ }^{16} \mathrm{O}$ e ${ }^{19} \mathrm{~F}$ com energias entre 9 e $12 \mathrm{MeV}$. Os raios x foram detetados com um espectrômetro Si-PIN com resolução de $158 \mathrm{eV}$. As intensidades dos grupos $\mathrm{L} \gamma$ e $\mathrm{L} \beta_{1,3,4}$ foram usadas para normalização, depois de verificada a emissão isotrópica desses multipletos. Os resultados mostraram uma nítida anisotropia na emissão da linha L $\ell$, contudo, devido à estreita faixa de energia investigada, não foi possível observar uma alteração no sinal do parâmetro de alinhamento.

Jitschin et al. [80], ampliando os trabalhos prévios [78,79], ionizaram alvos de alto número atômico com íons de número atômico entre 1 e 79. Os raios x foram detetados com um $\mathrm{Si}(\mathrm{Li})$ com resolução de $180 \mathrm{eV}$, e a análise foi conduzida somente com a medida da distribuição angular da linha $\mathrm{L} \ell$ normalizado pelo dubleto $\mathrm{L} \alpha$. Os resultados confirmam a emissão anisotrópica, e evidenciam que a anisotropia dos raios x emitidos diminui com o número atômico do projétil incidente, conforme encontrado nos trabalhos prévios do grupo [78, 79].

\subsubsection{Ionização por impacto de elétrons}

As primeiras medidas de distribuição angular de raios x por impacto de elétrons foram realizadas por Motz e Placious [84] e por Middleman et al. [85], que analisaram a emissão de raios x K do $\mathrm{Sn}(Z=50)$ e $\mathrm{Au}(Z=79)$ na região de energia entre $50 \mathrm{keV}$ e $500 \mathrm{keV}$, 
e de raios x $\mathrm{K}$ do $\mathrm{Cu}(Z=29)$ e In $(Z=49)$ entre 300 e $500 \mathrm{MeV}$, respectivamente. Em ambos os trabalhos uma emissão isotrópica dentro das barras de incerteza foi encontrada. A primeira confirmação experimental da anisotropia na emissão de raios x resultantes do preenchimento de vacâncias com $J>1 / 2$ por impacto de elétrons foi realizado por Hrdý et al. [1], pela medida da polarização da linha $\operatorname{L} \alpha_{1}$ do $\operatorname{Hg}(Z=80)$. A medida foi realizada com elétrons de $30 \mathrm{keV}$, aproximadamente $2,4 E_{\mathrm{L}_{3}}$. Os resultados mostraram uma polarização não nula de -14(4)\% (o sinal decorre da definição de polarização adotada no artigo, que é oposta a adotada usualmente [1,15]), que corresponde a um parâmetro de alinhamento de $A_{20}=-0,98(25)$.

Aydinol et al. [2] apresentaram medidas de polarização das linhas características L do $\operatorname{Ar}(Z=18), \operatorname{Kr}(Z=36)$ e Xe $(Z=54)$ para energias de impacto entre 3 e $15 \mathrm{keV}$, sendo as medidas realizadas com um detector de $\mathrm{Si}(\mathrm{Li})$ com resolução de $205 \mathrm{eV}$. Os resultados evidenciaram uma polarização não nula do dubleto $\mathrm{L} \alpha_{1,2}$, sendo que ela diminui com o aumento da energia do feixe incidente, chegando a sugerir uma mudança de sinal, que não fica evidente devido às grandes barras de incerteza. Para o alvo de Xe, quando a energia dos elétrons incidentes foi de $6 \mathrm{keV}$ a polarização foi de aproximadamente $6,6(22) \%$, que corresponde a um parâmetro de alinhamento de $A_{20}=-0,91(31)$.

Posteriormente, Küst e Mehlhorn [3] estudaram o alinhamento do Xe $(Z=54)$ por meio da distribuição angular da linha L $\ell$ nas energias de 5; 5, 438 e $6 \mathrm{keV}$. A intensidade da linha estudada foi normalizada em relação à área do dubleto $\mathrm{K} \alpha_{1,2}$ do Ar, que esteve misturado ao gás de Xe. Os raios x foram observados com um detetor de baixa energia com cristal de Ge com resolução de $164 \mathrm{eV}$. Os resultados mostraram uma emissão anisotropica para as duas energias maiores, e uma emissão isotrópica para a menor. Contudo, a anisotropia encontrada foi muito menor do que a reportada por Aydinol et al. [2]. Os valores do parâmetro de alinhamento foram 0,03(7); 0,048(8) e 0,060(12) para as energias de 5, 5, 438 e $6 \mathrm{keV}$, respectivamente.

Pálinkás et al. [86] fizeram medidas da distribuição angular da radiação K e L do Se $(Z=34)$ em 300 e $600 \mathrm{keV}$, para as transições da camada M e para as linhas L $\ell, \mathrm{L} \alpha$, L $\beta$ e $\mathrm{L} \gamma$ do $\mathrm{Bi}(Z=83)$. As medidas foram realizadas com um detector de $\mathrm{Si}(\mathrm{Li})$ com resolução de $194 \mathrm{eV}$ na energia de 6,4 keV. Dentro das barras de incerteza, nenhuma anisotropia foi encontrada.

Medidas recentes de distribuição angular dos raios x provenientes de vacâncias geradas na subcamada $\mathrm{L}_{3}$ do $\mathrm{Au}(Z=79)$ foram realizados por Sestric et al. [33]. O alvo foi ionizado com um feixe de $15 \mathrm{keV}$, e os raios x emitidos foram detetados com um $\mathrm{Si}(\mathrm{Li})$ 
com resolução de $247 \mathrm{eV}$ em 9, $7 \mathrm{keV}$. Nenhuma correção foi realizada para incluir os efeitos das transições Coster-Kronig e da abertura do feixe de elétrons no alvo, sendo esta última uma correção importante no dado experimental, uma vez que o alvo empregado na medida tinha alguns $\mathrm{mg} / \mathrm{cm}^{2}$. Os resultados sugeriram uma emissão isotrópica dos grupos L $\alpha$ e $\mathrm{L} \beta$, enquanto que a linha $\mathrm{L} \ell$ pareceu apresentar uma fraca anisotropia, contudo devido às barras de incerteza a emissão anisotópica desta linha não pôde ser confirmada. Nenhum parâmetro de alinhamento foi fornecido no trabalho.

\subsubsection{Apreciação dos trabalhos experimentais}

De forma geral, os estudos do alinhamento atômico pela distribuição angular de elétrons Auger encontraram uma emissão anisotrópica para as transições decorrentes do preenchimento de vacâncias com $J>1 / 2$. Contudo as incertezas dessas medidas na região próxima ao limiar foram grandes, em particular, os resultados de Weber et al. [64] para $1,08 \mathrm{E} / E_{\mathrm{L}_{3}}$ e Borucki et al. [66] para 1,04 E/ $E_{\mathrm{L}_{3}}$ são compatíveis com zero dentro de dois desvios padrões.

Alguns trabalhos realizados com elétron Auger estudaram a dependência do parâmetro de alinhamento com a energia do feixe incidente, sendo que os trabalhos de Weber et al. [64] e Sandner e Schmitt [63] tiveram como motivação principal investigar essa dependência. Os resultados desses trabalhos indicaram uma queda do parâmetro de alinhamento com a energia do feixe incidente, mas não permitiram outras conclusões acerca dessa dependência, ou devido ao intervalo de energia limitado, (Weber et al. [64]), ou devido às grandes barras de incerteza (Sandner e Schmitt [63]).

A grande vantagem de estudar o alinhamento atômico por meio da distribuição angular dos elétrons Auger está no fato de que nesse caso o coeficiente $\alpha$ da expressão (3.28) tem módulo um [68], com isso não há atenuação da distribuição angular associada à transição, independente de qual seja a camada para onde a vacância seja transferida. Por outro lado, nessas medidas a interação pós-colisão entre os dois elétrons emergentes e o elétron Auger tende a deformar os picos observados no espectro e a atenuar a distribuição angular, introduzido uma dificuldade na medida do alinhamento, sobretudo na região próxima ao limiar de ionização, conforme destacado em DuBois e Rødbro [57] e Weber et al. [64]. Este último chega a mencionar a necessidade de medidas de alinhamento em situações experimentais onde a interação pós-colisão não ocorre, como nos estudos via distribuição angular dos raios $\mathrm{x}$.

Situação semelhante a dos elétrons Auger ocorreu para o estudo do alinhamento atô- 
mico por meio da distribuição angular dos raios x decorrentes da ionização por impacto de prótons e/ou íons. A maior parte dos trabalhos confirmou a existência da anisotropia nas linhas estudadas e, alguns deles conseguiram observar anisotropias de sinais opostos para as linhas $\mathrm{L} \ell, \mathrm{L} \alpha_{1}$ e $\mathrm{L} \alpha_{2}$, como foi o caso de Papp et al. [82]. Além disso, a dependência do parâmetro de alinhamento com a energia do feixe incidente foi analizada para um número maior de elementos [79-83], quando comparado com o estudo realizado por meio da distribuição angular dos elétron Auger.

Contudo, quando o alinhamento foi estudado por meio da distribuição angular ou polarização dos raios x emitidos em consequência da fotoionização nota-se que há três grupos, aqueles que encontram uma alta anisotropia [4,69,70], aqueles que observaram uma anisotropia fraca [5-10,71], e aqueles que concluiram que a emissão dos raios x é sempre isotrópica $[72,75,77]$, independente da subcamada onde a vacância foi gerada. $\mathrm{O}$ fato de os trabalhos terem sido realizados com energias e alvos diferentes torna difícil a comparação entre todos eles. Além disso, alguns fizeram conclusões sobre a existência ou não da anisotropia a partir da análise qualitativa da distribuição angular, sem fornecer a estimativa do parâmetro de alinhamento.

Entre as metodologias empregadas nos trabalhos de fotoionização, foi possivel ainda notar certos problemas, como no caso de Tartari et al. [72] que usou o grupo L $\beta$, suposto isotrópico no trabalho, para normalizar os dados de L $\alpha$, que são esperados apresentarem uma emissão anisotrópica pequena, e além disso o detetor empregado no experimento não tinha resolução para separar as linhas $\mathrm{L} \alpha_{1}$ e $\mathrm{L} \alpha_{2}$, fazendo com que o $\alpha_{\text {eff }}$, expressão (3.28) e tabela 3.1, deste multipleto fosse de aproximadamente 0, 05 [87,88]. Para que a razão $I_{\mathrm{L} \alpha} / I_{\mathrm{L} \beta}$ mostre uma emissão anisotrópica fora das barras incerteza estas deveriam ser inferiores a aproximadamente $0,4 \%$, supondo um alinhamento $A_{20}=0,1$ para $60 \mathrm{keV}$. Contudo, as incertezas do experimento foram da ordem de $1 \%$, de forma que qualquer pequena anisotropia que poderia existir não seria perceptível devido à magnitude das incertezas. Por outro lado, Kampfer et al. [10] supõem que a polarização depende suavemente da energia, e estimam o parâmetro de alinhamento para uma energia média do feixe não monocromático empregado no experimento. Porém, a faixa de energia do feixe variou de $10,2 \mathrm{keV}$ a $30 \mathrm{keV}$, que corresponde a $1 E_{\mathrm{L}_{3}}$ e $3 E_{\mathrm{L}_{3}}$, respectivamente, e o alinhamento é previsto cair rapidamente com a energia do feixe incidente, podendo inclusive mudar de sinal, dentro deste intervalo de energia [68,89], o que afetou de forma significativa o resultado encontrado pelos autores.

No grupo de trabalhos por fotoionização, os experimentos foram realizados em sua 
grande maioria para uma única energia, sendo poucos os casos em que se estudou o alinhamento para duas ou três, de forma que a dependência do parâmetro de alinhamento com a energia ainda não foi explorada detalhadamente neste caso.

A comparação dos parâmetros de anisotropia encontrados no grupo de fotoionização deve ser feita com cuidado, uma vez que este parâmetro varia com a maneira como o ângulo $\theta$ da expressão (3.40) é definido, e também com relação ao tipo de radiação usada para a ionização, além da dependência com a energia do fóton incidente. Se o ângulo é aquele entre a direção do raio x emitido e o vetor campo elétrico da radiação incidente, então o valor de $A_{20}$ será negativo, se ele corresponde ao ângulo entre o raio x emitido e a direção de propagação, o que é usual para ionização por impacto de elétrons, então esse parâmetro será positivo. No que diz respeito ao tipo de radiação usada na ionização, quando essa radiação é linearmente polarizada, observa-se uma anisotropia no plano que contém a polarização da radiação incidente, mas no plano perpendicular a esse a distribuição angular observada é isotrópica. Por outro lado, quando uma radiação não polarizada é usada para ionizar o alvo de interesse, observa-se uma média referente aos dois planos, de modo que os valores de $A_{20}$ para fótons não polarizados são iguais à metade dos valores encontrados com o uso de fótons linearmente polarizados.

Os trabalhos realizados pela distribuição angular dos raios x emitidos pela ionização por impacto de elétrons são mais escassos do que nos demais casos. De forma análoga ao que ocorre com os trabalhos de fotoionização, boa parte dos poucos resultados existentes não podem ser comparados entre si, uma vez que foram realizados para diferentes energias de impacto $[3,33,86]$, e aqueles que puderam ser comparados [2,3], apresentaram resultados inconsistentes. Além disso, alguns resultados foram afetados por grandes incertezas [33], tornando o dado inconclusivo, e a metodologia de análise de alguns trabalhos pareceu incompleta. Nenhum deles, por exemplo, incluiu a atenuação da distribuição angular pela abertura do feixe de elétrons no alvo, que é tanto mais importante quanto menor a energia do feixe de elétrons e maior a espessura do alvo sólido empregado. Dentre esses trabalhos, somente Aydinol et al. [2] realizou medidas para um número maior de energias, contudo as barras de incerteza foram grandes de forma que o alinhamento na região distante do limiar foi compatível com zero. Adicionalmente, a inversão do sinal da polarização, e consequentemente, do parâmetro de alinhamento não pode ser confirmada.

A figura 3.8 traz os valores do parâmetro de alinhamento $A_{20}$ encontrados nos trabalhos acima descritos, com ionização por impacto de fótons e elétrons, em função do quociente $E / E_{\mathrm{L}_{3}}$, todos eles obtidos pelo estudo dos raios x emitidos. A fim de compara- 
ção, os resultados das referências Yamaoka et al. [7,8] e Küst et al. [6] foram multiplicados por -1 e dividido por dois, uma vez que eles foram obtidos com radiação sincrotron. Esses resultados deixam claro que na fotoionização o alinhamento foi observado conclusivamente na faixa estreita de $1,0 E_{\mathrm{L}_{3}}<E<1,5 E_{\mathrm{L}_{3}}$, sendo que a dependência do parâmetro de alinhamento $A_{20}$ com a energia do feixe incidente ainda permanecia um problema em aberto, enquanto que na ionização por impacto de elétrons o problema continuava em aberto para qualquer energia dos elétrons incidentes. Um conjunto de figuras semelhante a figura 3.8 para as medidas realizadas com elétrons Auger pode ser encontrada em Mehlhorn [36], de onde fica claro que o alinhamento atômico via distribuição angular dos elétrons Auger foi confirmado apenas no intervalo $1,5 E_{\mathrm{L}_{3}}<E<4 E_{\mathrm{L}_{3}}$.

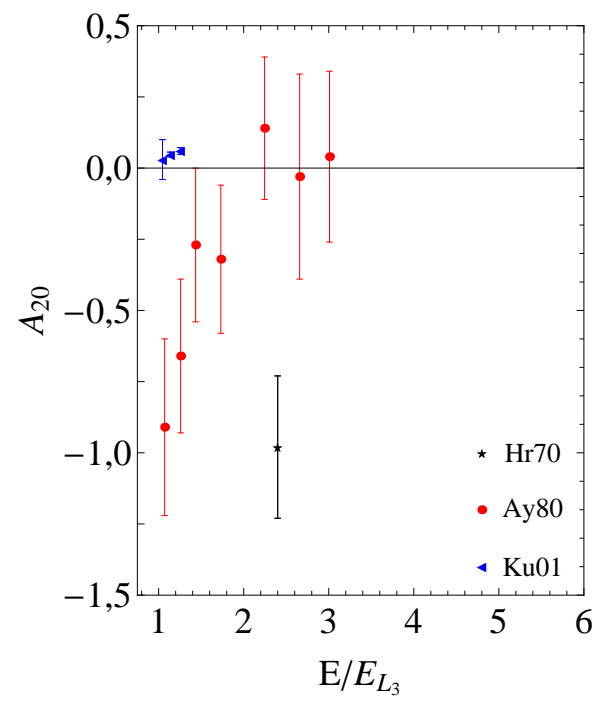

(a)

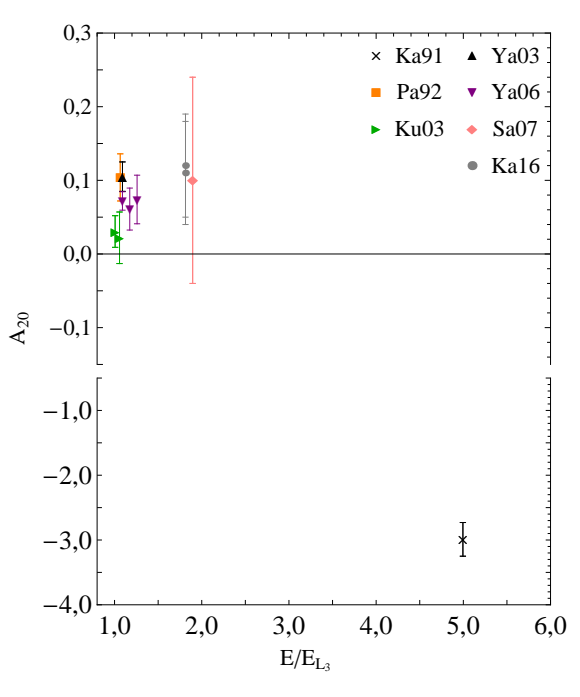

(b)

Figura 3.8: Estimativas do parâmetro de alinhamento $A_{20}$, via distribuição angular ou polarização dos raios $\mathrm{x}$, encontradas na literatura para ionização a) por impacto de elétrons [1-3] e b) por fótons [4-10]. O ponto em estrela (preto) é da referência Hrdý et al. [1] para $\mathrm{Hg}$, o ponto em círculo (vermelho) é da referência Aydinol et al. [2] para Xe, o ponto em cruz (preto) é da referência Kahlon et al. [4] para Au, o ponto quadrado (laranja) é da referência Papp e Campbell [5] para Er, os triângulos apontando para a esquerda (azuis) e para direita (verdes) são das referências Küst et al. [3] e [6], respectivamente, para Xe, os triângulos apontando para cima e para baixo (preto e roxo) são das referências Yamaoka et al. [7] e [8], respectivamente, para Au, o ponto em diamente (rosa) é da referência Santra et al. [9] para $\mathrm{Au}$, e os pontos em círculos (cinzas) são da referência Kampfer et al. [10] para W.

Em nenhuma das metodologias descritas nos artigos de alinhamento atômico citados acima as linhas $\mathrm{L} \ell, \mathrm{L} \alpha_{1}$ e $\mathrm{L} \alpha_{2}$ foram empregadas simultaneamente na estimativa do parâmetro de alinhamento $A_{20}$. Na grande maioria dos estudos, o alinhamento é investigado somente por meio da linha $\mathrm{L} \ell$ ou do dubleto $\mathrm{L} \alpha_{1,2}$ separadamente. 


\title{
Capítulo 4
}

\section{Arranjo e procedimento experimental}

\author{
Neste capitulo serão descritos a linha de feixe do acelerador \\ Microtron, os instrumentos usados, a configuração dos parâ- \\ metros do sistema eletrônico de aquisição de dados, e os proce- \\ dimentos experimentais para a medida de distribuição angular \\ de raios $x$ L dos elementos $T a, W$ e Au e para a medida de \\ seção de choque de ionização das subcamadas $L$ do Au.
}

\subsection{Linha de feixe do acelerador Microtron}

O Microtron de São Paulo [37] dispõe de um acelerador de elétrons com três linhas de feixe: 10 a $100 \mathrm{keV}$, direto do canhão eletrostático; $1,9 \mathrm{MeV}$, proveniente do injetor do Microtron e $5 \mathrm{MeV}$, em comissionamento. Em todos os casos o diâmetro do feixe é de aproximadamente $2 \mathrm{~mm}$ e a corrente varia de dezenas de $\mathrm{nA}$ a alguns $\mu \mathrm{A}$. A figura 4.1 apresenta um esquema geral do acelerador, com as três linhas citadas, e a figura 4.2, uma imagem da linha de $10-100 \mathrm{keV}$, onde os experimentos de distribuição angular e seção de choque foram realizados [37].

Na linha de baixa energia, o feixe contínuo proveniente do canhão de elétrons passa por dois solenóides de focalização, é desviado para a linha de $10-100 \mathrm{keV}$ por um dipolo e na sequência passa por mais um solenóide antes de chegar à câmara de irradiação. A câmara empregada nos experimentos tem a parede lateral em aço, com diâmetro de $500 \mathrm{~mm}$ e flanges nos ângulos de $31,1^{\circ}, 34,8^{\circ}, 48,9^{\circ}, 55,0^{\circ}, 69,9^{\circ}, 89,9^{\circ}, 90,2^{\circ}, 109,9^{\circ}, 125,0^{\circ}$, $131,1^{\circ}, 149,1^{\circ}, 149,9^{\circ}, 166,0^{\circ}$ e $180^{\circ}$, todos com incerteza de $0,5^{\circ}$. Estes correspondem aos ângulos mais próximos dos zeros e extremos dos polinômios de Legendre de ordens dois e quatro, tendo em vista a medida da anisotropia da radiação. As janelas espectros- 


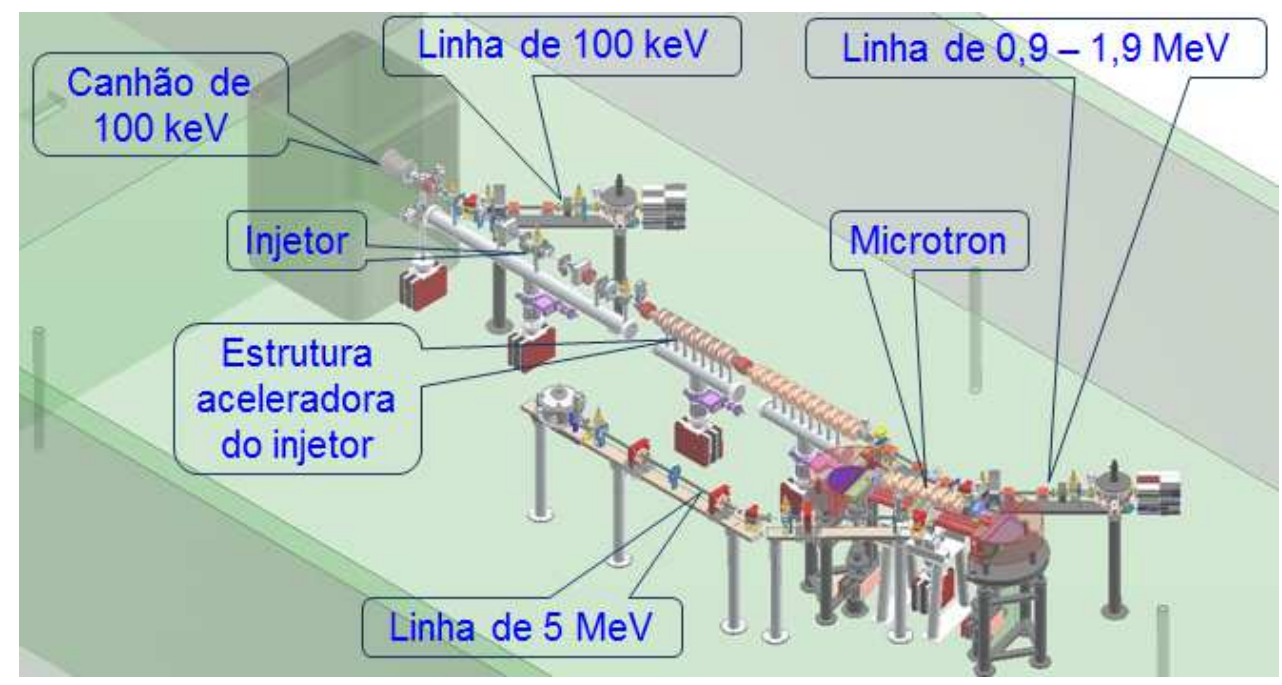

Figura 4.1: Esquema das três linhas de feixe do acelerador Microtron de São Paulo.

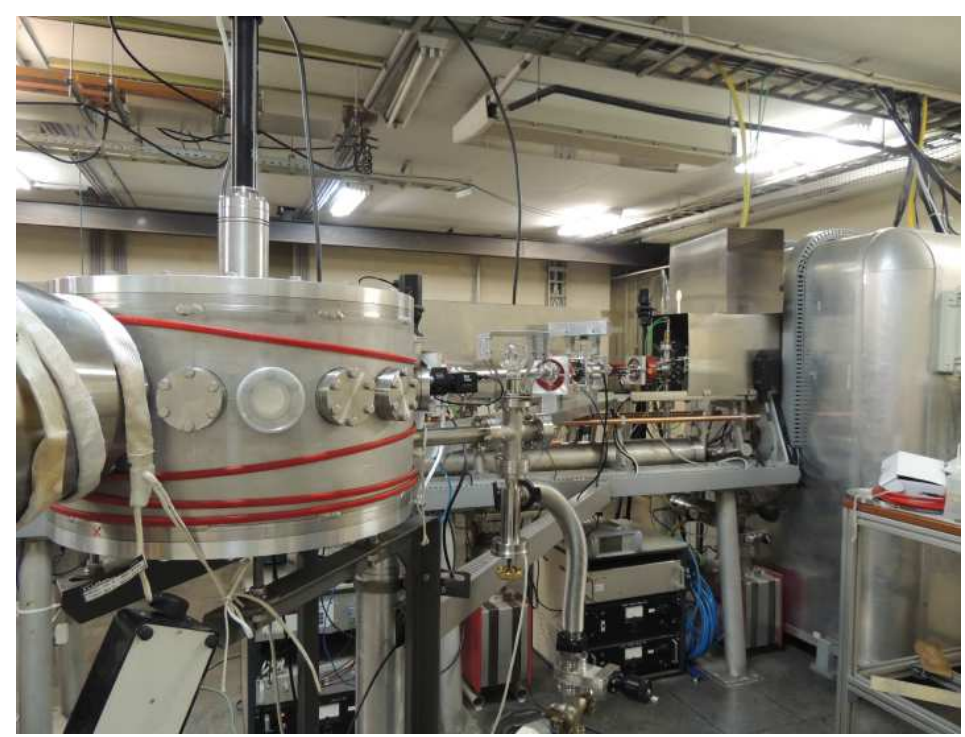

Figura 4.2: Imagem da linha de $10-100 \mathrm{keV}$ do acelerador Microtron de São Paulo, com o canhão de elétrons dentro da grande gaiola de Faraday à direita, e a câmara de irradiação à esquerda.

cópicas da câmara usada no experimento de distribuição angular são de Al e Kapton, com espessuras de aproximadamente $5 \mu \mathrm{m}$ e $25 \mu \mathrm{m}$, respectivamente.

Nos flanges empregados no experimento de distribuição angular, situados em $31,1^{\circ}$, $90,2^{\circ}$ e $125,0^{\circ}$, foram instalados colimadores cilíndricos de $\mathrm{Al}$ com $9 \mathrm{~mm}$ de diâmetro e $70 \mathrm{~mm}$ de comprimento, com o objetivo de reduzir a área da parede interna da câmara visível aos detetores, sem afetar a área ativa destes. Além disso, foram realizadas simulações Monte Carlo com o código PENELOPE [90] com o intuito de quantificar a área da câmara diametralmente oposta ao detetor e que é visível por ele. Essa área foi revestida com folhas de Kapton de $100 \mu \mathrm{m}$ de espessura e aluminizado $(<1 \mu \mathrm{m})$ para reduzir a 
radiação de bremsstrahlung gerada quando os elétrons espalhados atingem as paredes da câmara. A figura 4.3 compara dois espectros de um alvo de Au irradiado com um feixe de elétrons de aproximadamente $31 \mathrm{keV}$, adquiridos com o detetor na posição de $90^{\circ} \mathrm{com}$ relação à direção do feixe incidente, sem e com o colimador instalado na câmara e o revestimento de Kapton na região diametralmente oposta ao detetor. É possível notar que o espectro é mais limpo no segundo caso, com a linha L $\ell$ do Au isolada dos demais picos de raios x K provenientes dos elementos da parede da câmara (Cr, Mn, Fe e Ni).

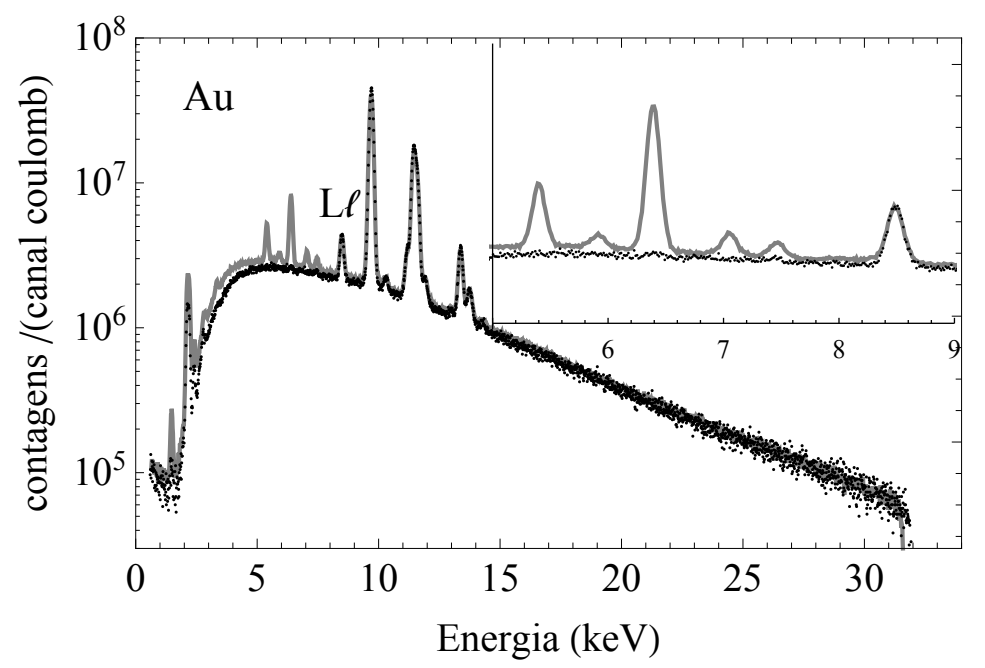

Figura 4.3: Espectros de um alvo de Au irradiado com um feixe de elétrons com cerca de $31 \mathrm{keV}$ normalizados pela carga. A linha contínua (em preto) corresponde à medição sem colimador e sem o revestimento interno da câmara, enquanto que os pontos (em cinza), à com o colimador de $\mathrm{Al}$ instalado no flange e com a região da câmara diametralmente oposta ao detetor revestida por Kapton de $100 \mu \mathrm{m}$ aluminizado.

A tampa da câmara, de Al, possui um suporte para torre de alvos que permite alocar até seis deles, além de um monitor de posição de óxido de Be (view screen). Um acionador permite centralizar um dos seis alvos, o monitor de posição, ou suspender todo o conjunto, deixando o centro da câmara livre para a passagem do feixe.

Um copo de Faraday cônico com ângulo de semiabertura de $12^{\circ}, 200 \mathrm{~mm}$ de profundidade e feito em carbono, figura 4.4, está acoplado à câmara em $0^{\circ}$ com relação à direção do feixe incidente. Simulações Monte Carlo realizadas com o código PENELOPE [90] mostraram que o copo de Faraday com as características descritas diminui de forma significativa a probabilidade de retroespalhamento dos elétrons que tenham chegado ao copo, além de reduzir a produção de fótons. Tanto o copo de Faraday quanto a câmara estão eletricamente isolados, o que permite a coleção de toda a carga incidente nos alvos com o uso de integradores de corrente.

A figura 4.5 traz um esquema da câmara de irradiação com o copo de Faraday, indi- 


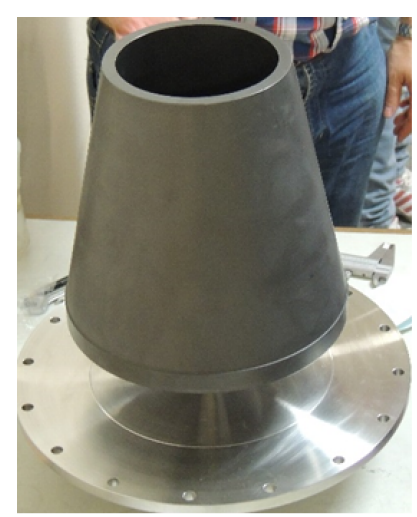

Figura 4.4: Imagem do copo de Faraday instalado na base de montagem na câmara.

cando a posição das janelas, da torre de alvos e a direção do feixe incidente, e a figura 4.6 mostra uma imagem da câmara, junto com o copo de Faraday, à esquerda, e da torre de alvos, à direita.

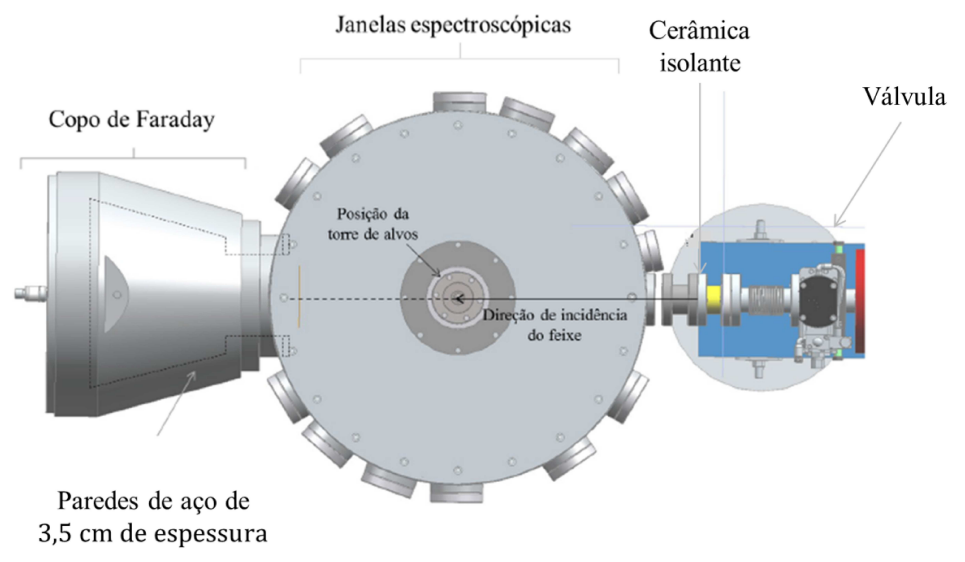

Figura 4.5: Esquema da câmara de irradiação da linha de 10-100 keV.

\subsection{Alvos}

Os alvos de $\mathrm{Cu}, \mathrm{Ta}, \mathrm{W}$ e $\mathrm{Au}$ foram fabricados por diferentes técnicas no Instituto de Física da Univesidade de São Paulo. Os alvos de Cu, Ta e W foram confeccionados pela técnica de sputtering no Laboratório de Materiais Magnéticos, e o alvo de Au no Laboratório de Filmes Finos pela técnica de deposição física de vapor. Todos eles foram depositados sobre backings de $\mathrm{C}$ com espessuras da ordem de $20 \mathrm{~nm}$, sendo que estes estão sobre molduras de fibras de carbono com dimensões de $15 \times 30 \times 0,3 \mathrm{~mm}^{3}$ e com abertura central circular com diâmetro de $10 \mathrm{~mm}$. A figura 4.7 mostra a imagem de um alvo de Au confeccionado por deposição física de vapor. 

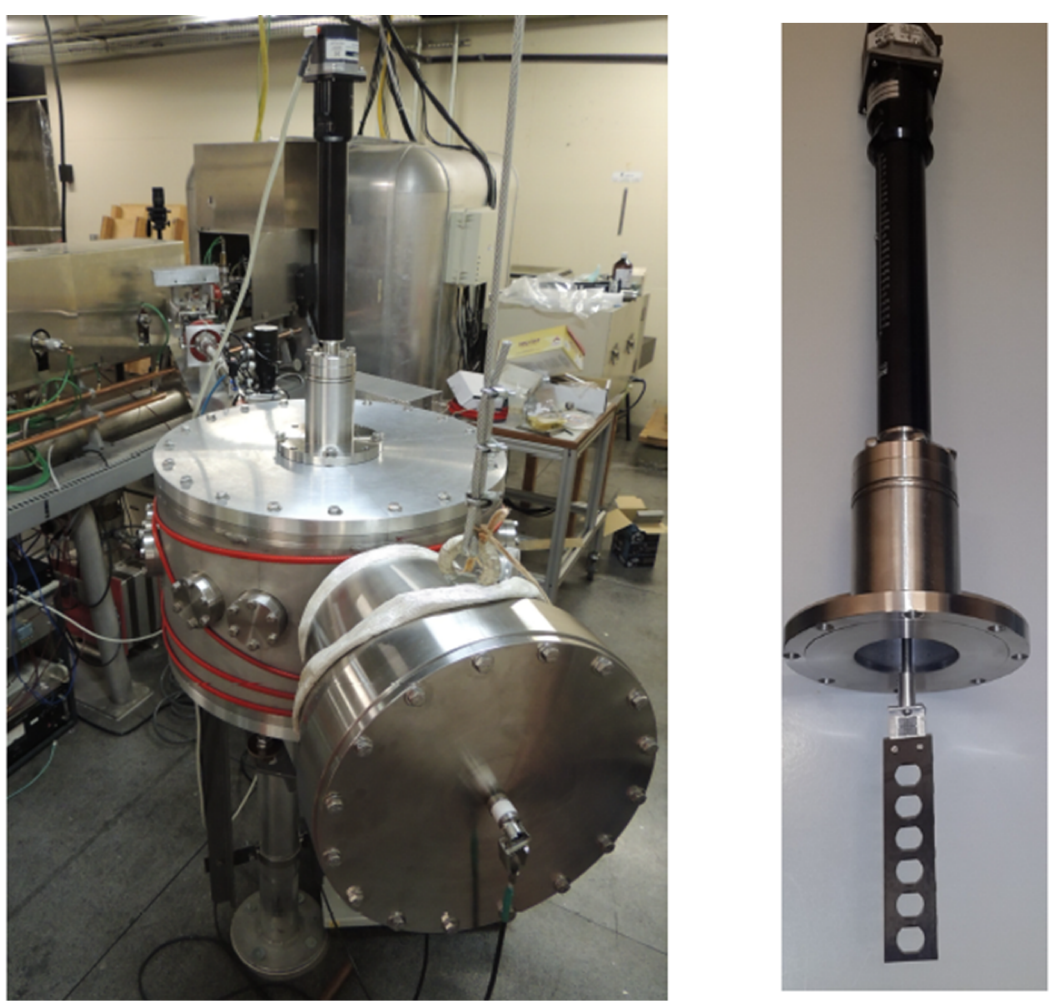

Figura 4.6: Imagem da câmara de irradiação com o copo de Faraday, à esquerda, e da torre de alvos, à direita. Na parte superior da torre, o cilindro preto corresponde ao acionador.

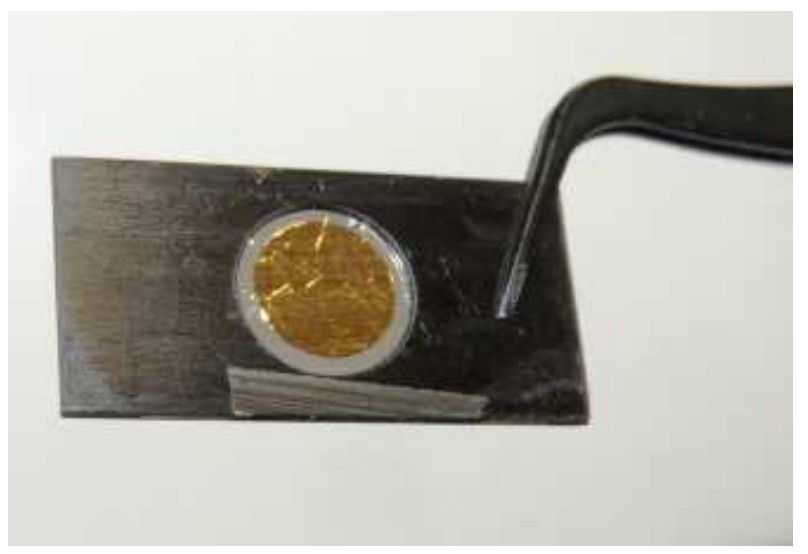

Figura 4.7: Imagem de um alvo de $\mathrm{Au}$ sobre um filme fino de $\mathrm{C}$ depositado em uma moldura de fibra de carbono.

As espessuras dos alvos foram medidas pelo método de retro-espalhamento de Rutherford (RBS), que devido a sua precisão, é uma das técnicas mais empregadas na caracterização de filmes finos. O procedimento consiste em irradiar as amostras com feixes monoenergéticos de ${ }^{1} \mathrm{H}^{+},{ }^{4} \mathrm{He}^{+}$ou ${ }^{4} \mathrm{He}^{2+}$ com correntes da ordem de $\mathrm{nA}$, e detetar as partículas retro-espalhadas nos átomos da amostra. Conhecendo o número de partículas espalhadas pela amostra e a seção de choque de Rutherford é possível estimar sua espessura. 
Os alvos deste experimento foram irradiados no Pelletron-tandem do Laboratório de Materiais e Feixes Iônicos (LAMFI) da Universidade de São Paulo. Um feixe de ${ }^{4} \mathrm{He}^{+}$ com energia de $2200 \mathrm{keV}$ incidiu sobre os alvos com uma inclinação de $7^{\circ} \mathrm{em}$ uma câmara de irradiação cilíndrica (diâmetro interno de $430 \mathrm{~mm}$, altura de $150 \mathrm{~mm}$ ) com pressão de base de $2 \times 10^{-5}$ torr. Os alvos foram posicionados em um porta amostras que permite alocar até três deles, e os espectros dos íons retro-espalhados foram obtidos com detetores de Si de barreira de superfície posicionados a $120^{\circ}$ e $170^{\circ}$ em relação à direção do feixe incidente. A descrição detalhada do arranjo experimental está apresentada no sítio do LAMFI [91] e os conceitos físicos da técnica de RBS podem ser encontrados no livro clássico de Chu et al. [92].

As análises dos espectros de RBS foram realizadas com os softwares SIMNRA [93] e MultiSIMNRA [94]. No SIMNRA a simulação dos espectros é feita a partir dos parâmetros de entrada relacionados com o arranjo experimental e a composição do alvo. No primeiro caso, entram as informações sobre o tipo de partícula incidente, a energia do feixe, o ângulo de incidência, a calibração de energia e a resolução dos detetores. Já no segundo entram as informações específicas da amostra como os elementos presentes, o tipo de substrato, a presença de rugosidade, entre outros. O programa permite o ajuste dos parâmetros de interesse como a composição e a espessura das camadas, a rugosidade, a calibração de energia, a resolução do detetor, e o produto do número de partículas incidentes pelo ângulo sólido subtendido pelo detector em relação ao alvo. A estimativa dos parâmetros de interesse do espectro é conduzida de maneira que seja minimizada a quantidade:

$$
Q=\sum_{i}\left[\frac{N(i)-N_{\operatorname{sim}}(i)}{\sigma(i)}\right]^{2}
$$

em que $N_{\text {sim }}(i)$ corresponde ao número de contagens simulada para o canal $i, N(i)$ o número de contagens experimental no mesmo canal, e $\sigma(i)$ o desvio padrão associado a esse número de contagens.

O programa MultiSIMNRA [94] se baseia nos cálculos do SIMNRA e faz uma análise autoconsistente impondo restrições entre os parâmetros ajustados que possuem ligações físicas.

A figura 4.8 apresenta os espectros de RBS experimentais adquiridos com o detetor na posição de $120^{\circ}$ junto com os simulados para os alvos de $\mathrm{Cu}$, Ta, W e Au empregados neste experimento, em escalas logarítmica e linear. Em todos eles nota-se que os picos dos elementos $\mathrm{Cu}$, Ta, W e Au são estreitos, o que evidencia que os alvos são finos. Além disso, apenas o alvo de Ta apresenta uma cauda mais pronunciada à esquerda, que se deve 
à rugosidade do alvo. Por outra lado, a figura $4.8 \mathrm{~d}$ ), em escala linear, mostra que a área perdida dessa cauda pode ser ignorada em relação à área total do pico. Nos espectros do alvo de Ta, W e Au nota-se picos de $\mathrm{O}$, indicando a presença deste elemento nos alvos. A quantidade de $\mathrm{O}$, no entanto, é pequena e provavelmente deve ter se fixado aos alvos durante o processo de confecção ou manipulação destes. No alvo de Cu se identifica um pico de $\mathrm{O}$ e outro de $\mathrm{S}$, as proporções sugerem uma contaminação de $\mathrm{SO}_{4}$, com uma concentração que é inferior a do $\mathrm{Cu}$ em pelo menos uma ordem de magnitude.

Com o intuito de quantificar a uniformidade dos alvos, alguns deles foram irradiados com o feixe de ${ }^{4} \mathrm{He}^{+}$em mais de uma posição. Os alvos de Ta e Au foram irradiados no centro, acima e abaixo dele, e o alvo de $\mathrm{Cu}$ foi irradiado nas posições centro, abaixo, acima, à esquerda e à direita dele, todos com um feixe de aproximadamente $2 \mathrm{~mm}$ de diâmetro, e os deslocamentos da ordem de $3 \mathrm{~mm}$. A figura 4.9 apresenta as espessuras encontradas para todos os alvos de $\mathrm{Ta}$ e $\mathrm{Au}$ que foram confeccionados em um único processo e irradiados em diversos pontos. O desvio padrão desses valores forneceu uma estimativa da homogeneidade dos alvos, que foi de 0,$5 ; 0,5$ e $0,3 \mu \mathrm{g} / \mathrm{cm}^{2}$ para os alvos de $\mathrm{Cu}$, Ta e Au, respectivamente. Para o alvo de W apenas a posição central dos dois alvos fabricados no mesmo processo foi medida.

A estimativa da incerteza associada à espessura dos alvos foi feita somando-se quadraticamente a incerteza fornecida pelo software MultiSIMNRA [94] com a estimativa da não uniformidade dos alvos. A tabela 4.1 traz as espessuras estimadas, junto com as suas respectivas incertezas.

Tabela 4.1: Estimativas das densidades superficiais de massa dos alvos de $\mathrm{Cu}$, Ta, W e $\mathrm{Au}$ determinadas pela técnica de RBS. Em parênteses, o desvio padrão em unidades do dígito menos significativo.

\begin{tabular}{cc}
\hline \hline Elementos & densidade superficial $\left(\mu \mathrm{g} / \mathrm{cm}^{2}\right)$ \\
\hline $\mathrm{Cu}$ & $16,9(6)$ \\
$\mathrm{Ta}$ & $16,5(9)$ \\
$\mathrm{W}$ & $3,8(3)$ \\
$\mathrm{Au}$ & $10,1(3)$ \\
\hline \hline
\end{tabular}

\subsection{Silicon Drift Detectors - SDD}

O conceito do SDD foi introduzido em 1984 por Gatti e Rehak [95,96]. Estes detetores consistem em um disco de Si com dopagem tipo $n$ com propriedades diferentes nas suas 


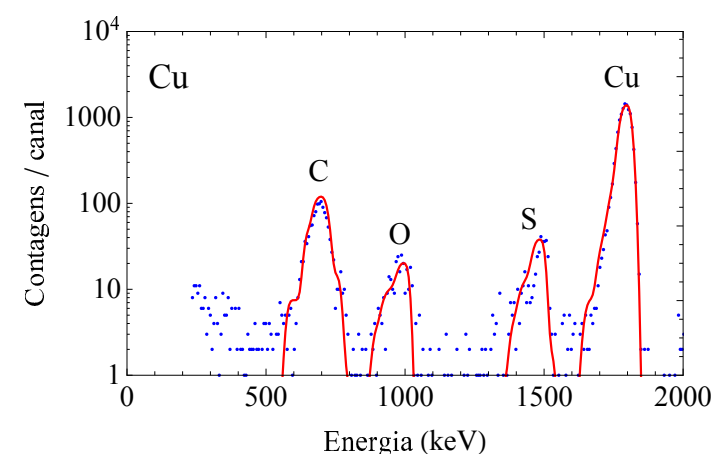

(a)

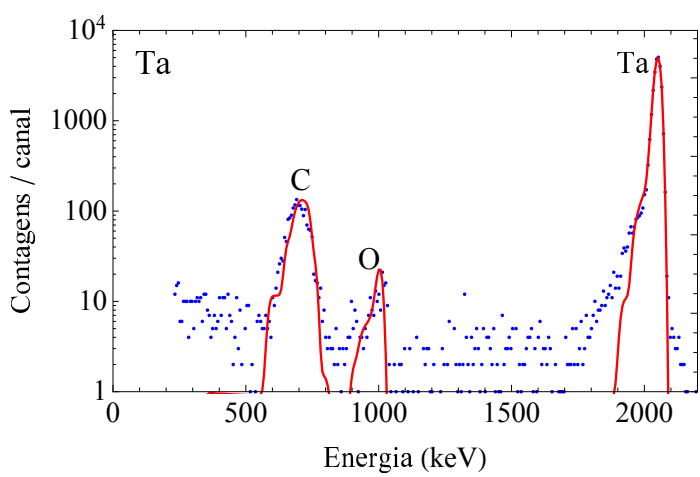

(c)

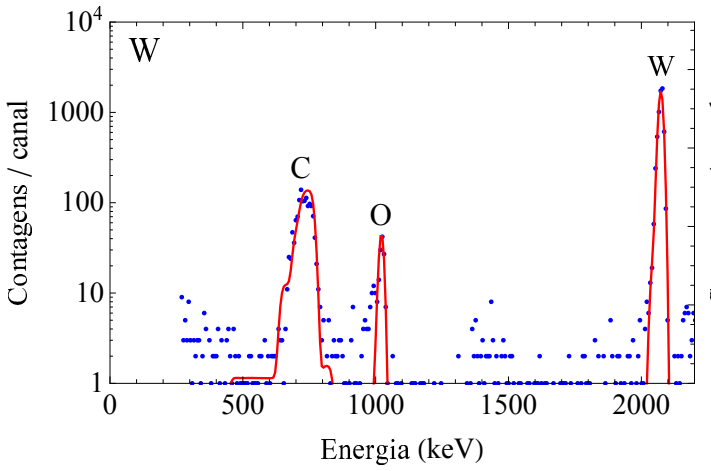

(e)

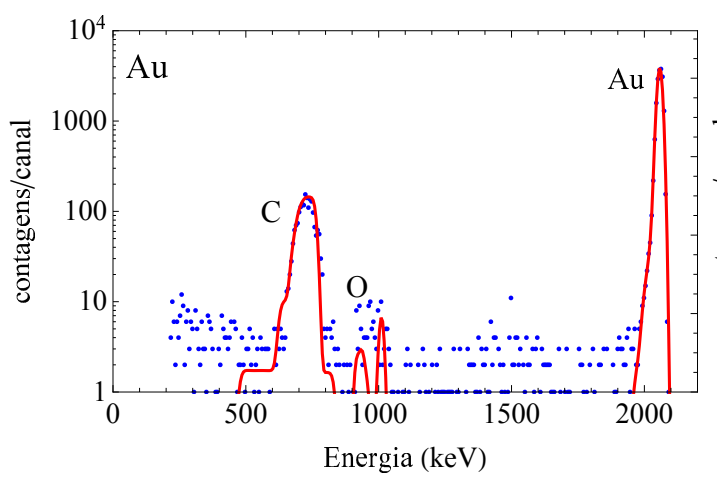

(g)

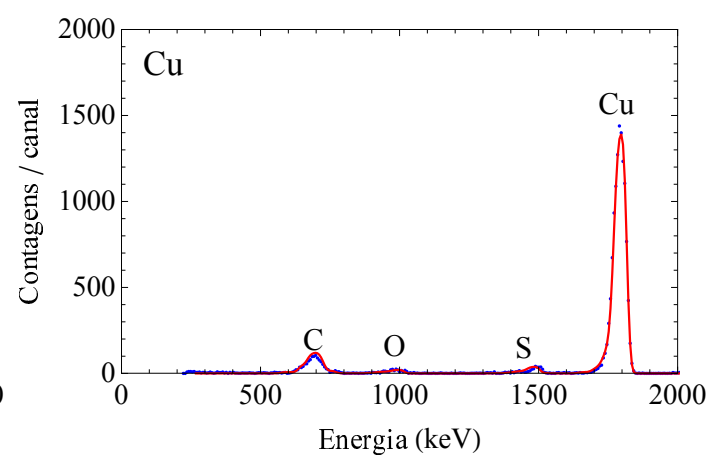

(b)

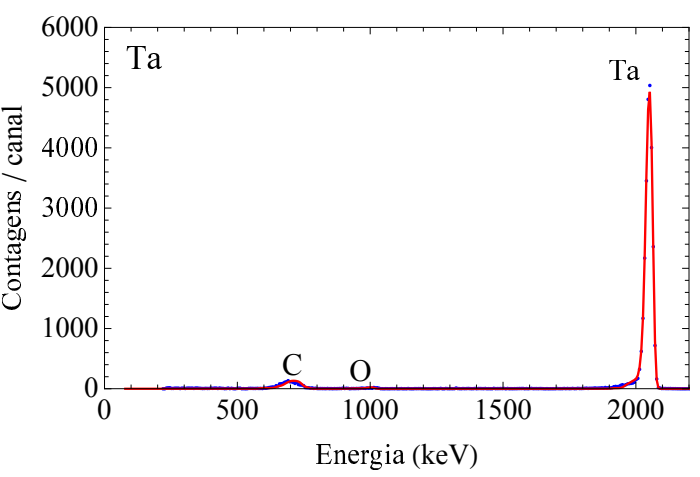

(d)

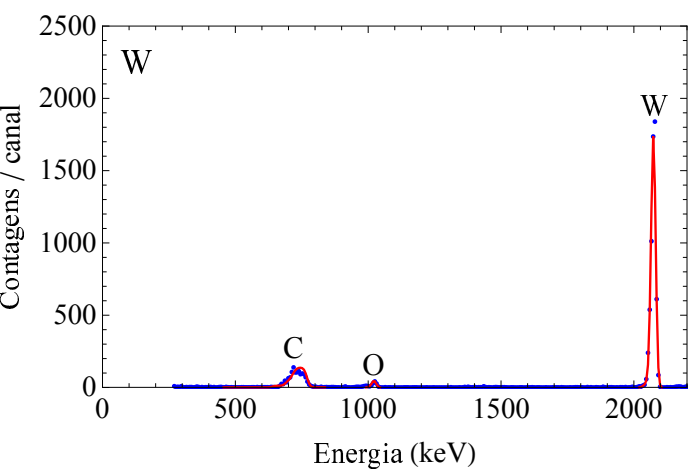

(f)

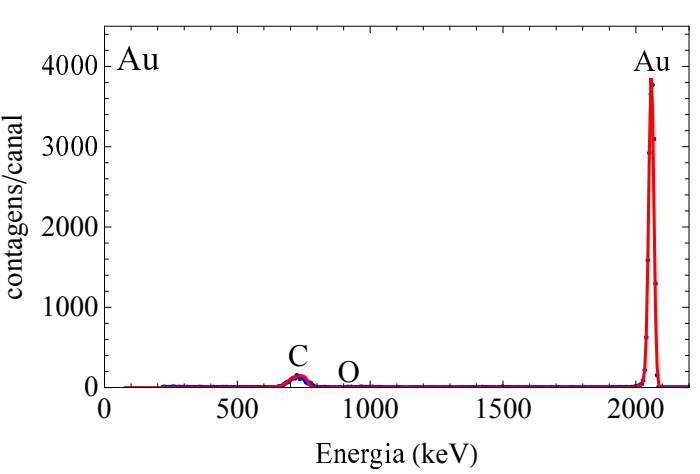

(h)

Figura 4.8: Espectros de RBS de partículas de ${ }^{4} \mathrm{He}^{+}$experimental (pontos azuis) e simulado (linha contínua vermelha) medido a $120^{\circ}$ com relação à direção do feixe incidente em escalas logarítmica (à esquerda) e linear (à direita) para os alvos de: a) e b) Cu, c) e d) Ta, e) e f) W e g) e h) Au. A dispersão em energia é de 6 keV/canal. 


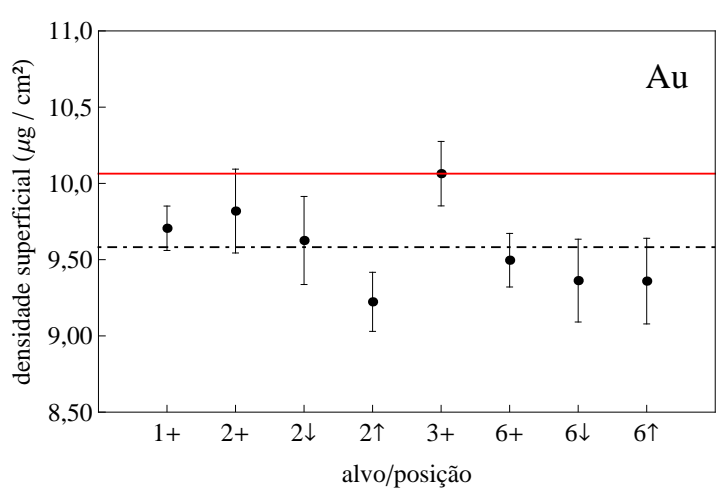

(a)

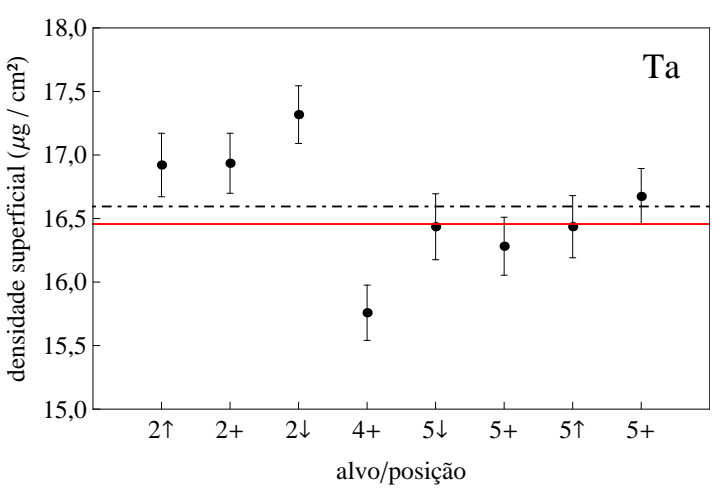

(b)

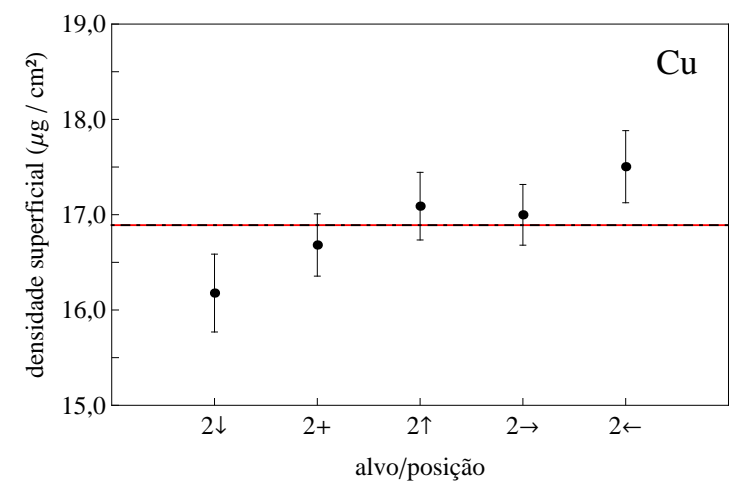

(c)

Figura 4.9: Espessuras de: a) quatro alvos de Au, b) três de Ta e c) um alvo de Cu. Os números indicam os diferentes alvos e os símbolos, as diferentes posições. A linha tracejada (em preto) corresponde à média dos dados experimentais e a linha contínua (em vermelho) corresponde à espessura do alvo deste experimento. Para esses alvos a não uniformidade foi estimada em 0,$5 ; 0,5$ e $0,3 \mu \mathrm{g} / \mathrm{cm}^{2}$ para os alvos de $\mathrm{Cu}$, Ta e $\mathrm{Au}$, respectivamente

superfícies frontais. A superfície pela qual os raios x entram no detetor é uma junção do tipo $p$ - $n$ homogênea ao longo de toda a área, enquanto que a superfície oposta apresenta uma estrutura de anéis circulares concêntricos dopados para formar um semicondutor tipo $p$, com um pequeno ânodo coletor localizado no centro da superfície.

A grande vantagem deste tipo de detetor é o tamanho pequeno do ânodo quando comparado com a área frontal. Os portadores de carga (elétrons e buracos) gerados pela radiação incidente são guiados ao longo das linhas de campo elétrico até a região do ânodo. O tamanho reduzido do ânodo, praticamente independente da área frontal do detetor, faz com que ele possua uma capacitância pequena, gerando um ruído menor e, portanto, melhor resolução nos espectros adquiridos. O ruído é pequeno o bastante para que o detetor possa operar com temperaturas da ordem de $-20^{\circ} \mathrm{C}$, que podem ser alcançadas com um dispositivo Peltier, dispensando o nitrogênio líquido comumente usado no processo de refrigeração de detetores semicondutores de alta resolução. 
No experimento deste trabalho três SDDs da Amptek foram empregados. As especificações do fornecedor são: área frontal dos detetores de $25 \mathrm{~mm}^{2}$; espessura de $0,5 \mathrm{~mm}$; colimador interno de $\mathrm{W}(100 \mu \mathrm{m}), \mathrm{Cr}(35 \mu \mathrm{m}), \mathrm{Ti}(15 \mu \mathrm{m})$ e $\mathrm{Al}(75 \mu \mathrm{m})$, com área livre de $17 \mathrm{~mm}^{2}$. A espessura da janela de Be é de $12,7 \mu \mathrm{m}$, os detetores não apresentam contato frontal, e o fornecedor sugere uma camada morta com espessura de aproximadamente $0,15 \mu \mathrm{m}$. A resolução do detetor (FWHM), que será apresentada de forma mais detalhada no capítulo 5, é de aproximadamente $140 \mathrm{eV}$ para a energia de 6, $4 \mathrm{keV}$ (dubleto $\mathrm{K} \alpha$ do $\mathrm{Fe})$.

\subsection{Arranjo experimental e sistema de aquisição}

Os três SDDs foram posicionados nos flanges correspondentes aos ângulos de $31,1^{\circ}, 90,2^{\circ}$ e $125,0^{\circ}$, que daqui em diante serão referidos no texto pelos valores arredondados para $31^{\circ}, 90^{\circ}$ e $125^{\circ}$, respectivamente. Os eixos de simetria dos detetores foram alinhados com o ponto central da câmara de irradiação, onde ficaram alocados os alvos durante o experimento, com o auxílio dos adaptadores de acrílico que foram confeccionados para encaixarem diretamente no flange da câmara. A figura 4.10 mostra a imagem de um deles acoplados ao detetor e encaixado no flange. A verificação do alinhamento foi realizada com o auxílio de um dispositivo laser, como pode ser visto na figura 4.11. Ímãs foram colocados dentro da câmara, acoplados aos três colimadores de Al, com o intuito de desviar os elétrons espalhados da superfície frontal dos detetores.

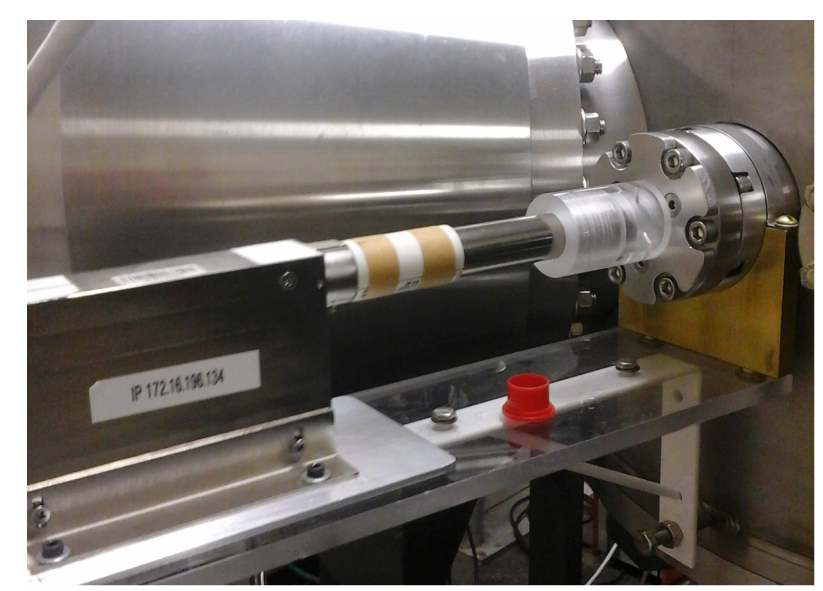

Figura 4.10: Imagem do adaptador de acrílico empregado para auxiliar no alinhamento do arranjo experimental.

O uso dos adaptadores de acrílico permitiu padronizar a espessura da camada de ar entre os detetores e as janelas da câmara em 12,5 mm, o que simplificou o processo de quantificar a eficiência de pico dos detetores posteriormente. A figura 4.12 traz uma 


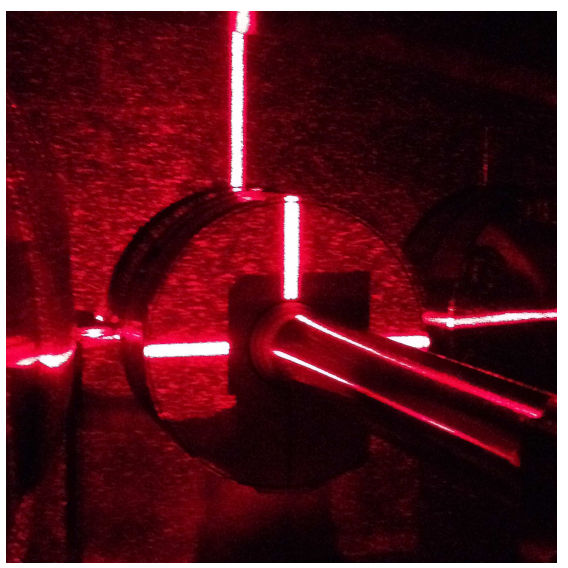

Figura 4.11: Imagem obtida durante o processo de verificação do alinhamento do arranjo experimental com um dispositivo laser.

imagem do arranjo experimental, onde as setas brancas indicam as posições dos três detetores.

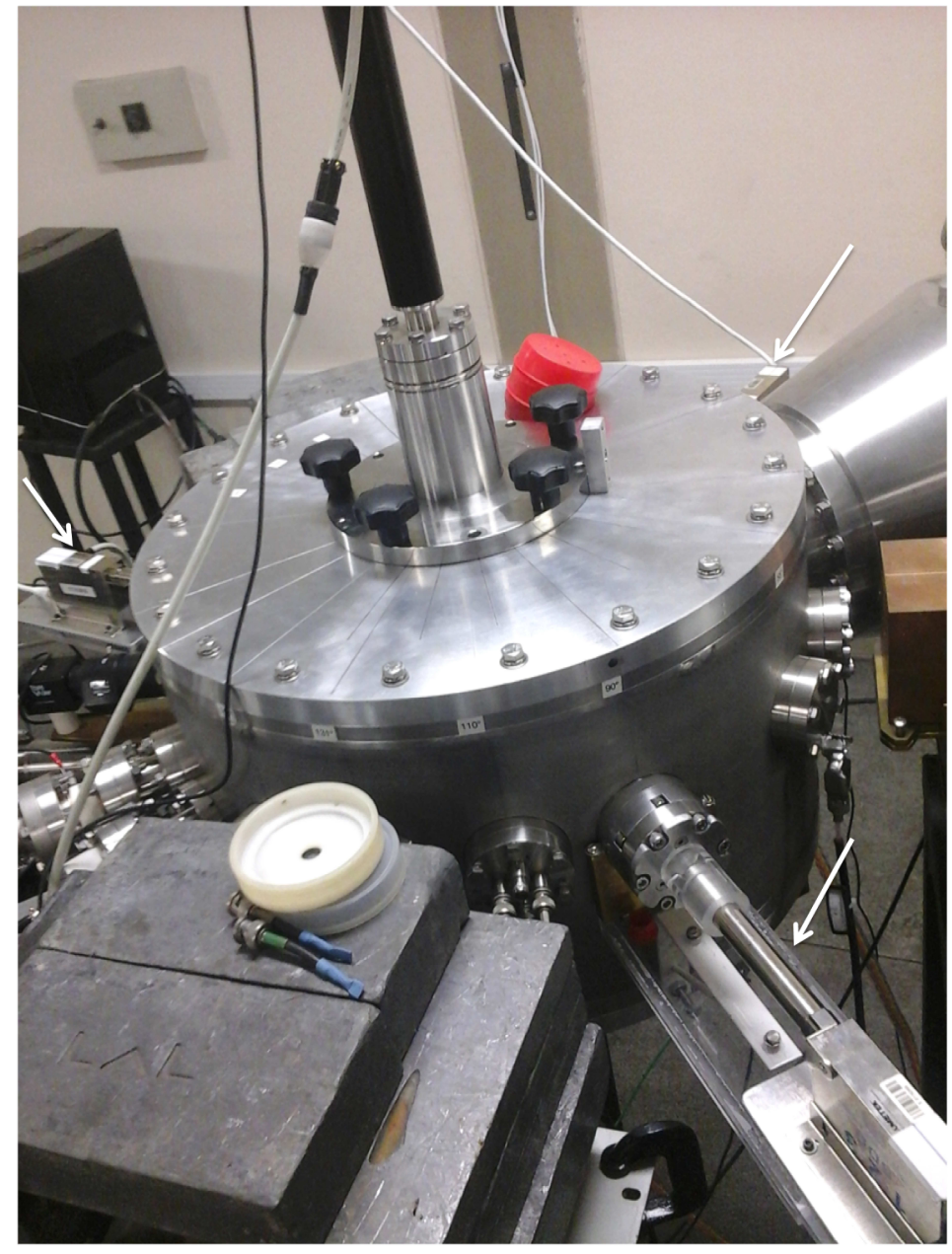

Figura 4.12: Arranjo experimental do experimento de distribuição angular com a medida simultânea dos fótons nos ângulos de $31^{\circ}, 90^{\circ}$ e $125^{\circ}$. As setas mostram cada um dos três detetores SD. 
O programa MCA 8000 fornecido pelo fabricante, junto com outros programas desenvolvidos pelo grupo, foram usados para o controle da aquisição dos espectros, bem como para sua gravação.

\subsection{Configuração dos parâmetros associados ao sistema de aquisição}

A anisotropia esperada para a emissão de algumas linhas do grupo L é da ordem de poucos por cento de acordo com Berezhko e Kabachnik [15], de modo que a estimativa da amplitude dessas linhas precisa apresentar uma incerteza pequena para que esse efeito seja observado de forma conclusiva. Trabalhar com altas taxas de contagem é uma grande vantagem neste caso, pois permite que o tempo de aquisição seja menor, diminuindo os efeitos decorrentes de pequenas variações do sistema de aquisição durante a medição. Outra necessidade para este tipo de estudo é a boa resolução em energia, uma vez que os picos devem estar separados o suficiente para que possam ser desmembrados com boa precisão. Nesse contexto, é interessante que o sistema esteja configurado de tal forma que seja possível realizar medições com uma taxa de contagem relativamente alta, um tempo morto pequeno e mantendo uma boa resolução.

Neste trabalho os raios $\mathrm{x}$ foram detetados com um detetor de alta resolução com um Processador de Pulso Digital (DPP). Os principais parâmetros do sistema de aquisição associados a forma dos picos são o tempo de subida, o patamar, o limiar do canal lento e o do rápido, que serão chamados de limiar lento e rápido, respectivamente, daqui em diante, e estão esquematizados na figura 4.13.

O canal de processamento digital processa numericamente os dados do ADC e controla uma função numérica trapezoidal, esquematizada na figura 4.14.

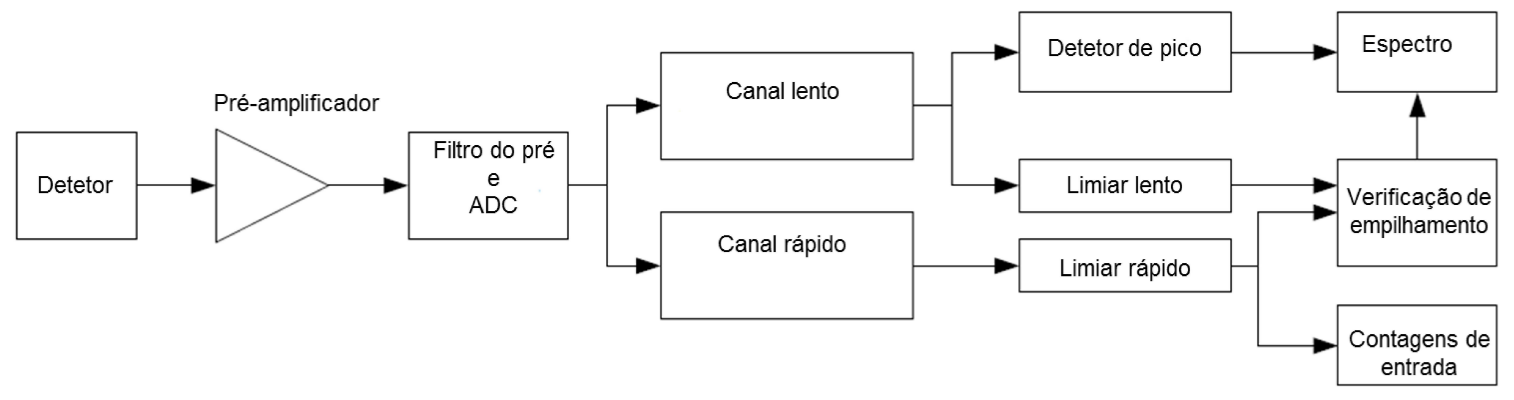

Figura 4.13: Esquema de blocos da eletrônica do SDD da Amptek [11]. Os tempos característicos associados com o canal lento estão diretamente relacionados com o tempo de subida e o patamar do sistema de aquisição. 


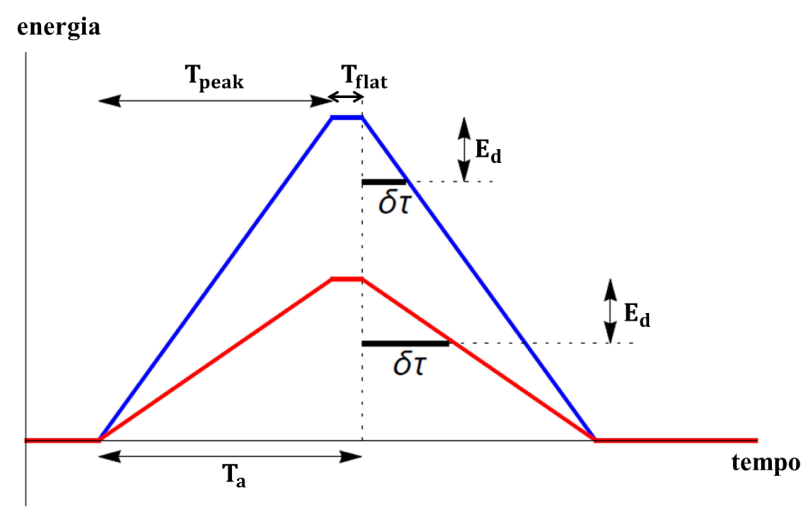

Figura 4.14: Forma do pulso do amplificador lento em um DPP. $\mathrm{T}_{\text {peak }}$ corresponde ao tempo de subida, $\mathrm{T}_{\text {flat }}$ ao patamar, $E_{d} \approx$ ao nível de ruído, e $\delta \tau$ depende da energia associada ao pulso.

\subsubsection{Tempo de subida e patamar}

O tempo de subida $T_{\text {peak }}$ corresponde ao intervalo de tempo que o pulso leva para chegar de sua linha de base até o máximo do pulso, enquanto que o patamar $T_{\text {flat }}$ corresponde ao intervalo de tempo em que o pulso permanece na amplitude máxima, conforme esquematizado na figura 4.14 .

A fim de encontrar os valores adequados de tempo de subida e patamar, foi realizado um experimento em que ficaram fixas as seguintes condições: alvo de Au inclinado $49^{\circ}$ em relação ao feixe de elétrons; detetor posicionado a $90^{\circ}$; energia dos elétrons igual a $18 \mathrm{keV}$; taxa de aquisição de aproximadamente $16 \mathrm{kHz}$; tempo de aquisição de $300 \mathrm{~s}$.

Para o estudo do tempo de subida, o patamar foi mantido em $0,3 \mu \mathrm{s}$, o limiar rápido em 1,1 keV e o lento em $660 \mathrm{eV}$. Foram realizadas medições para quatro valores de tempo de subida: 1,0;1,6;2,0 e 4,0 $\mu$ s. Já para a análise do patamar, o tempo de subida foi mantido em $2,0 \mu \mathrm{s}$ e o patamar variou entre 0,1 e $0,5 \mu \mathrm{s}$. As figuras 4.15 e 4.16 mostram os valores obtidos para a resolução (FWHM) e a amplitude da linha $\mathrm{L} \alpha_{1}$, normalizada pela carga e corrigida pelo tempo morto, além do tempo morto durante as aquisições, em função do tempo de subida e do patamar, respectivamente.

A figura 4.15 mostra que não há uma dependência evidente, dentro das barras de incerteza, entre o patamar e a resolução do detetor, e entre o patamar e a intensidade da linha $\mathrm{L} \alpha_{1}$, enquanto há uma ligeira dependência entre o patamar e o tempo morto. Por outro lado, o manual do fabricante da Amptek [11] sugere que, para taxas de contagem inferiores a $800 \mathrm{kHz}$, valores de patamar da ordem de $0,2 \mu$ s devem ser usados. Diante disso, optou-se por seguir a indicação do fornecedor e adotar $T_{\text {flat }}=0,2 \mu \mathrm{s}$. 


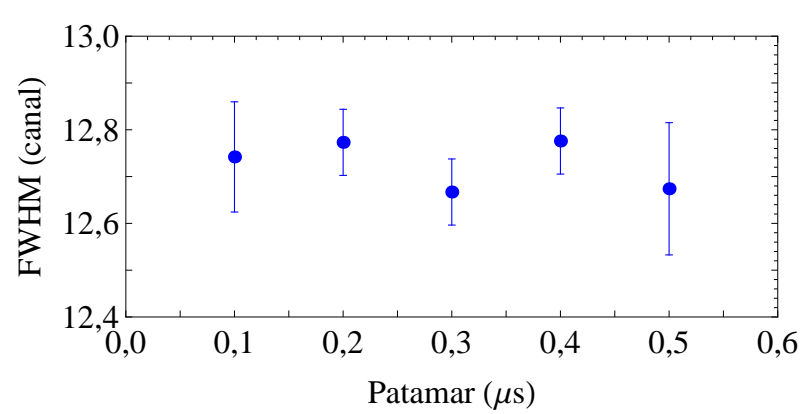

(a)

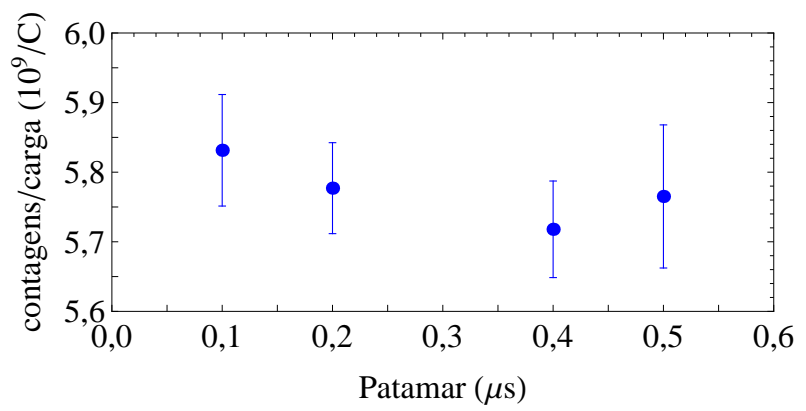

(b)

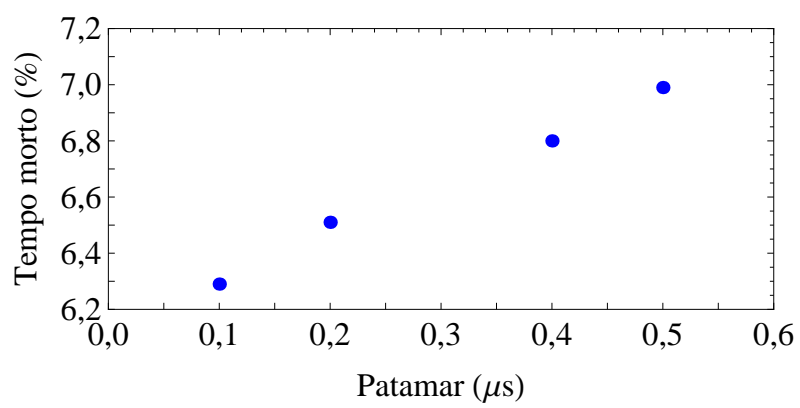

(c)

Figura 4.15: Dependência da a) resolução (FWHM) e b) da amplitude da linha L $\alpha_{1}$, normalizada pela carga e corrigida pelo tempo morto, e c) do tempo morto de aquisição com o patamar $T_{\text {flat }}$.

A figura 4.16 mostra, como esperado, que há uma melhora na resolução do detetor com o aumento do tempo de subida, ao mesmo tempo em que há um aumento do tempo morto de aquisição. Por outro lado, nota-se na figura 4.16 b) que o ponto de amplitude correspondente ao tempo de subida de 4,0 $\mu$ s está ligeiramente abaixo do valor constante determinado pelos demais, o que pode ser consequência da correção inadequada das perdas devido ao tempo morto. Diante desses resultados, optou-se por manter o tempo de subida em $T_{\text {peak }}=1,6 \mu \mathrm{s}$. 


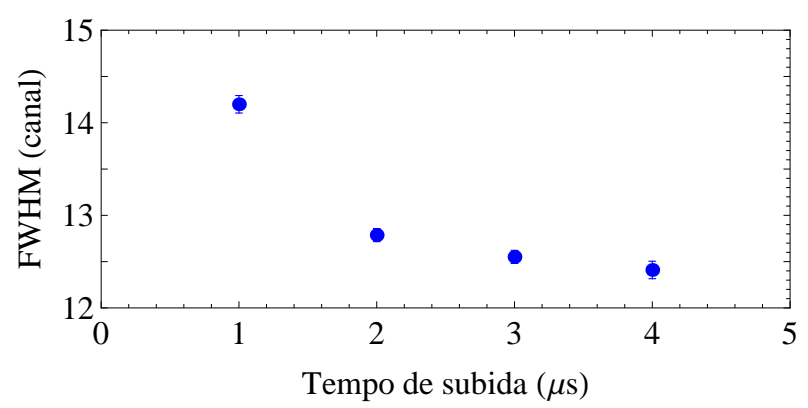

(a)

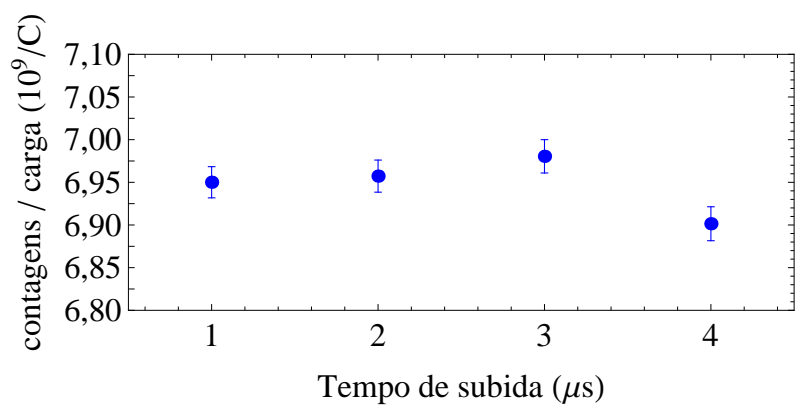

(b)

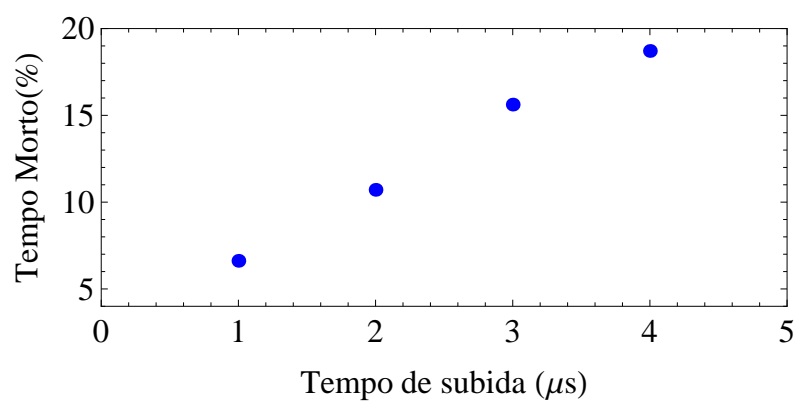

(c)

Figura 4.16: Dependência da a) resolução (FWHM) e b) da amplitude da linha L $\alpha_{1}$, normalizada pela carga e corrigida pelo tempo morto, e c) do tempo morto de aquisição com o tempo de subida $T_{\text {peak }}$.

\subsubsection{Limiar lento e rápido}

O detetor SD apresenta dois canais digitais de processamento, um rápido, com tempos de resposta característicos da ordem de $0,1 \mu \mathrm{s}$, e outro lento, da ordem de 2,0 $\mu$ s. Cada um desses canais contém um discriminador com limiares ajustáveis, chamados de limiar rápido e limiar lento, respectivamente, conforme esquematizado na figura 4.13. O canal rápido apresenta resolução baixa, enquanto que o lento apresenta uma resolução muito superior, de modo que os espectros analisados são os adquiridos neste canal. Além disso, o canal lento tem a opção de rejeição de empilhamento, que não está presente no canal rápido.

Uma vez que a rejeição de empilhamento do canal lento esteja acionada, ele irá regis- 
trar um pulso sempre que o máximo de sinal correspondente estiver acima do limiar lento, abaixo do fundo de escala de deteção e o sistema não tenha detetado dois pulsos no canal rápido dentro do tempo de conversão do canal lento. Caso o canal rápido identifique dois pulsos em um intervalo de tempo menor do que o do canal lento eles serão rejeitados. O rápido registra um pulso desde que ele esteja acima do limiar rápido, entretanto não há um limite superior para os pulsos registrados nesse canal, de modo que é importante certificar-se de que não há pulsos acima do fundo de escala, uma vez que eles não serão contabilizados, mas afetarão o tempo de contagem.

Para localizar o valor do limiar lento foram seguidas as instruções do fabricante [97]. Com o feixe de elétrons desligado foi feita uma aquisição de dados durante $60 \mathrm{~s}$ com a opção de rejeição de empilhamento PUR (Pile Up Rejection) desativada. O primeiro canal sem contagens de ruído, que esteve na posição de aproximadamente $220 \mathrm{eV}$, é sugerido como sendo a posição ideal para fixar o limiar lento. O limiar rápido foi escolhido depois da análise do tempo morto, da amplitude e da resolução da linha $L \alpha_{1}$ nos espectros adquiridos com o limiar rápido variando entre cerca de 700 e 1600 eV, figura 4.17.

A figura 4.17 c) mostra que o tempo morto de aquisição tem uma forte dependência com a posição do limiar rápido, afetando de forma significativa a correção das perdas de contagens no pico $\mathrm{L} \alpha_{1}$. Do gráfico 4.17 b) nota-se que para o limiar rápido acima de $1100 \mathrm{eV}$ a amplitude da linha normalizada pela carga e corrigida pelo tempo morto começa a ficar constante.

Uma vez que fótons com energia abaixo de $1000 \mathrm{eV}$ não atravessam a janela de Be do detetor, optou-se por escolher o limiar lento ligeiramente acima do valor estabelecido pelo nível do ruído. Com isso os valores finais para o limiar lento e rápido foram de 660 e $1100 \mathrm{eV}$, respectivamente.

\subsection{Escolha dos elementos, energias e ângulos de medi- ção no experimento de distribuição angular}

Os alvos escolhidos para o estudo da distribuição angular da emissão de raios x foram Ta $(Z=73), \mathrm{W}(Z=74)$ e $\mathrm{Au}(Z=79)$. Uma vez que a anisotropia esperada para a emissão de raios x é de poucos por cento [68], a medida deve ter alta precisão. Com isso os picos de raios x L devem estar bem resolvidos para que no processo de decomposição do multipleto $\mathrm{L}$ as áreas possam ser estimadas com incertezas baixas. Com os detetores $\mathrm{SD}$ empregados no experimento, o Ta é o elemento de menor número atômico que pode 


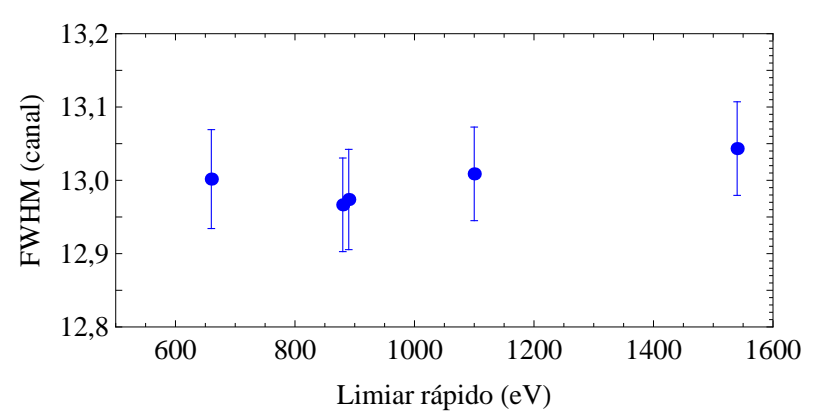

(a)

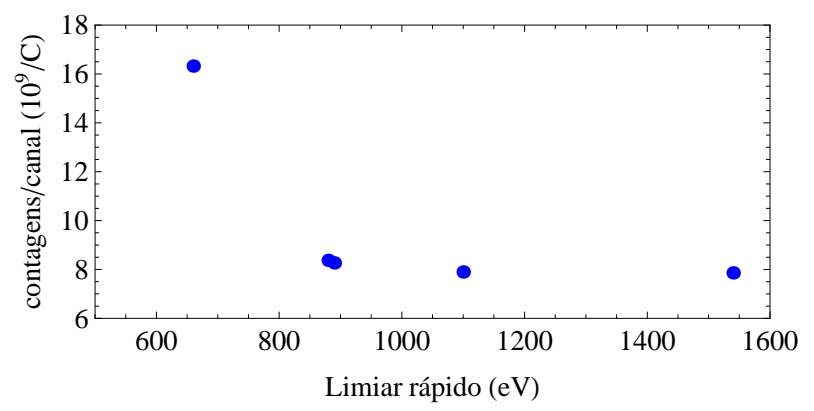

(b)

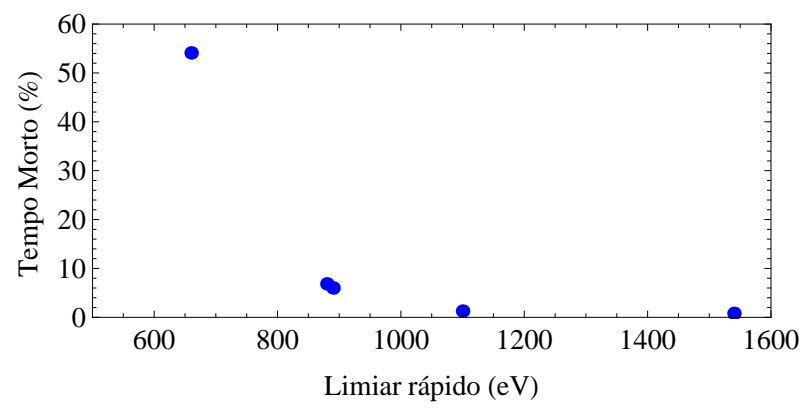

(c)

Figura 4.17: Dependência da a) resolução (FWHM) e b) da amplitude da linha L $\alpha_{1}$, normalizada pela carga e corrigida pelo tempo morto, e c) do tempo morto de aquisição com a posição do limiar rápido.

ser fabricado, manuseado e armazenado com razoável facilidade, e apresenta as linhas de raios x L suficientemente separadas nos espectros adquiridos com SDDs. Por outro lado, dos trabalhos experimentais encontrados na literatura com alvos sólidos, boa parte deles emprega alvos de $\mathrm{Au}$, assim os resultados do nosso experimento para esse elemento podem, de alguma forma, ser comparados com os trabalhos dos demais grupos. Adicionalmente, este trabalho pretende dar continuidade à pesquisa anterior [21,98], onde foram realizadas medidas de seções de choque de ionização das subcamadas L dos alvos de Ta e Au com a hipótese de que a emissão de raios x L fosse isotrópica. O alvo de Cu empregado para monitorar a anisotropia instrumental foi escolhido devido à proximidade em energia do dubleto $\mathrm{K} \alpha$ deste elemento com as linhas Li do Ta, W e Au, tabelas 2.3 e 2.5.

Dentre os trabalhos experimentais e teóricos encontrados na literatura, estima-se uma 
maior anisotropia para as energias próximas ao limiar de ionização da subcamada estudada $[7,8,68]$, e por isso buscou-se as energias mais próximas possíveis dos limiares de ionização da subcamada $\mathrm{L}_{3}$ dos elementos Ta e Au. Por outro lado, alguns destes trabalhos, sobretudo os estudos de anisotropia realizados com elétrons Auger [63] e os realizados com raios x que seguem a ionização por impacto de prótons e outros íons [80], prevêem uma inversão no sinal do parâmetro de alinhamento para energias maiores. Com o intuito de investigar essa inversão, variou-se a energia do feixe desde o limiar de ionização da subcamada $\mathrm{L}_{3}$ até a energia máxima da linha de feixe empregada, $100 \mathrm{keV}$.

Por fim, o experimento preliminar deste projeto deixou evidente que a medida de distribuição angular somente seria possível com uma medição simultânea em todos os ângulos estudados, sobretudo devido à dificuldade em se reproduzir a mesma energia do feixe com precisão melhor do que $100 \mathrm{eV}$, o que é imprescindível em um intervalo de cerca de $10 \mathrm{keV}$ logo acima do limiar de ionização $\mathrm{L}_{3}$, onde a seção de choque de ionização muda rapidamente com a energia. Por outro lado, o menor número de ângulos necessários para o ajuste dos parâmetros da função teórica, expressão (3.40), aos dados experimentais é três, o que envolve, portanto, a necessidade de pelo menos três SDDs. Por isso escolheu-se posicionar os detetores nos ângulos mais próximos possíveis do máximo, mínimo e zero do polinômio de Legendre de ordem dois.

\subsection{Procedimento experimental da medida de distribui- ção angular}

A carga incidente no alvo durante a medição foi determinada pela soma das cargas registradas no copo de Faraday e na câmara de irradiação com o uso de integradores de corrente.

A torre de alvos, figura 4.6, foi carregada com os alvos de $\mathrm{Au}, \mathrm{Cu}$, Ta e $\mathrm{Pd}$, na primeira etapa do experimento, e na segunda com os alvos de $\mathrm{Cu}, \mathrm{Pd}$ e W, e com duas molduras vazadas de fibra de carbono, idênticas às molduras dos alvos em dimensão, mas com furos de diâmetros de $8 \mathrm{~mm}$ e $10 \mathrm{~mm}$.

As duas molduras vazadas foram empregadas para verificar a focalização do feixe durante cada uma das energias do experimento. A razão da carga coletada na câmara pela coletada no copo de Faraday permite uma estimativa aproximada do ângulo de dispersão médio do feixe, e deve permanecer constante ao longo da irradiação. Definida a energia e focalizado o feixe, foram feitas medidas de 10 a $60 \mathrm{~s}$ em cada uma das molduras 
e verificada a carga registrada na medição e o número total de contagens no espectro. A razão da carga registrada na câmara pela carga registrada no copo de Faraday foi usada para avaliar a focalização do feixe. Quando esta razão foi igual ou inferior a um valor previamente fixado, que variou de 0,4 a $0,6 \%$ a depender da energia incidente, para as duas molduras o feixe foi considerado bem focalizado, caso contrário ele foi re-focalizado e a medida com as duas molduras repetida. Os alvos de $\mathrm{Ta}, \mathrm{W}$ e $\mathrm{Au}$ foram empregados para o estudo da distribuição angular de raios x L, enquanto que os de $\mathrm{Cu}$ e $\mathrm{Pd}$ foram usados como monitores e na determinação da eficiência relativa.

As medições foram realizadas com taxas de aquisição variando de 2 a $12 \mathrm{kHz}$, e duraram entre 3 a $6 \mathrm{~h}$, com o intuito de garantir estatística superior a $10^{6}$ contagens no dubleto $\mathrm{L} \alpha$ e $10^{5}$ contagens na linha $\mathrm{L} \ell$ dos elementos estudados. A pressão interna na câmara de irradiação ficou em torno de $7 \times 10^{-5}$ Pa durante a realização dos experimentos.

As energias de irradiação dos alvos de Ta e Au foram escolhidas entre a energia do limiar de ionização da subcamada $\mathrm{L}_{3}$ destes elementos, listadas na tabela 2.4, até $100 \mathrm{keV}$, com alguns valores logo acima do limiar $\mathrm{L}_{3}$, e entre os limiares $\mathrm{L}_{2}$ e $\mathrm{L}_{1}$. Para o alvo de $\mathrm{W}$ as energias foram escolhidas na região onde havia um comportamento inesperado para o parâmetro de alinhamento, observado de forma conclusiva somente na ionização por impacto de prótons ou íons [78-80].

Cada uma das medições foi dividida em intervalos de $1 \mathrm{~h}$ para que fosse possível verificar a focalização do feixe ao longo da aquisição e controlar a anisotropia instrumental. Essa verificação foi feita de forma qualitativa e quantitativa. Para a análise qualitativa, foi observada a posição do feixe em relação ao view screen. Na figura 4.18 é apresentada uma sequência de imagens da seção transversal do feixe obtidas durante medição com elétrons de $15,50(10) \mathrm{keV}$; nota-se que na imagem 4.18 e) o feixe saiu do centro, ele foi então refocalizado para a medição seguinte. Por outro lado, do ponto de vista teórico, as linhas de raios x K apresentam emissão isotrópica [15], o que foi verificado experimentalmente por Yamaoka et al. [8]. Diante disso, optou-se por empregar os raios x K do Cu como monitor da anisotropia do arranjo experimental. A cada intervalo de $1 \mathrm{~h}$ durante a medição com os alvos de Ta, W e Au foram feitas medidas dos raios x $\mathrm{K} \alpha$ do alvo de $\mathrm{Cu}$ com duração de 5 a 10 minutos, e assim foi possível obter uma medida quantitativa desta anisotropia. 


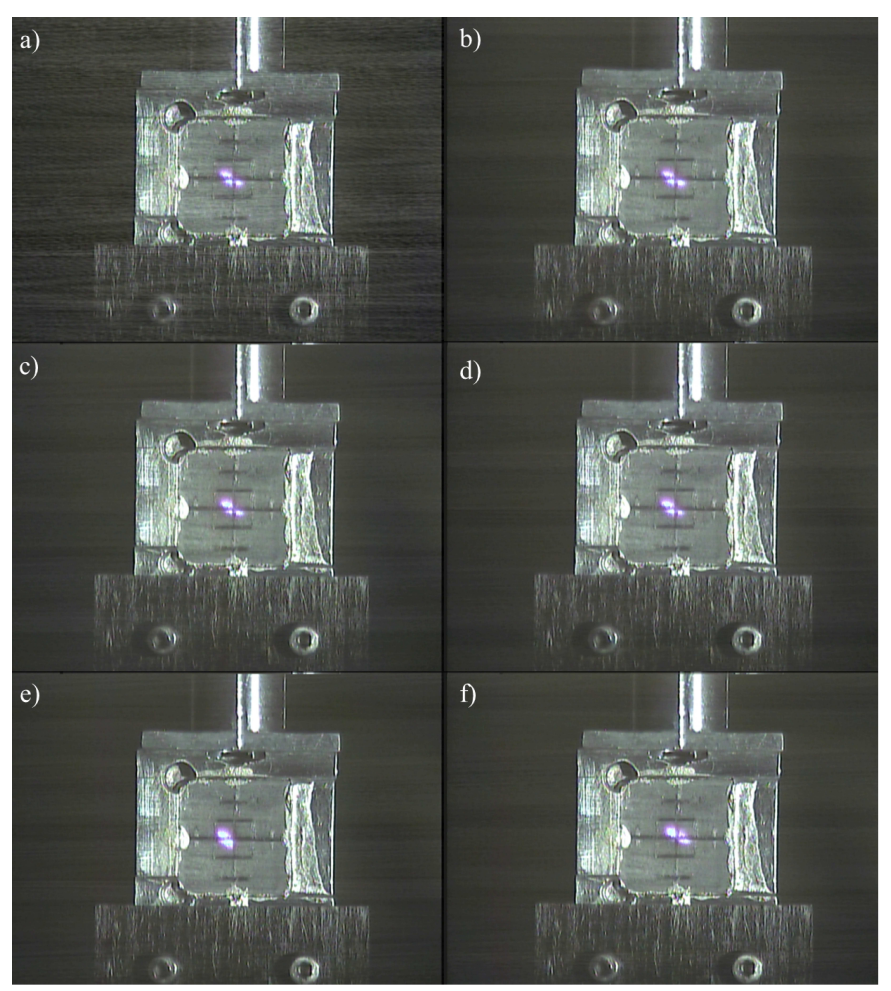

Figura 4.18: Sequência de imagens obtidas da seção transversal do feixe de elétrons atingindo o view screen durante a irradiação com elétrons 15,50(10) keV. A separação entre os traços pretos no view screen é de $2 \mathrm{~mm}$.

\subsection{Procedimento experimental da medida de seção de choque de ionização das subcamadas $\mathrm{L}$ do $\mathrm{Au}$}

No experimento de medida de seção de choque de ionização das subcamadas L do Au, a torre de alvos foi carregada com o alvo de Au e com duas molduras vazadas, usadas para verificar a focalização do feixe, como realizado no experimento de distribuição angular. A torre foi posicionada no centro da câmara de irradiação de modo que a superfície do alvo fizesse um ângulo de $30^{\circ}$ com a direção do feixe incidente.

As irradiações foram realizadas em dezenove energias entre 12 e $100 \mathrm{keV}$, com alguns valores escolhidos entre os limiares de ionização das subcamadas $\mathrm{L}_{3}$ e $\mathrm{L}_{2}$, e $\mathrm{L}_{2}$ e $\mathrm{L}_{1}$ do $\mathrm{Au}$, tabela 2.4. A corrente do feixe variou entre $600 \mathrm{nA}$ e $2 \mu \mathrm{A}$, e o tempo de medição ficou entre 600 e 1800 s com intuito de garantir alta estatística de contagem nos picos.

A carga incidente no alvo foi determinada da mesma maneira realizada no experimento de distribuição angular. 


\section{Capítulo 5}

\section{Caracterização do arranjo experimental}

Neste capítulo serão apresentados os procedimentos de calibração de largura e eficiência de pico, e energia e tempo morto dos detetores empregados.

\subsection{Calibração de energia e resolução dos detetores}

Em espectroscopia de raios x e gama, os espectros são obtidos sob a forma de histogramas multicanais. Quando a faixa de energia vai de alguns keV até centenas de keV, cada canal $n$ do histograma se relaciona com a energia $E$ dos fótons detetados por meio da relação:

$$
E(n)=a+b n+d n^{2}
$$

em que o parâmetro $a$ está relacionado à voltagem da linha de base do amplificador, o parâmetro $b$ depende do ganho deste amplificador, e o parâmetro $d$ é introduzido para levar em consideração, em princípio, a não linearidade dos elementos do sistema de aquisição.

Tanto para as calibrações de energia e largura de pico, quanto para a determinação experimental da eficiência de pico, descrita nas seções seguintes, foram usados os picos de raios x e gama de fontes de ${ }^{57} \mathrm{Co},{ }^{133} \mathrm{Ba}$ e ${ }^{241} \mathrm{Am}$, montadas e calibradas no LMNIPEN/CNEN-SP (Laboratório de Metrologia Nuclear do Instituto de Pesquisas Energéticas e Nucleares da Universidade de São Paulo). O material radioativo foi depositado sobre duas folhas de Kapton com espessuras de 7,5 $\mu \mathrm{m}$, formando uma mancha com diâmetro médio aproximado de $4 \mathrm{~mm}$. Esse arranjo foi montado na mesma moldura empregada na confecção dos alvos, com o objetivo de reproduzir a geometria e as condições da irradiação durante o processo de calibração. 
Os parâmetros da expressão (5.1) foram ajustados aos dados experimentais para os três detetores. Os resíduos reduzidos, equação (2.17), destes ajustes estão apresentados na figura 5.1. A diferença em eV entre o valor calculado com a calibração realizada e os valores apresentados nas referências Deslattes et al. [12] para raios x, e na base de dados Laboratoire National Henri Becquerel [13] para raios $\gamma$, é apresentada na figura 5.2. A tabela 5.1 traz as estimativas encontradas para os coeficientes $a, b, d$ da expressão (5.1) para os três detetores, junto com a estimativa do desvio padrão para uma energia de $10 \mathrm{keV}$ calculada com a calibração realizada. Os qui quadrados reduzidos dos ajustes foram de 1,9, 1,9 e 0,7 para os detetores posicionados a $31^{\circ}, 90^{\circ}$ e $125^{\circ}$ em relação à direção do feixe incidente, respectivamente, o que corresponde a uma probabilidade do qui quadrado ser excedido de 10\%,10\% e 67\%, respectivamente, evidenciando a boa qualidade do ajuste nos três casos.

Tabela 5.1: Estimativas dos parâmetros $a, b$ e $d$, expressão (5.1), da calibração de energia $($ em $\mathrm{keV})$ dos detetores posicionados a $31^{\circ}$, $90^{\circ}$ e $125^{\circ}$ em relação à direção do feixe incidente. Em parênteses, o desvio padrão em unidades do dígito menos significativo. Na última coluna é apresentando o desvio padrão (em eV) para a energia de $10 \mathrm{keV}$ calculada com a calibração realizada.

\begin{tabular}{ccccc}
\hline \hline Detetor & $a(\mathrm{keV})$ & $b(\mathrm{keV} / \mathrm{canal})$ & $d\left(\mathrm{keV} / \mathrm{canal}^{2}\right)$ & $\sigma_{E}(E=10 \mathrm{keV})(\mathrm{eV})$ \\
\hline $31^{\circ}$ & $-0,0027(21)$ & $0,013039(5)$ & $2,98(18) 10^{-8}$ & 2,0 \\
$90^{\circ}$ & $-0,0338(16)$ & $0,012595(4)$ & $1,2(13) 10^{-9}$ & 1,6 \\
$125^{\circ}$ & $-0,0163(14)$ & $0,012764(3)$ & $3,0(13) 10^{-9}$ & 1,4 \\
\hline \hline
\end{tabular}

Uma vez que o ganho pode sofrer alterações ao longo das medições, a calibração de energia construída foi avaliada por meio da posição da linha $\mathrm{L} \alpha_{1}$ do Au. Foi calculada a diferença em energia entre o valor experimental de $L \alpha_{1}$ apresentado na referência [12] e aquele encontrado com os parâmetros da tabela 5.1 para cada um dos dias de irradiação. A figura $5.3^{1}$ mostra que a variação foi inferior a um canal para os três detetores, dispensando a necessidade de autocalibração dos espectros.

O quadrado da resolução (FWHM) do detetor pode ser escrito como [42]:

$$
\operatorname{FWHM}^{2}(E)=8 \ln 2(\mu+\rho E)
$$

em que o parâmetro $\mu$ está relacionado ao processo de amplificação, e $\rho=F \epsilon_{0}$, com $F$ o fator de Fano e $\epsilon_{0}$ a energia média necessária para a formação de um par elétronburaco no cristal semicondutor; para um cristal de Si, $\rho \approx 0,4 \mathrm{eV}$ [99]. A tabela 5.2

\footnotetext{
${ }^{1} \mathrm{O}$ gráfico está em função da energia do elétron incidente, uma vez que cada energia corresponde a um dia diferente de irradiação.
} 


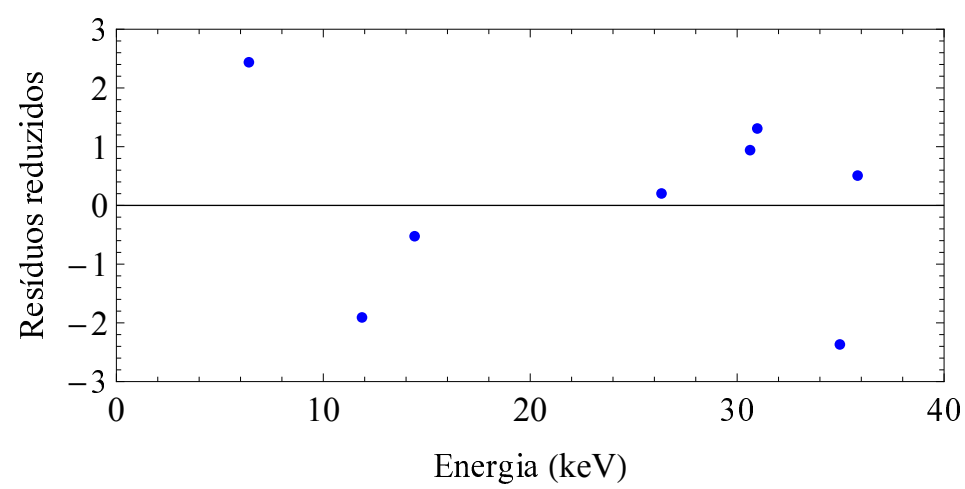

(a)

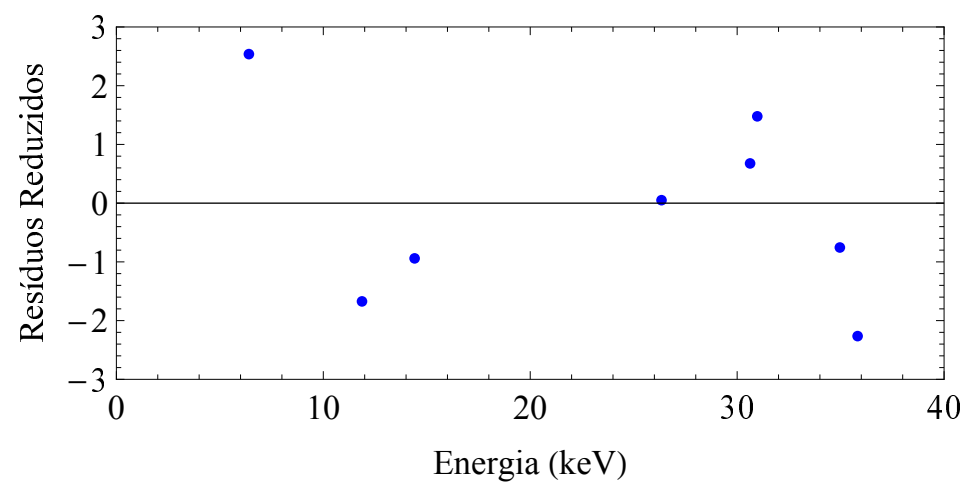

(b)

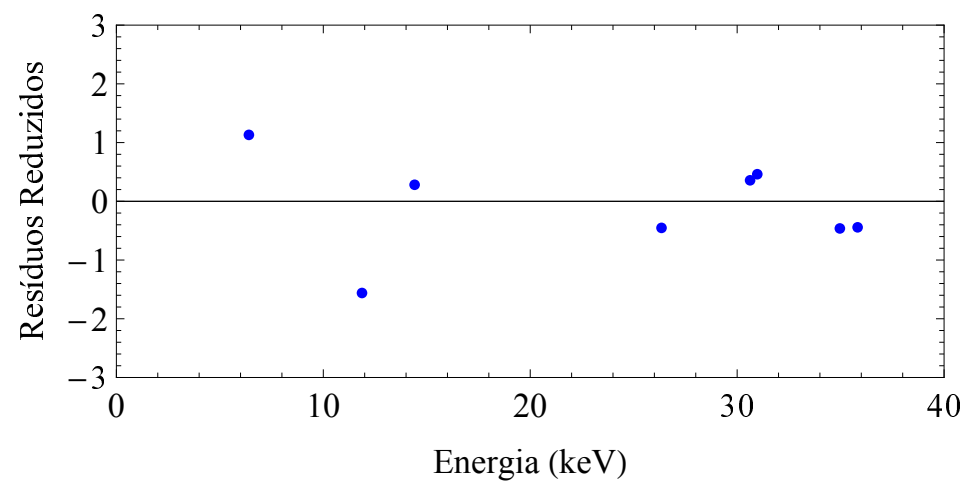

(c)

Figura 5.1: Resíduos reduzidos dos ajustes dos parâmetros da calibração de energia dos detetores posicionados a a) $31^{\circ}$, b) $90^{\circ}$ e c) $125^{\circ}$ em relação à direção do feixe incidente.

apresenta as estimativas encontradas para os coeficientes $\mu$ e $\rho$, e a figura 5.4 traz a dependência da largura a meia altura ao quadrado, $\operatorname{FWHM}^{2}(E)$, com a energia $E$ para os três detetores do experimento. Nota-se um acordo razoável do parâmetro $\rho$ estimado com aquele encontrado na literatura. 


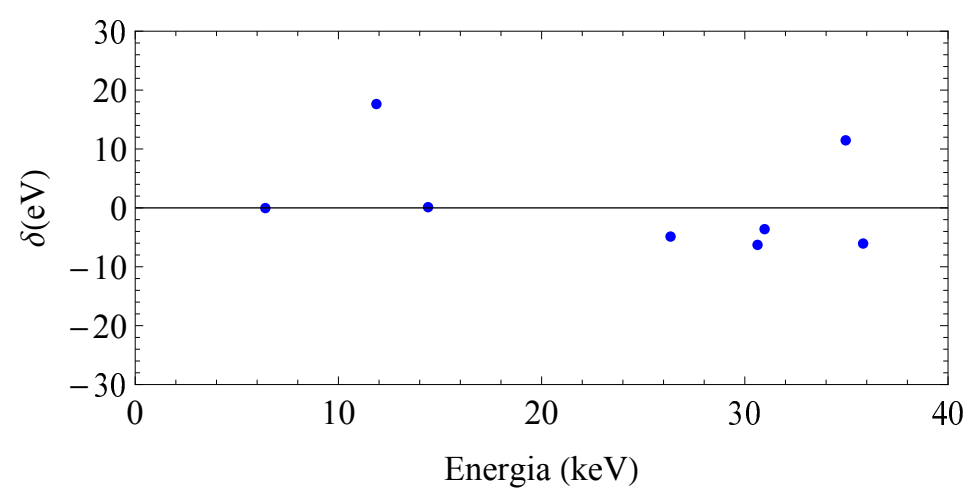

(a)

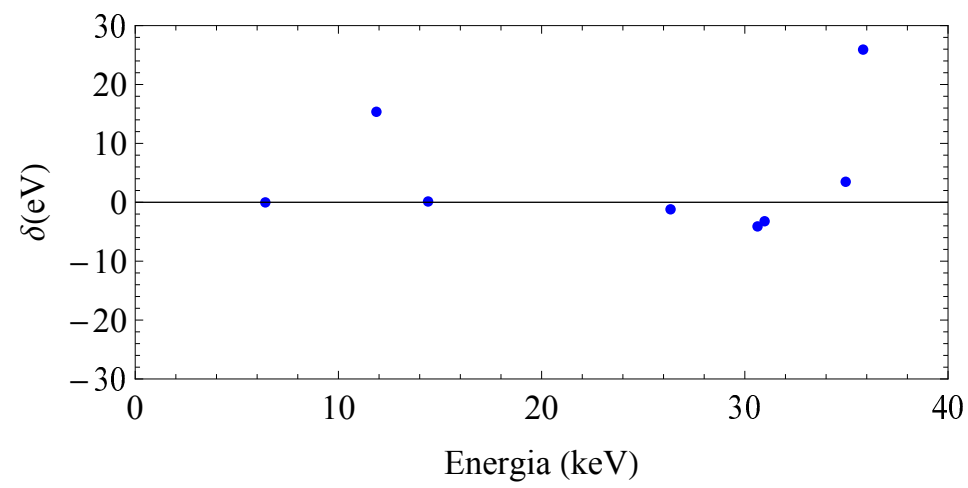

(b)

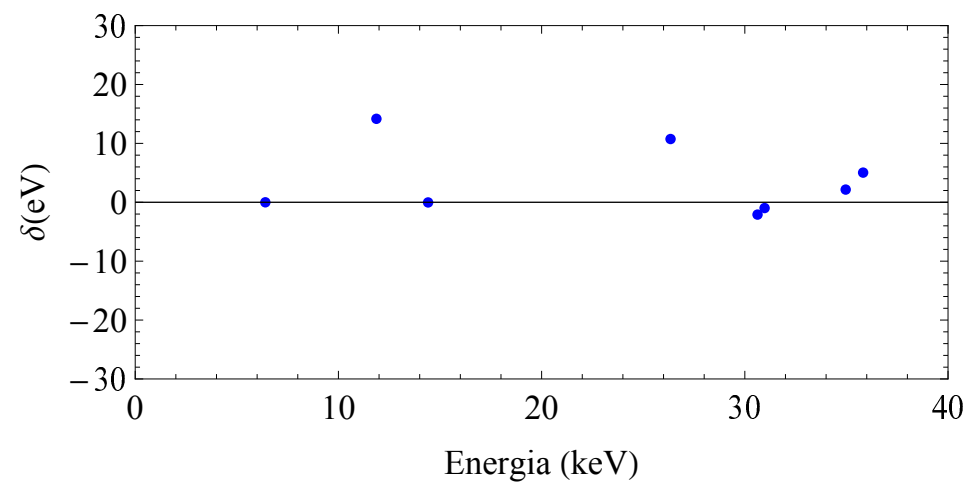

(c)

Figura 5.2: Diferença em eV entre os valores de energia dos picos calculados com a calibração obtida e os valores apresentados na referência Deslattes et al. [12] para raios $\mathrm{x}$, e na base de dados Laboratoire National Henri Becquerel [13] para raios $\gamma$, para os detetores posicionados a $31^{\circ}$ a), $90^{\circ}$ b) e $125^{\circ}$ c) em relação à direção do feixe incidente.

\subsection{Determinação da eficiência de pico}

Existe na literatura uma quantidade razoável de trabalhos que propõem modelos analíticos para a curva de eficiência de pico de detetores semicondutores [42, 100-104] com o objetivo de calculá-la em uma dada energia com maior precisão do que a estimativa obtida pela interpolação dos dados, sobretudo em regiões de energia onde há poucos dados experimentais. A grande maioria desses modelos leva em conta a atenuação do fluxo de 


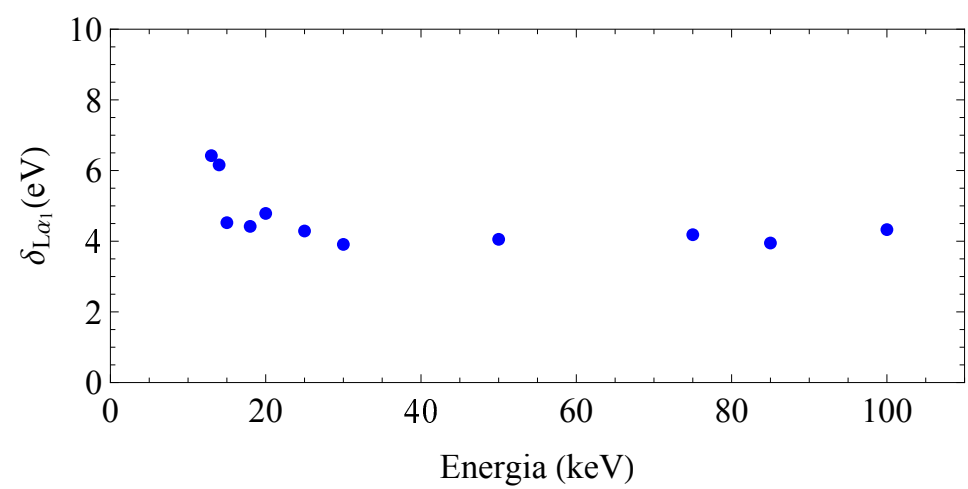

(a)

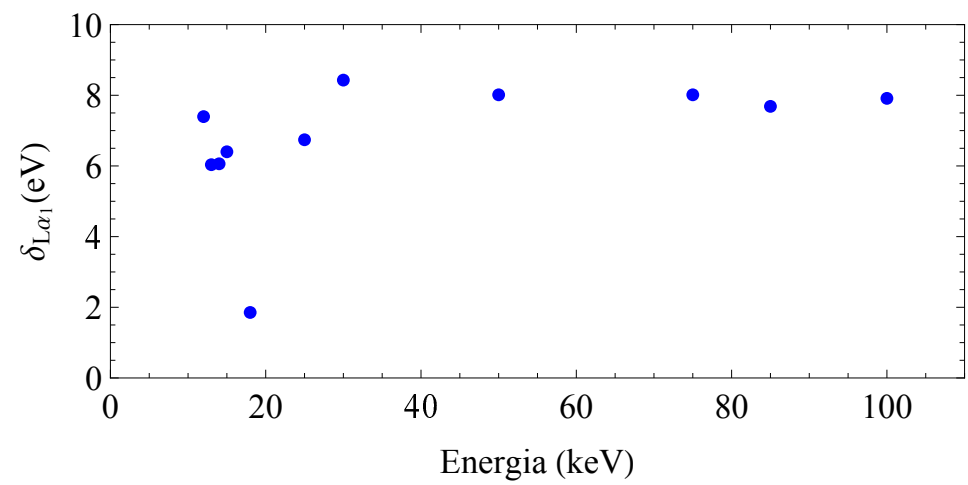

(b)

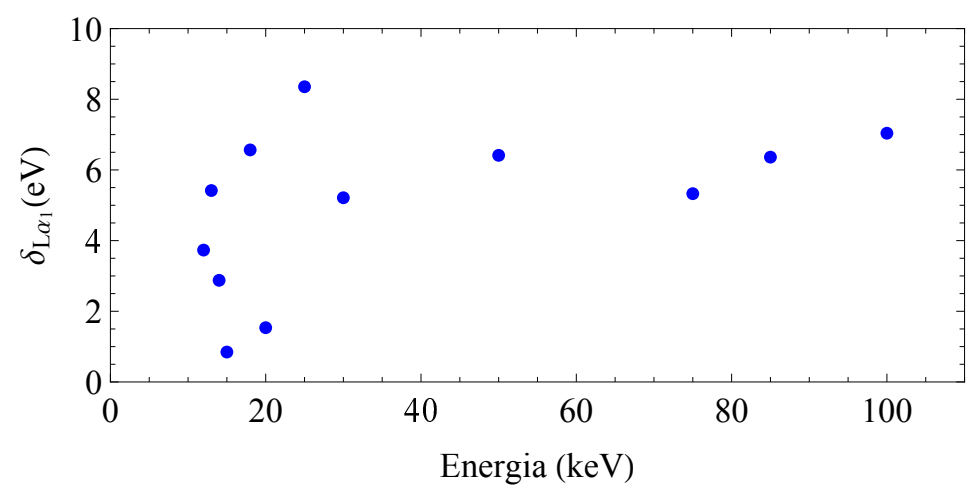

(c)

Figura 5.3: Diferença em eV da energia da linha $L \alpha_{1}$ do $A u$ calculada com a calibração de energia realizada e com o valor tabelado [12], em função da energia do elétron incidente, para os detetores posicionados a a) $31^{\circ}$, b) $90^{\circ}$ e c) $125^{\circ}$ em relação à direção do feixe incidente.

fótons desde a fonte até o detetor e o escape de raios x do volume ativo do detetor. A diferença entre eles se encontra, principalmente, no modelo usado para descrever a eficiência intrínseca, bem como nos efeitos secundários de deteção incluídos. 
Tabela 5.2: Estimativas dos parâmetros $\mu$ e $\rho$ da resolução (FWHM), equação (5.2), dos detetores posicionados a $31^{\circ}, 90^{\circ}$ e $125^{\circ}$ em relação à direção do feixe incidente. Em parênteses, o desvio padrão em unidades do dígito menos significativo.

\begin{tabular}{ccc}
\hline \hline Detetor & $\mu\left(\mathrm{keV}^{2}\right)$ & $\rho(\mathrm{keV})$ \\
\hline $31^{\circ}$ & $0,061(17)$ & $0,510(13)$ \\
$90^{\circ}$ & $0,096(12)$ & $0,425(9)$ \\
$125^{\circ}$ & $0,097(10)$ & $0,408(9)$ \\
\hline \hline
\end{tabular}
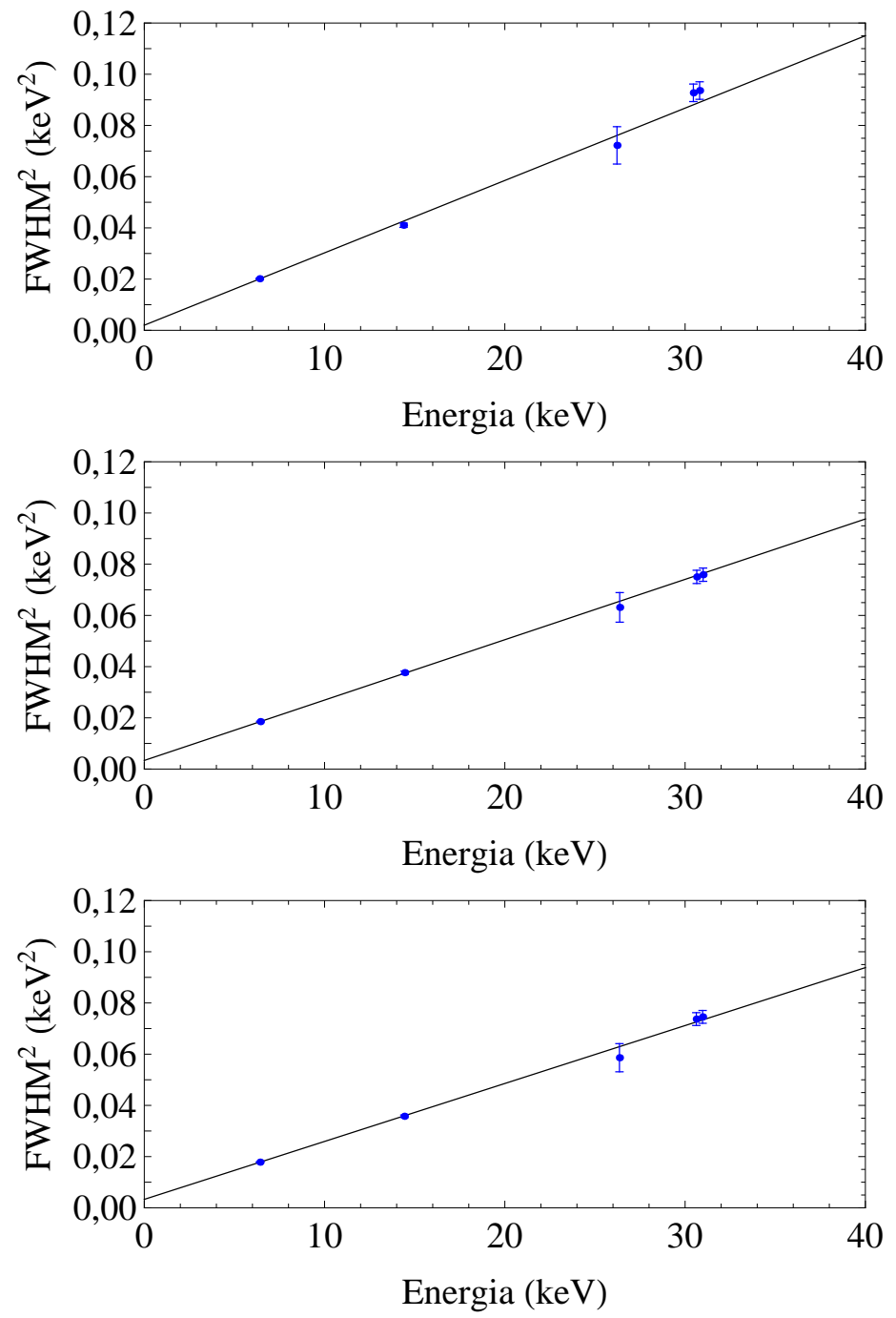

Figura 5.4: Calibração da resolução (FWHM) dos SDDs, para os detetores posicionados a a) $31^{\circ}$, b) $90^{\circ}$ e c) $125^{\circ}$ em relação à direção do feixe incidente.

\subsubsection{Modelo analítico para a eficiência de pico}

Optou-se por seguir nesta pesquisa o trabalho desenvolvido por Seltzer [42], que propõe um modelo analítico para a função resposta de detetores de Ge para energias de até 
$300 \mathrm{keV}$. Este modelo foi testado em detetores de HPGe [105] e $\mathrm{Si}(\mathrm{Li})$ [46,98], apresentando resultados satisfatórios em todos eles. Apresenta-se abaixo um resumo do modelo analítico empregado. Os detalhes podem ser obtidos dessas referências e da referência original de Seltzer [42], da qual foram selecionadas a maior parte das fórmulas e considerações a seguir.

Primeiro, constroe-se uma função resposta para fótons de energia $E$, que formam um feixe incidente bem colimado e que atinge a região central do detetor, considerado cilíndrico. É incluído o escape do volume ativo do detetor tanto dos raios x característicos decorrentes das vacâncias produzidas por efeito fotoelétrico, quanto dos fótons espalhados incoerentemente. A eficiência de pico $\varepsilon_{\mathrm{A}}(E)$, neste caso, pode ser obtida integrando essa função resposta para todas as energias. Para um detetor com cristal cilíndrico de espessura $L$ e raio $R$, a expressão encontrada é:

$$
\varepsilon_{\mathrm{A}}(E)=\frac{\Omega}{4 \pi} \exp \left[-\sum_{i} \mu_{i}(E) d_{i}\right] \varepsilon(E)
$$

em que $\Omega$ é o ângulo sólido do detetor visto desde a fonte, $\mu_{i}$ e $d_{i}$ correspondem ao coeficiente de atenuação linear e à espessura, respectivamente, do material $i$ que o fóton atravessa no caminho entre a fonte emissora e o detetor, e $\varepsilon(E)$ corresponde à eficiência intrínseca do detetor. Seltzer [42] propõe que $\varepsilon(E)$ seja calculada pela expressão

$$
\varepsilon=1-P_{0}-\left(P_{\mathrm{K} \alpha}+P_{\mathrm{K} \beta}\right)-P_{\mathrm{inc}}
$$

em que $P_{0}$ é a probabilidade do fóton atravessar o cristal sem interagir, $P_{\mathrm{K} \alpha}$ e $P_{\mathrm{K} \beta}$ são as probabilidades de escape dos raios x $\mathrm{K} \alpha$ e $\mathrm{K} \beta$ do Si, respectivamente, e $P_{\text {inc }}$ corresponde à probabilidade de que o fóton deixe o cristal depois do espalhamento incoerente.

O primeiro dos termos da expressão de eficiência intrínseca, equação (5.4), é dado por

$$
P_{0}=P_{0}(E ; L)=\exp [-\mu(E) L]
$$

com $\mu(E)$ o coeficiente de atenuação linear do cristal do detetor para fótons de energia $E$, excluindo o espalhamento coerente (Rayleigh).

A probabilidade de escape dos raios x característicos, quando o fluxo de fótons pelos lados e pela face traseira do detetor pode ser ignorado, é deduzida supondo o detetor como um plano semi infinito $(R=L=\infty)$

$$
P_{\mathrm{K} \tau}(E)=\frac{1}{2} p_{\mathrm{K} \tau} \omega_{\mathrm{K}} q_{\mathrm{K}}(E) \frac{\mu_{\mathrm{pe}}(E)}{\mu(E)}\left[1-\frac{\mu\left(E_{\mathrm{K} \tau}\right)}{\mu(E)}\right] \ln \left[1+\frac{\mu(E)}{\mu\left(E_{\mathrm{K} \tau}\right)}\right]
$$


em que $\tau$ é $\alpha$ ou $\beta$, as quantidades $E_{\mathrm{K} \tau}$ e $p_{\mathrm{K} \tau}$ representam, respectivamente, as energias e as probabilidades de emissão relativa dos raios $\mathrm{x} K \alpha$ e $\mathrm{K} \beta, \omega_{\mathrm{K}}$ é o yield fluorescente $\mathrm{K}$ do material do detetor, $q_{\mathrm{K}}(E)$ é a fração de absorção fotoelétrica que acontece na camada $\mathrm{K}$, e $\mu_{\text {pe }}(E)$ é o coeficiente de atenuação para absorção fotoelétrica de fótons com energia $E$.

A contribuição dominante ao termo $P_{\text {inc }}$ corresponde aos fótons que espalham inelasticamente uma única vez dentro do volume ativo do detetor, com o subsequente escape do fóton espalhado. Este termo pode ser aproximado com razoável precisão pela integral sobre a energia $e$ depositada no volume ativo do detetor,

$$
P_{\text {inc }}(E ; L, R)=\int_{0}^{e_{\mathrm{C}}} C_{1}(e, E ; L, R) \mathrm{d} e
$$

$\operatorname{com} e_{\mathrm{C}} \equiv E\left[1-\left(1+2 E / m_{\mathrm{e}} c^{2}\right)^{-1}\right]$ e a função densidade de probabilidade de $e$

$$
C_{1}(e, E ; L, R) \propto \frac{\sigma_{\mathrm{inc}}(E)}{Z \sigma_{\mathrm{KN}}(E)} \frac{\mathrm{d} \sigma_{\mathrm{KN}}}{\mathrm{d} e} G(e, E ; L, R),
$$

em que $Z$ é o número atômico do material do detetor, $\mathrm{d} \sigma_{\mathrm{KN}} / \mathrm{d} e$ e $\sigma_{\mathrm{KN}}$ são a seção de choque diferencial e a seção de choque total de Klein-Nishina (por elétron), respectivamente, e $\sigma_{\text {inc }}$ é a seção de choque total para espalhamento incoerente [42]. O fator adimensional $G(e, E ; L, R)$ contém a dependência geométrica com a forma e o tamanho do cristal do detetor [42].

Uma vez que existem alguns eventos que surgem de dois espalhamentos, Seltzer [42] adotou $C=C_{1}+C_{2}$, em que o termo $C_{2}$ é uma expressão empírica, baseada em simulações Monte Carlo, destinada a corrigir as diferenças entre $C$ e $C_{1}$. Neste trabalho, optou-se por desconsiderar o termo $C_{2}$ devido à falta de informações deste para o Si e à expectativa de que essa contribuição seja menor do que no Ge, que é $<1 \%$.

\subsubsection{Determinação experimental da eficiência de pico}

As fontes radioativas de ${ }^{57} \mathrm{Co},{ }^{133} \mathrm{Ba}$ e ${ }^{241} \mathrm{Am}$, já descritas anteriormente, foram posicionadas no centro da câmara de irradiação onde os experimentos de distribuição angular e de seções de choque de ionização foram conduzidos, com o intuito de medir a eficiência de pico em alguns pontos entre 6,4 e $40 \mathrm{keV}$. Como os detetores foram acoplados à câmara de irradiação com o auxílio de adaptadores de acrílicos, a distância entre a fonte radioativa e a superfície frontal dos três detetores foi a mesma, de $312(2) \mathrm{mm}$.

Quando a fonte radioativa é localizada longe do detetor, a eficiência de pico em uma 
dada energia $E_{i}$ pode ser determinada a partir da área $N_{i}$ do pico pela expressão [106]

$$
\varepsilon_{\mathrm{A}}^{\exp }\left(E_{i}\right)=\frac{N_{i}}{A_{t} I_{i} \Delta t}
$$

onde $I_{i}$ é a intensidade da transição de raio x ou $\gamma$ no decaimento de uma fonte com atividade $A_{t}$, durante um intervalo de tempo $\Delta t$.

A estimativa do número de contagens $N_{i}$ no pico de interesse foi obtida pelo ajuste dos parâmetros de uma gaussiana para picos de raios $\gamma$, e dos parâmetros da função Voigt para picos de raios x. A componente contínua do espectro foi modelada com um polinômio do primeiro ou segundo grau. Depois de um estudo investigatório $[46,98]$ chegou-se a conclusão de que ajustar os parâmetros dos picos de raios x com funções gaussianas pode conduzir a erros significativos na estimativa das áreas, e consequentemente, na eficiência de pico. Isso justifica o uso de funções Voigt para os picos de raios x durante a determinação experimental da eficiência.

\subsubsection{Procedimento de ajuste e resultados}

Os parâmetros de $\varepsilon_{\mathrm{A}}(E)$, expressão (5.3), foram ajustados aos logarítmos dos dados experimentais de eficiência de pico usando o método dos mínimos quadrados descrito na seção 2.2, sendo que os únicos parâmetros de ajuste foram a espessura $L$ do cristal e o ângulo sólido da fonte $\Omega$, que irá fornecer a estimativa do raio ativo do detetor. Optou-se por trabalhar com o logaritmo de $\varepsilon_{\mathrm{A}}(E)$ no ajuste porque nessas condições o único parâmetro com dependência não linear é a espessura $L$, o que torna mais prática a estimava de outros parâmetros, em especial, de qualquer uma das espessuras das camadas atenuadoras, como detalhado em [46]. Neste caso, a função de mérito, definida pela expressão (2.11), tomou a forma

$$
\hat{Q}(L ; \Omega)=\left(\ln \vec{\varepsilon}_{\mathrm{A}}-\ln \hat{\vec{\varepsilon}}_{\mathrm{A}}\right)^{\mathrm{t}} \mathbb{V}_{\exp }^{-1}\left(\ln \vec{\varepsilon}_{\mathrm{A}}-\ln \hat{\vec{\varepsilon}}_{\mathrm{A}}\right)
$$

com $\vec{\varepsilon}_{\mathrm{A}}$ o vetor construído com os valores das eficiências experimentais, $\ln \vec{\varepsilon}_{\mathrm{A}}$ o logaritmo da eficiência experimental, $\ln \hat{\vec{\varepsilon}}_{\mathrm{A}}$ o logaritmo da eficiência calculada usando o parâmetro $\Omega$ que minimiza a soma ponderada dos quadrados dos resíduos para um valor fixo de espessura $L$, e $\mathbb{V}_{\exp }$ a matriz de covariância do logaritmo dos dados experimentais. O chapéu no símbolo $Q$ significa que $\Omega$ é a estimativa de mínimos quadrados para um dado valor do parâmetro $L$. A matriz de covariância dos parâmetros estimados foi calculada com a expressão (2.14).

A figura 5.5 mostra a curva da função de mérito $\hat{Q}(L ; \Omega)$, a partir da qual a espessura 
Tabela 5.3: Valores ajustados para a espessura $L$ e o raio ativo $r_{\mathrm{c}}$ dos três detetores SD empregados no experimento. Os valores fornecidos pelo fabricante para esses parâmetros são de $0,5 \mathrm{~mm}$ e 2,3 mm, respectivamente. Em parênteses, o desvio padrão em unidades do dígito menos significativo.

\begin{tabular}{ccc}
\hline \hline Detetor & $L(\mathrm{~mm})$ & $r_{\mathrm{c}}(\mathrm{mm})$ \\
\hline $31^{\circ}$ & $0,514(15)$ & $2,34(3)$ \\
$90^{\circ}$ & $0,497(14)$ & $2,35(3)$ \\
$125^{\circ}$ & $0,492(13)$ & $2,33(3)$ \\
\hline \hline
\end{tabular}

$L$ do detetor posicionado a $90^{\circ}$ em relação à direção do feixe incidente foi estimada. Os demais detetores apresentaram curvas semelhantes. A tabela 5.3 traz os valores encontrados para a espessura $L$ e o raio ativo $r_{\mathrm{c}}$ dos três detetores, e as figuras 5.6, 5.7 e 5.8 os pontos experimentais junto com as curvas ajustadas, e os respectivos gráficos dos resíduos reduzidos. Nestas figuras a curva contínua corresponde à condição experimental durante a medição com as fontes radioativas, e a tracejada à condição de irradiação, quando a câmara está em vácuo e a única folha de Kapton existente é a da janela da câmara.

Quando comparado com os valores fornecidos pelo fabricante para $r_{\mathrm{c}}$ e $L$, de $2,3 \mathrm{~mm}$ e $0,5 \mathrm{~mm}$, respectivamente, as estimativas apresentadas na tabela 5.3 mostram bom acordo. Além disso, o detetor posicionado a $31^{\circ}$ em relação à direção do feixe incidente foi o mesmo empregado nos trabalhos Barros el al. [46,48], nos quais os valores ajustados para a espessura do detetor, 0,497(6) e 0,527(24) mm, respectivamente, também estão em bom acordo com os apresentados na tabela 5.3.

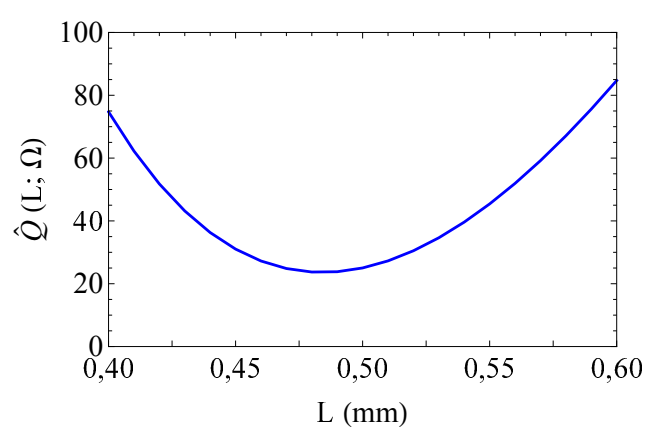

Figura 5.5: Dependência da função de mérito $\hat{Q}(L ; \Omega)$ com a espessura $L$ do detetor posicionado a $90^{\circ}$ em relação à direção do feixe incidente. 

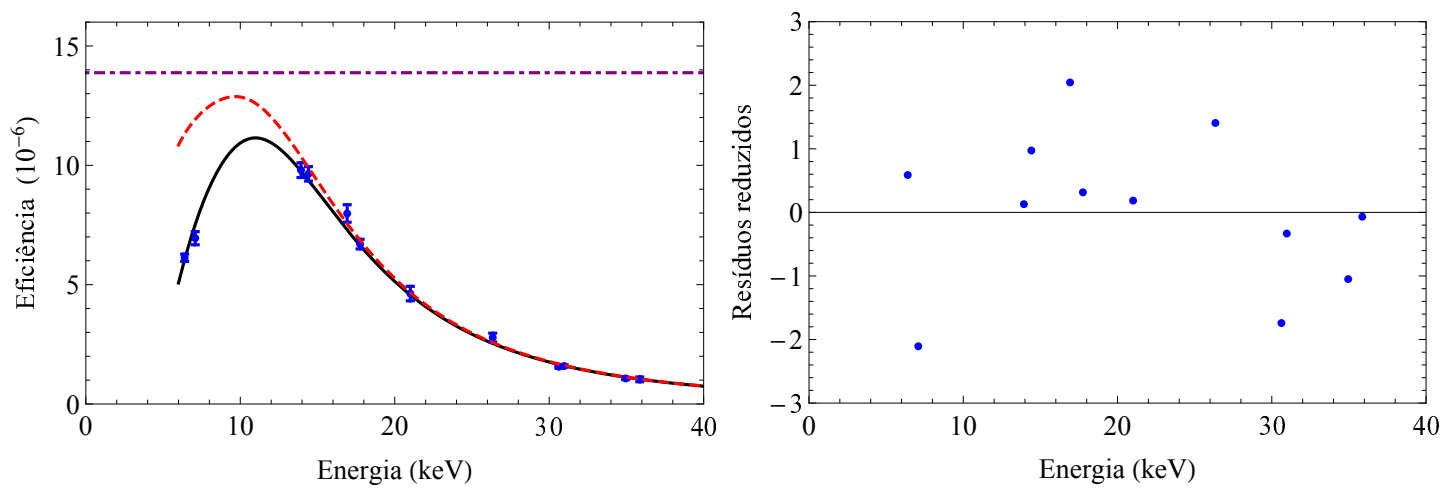

Figura 5.6: a) Função modelo com os parâmetros ajustados e os pontos experimentais para a eficiência de pico do SDD posicionado a $31^{\circ}$ em relação à direção do feixe incidente. A curva contínua corresponde à situação experimental com a fonte radioativa e a tracejada, com o feixe de elétrons. A linha ponto-tracejada corresponde à eficiência geométrica do detetor. b) Resíduos reduzidos para o ajuste.
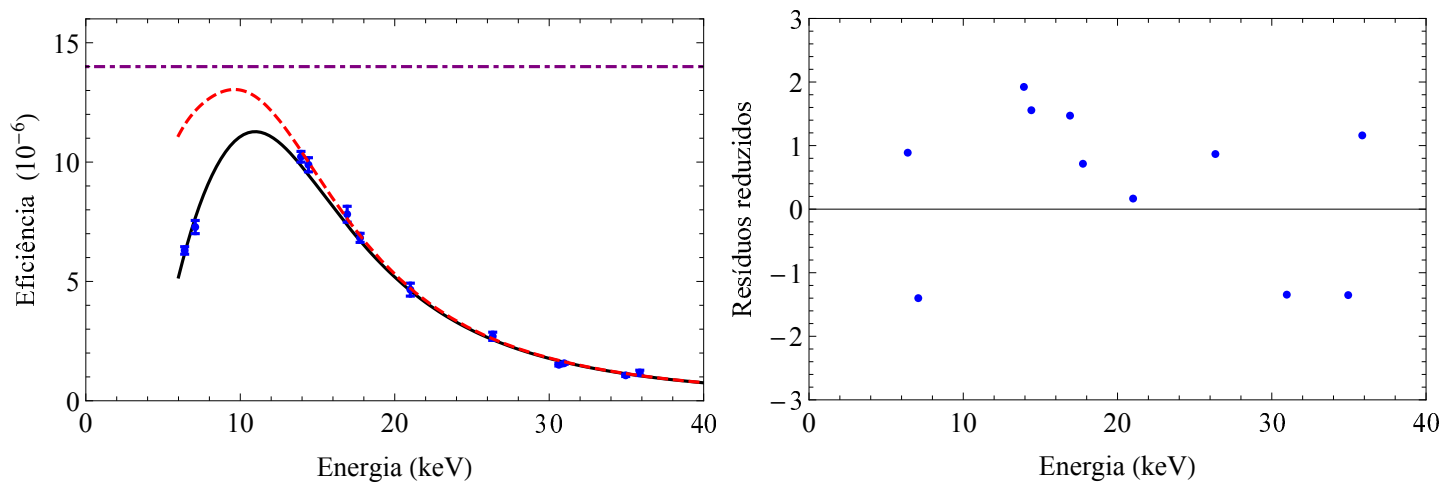

Figura 5.7: Mesmo que a figura 5.6, mas para o detetor posicionado a $90^{\circ}$ em relação à direção do feixe incidente.
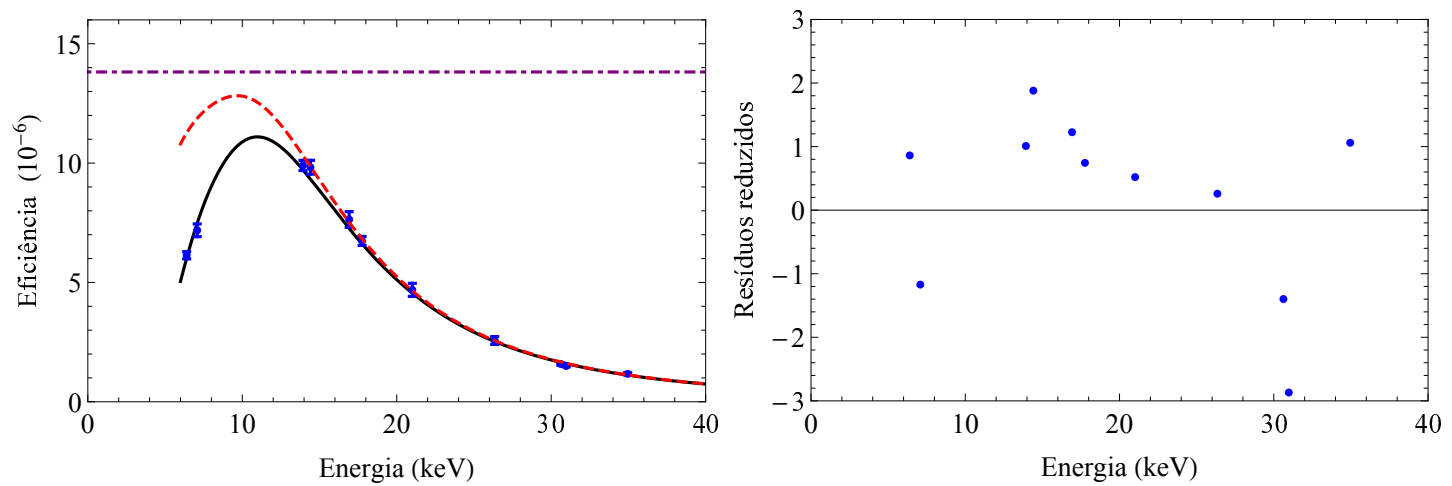

Figura 5.8: Mesmo que a figura 5.6, mas para o detetor posicionado a $125^{\circ}$ em relação à direção do feixe incidente.

\subsection{Estimativa da eficiência de pico relativa}

Nesta seção iremos nos referir às espessuras $L_{\nu}$ dos três detetores, em que o índice $\nu$ indica cada um deles, e às linhas L $i$, com $i$ a linha de interesse. A fim de evitar confusões 
com esses símbolos, exclusivamente nessa seção será usado o símbolo $\mathcal{L}_{\nu}$ para se referir à espessura do detetor $\nu$.

As intensidades de todas as linhas empregadas no estudo da distribuição angular foram normalizadas pela do dubleto $\mathrm{K} \alpha$ do $\mathrm{Cu}$. Essa normalização teve o objetivo de levar em conta pequenas anisotropias introduzidas pelo arranjo experimental. Tal procedimento exige que o quociente das eficiências de pico das linhas envolvidas ( $\mathrm{K} \alpha$ do $\mathrm{Cu}$ e a linha Li do elemento estudado) seja conhecido com alta precisão. A razão das eficiências para a linha $i$ do elemento analisado é dada por

$$
r_{i}=\frac{\varepsilon_{\mathrm{A}}\left(E_{\mathrm{ref}}\right)}{\varepsilon_{\mathrm{A}}\left(E_{i}\right)}
$$

em que $\varepsilon_{\mathrm{A}}\left(E_{\mathrm{ref}}\right)$ e $\varepsilon_{\mathrm{A}}\left(E_{i}\right)$ correspondem às eficiências de pico, expressão $(5.3)$, da linha ref usada como referência para normalização dos dados, e da linha L $i$ do elemento de interesse, respectivamente. Observe que a fração de ângulo sólido $\Omega / 4 \pi$ não entra no cálculo de $r_{i}$, já que ela aparece tanto no numerador quanto no denominador da expressão (5.11), e por isso, pode ser cancelada ${ }^{2}$.

O cálculo da incerteza de $r_{i}$ foi conduzido seguindo a propagação convencional, conforme a expressão (2.5), levando-se em conta a covariância entre o numerador e o denominador da expressão (5.11), que foi calculada de acordo com a expressão (2.4).

Como o ângulo sólido não entra no cálculo de $r_{i}$, o único parâmetro ajustado que contribui para a incerteza do quociente $r_{i}$ é a espessura do cristal do detetor. Cálculos prévios com os valores de espessuras, e suas respectivas incertezas, estimados de acordo com o procedimento descrito na seção 5.2, evidenciaram a necessidade de uma estimativa da espessura $\mathcal{L}_{\nu}$ do detetor com precisão maior do que a apresentada na tabela 5.3, para que a incerteza de $r_{i}$ não comprometesse o dado final de distribuição angular.

Para o cálculo da nova estimativa da espessura $\mathcal{L}_{\nu}$, com sua respectiva incerteza, foi proposto um procedimento que empregou as curvas analíticas de eficiência obtidas na seção 5.2, junto com as intensidades linhas de raios x $\mathrm{K} \alpha_{1}$ do $\mathrm{Cu}$ e do $\mathrm{Pd}$. Estas linhas foram obtidas pela irradiação dos alvos desses elementos com elétrons de 55, 65, 75, 85 e $100 \mathrm{keV}$.

Conforme as previsões teóricas de Berezhko e Kabachnik [15], as linhas de raios x K

\footnotetext{
${ }^{2}$ Essa afirmação só é válida quando as energias dos raios $\mathrm{x}$ incidentes são próximas, caso contrário é necessário analisar a dependência do ângulo sólido com a energia do raio x incidente para a geometria específica do experimento [107].
} 
devem apresentar emissão isotrópica. Com isso o quociente

$$
r_{E, \nu}^{\exp }=\frac{A_{\mathrm{Pd}}}{A_{\mathrm{Cu}}} C_{\mathrm{Q}} T_{\mathrm{M}}
$$

com $A_{\mathrm{Pd}}$ e $A_{\mathrm{Cu}}$ as áreas dos picos $\mathrm{K} \alpha_{1}$ do $\mathrm{Pd}$ e do $\mathrm{Cu}$, respectivamente, e $C_{\mathrm{Q}}$ e $T_{\mathrm{M}}$ os fatores que levam em conta a normalização das áreas pela carga e a correção pelo tempo morto, respectivamente, dependerá somente da energia $E$ dos elétrons incidentes, e da eficiência do detetor $\nu$ empregado. Assim, pode-se escrever

$$
r_{E, \nu}=A_{E} R_{\varepsilon_{\mathrm{A}}}\left(\mathcal{L}_{\nu}\right)
$$

em que $R_{\varepsilon_{\mathrm{A}}}\left(\mathcal{L}_{\nu}\right)=\varepsilon_{\mathrm{A}}\left(E_{\mathrm{K} \alpha_{1}, \mathrm{Pd}}, \mathcal{L}_{\nu}\right) / \varepsilon_{\mathrm{A}}\left(E_{\mathrm{K} \alpha_{1}, \mathrm{Cu}}, \mathcal{L}_{\nu}\right), E_{\mathrm{K} \alpha_{1}, \mathrm{Cu}}$ e $E_{\mathrm{K} \alpha_{1}, \mathrm{Pd}}$ correspondem às energias da linha $\mathrm{K} \alpha_{1}$ do $\mathrm{Cu}$ e do $\mathrm{Pd}$, respectivamente. O modelo da expressão (5.13) permite escrever a função de mérito, definida pela expressão (2.11), como

$$
\hat{Q}\left(\mathcal{L}_{1}, \mathcal{L}_{2}, \mathcal{L}_{3}\right)=\sum_{E} \sum_{\nu}\left[\frac{r_{E, \nu}^{\exp }-A_{E} R_{\varepsilon_{\mathrm{A}}}\left(\mathcal{L}_{\nu}\right)}{\sigma_{r_{E, \nu}}}\right]^{2}
$$

em que $\sigma_{r_{E, \nu}}$ é o desvio padrão de $r_{E, \nu}^{\exp }$, e o chapéu no símbolo $Q$ significa que $A_{E}$ é a estimativa de mínimos quadrados para um dado valor do parâmetro $\mathcal{L}_{\nu}$, e a eficiência $\varepsilon_{\mathrm{A}}\left(\mathcal{L}_{\nu}\right)$ para cada valor de $\mathcal{L}_{\nu}$ foi calculada a partir do ajuste do modelo analítico de Seltzer descrito na seção anterior.

O ajuste foi conduzido empregando o método dos mínimos quadrados, apresentado na seção 2.2.2. Os elementos da expressão (2.13) foram construídos da seguinte maneira: o vetor $\vec{y}$ contém os valores experimentais de $r_{E, \nu}^{\exp }$ obtidos com as áreas do pico $\mathrm{K} \alpha_{1}$ do $\mathrm{Cu}$ e do Pd para todas as energias em que esses alvos foram irradiados, a matriz $\mathbb{X}$ foi montada com os valores de $R_{\varepsilon_{\mathrm{A}}}\left(\mathcal{L}_{\nu}\right)$ para um dado valor de $\mathcal{L}_{\nu}$, calculados a partir das curvas de eficiência de pico obtidas previamente pelo ajuste do modelo analítico do Seltzer [42] aos dados experimentais, e a matriz $\mathbb{V}$ é uma matriz diagonal com as variâncias dos dados que entraram no vetor $\vec{y}$.

As curvas de nível da função de mérito, dada pela expressão (5.14), formam um gráfico 3D, e cortes nesse gráfico permitiram estimar graficamente as espessuras $\mathcal{L}_{1}, \mathcal{L}_{2}$ e $\mathcal{L}_{3}$ que minimizaram a relação (5.14). A figura 5.9 mostra três cortes realizados nas posições de $\mathcal{L}_{3}=0,486 ; 0,4886$ e 0,491 mm para $\hat{Q}\left(\mathcal{L}_{1}, \mathcal{L}_{2}, \mathcal{L}_{3}\right)+n^{2}$ com $n=1, \ldots, 8$. A incerteza das estimativas foi calculada a partir da expressão (2.14) usando os valores encontrados para as espessuras. A tabela 5.4 traz os resultados para os três detetores. O qui quadrado do ajuste com nove graus de liberdade foi de 18,2, com probabilidade de ser excedido de $4 \%$, que corresponde a uma aprovação marginal no teste do $\chi^{2}$. 

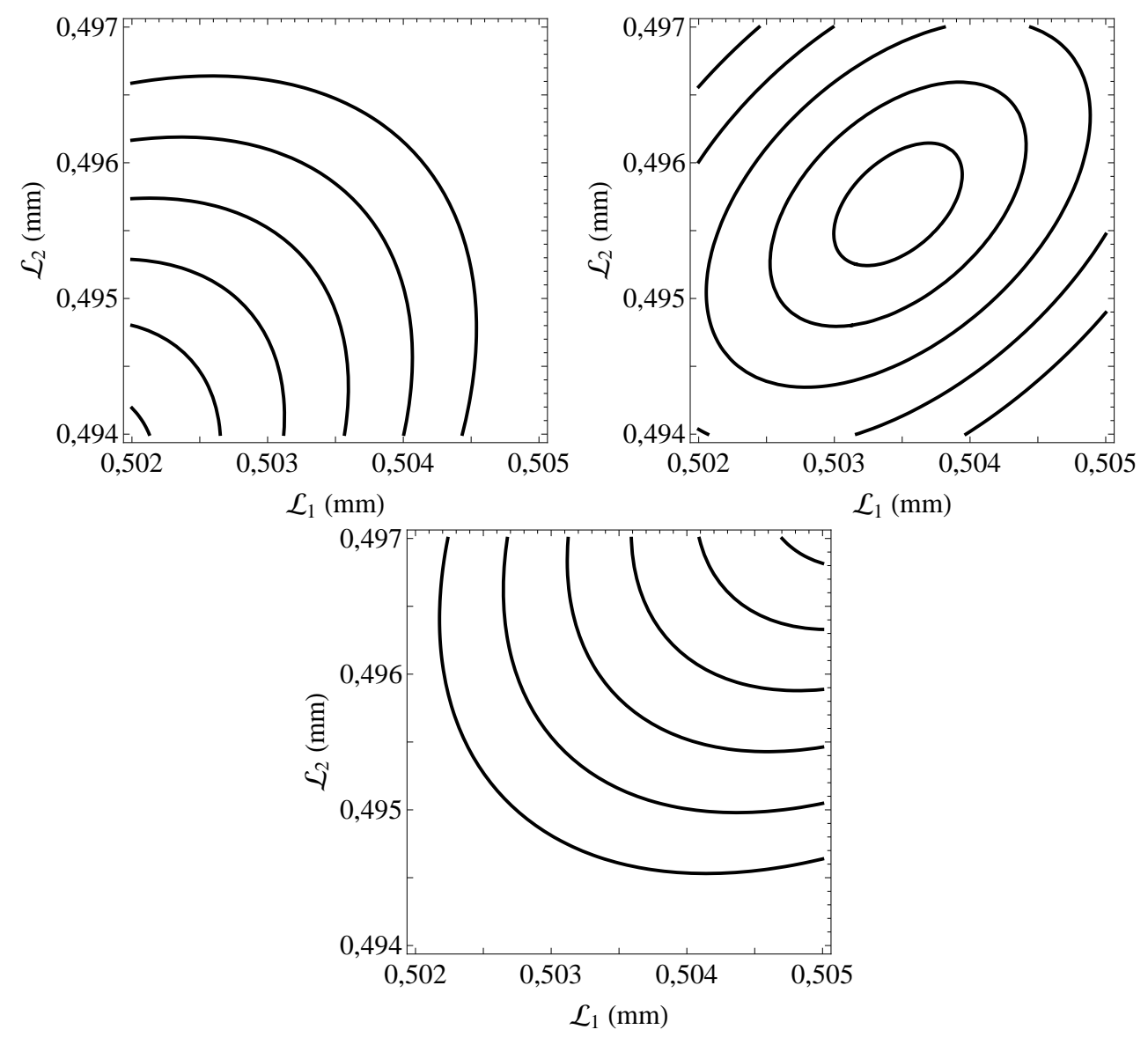

Figura 5.9: Cortes nas superfícies de nível 3D da função de mérito $\hat{Q}\left(\mathcal{L}_{1}, \mathcal{L}_{2}, \mathcal{L}_{3}\right)+n^{2}$ com $n=1, \ldots, 8$ para: a) $\mathcal{L}_{3}=0,486 \mathrm{~mm}$, b) $\mathcal{L}_{3}=0,4886 \mathrm{~mm} \mathrm{e} \mathrm{c)} \mathcal{L}_{3}=0,491 \mathrm{~mm}$, para o menor valor de $\hat{Q}$ encontrado, que foi de 18,7 .

Tabela 5.4: Estimativas de alta precisão para a espessura $\mathcal{L}$ dos três detetores SD do experimento. Em parênteses, o desvio padrão em unidades do dígito menos significativo.

\begin{tabular}{cc}
\hline \hline Detetor & $\hat{\mathcal{L}}(\mathrm{mm})$ \\
\hline $31^{\circ}$ & $0,5034(3)$ \\
$90^{\circ}$ & $0,4956(3)$ \\
$125^{\circ}$ & $0,4885(3)$ \\
\hline \hline
\end{tabular}

Os valores de espessura estimados com essa metodologia e apresentados na tabela 5.4, estão em bom acordo com os que foram apresentados na tabela 5.3, encontrados a partir do ajuste dos parâmetros do modelo do Seltzer aos dados experimentais de eficiência de pico, mas com um ganho de uma ordem de grandeza na precisão da estimativa das incertezas.

Cabe destacar que, além de estimativas de $\mathcal{L}_{\nu}$ com alta precisão, é de fundamental importância que a correlação entre e numerador e o denominador da expressão (5.11) seja 
Tabela 5.5: Razão $r_{i}$, equação (5.11), com $i$ as linhas L $\ell, \mathrm{L} \alpha_{1}$ e L $\alpha_{2}$ dos elementos Ta, W e $\mathrm{Au}$, para o detetor posicionado a $31^{\circ}$ com relação a direção do feixe incidente, empregando como elemento de referência ref o $\mathrm{Cu}$. Em parênteses, o desvio padrão em unidades do dígito menos significativo.

\begin{tabular}{cccc}
\hline \hline Elemento & $r_{\mathrm{L} \ell}$ & $r_{\mathrm{L} \alpha_{1}}$ & $r_{\mathrm{L} \alpha_{2}}$ \\
\hline $\mathrm{Ta}$ & $1,0418(5)$ & $0,99630(4)$ & $0,998316(19)$ \\
$\mathrm{W}$ & $1,0294(3)$ & $0,98846(14)$ & $0,99028(12)$ \\
$\mathrm{Au}$ & $0,98585(17)$ & $0,9703(5)$ & $0,9703(5)$ \\
\hline \hline
\end{tabular}

incluída no cálculo do desvio padrão de $r_{i}$. Quando as energias das linhas L $i$ do elemento estudado e da linha ref do elemento de referência são próximas, a atenuação de ambas pelos materiais atenuadores e pelo cristal do detetor são semelhantes, e isso faz com que a correlação entre o numerador e o denominador da expressão (5.11) seja grande, para o dubleto $\mathrm{K} \alpha$ do $\mathrm{Cu}$ e a linha $\mathrm{L} \ell$ do $\mathrm{Au}$, por exemplo, ela chega a 0,99, neste caso não levar em conta a covariância entre esses termos na estimativa do desvio padrão de $r_{i}$ pode conduzir a erros significativos. Para o caso das linhas $\mathrm{K} \alpha$ do $\mathrm{Cu}$ e $\mathrm{L} \ell$ do $\mathrm{Au}$, o desvio padrão é de 0,00017, e vai para 0,0018 quando a covariância é ignorada.

A tabela 5.5 traz os valores de $r_{i}$, junto com suas respectivas incertezas, para as linhas $\mathrm{L} \ell, \mathrm{L} \alpha_{1}$ e $\mathrm{L} \alpha_{2}$, dos elementos Ta, W e Au, sendo a referência ref o dubleto $\mathrm{K} \alpha$ do $\mathrm{Cu}$, para o detetor posicionado a $31^{\circ} \mathrm{com}$ relação à direção do feixe incidente. Neste cálculo, as espessuras (e desvios padrões) empregadas para três detetores foram as apresentadas na tabela 5.4 .

\subsection{Correção de empilhamento e tempo morto}

Na grande maioria dos sistemas de deteção, existe um tempo mínimo que deve separar dois eventos para que eles possam ser contabilizados como eventos distintos. Esse intervalo de tempo está associado ao tempo necessário para o sistema registrar a ocorrência de um evento e recebe o nome de tempo morto por pulso [51,106]. Quando dois pulsos se sobrepõem em um mesmo intervalo de tempo, a amplitude dos picos será distorcida, dando origem a picos de empilhamento e conduzindo a modificações no espectro observado. Devido a isso, modelos de tempo morto, bem como de empilhamento, tornam-se necessários para corrigir os espectros adquiridos.

A fim de verificar a validade e a qualidade dos modelos aqui propostos, foram realizadas medições com um alvo de $\mathrm{Au}$ inclinado $45^{\circ}$ e com o detetor posicionado a $90^{\circ}$ 
em relação à direção do feixe incidente. As aquisições foram feitas em duas situações, tanto sem nenhum atenuador de raios x, quanto com um atenuador de $25 \mu \mathrm{m}$ de Kapton colocado à frente do detetor, com o intuito de reduzir a intensidade dos raios x M do Au. Em ambos os casos a energia do feixe foi mantida em $18 \mathrm{keV}$.

\subsubsection{Distribuição de empilhamento}

O espectro de empilhamento gerado durante uma aquisição pode ser bem aproximado por [39]

$$
p(\ell)=\eta \sum_{n} y(\ell-n-k) y(n)
$$

em que $\eta$ é uma constante de proporcionalidade que depende do tempo de conversão do detetor e do intervalo de tempo da aquisição, $y(n)$ é o número de contagens no canal $n$, e $k$ é o número do canal correspondente à energia nula do espectro.

Escolhendo a região do espectro que se estende desde poucos canais depois do tip de bremsstrahlung até o canal de maior valor onde não há mais contagens, a razão entre a área total experimental e o termo dentro da soma na equação (5.15) fornece o valor da constante $\eta$.

A figura 5.10 traz os espectros de empilhamento obtidos com uma taxa de aquisição de $56 \mathrm{kHz}$, junto com o modelo descrito pela expressão (5.15) para as duas condições experimentais. Nota-se que o modelo de empilhamento descreve bem os dados, além de estimar a amplitude dos picos de empilhamento com boa precisão.

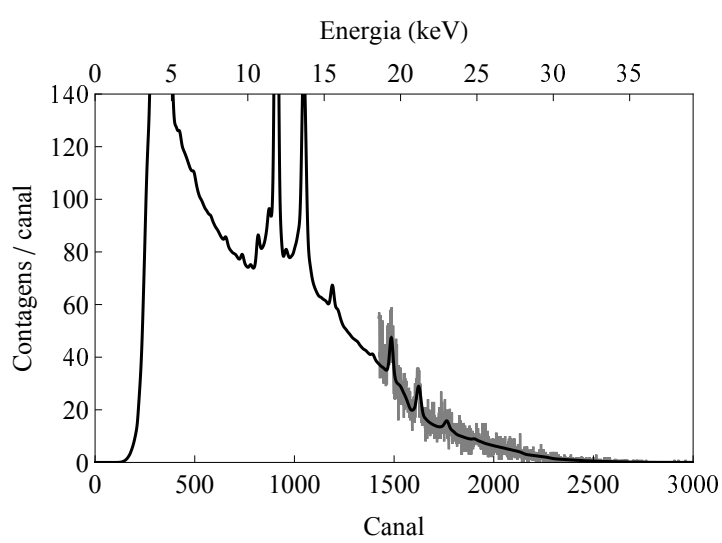

(a)

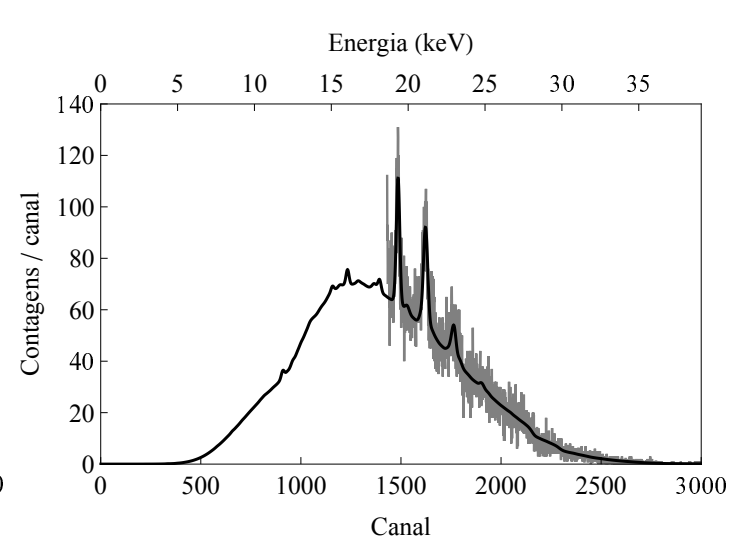

(b)

Figura 5.10: Espectros de empilhamento experimental (em cinza) e modelo (em preto), expressão (5.15). A taxa de aquisição foi de aproximadamente $56 \mathrm{kHz}$ em ambos os casos. a) Linhas $\mathrm{M}$ não foram atenuadas. b) Atenuador de raios $\mathrm{x}$ foi usado para barrar os raios $\mathrm{x}$ M. 


\subsubsection{Estimativa do tempo morto de aquisição}

A fim de ilustrar a magnitude das perdas por tempo morto como função da taxa de aquisição dos espectros, a figura 5.11 mostra a razão de espectros de Au adquiridos com diferentes taxas pelo espectro adquirido a $1 \mathrm{kHz}$. Nota-se que a perda por tempo morto é um efeito de ordem zero, que chega a ser responsável por cerca de $30 \%$ das perdas do espectro quando a taxa de aquisição é da ordem de $50 \mathrm{kHz}$. Além disso, a figura 5.11 evidencia que os espectros não são afetados uniformemente, com as perdas abaixo de $3 \mathrm{keV}$ sendo maiores do que para o restante do espectro. Quando se estuda linhas de raios x com energias inferiores a $3 \mathrm{keV}$, onde as variações das perdas por tempo morto são mais pronunciadas, é de fundamental importância quantificar essas perdas corretamente para que as estimativas das áreas dos picos não apresentem erros sistemáticos.

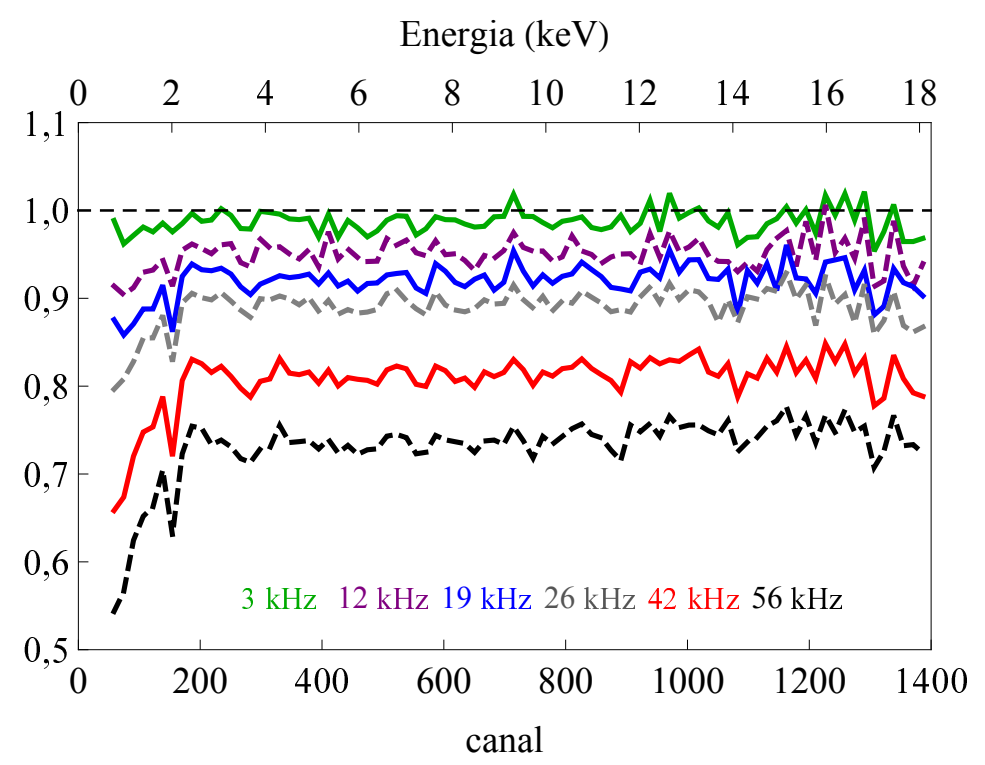

Figura 5.11: De cima para baixo, as linhas representam espectros de Au adquiridos a taxas de: $3,12,19,26,42$, e $56 \mathrm{kHz}$, normalizados pela carga e divididos pelo espectro adquirido a $1 \mathrm{kHz}$, também normalizado pela carga. Os espectros foram agrupados de forma que a dispersão em energia é $210 \mathrm{eV} /$ canal.

Duas referências clássicas que apresentam modelos de tempo morto são Jenkins et al. [51] e Knoll [106]. Contudo, as expressões apresentadas nessas referências não levam em conta a dependência das perdas por tempo morto com a energia do fóton incidente. A fim de estimar essas perdas com alta precisão foi realizado um estudo específico de tempo morto, cujos resultados inéditos foram publicados em Barros et al. [47] e estão apresentados do apêndice A. O modelo proposto neste trabalho teve como base os trabalhos de Jenkins et al. [51] e Redus et al. [108], que já tinham observado a variação do tempo morto de aquisição com a energia do fóton incidente, mas ainda não haviam quantificado esse 
efeito. Para validar o modelo analítico foram usados espectros de um alvo de Au adquiridos em diferentes taxas, e com alta ("espectros ML") e baixa ("espectros L") estatística de contagem na região de baixa energia. Os resultados mostraram que para os "espectros L", ainda é possível obter estimativas das perdas por tempo morto com boa precisão com a expressão

$$
\frac{T_{\mathrm{d}}}{T_{\mathrm{aq}}} \approx \frac{N_{\text {fast }}-N_{\text {slow }}}{N_{\text {fast }}}
$$

em que $N_{\text {fast }}$ e $N_{\text {slow }}$ correspondem ao total de contagens nos canais rápido e lento, respectivamente, e $T_{\mathrm{aq}}$ o tempo de aquisição do espectro. Porém, para os "espectros ML", essa expressão não fornece estimativas corretas para a fração das perdas por tempo morto mesmo em baixas taxas de aquisição, figura A.2.

A maior dificuldade em corrigir os "espectro ML", quando comparada com a correção dos "espectros L", e a perda de precisão decorrente, indicaram que a melhor solução para a observação das linhas L do Ta, W e Au era manter os detetores fora da câmara e usar janelas de espectroscopia muito finas, junto com uma camada de ar fina, para atenuar as intensas linhas de raios x M, de modo a evitar que eles aumentassem a taxa de contagem, uma vez que eles não seriam necessários na medida. 


\section{Capítulo 6}

\section{Análise de dados}

Na primeira parte deste capítulo será descrito o procedimento adotado no ajuste dos parâmetros dos picos de raios $x \mathrm{~K}$ e L. Na seqüência, serão apresentadas a metodologia para a análise da distribuição angular na emissão das linhas de raios $x \mathrm{~L}$, e o procedimento para estimar o parâmetro de alinhamento $A_{20}$. O capitulo encerra com um resumo da metodologia de análise para as seções de choque de ionização das subcamadas L do Au.

\subsection{A função Voigt}

A distribuição de frequências de uma linha de emissão de raios x característicos é descrita pela função de Lorentz, enquanto que a função resposta de detetores semicondutores é bem descrita por uma gaussiana [42]. Desta forma, o perfil de uma linha de raio x medida com um detetor semicondutor é dado pela função Voigt, que corresponde à convolução da gaussiana com a lorentziana, cujo uso é recorrente em uma grande variedade de contextos, como ótica, física do laser, plasma e espectroscopia de raios x [109-111]. Essa função, no entanto, não tem uma expressão analítica fechada, sendo calculada a partir de uma representação integral, que consome tempo de cálculo, mesmo em computadores rápidos. Das muitas tentativas para encontrar um algoritmo eficiente para a função Voigt, ressalta-se Kielkopf [112], cujos procedimentos computacionais foram reconstruídos por Drayson [113] e empregados por Wegrzynek et al. para modificar o código AXIL [114,115].

Escrevendo as funções Lorentziana, Gaussiana e Voigt normalizadas de tal forma que 
a integral sobre todo o eixo das abscissas seja um, tem-se, respectivamente,

$$
\begin{gathered}
L(n)=\frac{1}{\pi \gamma_{\mathrm{L}}} \frac{1}{\left(n / \gamma_{\mathrm{L}}\right)^{2}+1}, \\
G(n)=\frac{\sqrt{\ln 2}}{\sqrt{\pi} \gamma_{\mathrm{G}}} \exp \left[-\ln 2\left(n / \gamma_{\mathrm{G}}\right)^{2}\right]
\end{gathered}
$$

$\mathrm{e}$

$$
V(n)=\int_{-\infty}^{+\infty} G\left(n^{\prime}\right) L\left(n-n^{\prime}\right) \mathrm{d} n^{\prime}=\frac{\sqrt{\ln 2} \gamma_{\mathrm{L}}}{\pi^{3 / 2} \gamma_{\mathrm{G}}} \int_{-\infty}^{+\infty} \frac{\exp \left[-\ln 2\left(n^{\prime} / \gamma_{\mathrm{G}}\right)^{2}\right]}{\left(n-n^{\prime}\right)^{2}+\gamma_{\mathrm{L}}^{2}} \mathrm{~d} n^{\prime}
$$

onde $\gamma_{\mathrm{L}}$ e $\gamma_{\mathrm{G}}$ são metade da largura a meia altura de $L(n)$ e $G(n)$, respectivamente; especificamente, $\gamma_{\mathrm{L}}=\Gamma / 2$ ( $\Gamma$ é a largura natural da linha de raio $\mathrm{x}$ ) e $\gamma_{\mathrm{G}}=\mathrm{FWHM} / 2$. Definindo o parâmetro $a$ e duas variáveis $\xi$ e $\xi^{\prime}$,

$$
a=\sqrt{\ln 2} \frac{\gamma_{\mathrm{L}}}{\gamma_{\mathrm{G}}}, \quad \xi=\sqrt{\ln 2} \frac{n}{\gamma_{\mathrm{G}}} \quad \text { e } \quad \xi^{\prime}=\sqrt{\ln 2} \frac{n^{\prime}}{\gamma_{\mathrm{G}}}
$$

todos eles sem dimensão, a expressão (6.3) pode ser reescrita como

$$
V(a, \xi)=\frac{a^{2}}{\pi^{3 / 2} \gamma_{\mathrm{L}}} \int_{-\infty}^{+\infty} \frac{\exp \left(-\xi^{\prime 2}\right)}{\left(\xi^{\prime}-\xi\right)^{2}+a^{2}} \mathrm{~d} \xi^{\prime}
$$

Introduzindo a função

$$
\operatorname{Re}\left[\exp \left(z^{2}\right) \operatorname{erfc}(z)\right]=\frac{a}{\pi} \int_{-\infty}^{+\infty} \frac{\exp \left(-\xi^{\prime 2}\right)}{\left(\xi^{\prime}-\xi\right)^{2}+a^{2}} \mathrm{~d} \xi^{\prime}
$$

em que

$$
z=a+\mathrm{i} \xi
$$

e $\operatorname{erfc}(z)$ é a função erro complexa [111], chega-se na expressão final para a função Voigt

$$
V(z)=\frac{a}{\sqrt{\pi} \gamma_{\mathrm{L}}} \operatorname{Re}\left[\exp \left(z^{2}\right) \operatorname{erfc}(z)\right]
$$

Aqui é importante lembrar que a cargo de simplificar a notação foi empregado somente o símbolo $z$ na expressão (6.8), mas $z=z(a, \xi)=z\left(\gamma_{\mathrm{G}}, \gamma_{\mathrm{L}} ; n\right)$ para a função Voigt centrada em zero.

Neste trabalho, esta função foi implementada por meio da função Faddeeva, cujo código em $\mathrm{C}++$ é disponibilizado abertamente [116,117].

Para verificar a precisão da função implementada, os resultados numéricos para alguns valores de $a$ e $\xi$ foram comparados com os cálculos de Hummer [118] e Zaghloul [119]. Hummer tabelou valores da função Voigt com oito dígitos de precisão para $0<a<0,5$ 
e $0<\xi<10$. Para o teste calculou-se os valores da função Voigt para $a=0,002 ; 0,02$ e 0,2 , com $0<\xi<10$. Nossos resultados coincidem com os da tabela de Hummer dentro de $\sim 4 \times 10^{-9}$, o que está compatível com a precisão indicada na referência.

Da mesma forma, nossos valores foram comparados com os de Zaghloul [119], que fornece uma precisão que depende de $a$, e que para a região de interesse deste trabalho, $0<a<1$, é $\sim 10^{-13}$. Para $a=0,01$ e 0,5 , foram encontradas diferenças maiores do que esta quando $\xi=1,2,3$, para os demais valores de $\xi$ até 200, os resultados concordaram. A discrepância para $1 \leq \xi \leq 3$ também foi encontrada por Limandri [120] em uma comparação similar.

\subsection{Ajuste dos picos de raios $\mathrm{x}$}

Além dos raios x L de interesse, também foi necessário ajustar os raios x $\mathrm{K}$ do $\mathrm{Cu}$ para fins de monitoração das medidas, como será detalhado mais adiante. O ajuste dos parâmetros dos picos dos raios $\mathrm{x}$ foi feito por um código de mínimos quadrados escrito em $\mathrm{C}++\mathrm{e}$ acionado por um programa desenvolvido no Mathematica, versão 10.1. As duas subseções seguintes apresentam o procedimento de ajuste empregado para desmembrar os raios $\mathrm{x} K$ e L.

\subsubsection{Ajuste dos picos de raios $\mathrm{x} \mathrm{K}$ do $\mathrm{Cu}$}

Embora somente os raios $\mathrm{x} K \alpha$ tenham sido usados na análise, os $\mathrm{K} \beta$ foram incluídos no procedimento de ajuste, de forma a estimar melhor a componente contínua do espectro na região de interesse. Quatro funções Voigt foram usadas para descrever os picos $\mathrm{K} \alpha_{1}$, $\mathrm{K} \alpha_{2}, \mathrm{~K} \beta_{1,3}$ e um pico observado à esquerda de $\mathrm{K} \beta_{1,3}$, que provavelmente se deve a linhas satélites e transições Auger radiativas [120]. Devido à resolução do detetor, as linhas $\mathrm{K} \alpha_{1}$ e $\mathrm{K} \alpha_{2}$ não apareceram separadas no espectro, contudo o grupo $\mathrm{K} \beta_{1,3}$ apareceu totalmente resolvido do dubleto $\mathrm{K} \alpha$.

No procedimento de ajuste, optou-se por manter livre a posição da linha $K \alpha_{1}$ e fixar as posições das linhas $\mathrm{K} \alpha_{2}$ e $\mathrm{K} \beta_{1,3}$ com relação à $\mathrm{K} \alpha_{1}$ com base nas energias de Deslattes et al. [12] e na calibração de energia realizada previamente, seção 5.1. Como a separação entre $\mathrm{K} \alpha_{1}$ e $\mathrm{K} \alpha_{2}$ é de aproximadamente $20 \mathrm{eV}$, fixar não só a posição de $\mathrm{K} \alpha_{2}$, mas também a de $\mathrm{K} \beta_{1,3}$ se mostrou um procedimento adequado para obter boas estimativas da posição de $K \alpha_{1}$. Com isso, a razão de intensidades $I_{\mathrm{K} \alpha_{2}} / I_{\mathrm{K} \alpha_{1}}$ obtida foi compatível com o valor calculado por Scofield [121], de 0,5133. As larguras naturais $\Gamma$ das linhas foram fixadas 
com base em Krause e Oliver [53], enquanto que na resolução do detetor (FWHM), equação (5.2), o parâmetro $\rho$ foi fixado com base na calibração de largura realizada previamente, seção 5.1, e o parâmetro $\mu$ ficou livre no ajuste. A componente contínua do espectro foi descrita por um polinômio de segundo grau para os três ângulos estudados.

A figura 6.1 traz os pontos experimentais junto com a curva construída a partir dos parâmetros estimados, bem como o gráfico dos resíduos reduzidos para os espectros de $\mathrm{Cu}$ adquiridos com o detetor no ângulo de $31^{\circ}$ com relação à direção do feixe incidente de $15 \mathrm{keV}$; as figuras para os outros dois ângulos, figuras B.1 e B.2, estão apresentadas no apêndice B. Em todos os ajustes, a incerteza relativa na área do dubleto $\mathrm{K} \alpha$ do $\mathrm{Cu}$ foi inferior a $0,02 \%$.

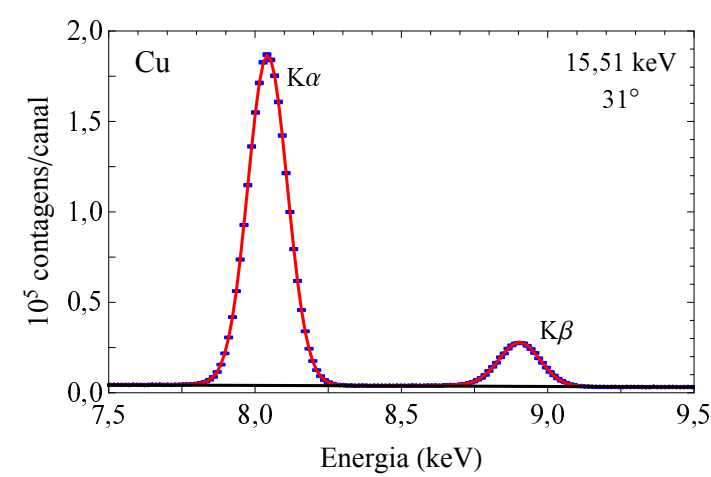

(a)

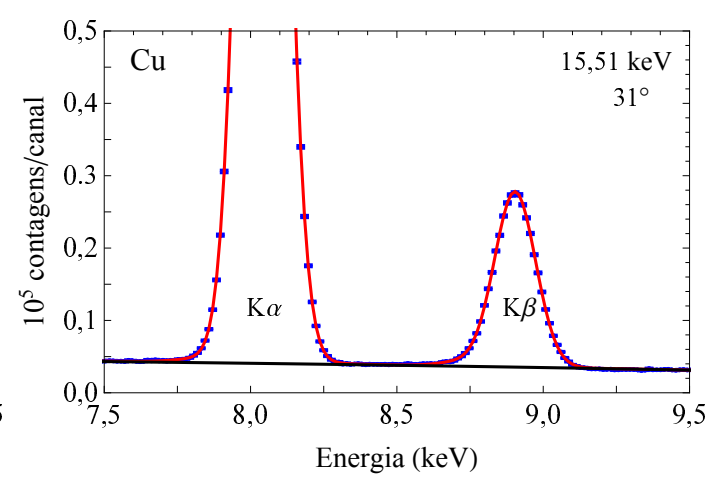

(b)

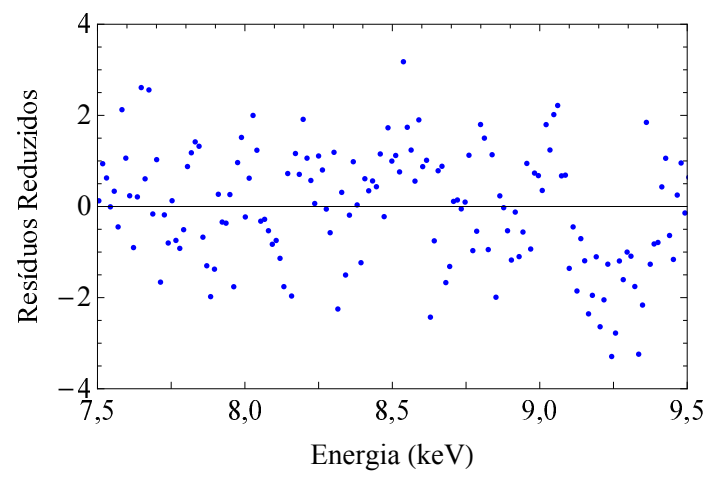

(c)

Figura 6.1: Espectro de raios x experimental (em pontos) e curva calculada com os parâmetros ajustados (em linha contínua) para o espectro de $\mathrm{Cu}$ obtido com elétrons de $15,51(9) \mathrm{keV}$ com o detetor na posição de $31^{\circ}$ com relação à direção do feixe incidente. a) Espectro completo e b) escala expandida para visualização dos picos de raios $\mathrm{x} \mathrm{K} \beta$. c) Resíduos reduzidos do ajuste. O $\chi^{2}$ reduzido do ajuste de 1,8 . 


\subsubsection{Ajuste dos picos de raios $\mathrm{x} \mathrm{L}$ do $\mathrm{Ta}, \mathrm{W}$ e do $\mathrm{Au}$}

\subsubsection{Modelo}

O ajuste dos parâmetros das linhas de raios x na região do multipleto L foi realizado em um único processo, incluindo os picos dos multipletos $\mathrm{L} \alpha, \mathrm{L} \beta$ e $\mathrm{L} \gamma$, e as linhas $\mathrm{L} \ell$ e L $\eta$, além das linhas Lt e L $s$ que são proibidas na aproximação de dipolo elétrico. Como os espectros obtidos tinham alta estatística de contagem, as linhas Lt e Ls, embora proibidas, foram observadas nos espectros, de modo que elas tiveram que ser incluídas no ajuste para que os parâmetros da componente contínua do espectro não fossem ajustados erroneamente. Contudo, as estimativas de áreas destas linhas apresentaram grandes incertezas, e por isso elas não foram incluídas no estudo de distribuição angular.

Antes do ajuste dos picos o espectro experimental bruto $y(n)$ foi reduzido de algumas componentes. O modelo adotado para esse espectro corrigido foi

$$
y_{\mathrm{r}}(n)=y(n)-p(n)-p_{\mathrm{esc}}(n)-B(n)
$$

em que $p(n)$ é a distribuição de empilhamento, construída de acordo com a expressão (5.15), $p_{\text {esc }}(n)$ é a distribuição de escape de fótons do detetor e $B(n)$ o espectro de bremsstrahlung teórico.

Com isso, a expressão empregada no ajuste, realizado com o espectro em canais, foi

$$
\begin{aligned}
y_{\mathrm{r}}(n)= & \sum_{i=1}^{M} A_{i}\left[V\left(n_{i}, \sigma\left(n_{i}\right), \Gamma_{i} ; n\right)+h \operatorname{erfc}\left(n_{i}, \sigma\left(n_{i}\right) ; n\right)\right] \\
& +c_{0}+c_{1}\left(n-n_{0}\right)+c_{2}\left(n-n_{0}\right)^{2},
\end{aligned}
$$

com $V$ a função Voigt, $A_{i}, n_{i}$ e $\Gamma_{i}$ as áreas, as posições e as larguras naturais, dos $M$ picos incluídos no ajuste, respectivamente, $\sigma\left(n_{i}\right)=\operatorname{FWHM}\left(n_{i}\right) /(2 \sqrt{2 \ln 2}), c_{j}$ os coeficientes do polinômio de segundo grau que descreve a componente contínua residual do espectro, $h$ a amplitude do degrau localizado à direita dos picos e erfc a função erro complementar, que corresponde a convolução da função gaussiana com a função degrau. A constante arbitrária $n_{0}$ foi fixada como o canal central da região de ajuste; esta escolha reduz fortemente a correlação estatística entre os coeficientes $c_{j}$.

A distribuição de empilhamento foi construída de acordo com o modelo apresentado na expressão (5.15). Para construir a distribuição de escape $p_{\text {esc }}(E(n))$ de raios $\mathrm{x}$, foi 
desenvolvido um modelo a partir da expressão (5.6), dado por,

$$
p_{\mathrm{esc}}(E)=\left\{1+\exp \left[-\mu\left(E+E_{\mathrm{K} \tau}\right)\right] L\right\} P_{\mathrm{K} \tau}\left(E+E_{\mathrm{K} \tau}\right) \frac{y\left(E+E_{\mathrm{K} \tau}\right)}{\varepsilon\left(E+E_{\mathrm{K} \tau}\right)}
$$

em que $\tau$ representa $\alpha$ ou $\beta, \mu(E)$ o coeficiente de atenuação total do material do cristal do detetor, $L$ a espessura do cristal, $y(E)$ o espectro experimental bruto, $\varepsilon(E)$ a eficiência intrínseca do detetor, e $P_{\mathrm{K} \tau}(E)$ a probabilidade de escape do raios x $\mathrm{K} \tau$, dada pela expressão (5.6). Uma vez que o espectro bruto é na verdade $y(n)$ e não $y(E)$, e a relação entre o canal $n$ e a energia $E$ foi determinada na calibração prévia de energia, expressão (5.1), o jacobiano $\mathrm{d} n / \mathrm{d} E$ deve ser incluído no cálculo dessa distribuição. O primeiro termo dentro das chaves na expressão (6.11) corresponde ao escape pela face frontal do cristal de Si e o segundo, pela face traseira. A figura 6.2 traz a distribuição de escape, construída com a expressão (6.11) a partir do espectro de $\mathrm{Au}$, para a energia de $25 \mathrm{keV}$ e adquirido no ângulo de $31^{\circ}$.

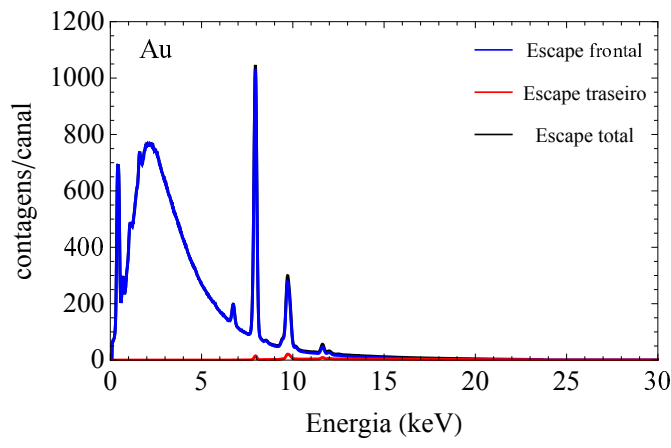

(a)

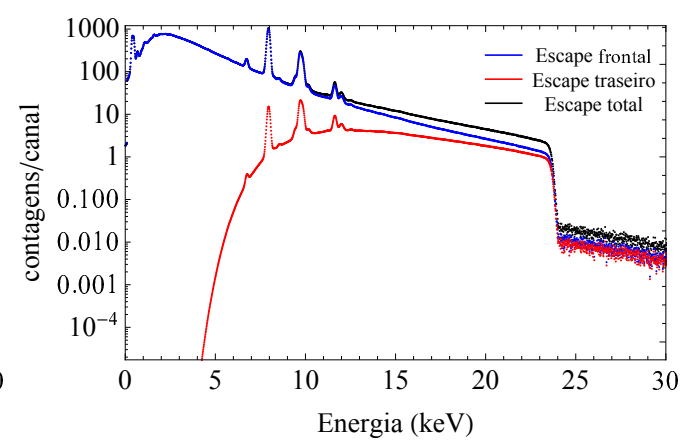

(b)

Figura 6.2: Distribuição de escape construída a partir da expressão (6.11) para o alvo de $\mathrm{Au}$ irradiado com um feixe de elétrons de $25 \mathrm{keV}$ e adquirido com um SDD posicionado a $31^{\circ}$ em relação à direção do feixe incidente. A linha preta corresponde ao espectro total, a azul, ao escape frontal e a vermelha, ao escape traseiro. a) Escala linear. b) Escala logarítmica.

O espectro de bremsstrahlung teórico $B(n)$ foi construído de acordo com a metodologia apresentada por Fernández-Varea et al. [38]. O procedimento consiste em ajustar a região do tip de bremsstrahlung do espectro experimental com o modelo teórico de bremsstrahlung de Pratt et al. [122] e Kissel et al. [123] levando-se em conta a função resposta do detetor e a eficiência de pico do mesmo. Neste caso, a função de mérito da expressão (2.11) é escrita como [38]

$$
\hat{Q}\left(C ; E_{\mathrm{e}}, \sigma_{\mathrm{e}}\right)=\sum_{i} \frac{\left[y_{i}^{\mathrm{f}}-C I_{\mathrm{B}}\left(E_{\mathrm{e}}, \sigma_{\mathrm{e}}\right)\right]^{2}}{\operatorname{var}\left(y_{i}^{\mathrm{f}}\right)}
$$

em que $y^{\mathrm{f}}$ corresponde ao espectro experimental corrigido pelo empilhamento, $C$ é um parâmetro diretamente proporcional à carga incidente no alvo e à espessura efetiva dele, 
$I_{\mathrm{B}}$ corresponde ao termo que contém a convolução do espectro de bremsstrahlug teórico com a função resposta do detetor, e $E_{\mathrm{e}}$ e $\sigma_{\mathrm{e}}$ são, respectivamente, a média e o desvio padrão da distribuição em energia do feixe de elétrons, adotada como uma gaussiana. Na expressão (6.12), o modelo é linear no parâmetro $C$, e não linear nos parâmetros $E_{\mathrm{e}}$ e $\sigma_{\mathrm{e}}$. Como conseqüência, para um dado par de $E_{\mathrm{e}}$ e $\sigma_{\mathrm{e}}$, a quantidade $\hat{C}$ é a estimativa para o parâmetro $C$ que minimiza a relação (6.12), e foi determinada pelo método dos mínimos quadrados, conforme a expressão (2.13).

A função (6.12) foi minimizada, e com isso obteve-se as $\hat{E}_{e}, \hat{\sigma}_{e}$ e $\hat{C}$, com as quais foi construído o espectro de bremsstrahlung teórico para a região de interesse. As figuras 6.3, 6.4 e 6.5 apresentam as curvas de nível e os espectros ajustados, para o alvo de W irradiado com o feixe de elétrons de $36,97(8) \mathrm{keV}$ nos três ângulos de medição.

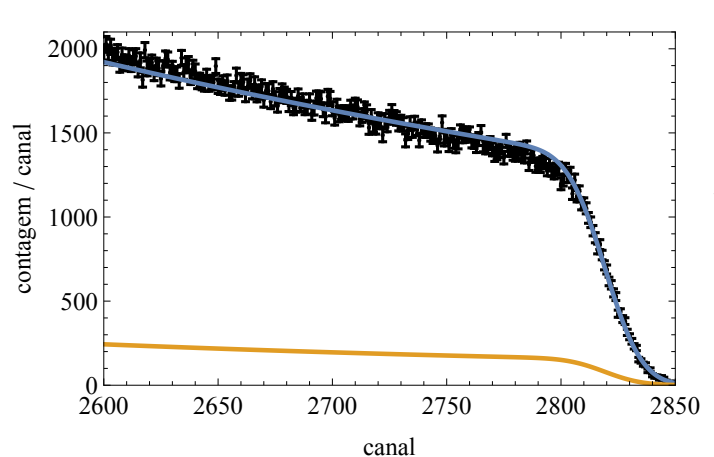

(a)

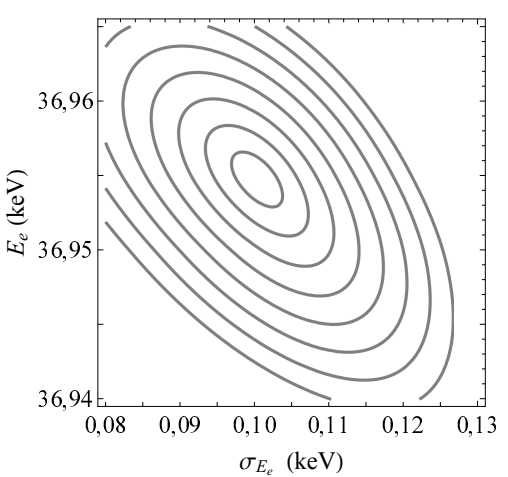

(b)

Figura 6.3: a) Espectro experimental do W e modelo ajustado na região do tip de bremsstrahlung. b) Curvas de nível $Q\left(\hat{E}_{\mathrm{e}}, \hat{\sigma}_{\mathrm{e}}\right)+n^{2}, n=1, \ldots, 8$ para o ajuste do espectro de W. Ambos para o feixe de elétrons de $36,97(8) \mathrm{keV}$ e o detetor na posição de $31^{\circ}$ em relação à direção do feixe incidente.

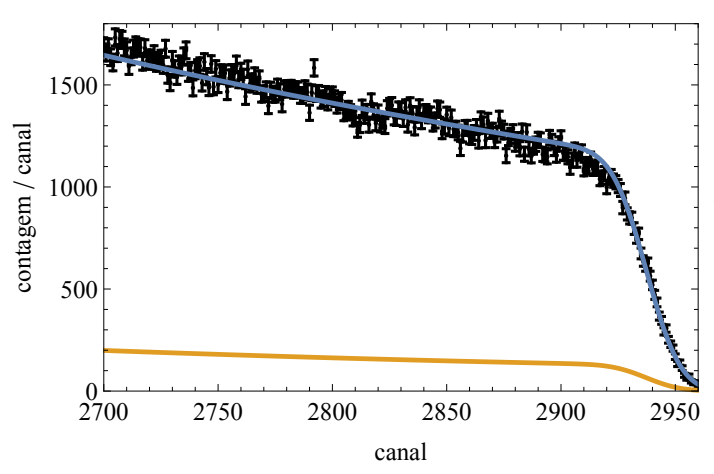

(a)

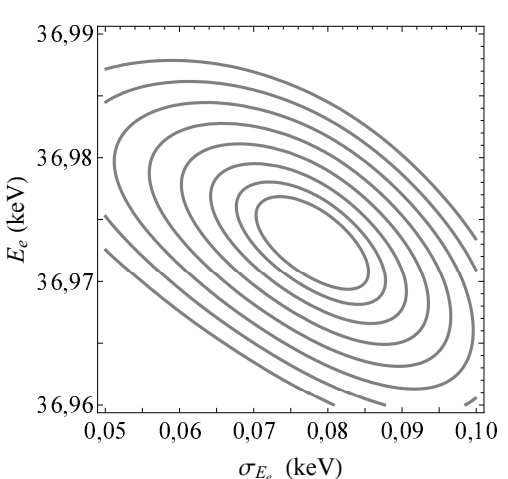

(b)

Figura 6.4: Mesmo que a figura 6.3, mas para o detetor na posição de $90^{\circ}$.

Uma vez que a região de ajuste inclui desde a linha $\mathrm{L} \ell$ até o multipleto $\mathrm{L} \gamma$, portanto uma faixa de energia que se estende de aproximadamente 8 a $15 \mathrm{keV}$, quando o espectro 


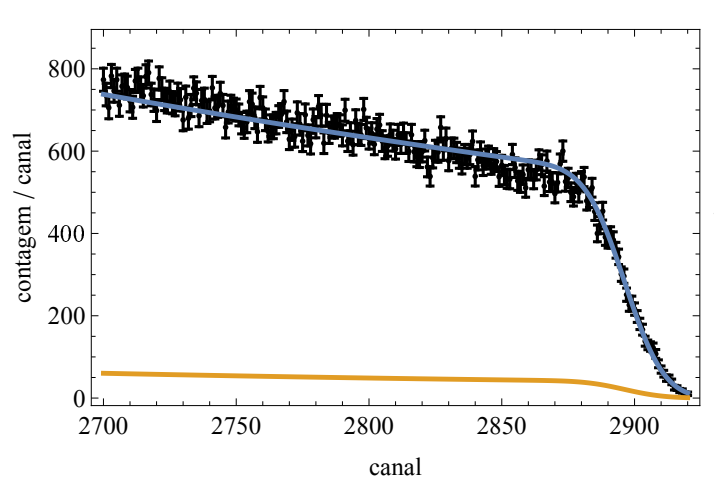

(a)

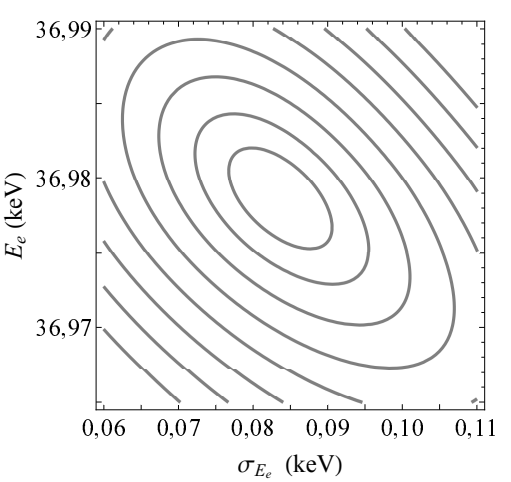

(b)

Figura 6.5: Mesmo que a figura 6.3, mas para o detetor na posição de $125^{\circ}$.

possui alta estatística de contagem, o ajuste da componente contínua com um polinômio do primeiro ou do segundo grau não é completamente adequado. Subtrair o espectro de bremsstrahlung teórico dos dados brutos permitiu incluir a concavidade da componente contínua do espectro que é característica do bremsstrahlung do elemento. Contudo, quando se compara o espectro experimental de bremsstrahlung com aquele calculado teoricamente, nota-se um desacordo que varia com o elemento e a energia do feixe incidente. Em particular, para a faixa de elementos estudados $Z=73-79$, quando a energia do feixe foi inferior a $15 \mathrm{keV}$, o espectro de bremsstrahlung teórico apresentou uma discrepância com o espectro experimental não só em magnitude mas também na forma. Maiores detalhes sobre essas discrepâncias podem ser encontrados em García-Alvarez et al. [40,107] e não serão discutidos aqui. Devido a esse comportamento, optou-se por subtrair o espectro de bremsstrahlung teórico dos dados brutos para as energias do feixe incidente superiores a $15 \mathrm{keV}$. Quando a energia do feixe foi igual ou inferior a $15 \mathrm{keV}$, somente os espectros de escape e empilhamento foram subtraídos, e a componente contínua foi descrita por um polinômio do segundo grau.

\subsubsection{Escolha dos parâmetros de ajuste}

A quantidade de picos incluídos no ajuste levou em consideração as subcamadas ionizadas, sendo que foram incluídos somente as linhas que aparecem na tabela 2.1 que provem delas. Quando a energia do feixe incidente foi superior à energia de ionização da subcamada $\mathrm{L}_{1}$ do elemento estudado, foram incluídas todas as linhas L apresentadas na tabela 2.1, cada uma descrita por uma função Voigt. No caso dos espectros de Au, uma função Voigt adicional foi introduzida para simular um pico observado à direita de $\mathrm{L} \alpha_{1}$, enquanto que para os alvos de Ta e W foram incluídos ainda os picos de raios x $\mathrm{K} \alpha$ e $\mathrm{K} \beta$ do Fe e do $\mathrm{Ni}$, que são provenientes da fluorescência da câmara de irradiação e estão próximos ao 
multipleto L destes elementos, cada um descrito por uma função Voigt.

Posição: no dubleto $\mathrm{L} \alpha$, a posição da linha $\mathrm{L} \alpha_{2}$ foi fixada em relação à da linha $\mathrm{L} \alpha_{1}$, mantida livre no ajuste. No multipleto $\mathrm{L} \beta$, a posição da linha $\mathrm{L} \beta_{1}$ ficou livre, e as demais foram fixadas com relação a ela. E no grupo $\mathrm{L} \gamma$, a única posição deixada como parâmetro de ajuste foi a da linha $\mathrm{L} \gamma_{1}$. Como no ajuste dos raios $\mathrm{x} \mathrm{K}$ do $\mathrm{Cu}$, as posições foram fixadas com base na calibração prévia de energia, seção 5.1, e na referência Deslattes et al. [12], exceto para as linhas $\mathrm{L} \beta_{5}, \mathrm{~L} \gamma_{4,4^{\prime}}$ e $\mathrm{L} \gamma_{6}$ para as quais se usou os valores de Bearden [29].

Áreas: as áreas dos picos Lt e L $s$ foram deixadas livres nos ajuste sempre que as razões das áreas $A_{\mathrm{L} t} / A_{\mathrm{L} \alpha}$ e $A_{\mathrm{L} s} / A_{\mathrm{L} \alpha}$ foram compatíveis com os valores de Scofield [88] dentro de dois desvios padrões, caso contrário, elas foram fixadas com base nesta referência. As áreas dos picos $\mathrm{L} \beta_{17}, \mathrm{~L} \beta_{15} \mathrm{e} \mathrm{L} \gamma_{6}$ foram fixadas com relação às áreas dos picos $\mathrm{L} \beta_{1}$, L $\alpha_{1} \mathrm{e}$ $\mathrm{L} \gamma_{1}$, respectivamente, tomando como referência os valores de Scofield [88] para a primeira e de Campbell e Wang [87] para as duas últimas. As demais áreas de pico ficaram livres no ajuste.

Larguras: de forma análoga ao adotado para o ajuste dos parâmetros dos picos de raios $\mathrm{x} \mathrm{K}$ do $\mathrm{Cu}$, todas as larguras naturais foram fixadas com base em Krause e Oliver [53], e para a largura dos picos (FWHM), equação (5.2), o parâmetro $\rho$ foi mantido fixo com base na calibração realizada previamente, e o parâmetro $\mu$ ficou livre.

\subsubsection{Exemplos dos resultados e avaliação do procedimento e dos desvios padrões}

As incertezas das áreas assim estimadas provêm da estatística de contagem nos picos e do procedimento de ajuste. Entretanto, os parâmetros que foram mantidos fixos no ajuste, como a largura natural e as diferenças de posições, apresentam incertezas que devem ser propagadas. Para tanto, a expressão (2.5) foi empregada, construindo os elementos da matriz $\mathbb{C}$ com as derivadas calculadas numericamente. Os desvios padrões das áreas aumentaram de $3 \%$ a 20\%, a depender da estatística de contagem no pico. As tabelas 6.1, 6.2 e 6.3 trazem os desvios padrões relativos das linhas $\mathrm{L} \ell, \mathrm{L} \alpha_{1}$ e $\mathrm{L} \alpha_{2}$ do Ta, W e $\mathrm{Au}$, respectivamente, enquanto que a tabela 6.4 traz alguns exemplos dos coeficientes de correlação entre as linhas empregadas na estimativa do parâmetro de alinhamento, realizada na seção seguinte. As figuras 6.6, 6.7 e 6.8 apresentam os espectros experimentais junto com a função modelo calculada com os parâmetros estimados nos ângulos de $31^{\circ}, 90^{\circ}$ e $125^{\circ}$ para os elementos Ta, W e Au nas energias de 20,79(9); 100,65(7) e 30,62(15) keV, 
Tabela 6.1: Razão entre os desvios padrões e as estimativas de áreas das linhas de raios x L $\ell, L \alpha_{1}$ e $\mathrm{L} \alpha_{2}$ do Ta para todas as energias do feixe de elétrons incidente, em \%.

\begin{tabular}{cccc}
\hline \hline Energia $(\mathrm{keV})$ & $\mathrm{L} \ell$ & $\mathrm{L} \alpha_{1}$ & $\mathrm{~L} \alpha_{2}$ \\
\hline $10,75(9)$ & 1 & 0,9 & 7 \\
$11,51(6)$ & 3 & 0,4 & 3 \\
$13,46(9)$ & 0,3 & 0,3 & 3 \\
$15,51(4)$ & 0,6 & 0,6 & 6 \\
$17,79(7)$ & 0,3 & 0,3 & 3 \\
$20,76(9)$ & 0,5 & 0,5 & 5 \\
$25,41(15)$ & 0,3 & 0,3 & 3 \\
$30,62(9)$ & 0,4 & 0,4 & 4 \\
$50,82(5)$ & 0,3 & 0,3 & 4 \\
$74,83(6)$ & 0,4 & 0,4 & 3 \\
$84,96(5)$ & 0,3 & 0,3 & 4 \\
$100,60(4)$ & 0,3 & 0,3 & 3 \\
\hline \hline
\end{tabular}

Tabela 6.2: Mesmo que a tabela 6.1, mas para o alvo de W.

\begin{tabular}{cccc}
\hline \hline Energia $(\mathrm{keV})$ & $\mathrm{L} \ell$ & $\mathrm{L} \alpha_{1}$ & $\mathrm{~L} \alpha_{2}$ \\
\hline $36,97(8)$ & 0,2 & 0,2 & 2 \\
$58,28(3)$ & 0,3 & 0,3 & 3 \\
$100,65(7)$ & 0,3 & 0,3 & 3 \\
\hline \hline
\end{tabular}

respectivamente, junto com os gráficos dos resíduos reduzidos. Os gráficos para os ajustes destes elementos e com essas energias para os outros dois ângulos estão apresentados no apêndice A.

Um pequeno ombro no lado direito do dupleto L $\alpha$ foi observado em todos os espectros de $\mathrm{Au}$ medidos e, por isso, simulado com um pico. Devido à resolução dos detetores empregados, não foi possível verificar se corresponde a uma linha satélite, uma transição que está proibida na aproximação do dipolo elétrico ou algum efeito de deteção secundário. Contudo, quando o alvo foi irradiado por um feixe de elétrons cuja energia era menor do que a do limiar de ionização $\mathrm{L}_{3}$ do $\mathrm{Au}$, nenhum pico foi observado nesta região, portanto, provavelmente não se trata de um contaminante do alvo. A área do pico ajustado que reproduz esse ombro é cerca de metade da área da linha L $\eta$, e, portanto, não compromete a estimativa da área do dubleto L $\alpha$ dentro das barras de incerteza. 
Tabela 6.3: Mesmo que a tabela 6.1, mas para o alvo de Au.

\begin{tabular}{cccc}
\hline \hline Energia $(\mathrm{keV})$ & $\mathrm{L} \ell$ & $\mathrm{L} \alpha_{1}$ & $\mathrm{~L} \alpha_{2}$ \\
\hline $12,19(9)$ & 3 & 1 & 0,11 \\
$13,35(9)$ & 0,8 & 0,3 & 3 \\
$14,03(9)$ & 0,7 & 0,4 & 3 \\
$15,51(9)$ & 0,9 & 0,5 & 5 \\
$17,79(11)$ & 0,5 & 0,2 & 2 \\
$20,76(8)$ & 0,6 & 0,3 & 3 \\
$25,41(9)$ & 0,3 & 0,1 & 1 \\
$30,62(15)$ & 0,4 & 0,3 & 3 \\
$50,82(7)$ & 0,4 & 0,2 & 2 \\
$74,83(7)$ & 0,3 & 0,2 & 2 \\
$84,96(6)$ & 0,4 & 0,2 & 2 \\
$100,60(7)$ & 0,3 & 0,2 & 2 \\
\hline \hline
\end{tabular}

Tabela 6.4: Coeficientes de correlação entre as estimativas das áreas dos picos L $\ell$, L $\alpha_{1}$ e $\mathrm{L} \alpha_{2}$ do Ta, W e Au nos espectros adquiridos com elétrons de aproximadamente 20,79(9), $100,65(7)$ e $30,62(15) \mathrm{keV}$, respectivamente, para o detetor em $31^{\circ}$.

\begin{tabular}{cccc}
\hline \hline Correlação & $\mathrm{Au}$ & $\mathrm{Ta}$ & $\mathrm{W}$ \\
\hline$\rho\left(A_{\mathrm{L} \ell}-A_{\mathrm{L} \alpha_{1}}\right)$ & 0,21 & 0,12 & 0,10 \\
$\rho\left(A_{\mathrm{L} \ell}-A_{\mathrm{L} \alpha_{2}}\right)$ & $-0,19$ & $-0,11$ & 0,09 \\
$\rho\left(A_{\mathrm{L} \alpha_{1}}-A_{\mathrm{L} \alpha_{2}}\right)$ & $-0,98$ & $-0,99$ & $-0,99$ \\
\hline \hline
\end{tabular}




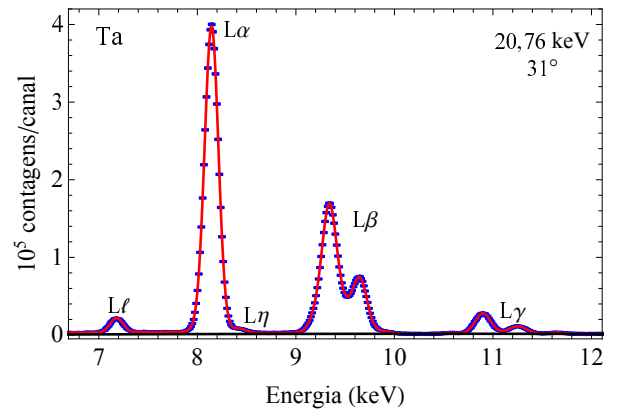

(a)

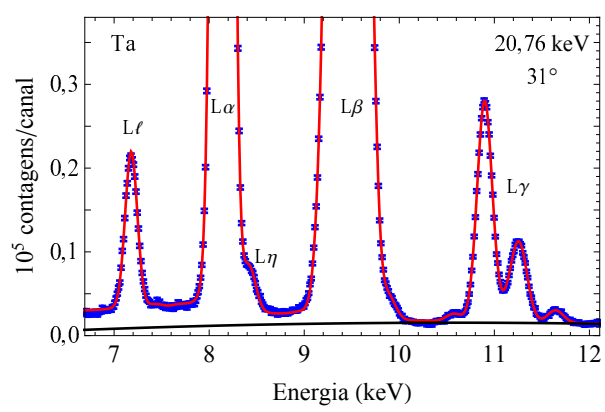

(b)

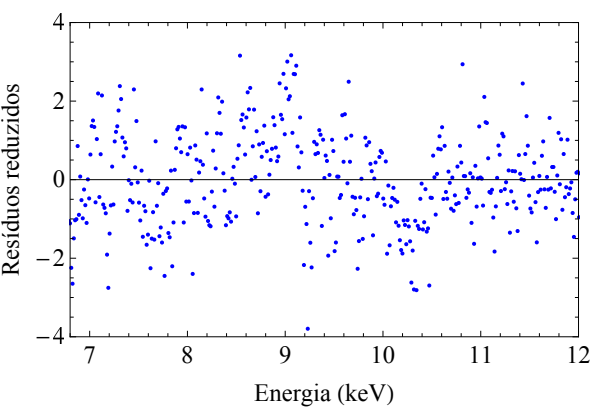

(c)

Figura 6.6: Espectro de raios x experimental (em pontos) e curva calculada com os parâmetros ajustados (em linha contínua) para o espectro de Ta obtido com elétrons de $20,76(9) \mathrm{keV}$ no ângulo de $31^{\circ}$ com relação à direção do feixe incidente. a) Espectro completo, b) escala expandida e c) resíduos reduzidos do ajuste. O $\chi^{2}$ reduzido do ajuste foi de 1,4 .

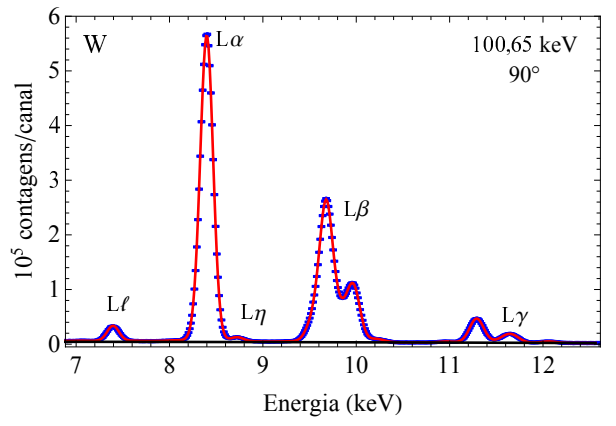

(a)

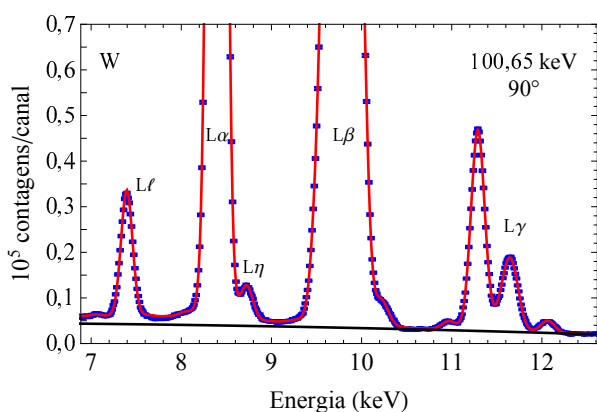

(b)

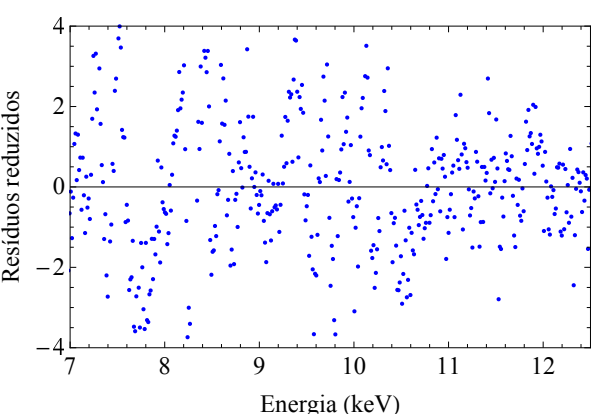

(c)

Figura 6.7: Mesmo que a figura 6.6, mas para o alvo de $\mathrm{W}$ irradiado com o feixe de elétrons de $100,65(7) \mathrm{keV}$ no ângulo de $90^{\circ}$. O $\chi^{2}$ reduzido do ajuste foi de 2,6. 


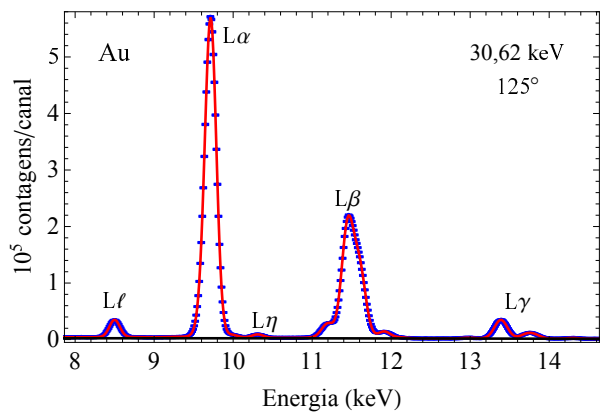

(a)

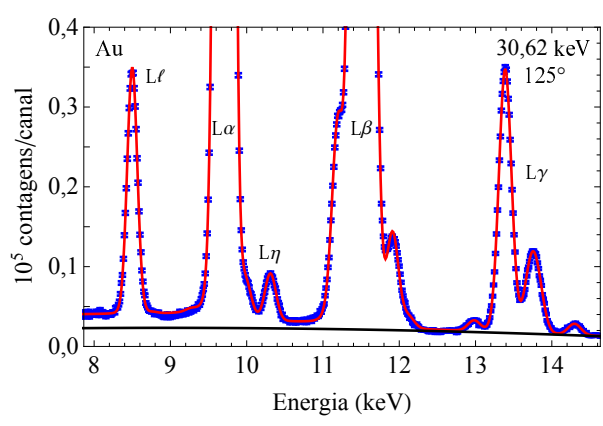

(b)

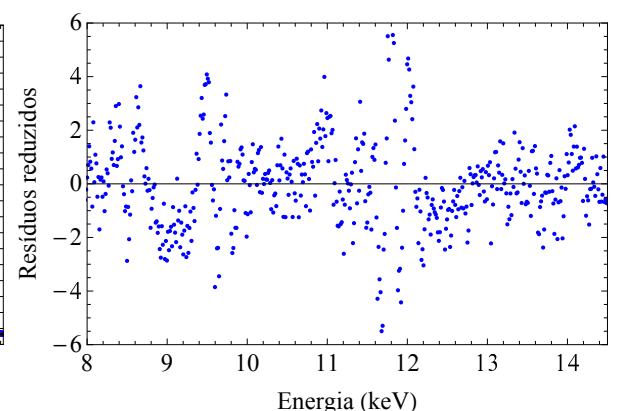

(c)

Figura 6.8: Mesmo que a figura 6.6, mas para o alvo de $\mathrm{Au}$ irradiado com o feixe de elétrons de $30,62(15) \mathrm{keV}$ no ângulo de $125^{\circ}$. O $\chi^{2}$ reduzido do ajuste foi de 2,6.

\subsection{Estimativa do parâmetro de alinhamento}

\subsubsection{Anisotropia do arranjo experimental}

A anisotropia introduzida pelo arranjo experimental foi levada em conta no procedimento descrito acima por meio da normalização dos dados de $\mathrm{L} \ell$, $\mathrm{L} \alpha_{1}$ e $\mathrm{L} \alpha_{2}$ pela linha $\mathrm{K} \alpha$ do $\mathrm{Cu}$, que do ponto de vista teórico é esperada apresentar emissão isotrópica [15]. Contudo, Yamaoka et al. [7] alertam para o fato de que as linhas satélites do $\mathrm{Cu}$ podem introduzir uma anisotropia no dubleto $\mathrm{K} \alpha$. A fim de verificar essa afirmação, para todas as energias do estudo, foi determinada a dependência angular da razão das áreas $A_{\mathrm{K} \beta} / A_{\mathrm{K} \alpha}$ corrigidas pelas respectivas eficiências de pico. A figura 6.9 mostra a razão $A_{\mathrm{K} \beta} / A_{\mathrm{K} \alpha}$ obtida com as energias de 11,51(6), 58,28(3), e 100,60(3) keV, que foram empregadas durante a irradiação dos alvos de Ta, W e Au, respectivamente, e a tabela 6.5 o produto $\xi \alpha A_{20}$ estimado com o ajuste dos parâmetros da expressão (3.40) aos dados experimentais. Essas análises não mostraram evidência de anisotropia na emissão de $\mathrm{K} \alpha$ para nenhuma das situações estudadas, com uma precisão melhor ou igual a 0,1\%. Diante deste resultado, o dubleto $\mathrm{K} \alpha$ foi empregado para normalização das áreas de raios $\mathrm{x}$ L. 
Tabela 6.5: Estimativas do produto $\xi \alpha A_{20}$ obtidas pelo ajuste dos parâmetros da expressão (3.40) aos dados experimentais referente a razão $A_{\mathrm{K} \beta} / A_{\mathrm{K} \alpha}$. Em parênteses, o desvio padrão em unidades do dígito menos significativo.

\begin{tabular}{cc}
\hline \hline Energia $(\mathrm{keV})$ & $\xi \alpha A_{20}$ \\
\hline $11,51(6)$ & $0,0008(10)$ \\
$58,28(3)$ & $0,0001(6)$ \\
$100,60(3)$ & $0,0002(6)$ \\
\hline \hline
\end{tabular}

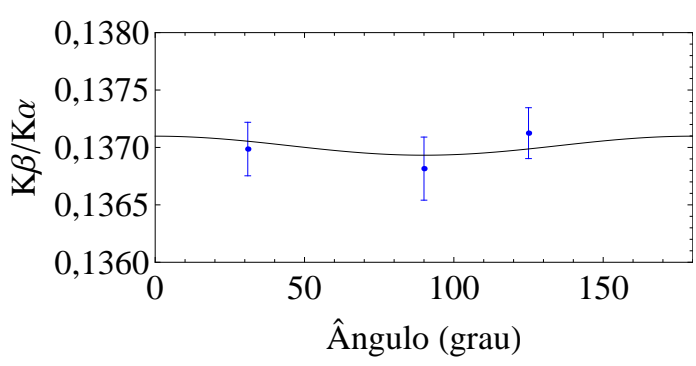

(a)

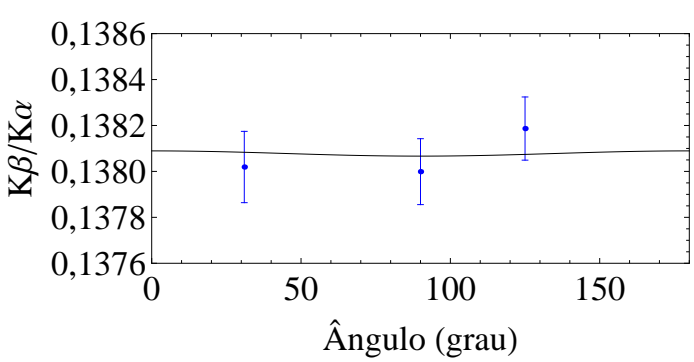

(b)

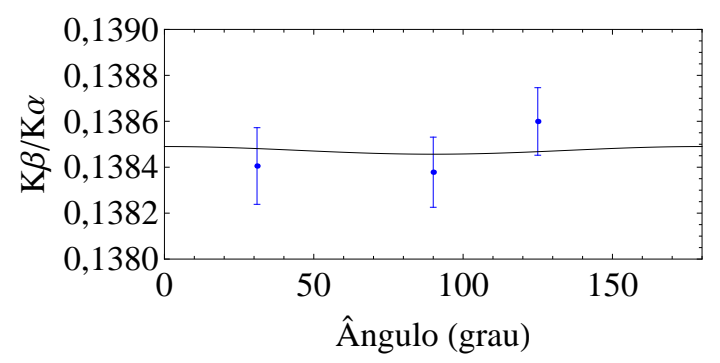

(c)

Figura 6.9: Pontos experimentais e curvas calculadas com os parâmetros estimados para o alvo de $\mathrm{Cu}$ nas energias de a) 11,51(6), b) 58,28(3), e c) $100,60(3) \mathrm{keV}$ para a razão das áreas $A_{\mathrm{K} \beta} / A_{\mathrm{K} \alpha}$ corrigidas pelas respectivas eficiências de pico.

\subsubsection{Análise com as linhas $\mathrm{L} \ell, \mathrm{L} \alpha_{1}$ e $\mathrm{L} \alpha_{2}$}

A estimativa do parâmetro de alinhamento foi realizada levando em conta as linhas L $\ell$, $\mathrm{L} \alpha_{1}$ e $\mathrm{L} \alpha_{2}$ simultaneamente na análise. As linhas do grupo L $\beta$ que provêm da subcamada $\mathrm{L}_{3}$, e que, teoricamente, devem apresentar emissão anisotrópica, não foram incluídas no procedimento por dois motivos. Primeiro, quando, além da subcamada $\mathrm{L}_{3}$, as $\mathrm{L}_{1}$ e $\mathrm{L}_{2}$ também são ionizadas, outras linhas do grupo L $\beta$ que provêm destas subcamadas estão presentes, e como elas apresentam emissão isotrópica e não estão bem resolvidas, poderiam afetar a estimativa das áreas com emissão anisotrópica. Depois, a linha $\mathrm{L} \beta_{2}$, que é a de maior intensidade do grupo $\mathrm{L} \beta$ com emissão anisotrópica, está próxima da linha $\mathrm{L} \beta_{15}$, cerca de 17, $9 \mathrm{eV}$ no $\mathrm{Au}$ e 12,5 eV no Ta [12], e apresenta anisotropia oposta à de $\mathrm{L} \beta_{15}$, fazendo com que a anisotropia efetiva do dubleto $\mathrm{L} \beta_{2,15}$ seja pequena, portanto, não traria 
informação significativa para estimativa do parâmetro $A_{20}$.

O procedimento empregado teve duas etapas. Na primeira delas, os parâmetros $a, b$, da expressão (3.40), com

$$
a=W_{0} / 4 \pi \quad \text { e } \quad b=\left(W_{0} / 4 \pi\right) \xi \alpha A_{20}
$$

foram estimados para as linhas $\mathrm{L} \ell, \mathrm{L} \alpha_{1}$ e $\mathrm{L} \alpha_{2}$ simultaneamente, levando em conta a correlação entre as estimativas de intensidade dessas linhas, que foi maior entre $\mathrm{L} \alpha_{1}$ e $\mathrm{L} \alpha_{2}$ para os elementos estudados, tabela 6.4.

O ajuste foi realizado com as áreas das linhas de interesse normalizadas pela carga e corrigidas pela eficiência do detetor e pelas perdas devido ao tempo morto durante a aquisição, expressão (3.31), fazendo-se a correção devido à anisotropia introduzida pelo arranjo experimental, com a área do dubleto $\mathrm{K} \alpha$ do elemento escolhido como referência, de acordo com

$$
\Upsilon_{\mathrm{X}, i}=\frac{v_{\mathrm{X}, i}}{v_{\mathrm{ref}}}=\frac{A_{\mathrm{X}, i}}{A_{\mathrm{ref}}} \frac{Q_{\mathrm{ref}}}{Q_{\mathrm{X}}} \frac{\varepsilon_{\mathrm{A}}\left(E_{\mathrm{ref}}\right)}{\varepsilon_{\mathrm{A}}\left(E_{\mathrm{X}, i}\right)} \frac{1-\phi_{\mathrm{ref}}}{1-\phi_{\mathrm{X}}} \frac{\nu_{\mathrm{ref}}}{\nu_{\mathrm{X}}}
$$

em que os sub índices $\mathrm{X}$ e ref representam o elemento estudado e o elemento empregado na normalização dos dados, respectivamente, $A_{\mathrm{X}, i}$ e $A_{\text {ref }}$ correspondem às áreas da linha L $i$ do elemento $\mathrm{X}$ e do dubleto $\mathrm{K} \alpha$ do elemento ref, respectivamente, $Q_{\mathrm{X}}$ e $Q_{\mathrm{ref}}$, e $\phi_{\mathrm{X}}$ e $\phi_{\text {ref }}$ correspondem à carga incidente e à fração de tempo morto na contagem de fótons durante a irradiação dos alvos do elementos $\mathrm{X}$ e ref, respectivamente, $\varepsilon_{\mathrm{A}}\left(E_{\mathrm{X}, i}\right)$ e $\varepsilon_{\mathrm{A}}\left(E_{\mathrm{ref}}\right)$ à eficiência de pico do detetor, para a linha $\mathrm{L} i$ do elemento $\mathrm{X}$, com energia $E_{\mathrm{X}, i}$, e para o dubleto $\mathrm{K} \alpha$ do elemento ref, com energia $E_{\text {ref }}$, respectivamente, e $\nu_{\text {ref }}$ e $\nu_{\mathrm{X}}$ correspondem à atenuação dos fótons nos alvos ref e X.

Uma vez que a expressão (3.40) apresenta uma dependência linear nos parâmetros $a$ e b, equação (6.13), o método dos mínimos quadrados foi empregado para estimá-los de acordo com a expressão (2.13). O vetor de dados $\Upsilon$ foi construído a partir dos valores de $\Upsilon_{\mathrm{X}, i}$ da expressão (6.14), onde $i=1,2,3$ corresponde às linhas $\mathrm{L} \ell, \mathrm{L} \alpha_{1}$ e $\mathrm{L} \alpha_{2}$, a matriz de planejamento $\mathbb{X}_{1}$ foi montada de acordo com a expressão (3.40), o vetor de parâmetros a ser estimado $p_{1}$ contém as estimativas dos parâmetros $a$ e $b$ para cada uma das três linhas estudadas do elemento $X$, e a matriz de variância e covariância $\mathbb{V}_{\Upsilon}$ dos dados do vetor $\Upsilon$ foi calculada pela propagação usual de incertezas da expressão (2.5). As matrizes do ajuste com a expressão (2.13) para o elemento X foram, portanto: 


$$
\Upsilon=\left(\begin{array}{c}
\Upsilon_{\mathrm{x}, \mathrm{L} \ell-31^{\circ}} \\
\Upsilon_{\mathrm{x}, \mathrm{L} \alpha_{1}-31^{\circ}} \\
\Upsilon_{\mathrm{x}, \mathrm{L} \alpha_{2}-31^{\circ}} \\
\Upsilon_{\mathrm{x}, \mathrm{L} \ell-90^{\circ}} \\
\Upsilon_{\mathrm{x}, \mathrm{L} \alpha_{1}-90^{\circ}} \\
\Upsilon_{\mathrm{x}, \mathrm{L} \alpha_{2}-90^{\circ}} \\
\Upsilon_{\mathrm{x}, \mathrm{L} \ell-125^{\circ}} \\
\Upsilon_{\mathrm{x}, \mathrm{L} \alpha_{1}-125^{\circ}} \\
\Upsilon_{\mathrm{x}, \mathrm{L} \alpha_{2}-125^{\circ}}
\end{array}\right), \quad \mathbb{X}_{1}=\left(\begin{array}{ccc}
M_{\mathrm{C} 1}\left(31^{\circ}\right) & M_{\mathrm{C} 2}\left(31^{\circ}\right) & M_{\mathrm{C} 3}\left(31^{\circ}\right) \\
M_{\mathrm{C} 1}\left(90^{\circ}\right) & M_{\mathrm{C} 2}\left(90^{\circ}\right) & M_{\mathrm{C} 3}\left(90^{\circ}\right) \\
M_{\mathrm{C} 1}\left(125^{\circ}\right) & M_{\mathrm{C} 2}\left(125^{\circ}\right) & M_{\mathrm{C} 3}\left(125^{\circ}\right)
\end{array}\right), \quad p_{1}=\left(\begin{array}{c}
a_{\mathrm{L} \ell} \\
b_{\mathrm{L} \ell} \\
a_{\mathrm{L} \alpha_{1}} \\
b_{\mathrm{L} \alpha_{1}} \\
a_{\mathrm{L} \alpha_{2}} \\
b_{\mathrm{L} \alpha_{2}}
\end{array}\right),
$$

com

$$
M_{C 1}=\left(\begin{array}{cc}
1 & P_{2}(\cos \theta) \\
0 & 0 \\
0 & 0
\end{array}\right), \quad M_{C 2}=\left(\begin{array}{cc}
0 & 0 \\
1 & P_{2}(\cos \theta) \\
0 & 0
\end{array}\right), \quad M_{C 3}=\left(\begin{array}{cc}
0 & 0 \\
0 & 0 \\
1 & P_{2}(\cos \theta)
\end{array}\right),
$$

e

$$
\mathbb{V}_{\Upsilon}=\mathbb{C} \mathbb{V}_{t} \mathbb{C}^{\mathrm{t}}
$$

em que $\mathbb{V}_{t}$ corresponde a matriz construída com as matrizes de variâncias e covariâncias das áreas das linhas $\mathrm{L} \ell, \mathrm{L} \alpha_{1}$ e $\mathrm{L} \alpha_{2}$ do elemento $\mathrm{X}, \mathbb{V}_{\mathrm{X}}$, e do dubleto $\mathrm{K} \alpha$ do elemento usado como referência, $\mathbb{V}_{\text {ref. }}$. Uma vez que o procedimento incluiu as três linhas L $\ell$, L $\alpha_{1}$ e $\mathrm{L} \alpha_{2}$ simultaneamente, $\mathbb{V}_{\mathrm{X}}$ será uma matriz diagonal em bloco, onde cada bloco traz a matriz de variâncias $\mathbb{V}_{\theta}$ das estimativas de intensidade das três linhas empregadas na análise obtidas durante a medição no ângulo $\theta$, e $\mathbb{V}_{\text {ref }}$ será uma matriz diagonal, sendo que cada elemento da diagonal traz a variância da área do dubleto K $\alpha$ medida no ângulo $\theta$, já que apenas uma linha deste elemento foi empregada na análise,

$$
\mathbb{V}_{t}=\left(\begin{array}{cc}
\mathbb{V}_{\mathrm{X}} & 0 \\
0 & \mathbb{V}_{\text {ref }}
\end{array}\right), \quad \mathbb{V}_{\mathrm{X}}=\left(\begin{array}{ccc}
\mathbb{V}_{31^{\circ}} & 0 & 0 \\
0 & \mathbb{V}_{90^{\circ}} & 0 \\
0 & 0 & \mathbb{V}_{125^{\circ}}
\end{array}\right)
$$

e $\mathbb{C}$ é a matriz de dimensão nove por doze que contém as derivadas de cada um dos nove quocientes que aparecem na matriz $\Upsilon$ com relaçao às doze áreas envolvidas no procedimento, a saber, as nove (três de cada ângulo) do elemento X e as três do elemento ref empregado na normalização.

O desvio padrão da carga foi inferior a 0,3\% em todas as irradiações, e uma vez que as cargas associadas a cada detetor são praticamente as mesmas, elas são altamente correlacionadas, de forma que a incerteza introduzida por elas na análise é pequena em relação as outras incertezas. 
As taxas de entrada $R_{\text {in }}$ foram mantidas sempre inferiores a cerca de $12 \mathrm{kHz}$, e como os espectros deste experimento são análogos aos "espectros L", definidos na seção 5.4.2, o modelo $\mathrm{SMP}_{f}$ é capaz de corrigir os espectros ao longo de toda a sua extensão com boa precisão, como mostra a figura A.4, não havendo a necessidade de empregar o modelo que leva em conta a dependência do tempo morto com a energia. Por outro lado, a figura A.2 mostra que para esse valor de taxa de aquisição a fração de tempo morto estimada com o modelo $\mathrm{SMP}_{f}$ é semelhante àquela fornecida pelo DPP, que é obtida com a expressão (5.16). Optamos por empregar esta expressão para estimar a fração do tempo morto de aquisição, o que forneceu valores inferiores a 6\%, com uma incerteza de cerca de 0,5\% [47], sendo assim a razão $\left(1-\phi_{\text {ref }}\right) /\left(1-\phi_{\mathrm{x}}\right)$ introduz uma incerteza inferior a $0,05 \%$, que pôde ser ignorada.

Por fim, o desvio padrão associado à razão das eficiências $\varepsilon_{\mathrm{A}}\left(E_{\mathrm{ref}}\right) / \varepsilon_{\mathrm{A}}\left(E_{\mathrm{X}, i}\right)$ foi uma ordem de grandeza inferior à incerteza das áreas dos picos, pelo menos, conforme pode ser visto nas tabelas 6.1, 6.2, 6.3 e 5.5. Como a mesma linha foi usada como referência, e portanto, a mesma $\varepsilon_{\mathrm{A}}\left(E_{\mathrm{ref}}\right)$ foi empregada para normalizar as linhas $\mathrm{L} \ell, \mathrm{L} \alpha_{1}$ e $\mathrm{L} \alpha_{2}$ em cada ângulo, as correlações dos dados normalizados foram importantes, fazendo com que a contribuição da incerteza da eficiência pudesse ser ignorada no cálculo.

Diante das estimativas dos desvios padrões apresentadas acima, optou-se por calcular a matriz de variância e covariância dos parâmetros estimados $\mathbb{V}_{p_{1}}$ de acordo com a expressão (2.14).

Na segunda etapa do procedimento, o vetor de parâmetros estimados previamente, $\hat{\Upsilon}$, foi empregado para estimar o produto $\xi A_{20}$, equação (3.40), levando em conta que

$$
\frac{b_{i}}{a_{i}}=\xi \alpha_{i} A_{20}
$$

onde o índice $i=1,2,3$ se refere às linhas $\mathrm{L} \ell, \mathrm{L} \alpha_{1}$ e $\mathrm{L} \alpha_{2}$, conforme definido anteriormente. $\mathrm{Na}$ equação $(6.15)$ o produto $\xi A_{20}$ apresenta uma dependência linear na expressão, e o método dos mínimos quadrados foi usado para estimá-lo. Nessa etapa, as matrizes que entraram na expressão (2.13) foram

$$
\mathcal{A}=\left(\begin{array}{c}
a_{\mathrm{L} \ell} \\
b_{\mathrm{L} \ell} / a_{\mathrm{L} \ell} \\
a_{\mathrm{L} \alpha_{1}} \\
b_{\mathrm{L} \alpha_{1}} / a_{\mathrm{L} \alpha_{1}} \\
a_{\mathrm{L} \alpha_{2}} \\
b_{\mathrm{L} \alpha_{2}} / a_{\mathrm{L} \alpha_{2}}
\end{array}\right), \quad \mathbb{X}_{2}=\left(\begin{array}{cccc}
1 & 0 & 0 & 0 \\
0 & 0 & 0 & \alpha_{\mathrm{L} \ell} \\
0 & 1 & 0 & 0 \\
0 & 0 & 0 & \alpha_{\mathrm{L} \alpha_{1}} \\
0 & 0 & 1 & 0 \\
0 & 0 & 0 & \alpha_{\mathrm{L} \alpha_{2}}
\end{array}\right), \quad p_{2}=\left(\begin{array}{c}
a_{\mathrm{L} \ell} \\
a_{\mathrm{L} \alpha_{1}} \\
a_{\mathrm{L} \alpha_{2}} \\
\xi A_{20}
\end{array}\right)
$$


$\mathrm{e}$

$$
\mathbb{V}_{\mathcal{A}}=\mathbb{C} \mathbb{V}_{p_{1}} \mathbb{C}^{\mathrm{t}}
$$

O vetor de dados $\mathcal{A}$ foi construído a partir do vetor de parâmetros ajustados $\hat{p}_{1}$ na primeira etapa, e a matriz de planejamento $\mathbb{X}_{2}$ a partir da expressão (6.15). A matriz de variância e covariância $\mathbb{V}_{\mathcal{A}}$ foi calculada de acordo com a expressão (2.5), sendo que neste caso a matriz $\mathbb{V}_{\mathrm{y}}$ da expressão (2.5) é a matriz $\mathbb{V}_{p_{1}}$ obtida na primeira etapa do procedimento, a matriz $\mathbb{C}$ contém as derivadas de cada um dos seis termos da matriz $\mathcal{A}$ em relação a cada um dos elementos do vetor $p_{1}$, e o parâmetro $\alpha_{i}$ foi calculado de acordo com a expressão (3.28). De forma análoga à primeira etapa do procedimento, a matriz de variância e covariância dos parâmetros estimados $\mathbb{V}_{p_{2}}$ foi calculada de acordo com a expressão (2.14).

A fim de avaliar a qualidade do ajuste, o qui quadrado, de cada uma das etapas individuais foi calculado de acordo com a expressão (2.11) e depois totalizado.

Conforme descrito no capítulo 4, durante a irradiação de cada alvo, a cada intervalo de uma hora foi feita uma medida curta com o alvo de $\mathrm{Cu}$ a fim de avaliar a anisotropia do arranjo experimental. Contudo, na normalização das linhas L estudadas, equação (6.14), foi usada a soma de todos os espectros de Cu obtidos durante a irradiação em cada energia. A fim de avaliar esse procedimento, a correção das anisotropias individuais foi realizada para o caso mais crítico durante a realização do experimento, que foi para a irradiação do alvo de Au com elétrons de $13 \mathrm{keV}$. Neste caso, a anisotropia do arranjo experimental variou de cerca $0,7 \%$ a $-0,1 \%$ de forma sistemática, sendo maior na primeira medida do dia e menor na última. A correção individual dos espectros foi realizada e o parâmetro de anisotropia estimado foi compatível com aquele obtido quando a normalização foi realizada com a soma de todos os espectros de $\mathrm{Cu}$ dentro de um desvio padrão. Devido a isto, optou-se por usar sempre a soma dos espectros de $\mathrm{Cu}$ ao longo da irradiação de cada energia.

Com o procedimento de duas etapas descrito nesta seção, foi possível estimar o produto $\xi A_{20}$ com sua respectiva incerteza, que será chamado neste trabalho de $A_{20}^{\text {raw }}$. O parâmetro $\xi$, que corresponde ao produto $q_{2} \kappa_{\mathrm{CK}}$, equações (3.40) e (3.55), será calculado nas seções seguintes de forma a ser possível estimar $A_{20}$, que será chamado aqui de $A_{20}^{\exp }$. O desvio padrão de $A_{20}^{\exp }$ foi calculado com a propagação usual de incerteza dos termos envolvidos, mas sem uma expressão que envolve as incertezas relativas. 


\subsection{Linhas e grupos com emissão isotrópica}

Uma vez que as linhas de raios x $\mathrm{L} \eta$ e $\mathrm{L} \gamma$ provêm de vacâncias criadas nas subcamadas $\mathrm{L}_{1}$ ou $\mathrm{L}_{2}$, o parâmetro $\alpha$ da expressão (3.28) é nulo, de forma que se espera uma estimativa de $\xi \alpha A_{20}$, expressão (6.15), compatível com zero. A expectativa de emissão isotrópica da linha $\mathrm{L} \eta$ e do multipleto $\mathrm{L} \gamma$ foi verificada pelo ajuste da expressão (3.40) aos dados experimentais, de forma análoga à primeira etapa do procedimento de análise descrito na seção anterior. Neste caso, o parâmetro $\Upsilon$ da equação (6.14) contém as áreas ou do pico $\mathrm{L} \eta$ ou do grupo $\mathrm{L} \gamma$ do elemento X para cada um dos três ângulos. Os parâmetros ajustados foram $a$ e $b$, definidos de acordo com (6.13), para a linha L $\eta$ e para o grupo L $\gamma$. Para verificar essa compatibilidade, um teste $z$ foi conduzido com o valor médio sobre todas as energias de irradiação do produto $\xi \alpha A_{20}$ para a linha $\mathrm{L} \eta$ e o grupo $\mathrm{L} \gamma$.

\subsection{Correções devido às transições Coster-Kronig}

O parâmetro $\kappa_{\mathrm{CK}}$ da expressão (3.44) foi estimado a partir das seções de choque $\sigma_{\mathrm{L}_{1}}$, $\sigma_{\mathrm{L}_{2}}$ e $\sigma_{\mathrm{L}_{3}}$ de ionização das subcamadas $\mathrm{L}_{1}, \mathrm{~L}_{2}$ e $\mathrm{L}_{3}$, respectivamente, calculadas com a aproximação de Born de ondas distorcidas, que é uma das mais confiáveis até o momento [124], e reproduz as seções de choque experimentais de ionização L do Au dentro de 10$15 \%$ [21]. Os coeficientes de Coster-Kronig foram extraídos do trabalho de Krause [31] para o Ta e o W, e de Kolbe et al. [30] para o Au. A tabela 6.6 traz os valores empregados, e a figura 6.10 traz as curvas de $\kappa_{\mathrm{CK}}$ versus a energia do feixe incidente para os três elementos no intervalo de energia de interesse deste trabalho.

A incerteza estimada para essa correção foi de aproximadamente $13 \%$, calculada com a propagação de incertezas usual adotando os desvios padrões fornecidas nas referências [30] e [31] para os coeficientes de Coster-Kronig, e atribuindo um desvio padrão relativo de $10 \%$ para as seções de choque de ionização das subcamadas L. Esse valor foi escolhido com base nos resultados experimentais de Barros el al. [21,48], que evidenciam uma diferença de cerca de $10 \%$ entre as seções de choque calculadas com a DWBA e os valores experimentais para o $\mathrm{Au}$. 
Tabela 6.6: Probabilidades de transições Coster-Kronig para os elementos Ta, W e Au, obtidas das referências Kolbe et al. [30] para o Au, e de Krause [31] para o Ta e o W. A incerteza de $f_{13}^{\prime}$ não foi divulgada pelos autores; foi escolhido um valor típico, mas arbitrário, que pode ser multiplicado por 10 e não afetará a incerteza do coeficiente $\kappa_{\mathrm{CK}}$.

\begin{tabular}{cllcc}
\hline \hline Set & \multicolumn{1}{c}{$f_{12}$} & \multicolumn{1}{c}{$f_{13}$} & \multicolumn{1}{c}{$f_{23}$} & $f_{13}^{\prime}$ \\
\hline Ta & $0,18(4)$ & $0,28(2)$ & $0,134(13)$ & $0,0026(3)$ \\
W & $0,17(3)$ & $0,28(2)$ & $0,133(13)$ & $0,0028(3)$ \\
$\mathrm{Au}$ & $0,064(40)$ & $0,524(75)$ & $0,180(40)$ & $0,0028(3)$ \\
\hline \hline
\end{tabular}

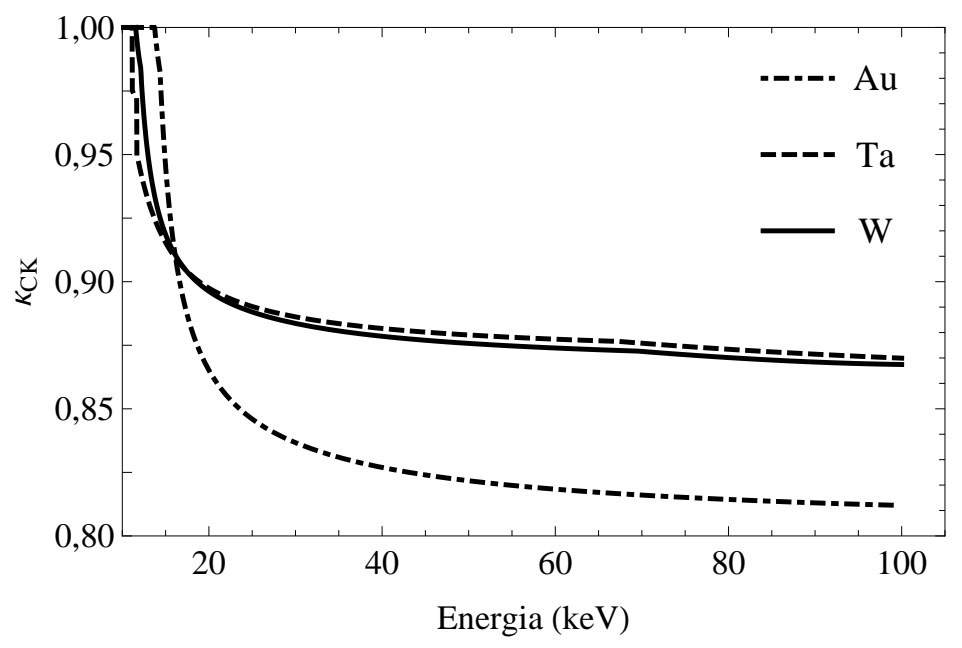

Figura 6.10: Fator de correção na distribuição angular devido às transições Coster-Kronig $\kappa_{\mathrm{CK}}$ em função da energia do feixe de elétrons, para Ta (linha tracejada), W (linha contínua) e Au (linha ponto tracejada).

\subsection{Correção devido à abertura do feixe de elétrons no alvo}

As funções densidade de probabilidade da abertura do feixe de elétrons dentro do alvo, subseção 3.5.2, foram calculadas levando-se em conta tanto o espalhamento elástico quanto o inelástico [125], empregando os modelos de Goudsmit e Saunderson [126,127] e SternheimerLiljequist, respectivamente. Os cálculos foram realizados de acordo com a referência [128], de onde também foram extraídas as seções de choque diferenciais de espalhamento elástico.

Considerou-se alvos de Ta, W e Au com densidades superficiais de massa de 19, $6 \mu \mathrm{g} / \mathrm{cm}^{2}$, $4,4 \mu \mathrm{g} / \mathrm{cm}^{2}$ e $11,7 \mu \mathrm{g} / \mathrm{cm}^{2}$, respectivamente, que correspondem às espessuras efetivas dos alvos de Ta, W e Au deste experimento, tabela 4.1, inclinados de $30^{\circ}$ com relação à direção do feixe incidente. 
Empregando as expressões deduzidas ao longo da seção 3.5.2, foi possível estimar a fração do feixe que passa pelo alvo sem nenhuma abertura, equação (3.48), o parâmetro $q_{2}$, equação (3.53), além da raiz quadrada do ângulo quadrático médio $\sqrt{\left\langle\theta^{2}\right\rangle}$. Os resultados obtidos para esses três parâmetros estão apresentados nas figuras 6.11 e 6.12 .

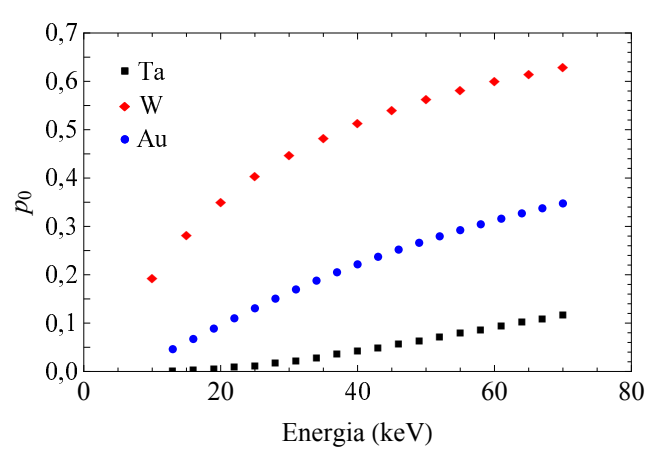

(a)

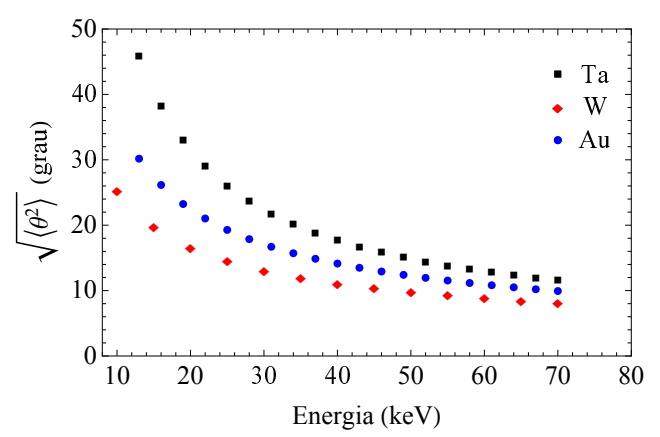

(b)

Figura 6.11: Características do feixe de elétrons ao atravessar o alvo: a) Fração do feixe que passa pelo alvo sem nenhuma abertura $\left(\mathrm{p}_{0}\right)$ em função da energia do elétron incidente, b) dependência do ângulo $\sqrt{\left\langle\theta^{2}\right\rangle}$ com a energia do elétron incidente, para os elementos Ta, W e Au.

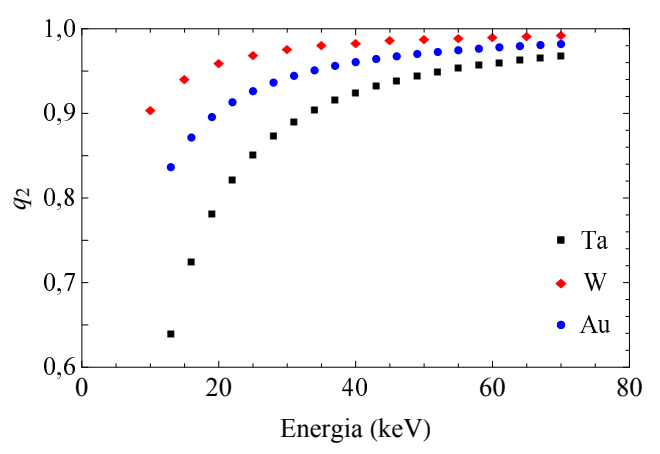

Figura 6.12: Dependência do parâmetro de atenuação da distribuição angular $q_{2}$, expressão (3.53), com a energia do elétron incidente, para os elementos Ta, W e Au.

A perda de energia do feixe de elétrons dentro do alvo não é levada em conta no cálculo do coeficiente $q_{2}$ com a equação (3.53). Nesta expressão, a integral em $\theta$ é calculada para $0 \leq \theta^{\prime} \leq \pi$. Quando $\theta^{\prime}$ assume valores pequenos, a perda de energia dos elétrons no alvo fino é pequena, contudo quando $\theta^{\prime}$ assume valores perto de $90^{\circ}$, a perda de energia dos elétrons no alvo é significativa e precisa ser considerada.

A fim de investigar a parcela do feixe de elétrons que sofre abertura próximo a $\pi / 2$, o intervalo de integração da expressão (3.53) foi dividido em duas regiões

$$
q_{2}^{\prime}=2 \pi\left(\int_{0}^{\frac{\pi}{2}-\delta} \mathrm{f}\left(\theta, \theta^{\prime}\right) P_{2}\left(\cos \theta^{\prime}\right) \sin \theta^{\prime} \mathrm{d} \theta^{\prime}+\int_{\frac{\pi}{2}+\delta}^{\pi} \mathrm{f}\left(\theta, \theta^{\prime}\right) P_{2}\left(\cos \theta^{\prime}\right) \sin \theta^{\prime} \mathrm{d} \theta^{\prime}\right)+\mathrm{A}
$$


e avaliado $\operatorname{com} \delta$ igual a $2^{\circ}, 5^{\circ}, 10^{\circ}, 20^{\circ}$ e $30^{\circ}$. A figura 6.13 mostra o resultado do quociente $q_{2}^{\prime} / q_{2}$, expressões (6.16) e (3.53), respectivamente. Quando as curvas da figura 6.13 são extrapoladas para as menores energias de irradiação do experimento deste trabalho, a saber, 10,75(9) keV para o Ta e 12, $19 \mathrm{keV}$ para o Au, nota-se que o caso mais crítico foi o do alvo de Ta, onde para a menor energia calculada e $\delta=30^{\circ}$ a diferença relativa entre os dois valores chegou a quase 10\%, nos demais casos essa diferença foi sempre inferior a $10 \%$. Estes resultados estão diretamente relacionados com as espessuras dos alvos empregados: quando ele é fino, o feixe de elétrons abre pouco dentro do alvo, de modo que a parcela do feixe que apresenta uma abertura entre $\pi / 2-\delta$ e $\pi / 2+\delta$ é pequena, e o fator $q_{2}$ pode ser avaliado com boa precisão por meio da expressão (3.53). Quando a espessura do alvo aumenta, a abertura dos elétrons dentro dele é maior, e o cálculo preciso de $q_{2}$ exige levar em conta a perda de energia dos elétrons dentro do alvo.

A fim de estimar uma incerteza para o parâmetro $q_{2}$, os resultados da figura 6.13 junto com as incertezas das espessuras do alvo foram considerados. Para tanto calculou-se a raiz da soma quadrática das diferenças relativas da figura 6.13, para as energias em que os alvos foram irradiados, com as incertezas relativas das espessuras dos alvos. As incertezas relativas de $q_{2}$ para o alvo de Ta variaram de $10,7 \%$ até $5,4 \%$, para $\mathrm{W}$ foi de $7,6 \%$ nas três energias, e para Au de 3,4\% até 2,9\%, sempre da menor para a maior energia de irradiação.

\subsection{Correções devido à atenuação dos fótons no alvo}

O modelo proposto na subseção 3.5.3 para a correção devido à atenuação dos fótons no alvo ignora a possibilidade de fótons espalhados em ângulos diferentes de $\theta$ atingirem o detetor, de modo que é conveniente verificar a qualidade dessa aproximação. Com este intuito, foram realizadas simulações com o programa PENELOPE [90], que supõe isotrópica a emissão das linhas características. Logo, qualquer anisotropia observada nas simulações será efeito da atenuação dos fótons dentro do alvo, ou da variação da seção de choque com a perda de energia dos elétrons no alvo. Uma vez que esta perda será mais acentuada para energias menores, foram feitas duas simulações para um feixe de elétrons de $13 \mathrm{keV}$ e para alvos de Au com densidades superficiais de 12 e $150 \mu \mathrm{g} / \mathrm{cm}^{2}$. Em ambos os casos, foram simulados $10^{10}$ fótons.

Os resultados são apresentados na figura 6.14 junto com a previsão da expressão (3.54), e mostram que essa expressão pode ser usada com boa aproximação para a correção das 


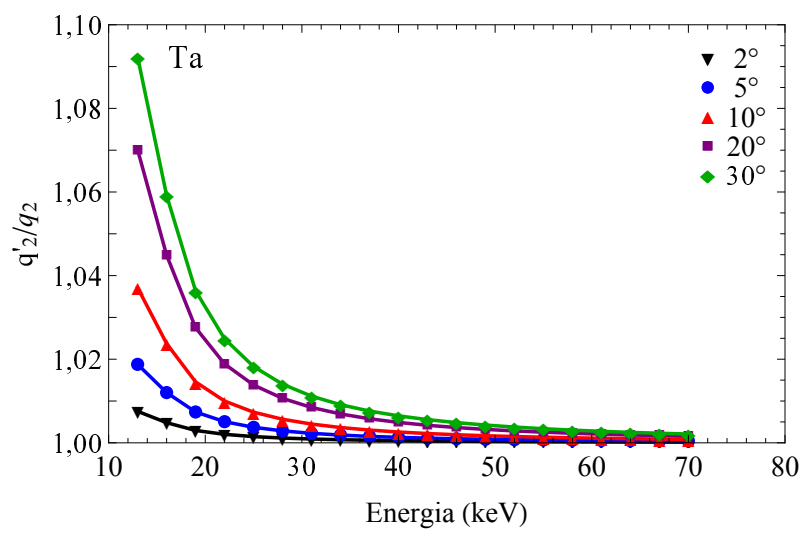

(a)

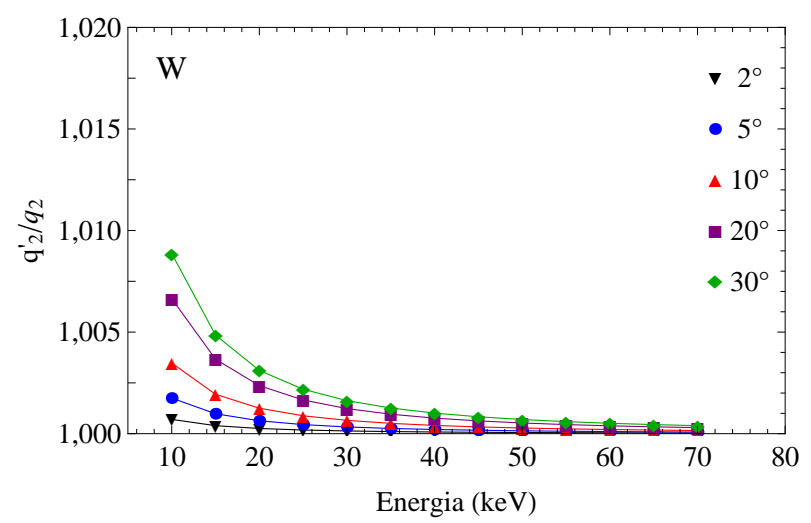

(b)

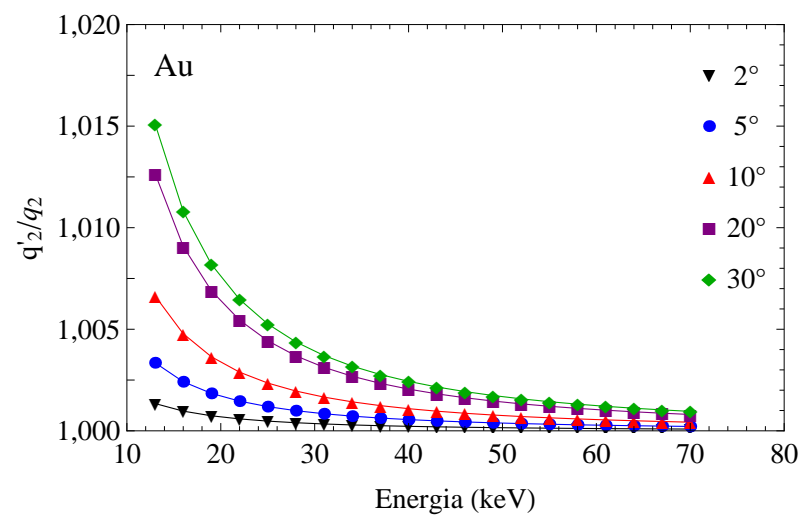

(c)

Figura 6.13: Quociente $q_{2}^{\prime} / q_{2}$, com as quantidades $q_{2}^{\prime}$ e $q_{2}$ calculadas de acordo com as expressões (6.16) e (3.53), respectivamente, para os alvos de: a) Ta, b) W e c) Au. 
intensidades experimentais, mesmo no caso em que a absorção dos fótons pelo alvo é expressiva, como pode ser visto na figura $6.14 \mathrm{~b}$ ). Além disso, até aproximadamente $70^{\circ}$ o alvo de $12 \mu \mathrm{g} / \mathrm{cm}^{2}$ não introduz nenhuma alteração na distribuição angular dos fótons detetados dentro das barras de incerteza, como mostra a figura 6.14 a). Diante desses resultados, a razão $\nu_{\text {ref }} / \nu_{\mathrm{X}}$ na expressão 6.14 foi considerada como sendo compatível com um, com incerteza de 0,002 para todas as energias de irradiação e alvos deste experimento.

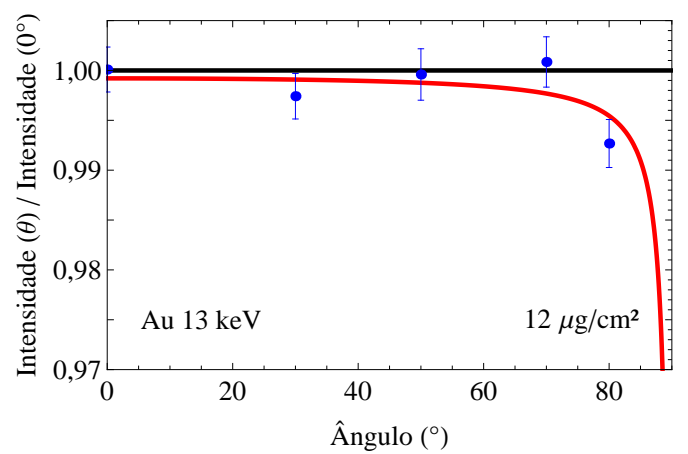

(a)

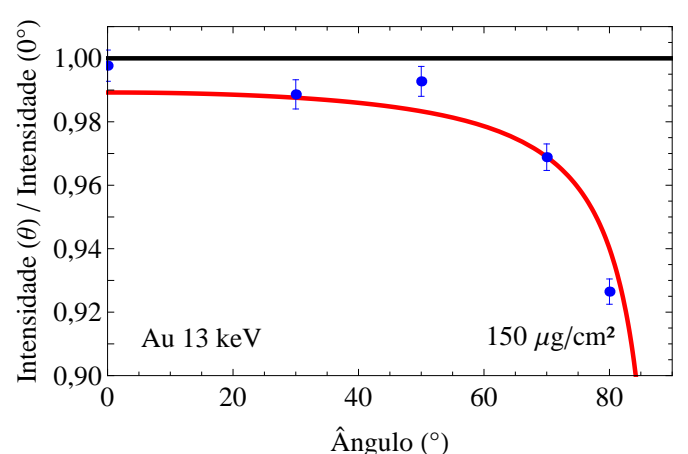

(b)

Figura 6.14: Fração dos raios x que conseguem escapar do alvo, sem espalhar inelasticamente, e atingir o detetor, fixo em uma posição $\theta$, para um feixe de elétrons de $13 \mathrm{keV}$ incidindo sobre um alvo de Au de a) $12 \mu \mathrm{g} / \mathrm{cm}^{2}$ e b) $150 \mu \mathrm{g} / \mathrm{cm}^{2}$. As barras de incerteza representam um desvio padrão, iguais a $0,2 \%$ e $0,4 \%$, nos gráficos a) e b), respectivamente.

\subsection{Seções de choque de produção de raios $\mathrm{x}$}

Quando os elétrons penetram em uma película autossustentável de um alvo seguindo uma trajetória retilínea e sem perda de energia, a seção de choque de produção de raio x $\sigma_{\mathrm{Lj}}^{\mathrm{x}}$ para um pico $\mathrm{L}_{\mathrm{j}}$ em uma irradiação com elétrons de energia $E$, pode ser escrita como:

$$
\sigma_{\mathrm{L} j}^{\mathrm{x}}(E)=\frac{N_{\mathrm{L} j}}{N_{\mathrm{e}}(\mathcal{N} d / \cos \theta) \varepsilon_{\mathrm{A}}\left(E_{\mathrm{L} j}\right)},
$$

onde $N_{\mathrm{L} j}$ é a área do pico L $j$ (com energia $\left.E_{\mathrm{L} j}\right), \mathcal{N}$ e $d$ são o número de átomos por unidade de volume e a espessura do alvo, respectivamente, $\theta$ é o ângulo de inclinação do alvo com relação ao feixe incidente, $N_{\mathrm{e}}$ é o número de elétrons incidentes e $\varepsilon_{\mathrm{A}}\left(E_{\mathrm{L} j}\right)$ é a eficiência de pico da linha com energia $E_{\mathrm{L} j}$. Na equação (6.17) é suposto que as linhas de raios x L apresentam emissão isotrópica, mesmo aquelas que resultam do preenchimento de vacâncias geradas na subcamada $L_{3}$. Os parágrafos seguintes descrevem brevemente como foi avaliado cada um dos parâmetros da expressão (6.17).

O ajuste dos picos do multipleto L foi conduzido conforme apresentado na seção 6.2, 
sendo que foram incluídas somente as linhas $\mathrm{L} \ell, \mathrm{L} \eta$, as do dubleto $\mathrm{L} \alpha$ e as do multipleto $\mathrm{L} \gamma$, ver tabela 2.1 .

As áreas do dubleto $\mathrm{L} \alpha$ e do grupo $\mathrm{L} \gamma$ foram estimadas somando-se as áreas dos picos que compõem esses grupos e, em ambos os casos, os desvios padrões foram calculadas levando-se em conta as covariâncias entre as estimativas das áreas envolvidas. A área L $\beta$ foi estimada pela soma das contagens na região deste multipleto, subtraindo-se o fundo correspondente, que foi calculado com os parâmetros da componente contínua do espectro ajustados aos dados experimentais.

A eficiência de pico foi calculada com o procedimento descrito na seção 5.2, e, de modo análogo ao procedimento adotado na análise dos dados do experimento de distribuição angular, as perdas por tempo morto ao longo das aquisições foram avaliadas com a expressão (5.16).

O alvo de Au empregado no experimento de seção de choque corresponde ao alvo de número 2 da figura 4.9. Sua caracterização foi realizada como descrito na seção 4.2, e o valor obtido para sua densidade superficial foi de $9,6(5) \mu \mathrm{g} / \mathrm{cm}^{2}$.

Quando os elétrons atingem um alvo sólido, eles sofrem colisões inelásticas e elásticas que mudam sua energia e direção de propagação. Em particular, isso faz com que o comprimento do caminho efetivo do feixe de elétrons dentro do alvo seja ligeiramente maior do que $d / \cos \theta$. A fim de estimar o fator multiplicativo que faz essa correção, foram realizadas simulações Monte Carlo com o código PENELOPE [90]. A figura 6.15 mostra o fator de correção simulado para o alvo de Au com $\rho d=9,6(5) \mu \mathrm{g} / \mathrm{cm}^{2}$ e $\theta=30^{\circ}$ em função da energia do feixe de elétrons incidente.

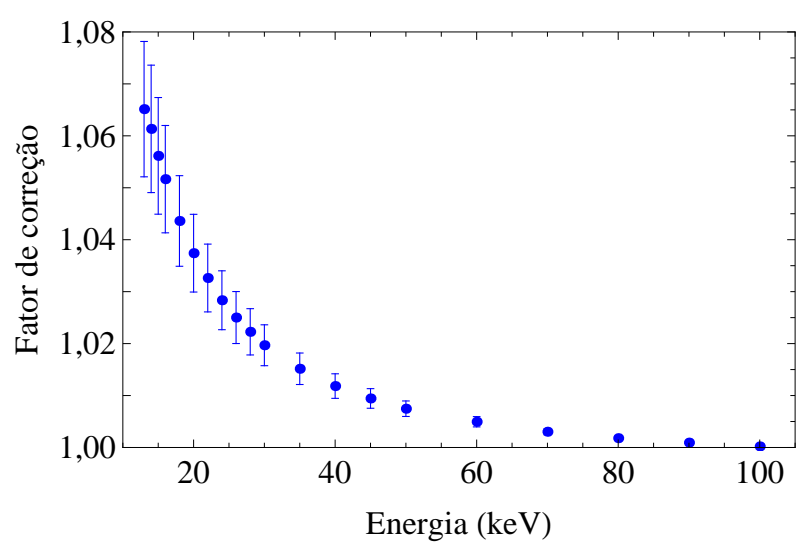

Figura 6.15: Razão entre o comprimento do caminho efetivo dos elétrons e a espessura do alvo, calculada para um alvo de Au com densidade superficial de 9,6(5) $\mu \mathrm{g} / \mathrm{cm}^{2}$ e inclinado de $30^{\circ}$ com relação à direção do feixe incidente, em função da energia do feixe de elétrons incidente. 


\subsection{Seções de choque de ionização das subcamadas L}

Com os procedimentos descritos na seção anterior, foi possível estimar as seções de choque de produção de raios x $\mathrm{L} \alpha, \mathrm{L} \beta, \mathrm{L} \gamma_{1}, \mathrm{~L} \gamma_{2,3,6}, \mathrm{~L} \gamma_{4,4^{\prime}}, \mathrm{L} \gamma_{5}$, L $\ell$ and $\mathrm{L} \eta$. Todas essas foram usadas para estimar as seções de choque de ionização das subcamadas $L_{1}, L_{2}$ e $L_{3}$ empregando a metodologia já detalhada em Barros et al. [21,98], e que será descrita aqui sucintamente.

As seções de choque de produção de raios x $\mathrm{L} \alpha, \mathrm{L} \beta, \mathrm{L} \gamma_{1}, \mathrm{~L} \gamma_{2,3,6}, \mathrm{~L} \gamma_{4,4^{\prime}}, \mathrm{L} \gamma_{5}$, L $\ell$ e $\mathrm{L} \eta$ se relacionam com as seções de choque de ionização das subcamadas $\mathrm{L}, \sigma_{\mathrm{L}_{1}}, \sigma_{\mathrm{L}_{2}}$ e $\sigma_{\mathrm{L}_{3}}$, por meio das seções de choque de produção de uma vacância $\sigma_{\mathrm{L}_{1}}^{\mathrm{h}}, \sigma_{\mathrm{L}_{2}}^{\mathrm{h}}$ e $\sigma_{\mathrm{L}_{3}}^{\mathrm{h}}$ nas subcamadas $\mathrm{L}_{1}, \mathrm{~L}_{2}$ e $\mathrm{L}_{3}$, respectivamente, definidas nas equações (3.41), (3.42) e (3.43), de acordo com as expressões,

$$
\begin{aligned}
\sigma_{\mathrm{L} \alpha}^{\mathrm{x}} & =\frac{\Gamma_{\mathrm{L}_{3} \mathrm{M}_{4,5}}}{\Gamma_{3, \text { tot }}} \omega_{3} \sigma_{\mathrm{L}_{3}}^{\mathrm{h}}, \\
\sigma_{\mathrm{L} \beta}^{\mathrm{x}} & =\frac{\Gamma_{1 \beta}}{\Gamma_{1, \text { tot }}} \omega_{1} \sigma_{\mathrm{L}_{1}}^{\mathrm{h}}+\frac{\Gamma_{2 \beta}}{\Gamma_{2, \text { tot }}} \omega_{2} \sigma_{\mathrm{L}_{2}}^{\mathrm{h}}+\frac{\Gamma_{3 \beta}}{\Gamma_{3, \text { tot }}} \omega_{3} \sigma_{\mathrm{L}_{3}}^{\mathrm{h}}, \\
\sigma_{\mathrm{L} \gamma_{1}}^{\mathrm{x}} & =\frac{\Gamma_{\mathrm{L}_{2} \mathrm{~N}_{4}}}{\Gamma_{2, \text { tot }}} \omega_{2} \sigma_{\mathrm{L}_{2}}^{\mathrm{h}}, \\
\sigma_{\mathrm{L} \gamma_{2,3,6}}^{\mathrm{x}} & =\frac{\Gamma_{\mathrm{L}_{1} \mathrm{~N}_{2,3}}}{\Gamma_{1, \text { tot }}} \omega_{1} \sigma_{\mathrm{L}_{1}}^{\mathrm{h}}+\frac{\Gamma_{\mathrm{L}_{2} \mathrm{O}_{4}}}{\Gamma_{2, \text { tot }}} \omega_{2} \sigma_{\mathrm{L}_{2}}^{\mathrm{h}}, \\
\sigma_{\mathrm{L} \gamma_{4,4^{\prime}}}^{\mathrm{x}} & =\frac{\Gamma_{\mathrm{L}_{1} \mathrm{O}_{2,3}}}{\Gamma_{1, \text { tot }}} \omega_{1} \sigma_{\mathrm{L}_{1}}^{\mathrm{h}}, \\
\sigma_{\mathrm{L} \gamma_{5}}^{\mathrm{x}} & =\frac{\Gamma_{\mathrm{L}_{2} \mathrm{~N}_{1}}}{\Gamma_{2, \text { tot }}} \omega_{2} \sigma_{\mathrm{L}_{2}}^{\mathrm{h}}, \\
\sigma_{\mathrm{L} \ell}^{\mathrm{x}} & =\frac{\Gamma_{\mathrm{L}_{3} \mathrm{M}_{1}}}{\Gamma_{3, \text { tot }}} \omega_{3} \sigma_{\mathrm{L}_{3}}^{\mathrm{h}}, \\
\sigma_{\mathrm{L} \eta}^{\mathrm{x}} & =\frac{\Gamma_{\mathrm{L}_{2} \mathrm{M}_{1}}}{\Gamma_{2, \text { tot }}} \omega_{2} \sigma_{\mathrm{L}_{2}}^{\mathrm{h}},
\end{aligned}
$$

onde $\omega_{i}$ é o yield fluorescente da subcamada $\mathrm{L}_{i}, \Gamma_{i \beta}$ são as taxas de emissão para as transições que pertencem ao grupo $\mathrm{L} \beta, \Gamma_{\mathrm{L}_{i}(\mathrm{M}, \mathrm{N}, \mathrm{O})_{j}}$ são as taxas de emissão para as transições do tipo $\mathrm{L}_{i}(\mathrm{M}, \mathrm{N}, \mathrm{O})_{j}$, e $\Gamma_{i \text {,tot }}$ é a soma das taxas de emissão para todas as transições possíveis para a subcamada $\mathrm{L}_{i}$.

Como descrito em Barros et al. [21], as seções de choque de produção de raios x das equações de (6.18) a (6.25) podem ser escritas na forma matricial da equação (2.10), com 
o vetor $\vec{y}$ construído com os dados de seções de choque de produção de raios $\mathrm{x}$, o vetor $\hat{\vec{p}}$ com as seções de choque de ionização das subcamadas $\mathrm{L}_{1}, \mathrm{~L}_{2}$ e $\mathrm{L}_{3}$, a serem estimadas, e a matriz $\mathbb{X}$ com os yields fluorescentes, as taxas de emissões e os coeficientes de CosterKronig, de acordo com as equações de (6.18) a (6.25) e as expressões (3.41), (3.42) e (3.43). Conseqüentemente, as estimativas das seções de choque de ionização das subcamadas $\mathrm{L}_{1}$, $\mathrm{L}_{2}$ e $\mathrm{L}_{3}$ podem ser calculadas com a expressão (2.13), em que a matriz $\mathbb{V}$ será construída com as variâncias dos dados que compõem o vetor $\vec{y}$.

Para a estimativa da matriz de variâncias e covariâncias dos dados do vetor $\hat{\vec{p}}$, deve-se lembrar que, como os parâmetros atômicos que entram nas expressões de (6.18) a (6.25) têm incertezas, elas devem ser propagadas para as variâncias do vetor de parâmetros estimados $\hat{\vec{p}}$, assim $\mathbb{V}_{\hat{\vec{p}}}$ será dada pela soma das expressões $(2.5)$ e (2.14), onde a matriz $\mathbb{C}$ da expressão (2.5) será construída com as derivadas de cada uma das seções de choque $\sigma_{\mathrm{L}_{1}}, \sigma_{\mathrm{L}_{2}}$ e $\sigma_{\mathrm{L}_{3}}$ em relação a cada um dos parâmetros atômicos.

É importante destacar que, quando a energia do elétron incidente é maior do que a energia de ionização da camada $\mathrm{K}$ do elemento estudado (no caso do $\mathrm{Au}, E_{\mathrm{K}}=80,7 \mathrm{keV}$ [12]), a migração da vacância da camada K para qualquer uma das subcamadas L deve ser considerada. Neste experimento, para $E=90$ e $100 \mathrm{keV}$ a seção de choque de ionização da camada $\mathrm{K}, \sigma_{\mathrm{K}}$ foi adicionada ao vetor $\hat{\vec{p}}$ de parâmetros a serem estimados, e no vetor coluna $\vec{y}$ foram adicionadas as seções de choque de produção de raios x $\mathrm{K} \alpha_{1,2}$ e $\mathrm{K} \beta_{1,3}$. Contudo, o SDD empregado neste experimento tem baixa eficiência na região de energia dos dubletos $\mathrm{K} \alpha_{1,2}$ e $\mathrm{K} \beta_{1,3}$ do $\mathrm{Au}\left(E_{\mathrm{K} \alpha_{1,2}}=68,1 \mathrm{keV}, E_{\mathrm{K} \beta_{1,3}}=77,3 \mathrm{keV}\right.$ [12]). Assim, para essas duas energias do experimento, as seções de choque de produção de raios $\mathrm{x} K \alpha_{1,2}$ e $\mathrm{K} \beta_{1,3}$ foram obtidas pela interpolação dos dados de Fernández-Varea et al. [38]; os valores adotados para $\sigma_{\mathrm{K} \alpha_{1,2}}^{\mathrm{x}}$ e $\sigma_{\mathrm{K} \beta_{1,3}}^{\mathrm{x}}$ foram de $1,38 \mathrm{~b}$ e $0,30 \mathrm{~b}$ para $90,06 \mathrm{keV}$ e $2,45 \mathrm{~b}$ e $0,51 \mathrm{~b}$ para $100,15 \mathrm{keV}$, respectivamente.

As seções de choque de ionização atômica foram calculadas empregando os parâmetros atômicos de acordo com: yields fluorescentes e coeficientes de Coster-Kronig extraídos de Kolbe et al. [30], probabilidades de transferência de vacância radiativa e não radiativa da camada K para as subcamadas $\mathrm{L}_{i}$ calculadas com Scofield [121] e Rao [129], respectivamente, e as taxas de emissão tabuladas por Campbell e Wang [87]. As probabilidades de transferência de vacância de Scofield [121] apresentam incertezas da ordem de 2\%. A fração da contribuição Auger em $\eta_{\mathrm{KL}_{i}}$, equações (3.41), (3.42) e (3.43), introduzem uma incerteza da ordem de $15 \%$ [129]. 



\section{Capítulo 7}

\section{Cálculo teórico do parâmetro de alinha- mento}

Neste capítulo, será apresentado o procedimento empregado no cálculo do parâmetro de alinhamento conforme desenvolvido no capítulo 3. Os procedimentos implementados no programa que calcula o parâmetro de alinhamento serão discutidos na primeira seção. Na seqüência, serão apresentados os resultados para os elementos $\mathrm{Mg}$, Ar e Xe, a fim de avaliar se eles são compativeis com os da literatura. Por fim, estão detalhados os cálculos para os elementos e energias de interesse deste trabalho.

\subsection{Implementação do programa de alinhamento}

As expressões de (3.32) a (3.37) foram programadas no software Mathematica 10.1, que já conta com as funções esféricas de Bessel, os coeficientes $3 j$ e os $6 j$ de Wigner, e os coeficientes de Clebsch-Gordan implementados.

A soma no número quântico de momento angular da onda parcial $l^{\prime}$ na expressão (3.33) foi realizada com todos os valores necessários para garantir a convergência do somatório com a precisão de interesse para este trabalho. Para baixas energias do elétron incidente, $l^{\prime}$ foi até 2 , enquanto que para energias cerca de dez vezes a energia do limiar de ionização $E_{\mathrm{L}_{3}}$ ele foi até 20 .

As funções de onda dos estados livre e ligado foram geradas com o programa RADIAL [130] empregando o mesmo potencial para ambos os estados com o intuito de garantir a 
ortogonalidade das funções de onda, sendo que os cálculos para os elementos Ta, W e $\mathrm{Au}$ foram realizados com potenciais calculados na aproxmiação de Hartree-Slater (HS), não relativístico [43], e de Dirac-Hartree-Slater (DHS), que é relativístico [44, 45]; este último foi calculado com o programa desenvolvido por F. Salvat e J. M. Fernández-Varea [131]. Para ambos os potenciais, as energias de ionização da subcamada $\mathrm{L}_{3}$ dos elementos estudados foram extraídas da referência Deslattes et al. [12], conforme apresentado na tabela 2.4 .

\subsubsection{Cálculo do elemento de matriz}

O cálculo da integral na expressão (3.37) envolve as funções $P_{\epsilon l^{\prime}}(r)$ e $P_{n l}(r)$, que descrevem o elétron livre e ligado, respectivamente, e as funções esféricas de Bessel de ordem $\lambda$, $j_{\lambda}(q r)$, que são oscilatórias no infinito. A integração em $r$, que se estende desde de zero até infinito, pode apresentar problemas de convergência, além de consumir muito tempo de cálculo. Neste trabalho, ela foi calculada de duas formas diferentes a fim de avaliar a precisão dos resultados.

As funções de onda dos estados livre e ligado fornecidas pelo programa RADIAL apresentam uma grade de valores de $r$ em unidades de $a_{0}$ com um espaçamento que não é constante. Para pequenos valores de $r, r \approx 10^{-1} a_{0}$, esse espaçamento é de $\approx 10^{-7} a_{0}$, e na região de altos valores de $r \approx 10^{3} a_{0}$, ele é da ordem de $1 a_{0}$. Esse pequeno espaçamento permite que as funções sejam interpoladas e integradas numericamente com razoável precisão. Assim, o produto $P_{\epsilon l^{\prime}}(r) j_{\lambda}(q r) P_{n l}(r)$ foi calculado, interpolado e integrado numericamente com a função NIntegrate do software Mathematica 10.1.

Como outra opção, essa integral também pode ser calculada empregando a técnica de quadratura cúbica de Hermite [132], com

$$
I=\int_{x_{1}}^{x_{2}} f(x) \mathrm{d} x=\sum_{i=1}^{n}\left(\alpha_{i} y_{i}+\beta_{i} d_{i}\right)+R
$$

em que $x_{i}$ são valores das abscissas nos quais a função $f(x)$ é calculada, $y_{i}=f\left(x_{i}\right)$, $d_{i}=f^{\prime}\left(x_{i}\right), R$ é o erro associado ao método da integração numérica, e

$$
\alpha_{i}= \begin{cases}\left(x_{2}-x_{1}\right) / 2 & \text { se } i=1, \\ \left(x_{i+1}-x_{i-1}\right) / 2 & \text { se } 1<i<n, \\ \left(x_{n}-x_{n-1}\right) / 2 & \text { se } i=n,\end{cases}
$$




$$
\beta_{i}= \begin{cases}\left(x_{2}-x_{1}\right)^{2} / 12 & \text { se } i=1 \\ \left(x_{i+1}-x_{i-1}\right)\left(x_{i+1}-2 x_{i}+x_{i-1}\right) / 12 & \text { se } 1<i<n \\ -\left(x_{n}-x_{n-1}\right)^{2} / 12 & \text { se } i=n\end{cases}
$$

\subsubsection{Integração no momento e na energia do elétron ejetado}

A integral no momento transferido $q$ e na energia cinética do elétron ejetado $\epsilon$ foi realizada pelo método da quadratura de Gauss, onde

$$
\int_{a}^{b} f(x) \mathrm{d} x \approx \sum_{i=1}^{n} w_{i} f\left(x_{i}\right)
$$

com $w_{i}$ os pesos associados a cada um dos valores das abscissas $x_{i}$. Tanto os valores de $x_{i}$ quanto de $w_{i}$ foram calculados com a função GaussianQuadratureWeights já incorporada no software Mathematica 10.1.

A fim de determinar a integral com precisão conhecida foi empregado o método adaptativo [132]. Em um algoritmo adaptativo busca-se uma estimativa $\hat{I}$ para o valor da integral $I$, com um erro $R$ menor do que um certo valor pré-fixado $r$,

$$
|\hat{I}-I|=R<r
$$

A rotina do cálculo é composta por um módulo local de quadratura (MLQ), que fornece uma estimativa da integral da função de interesse $f(x)$, no respectivo intervalo $a<x<b$, seguida de um algoritmo que divide o intervalo inicial de integração $[a, b]$ em vários subintervalos, cada um deles tratado com o MLQ criado inicialmente, com o intuito de alcançar um valor para a estimativa $\hat{I}$ com erro inferior a $r$. Neste trabalho, empregou-se no MLQ uma quadratura de Gauss com $n=5$ pontos, e fixou-se $r$ em $10^{-2}$, a fim de garantir um valor com boa precisão, dentro de um tempo de cálculo razoável.

\subsection{Comparação com os resultados de Mg, Ar e Xe já publicados}

Em Berezhko et al. [14] são apresentadas curvas para o parâmetro $A_{20}^{q}$ em função de $q$ para várias energias do elétron ejetado $\epsilon$, com 


$$
A_{20}(q, \epsilon)=\frac{F_{2} / P_{2}\left(\cos \theta_{\mathrm{r}}\right)}{F_{0} / P_{0}\left(\cos \theta_{\mathrm{r}}\right)}
$$

Uma vez que a dependência na energia do elétron incidente $E_{0}$ em $F_{k}$ está no ângulo $\theta_{\mathrm{r}}$ entre o momento transferido e a direção do feixe incidente, as curvas de $A_{20}(q, \epsilon)$ em função do momento transferido $q$ serão universais, no sentido de que elas são independentes da energia do elétron incidente.

A figura 7.1 traz os valores de $A_{20}(q, \epsilon)$ em função de $q$ para as energias do elétron ejetado $\epsilon=0,01 ; 0,5 ; 2$ e 5 Ry empregando o potencial de HS [43] para o Ar. Em linha contínua estão os valores obtidos da leitura dos gráficos de Berezhko et al. [14], e em linha tracejada os valores calculados com o programa desenvolvido.

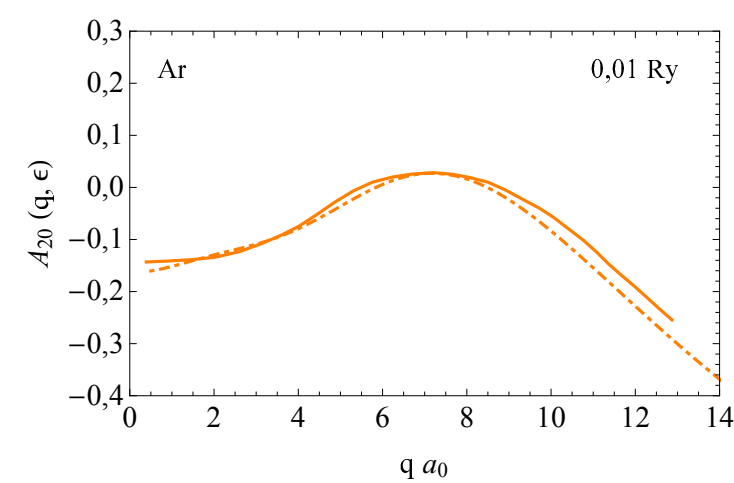

(a)

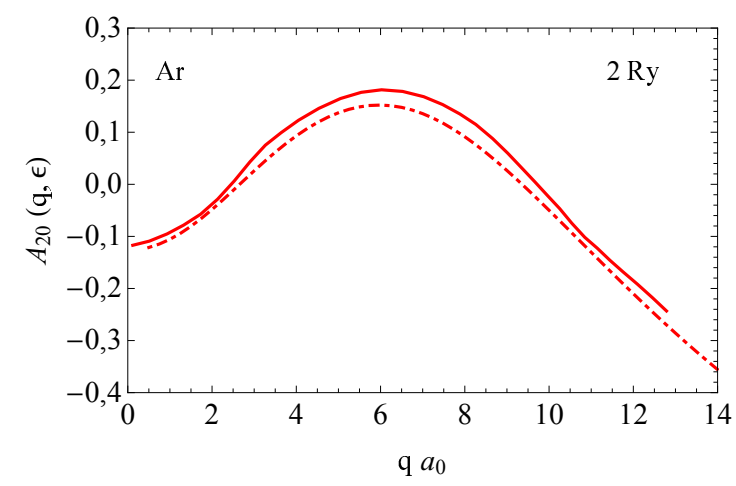

(c)

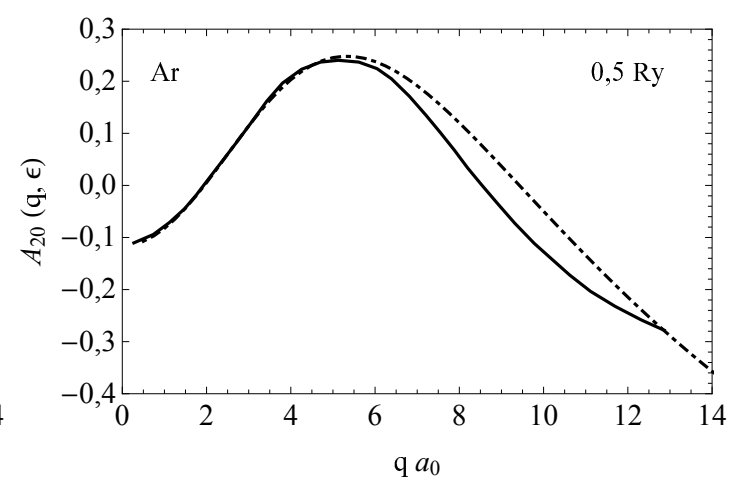

(b)

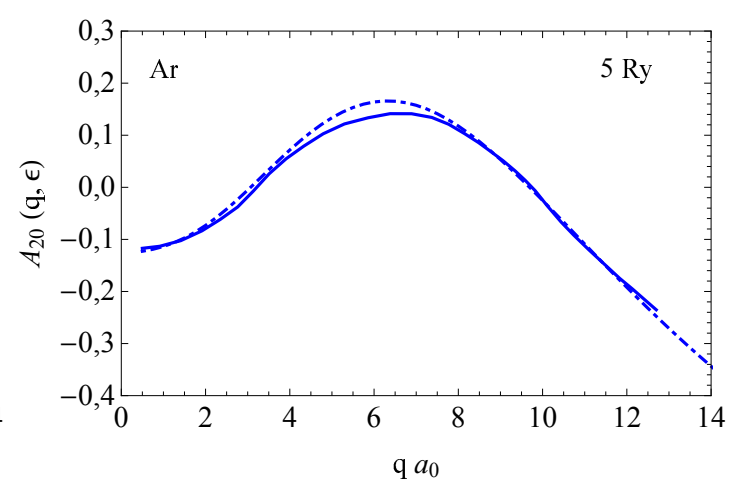

(d)

Figura 7.1: Dependência da função $A_{20}(q, \epsilon)$, equação (7.3), com o momento transferido $q$ para a subcamada $2 \mathrm{p}_{3 / 2}$ do Ar, com energias do elétron ejetado $\epsilon$ de: a) 0,01 Ry, b) 0, 5 Ry, c) 2 Ry e d) 5 Ry. A curva contínua corresponde ao cálculo da publicação [14], e a ponto-tracejada aos cálculos deste trabalho.

Berezhko et al. [15] traz curvas do parâmetro de alinhamento $A_{20}$ para átomos de $\operatorname{Mg}(Z=12)$ e $\operatorname{Ar}(Z=18)$ que tiveram um elétron da subcamada $2 \mathrm{p}_{3 / 2}$ removido. O cálculo foi realizado de acordo com a expressão (3.28) com os tensores $\rho_{k \kappa}$ calculados de acordo com a expressão (3.32). A figura 7.2 traz as curvas dessa publicação junto com 
alguns pontos, que correspondem aos resultados obtidos nesta pesquisa com o programa desenvolvido.

Na referência Küst e Mehlhorn [3] são apresentados valores do parâmetro de $A_{20}$ do Xe para três energias do elétron incidente: $5 ; 5,438$ e 6,0 keV. Segundo os autores os valores foram calculados empregando a aproximação de Born de ondas planas, mas nada é dito acerca dos potenciais empregados e da quantidade de ondas parciais incluídas no cálculo. Com o programa desenvolvido, foi calculado o parâmetro $A_{20}$, com os potenciais atômicos calculados na aproximação de HS e DHS; os resultados obtidos estão apresentados na tabela 7.1 junto com os valores da referência Küst e Mehlhorn [3].

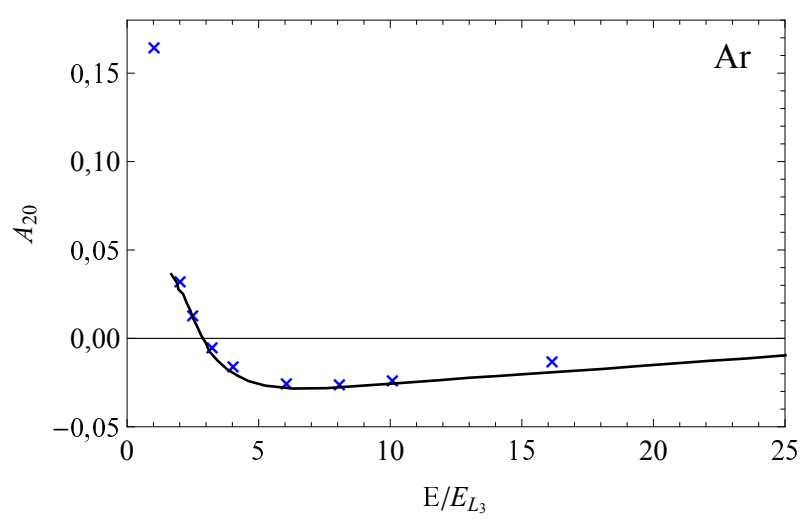

(a)

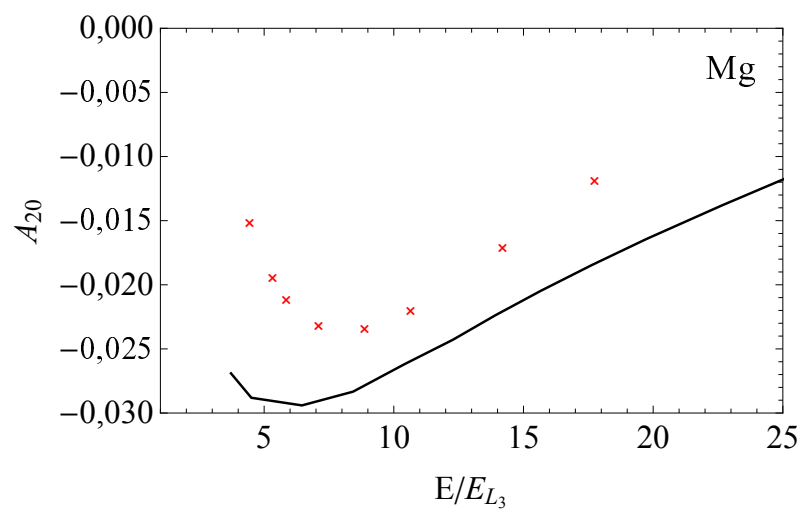

(b)

Figura 7.2: Parâmetro de alinhamento $A_{20}$ em função da energia do elétron incidente em unidades da energia do limiar de ionização $E_{\mathrm{L}_{3}}$ do a) Ar e b) $\mathrm{Mg}$ para uma vacância criada na subcamada $2 \mathrm{p}_{3 / 2}$ dos elementos. A curva contínua foi obtida da referência [15] e os pontos em forma de $\times$ correspondem aos resultados dos cálculos deste trabalho.

Os cálculos para o átomo de Ar, apresentados nas figuras 7.1 e 7.2 a), mostram bom acordo com os publicados em Berezhko et al. [14,15]. Uma vez que essas referências não trazem os valores em tabelas, não é possível saber exatamente para quais valores de q $a_{0}$ o parâmetro $A_{20}^{q}$ foi calculado, e em que regiões ele foi interpolado. Isso pode justificar as pequenas diferenças observadas nas curvas da figura 7.1. Por outro lado, a 
Tabela 7.1: Valores do parâmetro de alinhamento $A_{20}$ do Xe para as energias da referência Küst e Mehlhorn [3] e calculados com o programa deste trabalho empregando as aproximações de HS e DHS para descrever o potencial atômico.

\begin{tabular}{cccc}
\hline \hline & $5,0 \mathrm{keV}$ & $5,438 \mathrm{keV}$ & $6,0 \mathrm{keV}$ \\
\hline Küst e Mehlhorn & 0,117 & 0,093 & 0,071 \\
Este trabalho (HS) & 0,114 & 0,097 & 0,079 \\
Este trabalho (DHS) & 0,117 & 0,100 & 0,081 \\
\hline \hline
\end{tabular}

figura 7.2 b) deixa evidente a grande diferença entre os valores da referência Berezhko et al. [15] e os calculados neste trabalho para o átomo de Mg. Por se tratar de um átomo leve, os elétrons na camada $2 \mathrm{p}_{3 / 2}$ estão fracamente ligados. Isso faz com que a função de onda desses elétrons atinja maiores valores de $r$ quando comparada com a do Ar, o que pode exigir cálculos numéricos mais detalhados. A comparação dos valores deste trabalho com os da referência Küst e Mehlhorn [3], tabela 7.1, para o átomo de Xe $(Z=54)$ evidencia um bom acordo; como não foi informado o potencial empregado nos cálculos, não é possível afirmar se as pequenas diferenças observadas são decorrentes do potencial ou do programa.

Uma vez que encontramos bom acordo para os átomos de Ar e Xe, admitiremos que nossos cálculos são compatíveis com os de Berezhko e Kabachnik [15] para elementos com $Z \geq 18$.

\subsection{Testes prévios para o cálculo do parâmetro de ali- nhamento do Ta, W e Au}

Uma seqüência de testes foi realizada antes do cálculo final do parâmetro de alinhamento $A_{20}$ dos elementos de interesse, com o intuito de avaliar a convergência da soma em $l^{\prime}$ na expressão (3.33) e a precisão numérica nas três integrais envolvidas na expressão (3.32). Nas subseções seguintes serão apresentados os resultados de alguns deles.

\subsubsection{Integrais radiais, no momento e na energia do elétron eje- tado}

As figuras 7.3 e 7.4 mostram a diferença relativa dos resultados da integral dada pela expressão (3.37) calculados com ambos os procedimentos descritos na seção 7.1.1, a saber, com a função NIntegrate do software Mathematica 10.1 e com a quadratura de Hermite, 
para um alvo de $\mathrm{Au}$ ionizado com um feixe de elétrons de 20 e $50 \mathrm{keV}$, empregando o potencial de HS. Quando a energia do elétron incidente é $E$, a energia cinética do elétron ejetado $\epsilon$ pode variar de 0 a $E-E_{\mathrm{L}_{3}}$. Nas figuras a seguir são apresentadas diferenças relativas para três energias possíveis do elétron ejetado quando a energia do elétron incidente é $E$, uma perto do valor mínimo, uma intermediária e a outra próxima do valor máximo, em função do momento transferido $q$.

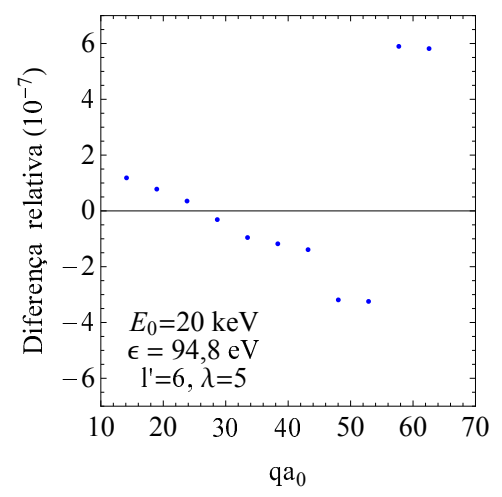

(a)

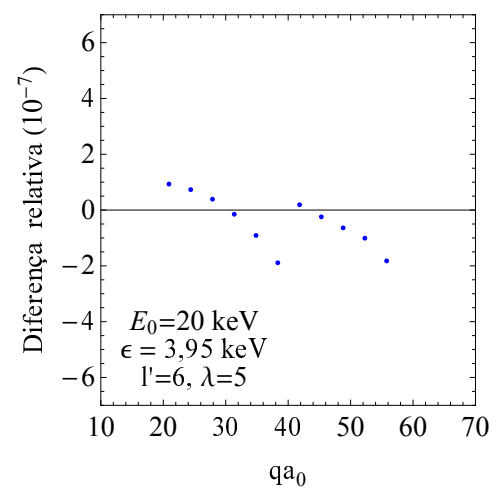

(d)

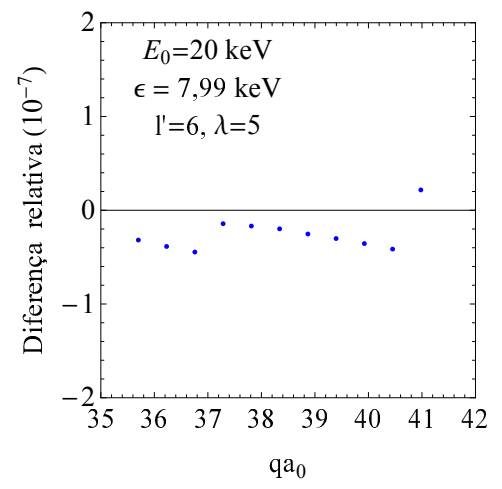

(g)

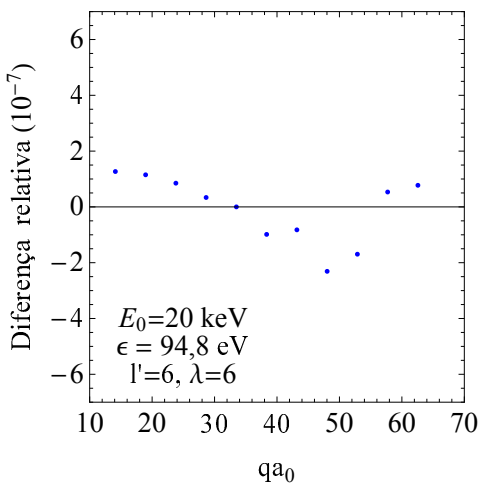

(b)

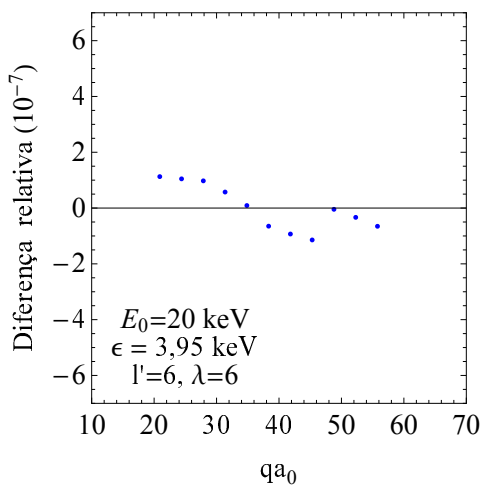

(e)

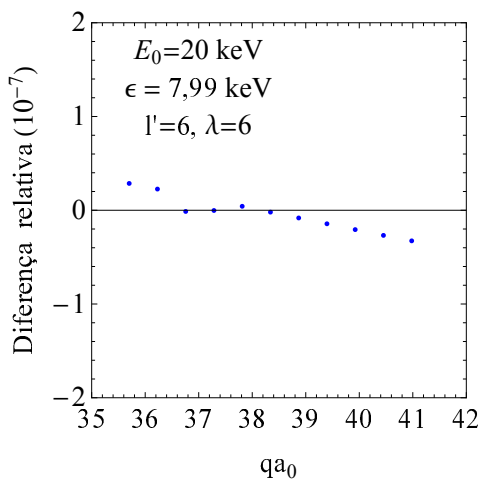

(h)

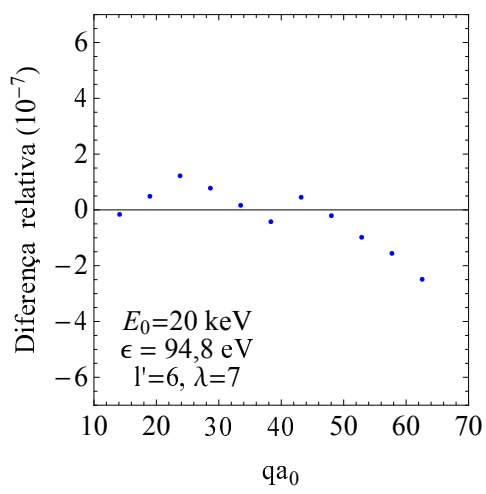

(c)

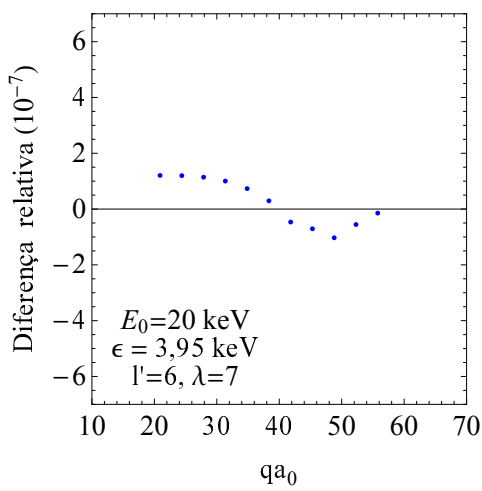

(f)

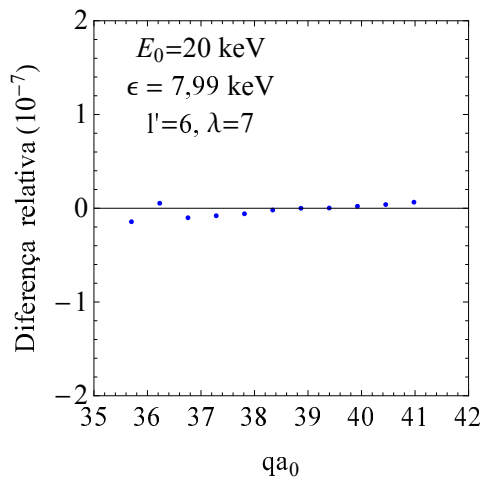

(i)

Figura 7.3: Diferença relativa do resultado da integral (3.37) em função do momento transferido $q$ empregando os dois procedimentos descritos na seção 7.1.1, para um alvo de $\mathrm{Au}$ descrito com o potencial de HS para a energia do elétron incidente de $E_{0}=20 \mathrm{keV}$, $\operatorname{com} l_{\max }^{\prime}=6$.

Em todos os casos analisados a diferença relativa entre os dois procedimentos empre- 


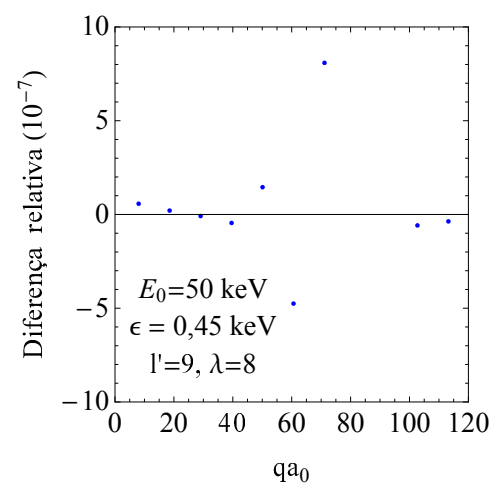

(a)

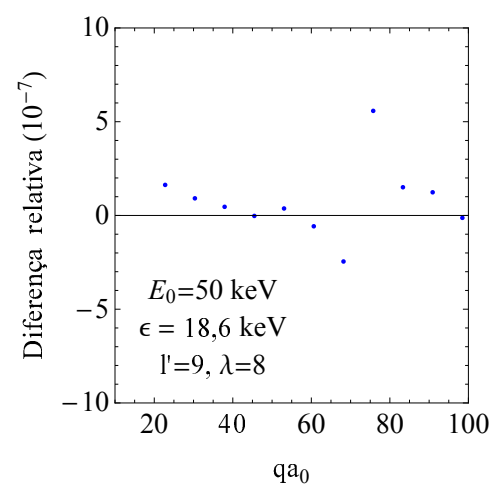

(d)

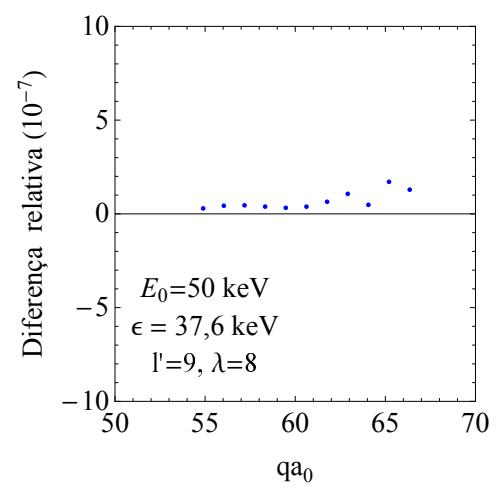

(g)

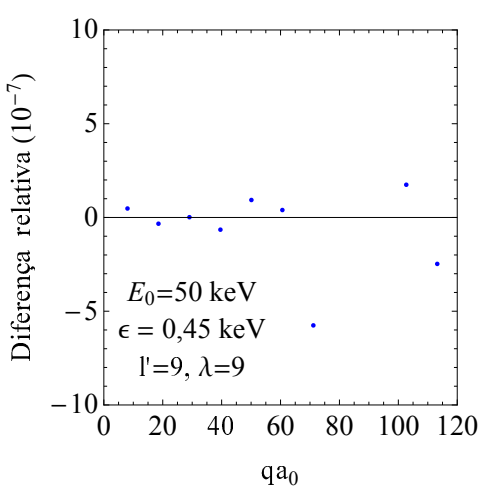

(b)

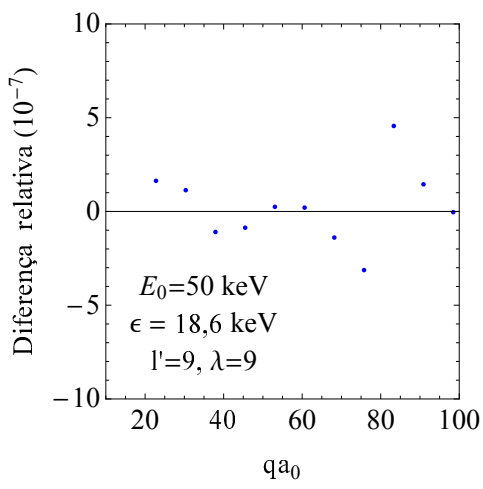

(e)

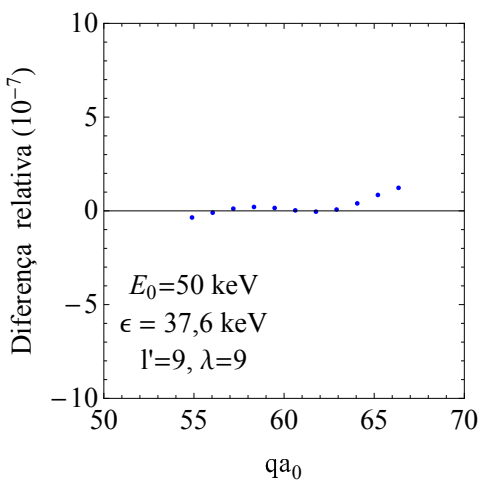

(h)

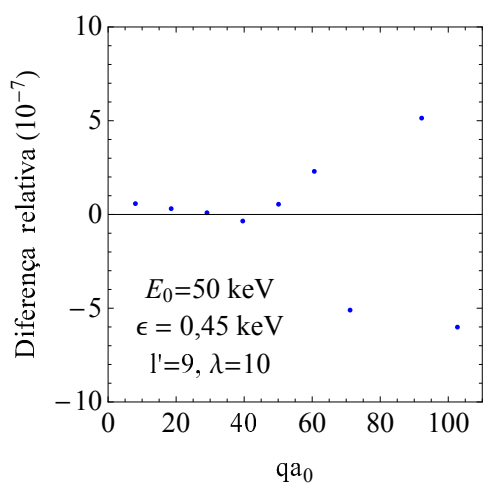

(c)

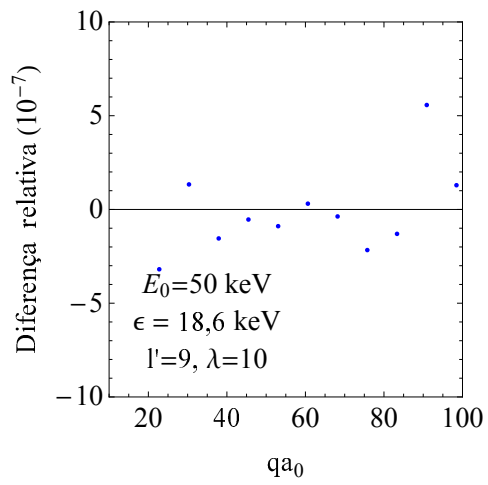

(f)

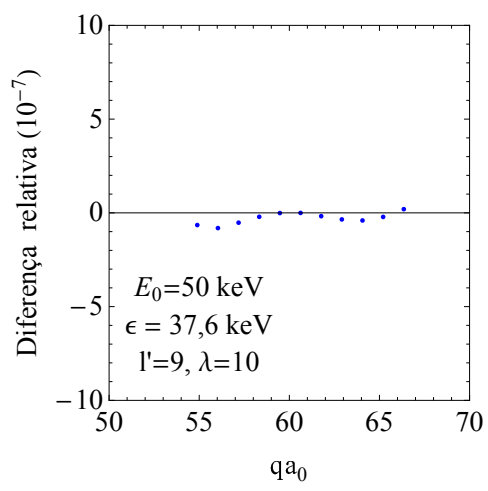

(i)

Figura 7.4: Mesmo que na figura 7.3, para a energia do elétron incidente de $E_{0}=50 \mathrm{keV}$, $\operatorname{com} l_{\max }^{\prime}=9$.

gados na integração da expressão (3.37) foi da ordem de $10^{-7}$. Este valor foi adotado como uma estimativa superior do erro relativo desta integração nos cálculos deste trabalho.

Para o teste na integral no momento transferido $q$ conforme descrito na seção 7.1.2, a diferença relativa do resultado na integração em toda a região com uma quadratura de Gauss com $n=5$ pontos, e para a região dividida em duas, integrando cada uma com outra quadratura de $n=5$ pontos, foi da ordem de $10^{-8}$ para toda a faixa de valores de $q$ possíveis com as energias de elétron incidente deste trabalho. Diante deste resultado, optou-se por realizar a integração em $q$ dividindo a região de interesse em duas, 
e realizando a integração de cada uma com uma quadratura de $n=5$ pontos.

Na última integral da expressão (3.32), que corresponde à integração na energia cinética do elétron ejetado $\epsilon$, implementou-se o método da quadratura adaptativa, confirme descrito na seção 7.1.2.

\subsubsection{Convergência com o momento angular do elétron ejetado $l^{\prime}$}

O cálculo do parâmetro de alinhamento envolve a soma sobre todos os valores possíveis do momento angular orbital $l^{\prime}$ do elétron ejetado, equação (3.33). A fim de estudar o comportamento da convergência do parâmetro de alinhamento $A_{20}$ com a quantidade de ondas parciais $l^{\prime}$ incluídas na soma, foi avaliada a estimativa do parâmetro $S_{A_{20}}$, que corresponde ao quociente $\rho_{20} / \rho_{00}$ da expressão (3.28), mas calculado com um número finito de ondas parciais na soma em $l^{\prime}$ da expressão (3.33). A quantidade de ondas parciais $l^{\prime}$ incluida no cálculo variou de 0 a $l_{\max }^{\prime}$. Para as energias do elétron incidente de: 12, 2; 20; 30; 60 e $90 \mathrm{keV}$ e um átomo de Au descrito com o potencial de HS [43] escolheu-se $l_{\max }^{\prime}=10$. A figura 7.5 mostra o resultado desses cálculos. Observe que o limite assintótico, quando $l^{\prime}$ tende a infinito pelo lado positivo, das curvas apresentadas na figura 7.5 corresponde ao parâmetro de alinhamento $A_{20}$ para a energia correspondente. Já a figura 7.6 apresenta o parâmetro $S_{A_{20}}$ em função da energia do elétron incidente em unidades da energia do limiar de ionização, calculado com $l_{\max }^{\prime}=6$. Ambas as figuras evidenciam que o parâmetro $A_{20}$ apresenta uma convergência suave, sendo mais rápida para as energias do elétron incidente mais próximas do limiar de ionização do elemento estudado.

Neste trabalho optou-se por avaliar a quantidade de ondas parciais $l^{\prime}$ a serem incluídas no cálculo olhando para o resultado de $A_{20}$ a cada valor de $l^{\prime}$ incluído. A soma sobre $l^{\prime}$ incluiu termos até que a diferença relativa entre os valores de $A_{20}$ calculados com $l^{\prime}$ e $l^{\prime}+1$ ondas parciais no somatório fosse da ordem de $10^{-4}$.

\subsection{Detalhes do cálculo para os elementos Ta, W e Au}

A fim de ilustrar etapas intermediárias do cálculo do parâmetro de alinhamento do Ta, W e Au, é apresentado na seqüência de figuras o resultado da expressão (7.4) em função da energia do elétron ejetado em unidades de Rydbergs, 


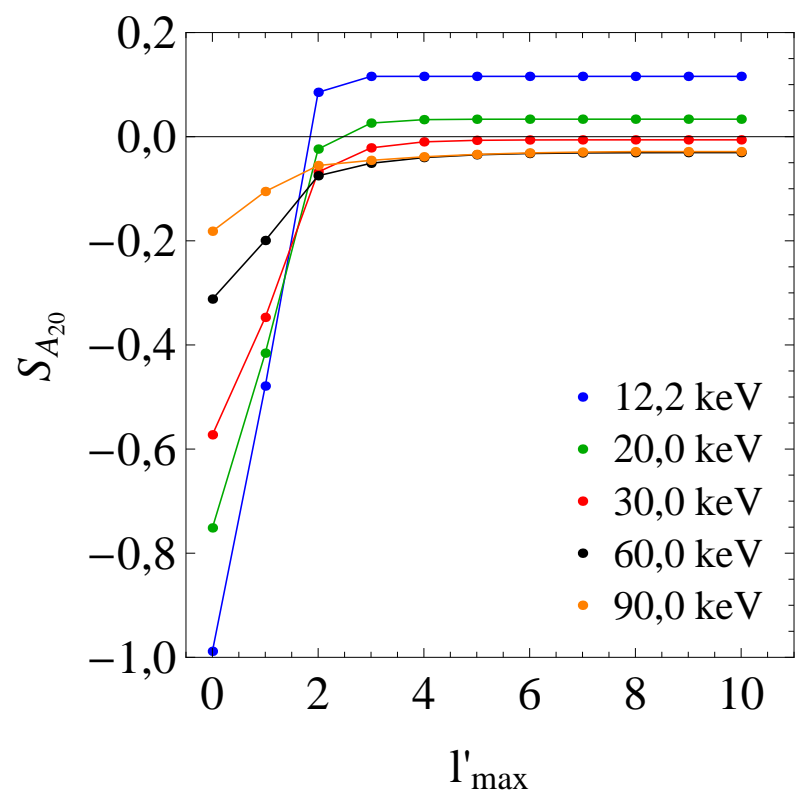

Figura 7.5: Dependência do parâmetro $S_{A_{20}}$ para as energias de: 12, 2; 20;30; 60 e $90 \mathrm{keV}$ com o número de valores do momento angular orbital $l^{\prime}$ do elétron ejetado incluídos no cálculo. O limite assintótico das curvas corresponde ao parâmetro de alinhamento $A_{20}$ para a energia correspondente.

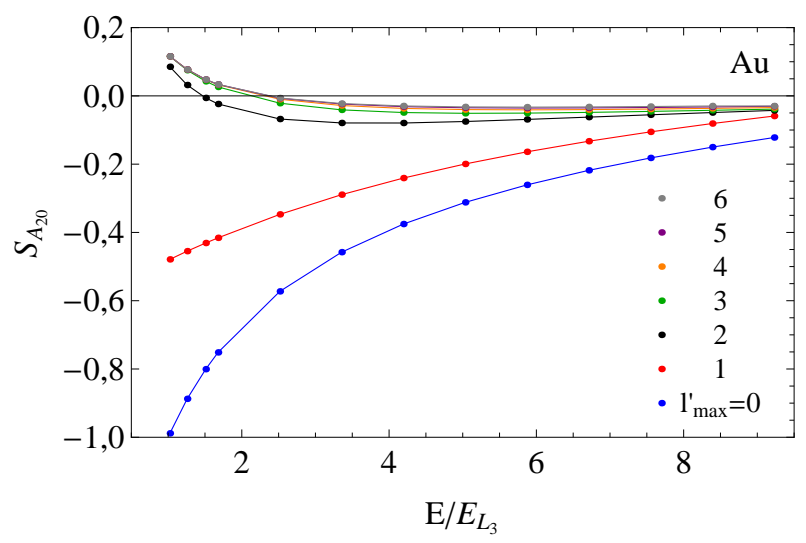

Figura 7.6: Dependência do parâmetro $S_{A_{20}}$ em função da energia do elétron incidente em unidades de limiar, para $l_{\max }^{\prime}=0$ (azul), $l_{\max }^{\prime}=1$ (vermelho), $l_{\max }^{\prime}=2$ (preto), $l_{\max }^{\prime}=3$ (verde), $l_{\max }^{\prime}=4$ (laranja), $l_{\max }^{\prime}=5$ (roxo) e $l_{\max }^{\prime}=6$ (cinza).

$$
I_{k}(\epsilon)=\int_{q_{\min }(\epsilon)}^{q_{\max }(\epsilon)} \frac{F_{k}(q, \epsilon)}{\left(q a_{0}\right)^{2}} \mathrm{~d} \ln \left(q a_{0}\right)^{2}
$$

que corresponde ao resultado da integral mais interna da expressão (3.32) para cada valor da energia cinética $\epsilon$ possível.

As figuras 7.7 e 7.8 mostram o resultado da expressão (7.4) com $k=0$ e $k=2$ para os alvos de Ta e Au, respectivamente, empregando o potencial de HS [43] com as energias do elétron incidente $E_{0}=15 ; 30$ e $70 \mathrm{keV}$, para o Ta, e com $E_{0}=12,2 ; 40$ e $100 \mathrm{keV}$, 
para o Au. O parâmetro de alinhamento $A_{20}$ corresponde à razão da integral das curvas $I_{2}$ e $I_{0}$.

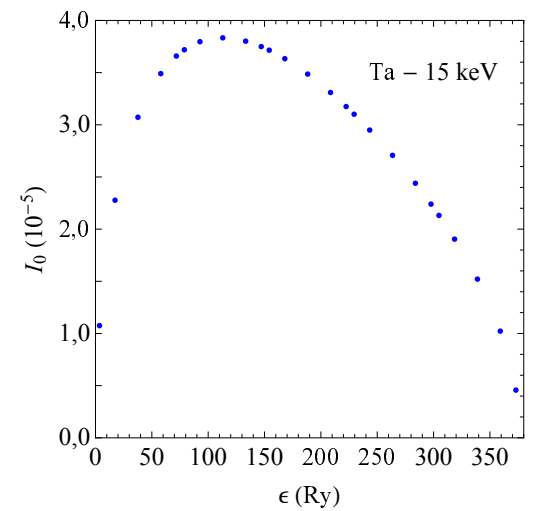

(a)

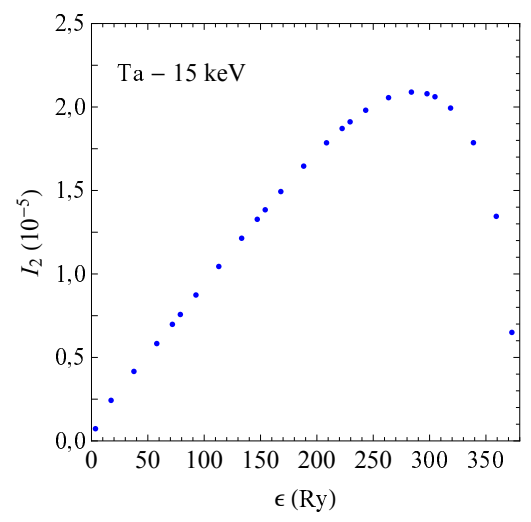

(d)

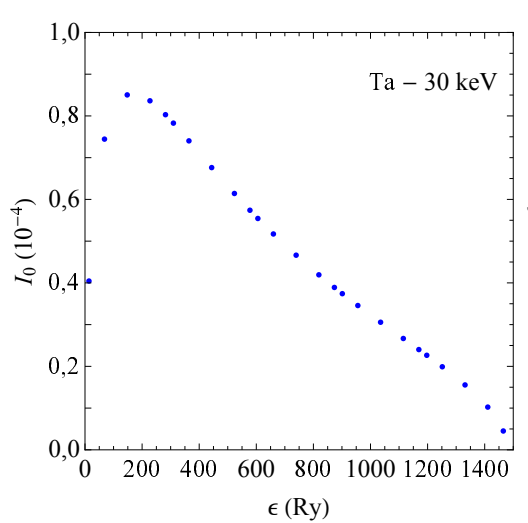

(b)

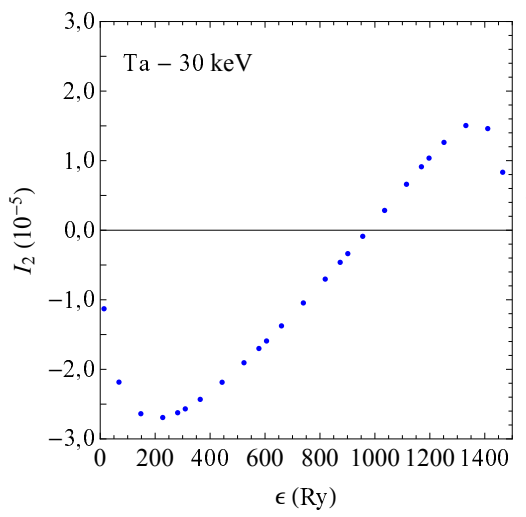

(e)

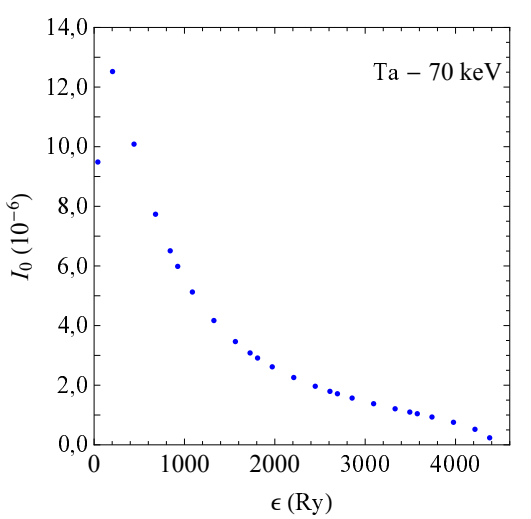

(c)

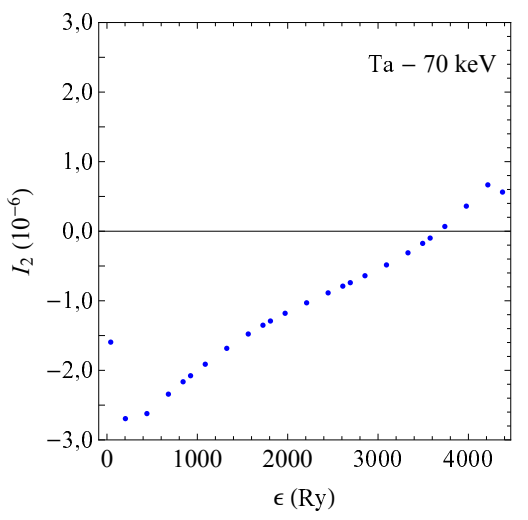

(f)

Figura 7.7: Valores de $I_{0}$ (figuras de a) até c)) e de $I_{2}$ (figuras de d) até f)) calculados com a expressão (7.4) para o Ta empregando o potencial de HS. As energias dos elétrons estão marcadas na parte superior da figura. 


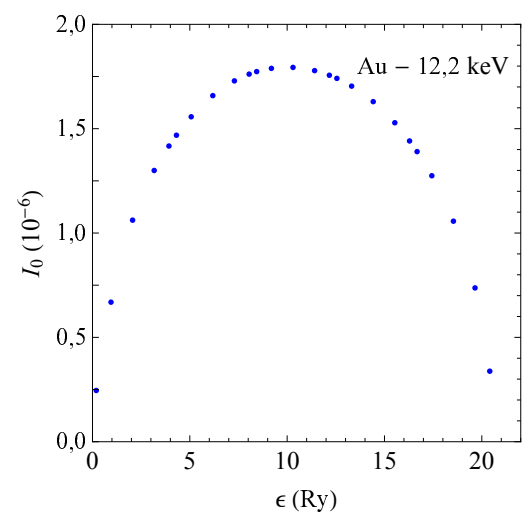

(a)

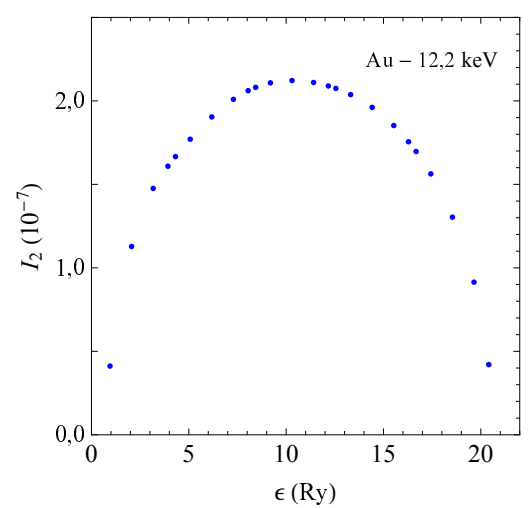

(d)

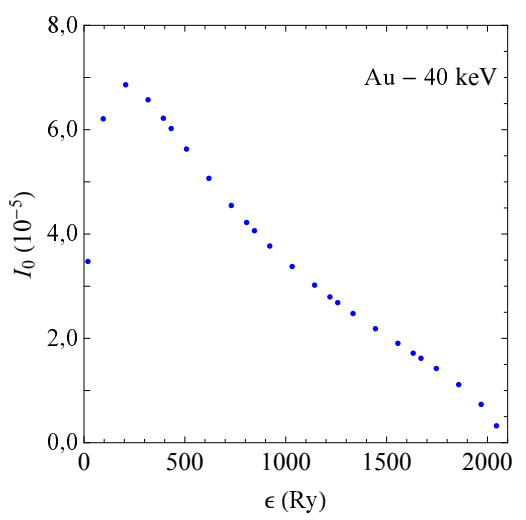

(b)

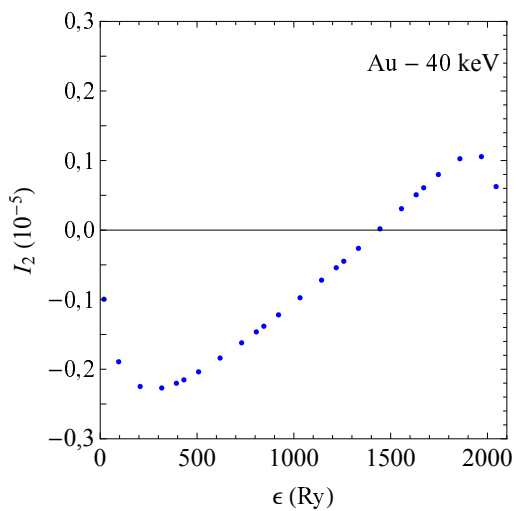

(e)

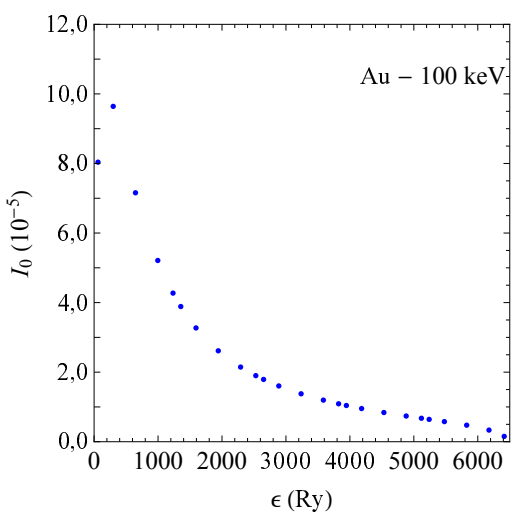

(c)

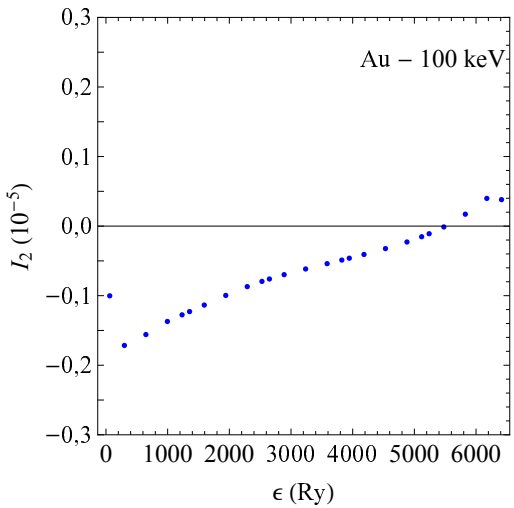

(f)

Figura 7.8: Mesmo que a figura 7.7, mas para o Au. 


\title{
Capítulo 8
}

\section{Resultados experimentais e teóricos}

\author{
Neste capitulo serão mostradas as distribuições angulares das \\ linhas Le, $\mathrm{L} \alpha_{1}$ e $\mathrm{L} \alpha_{2}$, normalizadas pelo dubleto $\mathrm{K} \alpha$ do $\mathrm{Cu}$, \\ para os elementos $W$, Ta e Au em cada uma das energias do ex- \\ perimento, junto com a curva da distribuição angular calculada \\ com os parâmetros estimados. Na seqüência, serão apresenta- \\ das as estimativas do parâmetro de alinhamento, junto com as \\ curvas teóricas obtidas empregando os potenciais de HS e DHS, \\ seguido dos resultados para a análise da distribuição angular da \\ linha L $\eta$ e do multipleto L $\gamma$ dos três elementos. Por fim, serão \\ apresentados os resultados das seções de choque de produção de \\ raios $x L \alpha$, L $\beta$ e $L \gamma$ e das seções de choque de ionização das \\ subcamadas $L_{1}, L_{2}$ e $L_{3}$ do $A u$.
}

\subsection{Distribuições angulares das linhas $\mathrm{L} \ell, \mathrm{L} \alpha_{1}$ e $\mathrm{L} \alpha_{2}$}

Os resultados experimentais da distribuição angular da expressão (6.14) junto com a curva teórica, equação (3.40), calculada a partir dos parâmetros $a$ e $b$ ajustados, equação (6.13), para as linhas $\mathrm{L} \ell, \mathrm{L} \alpha_{1}$ e $\mathrm{L} \alpha_{2}$ do Ta, W e Au estão na seqüência de figuras abaixo.

As figuras 8.1, 8.2 e 8.3 trazem os resultados para as irradiações do alvo de Ta nas energias de $11,51(6), 30,62(9)$ e $100,60(4) \mathrm{keV}$; a figura 8.4, para o W na energia de $58,28(3) \mathrm{keV}$, e as figuras 8.5, 8.6 e 8.7, para o alvo de Au nas energias de 13,35(9), $25,41(9)$ e $74,83(7) \mathrm{keV}$. Os resultados de distribuição angular obtidos para as demais energias do experimento estão apresentados nos apêndices C, D e E para os elementos Ta, $\mathrm{W}$ e $\mathrm{Au}$, respectivamente. 


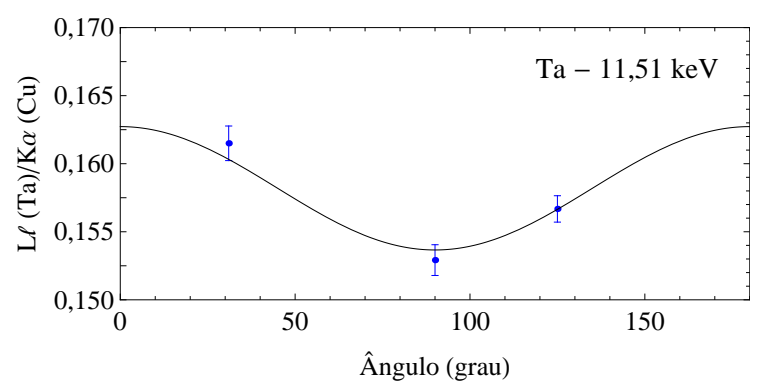

(a)

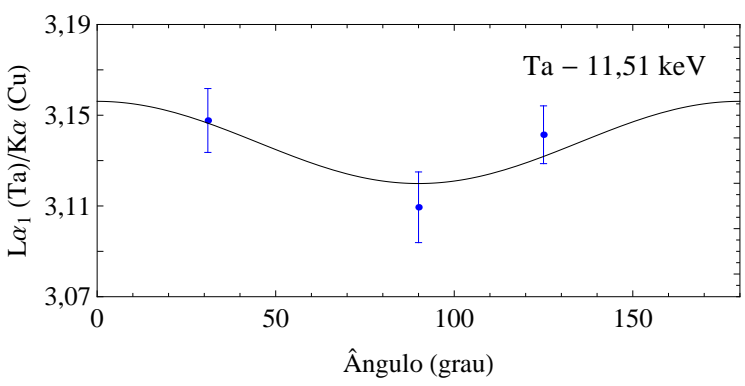

(b)

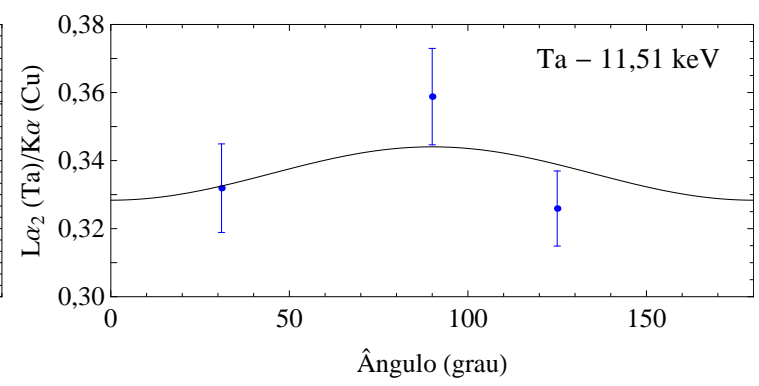

(c)

Figura 8.1: Os pontos com barras de incerteza (1 desvio padrão) representam os valores experimentais de intensidade das linhas $\mathrm{L}$ do Ta relativa ao dubleto $\mathrm{K} \alpha$ do $\mathrm{Cu}$, na energia de $11,51(6) \mathrm{keV}:$ a) L $\ell$, b) $\mathrm{L} \alpha_{1}$ e c) $\mathrm{L} \alpha_{2}$. As linhas contínuas são as curvas correspondentes calculadas com os parâmetros ajustados aos dados experimentais. O $\chi^{2}$ do ajuste com cinco graus de liberdade foi de 10,9.

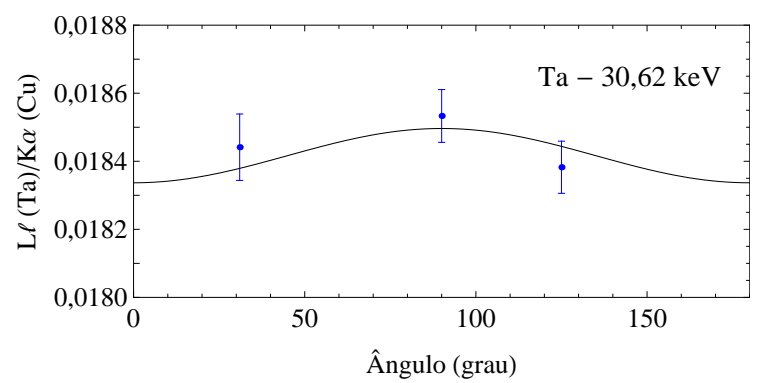

(a)

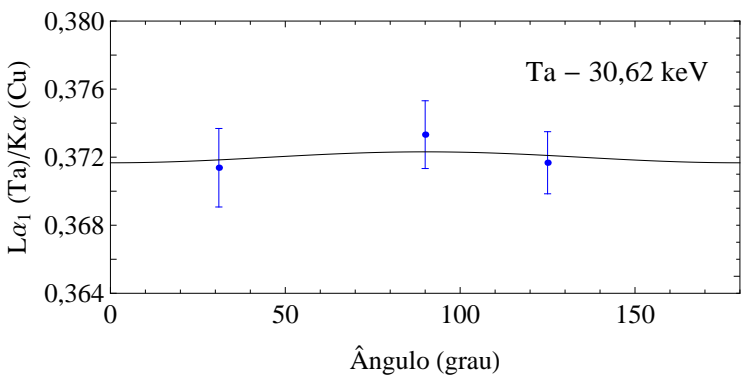

(b)

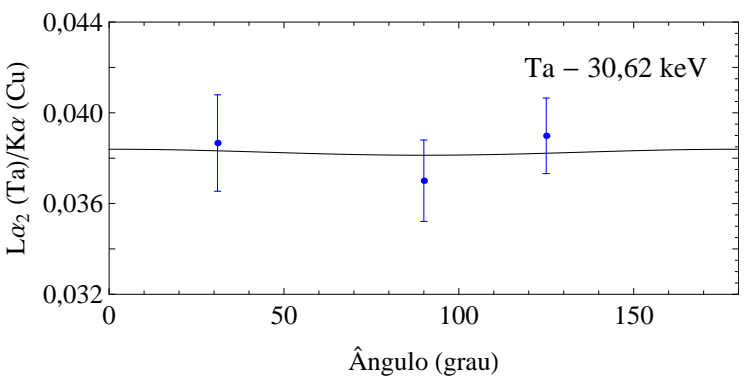

(c)

Figura 8.2: Mesmo que a figura 8.1 para a energia de $30,62(9) \mathrm{keV}$. O $\chi^{2}$ do ajuste com cinco graus de liberdade foi de 5,0 . 


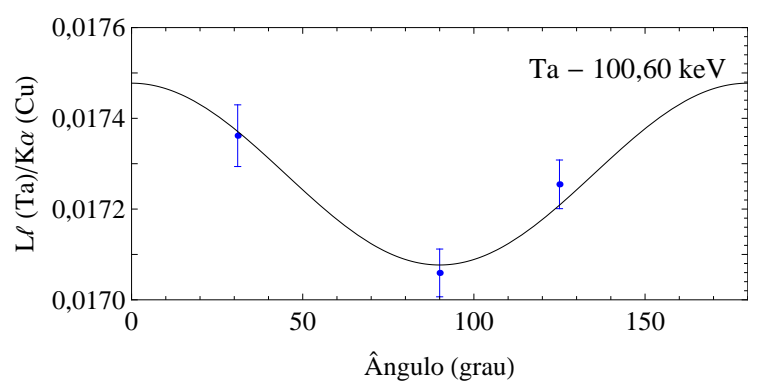

(a)

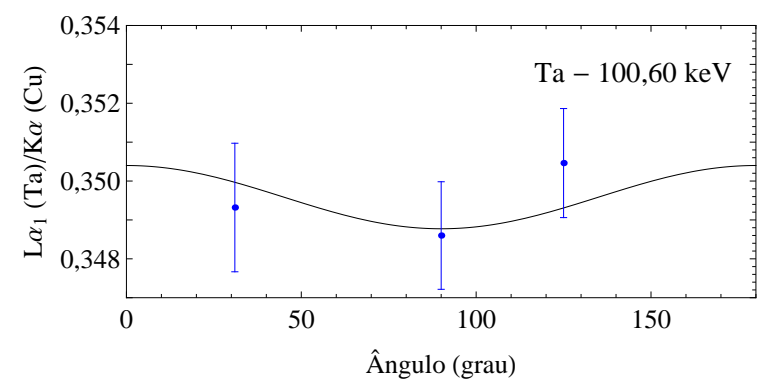

(b)

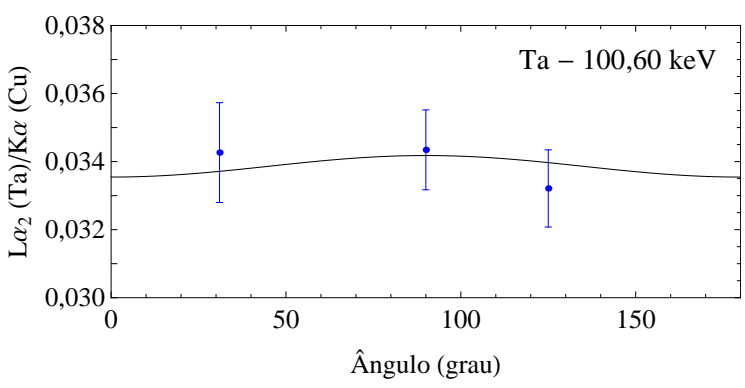

(c)

Figura 8.3: Mesmo que a figura 8.1 para a energia de $100,60(4) \mathrm{keV}$. O $\chi^{2}$ do ajuste com cinco graus de liberdade foi de 6,2 .

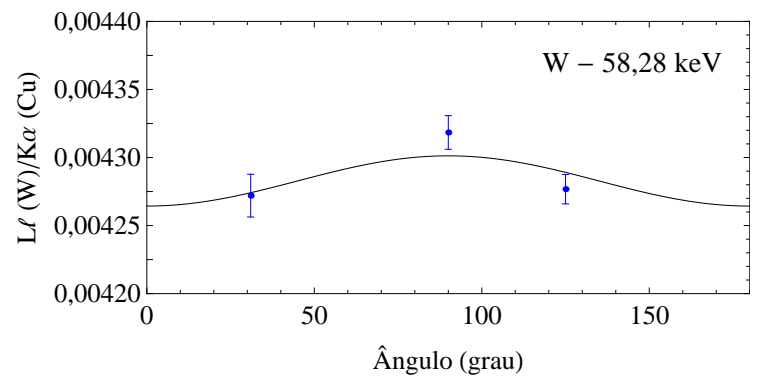

(a)

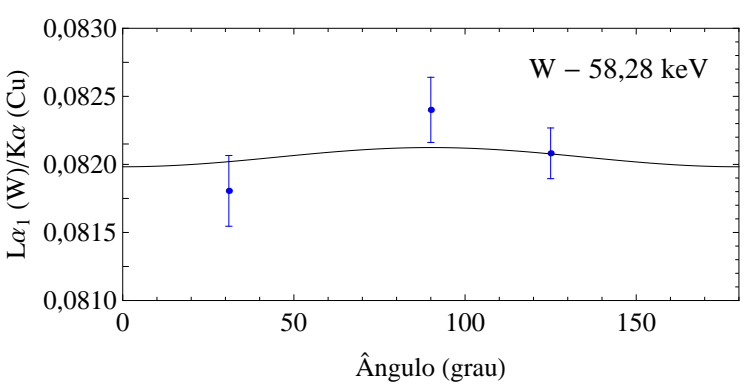

(b)

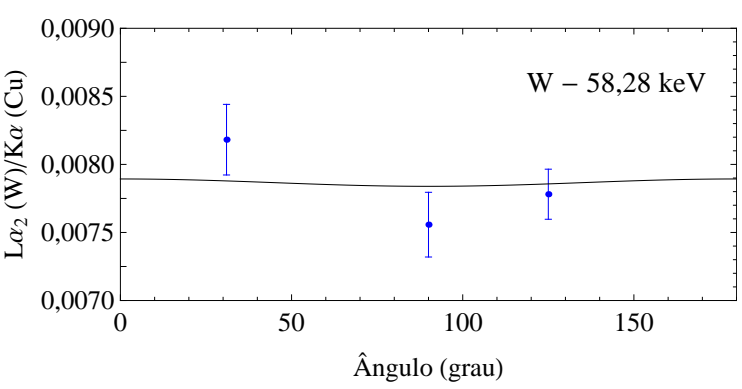

(c)

Figura 8.4: Mesmo que a figura 8.1 para W na energia de $58,28(3) \mathrm{keV}$. O $\chi^{2}$ do ajuste com cinco graus de liberdade foi de 12 .

A fim de avaliar a qualidade dos resultados obtidos, foi calculado o qui quadrado absoluto do ajuste conduzido em duas etapas, conforme apresentado na seção 6.3, em cada uma das energias em que os alvos de Ta, W e Au foram irradiados. Os valores encon- 


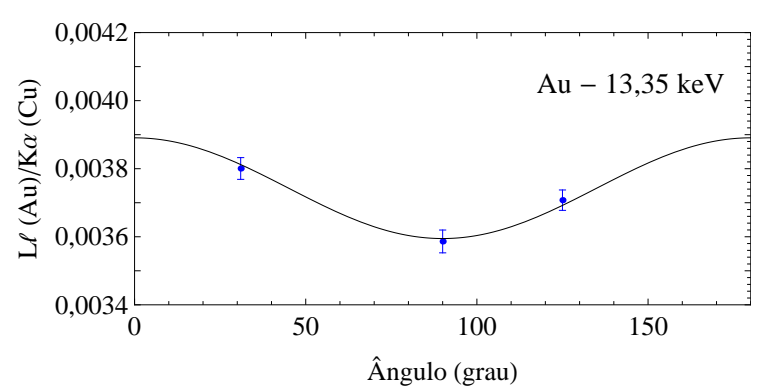

(a)

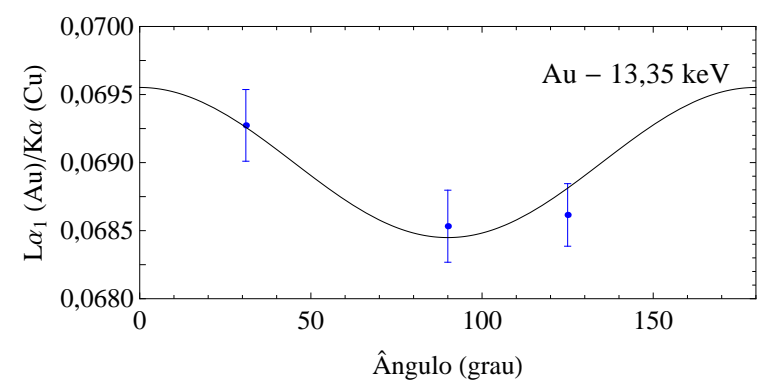

(b)

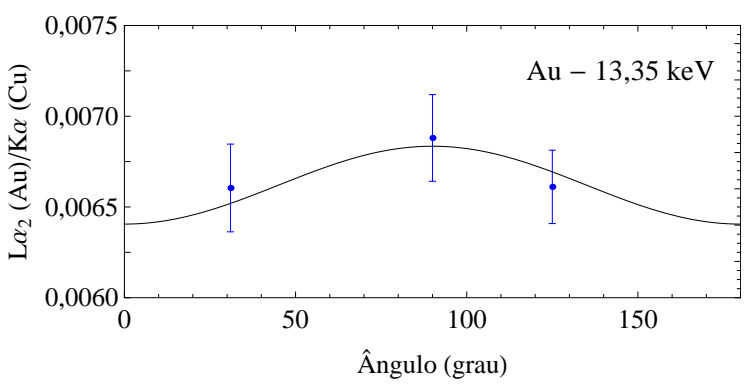

(c)

Figura 8.5: Mesmo que a figura 8.1 para Au na energia de $13,35(9) \mathrm{keV}$. O $\chi^{2}$ do ajuste com cinco graus de liberdade foi de 1, 6 .

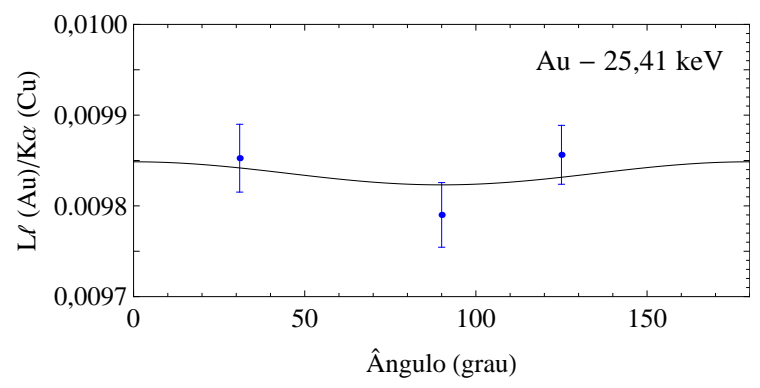

(a)

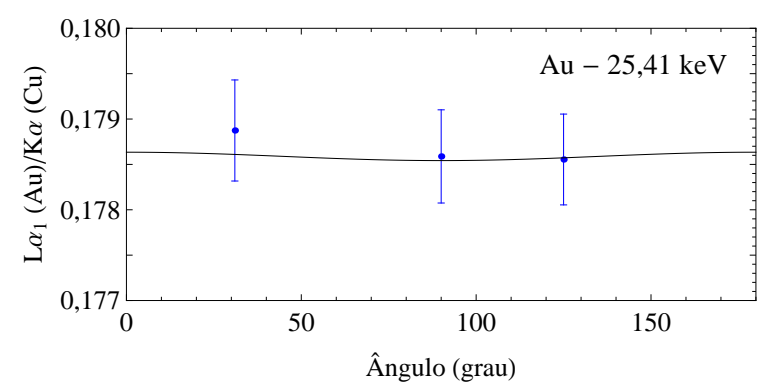

(b)

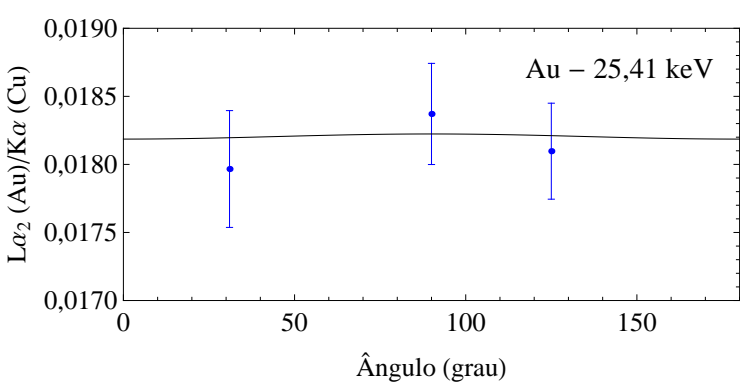

(c)

Figura 8.6: Mesmo que a figura 8.1 para Au na energia de 25,41(9) keV. O $\chi^{2}$ do ajuste com cinco graus de liberdade foi de 13,8 .

trados estão apresentados na figura 8.8. O ajuste leva em conta as linhas $\mathrm{L} \ell, \mathrm{L} \alpha_{1}$ e $\mathrm{L} \alpha_{2}$ simultaneamente, de forma que há nove dados experimentais e quatro parâmetros a serem ajustados, portanto, cinco graus de liberdade. A análise da figura 8.8 mostra que para o 


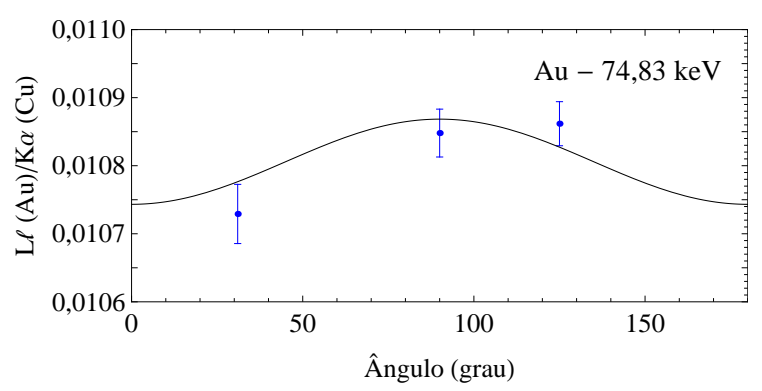

(a)

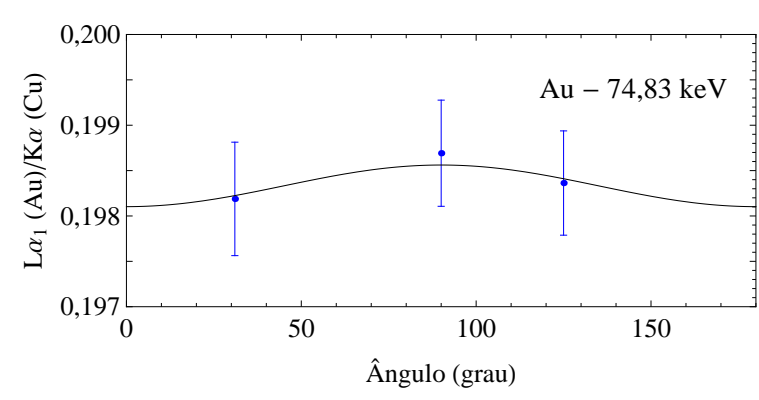

(b)

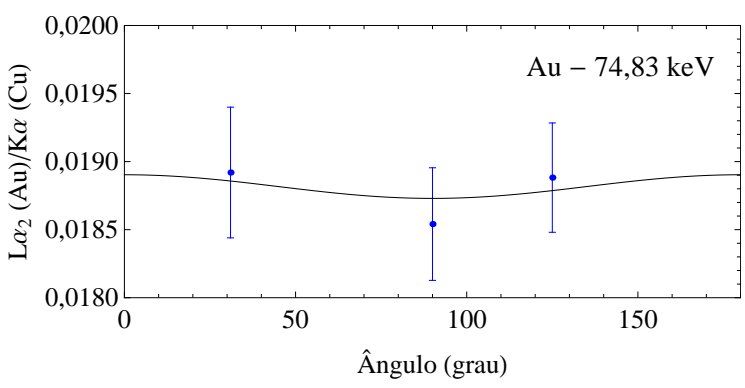

(c)

Figura 8.7: Mesmo que a figura 8.1 para Au na energia de $74,83(7) \mathrm{keV}$. O $\chi^{2}$ do ajuste com cinco graus de liberdade foi de 6,1 .

Ta, com exceção do ajuste dos dados de $84,96 \mathrm{keV}$, todos os demais passaram no teste do $\chi^{2}$ com probabilidade do qui quadrado ser excedido superior a $5 \%$. Avaliando a soma de todos os qui quadrados do Ta, que tem 60 graus de liberdade e qui quadrado absoluto de 82,34 , a probabilidade do qui quadrado ser excedido é de $3 \%$, o que corresponde a uma aprovação marginal no teste do $\chi^{2}$. Para o W, nota-se que o ajuste para a energia de $58,28 \mathrm{keV}$ passa marginalmente no teste, e os demais passam com probabilidade do qui quadrado ser excedido superior a 5\%. Por fim, a figura 8.8 mostra um resultado similar para o $\mathrm{Au}$, onde apenas o ajuste para a energia de $25,37 \mathrm{keV}$ não passa no teste do $\chi^{2}$ com bom nível de significância. A análise de todos os dados do Au, com 60 graus de liberdade e qui quadrado absoluto de 67, 63 passa no teste do $\chi^{2}$ com probabilidade de $23,3 \%$.

Quando calculado a probabilidade de que em um ajuste com 5 graus de liberdade se obtenha um qui quadrado absoluto maior do que 14 espera-se cerca de 2 eventos em 12 . Os poucos casos observados que não passaram no teste do $\chi^{2}$ devem estar relacionados à flutuação estatística do problema, e não a inadequação do método. De maneira análoga, para a análise de todos os ajustes, com um total de 25 valores de quadrado absoluto, a probabilidade de que 8 deles estejam abaixo dos $50 \%$ é de $5 \%$, o que corresponde a uma aprovação com nível de confiança marginal. A análise dos qui quadrados de cada um dos ajustes, e da soma de todos eles mostra que a metodologia foi adequada, fornecendo estimativas dos parâmetros e das respectivas incertezas não tendenciosas. 


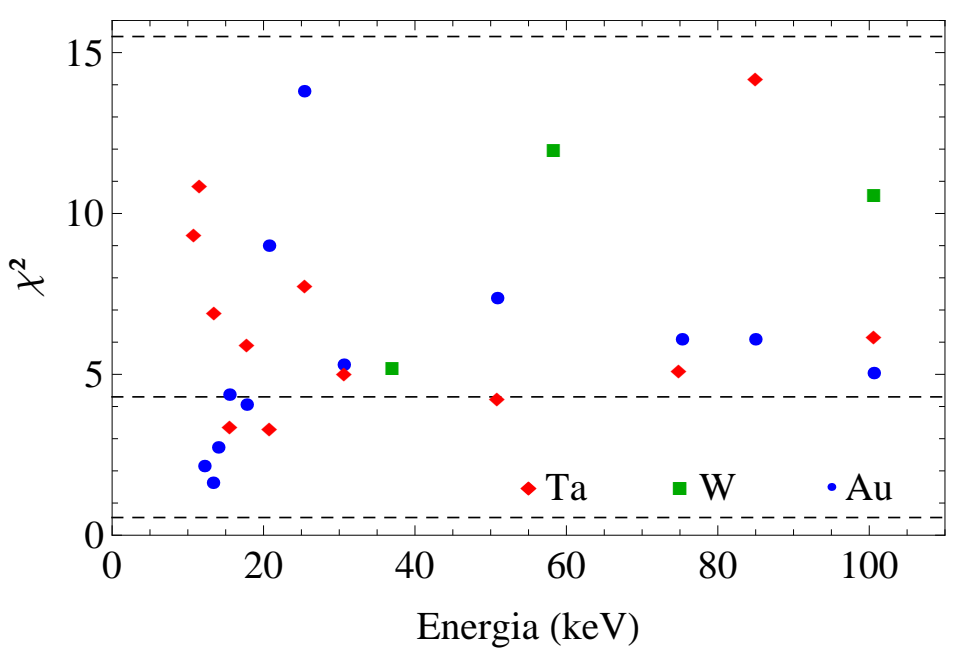

Figura 8.8: $\chi^{2}$ total para os ajustes dos parâmetros de alinhamento dos alvos de Ta (diamantes vermelhos), W (quadrados verdes) e $\mathrm{Au}$ (círculos azuis) realizado em duas etapas conforme apresentado na seção 6.3, para todas as energias de irradiação. O ajuste tem cinco graus de liberdade. As linhas tracejadas, de baixo para cima, representam níveis de confiança de 1\%, $50 \%$ e $99 \%$, respectivamente.

\subsection{Parâmetro de alinhamento $\boldsymbol{A}_{20}$}

As estimativas dos parâmetros de alinhamento $A_{20}$ para os alvos de Ta, W e Au em cada uma das energias de irradiação, obtidas a partir dos ajustes mostrados na seção anterior, junto com os valores teóricos calculados com a PWBA, equações (3.28) e (3.32), empregando o potencial de DHS, são apresentadas nas tabelas 8.1, 8.2 e 8.3, respectivamente. O parâmetro $A_{20}^{\text {raw }}$ corresponde ao valor ajustado para o produto $\xi A_{20}$, que é o resultado experimental sem incluir as correções analíticas para os efeitos das transições CosterKronig, da abertura do feixe de elétrons no alvo e da autoabsorção dos fótons, enquanto que o parâmetro $A_{20}^{\text {exp }}$ inclui essas correções. As figuras 8.9, 8.10 e 8.11 trazem as representações gráficas destes resultados, junto com os valores calculados com os potenciais de HS e DHS, enquanto que a figura 8.12 mostra os valores calculados do parâmetro de alinhamento para o Ta e o Au, calculados com os potenciais de HS e DHS, na região $E / E_{\mathrm{L}_{3}}<1,1$.

A fim de comparar os resultados obtidos para os três elementos, a figura 8.13 traz a dependência do parâmetro de alinhamento do Ta, W e Au com a energia do elétron incidente em unidades da energia do limiar de ionização da subcamada $\mathrm{L}_{3}$ do elemento estudado. 
Tabela 8.1: Estimativa do parâmetro de alinhamento do Ta para cada uma das energias de irradiação. $A_{20}^{\text {raw }}$ corresponde ao valor ajustado para o produto $\xi A_{20}, A_{20}^{\text {exp }}$ ao valor corrigido para os efeitos das transições Coster-Kronig, a abertura do feixe de elétrons no alvo e a autoabsorção dos fótons e $A_{20}^{\text {teo }}$ ao valor teórico obtido com aproximação de Born de ondas planas com o potencial atômico calculado na aproximação de DHS. O número entre parênteses é o desvio padrão estimado, em unidades do algarismo menos significativo do valor da grandeza.

\begin{tabular}{cccc}
\hline \hline Energia $(\mathrm{keV})$ & $A_{20}^{\text {raw }}$ & $A_{20}^{\text {exp }}$ & $A_{20}^{\text {teo }}$ \\
\hline $10,75(9)$ & $0,132(21)$ & $0,24(6)$ & 0,108 \\
$11,51(6)$ & $0,077(13)$ & $0,14(3)$ & 0,095 \\
$13,46(9)$ & $0,057(7)$ & $0,094(18)$ & 0,066 \\
$15,51(4)$ & $0,057(13)$ & $0,088(24)$ & 0,045 \\
$17,79(7)$ & $0,025(7)$ & $0,036(11)$ & 0,027 \\
$20,76(9)$ & $0,014(12)$ & $0,019(17)$ & 0,010 \\
$25,41(15)$ & $0,006(6)$ & $0,008(8)$ & $-0,006$ \\
$30,62(9)$ & $-0,012(10)$ & $-0,015(13)$ & $-0,018$ \\
$50,82(5)$ & $-0,021(7)$ & $-0,025(9)$ & $-0,030$ \\
$74,83(6)$ & $0,003(8)$ & $0,004(9)$ & $-0,028$ \\
$84,96(5)$ & $0,015(7)$ & $0,018(9)$ & $-0,026$ \\
$100,60(4)$ & $0,031(6)$ & $0,036(9)$ & $-0,022$ \\
\hline \hline
\end{tabular}

Tabela 8.2: Mesmo que a tabela 8.1, para o alvo de W.

\begin{tabular}{cccc}
\hline \hline Energia $(\mathrm{keV})$ & $A_{20}^{\text {raw }}$ & $A_{20}^{\text {exp }}$ & $A_{20}^{\text {teo }}$ \\
\hline $36,97(8)$ & $-0,019(5)$ & $-0,022(7)$ & $-0,024$ \\
$58,28(3)$ & $-0,011(7)$ & $-0,013(8)$ & $-0,031$ \\
$100,65(7)$ & $0,018(8)$ & $0,021(10)$ & $-0,022$ \\
\hline \hline
\end{tabular}

\subsection{Coeficientes de alinhamento da linha L $\eta$ e do mul- tipleto $\mathrm{L} \gamma$}

As tabelas 8.4, 8.5 e 8.6 apresentam as estimativas do coeficiente de alinhamento, representado pelo produto $\xi \alpha A_{20}$, equação (3.40), para a linha $\mathrm{L} \eta$ e o grupo L $\gamma$ dos elementos Ta, W e Au, respectivamente. A esses valores foi ajustado uma constante, e os resultados obtidos estão apresentados na última linha da tabela 8.6. A figura 8.14 traz os pontos experimentais junto com a reta constante ajustada aos dados experimentais para os alvos de $\mathrm{Ta}, \mathrm{W}$ e $\mathrm{Au}$, respectivamente. 
Tabela 8.3: Mesmo que a tabela 8.1, mas para o alvo de Au

\begin{tabular}{cccc}
\hline \hline Energia $(\mathrm{keV})$ & $A_{20}^{\text {raw }}$ & $A_{20}^{\text {exp }}$ & $A_{20}^{\text {teo }}$ \\
\hline $12,19(9)$ & $0,22(5)$ & $0,27(7)$ & 0,121 \\
$13,35(9)$ & $0,107(15)$ & $0,127(24)$ & 0,103 \\
$14,03(9)$ & $0,081(16)$ & $0,096(23)$ & 0,093 \\
$15,51(9)$ & $0,076(19)$ & $0,095(27)$ & 0,075 \\
$17,79(11)$ & $0,039(9)$ & $0,050(13)$ & 0,052 \\
$20,76(8)$ & $0,028(13)$ & $0,036(17)$ & 0,031 \\
$25,41(9)$ & $0,003(6)$ & $0,004(8)$ & 0,009 \\
$30,62(15)$ & $-0,011(8)$ & $-0,014(10)$ & $-0,007$ \\
$50,82(7)$ & $-0,015(8)$ & $-0,019(10)$ & $-0,029$ \\
$74,83(7)$ & $-0,015(7)$ & $-0,019(9)$ & $-0,031$ \\
$84,96(6)$ & $-0,012(7)$ & $-0,015(9)$ & $-0,029$ \\
$100,60(4)$ & $0,009(7)$ & $0,011(9)$ & $-0,026$ \\
\hline \hline
\end{tabular}

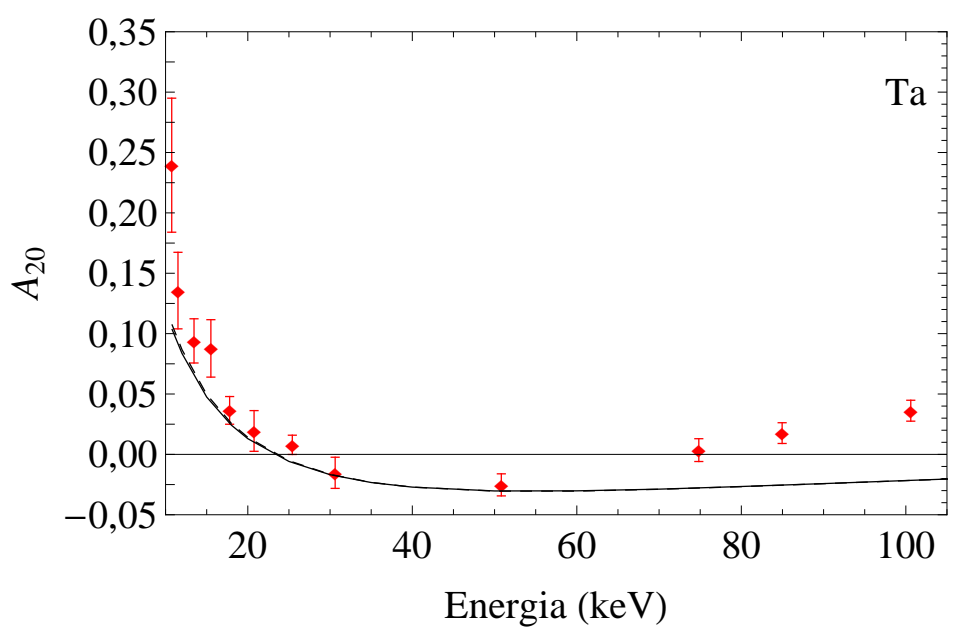

Figura 8.9: Parâmetro de alinhamento $A_{20}$ do elemento Ta em função da energia dos elétrons incidentes. Os pontos correspondem às estimativas experimentais deste trabalho, a curva contínua corresponde aos resultados do cálculo da equação (3.32) com o potencial de HS, e a tracejada com o potencial de DHS. As barras de incertezas correspondem a um desvio padrão.

\subsection{Seções de choque de produção de raios $\mathrm{x}$ e de ioni- zação atômica das subcamadas $\mathrm{L}$}

As estimativas experimentais das seções de choque de produção de raios x $\mathrm{L} \alpha, \mathrm{L} \beta, \mathrm{L} \gamma$, $\mathrm{L} \ell$ e $\mathrm{L} \eta$ estão listadas na tabela 8.7, e a figura 8.15 traz as representações gráficas desses valores, junto com os resultados experimentais reportados por outros autores [16-21] e com as seções de choque de produção de raios x calculadas com a DWBA [22,23]. A tabela 8.8 apresenta os resultados para as seções de choque de ionização das subcamadas $\mathrm{L}_{1}, \mathrm{~L}_{2}$ 


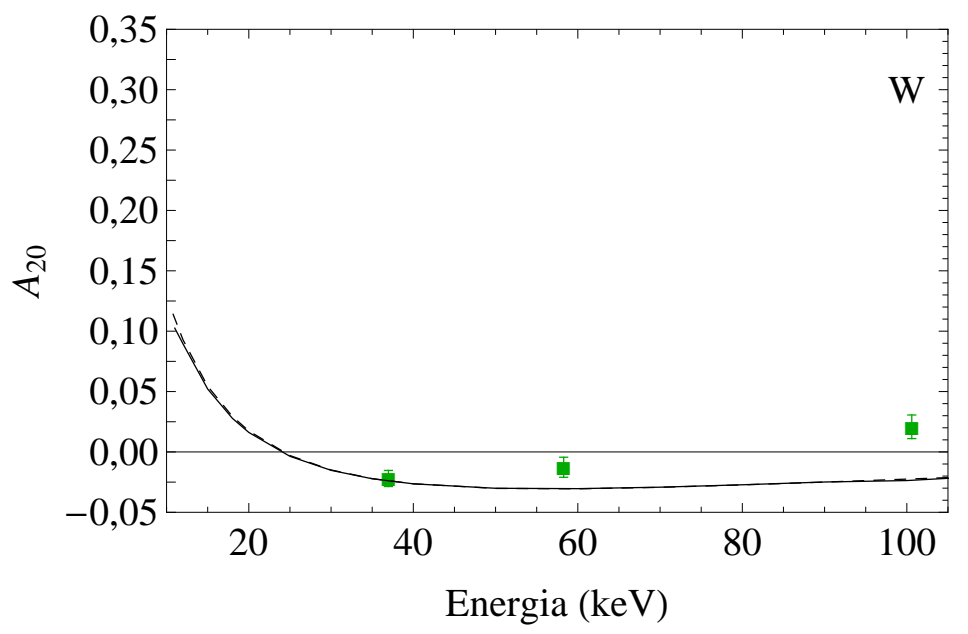

Figura 8.10: Mesmo que a figura 8.9, para o átomo de W.

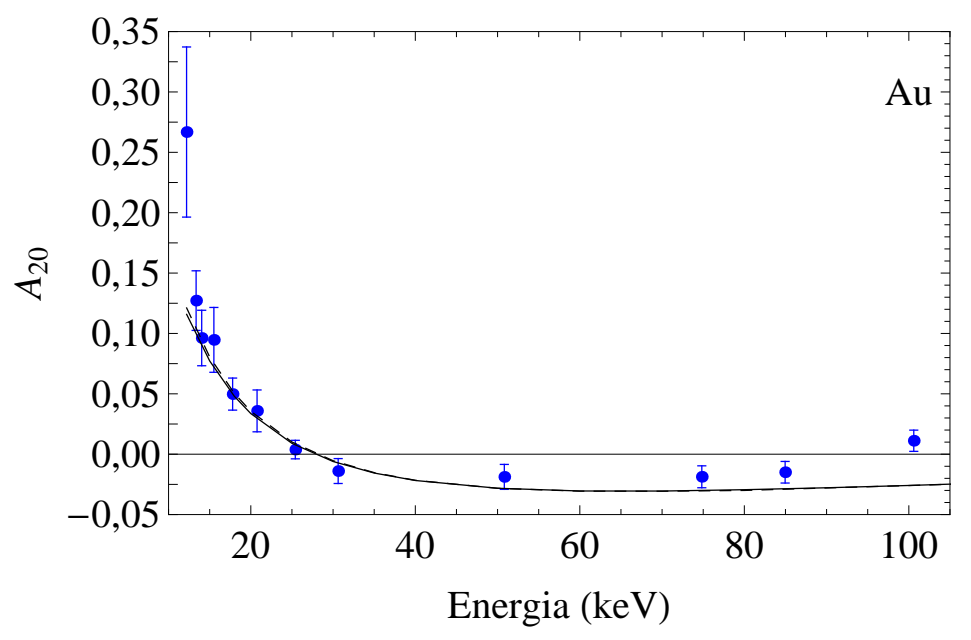

Figura 8.11: Mesmo que a figura 8.9, para o átomo de Au.

e $\mathrm{L}_{3}$, e a figura 8.16 compara essas seções de choque com outros resultados experimentais $[16,17,20,21,24-27]$ e com as previsões teorias, calculadas com a DWBA [22,23] e com o formalismo Subconfiguration-Average Distorted-Wave SCADW [28]. 


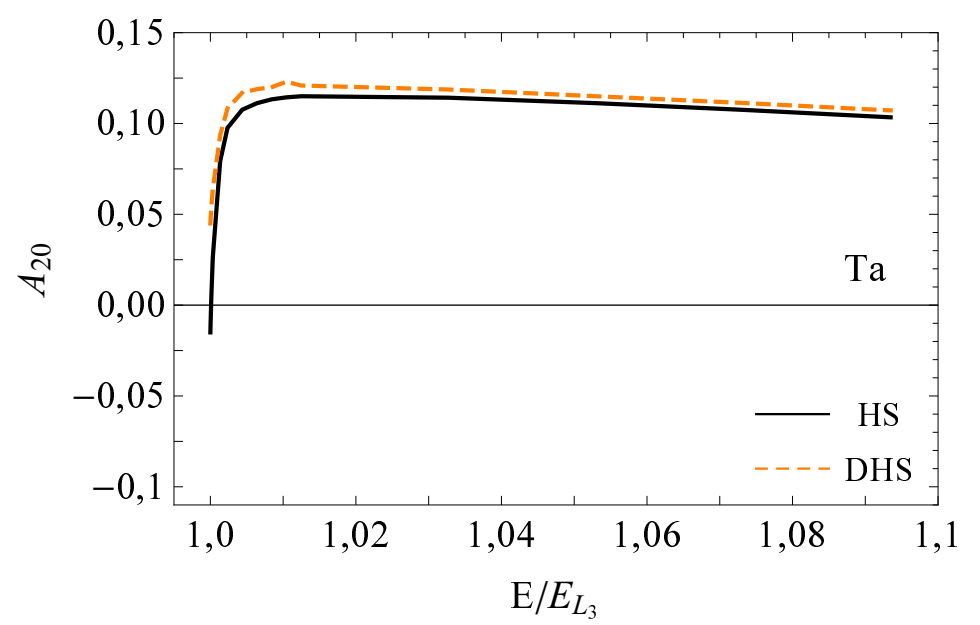

(a)

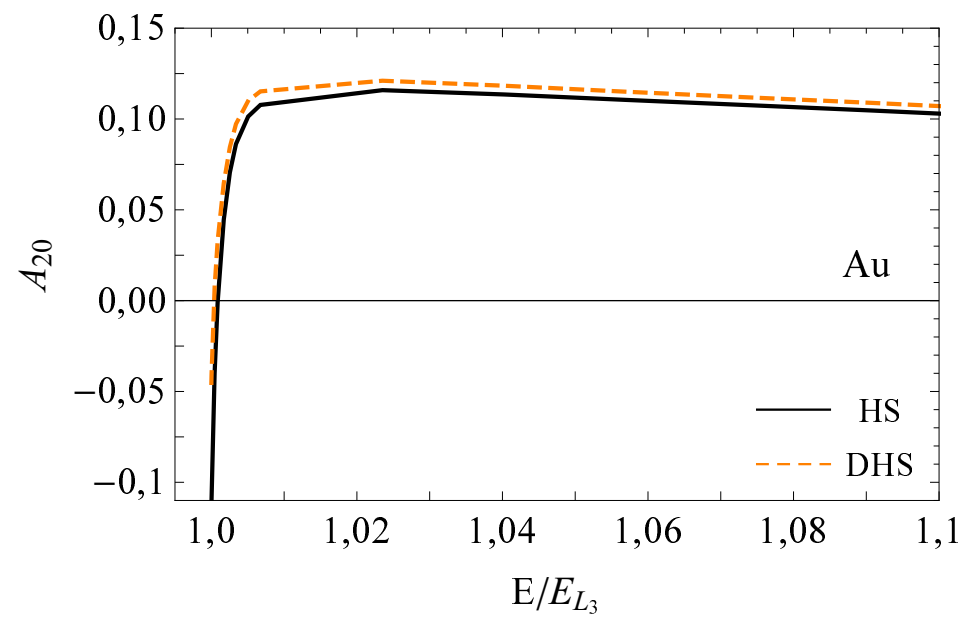

(b)

Figura 8.12: Valores do parâmetro de alinhamento $A_{20}$, calculados com os potenciais de HS (linha contínua em preto) e DHS (linha tracejada em laranja), na região $E / E_{\mathrm{L}_{3}}<1,1$ para a) Ta e b) Au. 


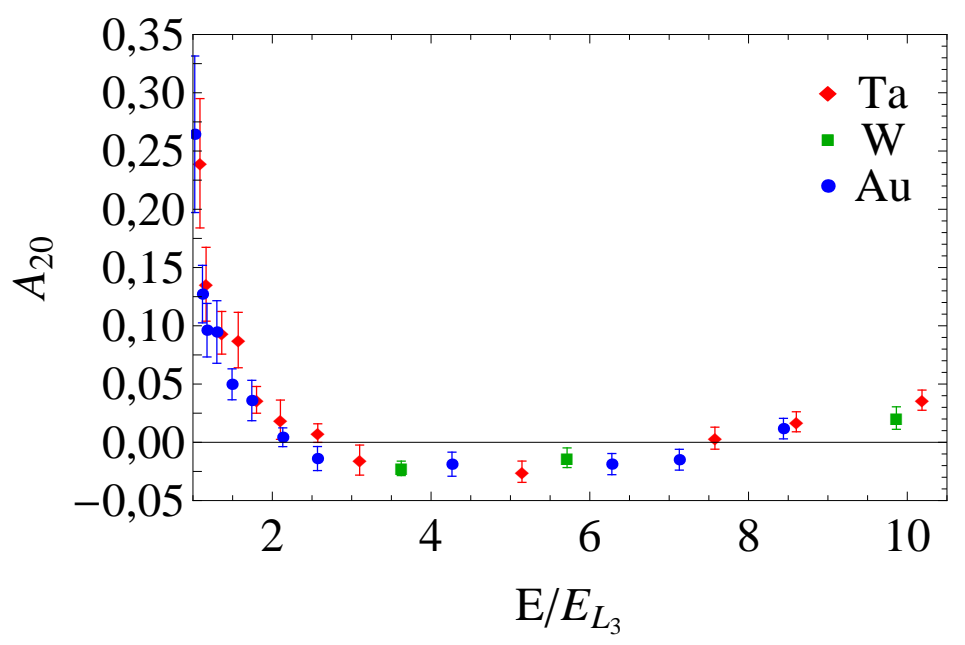

Figura 8.13: Parâmetro de alinhamento $A_{20}$ dos elementos Ta, W e Au em função da energia do elétron incidente em unidades da energia do limiar de ionização da subcamada $\mathrm{L}_{3}$ do elemento correspondente. As barras de incertezas correspondem a um desvio padrão.

Tabela 8.4: Estimativa do produto $\xi \alpha A_{20}$, equação (3.40), para a linha L $\eta$ e o multipleto $\mathrm{L} \gamma$ do Ta. O número entre parênteses é o desvio padrão estimado, em unidades do algarismo menos significativo do valor da grandeza.

\begin{tabular}{ccc}
\hline \hline Energia $(\mathrm{keV})$ & $\mathrm{L} \eta$ & $\mathrm{L} \gamma$ \\
\hline $13,46(9)$ & $0,003(15)$ & $0,0027(39)$ \\
$15,51(4)$ & $0,009(27)$ & $0,017(7)$ \\
$17,79(7)$ & $-0,001(14)$ & $-0,008(4)$ \\
$20,76(9)$ & $0,011(20)$ & $-0,011(5)$ \\
$25,41(15)$ & $-0,003(12)$ & $-0,005(3)$ \\
$30,62(9)$ & $0,002(17)$ & $-0,007(5)$ \\
$50,82(5)$ & $0,004(11)$ & $0,004(3)$ \\
$74,83(6)$ & $0,013(13)$ & $0,002(4)$ \\
$84,96(5)$ & $-0,007(12)$ & $0,000(3)$ \\
$100,60(4)$ & $-0,002(10)$ & $-0,0018(28)$ \\
\hline \hline Média externa & $0,001(4)$ & $-0,0019(11)$ \\
\hline \hline
\end{tabular}

Tabela 8.5: Mesmo que a tabela 8.4, para o alvo de W.

\begin{tabular}{ccc}
\hline \hline Energia (keV) & L $\eta$ & $\mathrm{L} \gamma$ \\
\hline $36,97(8)$ & $0,0092(92)$ & $-0,0076(22)$ \\
$58,28(3)$ & $0,000(13)$ & $-0,0060(31)$ \\
$100,65(7)$ & $0,008(15)$ & $-0,0061(33)$ \\
\hline \hline Média externa & $0,006(7)$ & $-0,0068(16)$ \\
\hline \hline
\end{tabular}


Tabela 8.6: Mesmo que a tabela 8.4, mas para o alvo de Au.

\begin{tabular}{ccc}
\hline \hline Energia $(\mathrm{keV})$ & $\mathrm{L} \eta$ & $\mathrm{L} \gamma$ \\
\hline $15,51(9)$ & $0,00(7)$ & $0,012(20)$ \\
$17,79(11)$ & $0,03(3)$ & $0,009(8)$ \\
$20,76(8)$ & $0,003(3)$ & $-0,005(8)$ \\
$25,41(9)$ & $0,015(7)$ & $0,008(4)$ \\
$30,62(15)$ & $0,009(19)$ & $-0,008(5)$ \\
$50,82(7)$ & $-0,001(17)$ & $0,003(4)$ \\
$74,83(7)$ & $-0,003(14)$ & $0,005(4)$ \\
$84,96(6)$ & $0,000(16)$ & $0,003(4)$ \\
$100,60(7)$ & $-0006(12)$ & $0,004(3)$ \\
\hline \hline Média externa & $0,002(6)$ & $0,0032(15)$ \\
\hline \hline
\end{tabular}

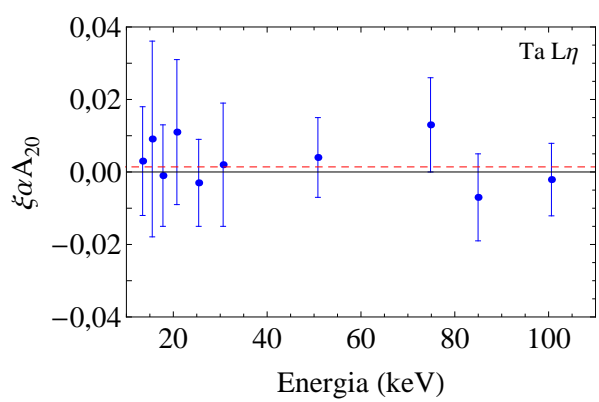

(a)

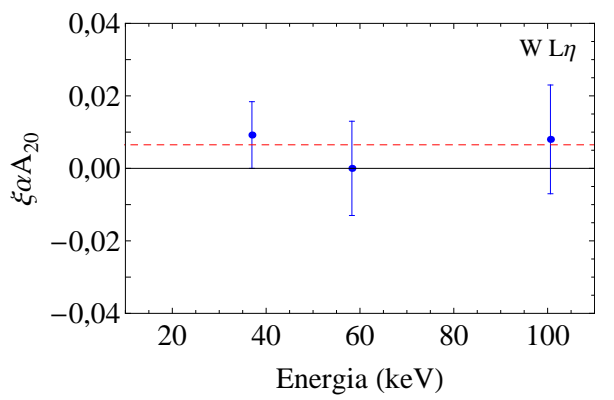

(c)

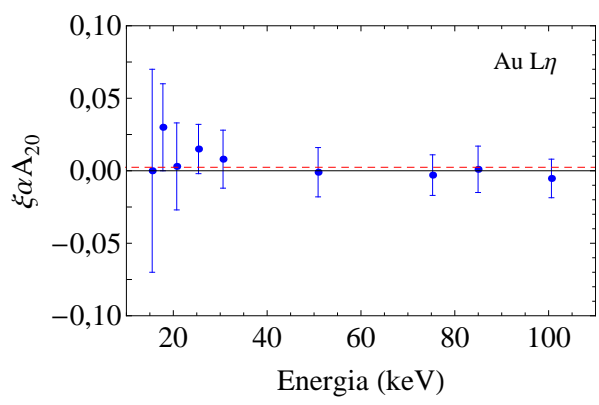

(e)

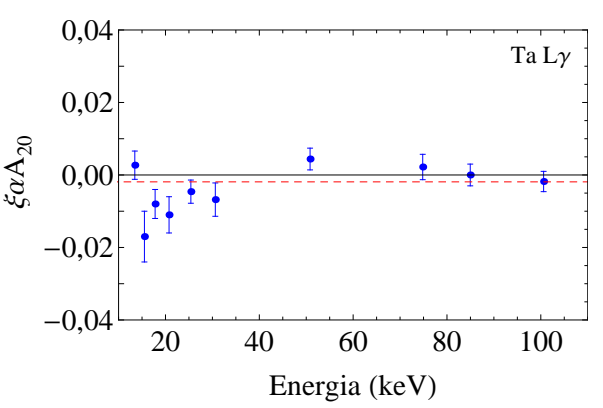

(b)

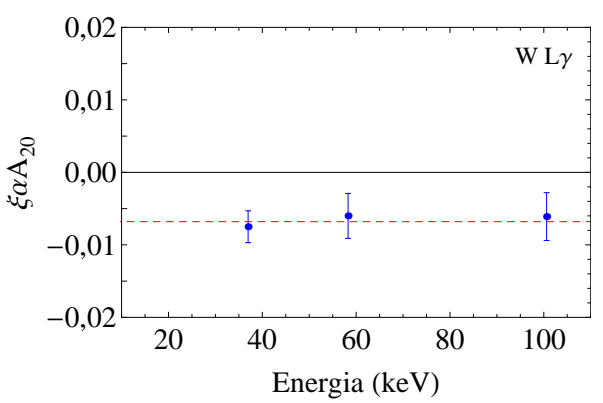

(d)

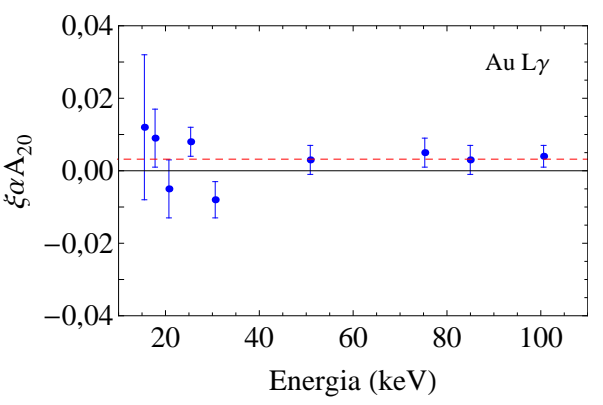

(f)

Figura 8.14: Estimativa do coeficiente representado pelo produto $\xi \alpha A_{20}$ da equação (3.40), para a linha L $\eta$ e multipleto $\mathrm{L} \gamma$ dos alvos de a) e b) Ta, c) e d) W e e) e f) Au. A linha tracejada corresponde à média ponderada dos valores. 
Tabela 8.7: Medidas das seções de choque de produção de raios x $\mathrm{L} \alpha, \mathrm{L} \beta, \mathrm{L} \gamma$, L $\ell$ e $\mathrm{L} \eta$ do Au por impacto de elétrons. Em parênteses, o desvio padrão em unidades do dígito menos significativo.

\begin{tabular}{cccccc}
\hline \hline$E(\mathrm{keV})$ & $\sigma_{\mathrm{L} \alpha}^{\mathrm{x}}(\mathrm{b})$ & $\sigma_{\mathrm{L} \beta}^{\mathrm{x}}(\mathrm{b})$ & $\sigma_{\mathrm{L} \gamma}^{\mathrm{x}}(\mathrm{b})$ & $\sigma_{\mathrm{L} \ell}^{\mathrm{x}}(\mathrm{b})$ & $\sigma_{\mathrm{L} \eta}^{\mathrm{x}}(\mathrm{b})$ \\
\hline $12,98(6)$ & $34(2)$ & $8,0(5)$ & & $1,62(11)$ & \\
$13,56(6)$ & $51(3)$ & $11,3(7)$ & & $2,44(15)$ & \\
$13,60(7)$ & $52(3)$ & $11,3(7)$ & & $2,62(16)$ & \\
$14,35(6)$ & $71(4)$ & $22,9(14)$ & $1,71(11)$ & $3,46(21)$ & \\
$15,08(7)$ & $90(5)$ & $37,4(22)$ & $5,2(3)$ & $4,37(27)$ & $0,38(18)$ \\
$16,16(6)$ & $111(7)$ & $56(3)$ & $8,0(5)$ & $5,4(3)$ & $0,79(25)$ \\
$17,85(8)$ & $138(8)$ & $78(5)$ & $11,7(7)$ & $6,7(4)$ & $1,0(3)$ \\
$22,45(7)$ & $173(10)$ & $108(6)$ & $17,4(10)$ & $8,5(5)$ & $1,8(4)$ \\
$25,01(8)$ & $183(11)$ & $117(7)$ & $19,2(11)$ & $9,0(5)$ & $1,8(4)$ \\
$31,62(7)$ & $194(11)$ & $129(8)$ & $21,1(12)$ & $9,6(6)$ & $2,0(4)$ \\
$35,53(8)$ & $194(11)$ & $131(8)$ & $21,8(13)$ & $9,6(6)$ & $2,1(4)$ \\
$45,42(4)$ & $191(11)$ & $131(8)$ & $21,7(13)$ & $9,5(6)$ & $2,1(4)$ \\
$50,88(13)$ & $186(11)$ & $128(7)$ & $21,5(13)$ & $9,2(6)$ & $2,0(4)$ \\
$51,70(4)$ & $184(11)$ & $127(7)$ & $21,1(12)$ & $9,1(5)$ & $1,9(4)$ \\
$60,98(5)$ & $175(10)$ & $123(7)$ & $20,4(12)$ & $8,6(5)$ & $1,8(4)$ \\
$71,30(4)$ & $166(10)$ & $117(7)$ & $19,4(11)$ & $8,2(5)$ & $1,8(4)$ \\
$80,55(6)$ & $159(9)$ & $112(7)$ & $19,1(11)$ & $7,9(5)$ & $1,7(3)$ \\
$90,06(8)$ & $152(9)$ & $107(6)$ & $18,1(11)$ & $7,6(5)$ & $1,7(3)$ \\
$100,15(9)$ & $148(8)$ & $105(6)$ & $18,0(10)$ & $7,4(4)$ & $1,7(3)$ \\
\hline \hline
\end{tabular}




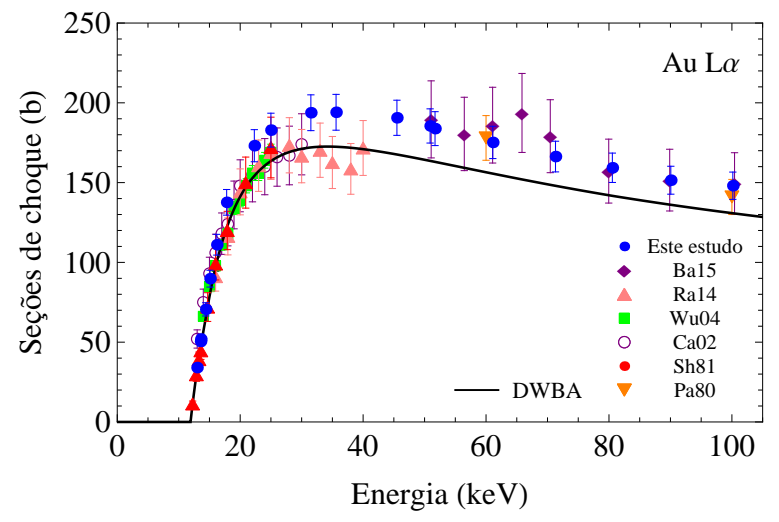

(a)

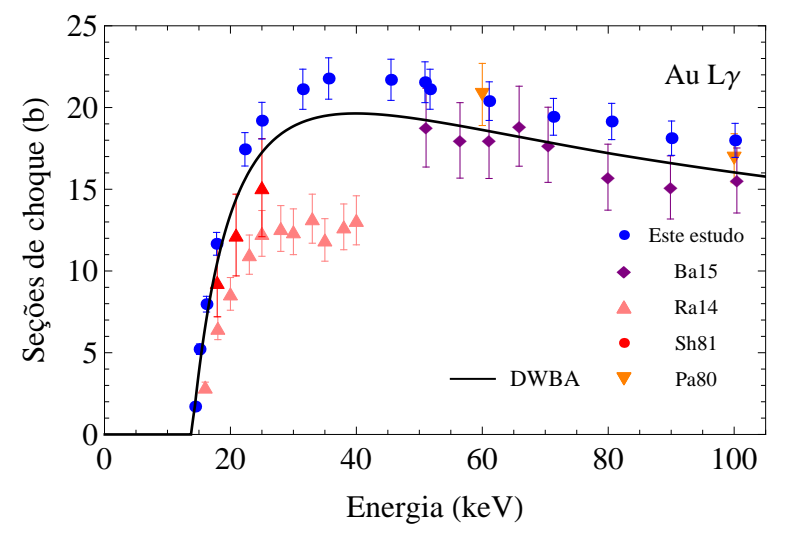

(c)

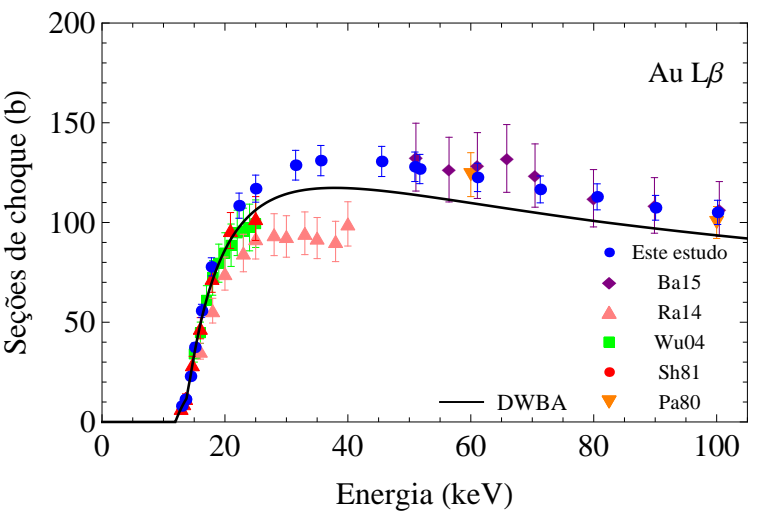

(b)

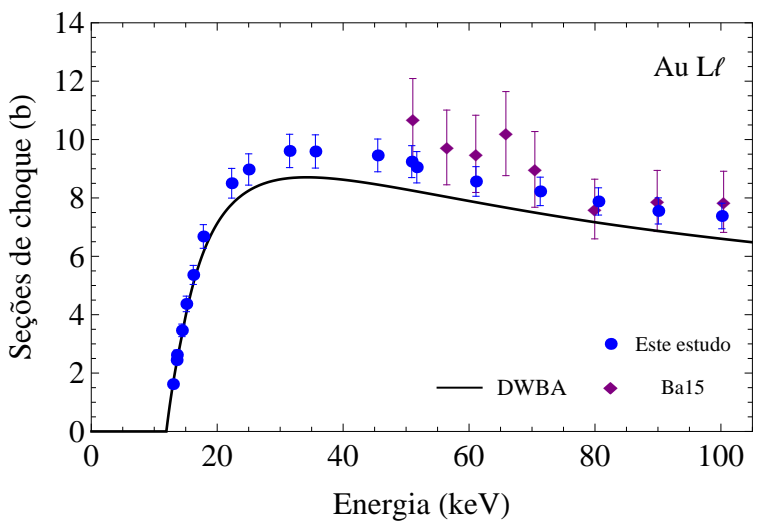

(d)

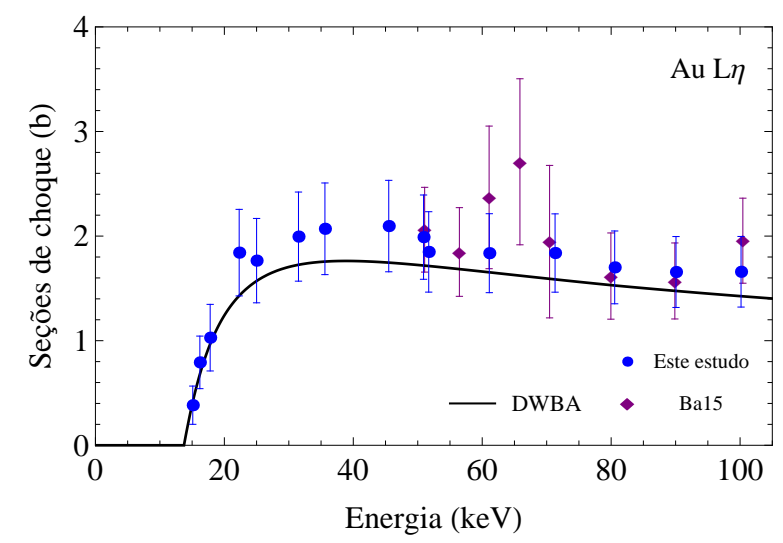

(e)

Figura 8.15: Seções de choque de produção de raios x $\mathrm{L} \alpha, \mathrm{L} \beta, \mathrm{L} \gamma$, L $\ell$ e $\mathrm{L} \eta$ do Au por impacto de elétrons. Os círculos (em azul) são os dados experimentais deste trabalho, os triângulos invertidos (em laranja), círculos (em vermelho), círculos vazios (em roxo), quadrados (em verde), triângulos (em rosa) e diamantes (em roxo) representam os dados das referências Pa80 [16], Sh81 [17], Ca02 [18], Wu04 [19], Ra14 [20] e Ba15 [21], respectivamente. As curvas contínuas são as seções de choque teóricas calculadas com a DWBA [22, 23]. 
Tabela 8.8: Seções de choque de ionização atômica das subcamadas $\mathrm{L}_{1}, \mathrm{~L}_{2}$ e $\mathrm{L}_{3}$ do $\mathrm{Au}$ por impacto de elétrons. Em parênteses, o desvio padrão em unidades do dígito menos significativo.

\begin{tabular}{cccl}
\hline \hline$E(\mathrm{keV})$ & $\sigma_{\mathrm{L}_{1}}(\mathrm{~b})$ & $\sigma_{\mathrm{L}_{2}}(\mathrm{~b})$ & $\sigma_{\mathrm{L}_{3}}(\mathrm{~b})$ \\
\hline $12,98(6)$ & & & $139(7)$ \\
$13,56(6)$ & & & $203(10)$ \\
$13,60(7)$ & & & $210(11)$ \\
$14,35(6)$ & & $27(2)$ & $279(16)$ \\
$15,08(7)$ & $38(4)$ & $56(4)$ & $328(20)$ \\
$16,16(6)$ & $57(6)$ & $91(7)$ & $400(26)$ \\
$17,85(8)$ & $86(8)$ & $134(10)$ & $488(32)$ \\
$22,45(7)$ & $132(11)$ & $199(14)$ & $598(41)$ \\
$25,01(8)$ & $152(12)$ & $215(15)$ & $624(44)$ \\
$31,62(7)$ & $163(12)$ & $242(17)$ & $663(47)$ \\
$35,53(8)$ & $168(13)$ & $249(17)$ & $658(47)$ \\
$45,42(4)$ & $168(12)$ & $246(17)$ & $647(46)$ \\
$50,88(13)$ & $174(12)$ & $240(16)$ & $625(45)$ \\
$51,70(4)$ & $175(12)$ & $237(16)$ & $613(44)$ \\
$60,98(5)$ & $169(12)$ & $236(16)$ & $579(42)$ \\
$71,30(4)$ & $160(11)$ & $219(15)$ & $555(40)$ \\
$80,55(6)$ & $149(10)$ & $217(14)$ & $532(39)$ \\
$90,06(8)$ & $143(10)$ & $204(14)$ & $510(37)$ \\
$100,15(9)$ & $141(10)$ & $205(13)$ & $495(36)$ \\
\hline \hline
\end{tabular}




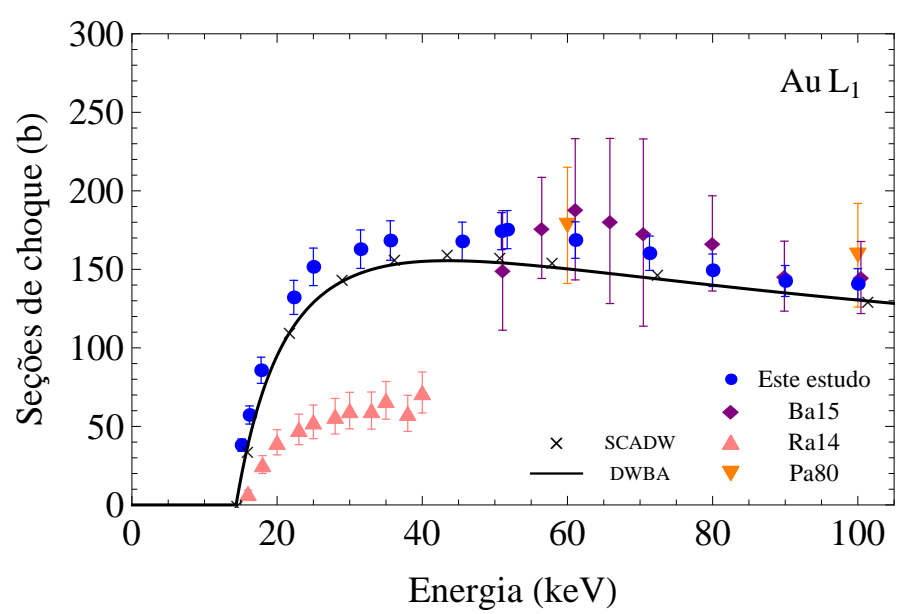

(a)

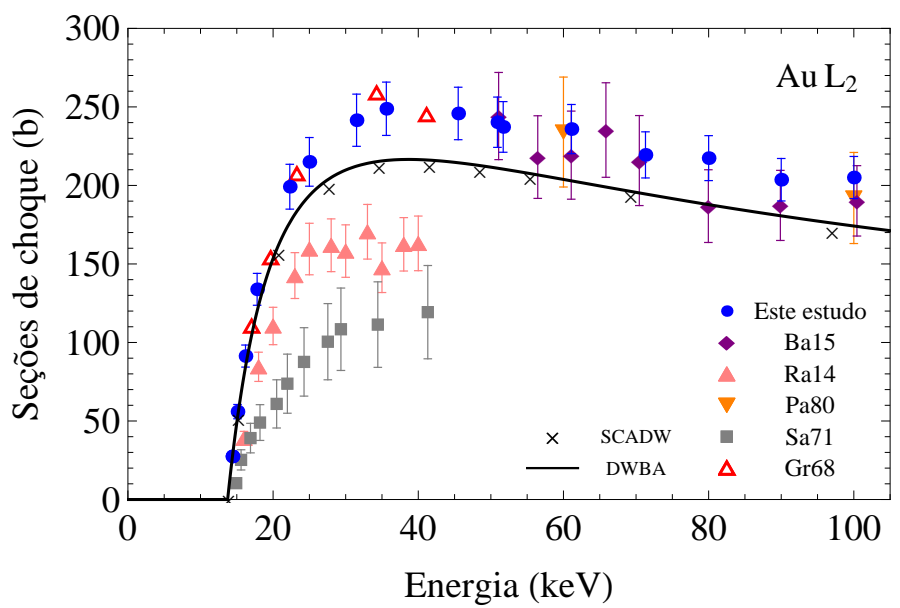

(b)

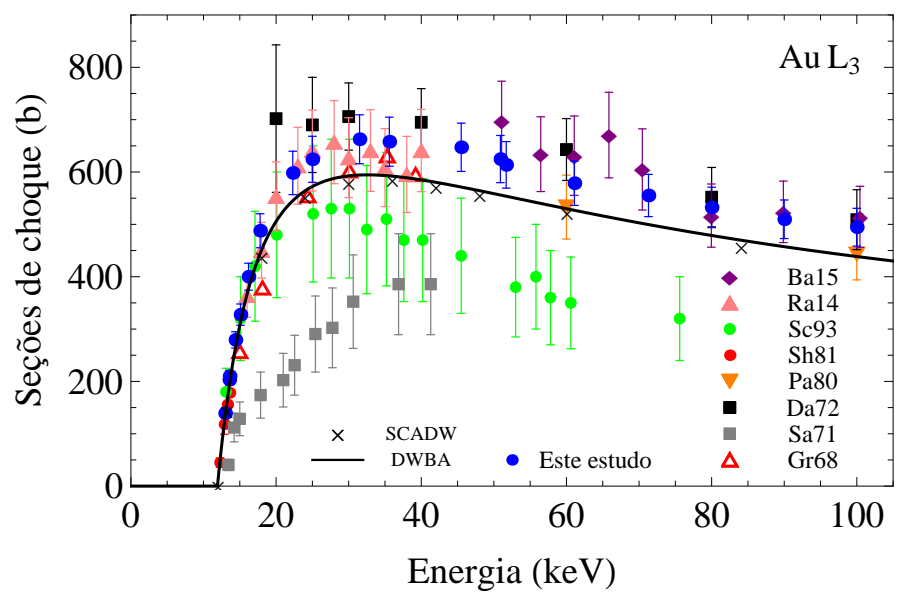

(c)

Figura 8.16: Seções de choque de ionização atômica das subcamadas $\mathrm{L}_{1}, \mathrm{~L}_{2}$ e $\mathrm{L}_{3}$ do $\mathrm{Au}$ por impacto de elétrons. Os círculos (em azul) são os valores experimentais deste trabalho. Os triângulos vazios (em vermelho), os quadrados (em verde), os quadrados (em preto), os triângulos invertidos (em laranja), os círculos (em vermelho), os círculos (em verde), os triângulos (em rosa) e os diamantes (em roxo) representam os dados das referências Gr68 [24], Sa71 [25], Da72 [26], Pa80 [16], Sh81 [17], Sc93 [27], Ra14 [20] e Ba15 [21], respectivamente. As curvas contínuas e os pontos em cruzes são as previsões teóricas da DWBA [22,23] e da SCADW [28], respectivamente. 


\section{Capítulo 9}

\section{Discussão}

Os resultados apresentados na seção anterior serão avaliados e comparados neste capítulo, começando pela distribuição angular na emissão das linhas $L \ell, L \alpha_{1}$ e $L \alpha_{2}$. Na seqüência serão discutidas as estimativas do parâmetro de alinhamento $A_{20}$, comparando os resultados experimentais com aqueles encontrados na literatura e com as previsões teóricas calculadas neste trabalho, tanto na região do limiar de ionização quanto fora dela. Comentam-se os resultados de distribuição angular en-

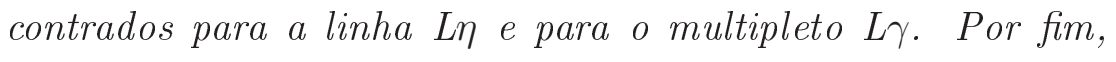
os resultados de seções de choque de produção de raios $x$ e de ionização das subcamadas $L$ serão discutidos.

\subsection{Anisotropia na emissão das linhas de raios x L}

As figuras de 8.1 a 8.7 deixam evidente que as linhas $\mathrm{L} \ell, \mathrm{L} \alpha_{1}$ e $\mathrm{L} \alpha_{2}$, todas provenientes do preenchimento de vacâncias na subcamada $\mathrm{L}_{3}$, podem ou não apresentar emissão anisotrópica, a depender da energia do feixe de elétrons incidente. Além disso, esses resultados também confirmam a expectativa teórica de que as linhas $\mathrm{L} \alpha_{1}$ e $\mathrm{L} \alpha_{2}$ apresentam anisotropias opostas, tabela 3.1. Cabe lembrar que, como as intensidades medidas dessas duas linhas são altamente correlacionadas (ver tabela 6.4), a maior parte das barras de incerteza são comuns a $\mathrm{L} \alpha_{1}$ e $\mathrm{L} \alpha_{2}$. Este é, a nosso saber, o primeiro trabalho experimetal com ionização por impacto de elétrons que confirma a anisotropia na emissão de $\mathrm{L} \alpha_{1}$ e $\mathrm{L} \alpha_{2}$ com sinais opostos. Resultados semelhantes foram encontrados por Yamaoka et al. $[7,8]$, mas com ionização do alvo de Au por impacto de fótons. 
Esse mesmo conjunto de figuras mostra que a anisotropia das três linhas, L $\ell, \mathrm{L} \alpha_{1}$ e $\mathrm{L} \alpha_{2}$, varia com a energia do feixe incidente, chegando a inverter de sinal duas vezes dentro do intervalo de energia explorado. Nas figuras 8.1 e 8.5 nota-se uma anisotropia não nula na emissão das três linhas, sendo positiva para as linhas $\mathrm{L} \ell$ e $\mathrm{L} \alpha_{1}$, e negativa para $\mathrm{L} \alpha_{2}$, já nas figuras 8.2 e 8.6 as três linhas apresentam emissão isotrópica, e finalmente nas figuras 8.3 e 8.7 observa-se uma emissão não isotrópica das linhas, sendo que na figura 8.3 as linhas $\mathrm{L} \ell$ e $\mathrm{L} \alpha_{1}$ estão com anisotropia positiva, e $\mathrm{L} \alpha_{2}$ com anisotropia negativa, enquanto que na figura 8.7 as anisotropias destas mesmas linhas aparecem com sinais opostos.

\subsection{Estimativa do parâmetro de alinhamento empre- gando três linhas simultaneamente}

Alguns dos trabalhos encontrados na literatura emprega somente uma linha de raios $\mathrm{x}$ para obter estimativas do parâmetro de alinhamento $A_{20}$. Küst e Mehlhorn [3,6], Barros Leite et al. [81] e Jitschin et al. [80], por exemplo, usam somente a linha L $\ell$, Yamaoka et al. [7] apesar de observar uma emissão anisotrópica na emissão da linha L $\alpha_{2}$, emprega somente L $\ell$, e Kämpfer et al. [10], em um experimento de polarização, emprega as linhas $\mathrm{L} \alpha_{1}$ e $\mathrm{L} \alpha_{2}$ separadamente, e obtém duas estimativas para $A_{20}$, uma por meio de $\mathrm{L} \alpha_{1}$ e outra por meio de $\mathrm{L} \alpha_{2}$.

Quando as intensidades dessas linhas não são incluídas simultaneamente, a estimativa do parâmetro de alinhamento pela distribuição angular das linhas de raios x se torna complicada devido ou à intensidade fraca ou à pequena anisotropia. Caso a análise seja conduzida somente pela linha $\mathrm{L} \alpha_{1}$, apesar de apresentar alta intensidade, o coeficiente $\alpha$ para esta linha é de $1 / 10$, de modo que a emissão é quase isotrópica. Olhando para linha $\mathrm{L} \alpha_{2}$ somente, apesar de $\alpha=-2 / 5$, a intensidade da linha é baixa, e sua estimativa apresenta forte correlação estatística com a intensidade da linha $L \alpha_{1}$, tabela 6.4, que precisa ser levada em conta na análise para que as incertezas finais não sejam superestimadas. Se a análise fosse feita com o dubleto $\mathrm{L} \alpha$, o coeficiente $\alpha_{\text {eff }}$ seria menor do que 1/10, uma vez que as linhas $\mathrm{L} \alpha_{1}$ e $\mathrm{L} \alpha_{2}$ apresentam anisotropias opostas, atenuando ainda mais a distribuição angular a ser observada. Por fim, basear a estimativa de $A_{20}$ somente nos dados de L $\ell$ também não é a metodologia mais adequada, porque embora essa linha apresente $\alpha=1 / 2$, sua intensidade é cerca de $5 \%$ da intensidade da linha $\mathrm{L} \alpha_{1}$, fazendo com que seja necessário um tempo de experimento grande para que se consiga boa precisão, sobretudo na região do limiar de ionização. 
A fim de ilustrar o ganho na precisão da estimativa de $A_{20}$ quando as três linhas, L $\ell$, $\mathrm{L} \alpha_{1}$ e $\mathrm{L} \alpha_{2}$, são empregadas juntas no ajuste, os parâmetros da expressão (3.55) foram ajustados aos dados de $\mathrm{L} \ell, \mathrm{L} \alpha_{1}$ e $\mathrm{L} \alpha_{2}$, separadamente e as curvas de mérito dos ajustes, definidas pela expressão (2.11), foram graficadas em função do parâmetro $A_{20}$. Observe que, nesta situação as correlações entre as linhas envolvidas na análise não são incluídas no ajuste. A figura 9.1 traz as curvas obtidas para o Au com elétrons de 13,35(19); 17, 79(11); $30,62(15)$ e $50,82(7) \mathrm{keV}$, e a tabela 9.1 apresenta os valores de $A_{20}$ encontrados para esses casos.

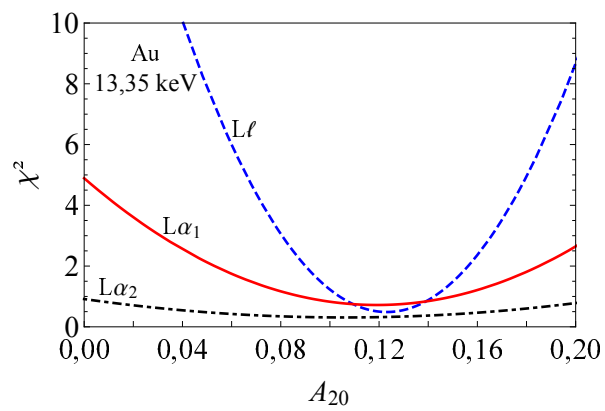

(a)

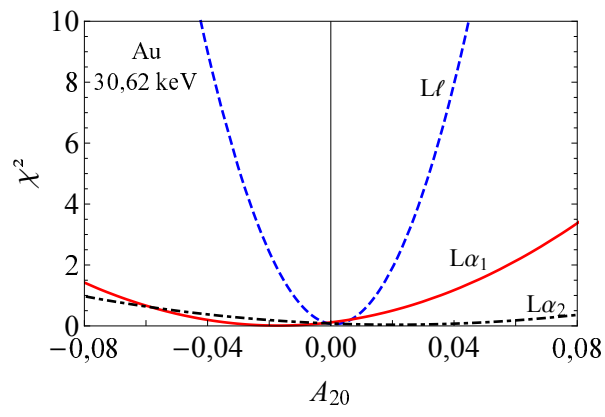

(c)

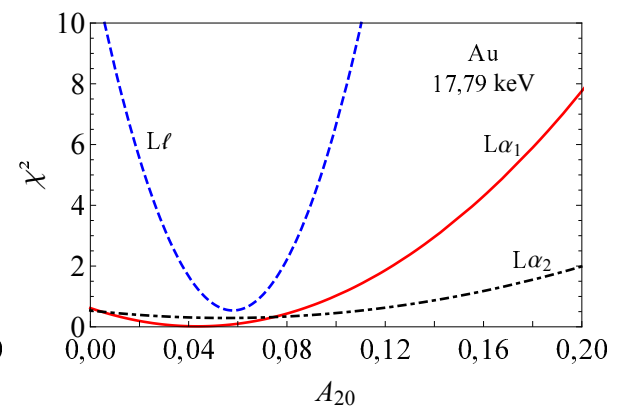

(b)

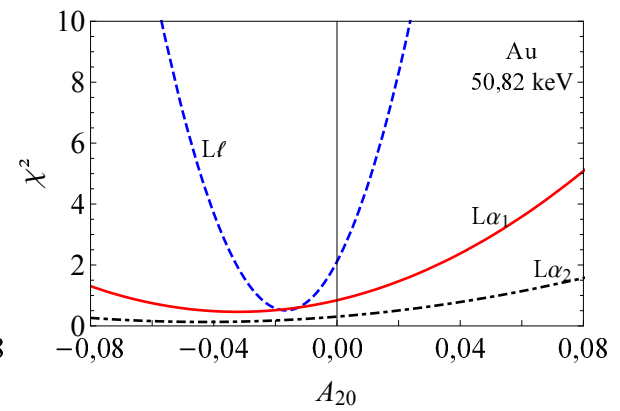

(d)

Figura 9.1: Dependência da função de mérito $\hat{Q}\left(A_{20}\right)$ com o parâmetro de alinhamento $A_{20}$ estimado a partir das linhas L $\ell$ (linha tracejada azul), L $\alpha_{1}$ (linha contínua vermelha) e $\mathrm{L} \alpha_{2}$ (linha ponto tracejada preta) do $\mathrm{Au}$, para as energias do elétron incidente de: a) $13,35(9)$, b) $17,79(11)$, c) $30,62(15)$ e d) $50,82(7) \mathrm{keV}$.

Tabela 9.1: Estimativa do parâmetro de alinhamento $A_{20}$ empregando as linhas L $\ell$, L $\alpha_{1}$ e $\mathrm{L} \alpha_{2}$ separadamente. O número entre parênteses é o desvio padrão estimado, em unidades do algarismo menos significativo do valor da grandeza.

\begin{tabular}{cccc}
\hline \hline Energia $(\mathrm{keV})$ & $\mathrm{L} \ell$ & $\mathrm{L} \alpha_{1}$ & $\mathrm{~L} \alpha_{2}$ \\
\hline $13,46(9)$ & $0,12(3)$ & $0,12(6)$ & $0,11(4)$ \\
$17,79(7)$ & $0,059(19)$ & $0,04(6)$ & $0,06(11)$ \\
$30,62(9)$ & $0,001(14)$ & $-0,02(5)$ & $0,00(3)$ \\
$50,82(5)$ & $-0,017(13)$ & $-0,03(5)$ & $-0,03(10)$ \\
\hline \hline
\end{tabular}


Nota-se na figura 9.1 que as curvas para as três linhas apresentam um mínimo definido, com valores de $A_{20}$ compatíveis entre si. Contudo, as estimativas obtidas por meio das linhas $\mathrm{L} \alpha_{1}$ e $\mathrm{L} \alpha_{2}$ individualmente não são conclusivas acerca do alinhamento, uma vez que a estimativa de $A_{20}$ encontrada por meio delas apresenta grandes incertezas, fazendo com que ele seja compatível com zero, na maioria dos casos, dentro de um a dois desvios padrões. Por outro lado, o dado obtido para $A_{20}$ somente com a linha L $\ell$ indica a existência do alinhamento, sobretudo na região próxima ao limiar de ionização onde a anisotropia é maior. Embora neste exemplo as incertezas obtidas para $A_{20}$ são apenas $16 \%$ superiores às incertezas encontradas quando emprega-se as três linhas simultaneamente no ajuste, esse aumento pode chegar a mais de $90 \%$ em certas energias do feixe incidente e da estatística de contagem nos picos, particularmente na região do limiar e quando $A_{20} \approx 0$. Na figura 9.2 são comparadas as estimativas de $A_{20}$ deste trabalho com as estimativas obtidas empregando somente a linha L $\ell$.

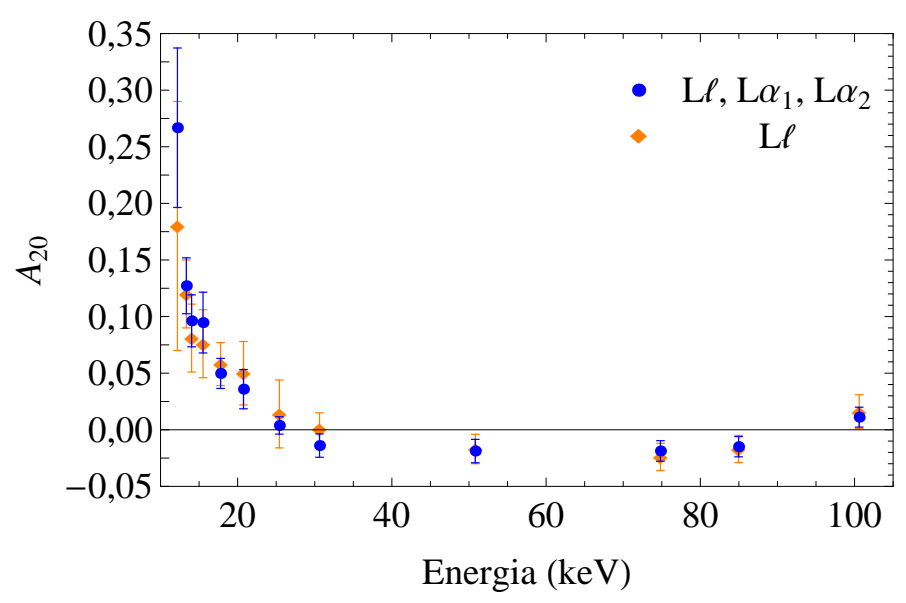

Figura 9.2: Estimativa do parâmetro de alinhamento $A_{20}$ com a metodologia apresentada na seção 6.3, círculos azuis, e empregando somente a linha L $\ell$, diamantes laranjas.

\subsection{Comportamento limiar do parâmetro de alinhamento $A_{20}$}

Entende-se como região de limiar neste trabalho aquela para a qual $E / E_{\mathrm{L}_{3}}<1,1$, conforme adotado por Berezhko et al. [65]. Dos resultados experimentais apresentados nas seções 8.1 e 8.2, estão nesta região aquele de $10,75 \mathrm{keV}$ da irradiação do Ta, e aquele de $12,19 \mathrm{keV}$ da irradiação do $\mathrm{Au}$, que correspondem a 1,09 e 1,02 $E_{\mathrm{L}_{3}}$, respectivamente. Nota-se nesta região um acordo razoável entre os cálculos empregando a aproximação de Born de ondas planas (PWBA) e os resultados experimentais, sendo a diferença entre ambos de dois desvios padrões, figuras 8.9 e 8.11. Cabe destacar que essa é uma região 
onde a seção de choque de produção de raios x é baixa, de modo que é necessário uma medição longa para garantir um dado conclusivo acerca da emissão anisotrópica.

Nessa região de limiar, as diferenças entre os valores teóricos de $A_{20}$ obtidos com os potenciais de HS e DHS foram de cerca de 5\%, de modo que os dados experimentais não permitiram qualquer distinção entre esses potenciais devido às barras de incerteza experimentais.

Boa parte dos trabalhos de alinhamento atômico pela distribuição angular na emissão de elétrons Auger teve como uma das motivações o estudo do parâmetro de anisotropia $A_{20}$ na região do limiar de ionização $[36,57,63,64]$. Esse interesse tem pelo menos duas razões. Por se tratar de uma região onde a seção de choque é baixa, há poucos dados existentes, e eles são afetados por grandes incertezas, o que motiva a busca por incertezas cada vez menores e dados cada vez mais conclusivos. Além disso, o valor do parâmetro $A_{20}$ na região próxima ao limiar, ou ainda no limiar, fornece informações das componentes $l^{\prime}$ da função de onda parcial do elétron livre. Na região do limiar, a energia do elétron ejetado é praticamente nula. Supondo que a ionização do átomo no alvo acontecesse somente via interação coulombiana, a componente $M$ do momento angular total $J$ do sistema ao longo do eixo $Z$, tomado como a direção do feixe incidente, seria conservada durante a colisão. Desde que o feixe incidente, bem como o átomo, tem $m=0$, o sistema total estaria inicialmente com $M_{i}=0$, logo, seguiria da conservação do momento angular que $M_{f}=0$. Na hipótese de que os dois elétrons escapem do átomo no limiar de ionização com momento angular $l^{\prime}=0$, então o átomo ionizado deveria ter $M\left(A^{+}\right)=0$, e da expressão (3.30) decorre que $A_{20}=-1$ no limiar. Portanto, se é encontrado um valor de $A_{20}$ tal que $\left|A_{20}\right|<1$ pode-se inferir que ondas parciais com $l^{\prime}>0$ contribuem no elétron ejetado, mesmo no limiar de ionização.

Dentre os trabalhos que estudaram a região do limiar estão os de Weber et al. [64] e os de Sandner e Schmitt [63]. Em ambos as medidas de $A_{20}$ na região do limiar foram diferentes de -1 . Weber et al. [64] encontraram $A_{20}=0,09(16)$ para $E=1,08 E_{\mathrm{L}_{3}}$, e Sandner e Schmitt [63] obtiveram $A_{20}=-0,0262(19)$ para $E=1,4 E_{\mathrm{L}_{3}}$. Estes resultados estão em acordo qualitativo com os resultados desta pesquisa, ver tabelas 8.1 e 8.3, uma vez que encontramos esta mesma tendência, mas para outros elementos, e por meio da análise da distribuição angular de raios x, o que confirma que valores de $l^{\prime}>0$ também contribuem na função de onda parcial do elétron ejetado, mesmo quando a energia dele é próxima de zero.

Destaca-se em Mehlhorn [36] e Weber et al. [64] que a interação pós-colisão dos dois 
elétrons livres, o do projétil e o ejetado, com o elétron Auger emitido pelo alvo, tende a distorcer a forma das linhas Auger e a atenuar a distribuição angular da emissão, sendo este efeito tanto maior quanto mais próximo da energia do limiar de ionização da subcamada estudada, e quanto menor o tempo de vida do estado excitado. Diante disso, Weber et al. [64] aponta a necessidade de medidas de alinhamento atômico em situações onde a interação pós-colisão não ocorre, como no estudo da anisotropia pela distribuição angular dos raios x L.

Os resultados experimentais do parâmetro de alinhamento $A_{20}$ para as energias na região do limiar de ionização $\mathrm{L}_{3}$ do Ta e Au deste trabalho estão em acordo qualitativo com os de Weber et al. [64], Sandner e Schmitt [63], Küst e Mehlhorn [3] e Yamaoka et al. [8], e em desacordo com os de Aydinol et al. [2]. Uma possível razão para o desacordo com os resultados de Aydinol et al. [2] pode estar relacionado à forma como os dados foram normalizados no artigo, empregando as áreas das linhas $\mathrm{L} \beta_{1,3,4}$, que são isotrópicas. A linha $\mathrm{L} \beta_{6}$ está localizada entre as três usadas, e apresenta uma emissão anisotrópica, com $\alpha=1 / 2$. Para energias de ionização logo acima do limiar $\mathrm{L}_{1}$, a área de $\mathrm{L} \beta_{6}$ pode ser uma parte significativa de $\mathrm{L} \beta_{1,3,4,6}$. Caso ela não tenha sido subtraída corretamente deste grupo a área usada na normalização pode estar afetada com uma contribuição que apresenta dependência angular, comprometendo o dado final.

Nas figuras 8.9, 8.10 e 8.11 somente foram apresentados os resultados dos cálculos teóricos para as energias superiores à menor energia estudada experimentalmente, uma vez que para energias menores foi verificado que o parâmetro de alinhamento varia rapidamente, exigindo dados experimentais para comparação com energias que variassem cerca de $10 \mathrm{eV}$, o que está além da variação mínima de energia dos elétrons do feixe da máquina usada no experimento. A cargo de comparar os valores obtidos com os dois potenciais empregados, HS e DHS, foi calculado o parâmetro de alinhamento $A_{20}$ desde a energia do limiar de ionização $\mathrm{L}_{3}$ até $E / E_{\mathrm{L}_{3}}=1,1$. Os valores encontrados estão apresentados na figura 8.12. Em particular, para a energia do limiar $\mathrm{L}_{3}$ os valores obtidos para o alvo de Ta foram de $-0,015$ e 0,045 e de Au de -0,116 e -0,045, com os potenciais de HS e DHS, respectivamente. Esses resultados sugerem que uma medição no limiar, ou muito próxima dele, poderia distinguir entre os dois potenciais empregados, contudo esta medição ainda está fora das condições experimentais desta pesquisa. 


\subsection{Estimativas do parâmetro de alinhamento $\boldsymbol{A}_{20}$ acima do limiar de ionização da subcamada $\mathrm{L}_{3}$}

As figuras 8.9, 8.10 e 8.11 trazem as estimativas experimentais do parâmetro de alinhamento, junto com os resultados dos cálculos empregando os potenciais de HS e DHS, em função da energia do elétron incidente em keV. As estimativas experimentais apresentam a mesma tendência nos três elementos; uma queda acentuada para energias logo acima do limiar de ionização $\mathrm{L}_{3}$ do elemento, duas inversões de sinal dentro do intervalo de energia estudado, e um valor não nulo para energias cerca de 10 vezes o limiar $\mathrm{L}_{3}$.

Como no caso do estudo na região do limiar de ionização, não foram encontrados dados experimentais de $A_{20}$ na literatura para os elementos e energias deste trabalho, de forma que a comparação com os dados de outros grupos será apenas qualitativa.

As medições do parâmetro de alinhamento $A_{20}$ do Ar pela distribuição angular dos elétrons Auger de Weber et al. [64] e Sandner e Schmitt [63] foram realizadas para a faixa de energia de 1, 08 até 4, $04 E_{\mathrm{L}_{3}}$ e de 1, 4 até $200 E_{\mathrm{L}_{3}}$, respectivamente. Ambos mostraram uma queda rápida do parâmetro de alinhamento em poucos eVs acima do limiar, com uma inversão de sinal na região em torno de 1,5-2 $E_{\mathrm{L}_{3}}$. Em Weber et al. [64] uma segunda inversão não é observada, provavelmente devido ao intervalo limitado de energia, enquanto que em Sandner e Schmitt [63] na região em torno de $10 E_{\mathrm{L}_{3}}$ parece existir uma segunda inversão, contudo ela não pode ser confirmada devido às barras de incerteza.

O estudo de Aydinol et al. [2] da polarização dos raios x do Xe com ionização por impacto de elétrons mostrou resultados semelhantes. Uma queda brusca da polarização logo acima do limiar, com uma inversão do sinal em torno de $1,5-2 E_{\mathrm{L}_{3}}$, e, para energias maiores, os resultados parecem sugerir uma segunda inversão, que não é conclusiva dentro das barras de incerteza, de forma que acima de $2 E_{\mathrm{L}_{3}}$ os resultados são consistentes com uma polarização nula, e portanto, uma emissão isotrópica.

Entre os trabalhos realizados com fotoionização, os resultados de Yamaoka [8] para o Au sugerem uma queda do parâmetro de alinhamento com a energia do fóton incidente, entretanto devido ao intervalo estreito de energias estudados, 1,09-1,26 $E_{\mathrm{L}_{3}}$, não foi possível observar nenhuma inversão no sinal do parâmetro de alinhamento.

Os resultados desta pesquisa estão em bom acordo com os citados nos parágrafos acima, sendo conclusivos acerca da segunda inversão de sinal do parâmetro de alinhamento em torno $8 E_{\mathrm{L}_{3}}$. Por outro lado, nossos resultados estão em total desacordo com os de Hrdý et al. [1] que encontraram uma polarização compatível com $A_{20}=-0,98(25)$ para 
$\mathrm{Hg}$ com energia do elétron incidente de $30 \mathrm{keV}$, aproximadamente $2,4 E_{\mathrm{L}_{3}}$.

A ideia apresentada por Hrdý et al. [1], de que a medida da polarização/anisotropia da radiação emitida é impossível de ser realizada com alvos sólidos devido ao espalhamento dos elétrons primários dentro do alvo é refutada pelos resultados desta pesquisa. Preocupações neste sentido também apareceram no trabalho de Cleff e Mehlhorn [62]. Empregando alvos sólidos finos, a atenuação da polarização/anisotropia pode ser corrigida com apenas um fator multiplicativo, conforme apresentado no capítulo 3, não comprometendo os resultados dentro da faixa de energia investigada neste trabalho.

Quando comparados com as curvas téoricas construídas na aproximação de Born de ondas planas com os potencias de HS e DHS, as figuras 8.9, 8.10 e 8.11 mostram que os resultados experimentais apresentam bom acordo com a teoria para a energia do elétron incidente inferior a cerca de $5 E_{\mathrm{L}_{3}}$. Acima desta energia, os resultados experimentais mostram uma segunda inversão do sinal do alinhamento, enquanto que a curva teórica não prevê essa inversão. Pode ser mostrado que essa divergência não tem relação com a produção indireta de vacância na subcamada $L_{3}$ via ionização da camada $\mathrm{K}$ e a subseqüente transferência da vacância para $\mathrm{L}_{3}$. Usando as seções de choque de ionização de Bote e Salvat [22] do Ta calculadas com a DWBA, a razão $\sigma\left(1 \mathrm{~s}_{1 / 2}\right) / \sigma\left(2 \mathrm{p}_{3 / 2}\right)$ é de aproximadamente $4 \times 10^{-3}$ para $70 \mathrm{keV}$; multiplicando esse fator pelo yield fluorescente da camada $\mathrm{K}$ do Ta, $\omega_{\mathrm{K}}=0,957$ [133], encontra-se uma probabilidade de produção indireta de vacância na subcamada $\mathrm{L}_{3}$ menor do que $4 \times 10^{-3}$. O mesmo procedimento para o Au resulta em uma probabilidade menor do que $3 \times 10^{-3}$, que podem ser ignoradas para os propósitos deste trabalho.

Os cálculos teóricos realizados nesta pesquisa não incluiram efeitos relativísticos no elétron incidente e espalhado. Quando a energia do feixe incidente é de $60 \mathrm{keV}$, a velocidade do elétron já é de aproximadamente $0,5 c$, de forma que cálculos relativísticos são necessários nesta região.

A comparação entre as curvas calculadas com os potenciais de HS e de DHS nas figuras 8.9, 8.10 e 8.11 deixa claro que elas são praticamente semelhantes para a região acima do limiar de ionização, $E>1,1 E_{\mathrm{L}_{3}}$, prevendo a mesma posição para a inversão de sinal do parâmetro $A_{20}$ e o mesmo comportamento de $A_{20}$ para a região de maior energia, de forma que também fora da região de limiar não foi possível observar qualquer distinção entre os potenciais HS e DHS, dentro das incertezas experimentais deste trabalho.

A comparação da dependência de $A_{20}$ com a energia para os três elementos, figura 8.13, parece seguir uma mesma curva, com aproximadamente os mesmos valores na região 
do limiar, nos pontos de inversão e no limite de cerca de 10 vezes o limiar de ionização, o que está de acordo com o encontrado nos trabalhos de Jitschin et al. [78,79] onde a ionização foi realizada por impacto de prótons e íons.

Cabe destacar aqui que este é, a nosso saber, o primeiro trabalho experimental onde a dependência do parâmetro de alinhamento com a energia do elétron incidente é investigada, na região entre 1 e $10 E_{\mathrm{L}_{3}}$, empregando um único sistema. Em Sandner e Schmitt [63] dois canhões de elétrons foram empregados para cobrir a faixa de energia de 1, 4 até $200 E_{\mathrm{L}_{3}}$, enquanto que Jitschin et al. usou 3 [78] e 5 [80] aceleradores diferentes de íons nos experimentos que realizaram.

\subsection{Distribuição angular da linha $L \eta$ e do multipleto $\mathrm{L} \gamma$}

Os resultados para a dependência angular na emissão da linha $\mathrm{L} \eta$ e do grupo $\mathrm{L} \gamma$ da figura 8.14 são compatíveis com uma emissão isotrópica. Os valores constantes das médias externas de $\xi \alpha A_{20}$ ajustadas aos conjuntos de dados e apresentadas nas tabelas 8.4 a 8.6 para L $\eta$ foram compatíveis com zero dentro de um desvio padrão para os três elementos estudados. Verificar a anisotropia na emissão da linha L $\eta$ é também um teste da qualidade do ajuste do multipleto, pois esta linha está na cauda do dubleto L $\alpha$ e próxima da linha $\mathrm{L} \beta_{6}$, que apresentam emissão anisotrópica. Se L $\eta$ se mostra isotrópico, o ajuste foi bem conduzido e não há vestígios das áreas de $\mathrm{L} \alpha$ e $\mathrm{L} \beta_{6}$ dentro da estimativa de área de $\mathrm{L} \eta$.

No caso do multipleto $\mathrm{L} \gamma$, a hipótese da média externa de $\xi \alpha A_{20}$ ser compatível com zero em um teste $z$ só não é rejeitada no caso do Ta, nos demais casos a hipótese é rejeitada com nível de confiança de $5 \%$. Como o grupo L $\gamma$ ocupa uma região de cerca de 1000 eV no espectro, é possível que no procedimento de ajuste a componente contínua do espectro ajustado possa não ter dado conta de todo o espectro de bremsstrahlung, fazendo com que uma distribuição angular residual deste esteja ainda presente nas linhas características do multipleto $\mathrm{L} \gamma$. Esse resultado, contudo, não compromete a estimativa de $A_{20}$ obtida por meio das linhas $\mathrm{L} \ell, \mathrm{L} \alpha_{1}$ e $\mathrm{L} \alpha_{2}$ porque, primeiramente, o dubleto $\mathrm{L} \alpha$ apresenta uma intensidade muito superior à do multipleto $\mathrm{L} \gamma$, de forma que se uma contribuição da distribuição angular do bremsstrahlung semelhante a que apareceu em L $\gamma$ estivesse também em L $\alpha$, ela poderia ser ignorada em relação à intensidade deste dubleto; por outro lado, as larguras a meia altura tanto do pico L $\ell$ quanto do pico L $\alpha$ são inferiores à do grupo L $\gamma$, assim têm-se uma parcela pequena da componente contínua do espectro 
envolvida nas estimativas das áreas de $\mathrm{L} \ell, \mathrm{L} \alpha_{1}$ e $\mathrm{L} \alpha_{2}$.

Nenhum dos trabalhos da literatura realizado com impacto de elétrons traz resultados para a linha $\mathrm{L} \eta$ e para o grupo $\mathrm{L} \gamma$. As medidas existentes para o grupo $\mathrm{L} \gamma$ foram realizadas por impacto de fótons [4,70,73], e em todos os casos uma emissão isotrópica foi encontrada, em acordo com os resultados deste trabalho. De forma análoga, Yamaoka et al. [77] encontram uma emissão isotrópica dentro das barras de incertezas para a linha L $\eta$.

\subsection{Seções de choque de produção de raios $\mathrm{x}$ L e de ionização das subcamadas L do Au}

As medidas de seções de choque de produção de raios x e de ionização das subcamadas L do Au por impacto de elétrons realizadas nesta pesquisa dão seqüência ao trabalho prévio Barros et al. [21,98]. Assim, uma completa revisão dos experimentos e medidas de seção de choque L do Au por impacto de elétrons pode ser encontrada nessas referências e na publicação [124]. Além disso, os dados aqui reportados ja foram publicados em Barros et al. [48], de forma que maiores detalhes são apresentados nesta referência.

Estimativas de seções de choque de produção de raios x podem ser realizadas de duas formas diferentes, pelo menos. Seguindo-se a classificação definida em Barros et al. [21], chama-se "medida direta" aquela onde $N_{\mathrm{e}}$ é obtido pela medida da corrente do feixe, e a densidade superficial da amostra é determinada em um experimento independente. A classificação "medida relativa" é empregada quando o produto $N_{\mathrm{e}} d$ é deduzido do mesmo conjunto de dados de onde se obtém as seções de choque, com a análise do espectro de bremsstrahlung experimental e usando as previões teóricas das seções de choque diferenciais de bremsstrahlung.

As medidas de seções de choque de produção de raios x apresentadas aqui foram obtidas empregando a "medida direta". Em relação aos dados prévios [21], elas estão em completo acordo para os multipletos $\mathrm{L} \alpha$ e $\mathrm{L} \beta$, e mostram uma pequena diferença para o grupo L $\gamma$, causada pela metodologia de ajuste dos picos $[21,48]$.

Essas novas medidas de seções de choque de produção de raios x têm incertezas da ordem de $6 \%$ para os grupos $\mathrm{L} \alpha, \mathrm{L} \beta$ e $\mathrm{L} \gamma$ e da ordem de $6 \%$ e $20 \%$ para as linhas L $\ell$ e L $\eta$, o que constitui uma melhora substancial da precisão em relação aos dados prévios, onde essas incertezas eram de 13\%, 15\% e 30\%, respectivamente [21]. Esta melhora se deve, principalmente, ao uso da "medida direta" para a obtenção das seções de choque de produção de raios x, que reduziu a incerteza da densidade superficial do alvo de Au de 11\% 
para 5\%. Como conseqüência, as incertezas relativas das seções de choque de ionização das subcamadas $\mathrm{L}_{1}, \mathrm{~L}_{2}$ e $\mathrm{L}_{3}$ do $\mathrm{Au}$ foram de aproximadamente $8 \%, 7 \%$ e $7 \%$, respectivamente, fazendo do presente resultado o conjunto de dados mais preciso da literatura.

Comparando com os cálculos teóricos, as seções de choque de produção de raios x L $\alpha$, $\mathrm{L} \beta$ e $\mathrm{L} \gamma$ deste trabalho estão entre 10 - 12\% acima das previsões da DWBA e da SCADW, enquanto que as seções de choque de ionização das subcamadas $\mathrm{L}_{1}, \mathrm{~L}_{2}$ e $\mathrm{L}_{3}$ estão cerca de $10 \%$ acima das previsões destes formalismos.

O uso da expressão (6.17) para estimar as seções de choque de produção de raios x supõe a emissão isotrópica destas. Contudo, como discutido na seção 9.1, os resultados desta pesquisa confirmaram a emissão anisotrópica das linhas de raios x L decorrentes do preenchimento de vacâncias criadas na subcamada $\mathrm{L}_{3}$, a depender da energia do feixe incidente. Por outro lado, o alinhamento produzido por impacto de elétrons é apreciável somente na região do limiar de ionização, caindo rapidamente com o crescimento da energia, figura 8.11. Os cálculos realizados com a aproximação de Born de ondas planas empregando tanto o potencial de HS quanto o de DHS, bem como nosso dado experimental em torno de $13 \mathrm{keV}$, sugerem um parâmetro de alinhamento de aproximadamente 0,12. Porém, a anisotropia da radiação emitida é atenuada pelo coeficiente $\alpha$, equação (3.28). Para as linhas $\mathrm{L} \alpha_{1}$ e L $\ell$ esse coeficiente é de $1 / 10$ e 1/2, respectivamente, tabela 3.1, que faz com que a anisotropia efetiva da emissão seja de aproximadamente $1,2 \%$ para $\mathrm{L} \alpha_{1}$ e $6 \%$ para L $\ell($ em $13 \mathrm{keV})$. Desde que a medida da seção de choque de ionização da subcamada $\mathrm{L}_{3}$ é dominada pela linha $\mathrm{L} \alpha_{1}$ (que é cerca de 17 vezes mais intensa que a linha $\mathrm{L} \ell$ ), e a incerteza de $\sigma_{\mathrm{L}_{3}}$ neste trabalho foi da ordem de $6 \%$, a suposição de emissão isotrópica causa erros de cerca de $1 / 5$ da incerteza indicada perto do limiar; para energias maiores os erros são ainda menores, e por isso ela não foi levada em conta nesta análise. 



\section{Capítulo 10}

\section{Conclusão}

Este trabalho traz as primeiras medidas de alinhamento atômico por impacto de elétrons no intervalo de 10 a $100 \mathrm{keV}$ empregando alvos finos de elementos pesados, via distribuição angular dos raios x. Esses resultados foram alcançados por meio de uma melhora significativa tanto no arranjo e procedimento experimental quanto na análise dos dados, em relação aos trabalhos já publicados. Como resultado desses avanços, foi possível observar e quantificar de forma conclusiva a distribuição angular na emissão dos raios x L, e conseqüentemente, o alinhamento atômico. Além disso, com esse aprimoramento foi possível obter o conjunto de dados mais preciso da literatura para as seções de choque de ionização das subcamadas L do Au desde o limiar de ionização até $100 \mathrm{keV}$, e evidenciar que as medidas de Rahangdale et al. [20] para a subcamada $\mathrm{L}_{1}$ são discrepantes.

Verificou-se que a distribuição angular de emissão das linhas $\mathrm{L} \ell, \mathrm{L} \alpha_{1}$ e $\mathrm{L} \alpha_{2}$ dos elementos Ta, W e Au desde o limiar de ionização $\mathrm{L}_{3}$ destes elementos até $100 \mathrm{keV}$ é anisotrópica. Os resultados permitiram afirmar que essa anisotropia é máxima próximo ao limiar de ionização $\mathrm{L}_{3}$, decrescendo rapidamente até anular-se em torno de $2,5 E / E_{3}$, inverte de sinal e torna a anular-se em $8 E / E_{3}$, quando inverte novamente de sinal. Adicionalmente, foi possível confirmar a expectativa teórica de que as linhas $\mathrm{L} \alpha_{1}$ e $\mathrm{L} \ell$ apresentam anisotropias opostas à da linha $\mathrm{L} \alpha_{2}$.

A partir dos dados de distribuição angular das linhas $\mathrm{L} \ell, \mathrm{L} \alpha_{1}$ e $\mathrm{L} \alpha_{2}$ foi possível medir o alinhamento atômico, verificar sua dependência com a energia do elétron incidente, e mostrar que esse não é um fenômeno restrito ao limiar de ionização. A dependência de $A_{20}$ com a energia do feixe incidente segue o comportamento da anisotropia: uma queda rápida de $A_{20} \operatorname{logo}$ acima do limiar de ionização, duas inversões de sinal antes dos $100 \mathrm{keV}$, para 
os três elementos analisados, sendo que para energias de cerca de $10 E_{\mathrm{L}_{3}}$ o valor de $A_{20}$ foi positivo nos três casos. As curvas de $A_{20}$ em função de $E / E_{\mathrm{L}_{3}}$ para os três elementos têm o mesmo comportamento tanto na região próxima ao limiar, quanto nos pontos de inversão e na região de aproximadamente $10 \mathrm{E} / \mathrm{E}_{\mathrm{L}_{3}}$.

A comparação dos resultados experimentais com os valores calculados com a aproximação de Born de ondas planas empregando os potenciais de HS e DHS mostra um bom acordo até cerca de $5 E_{\mathrm{L}_{3}}$ para os três elementos. Acima desta energia, os valores experimentais evidenciam uma segunda inversão no sinal do parâmetro de alinhamento, que não é prevista pelo modelo. Esses resultados abrem espaço para uma nova investigação teórica desse fenômeno, que empregue uma aproximação mais sofisticada para descrever a interação projétil-átomo incluindo os efeitos relativísticos. Por outro lado, os cálculos conduzidos na região do limiar deixaram evidente que com uma medição no limiar de ionização, ou poucos eV acima dele, seria possível distinguir quais aproximações descrevem de forma mais adequada o potencial atômico. Esta medição, contudo, esteve fora das condições experimentais deste trabalho.

Este é, a nosso saber, o primeiro experimento em que o parâmetro de alinhamento $A_{20}$ foi determinado a partir das intensidades das linhas $\mathrm{L} \ell, \mathrm{L} \alpha_{1}$ e $\mathrm{L} \alpha_{2}$ simultaneamente. A metodologia empregada permitiu incluir na análise a correlação estatística entre as estimativas das intensidades das linhas $\mathrm{L} \alpha_{1}$ e $\mathrm{L} \alpha_{2}$, que é muito alta nos espectros analisados, uma vez que elas não são resolvidas com o sistema de deteção usado, e aproveitar a estatística de contagem das três transições em um único procedimento. Embora esse procedimento seja pouco importante quando a anisotropia é grande, ele é fundamental quando ela é pequena, e permitiu observar as inversões de sinal do parâmetro de alinhamento e verificar a falha do modelo.

A isotropia na emissão das linhas decorrentes de vacâncias criadas nas subcamadas $\mathrm{L}_{1}$ e $\mathrm{L}_{2}$ foi verificada pela análise das distribuições angulares de emissão da linha L $\eta$ e do grupo $\mathrm{L} \gamma$.

No curso deste experimento de alinhamento atômico, foram medidas as seções de choque de produção de raios x $\mathrm{L} \alpha, \mathrm{L} \beta, \mathrm{L} \gamma, \mathrm{L} \ell$ e $\mathrm{L} \eta$ do $\mathrm{Au}$, das quais foram deduzidas as seções de choque de ionização das subcamadas $\mathrm{L}_{1}, \mathrm{~L}_{2}$ e $\mathrm{L}_{3}$ do Au por impacto de elétrons, para energias desde o limiar de ionização da subcamada $\mathrm{L}_{3}$ até $100 \mathrm{keV}$, com um resultado significativo. As incertezas das presentes medidas são substancialmente menores do que do nosso resultado prévio, que foi conduzido empregando a "medida relativa" entre 50 e $100 \mathrm{keV}$, e do que todas as outras medidas da literatura. Para nosso conhecimento, este 
corresponde aos primeiros resultados de seções de choque L do Au por impacto de elétrons realizado no intervalo de energia desde o limiar $\mathrm{L}_{3}$ até $100 \mathrm{keV}$, empregando um único arranjo experimental, e são os dados mais precisos para estas medidas até o momento.

Os resultados de seções de choque deste trabalho estão em razoável acordo com a maioria dos dados experimentais encontrados na literatura, e apontam que ambos os formalismos, DWBA e SCADW, subestimam as seções de choque de ionização $\mathrm{L}_{i}$ do $\mathrm{Au}$ em cerca de 10-12\%. Com a realização de medidas para outros elementos, será possível confirmar essa tendência de subestimação e determinar a faixa de números atômicos em que os modelos atuais falham, consubstanciando essa indicação da necessidade de melhora nos modelos. 



\section{Referências}

[1] J. Hrdý, A. Henins, and J. A. Bearden, "Polarization of the L $\alpha_{1}$ x-rays of mercury," Phys. Rev. A, vol. 2, no. 5, pp. 1708-1711, 1970.

[2] M. Aydinol, R. Hippler, I. McGregor, and H. Kleinpoppen, "Angular distribution of x-radiation following electron bombardment of free atoms," J. Phys. B: At. Mol. Phys., vol. 13, no. 5, pp. 989-998, 1980.

[3] H. Küst and W. Mehlhorn, "Alignment after $\mathrm{L}_{3}$ ionization of Xe atoms by electron impact near threshold," J. Phys. B: At. Mol. Opt. Phys., vol. 34, no. 21, p. 4155, 2001.

[4] K. S. Kahlon, N. Singh, R. Mittal, K. L. Allawadhi, and B. S. Sood, " $\mathrm{L}_{3}$-Subshell vacancy state alignment in photon-atom collisions," Phys. Rev. A, vol. 44, no. 7, pp. 4379-4385, 1991.

[5] T. Papp and J. L. Campbell, "Non-statistical population of magnetic substates of the erbium $\mathrm{L}_{3}$ subshell in photoionization," J. Phys. B: At. Mol. Opt. Phys., vol. 25, no. 18, pp. 3765-3770, 1992.

[6] H. Küst, U. Kleiman, and W. Mehlhorn, "Alignment after Xe $\mathrm{L}_{3}$ photoionization by synchrotron radiation," J. Phys. B: At. Mol. Opt. Phys., vol. 36, no. 10, pp. 20732082, 2003.

[7] H. Yamaoka, M. Oura, K. Takahiro, T. Morikawa, S. Ito, M. Mizumaki, S. Semenov, N. Cherepkov, N. Kabachnik, and T. Mukoyama, "Alignment following Au L 3 photoionization by synchrotron radiation," J. Phys. B: At. Mol. Opt. Phys., vol. 36, no. 19 , pp. 3889-3897, 2003.

[8] H. Yamaoka, M. Oura, K. Takahiro, K. Kawatsura, S. Ito, M. Mizumaki, H. Oohashi, Y. Ito, and T. Mukoyama, "The effect of Coster-Kronig transitions on the anisotropy of x-ray emission following Au L-shell photoionization," J. Phys. B: At. Mol. Opt. Phys., vol. 39, no. 12, pp. 2747-2756, 2006.

[9] S. Santra, D. Mitra, M. Sarkar, and D. Bhattacharya, "Angular distribution of Au and U L x rays induced by 22.6-keV photons," Phys. Rev. A, vol. 75, no. 2, p. 022901 , 2007.

[10] T. Kämpfer, I. Uschmann, Z. W. Wu, A. Surzhykov, S. Fritzsche, E. Förster, and G. Paulus, "Linear polarization of the characteristic x-ray lines following inner-shell photoionization of tungsten," Phys. Rev. A, vol. 93, no. 3, p. 033409, 2016.

[11] Application Note: AN-SDD-001 Rev B0, Amptek Silicon Drift Diode (SDD) at high count rates. 
[12] R. D. Deslattes, E. G. Kessler Jr, P. Indelicato, L. De Billy, E. Lindroth, and J. Anton, "X-ray transition energies: new approach to a comprehensive evaluation," Rev. Mod. Phys, vol. 75, no. 1, p. 35, 2003.

[13] DDEP, "Laboratoire National Henri Becquerel, Recommended data, http://www.nucleide.org, último acesso em 01 de fevereiro de 2018.."

[14] E. G. Berezhko, N. M. Kabachnik, and V. V. Sizov, "The theory of coincidence experiments on electron impact ionisation of inner atomic shells," J. Phys. B: At. Mol. Phys., vol. 11, no. 10, pp. 1819-1832, 1978.

[15] E. G. Berezhko and N. M. Kabachnik, "Theoretical study of inner-shell alignment of atoms in electron impact ionisation: angular distribution and polarisation of x-rays and Auger electrons," J. Phys. B: At. Mol. Phys., vol. 10, no. 12, pp. 2467-2477, 1977.

[16] J. Pálinkás and B. Schlenk, "L-subshell ionization cross sections for $\mathrm{Au}, \mathrm{Pb}$, and $\mathrm{Bi}$ by 60-600 keV electron impact," Z. Phys. A, vol. 297, no. 1, pp. 29-33, 1980.

[17] K. Shima, T. Nakagawa, K. Umetani, and T. Mikumo, "Threshold behavior of Cu-, Ge-, Ag- $K$-, and Au- $L_{3}$-shell ionization cross sections by electron impact," Phys. Rev. A, vol. 24, no. 1, pp. 72-78, 1981.

[18] C. S. Campos, M. A. Z. Vasconcellos, X. Llovet, and F. Salvat, "Measurements of L-shell x-ray production cross sections of W, Pt, and Au by $10-30-\mathrm{keV}$ electrons," Phys. Rev. A, vol. 66, no. 1, p. 012719, 2002.

[19] Y. Wu, Z. An, M. T. Liu, Y. M. Duan, C. H. Tang, and Z. M. Luo, "Measurements of L-shell x-ray production cross-sections of $\mathrm{Au}$ and $\mathrm{Ag}$ by low energy electron impact," J. Phys. B: At. Mol. Opt. Phys., vol. 37, no. 22, p. 4527, 2004.

[20] H. V. Rahangdale, M. Guerra, P. K. Das, S. De, J. P. Santos, D. Mitra, and S. Saha, "Determination of subshell-resolved L-shell-ionization cross sections of gold induced by 15-40-keV electrons," Phys. Rev. A, vol. 89, no. 5, p. 052708, 2014.

[21] S. F. Barros, V. R. Vanin, N. L. Maidana, and J. M. Fernández-Varea, "Ionization cross sections of the L subshells of Au by 50 to $100 \mathrm{keV}$ electron impact," J. Phys. B: At. Mol. Opt. Phys., vol. 48, no. 17, p. 175201, 2015.

[22] D. Bote and F. Salvat, "Calculations of inner-shell ionization by electron impact with the distorted-wave and plane-wave Born approximations," Phys. Rev. A, vol. 77, no. 4, p. 042701, 2008.

[23] X. Llovet, F. Salvat, D. Bote, F. Salvat-Pujol, A. Jablonski, and C. J. Powell, "NIST Database of Cross Sections for Inner-Shell Ionization by Electron or Positron Impact," Version, vol. 1, p. 164, 2014.

[24] M. Green and V. E. Cosslett, "Measurements of K, L and M shell X-ray production efficiencies," J. Phys. D: Appl. Phys., vol. 1, no. 4, p. 425, 1968.

[25] S. I. Salem and L. D. Moreland, "L $\mathrm{L}_{\mathrm{II}}$ and $\mathrm{L}_{\mathrm{III}}$ ionization cross sections in gold at very low energies," Phys. Lett. A, vol. 37, no. 2, pp. 161-162, 1971. 
[26] D. V. Davis, V. D. Mistry, and C. A. Quarles, "Inner shell ionization of copper, silver and gold by electron bombardment," Phys. Lett. A, vol. 38, no. 3, pp. 169-170, 1972.

[27] H. Schneider, I. Tobehn, F. Ebel, and R. Hippler, "Absolute cross sections for inner shell ionization by lepton impact," Phys. Rev. Lett., vol. 71, no. 17, pp. 2707-2709, 1993.

[28] M. S. Pindzola, "Electron-impact ionization of the inner subshells of Au," J. Phys. B: At. Mol. Opt. Phys., vol. 48, no. 1, p. 015201, 2014.

[29] J. A. Bearden, "X-ray wavelengths," Rev. Mod. Phys, vol. 39, no. 1, p. 78, 1967.

[30] M. Kolbe, P. Hönicke, M. Müller, and B. Beckhoff, "L-subshell fluorescence yields and Coster-Kronig transition probabilities with a reliable uncertainty budget for selected high- and medium-Z elements," Phys. Rev. A, vol. 86, no. 4, p. 042512 , 2012 .

[31] M. O. Krause, "Atomic radiative and radiationless yields for K and L shells," $J$. Phys. Chem. Ref. Data, vol. 8, no. 2, p. 307, 1979.

[32] B. Cleff and W. Mehlhorn, "On the angular distribution of Auger electrons," Phys. Lett. A, vol. 37, no. 1, pp. 3-4, 1971.

[33] G. Sestric, S. Ferguson, I. Wright, and S. Williams, "Angular distributions of Xrays emitted following $\mathrm{L}_{3}$ ionization of Au atoms by electron impact," Radiat. Phys. Chem., vol. 102, pp. 40-43, 2014.

[34] N. Andersen, J. W. Gallagher, and I. V. Hertel, "Collisional alignment and orientation of atomic outer shells I. Direct excitation by electron and atom impact," Phys. Rep., vol. 165, no. 1-2, pp. 1-188, 1988.

[35] K. Blum and H. Kleinpoppen, "Electron-photon angular correlation in atomic physics," Phys. Rep., vol. 52, no. 4, pp. 203-261, 1979.

[36] W. Mehlhorn, "Alignment after inner-shell ionization by electron impact near and at threshold," Nucl. Instrum. Methods Phys. Res., Sect. B, vol. 87, no. 1-4, pp. 227$231,1994$.

[37] V. R. Vanin, N. L. Maidana, A. Mangiarotti, R. R. Lima, A. A. Malafronte, S. F. Barros, and M. N. Martins, "The 10-100 keV beam line of the São Paulo Microtron electron accelerator," Radiat. Phys. Chem., vol. submitted for publication.

[38] J. M. Fernández-Varea, V. Jahnke, N. L. Maidana, A. A. Malafronte, and V. R. Vanin, "Cross sections of K-shell ionization by electron impact, measured from threshold to $100 \mathrm{keV}$, for Au and Bi," J. Phys. B: At. Mol. Opt. Phys., vol. 47, no. 15 , p. $155201,2014$.

[39] V. R. Vanin, M. V. Manso Guevara, N. L. Maidana, M. N. Martins, and J. M. Fernández-Varea, "Ag K-shell ionization by electron impact: New cross-section measurements between 50 and $100 \mathrm{keV}$ and review of previous experimental data," Radiat. Phys. Chem., vol. 119, pp. 14-23, 2016. 
[40] J. A. García-Alvarez, J. M. Fernández-Varea, V. R. Vanin, O. C. B. Santos, S. F. Barros, A. A. Malafronte, C. L. Rodrigues, M. N. Martins, M. F. Koskinas, and N. L. Maidana, "Measurement of doubly differential electron bremsstrahlung cross sections at the end point (tip) for C, Al, Te, Ta and Au," J. Phys. B: At. Mol. Opt. Phys., vol. 50, no. 15, p. 155003, 2017.

[41] O. C. B. Santos, "Medida da seção de choque de ionização atômica da camada K de Ta e Te por impacto de elétrons com energias do limiar até $100 \mathrm{keV,"} \mathrm{Dissertação}$ de Mestrado, 2016.

[42] S. M. Seltzer, "Calculated response of intrinsic germanium detectors to narrow beams of photons with energies up to $\sim 300 \mathrm{keV}, "$ Nucl. Instrum. Methods, vol. 188, no. 1, pp. 133-151, 1981.

[43] S. S. Herman, F, Atomic Structure Calculations. Englewood Cliffs, NJ: PrenticeHall, 1963.

[44] D. Liberman, J. T. Waber, and D. T. Cromer, "Self-consistent-field Dirac-Slater wave functions for atoms and ions. I. Comparison with previous calculations," Phys. Rev., vol. 137, no. 1A, pp. A27-A34, 1965.

[45] D. Liberman, D. Cromer, and J. Waber, "Relativistic self-consistent field program for atoms and ions," Comput. Phys. Commun., vol. 1, pp. 107-113, 1971.

[46] S. F. Barros, N. L. Maidana, J. M. Fernández-Varea, and V. R. Vanin, "Full-energy peak efficiency of $\mathrm{Si}$ drift and $\mathrm{Si}(\mathrm{Li})$ detectors for photons with energies above the Si K binding energy," X-Ray Spectrom., vol. 46, no. 1, pp. 34-43, 2017.

[47] S. F. Barros, V. R. Vanin, A. A. Malafronte, N. L. Maidana, and M. N. Martins, "Energy-dependent dead-time correction in digital pulse processors applied to silicon drift detector's x-ray spectra," Journal of Synchrotron Radiation, vol. 25, no. 2, 2018.

[48] S. F. Barros, V. R. Vanin, N. L. Maidana, M. N. Martins, J. A. García-Alvarez, O. C. B. Santos, C. L. Rodrigues, M. F. Koskinas, and J. M. Fernández-Varea, "Ionization cross sections of the $\mathrm{Au} \mathrm{L}$ subshells by electron impact from the $\mathrm{L}_{3}$ threshold to $100 \mathrm{keV,"} \mathrm{J.} \mathrm{Phys.} \mathrm{B:} \mathrm{At.} \mathrm{Mol.} \mathrm{Opt.} \mathrm{Phys.,} \mathrm{vol.} \mathrm{51,} \mathrm{no.} \mathrm{2,} \mathrm{p.} \mathrm{025201,}$ 2018.

[49] B. H. Bransden and C. J. Joachain, Physics of Atoms and Molecules. Pearson Education India, 2003.

[50] R. Eisberg and R. Resnick, Física Quântica: Átomos, Moléculas, Sólidos, Nucleos e Partículas. Rio de Janeiro: Elsevier, 1979.

[51] R. Jenkins, Quantitative X-ray Spectrometry. CRC Press, 1995.

[52] B. Crasemann, Atomic Inner-Shell Processes. Elsevier, 2012.

[53] M. O. Krause and J. H. Oliver, "Natural widths of atomic K and L levels, K $\alpha$ X-ray lines and several KLL Auger lines," J. Phys. Chem. Ref. Data, vol. 8, no. 2, pp. 329-338, 1979. 
[54] V. R. Vanin, P. Gouffon, and O. Helene, Notas de aula: Análise estatística em medidas em ciências exatas. 2012.

[55] K. Blum, Density Matrix Theory and Applications. New York:Plenum Press, 1981.

[56] A. J. Ferguson, Angular Correlation Methods in Gamma-Ray Spectroscopy. Amsterdam:North Holland Publishing Company, 1965.

[57] R. DuBois and M. Rødbro, "Near-threshold alignment and post-collision interactions for argon $\mathrm{L}_{3}-\mathrm{M}_{2,3}^{2}\left({ }^{1} \mathrm{~S}_{0}\right)$ Auger electrons," J. Phys. B: At. Mol. Phys., vol. 13, no. 19, pp. 3739-3744, 1980.

[58] V. V. Sizov and N. M. Kabachnik, "Inner-shell alignment of atoms in ion-atom collisions. I. Impact ionisation," J. Phys. B: At. Mol. Phys., vol. 13, no. 8, pp. 1601$1610,1980$.

[59] M. E. Rose, "The analysis of angular correlation and angular distribution data," Phys. Rev., vol. 91, no. 3, pp. 610-615, 1953.

[60] G. B. Arfken, Física matemática: métodos matemáticos para engenharia e física. Elsevier, 2007.

[61] E. Döbelin, W. Sandner, and W. Mehlhorn, "Experimental study of inner shell alignment of atoms in electron impact ionization," Phys. Lett. A, vol. 49, no. 1, pp. 7-8, 1974.

[62] B. Cleff and W. Mehlhorn, "Angular distribution of $\mathrm{L}_{3} \mathrm{M}_{2,3} \mathrm{M}_{2,3}\left({ }^{1} \mathrm{~S}_{0}\right)$ Auger electrons of argon," J. Phys. B: At. Mol. Phys., vol. 7, no. 5, pp. 605-611, 1974.

[63] W. Sandner and W. Schmitt, "Energy-dependence of the $\mathrm{L}_{3}$-shell alignment of argon following electron impact ionisation," J. Phys. B: At. Mol. Phys., vol. 11, no. 10, pp. 1833-1848, 1978.

[64] W. Weber, R. Huster, M. Kamm, and W. Mehlhorn, "Alignment of $\mathrm{Ar}^{+}\left(2 \mathrm{p}^{-1}\right.$ ${ }^{2} \mathrm{P}_{3 / 2}$ ) ions after electron impact ionisation in the range $1 \mathrm{keV}$ to $268 \mathrm{eV}, " Z$. Phys. D, vol. 22, no. 1, pp. 419-424, 1991.

[65] E. G. Berezhko and N. M. Kabachnik, "Application of distorted-wave approximation to the study of inner-shell alignment by electron impact," J. Phys. B: At. Mol. Phys., vol. 15, no. 13, pp. 2075-2086, 1982.

[66] B. Borucki, W. Weber, and W. Mehlhorn, "Alignment of $\mathrm{Mg}^{+}\left(\mathrm{L}_{3}\right)$ ions after electron impact ionization in the range from near threshold to $300 \mathrm{eV}, " J$. Phys. B: At. Mol. Opt. Phys., vol. 26, no. 7, pp. L197-L201, 1993.

[67] R. D. DuBois, L. Mortensen, and M. Rødbro, "Collisionally induced alignment produced by electron and light-ion impact: Auger electron emission following $2 \mathrm{p}$ ionisation and excitation," J. Phys. B: At. Mol. Phys., vol. 14, no. 10, pp. 16131624, 1981.

[68] E. G. Berezhko and N. M. Kabachnik, "Theoretical study of inner-shell alignment of atoms in electron impact ionisation: angular distribution and polarisation of X-rays and Auger electrons," J. Phys. B: At. Mol. Opt. Phys., vol. 10, no. 12, p. 2467, 1977. 
[69] K. S. Kahlon, N. Singh, R. Mittal, B. S. Sood, and K. L. Allawadhi, "Linear polarization of $\mathrm{L} \alpha_{1}$ and $\mathrm{L} \alpha_{2}$ x-ray lines of gold," Phys. Rev. A, vol. 48, no. 2, p. 1701, 1993.

[70] L. Demir, M. Şahin, Y. Kurucu, A. Karabulut, and Y. Şahin, "Angular dependence of $\mathrm{L} \ell, \mathrm{L} \alpha, \mathrm{L} \beta$ and $\mathrm{L} \gamma \mathrm{X}$-ray differential and fluorescence cross-sections for Er, Ta, W, Au, Hg and Tl," Radiat. Phys. Chem., vol. 67, no. 5, pp. 605-612, 2003.

[71] M. Alrakabi, S. Kumar, V. Sharma, G. Singh, and D. Mehta, "Alignment of $\mathrm{L}_{3}$ subshell vacancy states in $\mathrm{Au}, \mathrm{Bi}$, Th and $\mathrm{U}$ following photoionisation and effect of external magnetic field," Eur. Phys. J. D, vol. 67, no. 5, pp. 1-8, 2013.

[72] A. Tartari, C. Baraldi, E. Casnati, A. Da Re, J. E. Fernandez, and S. Taioli, "On the angular dependence of L x-ray production cross sections following photoionization at an energy of $59.54 \mathrm{keV}, "$ J. Phys. B: At. Mol. Opt. Phys., vol. 36, no. 5, pp. 843-851, 2003.

[73] T. Akkuş, Y. Şahin, and D. Yılmaz, "Azimuthal and polar angle dependence of L X-ray differential cross-sections of Yb at $59.54 \mathrm{keV}$ photon energy," Nucl. Instrum. Methods Phys. Res., Sect. B, vol. 366, pp. 145-149, 2016.

[74] A. Kumar, S. Puri, D. Mehta, M. Garg, and N. Singh, "Angular dependence of 1 x-ray emission in pb following photoionization at 22.6 and 59.5 kev," J. Phys. B: At. Mol. Opt. Phys., vol. 32, no. 15, p. 3701, 1999.

[75] A. Kumar, M. L. Garg, S. Puri, D. Mehta, and N. Singh, "Angular dependence of $\mathrm{L}_{3}$ x-ray emission following $\mathrm{L}_{3}$ sub-shell photoionization in $\mathrm{Pb}, " X$-Ray Spectrom., vol. 30, no. 5, pp. 287-291, 2001.

[76] J. K. Sharma and K. L. Allawadhi, "Angular distribution of L x-rays from decay of $\mathrm{L}_{3}$ subshell vacancies in uranium and thorium following photoionization," J. Phys. B: At. Mol. Opt. Phys., vol. 32, no. 10, pp. 2343-2349, 1999.

[77] H. Yamaoka, M. Oura, K. Takahiro, N. Takeshima, K. Kawatsura, M. Mizumaki, U. Kleiman, N. Kabachnik, and T. Mukoyama, "Angular distribution of $\mathrm{Au}$ and $\mathrm{Pb}$ $\mathrm{L} x$ rays following photoionization by synchrotron radiation," Phys. Rev. A, vol. 65, no. 6, p. 062713, 2002.

[78] W. Jitschin, H. Kleinpoppen, R. Hippler, and H. O. Lutz, "L-shell alignment of heavy atoms induced by proton impact ionisation," J. Phys. B: At. Mol. Phys., vol. 12 , no. 24 , p. 4077, 1979.

[79] W. Jitschin, A. Kaschuba, H. Kleinpoppen, and H. O. Lutz, "Proton-induced alignment of the $\mathrm{L}_{3}$-Subshell in heavy atoms," Zeitschrift für Physik A Hadrons and Nuclei, vol. 304, no. 1, pp. 69-73, 1982.

[80] W. Jitschin, R. Hippler, R. Shanker, H. Kleinpoppen, R. Schuch, and H. O. Lutz, "L X-ray anisotropy and L3-subshell alignment of heavy atoms induced by ion impact," J. Phys. B: At. Mol. Opt. Phys., vol. 16, no. 8, p. 1417, 1983.

[81] C. Barros Leite, N. de Castro Faria, R. Horowicz, E. Montenegro, and A. de Pinho, "Anisotropy of pb 13-subshell x rays excited by low-velocity-proton impact," Phys. Rev. A, vol. 25, pp. 1880-1886, 1982. 
[82] T. Papp, J. L. Campbell, and J. A. Maxwell, "Deviation from the single-particle model in the angular distribution of thorium $\mathrm{L}_{3}$ x-rays in proton-impact ionization," Phys. Rev. A, vol. 48, no. 4, p. 3062, 1993.

[83] O. G. de Lucio and J. Miranda, "L-shell alignment of rare earths atoms induced by ${ }^{12} \mathrm{C},{ }^{16} \mathrm{O}$ and ${ }^{19} \mathrm{~F}$ ion impact," Nucl. Instrum. Methods Phys. Res., Sect. B, vol. 248, no. 1, pp. 47-53, 2006.

[84] J. W. Motz and R. C. Placious, "K-ionization cross sections for relativistic electrons," Phys. Rev., vol. 136, no. 3A, pp. A662-A665, 1964.

[85] L. M. Middleman, R. L. Ford, and R. Hofstadter, "Measurement of cross sections for x-ray production by high-energy electrons," Phys. Rev. A, vol. 2, no. 4, pp. 14291443, 1970.

[86] J. Pálinkás, B. Schlenk, and A. Valek, "Experimental investigation of the angular distribution of characteristic x-radiation following electron impact ionisation," $J$. Phys. B: At. Mol. Phys., vol. 12, no. 19, pp. 3273-3279, 1979.

[87] J. L. Campbell and J. X. Wang, "Interpolated Dirac-Fock values of L-subshell x-ray emission rates including overlap and exchange effects," At. Data Nucl. Data Tables, vol. 43, no. 2, pp. 281-291, 1989.

[88] J. H. Scofield, "Relativistic Hartree-Slater values for K and L X-ray emission rates," At. Data Nucl. Data Tables, vol. 14, no. 2, pp. 121-137, 1974.

[89] E. G. Berezhko, N. M. Kabachnik, and V. S. Rostovsky, "Potential-barrier effects in inner-shell photoionisation and their influence on the anisotropy of x-rays and Auger electrons," J. Phys. B: At. Mol. Phys., vol. 11, no. 10, pp. 1749-1758, 1978.

[90] F. Salvat, J. M. Fernández-Varea, and J. Sempau, PENELOPE-2011: a Code System for Monte Carlo Simulation of Electron and Photon Transport. Universitat de Barcelona, 2011.

[91] LAMFI, "http://www2.if.usp.br/ lamfi/, último acesso em 21/04/2017.."

[92] W.-K. Chu, J. W. Mayer, and M.-A. Nicolet, "Backscattering Spectroscopy," 1978.

[93] M. Mayer, "SIMNRA User's Guide," AIP Conf. Proc., vol. 475, p. 541, 1999.

[94] T. F. Silva, C. L. Rodrigues, M. Mayer, M. V. Moro, G. F. Trindade, F. R. Aguirre, N. Added, M. A. Rizzutto, and M. H. Tabacniks, "MultiSIMNRA: A computational tool for self-consistent ion beam analysis using SIMNRA," Nucl. Instrum. Methods Phys. Res., Sect. B, vol. 371, pp. 86-89, 2016.

[95] E. Gatti and P. Rehak, "Semiconductor drift chamber an application of a novel charge transport scheme," Nucl. Instrum. Methods, vol. 225, no. 3, pp. 608-614, 1984.

[96] P. Rehak, E. Gatti, A. Longoni, J. Kemmer, P. Holl, R. Klanner, G. Lutz, and A. Wylie, "Semiconductor drift chambers for position and energy measurements," Nucl. Instrum. Methods Phys. Res., Sect. A, vol. 235, no. 2, pp. 224-234, 1985. 
[97] AN-SDD-001 Rev B0, Application Note.

[98] S. F. Barros, "Ionização atômica da camada L de Au e Ta por impacto de elétrons com o acelerador Microton de São Paulo," Dissertação de Mestrado, 2014.

[99] F. Gao, L. W. Campbell, R. Devanathan, Y. Xie, L. R. Corrales, A. J. Peurrung, and W. J. Weber, "Monte Carlo method for simulating $\gamma$-ray interaction with materials: A case study on Si," Nucl. Instrum. Methods Phys. Res., Sect. A, vol. 579, no. 1, pp. 292-296, 2007.

[100] J. S. Hansen, J. C. McGeorge, D. Nix, W. D. Schmidt-Ott, I. Unus, and R. W. Fink, "Accurate efficiency calibration and properties of semiconductor detectors for low-energy photons," Nucl. Instrum. Methods, vol. 106, no. 2, pp. 365-379, 1973.

[101] W. J. Gallagher and S. J. Cipolla, "A model-based efficiency calibration of a Si(Li) detector in the energy region from 3 to $140 \mathrm{keV}$," Nucl. Instrum. Methods, vol. 122, pp. 405-414, 1974.

[102] F. Scholze and M. Procop, "Modelling the response function of energy dispersive Xray spectrometers with silicon detectors," X-Ray Spectrom., vol. 38, no. 4, pp. 312$321,2009$.

[103] J. M. O’Meara and J. L. Campbell, "Corrections to the conventional approach to Si(Li) detector efficiency," X-Ray Spectrom., vol. 33, no. 2, pp. 146-157, 2004.

[104] J. L. Campbell, H. H. Jorch, and J. A. Thompson, "Parametric representation of xray detector efficiency curves," Nucl. Instrum. Methods, vol. 140, no. 1, pp. 167-173, 1977.

[105] N. L. Maidana, V. R. Vanin, V. Jahnke, J. M. Fernández-Varea, M. N. Martins, and L. Brualla, "Efficiency calibration of x-ray HPGe detectors for photons with energies above the Ge K binding energy," Nucl. Instrum. Methods Phys. Res., Sect. $A$, vol. 729, pp. 371-380, 2013.

[106] G. F. Knoll, Radiation Detection and Measurement. John Wiley \& Sons, 2010.

[107] J. A. García-Alvarez, Seções de choque de bremsstrahlung de elétrons, estudo experimental no Acelerador Microtron de São Paulo. PhD thesis, Universidade de São Paulo, 2016.

[108] R. H. Redus, A. C. Huber, and D. J. Sperry, "Dead time correction in the dp5 digital pulse processor," in Nuclear Science Symposium Conference Record, 2008. NSS'08. IEEE, pp. 3416-3420, IEEE, 2008.

[109] J. He and Q. Zhang, "Discussion on the full width at half maximum (FWHM) of the Voigt spectral line," Optik-International Journal for Light and Electron Optics, vol. 124, no. 21, pp. 5245-5247, 2013.

[110] S. P. Limandri, R. D. Bonetto, H. O. Di Rocco, and J. C. Trincavelli, "Fast and accurate expression for the Voigt function. Application to the determination of uranium M linewidths," Spectrochim. Acta B, vol. 63, no. 9, pp. 962-967, 2008. 
[111] W. J. Thompson et al., "Numerous neat algorithms for the Voigt profile function," Computers in Physics, vol. 7, no. 6, pp. 627-631, 1993.

[112] J. F. Kielkopf, "New approximation to the voigt function with applications to spectral-line profile analysis," JOSA, vol. 63, no. 8, pp. 987-995, 1973.

[113] S. R. Drayson, "Rapid computation of the voigt profile," J. Quant. Spectrosc. Radiat. Transfer, vol. 16, no. 7, pp. 611-614, 1976.

[114] P. Van Espen, H. Nullens, and F. Adams, "A method for the accurate description of the full-energy peaks in non-linear least-squares analysis of x-ray spectra," Nucl. Instrum. Methods, vol. 145, no. 3, pp. 579-582, 1977.

[115] P. Van Espen, H. Nullens, and F. Adams, "A computer analysis of X-ray fluorescence spectra," Nucl. Instrum. Methods, vol. 142, no. 1, pp. 243-250, 1977.

[116] S. G. Johnson, "Faddeeva package, http://ab-initio.mit.edu, último acesso em 12 de fevereiro de 2018."

[117] S. G. Johnson, "Faddeeva Package, http://ab-initio.mit.edu/Faddeeva.cc, último acesso em 12 de fevereiro de 2018.."

[118] D. G. Hummer, "The Voigt function: An eight-significant-figure table and generating procedure," Memoirs of the Royal Astronomical Society, vol. 70, p. 1, 1965.

[119] M. R. Zaghloul, "On the calculation of the voigt line profile: a single proper integral with a damped sine integrand," Mon. Notices Royal Astron. Soc., vol. 375, no. 3, pp. 1043-1048, 2007.

[120] S. P. Limandri, Estudio de parámetros atómicos y moleculares en espectroscopía de rayos $x$. Aplicación a la cuantificación sin estándares. $\mathrm{PhD}$ thesis, tesis de doctorado. FaMAF, Universidad Nacional de Córdoba, 2011.

[121] J. H. Scofield, "Exchange corrections of K X-ray emission rates," Phys. Rev. A, vol. 9, no. 3, p. 1041, 1974.

[122] R. H. Pratt, H. K. Tseng, C. M. Lee, L. Kissel, C. MacCallum, and M. Riley, "Bremsstrahlung energy spectra from electrons of kinetic energy $1 \mathrm{keV}<T_{1}<$ $2000 \mathrm{keV}$ incident on neutral atoms $2<Z<92$," At. Data Nucl. Data Tables, vol. 20, no. 2, pp. 175-209, 1977.

[123] L. Kissel, C. A. Quarles, and R. H. Pratt, "Shape functions for atomic-field bremsstrahlung from electrons of kinetic energy $1-500 \mathrm{keV}$ on selected neutral atoms $1<Z<92$," At. Data Nucl. Data Tables, vol. 28, no. 3, pp. 381-460, 1983.

[124] X. Llovet, C. J. Powell, F. Salvat, and A. Jablonski, "Cross sections for inner-shell ionization by electron impact," J. Phys. Chem. Ref. Data, vol. 43, no. 1, p. 013102 , 2014.

[125] A. Mangiarotti, "Comunicação privada," (São Paulo, SP, Brasil), 2015.

[126] S. A. Goudsmit and J. L. Saunderson, "Multiple scattering of electrons," Phys. Rev., vol. 57, no. 1, p. 24, 1940. 
[127] S. A. Goudsmit and J. L. Saunderson, "Multiple scattering of electrons. ii," Phys. Rev., vol. 58, no. 1, p. 36, 1940.

[128] "Elastic scattering of electrons and positrons," Journal of ICRU, vol. 7, no. 1, 2007.

[129] P. V. Rao, M. H. Chen, and B. Crasemann, "Atomic vacancy distributions produced by inner-shell ionization," Phys. Rev. A, vol. 5, no. 3, p. 997, 1972.

[130] F. Salvat, J. M. Fernández-Varea, and W. Williamson Jr, "Accurate numerical solution of the radial Schrödinger and Dirac wave equations," Comput. Phys. Commun., vol. 90, pp. 151-168, 1995.

[131] J. M. Fernández-Varea and F. Salvat, "Comunicação privada," (São Paulo, SP, Brasil), 2017.

[132] B. Carnahan, H. A. Luther, and J. O. Wilkes, Applied Numerical Methods. John Wiley \& Sons, Inc, 1969.

[133] M. O. Krause, "Atomic radiative and radiationless yields for K and L shells," J. Phys. Chem. Ref. Data, vol. 8, no. 2, pp. 307-327, 1979.

[134] J. Woicik, B. Ravel, D. Fischer, and W. Newburgh, "Performance of a four-element Si drift detector for X-ray absorption fine-structure spectroscopy: resolution, maximum count rate, and dead-time correction with incorporation into the ATHENA data analysis software," J. Synchrotron Rad., vol. 17, no. 3, pp. 409-413, 2010. 


\section{APÊNDICE A - Estimativa do tempo morto de aquisição}

Uma descrição detalhada dos modelos de tempo morto pode ser encontrada nas referências Jenkins et al. [51] e Knoll [106]. O modelo proposto nesta pesquisa teve como base os trabalhos de Jenkins et al. [51] e Redus et al. [108], que já tinham observado a variação do tempo morto de aquisição com a energia do fóton incidente. O trabalho detalhado decorrente da pesquisa sobre as várias correções de tempo morto com variado grau de complexidade e precisão resultou na publicação Barros et al. [47]. Neste apêndice serão apresentados apenas alguns dos modelos desta referência.

\section{A.0.0.1 Modelo analítico}

Sendo $R_{\text {in }}$ e $R_{\text {out }}$ as taxas de entrada e saída de contagem de pulso de um sistema de espectroscopia paralisável e $\tau_{\mathrm{C}}$ o tempo morto por pulso, segue das referências [108,134], que

$$
R_{\text {out }}\left(R_{\text {in }} ; \tau_{\mathrm{C}}\right)=R_{\text {in }} \exp \left(-R_{\text {in }} \tau_{\mathrm{C}}\right)
$$

Redus et al. [108] propõem que $\tau_{\mathrm{C}}$ seja dado pela expressão:

$$
\tau_{\mathrm{C}}=\left(1+\delta_{\mathrm{rej}}\right)(1+F) T_{a}
$$

em que $\delta_{\text {rej }}$ assume os valores 1 ou 0 , caso o empilhamento seja rejeitado ou não, $T_{a}$ é definido pelos tempos característicos do Processador de Pulso Digital (DPP) como

$$
T_{a}=T_{\text {peak }}+T_{\text {flat }}
$$

com $T_{\text {peak }}$ e $T_{\text {flat }}$, figura 4.14, o tempo de pico e de patamar, respectivamente, e $F$ a fração média de tempo de queda do pulso necessária para o sistema detetar a ocorrência do pico no pulso. Redus et al. [108] afirmam que quando o tempo de subida e de queda do pulso são iguais, o parâmetro $F$ pode ser estimado pela razão do nível do discriminador 
lento pelo valor da energia média do espectro, o que requer que o discriminador lento seja posicionado logo acima do ruído.

Como nos experimentos deste trabalho os raios $\mathrm{x}$ foram produzidos por impacto de elétrons sobre um alvo, a taxa de entrada $R_{\text {in }}$ será diretamente proporcional à corrente do feixe [134], enquanto que a forma do espectro de entrada, $\mathcal{R}_{\text {in }}(E)$, é independente da corrente. Desde que as quantidades observadas são a carga $C$ coletada durante a medição e o tempo de aquisição $T_{\text {aq }}$, a taxa de entrada total pode ser escrita como

$$
R_{\mathrm{in}}=P \frac{C}{T_{\mathrm{aq}}}
$$

com $P$ um parâmetro a ser estimado a partir dos espectros medidos. Por outro lado, a taxa de contagem observada durante a aquisição é usualmente avaliada como

$$
\tilde{R}_{\text {out }} \approx \frac{N_{\text {slow }}}{T_{\text {aq }}}
$$

Contudo, o espectro adquirido no canal lento contém eventos de empilhamento que não foram rejeitados porque também empilharam no canal rápido. Quando um evento de empilhamento não foi detetado, dois fótons entraram no detetor, mas somente um foi registrado. Então, a taxa de contagem é melhor aproximada por

$$
\hat{R}_{\text {out }} \approx \tilde{R}_{\text {out }}+R_{\text {pile,fast }}
$$

A relação entre a taxa de contagem observada, $\tilde{R}$, equação (A.5), e a taxa de contagem corrigida, equação (A.6), é obtida por substituir $\hat{R}_{\text {out }}$ e $R_{\text {in }}$, equações (A.6) e (A.4), na equação (A.1), o que resulta em

$$
\tilde{R}_{\text {out }}\left(C, T_{\mathrm{aq}} ; P, \tau_{\mathrm{C}}\right)=P \frac{C}{T_{\mathrm{aq}}} \exp \left(-P \frac{C}{T_{\mathrm{aq}}} \tau_{\mathrm{C}}\right)-R_{\text {pile,fast }}
$$

A expressão (A.2) supõe que as perdas por tempo morto sejam iguais em todas as regiões do espectro, o que não é correto, sobretudo para altas taxas de aquisição, conforme ilustra a figura 5.11.

Quando o tempo morto por pulso $\tau$ apresenta uma dependência com a energia $E$, as taxas de entrada e de saída também vão apresentar uma dependência com a energia [51], por isso a expressão (A.1) deve ser reescrita como

$$
R_{\text {out }}\left(E, R_{\text {in }}\right)=\mathcal{R}_{\text {in }}(E) \exp \left[-R_{\text {in }} \tau(E)\right]
$$

em que $\mathcal{R}_{\text {in }}(E)$ é a taxa de entrada de fótons com energia $E, R_{\text {in }}$ é a taxa de entrada 
total, somada sobre os fótons de todas as energias, e $\tau(E)$ é o tempo morto por pulso correspondente à energia $E$, relacionado ao tempo de conversão do canal de processamento e seu modo de operação.

Com base na figura 4.14 mostra-se que para o canal lento o tempo morto por pulso é dado por uma extensão da expressão (A.2)

$$
\tau\left(E ; E_{d}, T_{a}\right)=\left(1+\delta_{\text {rej }}\right)\left(1+\frac{E_{d}}{E}\right) T_{a}
$$

em que o termo $E_{d} T_{a} / E$ tem um significado análogo ao do parâmetro $F$. Ele leva em conta o tempo necessário para a deteção do pico do pulso, consequentemente, $E_{d}$ corresponde ao equivalente em energia da queda de voltagem no pulso do canal lento necessária para a identificação da ocorrência do pico.

Corrigir o espectro medido pelas distorções decorrentes do empilhamento requer subtrair os picos de empilhamento e somar as contagens que foram perdidas porque empilharam. Desta forma, a melhor aproximação para o que será chamado de "espectro líquido", $y_{l}(n),[47]$ é dada por

$$
y_{l}(n)=y(n)-p(n)-p_{\text {perda }}(n)
$$

em que $y(n)$ é o espectro medido, $p(n)$ é a distribuição de empilhamento, construída de acordo com a expressão (5.15), e $p_{\text {perda }}(n)$ a distribuição de contagens perdidas em virtude do empilhamento, que é dada por

$$
p_{\text {perda }}(n)=2 \eta N_{\text {slow }} y(n)
$$

O fator 2 vem do fato de que duas contagens foram perdidas no espectro medido para cada contagem registrada no espectro de empilhamento $p(n)$ da equação (5.15). Aplicando a expressão (A.8) para corrigir as perdas por tempo morto chega-se em

$$
S(n)=y_{l}(n) \exp \left[R_{\text {in }} \tau(n)\right]
$$

que será chamado daqui em diante de "espectro compensado", com $\tau(n)=\tau(E(n))$.

\section{A.0.0.2 Validação Experimental}

A fim de validar o modelo proposto foi realizado um experimento. Um alvo de Au com densidade superficial de aproximadamente $50 \mu \mathrm{g} / \mathrm{cm}^{2}$, posicionado no centro da câmara de irradiação e inclinado em $30^{\circ}$ com relação à direção do feixe incidente, foi irradiado com um feixe de elétrons de aproximadamente $18,5 \mathrm{keV}$ e corrente variando entre $10 \mathrm{a}$ 
$700 \mathrm{nA}$ para adquirir espectros com taxas de contagens de $1-56 \mathrm{kHz}$. O tempo de medição ficou entre 300 e 3600 s, de modo a garantir estatística de contagem semelhante em todos os espectros. As medidas sem o atenuador de Kapton foram realizadas com taxas de aquisição de $1,3,4,12,19,26,42$ e $56 \mathrm{kHz}$, e com o atenuador as taxas foram de $1,4,9,18,28$, e $42 \mathrm{kHz}$.

Os raios x emitidos foram detetados com um SDD posicionado a $90^{\circ}$ com relação ao feixe em duas situações diferentes: com um atenuador de Kapton de $25 \mu \mathrm{m}$ de espessura para atenuar os raios x $\mathrm{M}$ do $\mathrm{Au}$, e sem a presença deste atenuador, com o objetivo de obter espectros com alta estatística na região de baixa energia. Os espectros adquiridos com e sem o atenuador serão chamados de espectros L e ML, respectivamente, daqui em diante. O tempo de subida e de patamar do canal lento foram mantidos em 1,6 e 0,2 $\mu$ s, respectivamente, garantindo uma resolução em energia melhor do que $170 \mathrm{eV}$ na linha $\mathrm{L} \alpha_{1}$ do $\mathrm{Au}(9,71 \mathrm{keV})$.

\section{A.0.0.3 Análise de dados}

\section{Modelo Padrão (SM)}

Uma estimativa de primeira ordem da taxa de entrada $R_{\text {in }}$ pode ser obtida a partir da expressão (A.1), com $R_{\text {out }}$ calculado com a expressão (A.5) e estimando $\tau_{\mathrm{C}}$ de duas formas diferentes. Na situação mais simples, $\tau_{\mathrm{C}}$ pode ser calculado com a expressão (A.3) a partir das constantes de tempo do digitalizador fornecidas nos registros das configurações do DPP. Este é o modelo padrão com os parâmetros do fabricante, $\mathrm{SM}_{0}$. Quando se obtém espectros com diferentes taxas de aquisição, como neste experimento, é possível estimar $\tau_{\mathrm{C}}$ a partir do ajuste dos parâmetros da expressão (A.1) aos dados experimentais, com $R_{\text {in }}$ calculado de acordo com a expressão (A.4); neste caso, os parâmetros de ajuste são $\tau_{\mathrm{C}}$ e $P$, equação (A.4). Este procedimento corresponde ao modelo padrão com os parâmetros ajustados, $\mathrm{SM}_{f}$. Em ambas as situações, a dependência do tempo morto com a energia não é levada em conta, e o empilhamento no canal rápido é ignorado.

A fração de eventos perdidos $\phi$ para estes modelos corresponde à razão do tempo morto durante a medição pelo tempo de aquisição. Substituindo a expressão (A.4) em (5.16) chega-se em:

$$
\phi=1-\exp \left[-R_{\text {in }} \tau_{C}\right]
$$

O modelo padrão pode ser empregado levando-se em conta o empilhamento por meio da expressão (A.7), cujos parâmetros são ajustados aos dados experimentais em um único 
processo, o que pode ser realizado pelo métodos dos mínimos quadrados [47]. Os parâmetros de ajuste são $\tau_{\mathrm{C}}$ e $P$. Este procedimento foi classificado como $\mathrm{SPM}_{f}$. Neste caso a fração de eventos perdidos pode ser estimada com a expressão (A.13), sendo que $R_{\text {in }}$ deve ser calculado a partir da expressão (A.4) com o valor de $P$ encontrado no ajuste.

\section{Tempo morto com dependência na energia e com a correção do empilhamento $\left(\mathrm{EDP}_{i}\right)$}

Nesta aproximação os espectros adquiridos com diferentes taxas são normalizados pela carga incidente e dividido pelo espectro de referência, também normalizado pela respectiva carga. O espectro reduzido a uma dada taxa $R_{\mathrm{in}, i}$ é dado por

$$
z_{i}(E)=\frac{y_{i}(E)}{y_{\mathrm{LR}}(E)} \frac{C_{\mathrm{LR}}}{C_{i}}
$$

em que o subíndice LR indica a aquisição feita na menor taxa, $y_{i}$ corresponde ao "espectro líquido", equação (A.10), de taxa $i$, e $C_{i}$ a carga coletada durante a aquisição do espectro de taxa $i$. Supondo que na menor taxa de aquisição os efeitos de perda por tempo morto possam ser ignorados, o espectro reduzido $z_{i}(E)$ será uma boa aproximação para a razão $R_{\text {out }}(E) / \mathcal{R}_{\text {in }}(E)$ da equação (A.8), que é igual a $\exp \left(-R_{\text {in }} \tau(E)\right)$, $\operatorname{com} \tau(E)=\tau\left(E ; E_{d}, T_{a}\right)$ da equação (A.9). Com isso, os parâmetros $E_{d}$ e $T_{a}$ da função $\exp \left(-R_{\text {in }} \tau\left(E ; E_{d}, T_{a}\right)\right)$ podem ser ajustados aos dados experimentais de todos os espectros reduzidos $z_{i}(E), 2 \leq i \leq m$. Neste trabalho adotou-se como espectro de referência $y_{\mathrm{LR}}(E)=y_{1}(E)$. Esta função modelo pode ser linearizada tomando o logaritmo de ambos os lados, e os parâmetros de interesse podem ser ajustados aos dados experimentais pelo método dos mínimos quadrados, equação (2.13). Este modelo foi chamado de $\operatorname{EDP}_{i}$.

\section{A.0.0.4 Resultados}

A tabela A.1 mostra as estimativas do parâmetro $\tau_{\mathrm{C}}$ obtidas para as duas situações experimentais exploradas, junto com os valores calculados com a expressão (A.2) com os parâmetros necessários obtidos das configurações do DPP. As curvas na figura A.1 correspondem a taxas de saída calculadas com os parâmetros estimados como função da corrente do feixe incidente, para ambos os experimentos, com e sem o atenuador de Kapton.

Na figura A.2 são apresentadas as frações de eventos perdidos devido ao tempo morto durante as aquisições avaliadas de acordo com a expressão (A.13) pelos procedimentos $\mathrm{SM}_{0}$ e $\mathrm{SMP}_{f}$, junto com a fração de tempo morto fornecida pelo DPP, calculada de acordo com a expressão (5.16), para as duas situações experimentais investigadas, a saber, para 
Tabela A.1: Estimativas do parâmetro $\tau_{\mathrm{C}}$ em $\mu$ s empregando o procedimento $\mathrm{SMP}_{f}$. As estimativas classificadas de DPP foram deduzidas usando a equação (A.3) com $E_{d}=$ $220 \mathrm{eV}, F=0,08$ para o espectro ML e $F=0,03$ para o espectro L. Em parênteses, o desvio padrão em unidades do dígito menos significativo.

\begin{tabular}{ccc}
\hline \hline Espectro & SMP $_{f}$ & DPP \\
\hline ML & $4,23(2)$ & 3,87 \\
$\mathrm{~L}$ & $3,802(3)$ & 3,70 \\
\hline \hline
\end{tabular}

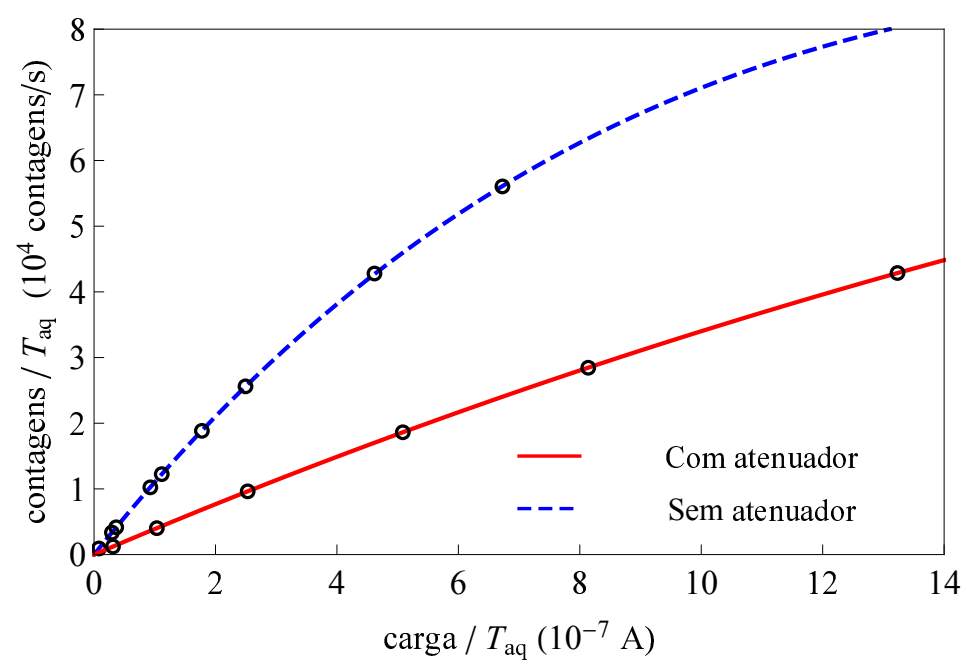

Figura A.1: Os pontos correspondem aos valores experimentais de $R_{\text {out }}$ versus a corrente do feixe. As linhas foram obtidas a partir do procedimento $\mathrm{SMP}_{f}$, equação (A.7), calculadas com os parâmetros estimados para os espectros ML (linha tracejada azul) e L (linha contínua vermelha).

os espectros ML e L.

As figuras A.3 e A.4 mostram os espectros reduzidos ML e L, respectivamente, calculados de acordo com a expressão (A.14), corrigidos de acordo com o procedimento $\mathrm{SMP}_{f}$ e $\mathrm{EDP}_{i}$. A tabela A.2 traz os valores médios de $T_{a}$ e $E_{d}$ encontrados com o ajuste do procedimento $\mathrm{EDP}_{i}$ aos dados experimentais para cada umas das taxas de aquisições $i$, para os espectros ML e L.

Tabela A.2: Valores médios dos parâmetros $T_{a}$ e $E_{d}$ encontrados a partir do ajuste do modelo $\mathrm{EDP}_{i}$ aos dados experimentais para os espectros ML e L. Em parênteses, o desvio padrão em unidades do dígito menos significativo.

\begin{tabular}{ccc}
\hline \hline Espectro & $\hat{T}_{a}(\mu \mathrm{s})$ & $\hat{E}_{d}(\mathrm{eV})$ \\
\hline $\mathrm{ML}$ & $1,80(2)$ & $680(30)$ \\
$\mathrm{L}$ & $1,79(4)$ & $460(30)$ \\
\hline \hline
\end{tabular}

As médias destes espectros reduzidos com seus respectivos desvios padrões, represen- 
Taxa de entrada $(\mathrm{kHz})$

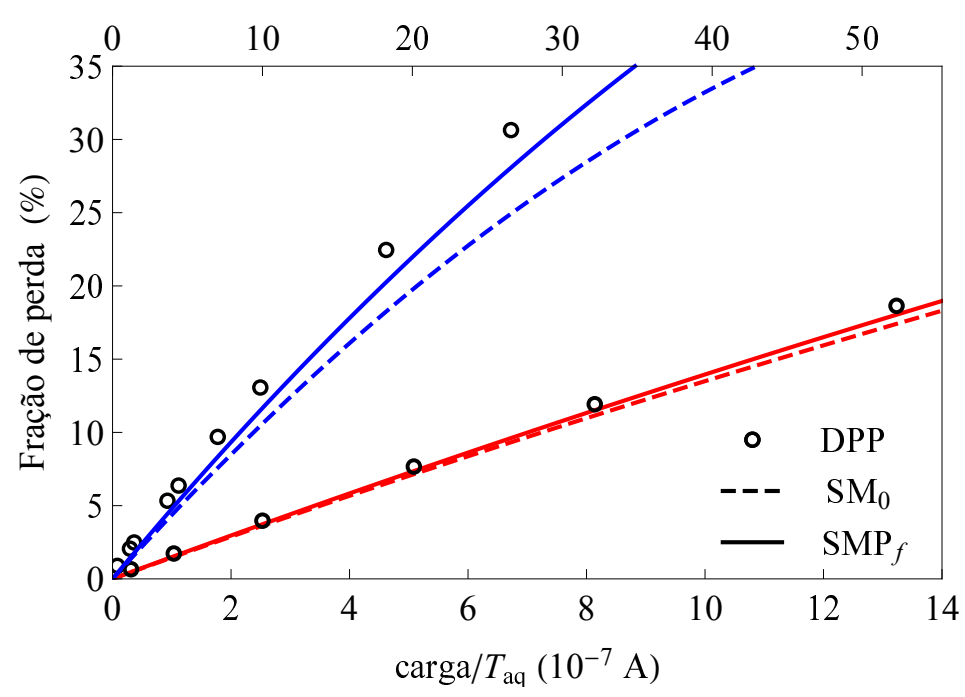

Figura A.2: Fração de perda estimada da taxa de entrada nos espectros ML (em azul) L (em vermelho), avaliada empregando: as informações do DPP (círculos), equação 5.16, $\mathrm{SM}_{0}$, linha pontilhada, e $\mathrm{SMP}_{f}$, linha contínua, equação A.13.

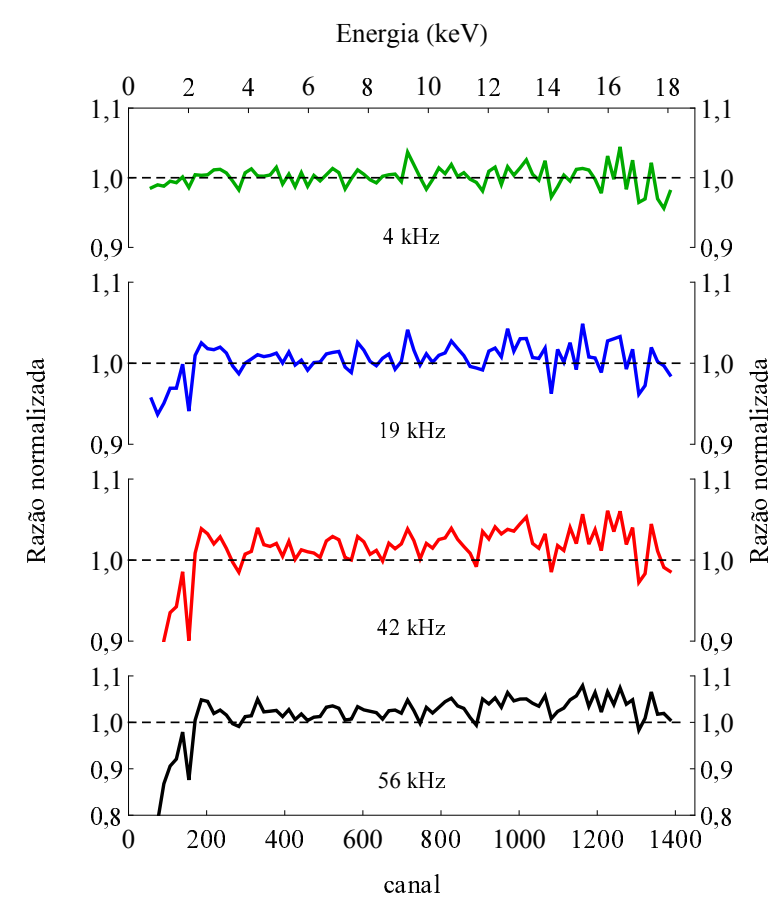

(a)

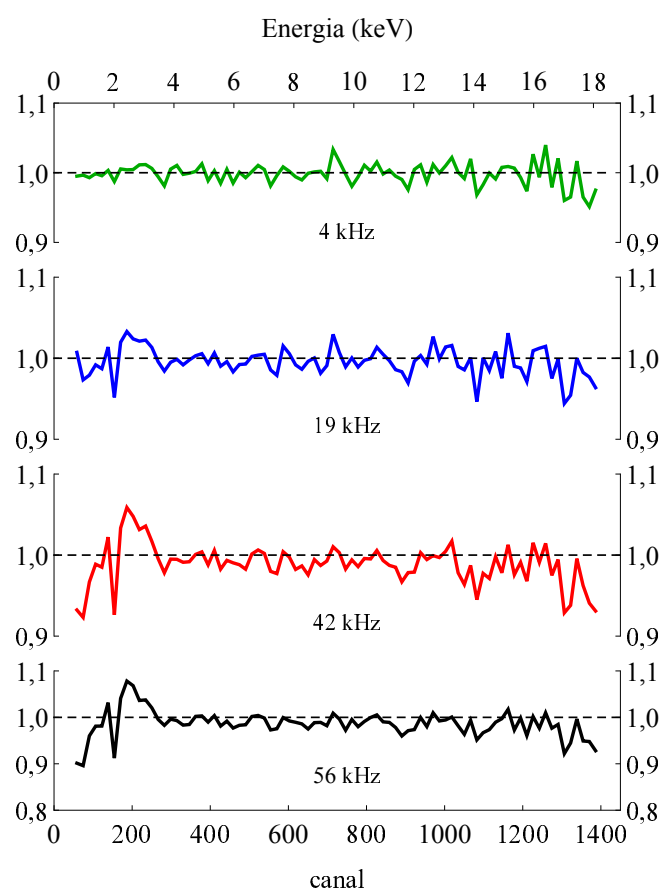

(b)

Figura A.3: Razão de alguns espectros ML, normalizados pela carga incidente e corrigidos pelas perdas por tempo morto pelos procedimentos a) $\mathrm{SMP}_{f}$ e b) $\mathrm{EDP}_{i}$, pelo espectro adquirido a baixa taxa, também normalizado pela carga, equação (A.14). Os espectros foram comprimidos de modo que cada bin corresponde a $210 \mathrm{eV}$.

tados como barras de incertezas, avaliadas com os modelos $\mathrm{SM}_{0}$ e $\mathrm{SM}_{f}$ são apresentados na figura A.5. A figura A.6 mostra as mesmas quantidades, agora avaliadas com o procedimento $\operatorname{EDP}_{i}$. Estes resultados são apresentados como função da taxa de saída $R_{\text {out }}$. 


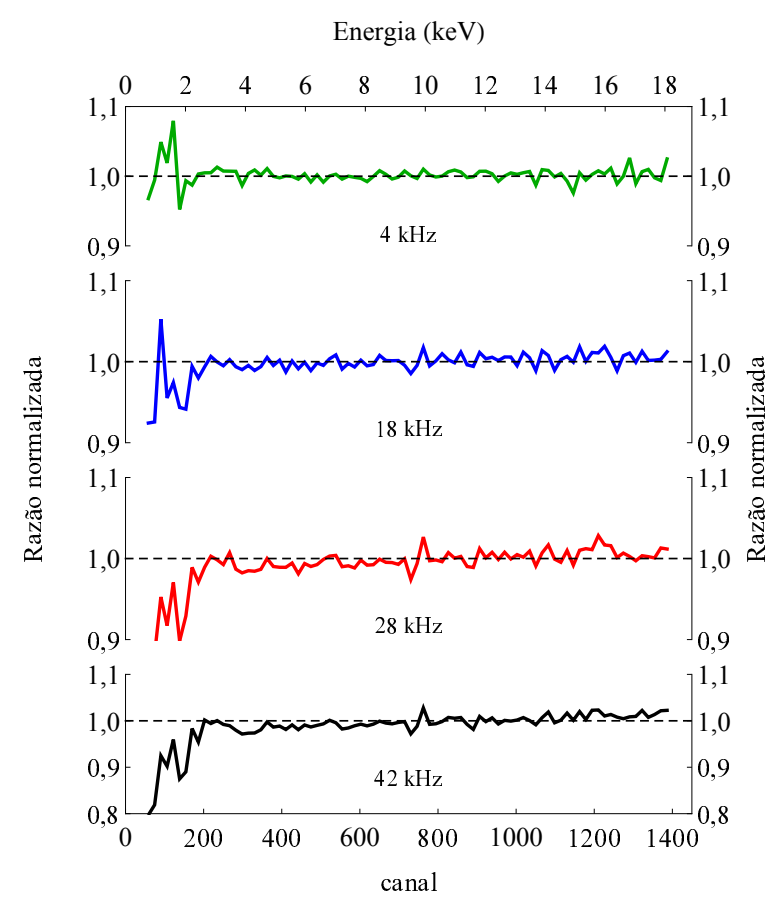

(a)

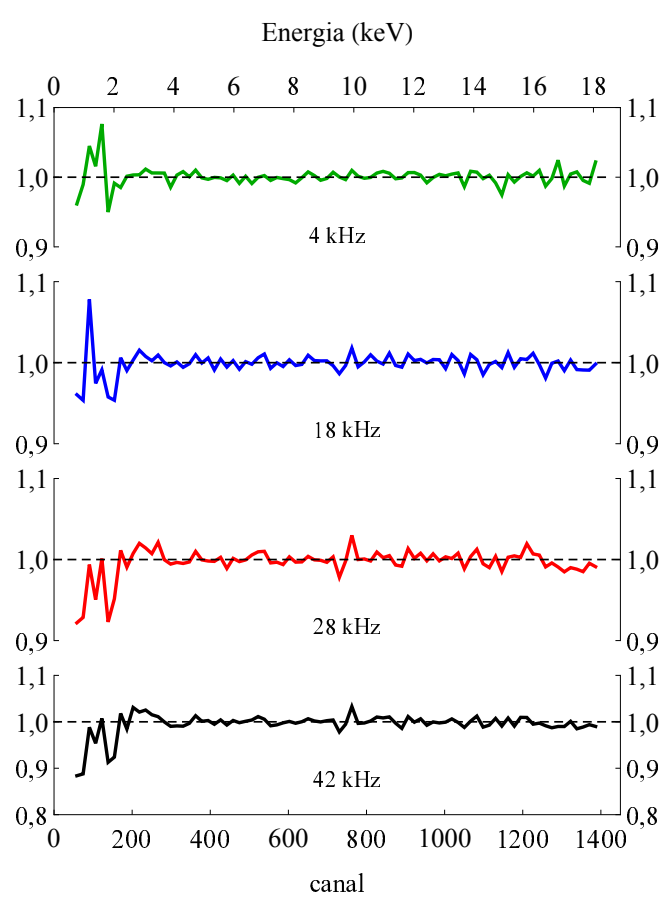

(b)

Figura A.4: Mesmo que a figura A.3, mas para os espectros L.

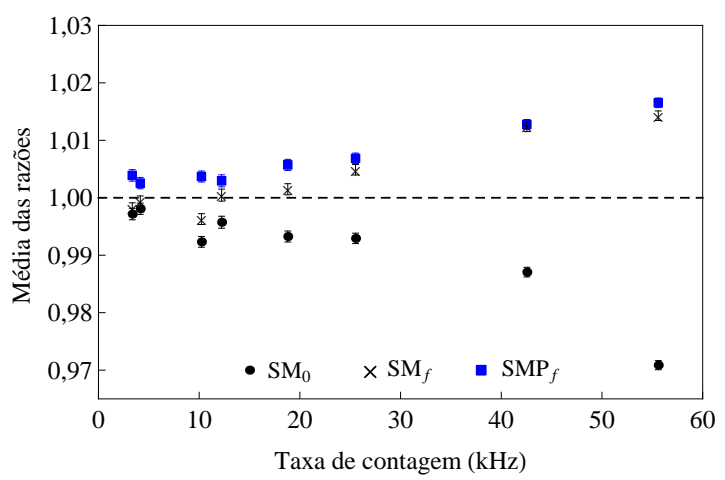

(a)

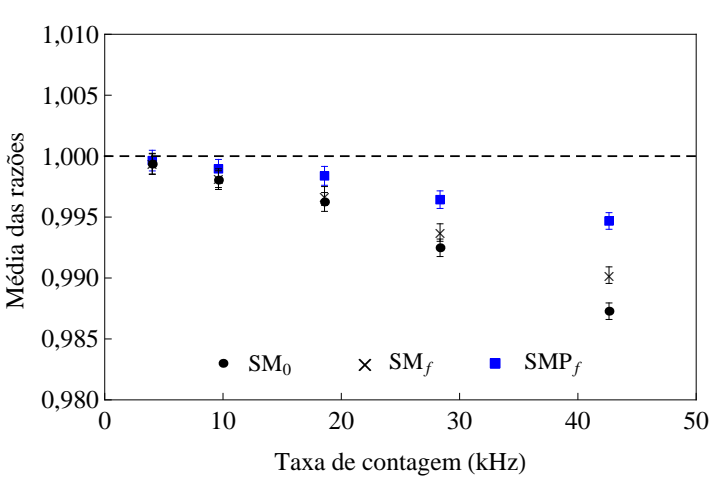

(b)

Figura A.5: Médias ponderadas das razões entre os espectros compensados e os espectros de referência para cada taxa de aquisição, normalizados pela carga, empregando os procedimento $\mathrm{SM}_{0}, \mathrm{SM}_{f}$ e $\mathrm{SMP}_{f}$, representados respectivamente por círculos, cruzes e quadrados para os espectros a) ML e b) L.

\section{A.0.0.5 Avaliação dos modelos para correção do tempo morto}

A figura A.2 mostra que a fração de perda de contagens fornecida pelo DPP apresenta bom acordo com aquelas encontradas com os modelos $\mathrm{SM}_{0}$ e $\mathrm{SMP}_{f}$ para os espectros $\mathrm{L}$ em todas as taxas de contagens do experimentos, mas não para o espectro ML, onde as diferenças são perceptíveis mesmo em baixas taxas de aquisição.

O bom acordo entre os dados experimentais de $R_{\text {out }}$ e os valores calculados com os 


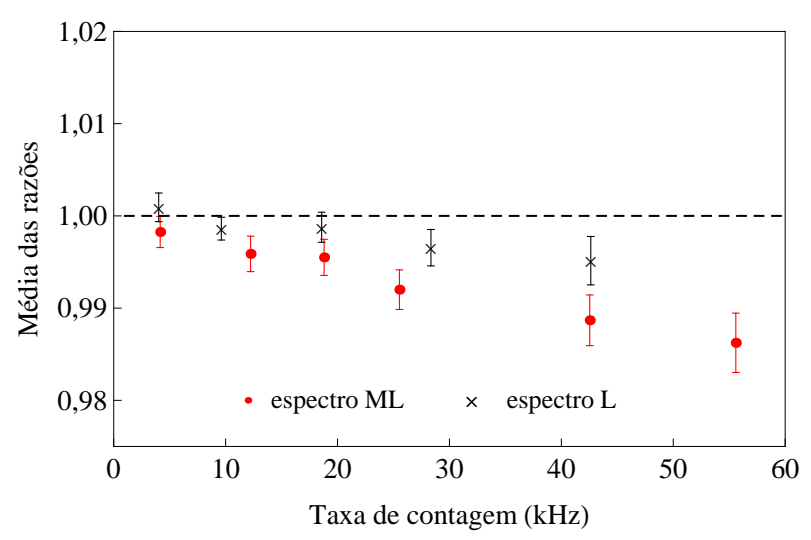

Figura A.6: Médias ponderadas das razões entre os espectros compensados e os espectros de referência para cada taxa de aquisição, normalizados pela carga, empregando o procedimento $\mathrm{EDP}_{i}$. Os círculos se referem aos espectros ML e as cruzes aos espectros L.

parâmetros ajustados na figura A.1 mostra que o modelo $\mathrm{SMP}_{f}$ pode estimar a taxa de saída $R_{\text {out }}$ com razoável precisão. Contudo, isso não significa que este modelo corrige adequadamente a forma dos espectros em toda sua extensão, sobretudo para os espectros ML, como pode ser visto na figura A.3 a). As estimativas do parâmetro $\tau_{\mathrm{C}}$ apresentadas na tabela A.1 concordam razoavelmente com os valores fornecidos pelo DPP somente para o caso dos espectros L. Este resultado indica que um valor constante para o parâmetro $F$, e portanto para $\tau_{\mathrm{C}}$, não fornece uma boa correção dos espectros ao longo de toda a sua extensão, principalmente para espectros do tipo ML, onde a estatística de contagem na região de baixa energia do espectro é alta.

As figuras A.3 a) e A.4 a) mostram que o modelo $\mathrm{SMP}_{f}$ corrige os espectros L razovelmente bem, e também os espectros ML para taxas de contagem abaixo de $20 \mathrm{kHz}$. Essas figuras também chamam a atenção para a distorção dos espectros com o aumento da energia, que é mais evidente na região de baixa energia, mas está presente em toda a extensão do espectro, onde é possível observar uma ligeira inclinação das linhas que representam os espectros corrigidos entre cerca de 3 e $18 \mathrm{keV}$.

A comparação entre os espectros corrigidos com o modelo $\mathrm{EDP}_{i}$, figuras A.3 b) e A.4 b), e com o modelo $\mathrm{SMP}_{f}$, figuras A.3 a) e A.4 a), evidencia que o modelo $\mathrm{EDP}_{i}$ corrige os espectros com uma precisão maior, sobretudo para altas taxas de aquisição. As figuras A.3 b) e A.4 b) mostram que os espectros corrigidos com o modelo $\mathrm{EDP}_{i}$ apresentam uma dispersão que é muito maior abaixo de $3 \mathrm{keV}$. Este comportamento está associado às distorções na forma do espectro devido a mudança na resolução com o aumento da taxa de aquisição e também ao empilhamento com ruído.

Os valores encontrados para o parâmetro $T_{a}$ quando o modelo $\mathrm{EDP}_{i}$ foi ajustado aos 
dados experimentais, tabela A.2, concordam entre si para os espectros ML e L, e também são compatíveis com o valor fornecido pelas configurações do DPP, de 1,8 $\mu$ s. Por outro lado, ao ajustar o parâmetro $E_{d}$ a cada um dos espectros $i$ notou-se que este parâmetro é sensível ao número de contagens na região de baixa energia do espectro. Quando a taxa de contagem é baixa nessa região o valor ajustado pode até mesmo ser negativo, sendo mais adequado nesse caso fixar este parâmetro no valor estabelecido para o limiar do digitalizador lento.

Por fim, a comparação das figuras A.5 e A.6 permite concluir que quando a taxa de aquisição dos espectros é inferior a $10 \mathrm{kHz}$, os modelos padrões, $\mathrm{SM}_{0}, \mathrm{SM}_{f}, \mathrm{SMP}_{f}$ fornecem correções com precisão semelhante à do modelo $\mathrm{EDP}_{i}$, além de corrigir os espectros ML de forma razoável em toda a sua extensão. Esta afirmação continua válida para os espectros L, mesmo para taxas maiores. Contudo, quando as taxas de aquisição são altas, superiores a cerca de $30 \mathrm{kHz}$, e os espectros apresentam alta estatística de contagem na região de baixa energia, somente o modelo $\mathrm{EDP}_{i}$ fornece correções com boa precisão ao longo de toda a extensão do espectro. 


\section{APÊNDICE B - Ajuste dos parâmetros dos picos de raios X K do Cu e L do Ta, W e Au}

No capítulo 6 foram apresentadas as figuras com os espectros experimentais, junto com a curva calculada com os parâmetros ajustados, para o alvo de $\mathrm{Cu}$ irradiado com o feixe de $15,51(9) \mathrm{keV}$ e observado no ângulo de $31^{\circ}$, para o alvo de Ta irradiado com o feixe de 20,76(9) $\mathrm{keV}$ e observado no ângulo de $31^{\circ}$, para o alvo de $\mathrm{W}$ irradiado com o feixe de $100,65(7) \mathrm{keV}$ e observado no ângulo de $90^{\circ}$, e para o alvo de Au irradiado com o feixe de 30,62(15) keV e observado no ângulo de $125^{\circ}$. Na seqüência de figuras abaixo são apresentadas as figuras destes mesmos alvos irradiados com essas mesmas energias, mas nos outros dois ângulos de medição. Para o $\mathrm{Cu}$, os espectros experimentais, junto com a curva calculada com os parâmetros ajustados, com o feixe de 15,51(9) keV e observado nos ângulos de $90^{\circ}$ e $125^{\circ}$, para o Ta com o feixe de 20,76(9) keV e observado nos ângulos de $90^{\circ}$ e $125^{\circ}$, para o $\mathrm{W}$ com o feixe de $100,65(7) \mathrm{keV}$ e observado nos ângulos de $31^{\circ} \mathrm{e}$ $125^{\circ}$, e para o alvo de Au irradiado com o feixe de $30,62(15) \mathrm{keV}$ e observado nos ângulos de $31^{\circ}$ e $90^{\circ}$, 


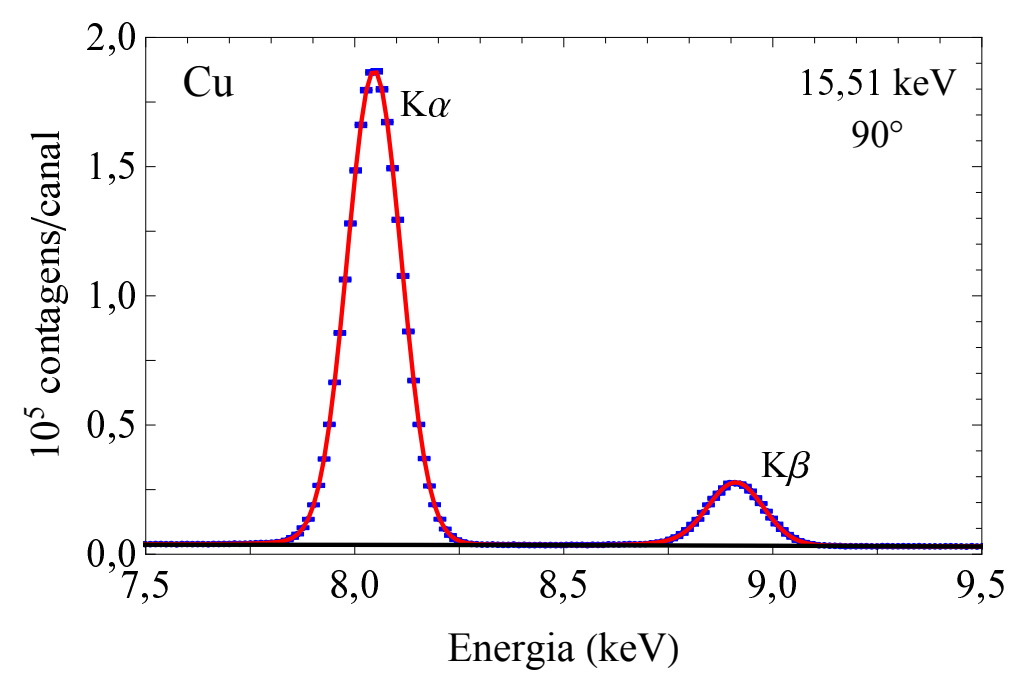

(a)

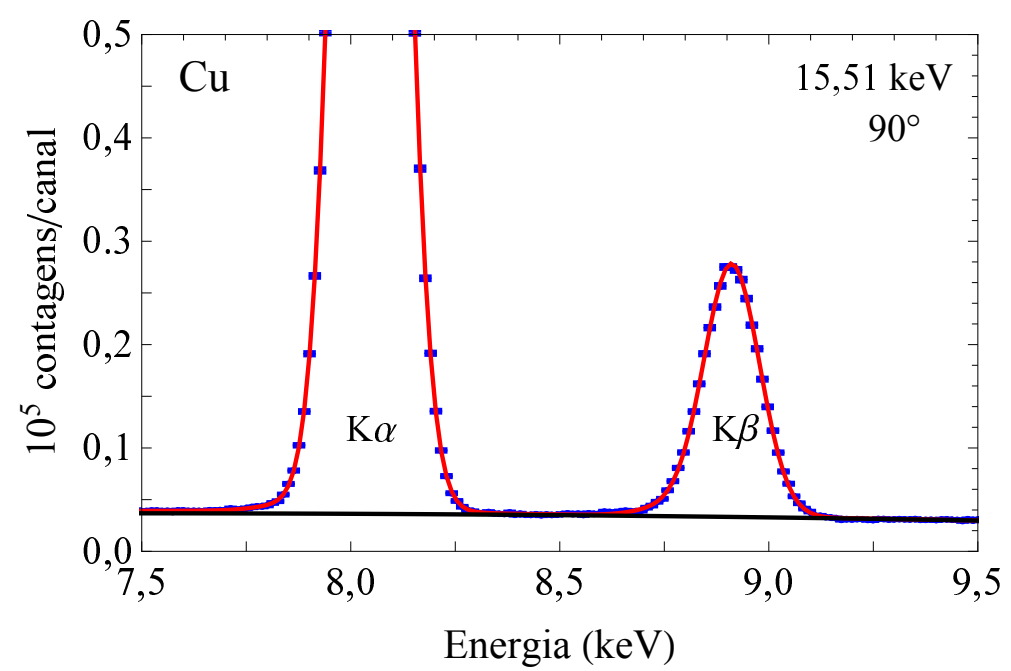

(b)

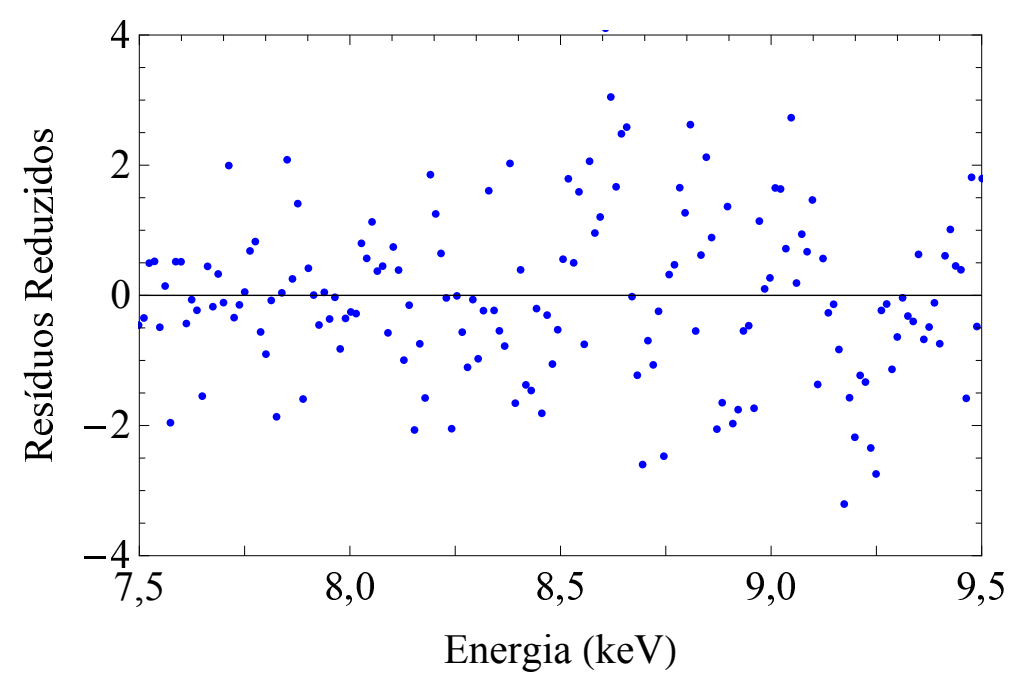

(c)

Figura B.1: a) e b) Comparação entre o espectro de raios x experimental e a curva calculadas com os parâmetros ajustados para o multipleto $\mathrm{K}$ do $\mathrm{Cu}$ irradiado com o feixe de elétrons de $15,51(9) \mathrm{keV}$ no ângulo de $90^{\circ}$. c) Resíduos reduzidos do ajuste. O $\chi^{2}$ reduzido do ajuste foi de 1,7 . 


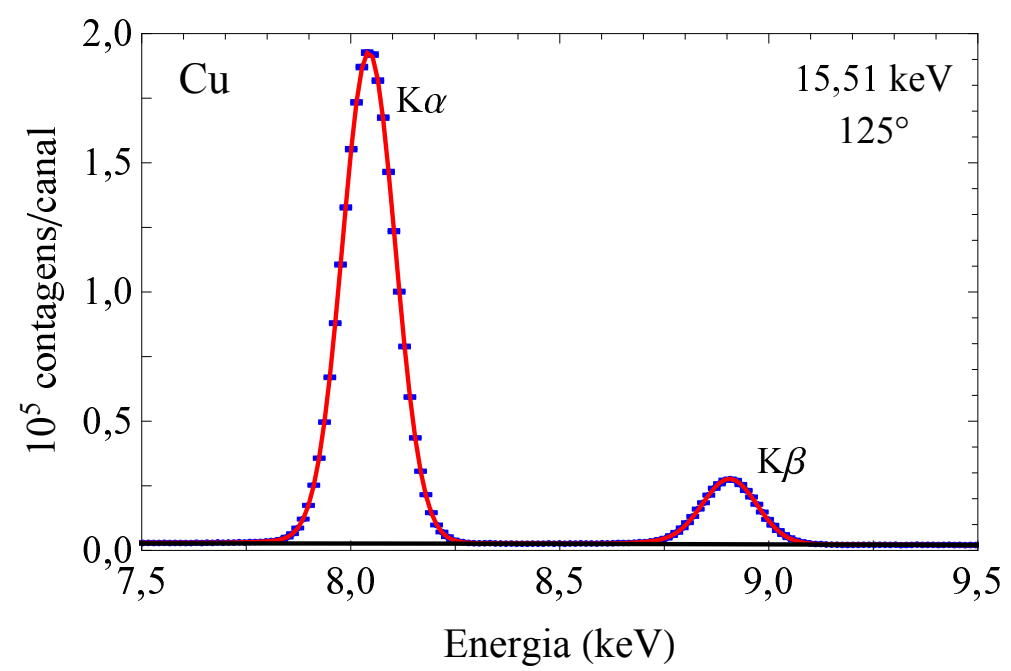

(a)

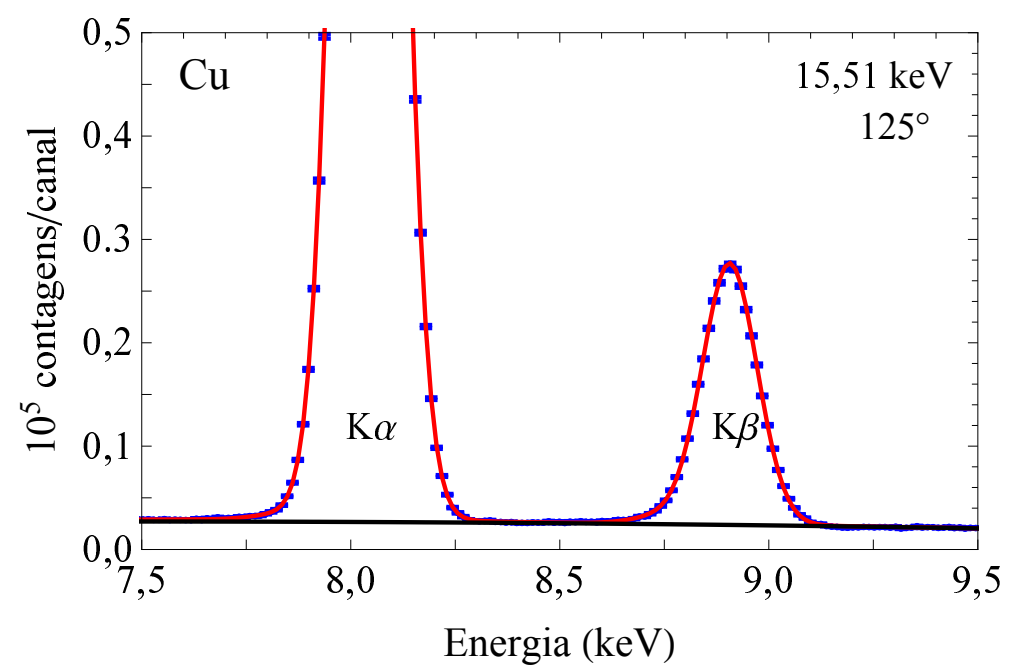

(b)

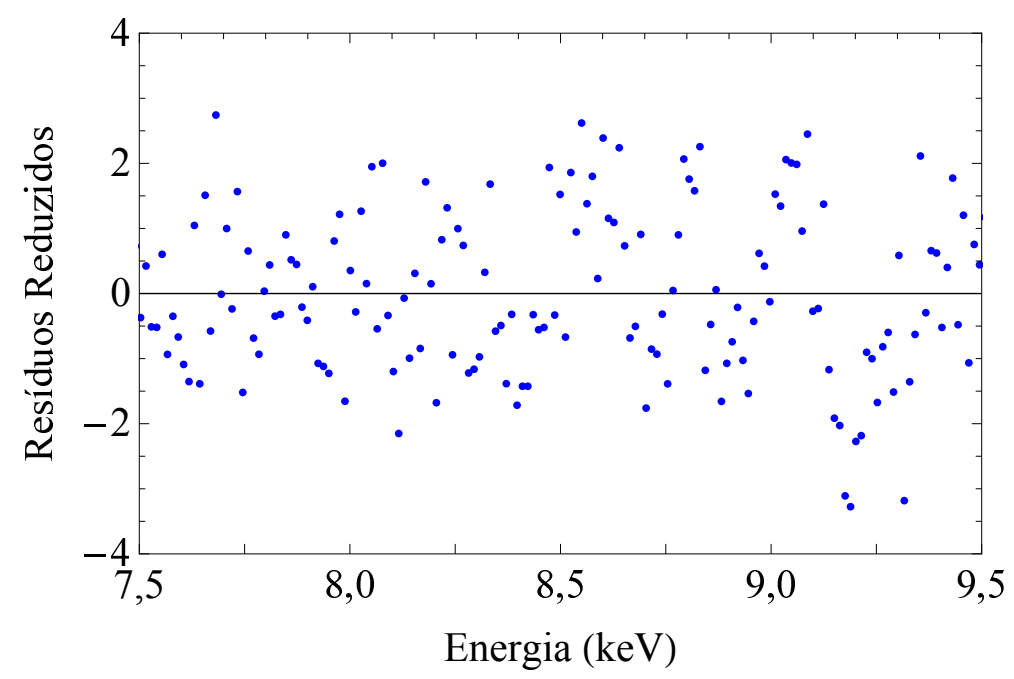

(c)

Figura B.2: Mesmo que a figura B.1, mas para o detector na posição de $125^{\circ}$. O $\chi^{2}$ reduzido do ajuste foi de 1,7 . 


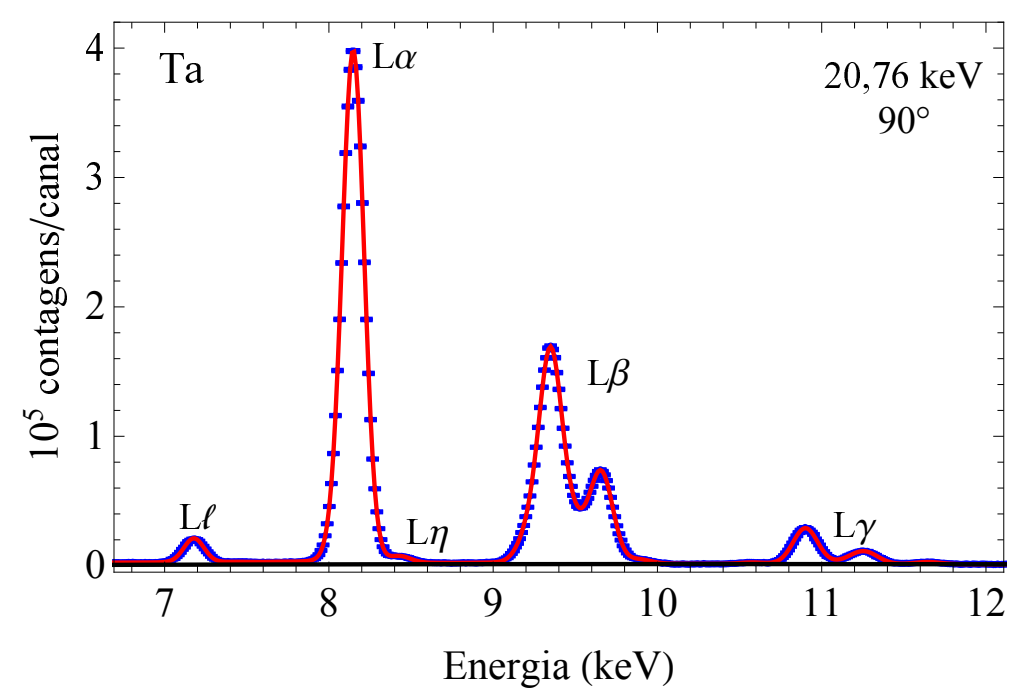

(a)

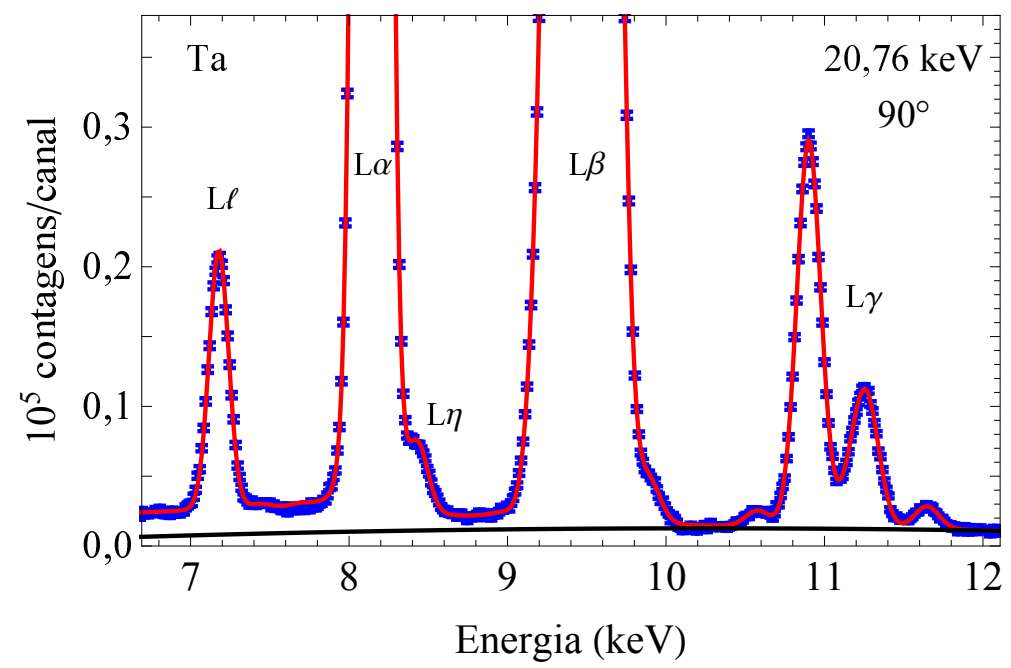

(b)

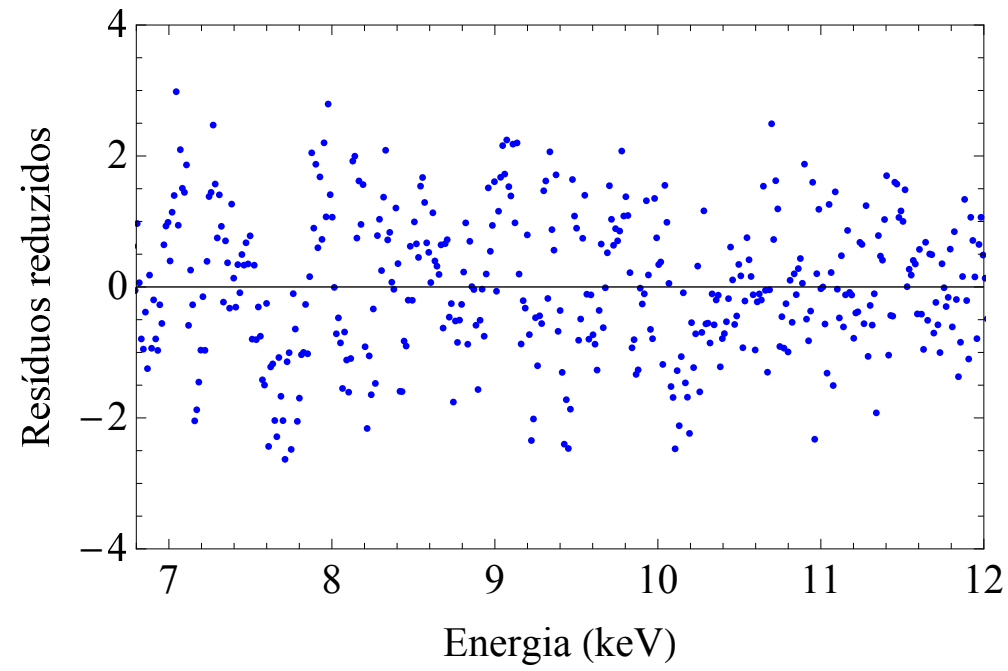

(c)

Figura B.3: a) e b) Comparação entre o espectro de raios x experimental e a curva calculadas com os parâmetros ajustados para o multipleto L do Ta irradiado com o feixe de elétrons de $20,76(9) \mathrm{keV}$ no ângulo de $90^{\circ}$. c) Resíduos reduzidos do ajuste. O $\chi^{2}$ reduzido do ajuste foi de 1,2 . 


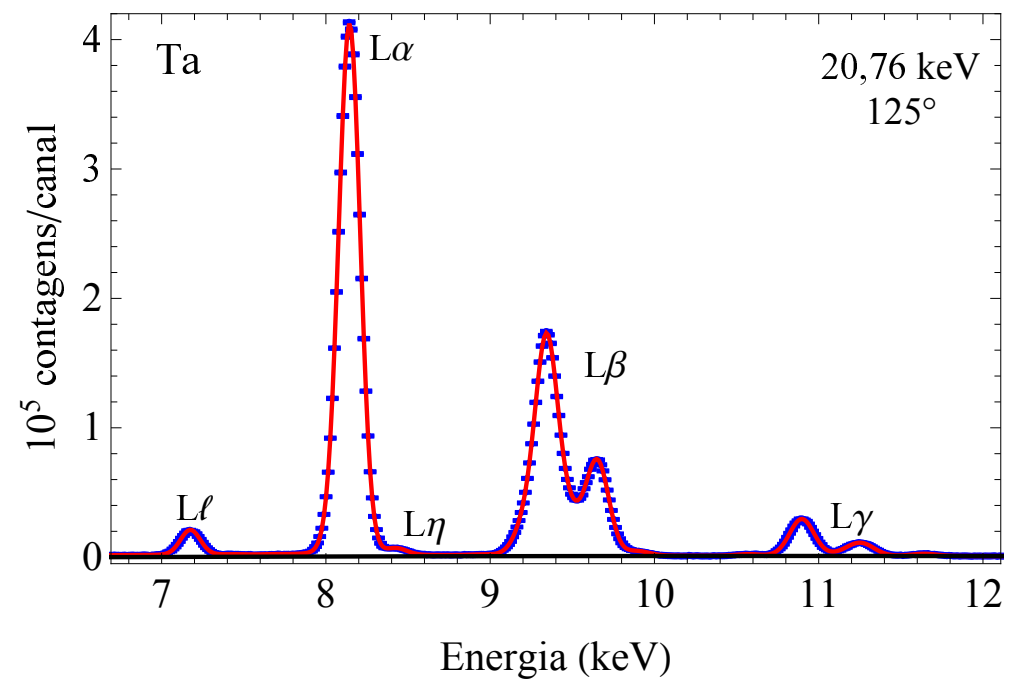

(a)

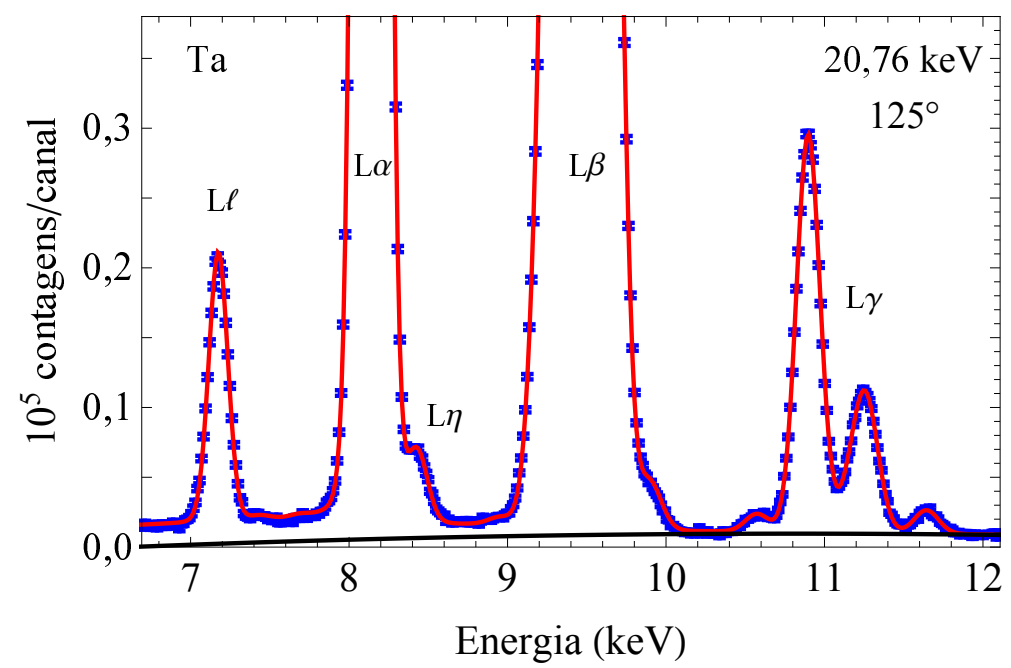

(b)

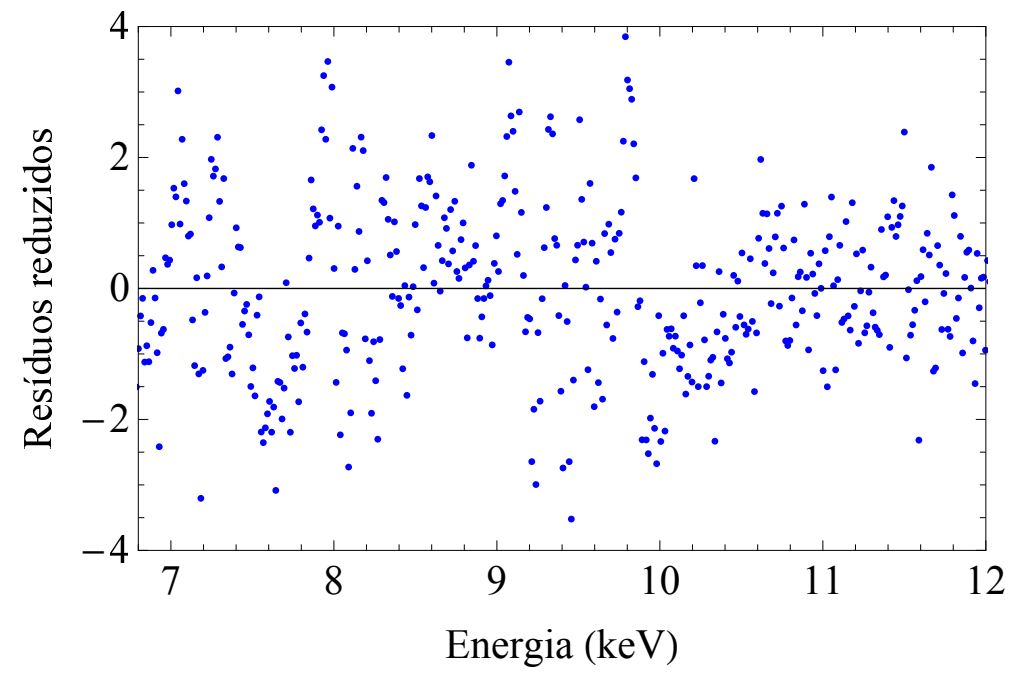

(c)

Figura B.4: Mesmo que a figura B.3, mas para o detector na posição de $125^{\circ}$. O $\chi^{2}$ reduzido do ajuste foi de 1,6 . 


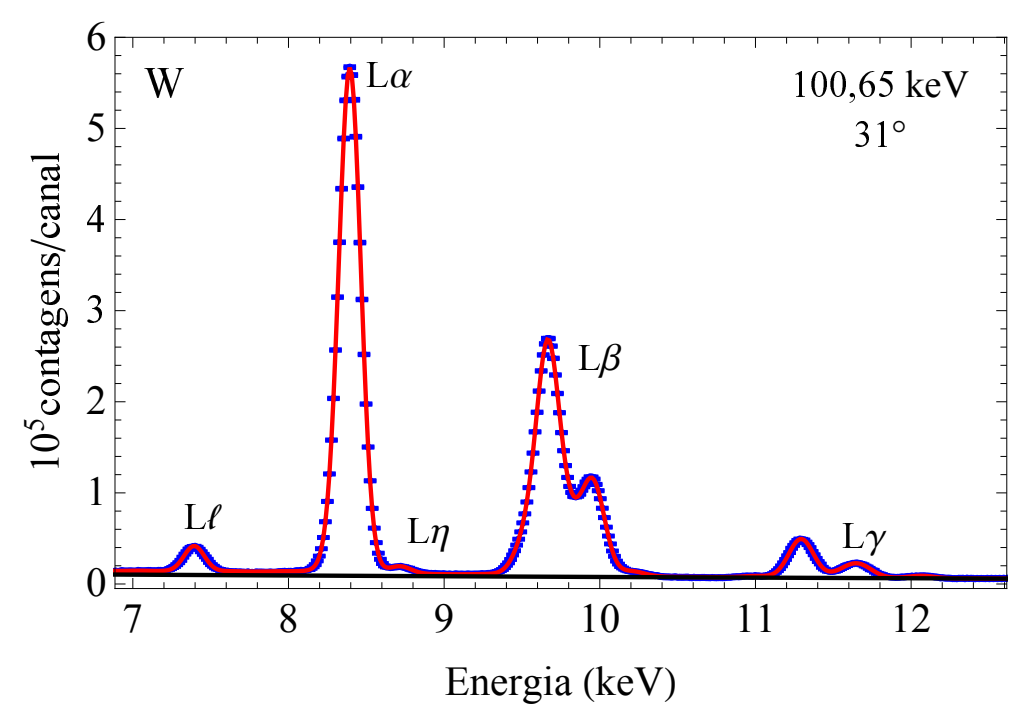

(a)

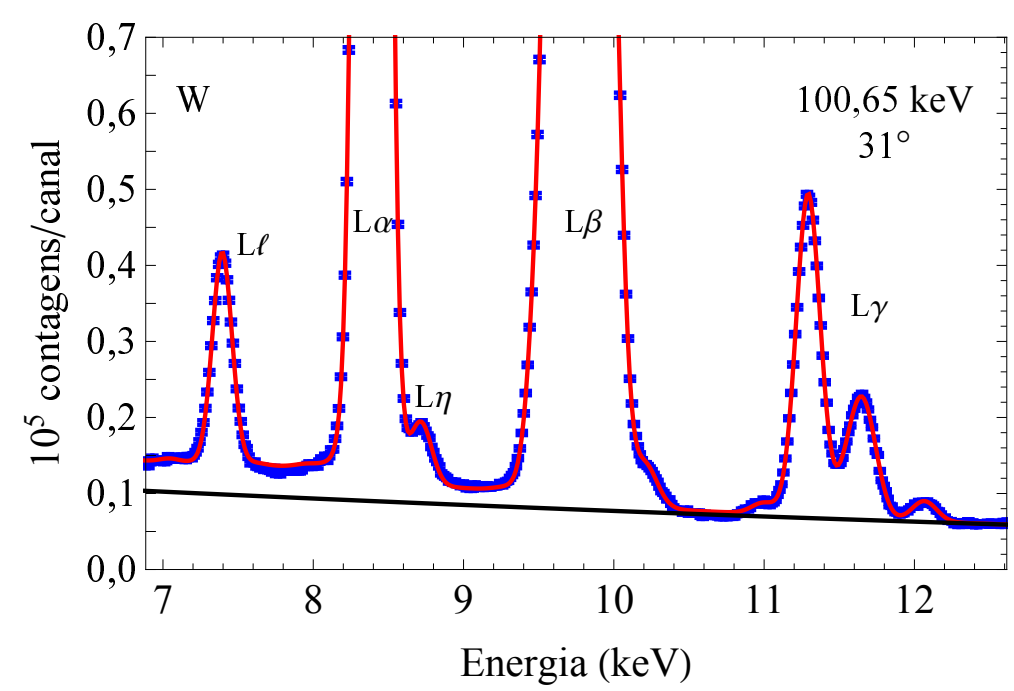

(b)

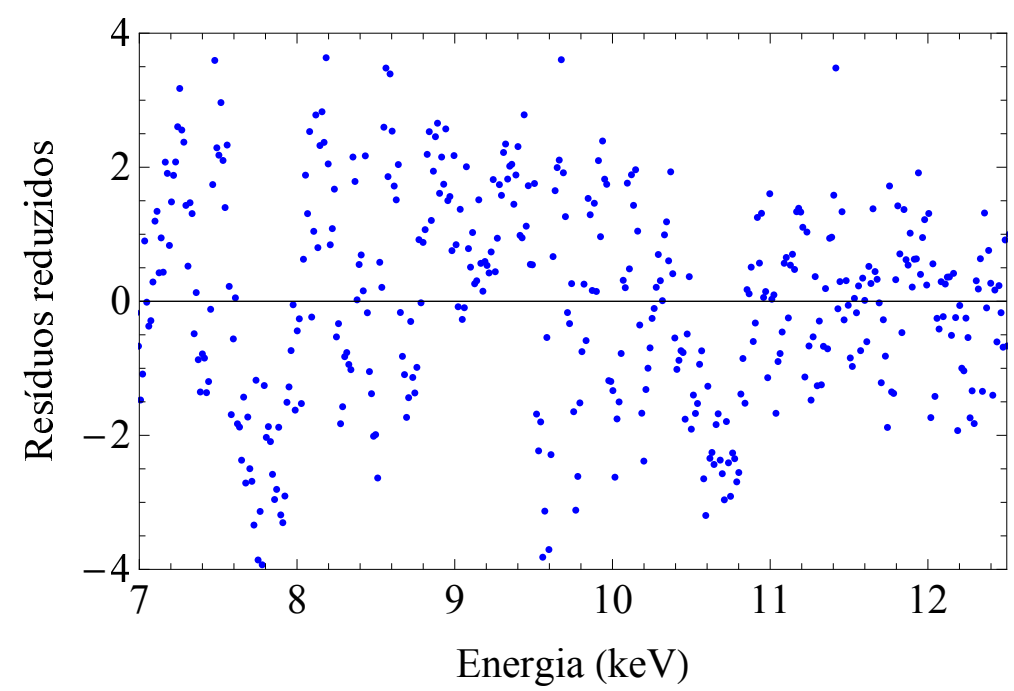

(c)

Figura B.5: a) e b) Comparação entre o espectro de raios x experimental e a curva calculadas com os parâmetros ajustados para o multipleto L do W irradiado com o feixe de elétrons de $100,65(7) \mathrm{keV}$ no ângulo de $31^{\circ}$. c) Resíduos reduzidos do ajuste. O $\chi^{2}$ reduzido do ajuste foi de 2,5 . 


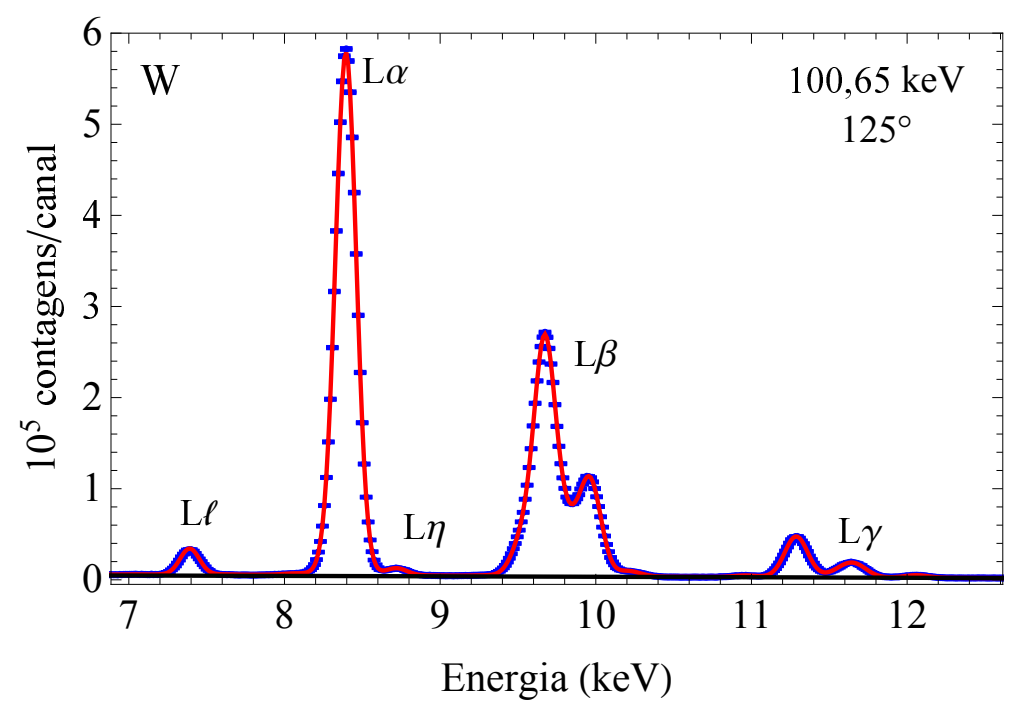

(a)

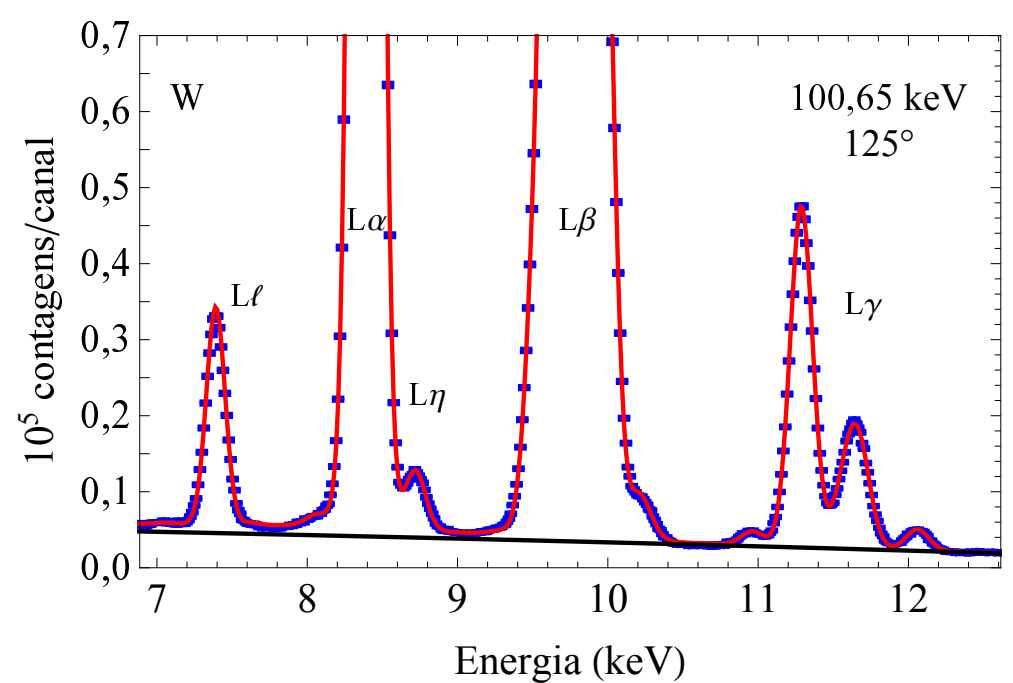

(b)

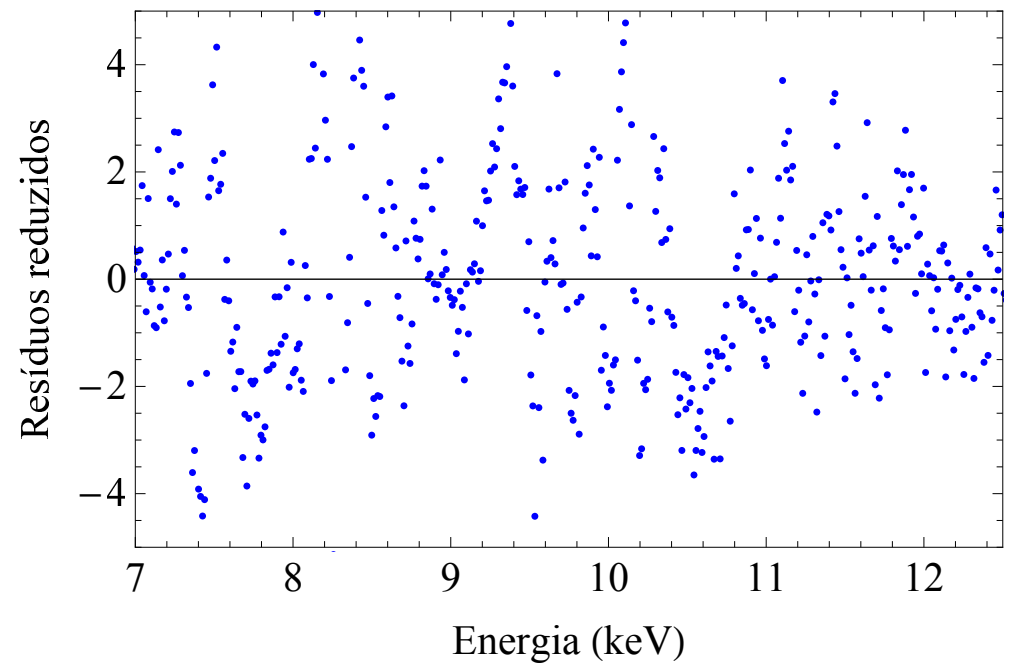

(c)

Figura B.6: Mesmo que a figura B.5, mas para o detetor na posição de $125^{\circ}$. O $\chi^{2}$ reduzido do ajuste foi de 2,4 . 


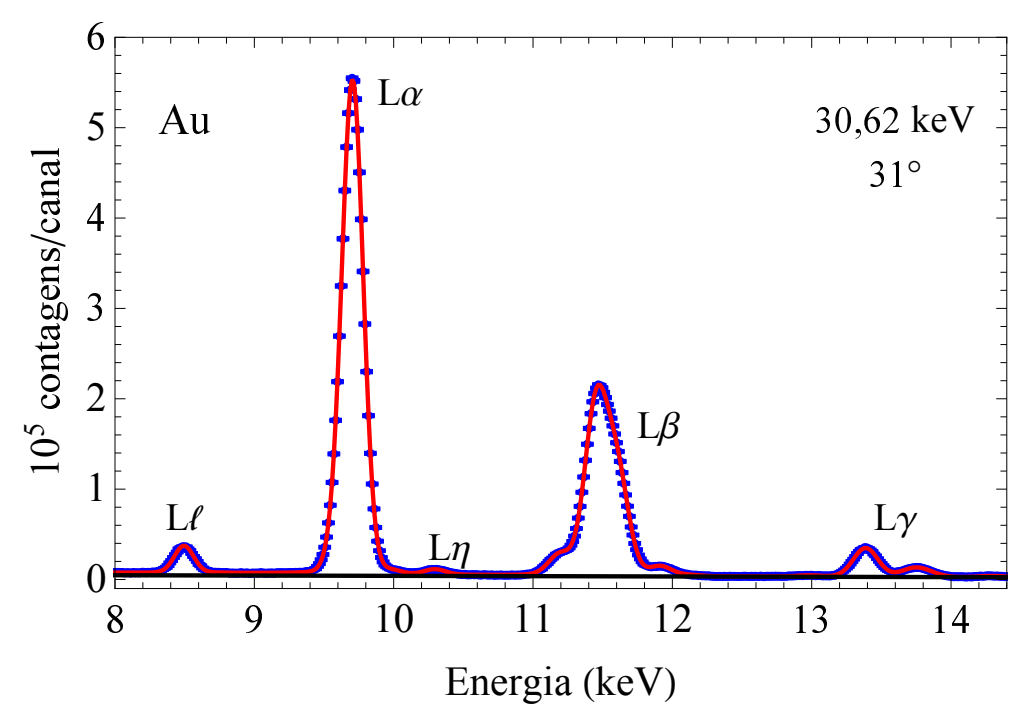

(a)

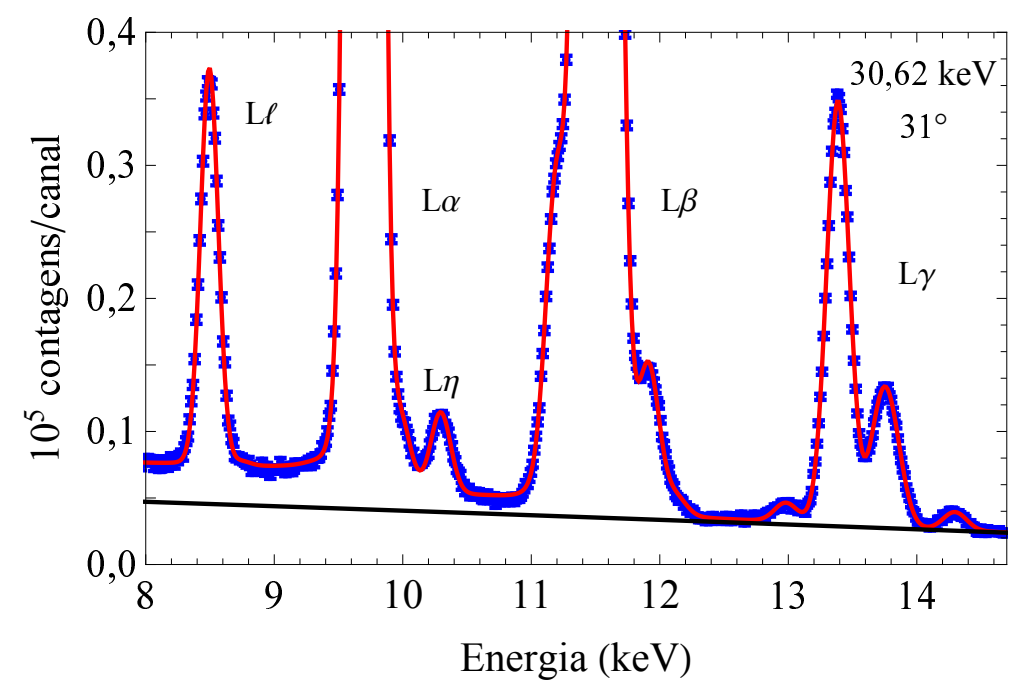

(b)

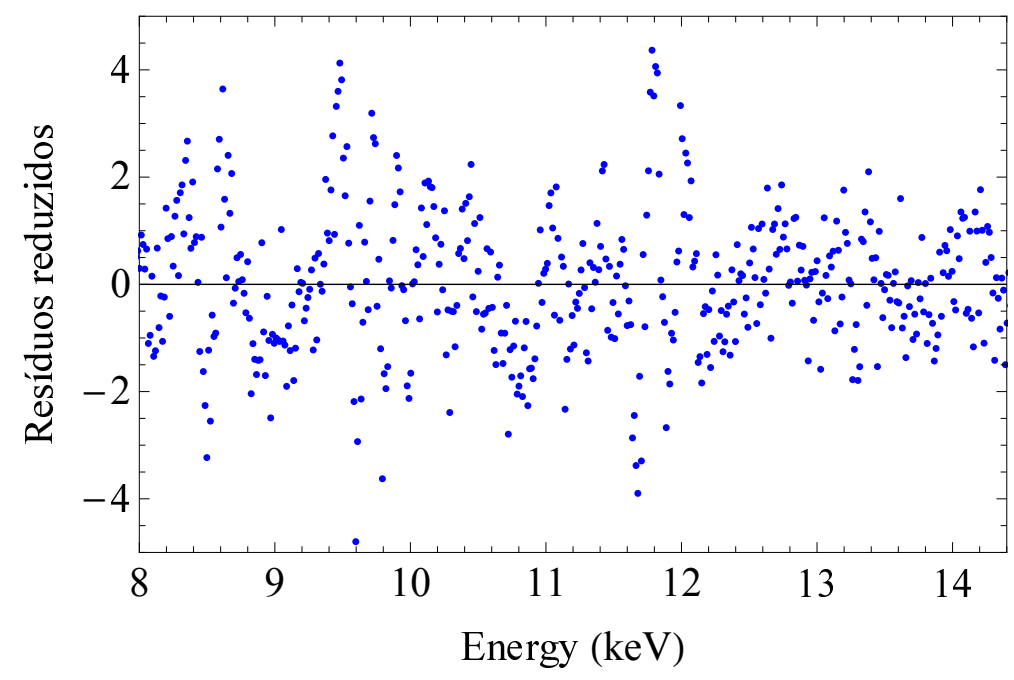

(c)

Figura B.7: a) e b) Comparação entre o espectro de raios x experimental e a curva calculadas com os parâmetros ajustados para o multipleto L do W irradiado com o feixe de elétrons de $30,62(15) \mathrm{keV}$ no ângulo de $31^{\circ}$. c) Resíduos reduzidos do ajuste. O $\chi^{2}$ reduzido do ajuste foi de 1,6 . 


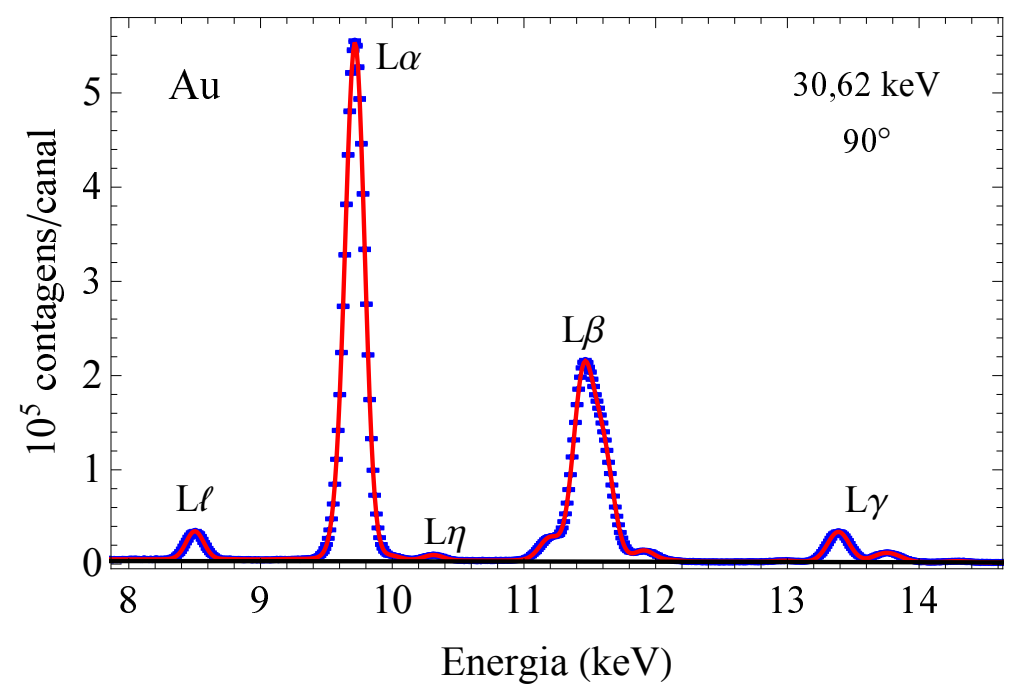

(a)

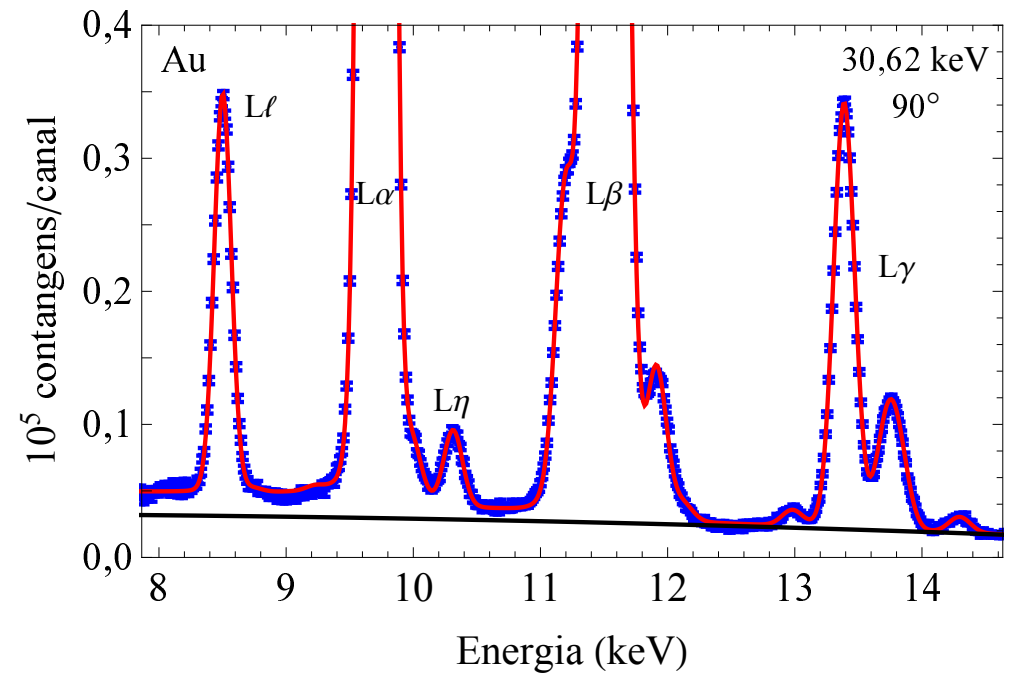

(b)

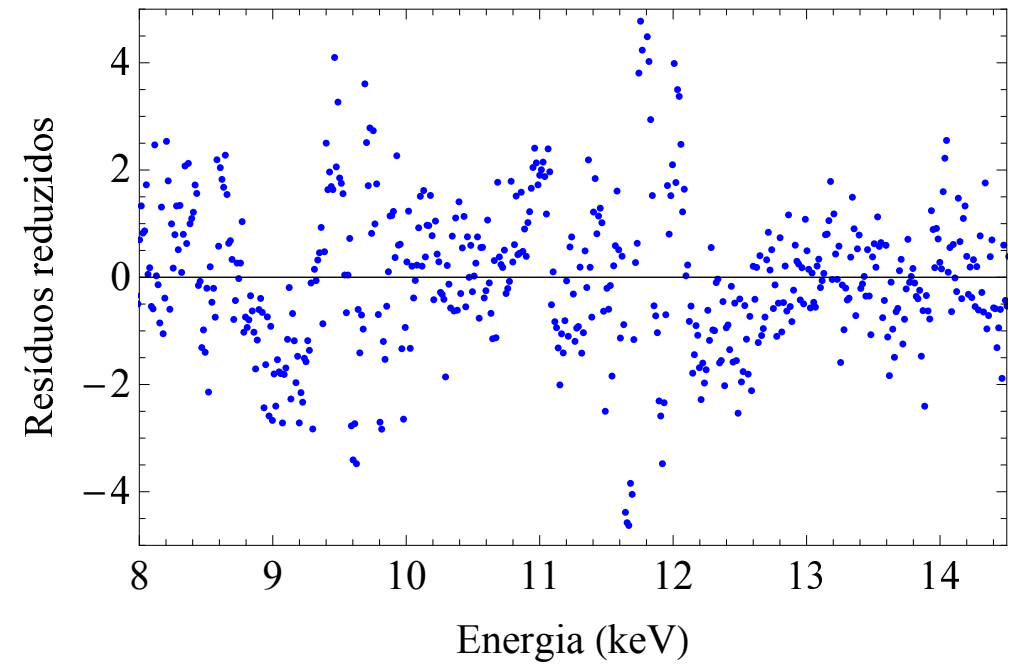

(c)

Figura B.8: Mesmo que a figura B.7, mas para o detetor na posição de $90^{\circ}$. O $\chi^{2}$ reduzido do ajuste foi de 1,8 . 


\section{APÊNDICE C - Distribuição angular das linhas L $\ell$, $\mathrm{L} \alpha_{1}$ e $\mathrm{L} \alpha_{2}$ do Ta}

No capítulo 8 foram apresentadas as figuras das distribuições angulares das linhas L $\ell$, $\mathrm{L} \alpha_{1}$ e $\mathrm{L} \alpha_{2}$ do Ta irradiado com as energias de 11,51(6); 30,62(9) e 100,60(4) keV. Neste apêndice são apresentadas as figuras dessas distribuições angulares para as demais energias em que este alvo foi irradiado. 


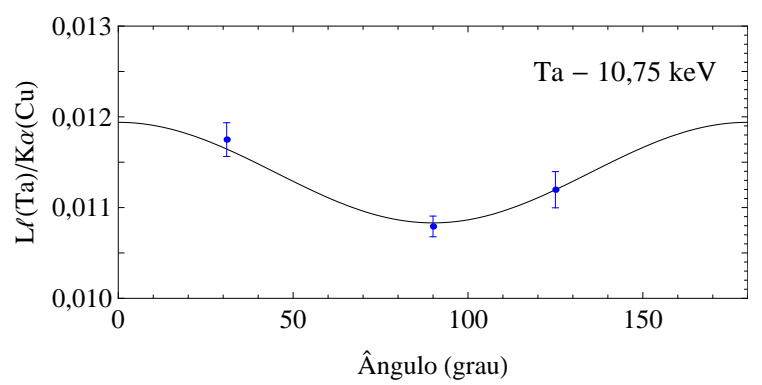

(a)

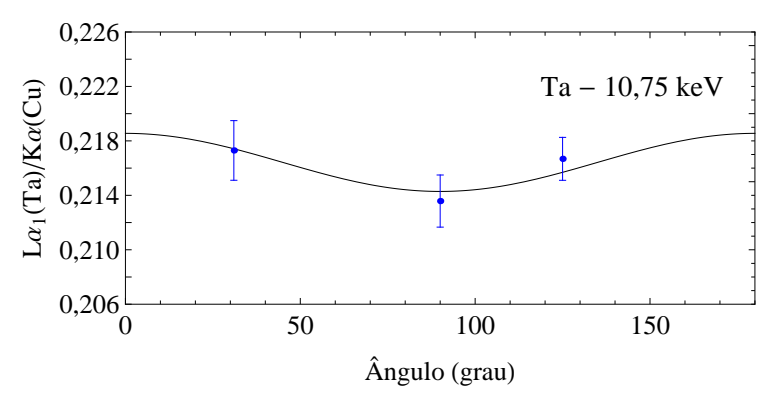

(b)

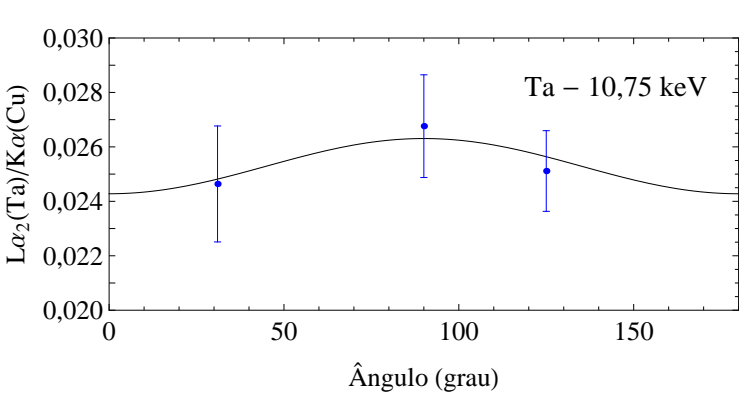

(c)

Figura C.1: Pontos experimentais e curva calculada com os parâmetros estimados para o alvo de Ta na energia de $10,75(9) \mathrm{keV}$. a) Linha $\mathrm{L} \ell$, b) $\mathrm{L} \alpha_{1}$ e c) $\mathrm{L} \alpha_{2}$. O $\chi^{2}$ do ajuste foi de 9,3 .

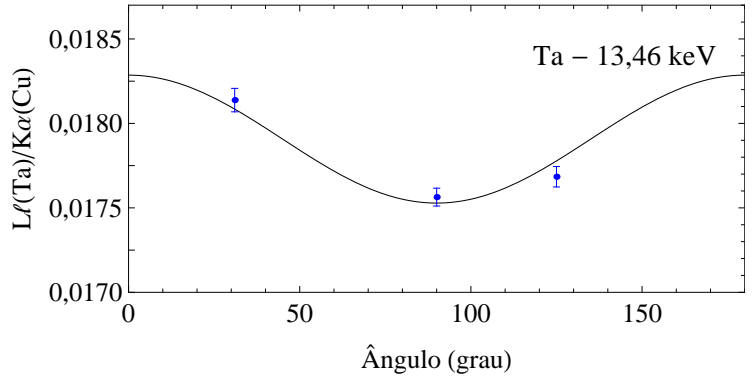

(a)

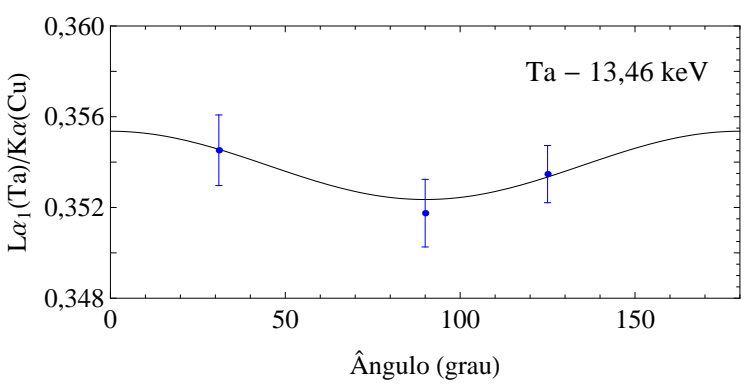

(b)

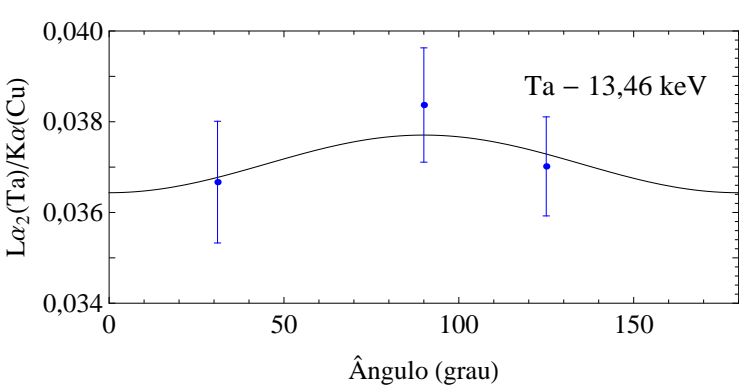

(c)

Figura C.2: Mesmo que a figura C.1, mas para a energia de $13,46(9) \mathrm{keV}$. O $\chi^{2}$ do ajuste foi de 6,9 . 


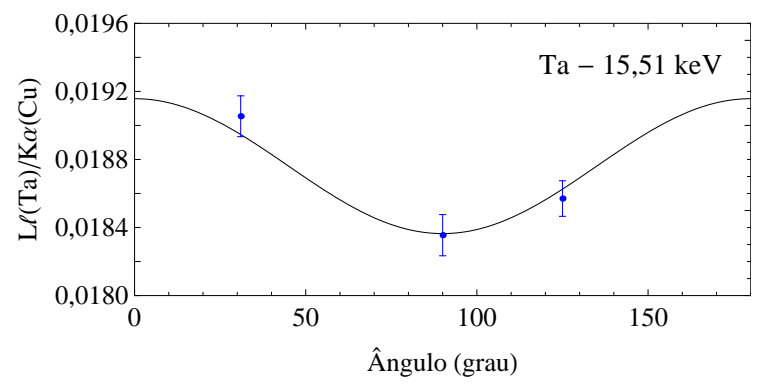

(a)

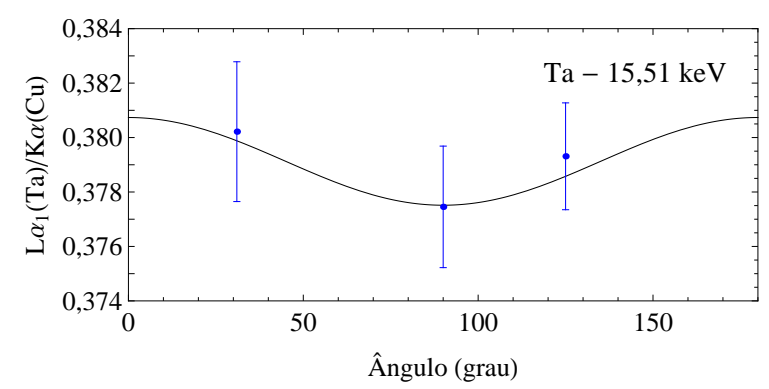

(b)

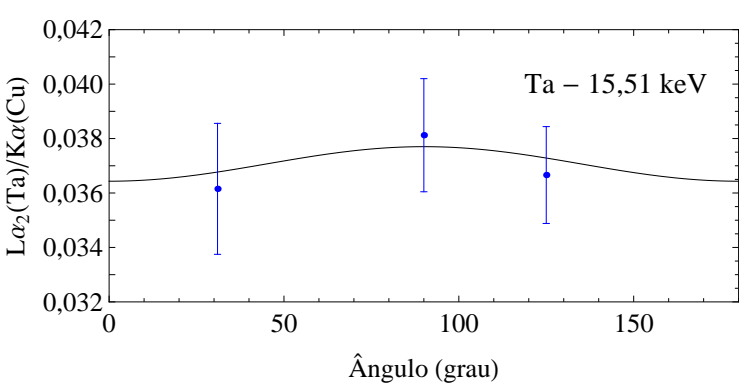

(c)

Figura C.3: Mesmo que a figura C.1, mas para a energia de 15, 51(4) keV. O $\chi^{2}$ do ajuste foi de 3,4 .

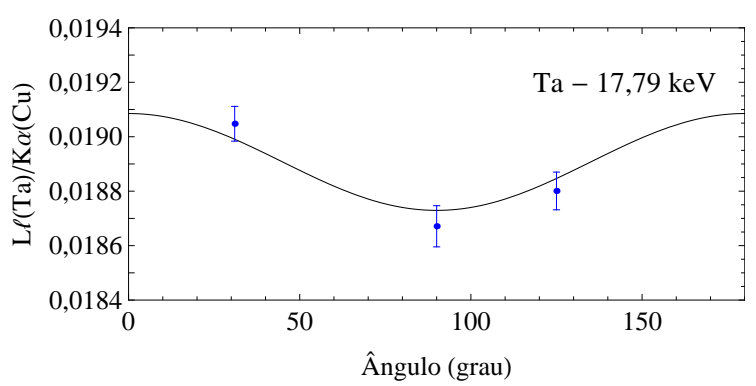

(a)

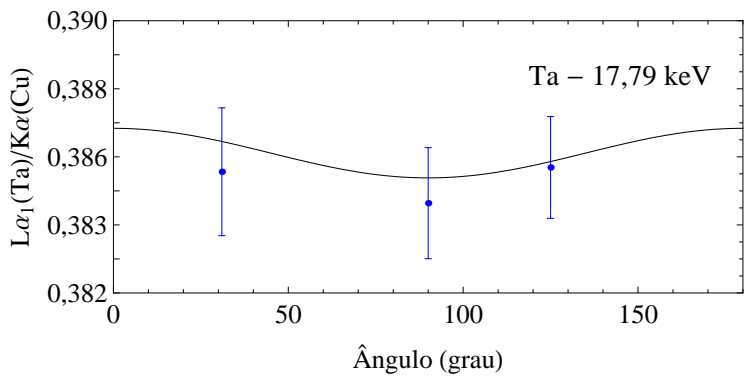

(b)

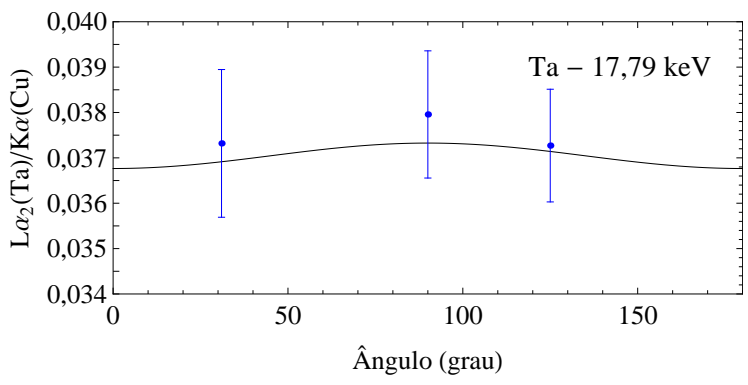

(c)

Figura C.4: Mesmo que a figura C.1, mas para a energia de $17,79(7) \mathrm{keV}$. O $\chi^{2}$ do ajuste foi de 5,9 . 


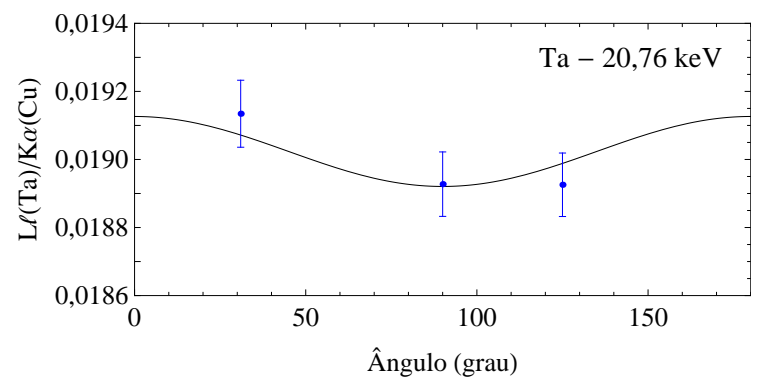

(a)

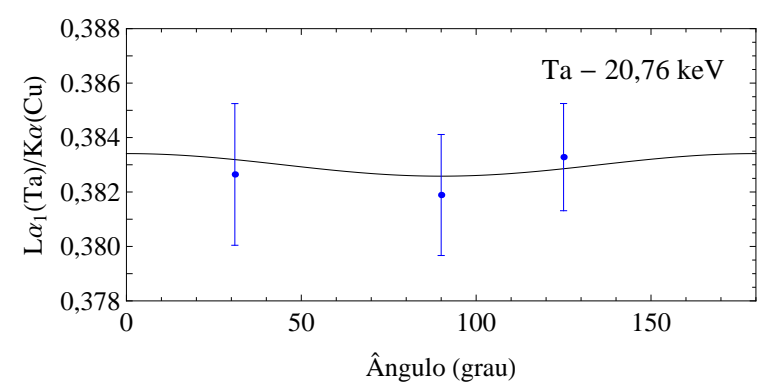

(b)

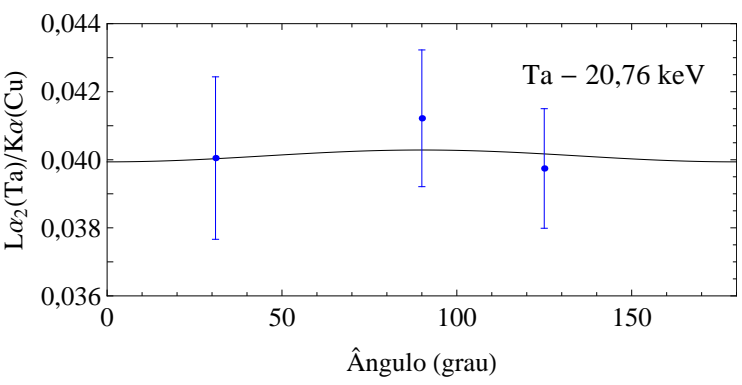

(c)

Figura C.5: Mesmo que a figura C.1, mas para a energia de 20,76(9) keV. O $\chi^{2}$ do ajuste foi de 3,3 .

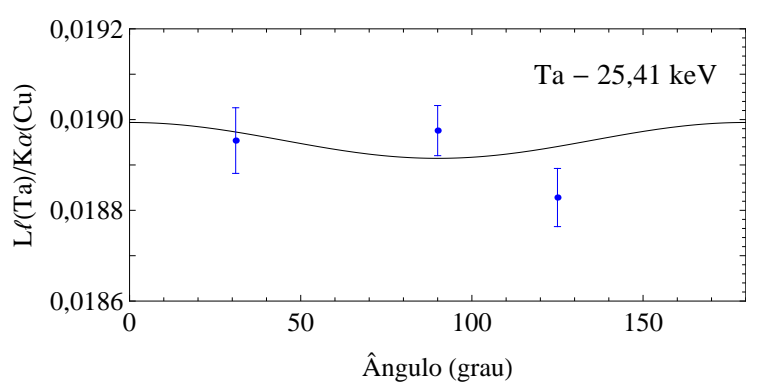

(a)

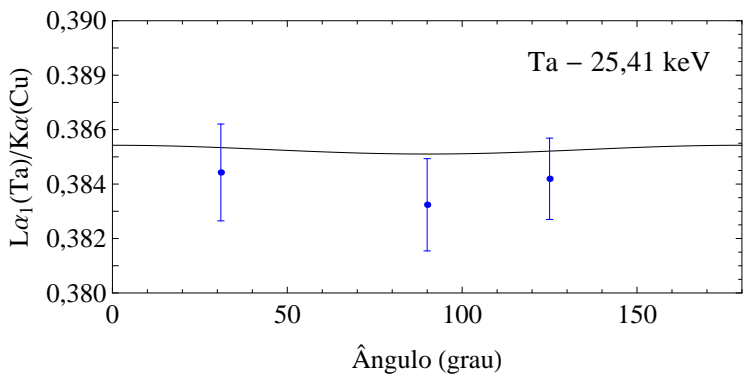

(b)

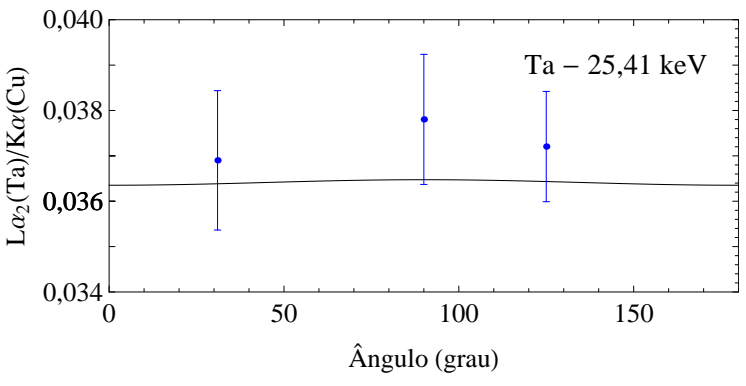

(c)

Figura C.6: Mesmo que a figura C.1, mas para a energia de 25, 41(15) keV. O $\chi^{2}$ do ajuste foi de 7,8 . 


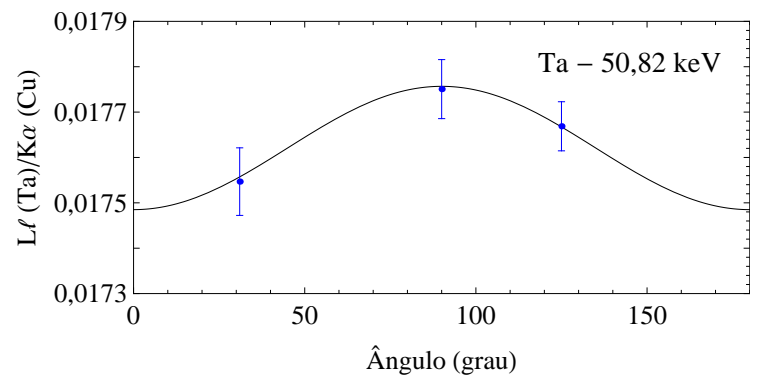

(a)

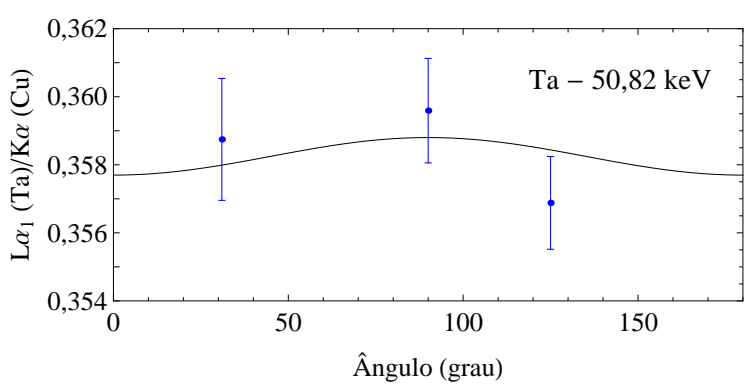

(b)

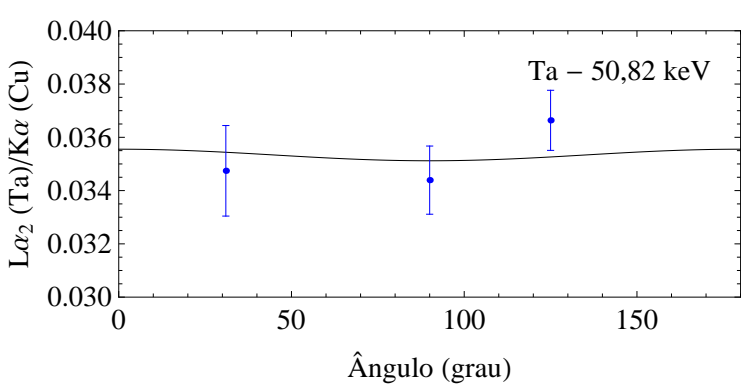

(c)

Figura C.7: Mesmo que a figura C.1, mas para a energia de $50,82(5) \mathrm{keV}$. O $\chi^{2}$ do ajuste foi de 4,3 .

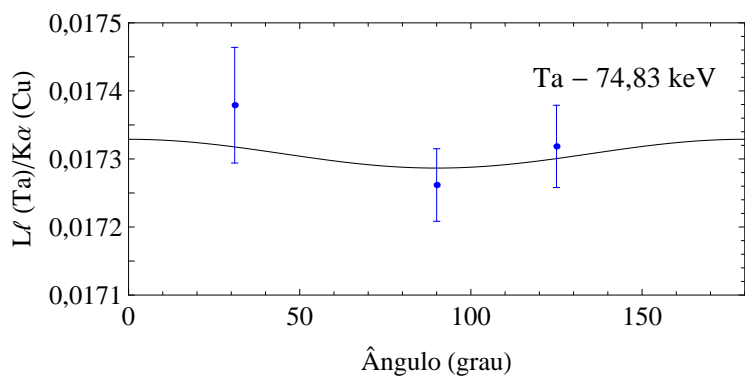

(a)

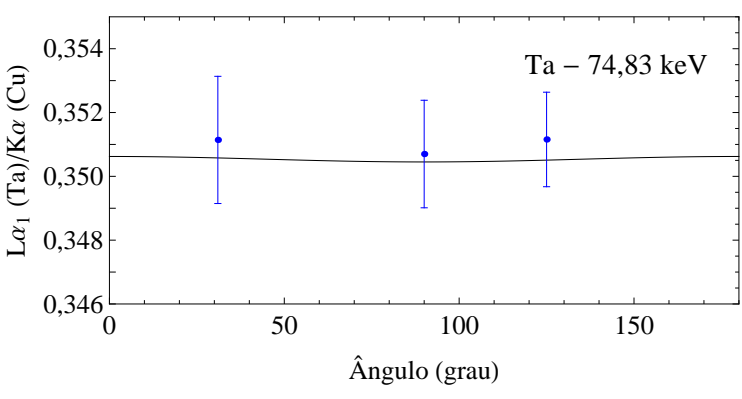

(b)

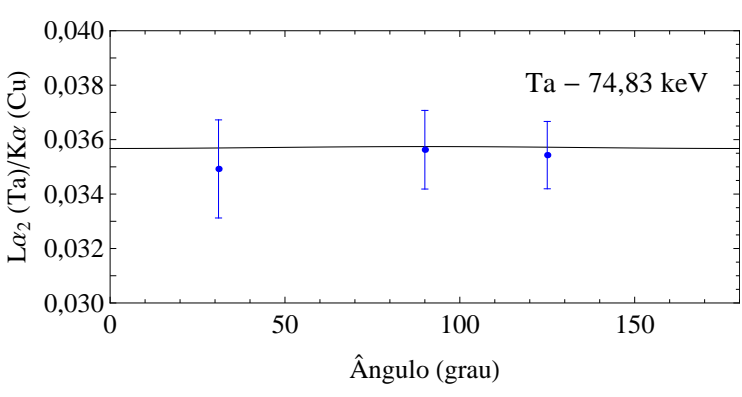

(c)

Figura C.8: Mesmo que a figura C.1, mas para a energia de $74,83(6) \mathrm{keV}$. O $\chi^{2}$ do ajuste foi de 5,2 . 


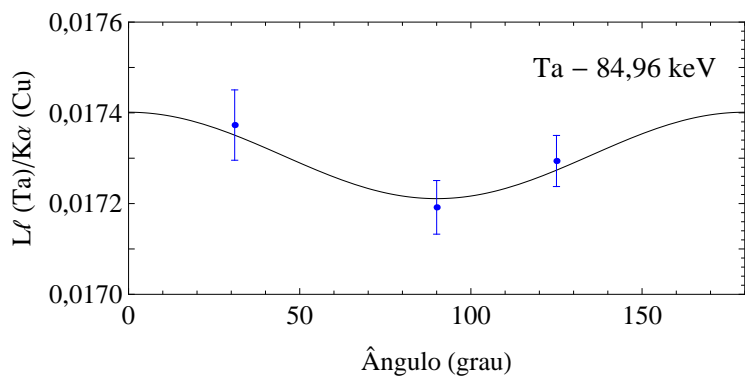

(a)

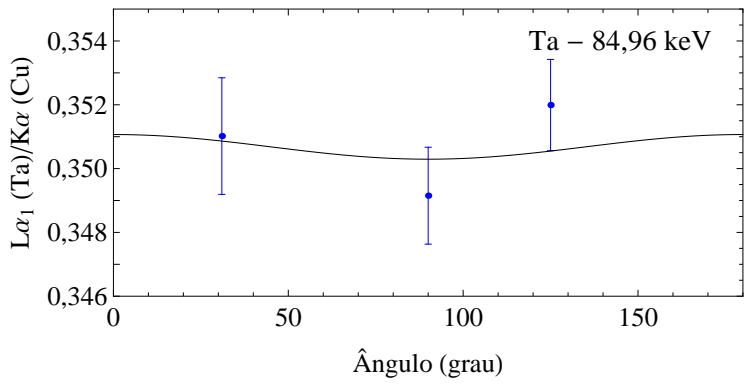

(b)

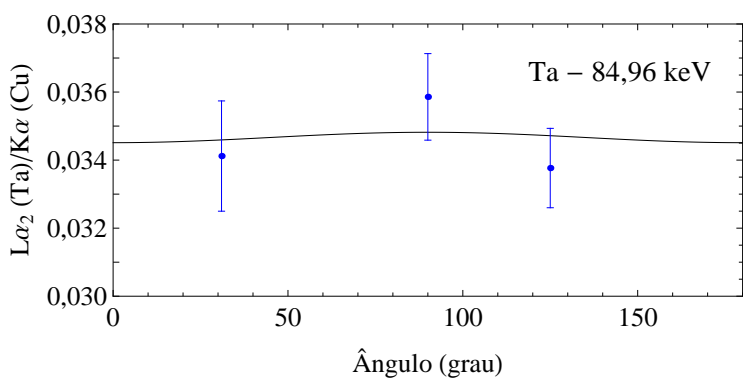

(c)

Figura C.9: Mesmo que a figura C.1, mas para a energia de $84,96(5) \mathrm{keV}$. O $\chi^{2}$ do ajuste foi de 14, 2 . 


\section{APÊNDICE D - Distribuição angular das linhas L $\ell$, $\mathrm{L} \alpha_{1}$ e $\mathrm{L} \alpha_{2}$ do $\mathrm{W}$}

No capítulo 8 foram apresentadas as figuras das distribuições angulares das linhas L $\ell, \mathrm{L} \alpha_{1}$

e $\mathrm{L} \alpha_{2}$ do W irradiado com a energia de $58,28(3) \mathrm{keV}$. Neste apêndice são apresentadas as figuras dessas distribuições angulares para as outras duas energias em que este alvo foi irradiado. 


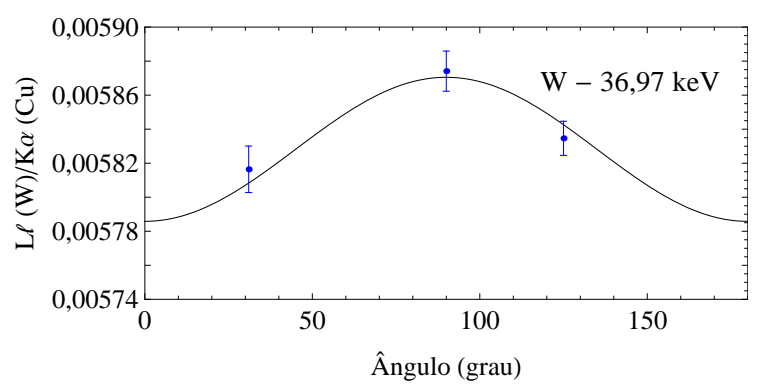

(a)

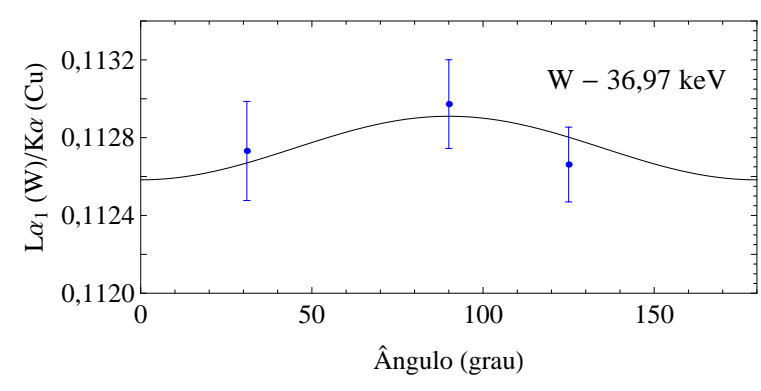

(b)

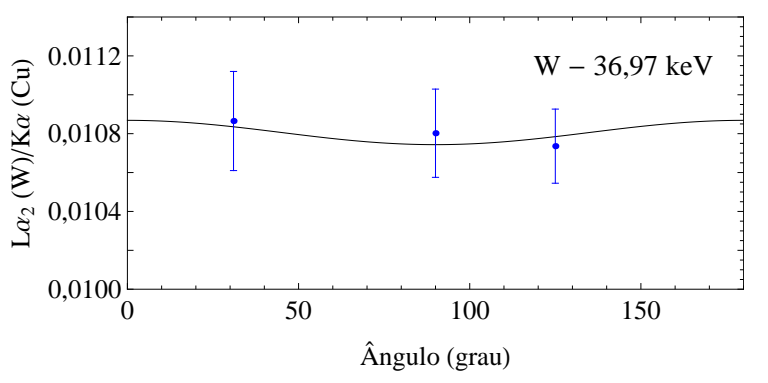

(c)

Figura D.1: Pontos experimentais e curva calculada com os parâmetros estimados para o alvo de $\mathrm{W}$ na energia de 36,97(8) $\mathrm{keV}$. a) Linha $\mathrm{L} \ell, \mathrm{b}) \mathrm{L} \alpha_{1}$ e c) $\mathrm{L} \alpha_{2}$. O $\chi^{2}$ do ajuste foi de 5,2 .

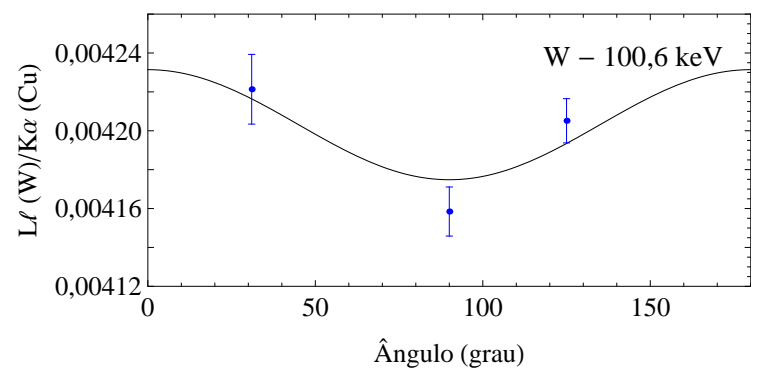

(a)

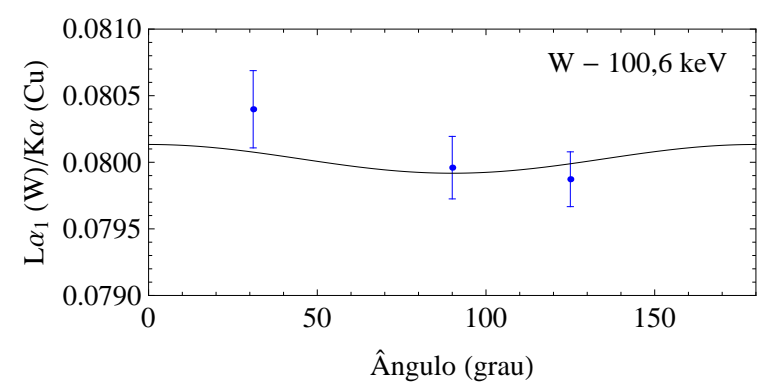

(b)

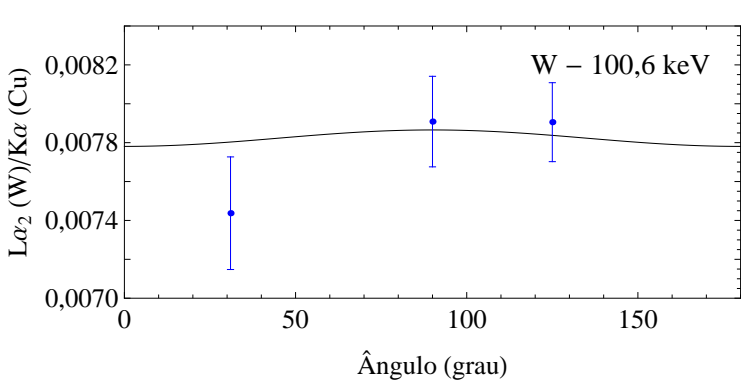

(c)

Figura D.2: Mesmo que a figura D.1, mas para a energia de $100,65(7) \mathrm{keV}$. O $\chi^{2}$ do ajuste foi de 10,6 . 


\section{APÊNDICE E - Distribuição angular das linhas L $\ell$, $\mathrm{L} \alpha_{1}$ e $\mathrm{L} \alpha_{2}$ do $\mathrm{Au}$}

No capítulo 8 foram apresentadas as figuras das distribuições angulares das linhas L $\ell$, $\mathrm{L} \alpha_{1}$ e $\mathrm{L} \alpha_{2}$ do $\mathrm{Au}$ irradiado com as energias de 13, 35(9); 25, 41(9) e 74, 83(7) keV. Neste apêndice são apresentadas as figuras dessas distribuições angulares para as demais energias em que este alvo foi irradiado. 


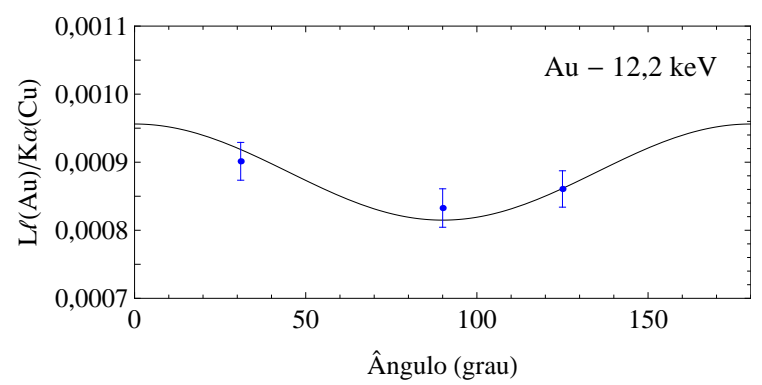

(a)

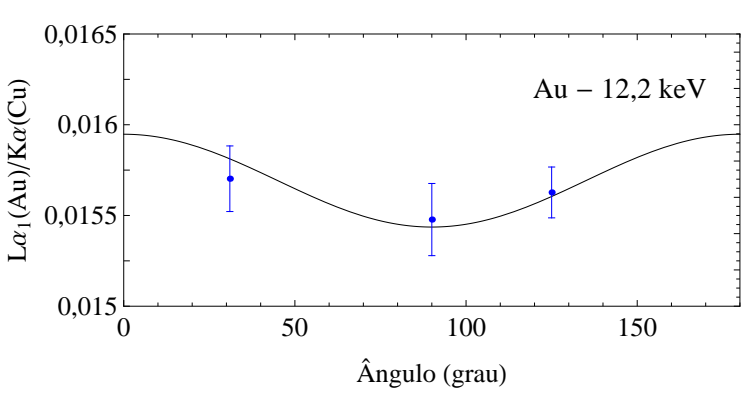

(b)

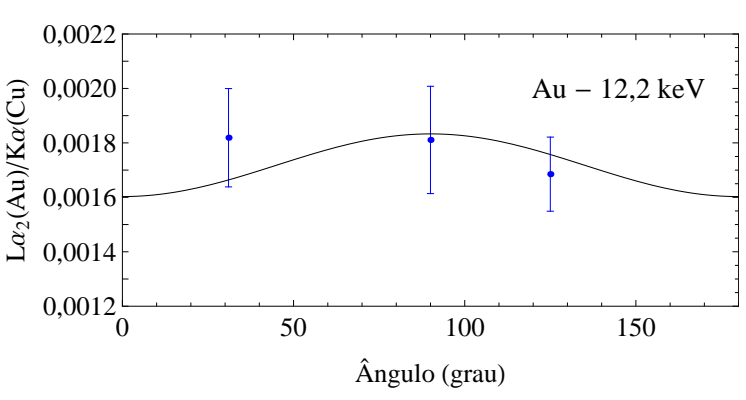

(c)

Figura E.1: Pontos experimentais e curva calculada com os parâmetros estimados para o alvo de Au na energia de $12,19(9) \mathrm{keV}$. a) Linha $\mathrm{L} \ell, \mathrm{b}) \mathrm{L} \alpha_{1}$ e c) $\mathrm{L} \alpha_{2}$. O $\chi^{2}$ do ajuste foi de 2,2 .

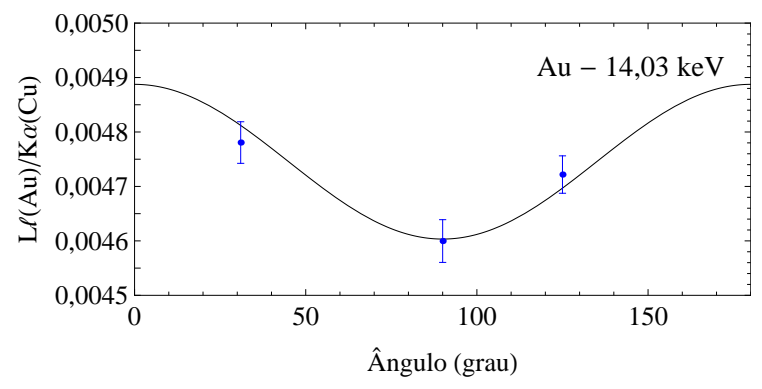

(a)

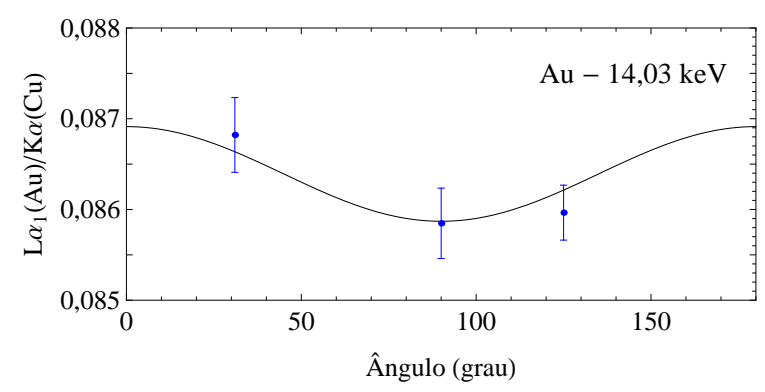

(b)

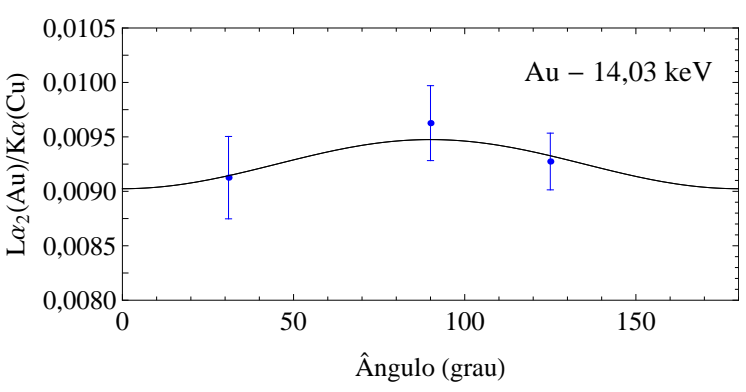

(c)

Figura E.2: Mesmo que a figura E.1, mas para a energia de $14,03(9) \mathrm{keV}$. O $\chi^{2}$ do ajuste foi de 2,7 . 


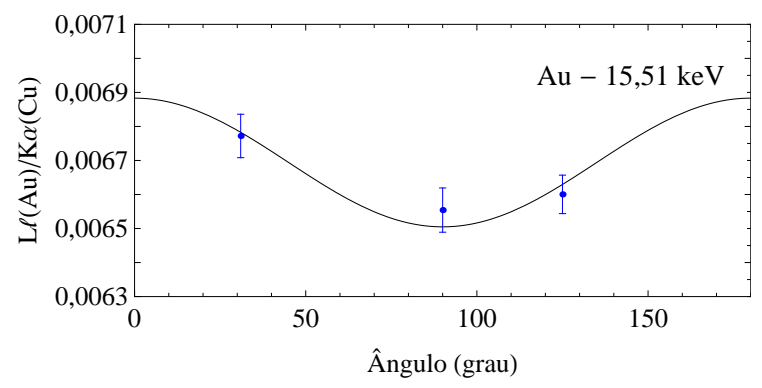

(a)

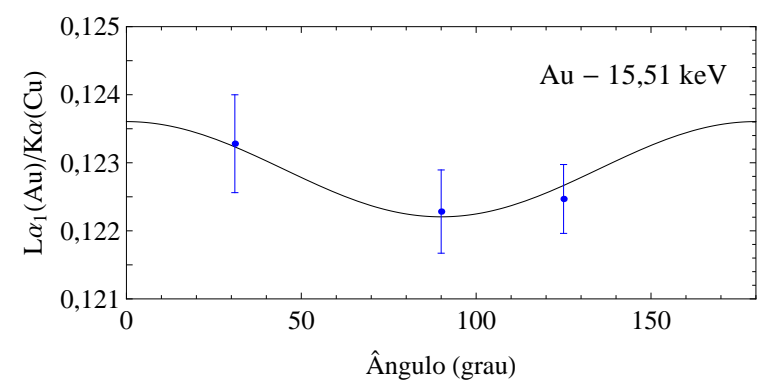

(b)

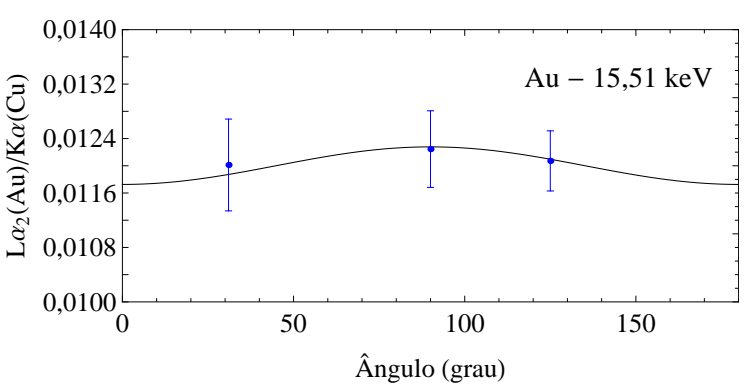

(c)

Figura E.3: Mesmo que a figura E.1, mas para a energia de $15,51(9) \mathrm{keV}$. O $\chi^{2}$ do ajuste foi de 4,4 .

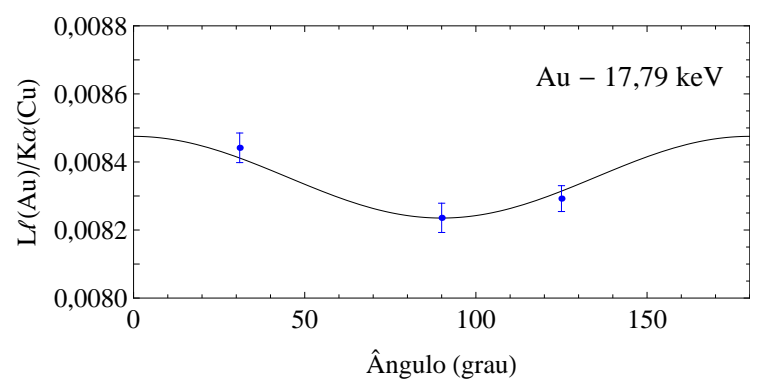

(a)

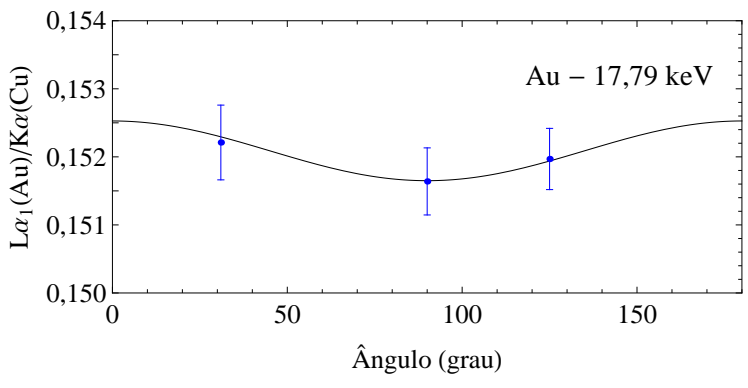

(b)

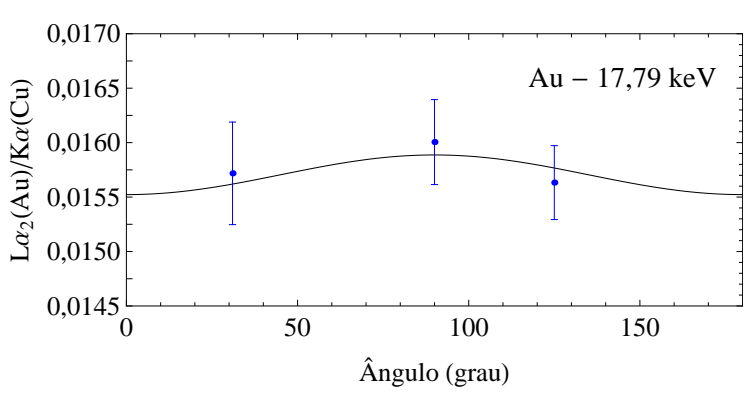

(c)

Figura E.4: Mesmo que a figura E.1, mas para a energia de 17,79(11) keV. O $\chi^{2}$ do ajuste foi de 4,1 . 


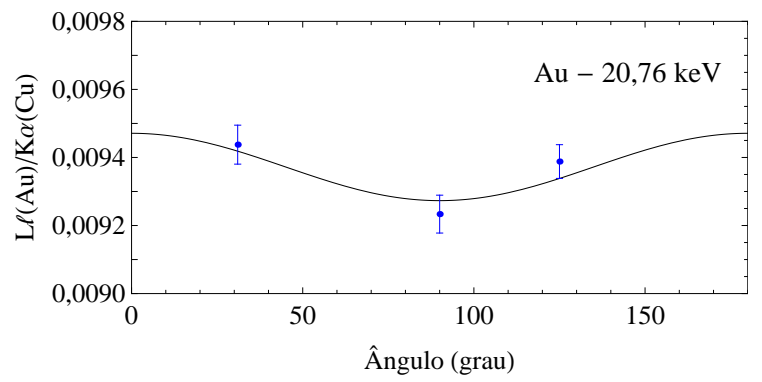

(a)

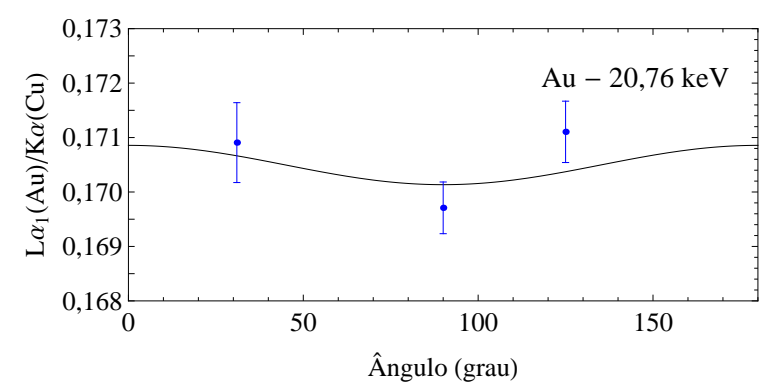

(b)

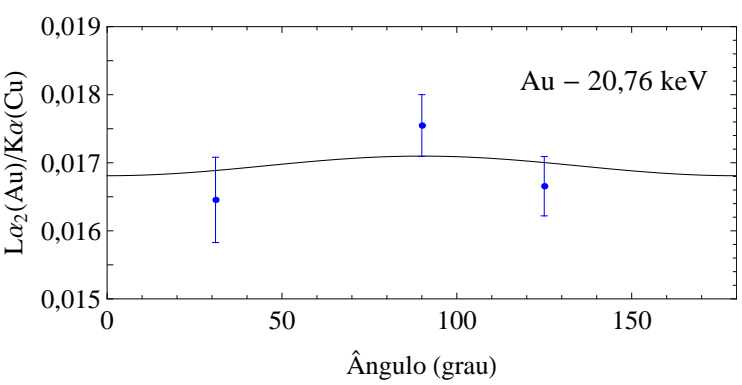

(c)

Figura E.5: Mesmo que a figura E.1, mas para a energia de $20,76(8) \mathrm{keV}$. O $\chi^{2}$ do ajuste foi de 8,9 .

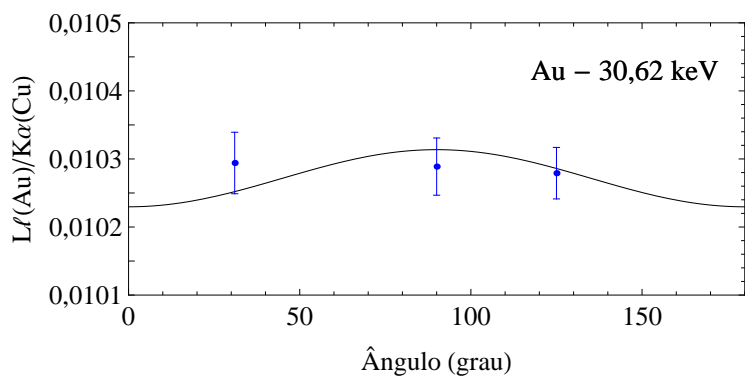

(a)

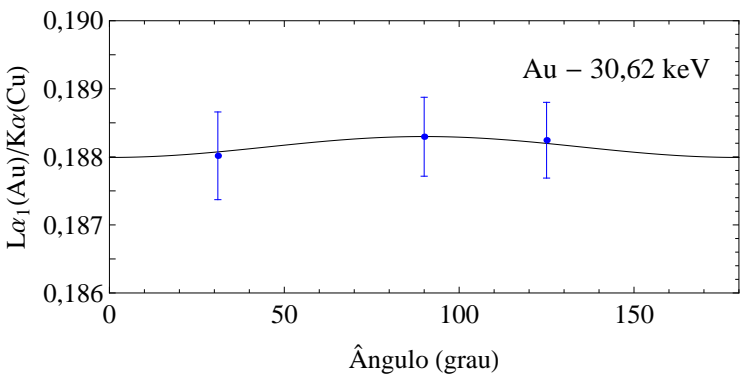

(b)

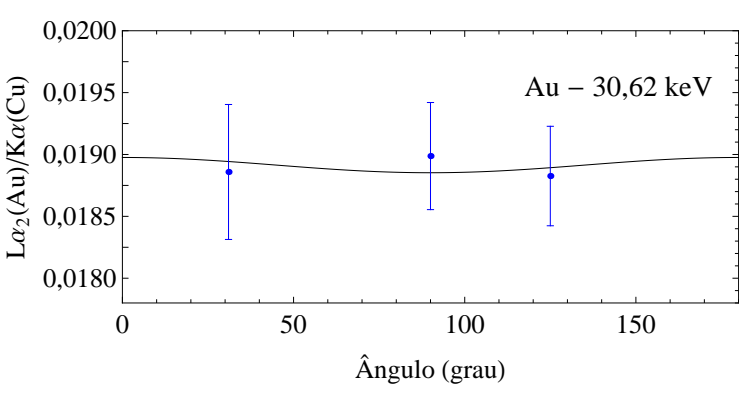

(c)

Figura E.6: Mesmo que a figura E.1, mas para a energia de $30,62(15) \mathrm{keV}$. O $\chi^{2}$ do ajuste foi de 5,3 . 


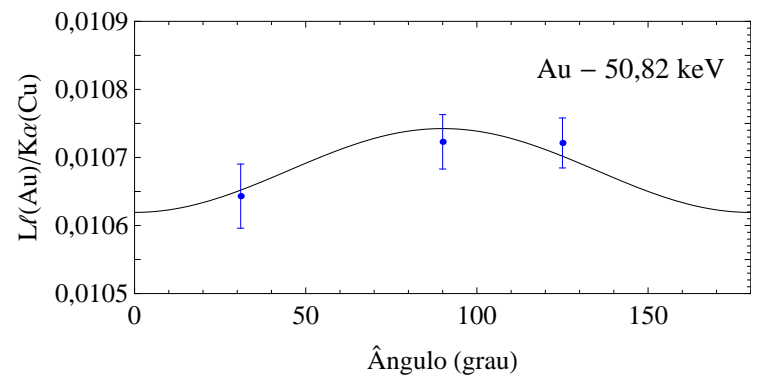

(a)

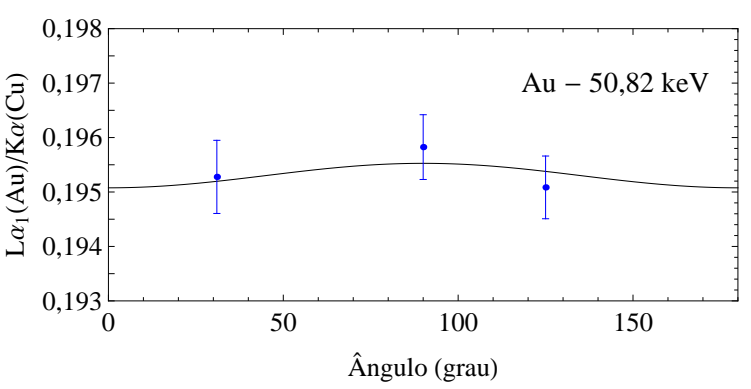

(b)

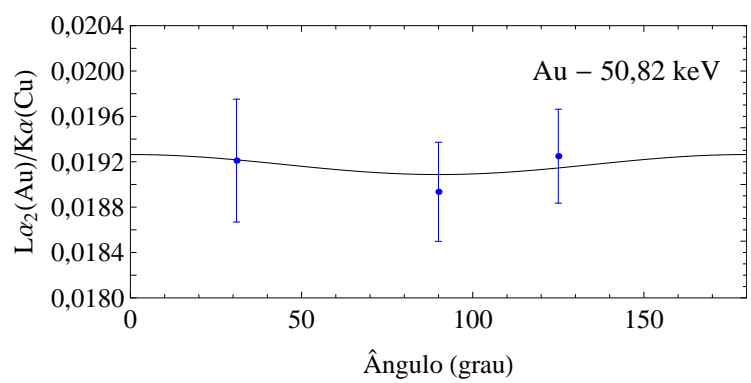

(c)

Figura E.7: Mesmo que a figura E.1, mas para a energia de $50,82(7) \mathrm{keV}$. O $\chi^{2}$ do ajuste foi de 7,4 .

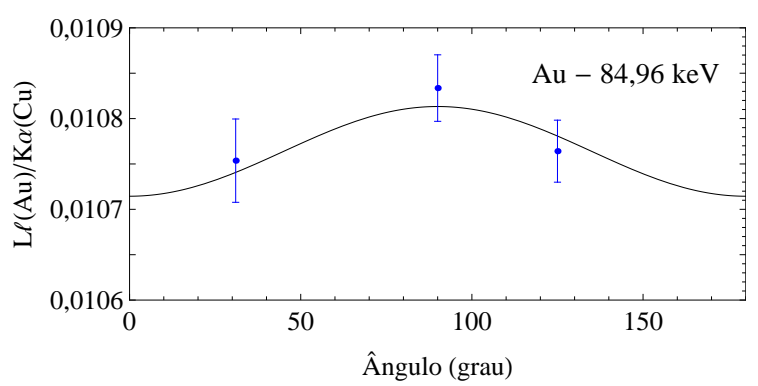

(a)

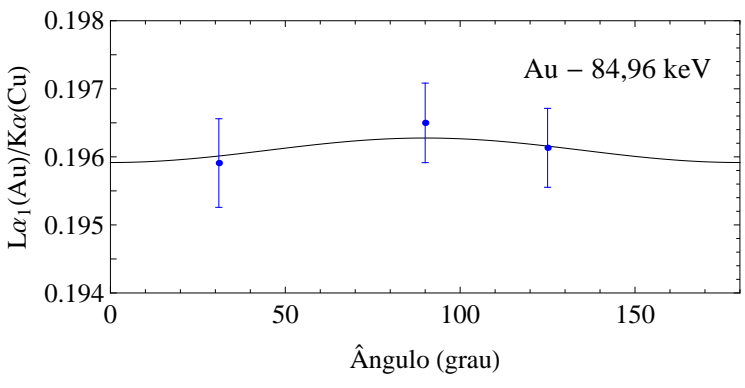

(b)

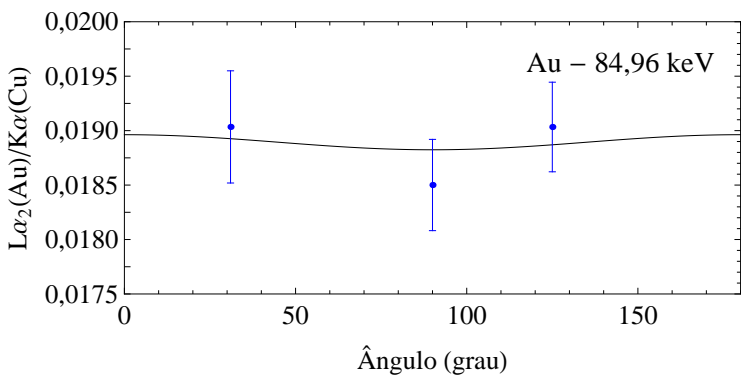

(c)

Figura E.8: Mesmo que a figura E.1, mas para a energia de 84,96(6) keV. O $\chi^{2}$ do ajuste foi de 6,1 . 


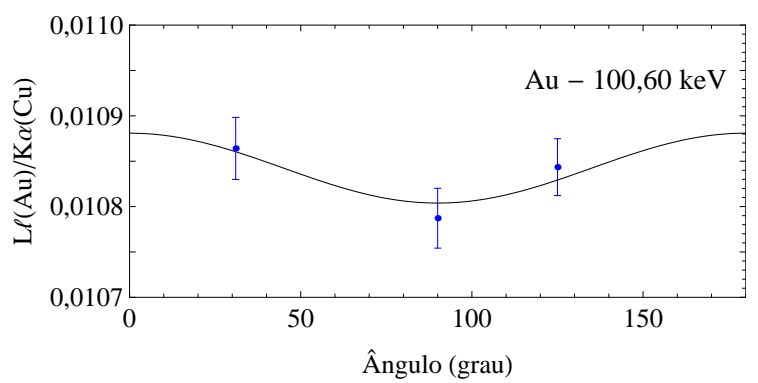

(a)

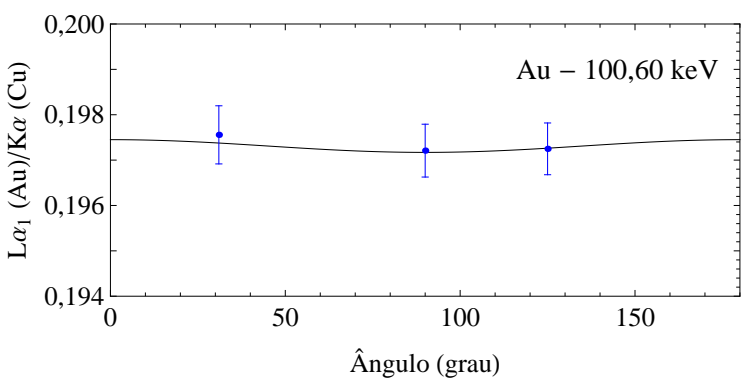

(b)

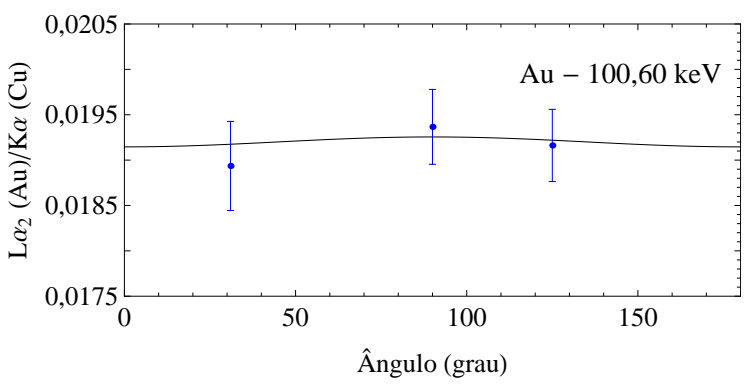

(c)

Figura E.9: Mesmo que a figura E.1, mas para a energia de 100,60(4) keV. O $\chi^{2}$ do ajuste foi de 5,0 . 